Florida International University FIU Digital Commons

7-11-1996

\title{
Investigation of spatial patterns of ground-water exchange with lakes, using a three-dimensional numerical model
}

Indranil Bandopadhyay

Florida International University

DOI: $10.25148 /$ etd.FI14050421

Follow this and additional works at: https://digitalcommons.fiu.edu/etd

Part of the Geology Commons

\section{Recommended Citation}

Bandopadhyay, Indranil, "Investigation of spatial patterns of ground-water exchange with lakes, using a three-dimensional numerical model" (1996). FIU Electronic Theses and Dissertations. 1384.

https://digitalcommons.fiu.edu/etd/1384 


\title{
FLORIDA INTERNATIONAL UNIVERSITY
}

\author{
Miami, Florida
}

\section{INVESTIGATION OF SPATIAL PATTERNS OF GROUND- WATER EXCHANGE WITH LAKES, USING A THREE- DIMENSIONAL NUMERICAL MODEL}

A thesis submitted in partial satisfaction of the requirements for the degree of

MASTER OF SCIENCE

IN

GEOLOGY

by

Indranil Bandopadhyay 
To: Dean Arthur W. Herriott College of Arts and Sciences

This thesis, written by Indranil Bandopadhyay, and entitled Investigation of Spatial Patterns of Groundwater Exchange with Lakes, Using a ThreeDimensional Numerical Model, having been approved in respect to style and intellectual content, is referred to you for judgement.

We have read this thesis and recommend that it be approved.

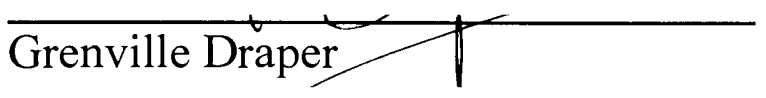

Jdmes Saiers

David Genereux, Major Professor

Date of Defense: July 11, 1996.

The thesis of Indranil Bandopadhyay is approved.

Dean Arthur W. Herriott

College of Arts and Sciences

Dr. Ríchard L. Campblell

Dean of Graduate Studies

Florida International University, 1996 
I dedicate this thesis to my wife Mousumi. Without her patience, understanding, support, and most of all love, the completion of this work would not have been possible. 


\section{ACKNOWLEDGEMENTS}

I wish to thank the members of my committee for their helpful comments and patience. I also want to thank my wife Mousumi, for her help in making the maps of some grids, Manjunath Somashekhar, for his assistance in the algorithms of the programs, Eric Slater, for his help in making a schematic diagram in Corel Draw.

A spacial thanks must go to my advisor, Dr. Dave Gereneux, for his support and encouraging comments, and especially for having the confidence in me in making this thesis a success. 


\section{ABSTRACT OF THE THESIS \\ INVESTIGATION OF SPATIAL PATTERNS OF GROUNDWATER \\ EXCHANGE WITH LAKES, USING A THREE-DIMENSIONAL \\ NUMERICAL MODEL \\ by}

Indranil Bandopadhyay

Florida International University, 1996

Miami, Florida

Professor David Genereux, Major Professor

Hydrogeologic variables controlling groundwater exchange with inflow and flow-through lakes were simulated using a three-dimensional numerical model (MODFLOW) to investigate and quantify spatial patterns of lake bed seepage and hydraulic head distributions in the porous medium surrounding the lakes. Also, the total annual inflow and outflow were calculated as a percentage of lake volume for flow-through lake simulations. The general exponential decline of seepage rates with distance offshore was best demonstrated at lower anisotropy ratio (i.e., $\mathrm{K}_{\mathrm{h}} / \mathrm{K}_{\mathrm{v}}=1,10$ ), with increasing deviation from the exponential pattern as anisotropy was increased to 100 and 1000 . 2-D vertical section models constructed for comparison with 3-D models showed that groundwater heads and seepages were higher in 3-D simulations. Addition of 
low conductivity lake sediments decreased seepage rates nearshore and increased seepage rates offshore in inflow lakes, and increased the area of groundwater inseepage on the beds of flow-through lakes. Introduction of heterogeneity into the medium decreased the water table and seepage rates nearshore, and increased seepage rates offshore in inflow lakes. A laterally restricted aquifer located at the downgradient side of the flow-through lake increased the area of outseepage. Recharge rate, lake depth and lake bed slope had relatively little effect on the spatial patterns of seepage rates and groundwater exchange with lakes. 


\section{TABLE OF CONTENTS}

CHAPTER

PAGE

1. INTRODUCTION $\ldots \ldots \ldots \ldots \ldots \ldots \ldots \ldots \ldots \ldots \ldots \ldots \ldots \ldots$

2. BACKGROUND ........................ 5

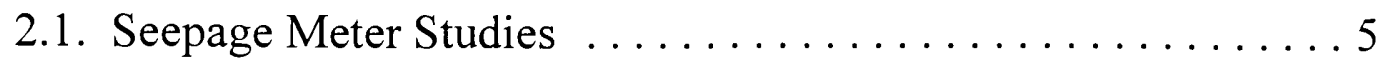

2.2. Modeling Studies $\ldots \ldots \ldots \ldots \ldots \ldots \ldots \ldots \ldots \ldots \ldots \ldots \ldots$

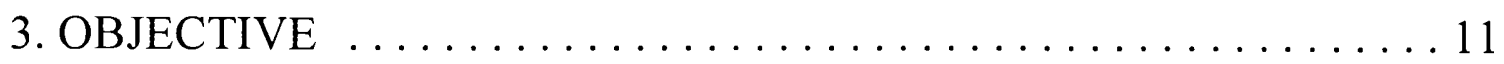

4. OVERVIEW OF THE MODEL ................ 14

5. SIMULATIONS AND MODEL PARAMETERS . . . . . . . . . . . 19

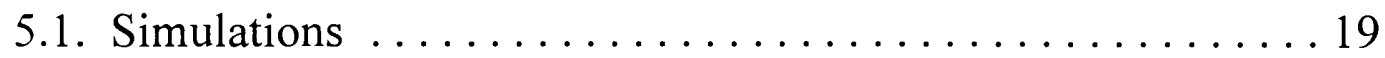

5.2. Model Parameters . . . . . . . . . . . . . . 20

5.2.1. Dimensions of Finite Difference Grid . . . . . . . 20

5.2.2. Lake Shape, Depth, and Bed Slope . . . . . . . . 21

5.2.3. Hydraulic Conductivities and Anisotropy ........ 23

5.2.4. Recharge Rate ... . . . . . . . . . . . . . 24

5.2.5. Hydraulic Gradient . . . . . . . . . . . 29

6. RESULTS: Comparison Between 2-D and 3-D Simulations . . . . . . 30

7. RESULTS: Grid Size ...................... 46

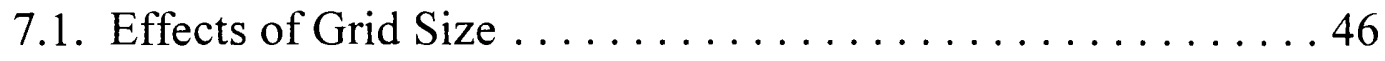

7.2. Inflow Lake . . . . . . . . . . . . . . . . . 49

7.3. Flow-through Lake $\ldots \ldots \ldots \ldots \ldots \ldots \ldots \ldots \ldots \ldots \ldots$

8. RESULTS: Recharge Rate $\ldots \ldots \ldots \ldots \ldots 7$

9. RESULTS: Lake Bed Sediments $\ldots \ldots \ldots \ldots \ldots \ldots \ldots$

9.1. Inflow Lake . . . . . . . . . . . . . . . 116

9.2. Flow-through Lake . . . . . . . . . . . . . . 119

10. RESULTS: Anisotropy Ratio . . . . . . . . . . . . . . . 138

10.1 Inflow Lake . . . . . . . . . . . . . . . 139 
10.2 Flow-through Lake .

11. RESULTS: Lake Depth . . . . . . . . . . . . . . . . . . 181

11.1 Inflow Lake .......................... 181

11.2 Flow-through Lake $\ldots \ldots \ldots \ldots \ldots \ldots \ldots \ldots \ldots \ldots$

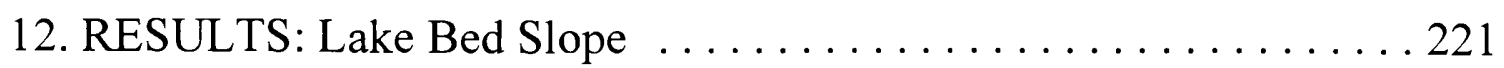

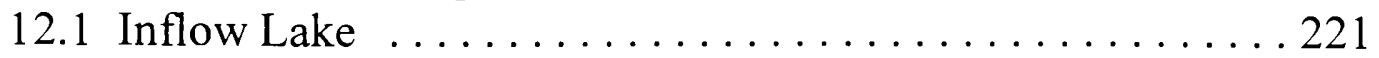

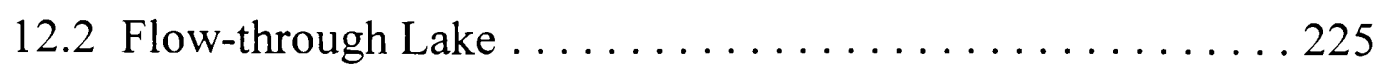

13. RESULTS: Orientation of Asymmetric Flow-through Lakes with Respect to Regional Gradient ......................... 257

14. RESULTS: Heterogeneity of the Porous Medium .......... 288

14.1. Horizontally Extensive Aquifer . . . . . . . . . . . . 289

14.1.1. Inflow Lake ....................... . 289

14.1.2. Flow-through Lake . . . . . . . . . . . . . . 293

14.2. Laterally Restricted Aquifer . . . . . . . . . . . . . . 297

14.2.1. Inflow Lake . .................... 298

14.2.2. Flow-through Lake ................... 300

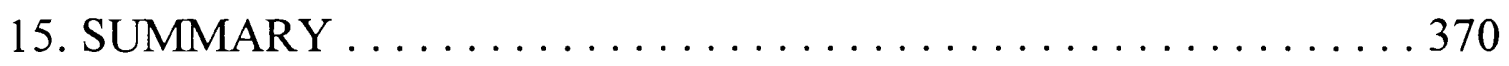

16. DISCUSSION AND CONCLUSIONS $\ldots \ldots \ldots \ldots \ldots \ldots \ldots \ldots \ldots$

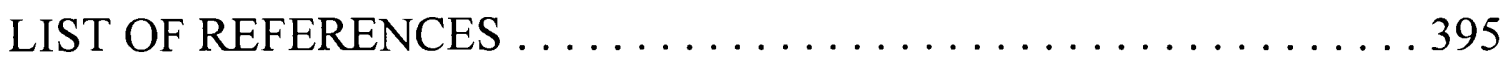

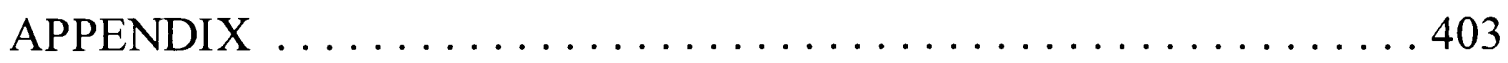




\section{LIST OF FIGURES}

Fig. 3.1. Schematic diagram of the model grid $\ldots \ldots \ldots \ldots \ldots \ldots 12$

Fig. 6.1. Map view of the top layer of 2-D and 3-D model $\ldots \ldots \ldots . \ldots 31$

Fig. 6.2-6.5. 2-D vs. 3-D model (cross-sections) . . . . . . . . 37-40

Fig. 6.6-6.9. 2-D vs. 3-D model (seepage plots) $\ldots \ldots \ldots \ldots \ldots .4$ 41-44

Fig. 7.1. Cross-section of the coarse grid $\ldots \ldots \ldots \ldots \ldots \ldots \ldots \ldots 47$

Fig. 7.2. Cross-section of the fine grid $\ldots \ldots \ldots \ldots \ldots \ldots \ldots \ldots 47$

Fig. 7.3-7.4. Coarse vs. Fine grid (inflow lake cross-sections) .... 55-56

Fig. 7.5-7.6. Coarse vs. Fine grid (inflow lake seepage plots) $\ldots$. 57-58

Fig. 7.7-7.14. Coarse vs. Fine grid (inflow lake seepage maps) . . . 59-66

Fig. 7.15-7.18. Coarse vs. Fine grid (flow-through lake cross-sections)

Fig. 7.19-7.20. Coarse vs. Fine grid (flow-through lake seepage plots)

Fig. 7.21-7.28. Coarse vs. Fine grid (flow-through lake seepage maps) ...

Fig. 8.1-8.6. Recharge rates (cross-sections) . . . . . . . . . . . 92-97

Fig. 8.7-8.10. Recharge rates (seepage plots) $\ldots \ldots \ldots \ldots . \ldots .69-101$

Fig. 8.11-8.22. Recharge rates (seepage maps) . . . . . . . . 102-113 
Fig. 9.1-9.2. Lake sediments (inflow lake cross-sections) . . . . 124-125

Fig. 9.3. Lake sediments (inflow lake seepage plots) $\ldots \ldots \ldots \ldots 126$

Fig. 9.4-9.6. Lake sediments (inflow lake seepage maps) . . . . . 127-129

Fig. 9.7-9.8. Lake sediments (flow-through lake cross-sections) . 130-131

Fig. 9.9. Lake sediments (flow-through lake seepage plots) . . . . . . 132

Fig. 9.10-9.12. Lake sediments (flow-through lake seepage maps) 133-135

Fig. 10.1-10.2. Anisotropy ratio (inflow lake cross-sections) ... . 150-151

Fig. 10.3-10.5. Anisotropy ratio (inflow lake seepage plots) ... 152-154

Fig. 10.6-10.9. Anisotropy ratio (inflow lake seepage maps) ... . 155-158

Fig. 10.10-10.11. Anisotropy ratio (flow-through lake cross-sections) $\ldots$.

Fig. 10.12-10.13. Anisotropy ratio (flow-through lake seepage plots) .....

$161-162$

Fig. 10.14-10.17. Anisotropy ratio (flow-through lake seepage maps) ..... $163-166$

Fig. 11.1-11.2. Lake depth (inflow lake cross-sections) . . . . . . 189-190

Fig. 11.3-11.6. Lake depth (inflow lake seepage plots) ........ 191-194

Fig. 11.7-11.10. Lake depth (inflow lake seepage maps) ...... 195-198

Fig. 11.11-11.12. Lake depth (flow-through lake cross-sections) .. 199-200 
Fig. 11.13-11.16. Lake depth (flow-through lake seepage plots) . 201-204

Fig. 11.17-11.20. Lake depth (flow-through lake seepage maps) . 205-208

Fig. 12.1. Cross-sections of three lake bed slopes . . . . . . . . 222

Fig. 12.2-12.3. Lake bed slope (inflow lake cross-sections) . . . . 230-231

Fig. 12.4-12.5. Lake bed slope (inflow lake seepage plots) $\ldots . .232-233$

Fig. 12.6-12.9. Lake bed slope (inflow lake seepage maps) . . . . 234-237

Fig. 12.10-12.11. Lake bed slope (flow-through lake cross-sections) $\ldots$.

Fig. 12.12-12.13. Lake bed slope (flow-through lake seepage plots) .....

Fig. 12.14-12.17. Lake bed slope (flow-through lake seepage maps) .....

Fig. 13.1-13.6. Lake orientation with regional gradient (cross-sections) ... $260-265$

Fig. 13.7-13.8. Lake orientation with regional gradient (seepage plots) .... $266-267$

Fig. 13.9-13.20. Lake orientation with regional gradient (seepage maps) .. $268-279$

Fig. 14.1-14.5. Horizontally extensive aquifer (inflow lake cross-sections) 
Fig. 14.6-14.7. Horizontally extensive aquifer (inflow lake seepage plots) .

Fig. 14.8-14.13. Horizontally extensive aquifer (inflow lake seepage maps)

Fig. 14.14-14.18. Horizontally extensive aquifer (flow-through lake cross-

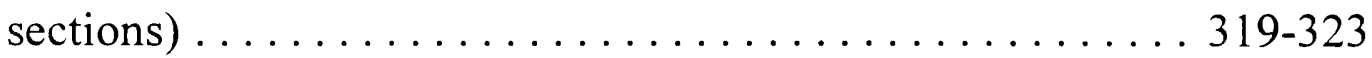

Fig. 14.19-14.20. Horizontally extensive aquifer (flow-through lake seepage

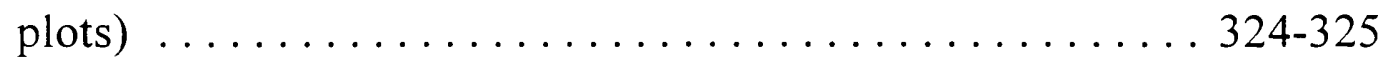

Fig. 14.21-14.26. Horizontally extensive aquifer (flow-through lake seepage maps) $326-331$

Fig. 14.27-14.28. Laterally restricted aquifer (inflow lake cross-sections) .

Fig. 14.29-14.30. Laterally restricted aquifer (inflow lake seepage plots) ..

Fig. 14.31-14.33. Laterally restricted aquifer (inflow lake seepage maps) .. $336-338$

Fig. 14.34-14.35. Laterally restricted aquifer (flow-through lake crosssections) 
Fig. 14.36-14.39. Laterally restricted aquifer (flow-through lake seepage

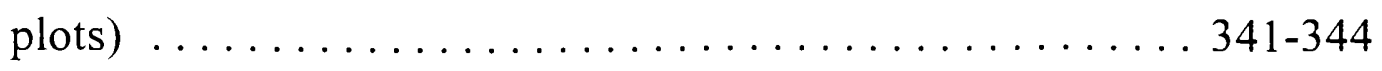

Fig. 14.40-14.42. Laterally restricted aquifer (flow-through lake seepage

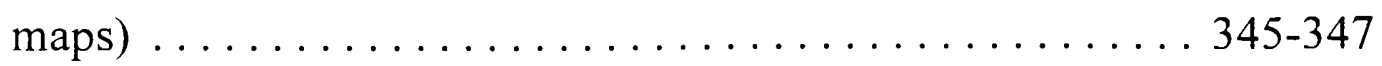




\section{LIST OF TABLES}

Table 5.1. Lake aspect ratios of lake-groundwater interaction $\ldots \ldots \ldots 22$

Table 5.2. Hydraulic conductivity and anisotropy ratio of the porous medium

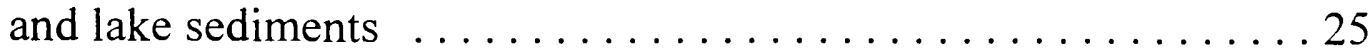

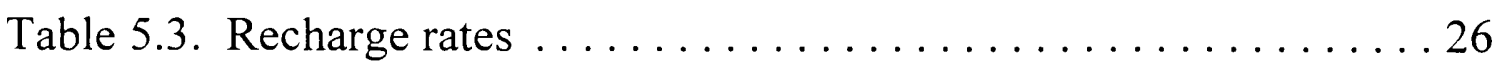

Table 5.4. Thickness of the surficial aquifer $\ldots \ldots \ldots \ldots \ldots \ldots \ldots 27$

Table 6.1. Representative heads for 2-D and 3-D simulations $\ldots \ldots \ldots 33$

Table 6.2. Seepage rate vs. Distance offshore for 2-D vs. 3-D simulations .

Table 7.1. Representative Head and seepage rates for 2 grid sizes for inflow lakes

Table 7.2. Location of seepage boundary and representative seepage rates for 2 grid sizes for flow-through lakes . . . . . . . . . . . . 50

Table 7.3. Seepage rate vs. Distance offshore for 2 grid sizes for inflow lakes

Table 7.4. Seepage rate vs. Distance offshore for 2 grid sizes for flow-

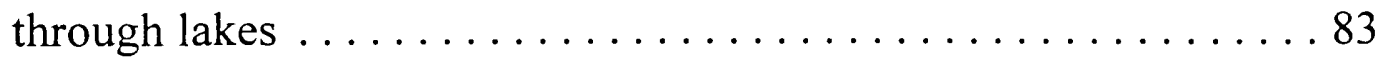

Table 8.1. Representative head and seepage rates for 2 recharge rates .. 88 Table 8.2. Seepage rate vs. Distance offshore for 2 recharge rates . . . 114 
Table 9.1. Representative head and seepage rates in presence and absence of lake sediments (inflow lakes) $\ldots \ldots \ldots \ldots \ldots \ldots \ldots \ldots \ldots$

Table 9.2. Location of seepage boundary and representative seepage rates in presence and absence of lake sediments (flow-through lakes) $\ldots 120$

Table 9.3. Groundwater inseepage and lake water outseepage in presence and absence of lake sediments

Table 9.4. Seepage rate vs. Distance offshore for in presence and absence of lake sediments (inflow lakes) $\ldots \ldots \ldots \ldots \ldots \ldots \ldots \ldots$

Table 9.5. Seepage rate vs. Distance offshore for in presence and absence of lake sediments (flow-through lakes) $\ldots \ldots \ldots \ldots \ldots \ldots \ldots \ldots$

Table 10.1. Representative head and seepage rates for 4 anisotropy ratios

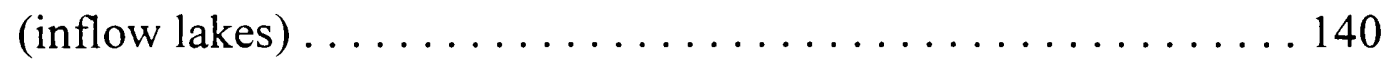

Table 10.2. Location of seepage boundary and representative seepage rates for 4 anisotropy ratios (flow-through lakes) $\ldots \ldots \ldots \ldots \ldots \ldots \ldots$

Table 10.3. Groundwater inseepage and lake water outseepage for 4

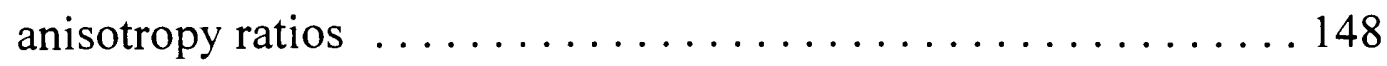

Table 10.4-10.8. Seepage rate vs. Distance offshore for inflow lakes with 4

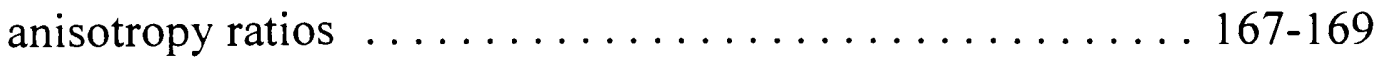

Table 10.9-10.14. Seepage rate vs. Distance offshore for flow-through lakes 
with 4 anisotropy ratios $170-180$

Table 11.1. Representative head and seepage rates for 2 lake depths (inflow

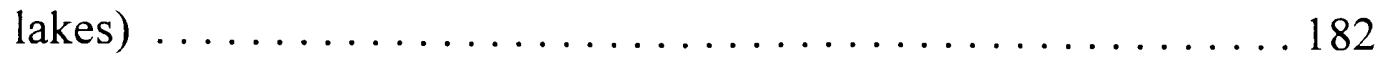

Table 11.2. Location of seepage boundary and representative seepage rates for 2 lake depths (flow-through lakes) $\ldots \ldots \ldots \ldots \ldots \ldots \ldots$

Table 11.3. Groundwater inseepage and lake water outseepage for 2 lake

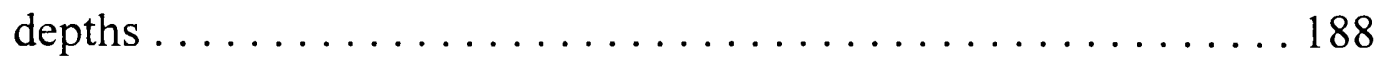

Table 11.4-11.7. Seepage rate vs. Distance offshore for 2 lake depths (inflow lakes)

Table 11.8-11.11. Seepage rate vs. Distance offshore for 2 lake depths (flow-

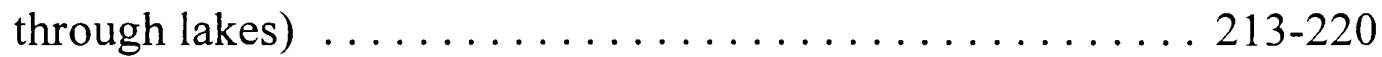

Table 12.1. Representative head and seepage rates for 3 lake bed slopes (inflow lakes) ........................... 223

Table 12.2. Location of the seepage boundary and representative seepage rates

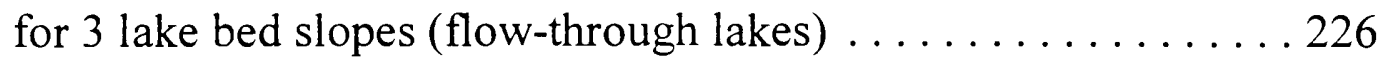

Table 12.3. Groundwater inseepage and lake water outseepage for 3 lake bed

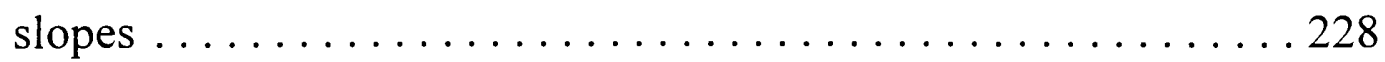

Table 12.4-12.7. Seepage rate vs. Distance offshore for 3 lake bed slopes (inflow lakes) . . . . . . . . . . . . . . . 246-249 
Table 12.8-12.11. Seepage rate vs. Distance offshore for 3 lake bed slopes

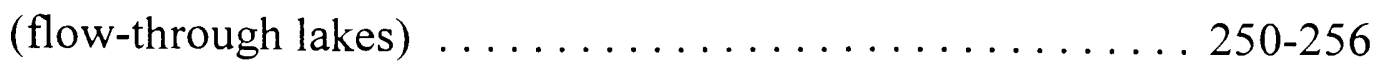

Table 13.1. Location of seepage boundary and representative seepage rates for 3 orientations of flow-through lakes $\ldots \ldots \ldots \ldots \ldots \ldots \ldots 258$

Table 13.2-13.5. Seepage rate vs. Distance offshore for 3 orientations of flowthrough lakes $\ldots \ldots \ldots \ldots \ldots \ldots \ldots \ldots \ldots \ldots \ldots \ldots . \ldots \ldots 280-287$

Table 14.1. Representative head and seepage rates for 3 positions of a horizontally extensive aquifer (inflow lakes) . . . . . . . . . 291

Table 14.2. Location of seepage boundary and representative seepage rates for 3 positions of a horizontally extensive aquifer (flow-through lakes) . 295

Table 14.3 groundwater inseepage and lake water outseepage for 3 positions of a horizontally extensive aquifer . . . . . . . . . . . 297

Table 14.4. Representative head and seepage rates for 3 positions of a laterally restricted aquifer (inflow lakes) . . . . . . . . . . . . . . . 299

Table 14.5. Location of seepage boundary and representative seepage rates for 3 positions of a laterally restricted aquifer (flow-through lakes) . . 302 Table 14.6. Groundwater inseepage and lake water outseepage for 3 positions of a laterally restricted aquifer $\ldots \ldots \ldots \ldots \ldots \ldots \ldots \ldots \ldots$ 
Table 14.7-14.10. Seepage rate vs. Distance offshore for 3 positions of a horizontally extensive aquifer (inflow lakes) . ....... 348-350

Table 14.11-14.14. Seepage rate vs. Distance offshore for 3 positions of a horizontally extensive aquifer (flow-through lakes) $\ldots \ldots$ 350-355

Table 14.15-14.18. Seepage rate vs. Distance offshore for 3 positions of a laterally restricted aquifer (inflow lakes) . . . . . . . 355-360

Table 14.19-14.26. Seepage rate vs. Distance offshore for 3 positions of a laterally restricted aquifer (flow-through lakes) . . . . . . 360-369 


\section{CHAPTER 1}

\section{Introduction}

The mutual exchange of water between lakes and the surrounding porous medium has an important contribution to the water, nutrient, and chemical budgets of some lakes (Winter, 1978b; Born et al., 1979; Hurley et al., 1985; Anderson and Bowser, 1986; Krabbenhoft et al., 1990b). The water budget of a lake depends in part on the distribution of hydraulic heads in the porous medium surrounding the lake, which in turn depends on a variety of hydrologic parameters such as anisotropy, heterogeneity of the porous medium, lake sediments, lake depth (Winter 1976, 1978a) and possibly the lake bed slope. Lake bed seepage can be studied by a variety of methods such as flownet analysis (McBride, 1969; Mann and McBride, 1972), installation of seepage measuring devices such as seepage meters in the lake (Fellows and Brezonik, 1980; Cherkauer and McBride, 1988), natural solutes (Stauffer, 1985), stable isotope tracers (Krabbenhoft et al., 1990a) and numerical simulation (McBride and Pfannkuch, 1975; Winter, 1976, 1978a). The earliest method of calculating the net groundwater flow around a lake was by considering the flow term as the residual in the water balance equation after estimating values for rainfall, evapotranspiration, stream discharge, changes in lake levels and 
artificial diversions if any (Cherkauer and Hensel, 1986). However estimates based on residuals provide only net inflow or outflow, with no information on the individual magnitudes of inflow and outflow or their spatial distribution across the lake bed (Winter, 1981b).

Direct measurement of seepage across lake beds has been accomplished with seepage meters that consist of a bag partly filled with water and attached to a collection device such as one end of a 55 gallon drum pressed into the lake sediment (Lee, 1977). Seepage into or out of the lake will cause a change in the volume of water in the bag and the seepage rate can be calculated from the change in volume and the time over which it occurred. While seepage meters can directly quantify seepage rates, their use is labor intensive (the meters are installed and the bags are changed by hand), and results from meters in the same area often show significant spatial variability in seepage rates (Fellows and Brezonik, 1980), suggesting many seepage meters may be needed to provide adequate statistics.

Numerical modeling is very important for predicting and analyzing field results on groundwater exchange with lakes (Winter, 1976, 1978a). Modeling studies of groundwater exchange near lakes have important implications for the design of field studies of lake/groundwater interaction and the transport of 
solutes in groundwater near lakes. Modeling studies could be useful in estimating heads and seepage rates that would be measured at different places in a lake/groundwater system, providing some basis for selecting measurement sites and interpreting field results. Another practical application of modeling lake/groundwater interaction is with respect to the water chemistry and ecology of lakes. Solute concentrations in groundwater are generally much different than those in precipitation or even surface runoff (Cherkauer et al., 1992). Thus, a better understanding of groundwater exchange with lakes could be useful in interpreting the chemistry and ecology of lakes.

Introduction of numerical models in calculation of groundwater head distributions and flow patterns near lakes began in the 1960s. Most of the earlier models were two-dimensional, which are easier to construct and faster to run than three-dimensional models. However, as Winter (1978a) mentioned, two-dimensional vertical section models assume that the flow is parallel to the section (i.e., that nothing changes in the direction normal to the section), whereas in nature most lakes are more round than linear. Therefore, three-dimensional models are more appropriate for simulating most real lakes. The development of a numerical model to study groundwater exchange with lakes requires hydrologic variables as input: (1) groundwater recharge 
rate, (2) geometry of the lake, (3) hydraulic conductivity, anisotropy, and heterogeneity of the surrounding porous medium, and (4) magnitude and orientation of the regional hydraulic gradient in the groundwater.

In this research the interaction of lakes with surrounding groundwater was investigated using a numerical, three-dimensional groundwater flow model called MODFLOW, originally developed by McDonald and Harbaugh (1988) and later revised by Geraghty and Miller Inc. in 1992 (version 3.01). To help create input files of hydrological values for MODFLOW, another software package known as ModelCad ${ }^{386}$ was used. SURFER and GRIDZO were used for gridding and contouring the model output. Three-dimensional steady state MODFLOW simulations were used to provide detailed information on spatial patterns of lake bed seepage in different hydrological settings (lakes of different shape, in porous media with different degrees of anisotropy and heterogeneity, and different types of regional head gradients, as described in detail in the following chapters). 


\section{CHAPTER 2}

\section{Background}

Early attempts to estimate the exchange of groundwater with lakes involved calculating the net exchange flux as the residual in the lake hydrologic budget. Because groundwater flow to lakes is more difficult to assess than other fluxes, it has often been treated as the residual term after measuring or otherwise estimating the values of rainfall, stream discharge, evaporation, lake outflow and artificial diversion if any. Estimates based on residuals provide only the net difference between groundwater inflow and outflow (Winter, 1981a).

\subsection{Seepage meter studies}

Seepage meter techniques were initially described by Israelson and Reeve (1944), and later many workers tried to quantify groundwater inflow to or outflows from lakes with seepage meters (Warnick, 1957; Manson et al., 1968; Allred et al., 1971). Eisenlohr et al. (1972) studied the relation of groundwater to prairie potholes in North Dakota. The general conclusion of these studies was that most of the lakes had a net outflow to the surrounding groundwater. In a study of Lake Sallie in Minnesota (McBride, 1969), the groundwater component to the lake water budget was a primary interest. Wells 
were placed within the entire drainage basin of the lake to define the groundwater movement. Generally the rate and amount of groundwater flow to the lake was greatest near the shore and decreased approximately exponentially with distance.

Studies similar to that of McBride (1969) were conducted by Possin (1973), and Hennings (1978) in Wisconsin. They also came to the same general conclusion. Barwell and Lee (1981) documented that where seepage does decrease offshore, the rate of decline with distance can be used to calculate bulk hydraulic anisotropy.

Cherkauer and Nader (1989a) documented three distinct types of seepage patterns on the upper Great Lakes and their connecting channels. Seepage rate decreased exponentially with distance offshore at 7 out of 24 sites (Type A distribution). Ten sites exhibited a decline in seepage offshore in the near shore area, with increasing seepage further offshore from the local minimum (Type B distribution). The Type $\mathrm{C}$ distribution reached a peak near shore and then declined further offshore. They also showed that the heterogeneity in sediment thickness was a more important factor in causing these spatial variations of seepage rate than was heterogeneity of the bedrock hydraulic conductivity. Cherkauer and Zager (1989b) observed that 
groundwater seepage decreased exponentially with distance from the shore on the upgradient side of a flow-through kettle hole lake in Wisconsin. Shaw and Prepas (1990) showed that at their site Central Alberta, deviation from the exponential decrease of seepage with distance from shore was probably the result of: (1) intertill sand and gravel lenses near the lake or (2) preglacial bedrock channels of sand and gravel underlying some lakes.

The seepage meters used in these studies directly quantified seepage rates, but they have some serious limitations. As noted earlier, seepage meter techniques are labor intensive and therefore are not cost effective. The meters are installed and the bags changed manually. Moreover, the results from seepage meters in the same area often vary widely. According to Fellows and Brezonik (1980, page 635) “ Lee (1977) reported seepage flows in lakes and estuaries ranging from from -8.6 to $223 \mathrm{~L} \mathrm{~m}^{-2} \mathrm{~d}^{-1}$. John and Lock (1977) reported a similar range in New Zealand lakes $\left(2.6\right.$ to $\left.216 \mathrm{~L} \mathrm{~m}^{-2} \mathrm{~d}^{-1}\right)$. These values are much higher than the range of 0.07 to $1.92 \mathrm{~L} \mathrm{~m}^{-2} \mathrm{~d}^{-1}$ reported by Downing and Peterka (1978) for Lake Metigoshe, North Dakota." These disparities among the seepage meter results substantiate the fact that many seepage meters may be needed to provide adequate statistics. 


\subsection{Modeling studies}

Numerical modeling of a lake-groundwater system was first attempted by McBride and Pfannkuch (1975). They showed that the seepage of water into or out of flow-through lakes was concentrated near the shore and usually seepage rates decreased exponentially away from the shore. Hydraulic conductivity was allowed to differ between (but not within) model layers in their simulations. They also pointed out that sometimes seepage is not concentrated near shore. The possible reason is that the seepage rates may fluctuate rapidly with time, perhaps from changes in lake level or barometric pressure.

Winter (1976) used a two-dimensional groundwater model for a variety of hypothetical lake groundwater settings. He showed that a groundwater mound and a stagnation point may develop on the downgradient side of a flowthrough lake, depending on the other hydrological conditions. He showed that if the stagnation point exists, the boundary between local (shallow) and regional (deeper) flow systems will be continuous, and the lake will not loose water. Cherkauer and Zager (1989b) pointed out that Winter's simulations included some where the littoral (near shore) zone was without lake sediments, hence this zone could serve as a high permeability conduit compared with the 
low permeability, sediment covered lake bottom, accentuating the tendency of seepage to occur near shores.

Winter (1978a) modeled a three-dimensional system to examine a more realistic geometric form of lake-groundwater systems. He documented that the general conclusions reached by 2-D modeling can be extrapolated qualitatively to 3-D models, with some important quantitative variations. The stagnation point identified by Winter (1976) in a 2-D vertical section model was shown in three dimensions to be associated with a stagnation zone, which is a line defined by a series of pseudo stagnation points. Results from 3-D groundwater flow simulations near lakes showed an increased tendency toward lake outseepage, compared with 2-D simulations. Pfannkuch and Winter (1984) showed the effect of geometry of lakes and the anisotropy of the surrounding porous medium through conductive paper electric analog models. They showed a general decline of seepage with distance offshore, with the distance over which the decline occurred increasing as the bulk anisotropy increased. Later Winter and Pfannkuch (1984) used numerical simulations and came to the same general conclusion. Winter (1986) studied the effects of groundwater recharge on water table configuration and direction of seepage through lake beds. He showed that for some situations lakes could have seepage from them 
even though the water table slopes toward the lake from all sides.

The present study differs from previous studies in focusing more on details of the spatial patterns of lake bed seepage; maps of lake bed seepage rate are compared for lakes in a variety of hydrogeologic settings. In addition, the present study is unique in treating both both inflow and flow-through lakes, and analyzing the effect of lake shape on lake bed seepage. 


\section{CHAPTER 3}

\section{Objectives}

The objective of this study was to use a three-dimensional (3-D) numerical groundwater flow model (MODFLOW) to investigate and quantify spatial patterns of water seepage across lake beds under different conditions of lake shape (depth and bed slope), and heterogeneity and anisotropy in the surrounding porous medium. In all simulations the head distribution was independent of time and therefore the simulations were steady state type. The model domain in each simulation consisted of a rectangular block of porous medium with a circular lake in the center. In each case the rectangular block was 6000 meters wide and long, and 50 meters thick; lake diameter was fixed at 2000 meters, and depth was varied between 10 and 20 meters (Fig. 3.1).

Details on dimensions and boundary conditions are given in chapters 4 and 5 .

Three types of plots were used to present hydraulic head and lakebed seepage results from each simulation: (1) vertical cross sections through the center of the lake and the porous medium, with equipotential lines showing the groundwater head distribution and flow pattern, (2) plots showing the variation of seepage rate with distance offshore, and (3) maps showing the distribution of seepage rate over the entire lake bed. A few two-dimensional (2-D) 


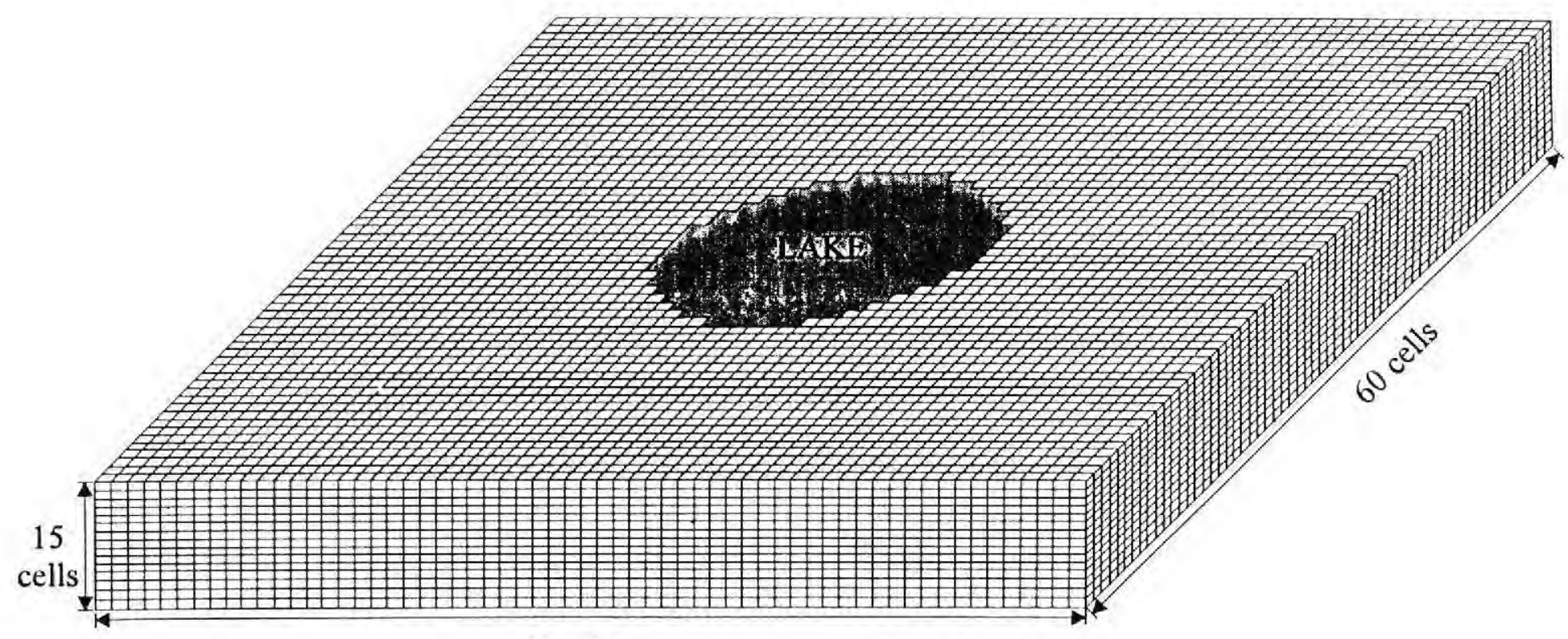

60 cells

Fig. 3.1. Schematic diagram of the coarse grid model domain used in this study, with the lake in the center of the domain. The fine grid used in some simulations was 120 cells $\times 120$ cells $\times 15$ layers. 
simulations analogous to the 3-D simulations were constructed for comparison.

Two fundamentally different types of lakes were investigated: inflow lakes, which sit in hydrologically closed basins and receive groundwater inflow over the entire extent of their lake beds, and flow-through lakes, which sit in regional groundwater gradients and hence experience groundwater inseepage on their upgradient sides and lake water out-seepage on their downgradient sides.

The general principle underlying the interaction of lake and groundwater was studied thoroughly by Winter (1976) through 2-D vertical section modeling. Winter (1978a) also did some 3-D steady state simulations, though he concentrated on only round flow-through lakes. The present study involves investigation of different lake shapes and both inflow and flow-through lakes. Results are presented as maps of seepage rate on lake beds and plots of seepage rate as a function of distance from the lake shore, items not included in Winter's work. In effect, this study focuses more on water fluxes across the lake bed, as compared to Winter's focus on groundwater flow in the surrounding porous medium. 


\section{CHAPTER 4}

\section{Overview of the model}

MODFLOW, a three-dimensional, block centered, finite difference groundwater flow model, was developed by McDonald and Harbaugh (1988).

ModelCad ${ }^{386}$ is a preprocessor developed by Geraghty and Miller, Inc., to simplify creation of input (model grids with parameters and boundary conditions) for MODFLOW. ModelCad ${ }^{386}$ was used to design MODFLOW simulations in this study. MODFLOW consists of a main program and a series of independent subroutines grouped into "packages" that each deal with a specific feature of the hydrologic system to be simulated (such as a boundary condition) or with a specific method of solving linear equations (such as the Strongly Implicit Procedure, SIP) (McDonald and Harbaugh, 1988).

The spatial discretization of a model domain in the horizontal direction is represented in terms of rows and columns in the model grid. The input values required are the total distance along the $\mathrm{X}$ and $\mathrm{Y}$ directions and the number of rows and columns. Discretization of space in the vertical direction is handled in the model by specifying the number of layers in the grid. The layer thicknesses are defined by entering top and bottom elevations. By defining rows, columns and layers the model domain is discretized into a finite 
difference grid containing cells or blocks (Harte et al., 1992). In MODFLOW a grid layer may be defined as always confined, always unconfined, or capable of being either confined or unconfined (Anderson and Bowser, 1992). The top layer is always unconfined and has an unspecified thickness (no defined top elevation, or ground surface). If the head is higher than the top elevation of a layer, the layer is assumed to be confined. Conversely, if the head in the layer is below the top elevation, but above the bottom elevation of a layer, the layer is treated as unconfined. Recharge is applied to the top layer, or to the uppermost active cells in case the cells in the top layer become "dry" (i.e., the water table drops below the bottom elevation of the cells), as happened in the upper layers in some of our simulations of flow-through lakes.

MODFLOW has several types of boundary conditions. The two specified head boundary conditions used in this study are constant head boundary and general head boundary. Water may flow across a constant head boundary in whatever amount is required to maintain continuity and the fixed head at the boundary, given the other boundary conditions (e.g., recharge) in the model. Constant head cells were used to represent the lake in each of our simulations (i.e., the lake bed, the upper surface of the lake, and the entire volume in between was assigned a single fixed head). Flow through a general 
head boundary is calculated as the product of boundary conductance and the difference between the head at the boundary and the head in the cell adjacent to the boundary. The conductance is calculated as the product of hydraulic conductivity, the thickness of the adjacent cell, and the width of the adjacent cell, divided by one half the length of the cell normal to the boundary (McDonald and Harbaugh, 1988). General head boundaries were used around the sides of the model domain in our simulations of flow-through lakes. Head values were calculated by the Strongly Implicit Procedure (SIP), and the head closure criterion was 0.001 meter.

The basic equation of steady state groundwater flow in saturated porous media is derived by coupling Darcy's equation with the equation of continuity (Trescott, 1975):

$$
\frac{\partial}{\partial x}\left(K_{x x} \frac{\partial h}{\partial x}\right)+\frac{\partial}{\partial y}\left(K_{y y} \frac{\partial h}{\partial y}\right)+\frac{\partial}{\partial z}\left(K_{z z} \frac{\partial h}{\partial z}\right)=0
$$

where $\mathrm{K}_{\mathrm{xx}}, \mathrm{K}_{\mathrm{yy}}$ and $\mathrm{K}_{\mathrm{zz}}$ are the principal components of the hydraulic conductivity tensor, $\partial \mathrm{h} / \partial \mathrm{x}, \partial \mathrm{h} / \partial \mathrm{y}$, and $\partial \mathrm{h} / \partial \mathrm{z}$ are the gradients of head in the three dimensions of space. The assumptions in this equation are as follows: (1) flow of water is laminar, (2) the fluid is incompressible, (3) the porous medium is rigid and (4) the coordinate axes are aligned with the principal 
directions of anisotropy. This was the basic equation solved by MODFLOW to compute groundwater heads and fluxes in our simulations. After completing each MODFLOW simulation, the results were prepared for contouring/plotting. A program called MODGRID was used to translate output generated by MODFLOW into grid files that could be read and contoured or plotted by SURFER or GRIDZO, two graphics programs purchased from Rockware Inc. of Golden, Colorado. MODGRID can only generate grid files of a particular layer. To contour the head distribution in a vertical cross section crossing several model layers, a separate program was written (see Appendix).

The boundary conditions were different for inflow and flow-through lakes. Boundary conditions for the inflow lakes were:

- No flow across vertical boundaries around the outside of the grid or across the base of the system (the domain was impermeable on five sides, all except the top).

- Constant head on the lake bed (and throughout the lake).

- Constant recharge rate.

For inflow lake simulations, the lakes behaved as a sink (the only sink) and recharge to the water table surrounding the lake was the only water source 
to the system.

The boundary conditions for the flow through lakes were:

- The regional gradient was set by specifying general head boundary conditions on the vertical boundaries around the outside of the grid; thus there was flow across these boundaries (unlike in the inflow lake simulations).

- No flow across the base of the system.

- $\quad$ Constant head on the lake bed (and throughout the lake).

- $\quad$ No Recharge. 


\section{CHAPTER 5}

\section{Simulations and model parameters}

\subsection{Simulations}

The following parameters were varied for the different simulations to determine their effects on spatial patterns of lake bed seepage:

- anisotropy ratio (ratio of horizontal to vertical conductivity, $\mathrm{K}_{\mathrm{h}} / \mathrm{K}_{\mathrm{v}}$ ) in the porous medium surrounding the lake,

- degree of penetration of the lake (i.e., depth),

- $\quad$ lake bed slope (steep, moderate, low, and a combination of steep and low in a lake lacking radial symmetry),

- $\quad$ vertical position of a "horizontally extensive aquifer" (i.e., a layer of high hydraulic conductivity that takes up an entire layer of the model domain under the lake),

- horizontal position of a "laterally restricted aquifer" (i.e., a layer of high hydraulic conductivity that takes up $1 / 3$ of a layer of the model domain, below the elevation of the lake bottom),

- $\quad$ grid spacing (coarse versus fine model grid),

- recharge rate (inflow lakes only),

- presence or absence of low conductivity lake sediments (inflow lakes 
only).

\subsection{Model parameters}

The following is the list of variables used in modeling the lakegroundwater system:

1. Dimensions of the finite difference grid,

2. Lake shape, depth and lake bed slope,

3. Hydraulic conductivity and anisotropy of the porous medium,

4. Recharge rates (for inflow lakes only),

5. Hydraulic gradient in the porous medium (for flow through lakes only),

6. Boundary head (for constant and general head boundaries), and

7. Boundary Conductance (for general head boundaries).

\subsubsection{Dimensions of the finite difference grid}

Two grid spacings were investigated to see whether the model results were dependent on grid spacing. Some simulations were done with a coarse grid having 60 rows, 60 columns, and 15 layers. A fine grid was also used, and was created by dividing the rows and columns of the coarse grid in half thus producing a grid of 120 rows, 120 columns, and 15 layers. A numerical model in principle is unitless, but input parameter values should be based on consistent set of units and hence assigning units to any one parameter defines 
units for the others and the output. For example, the top area of the grid is 6000 units by 6000 units, which could be 6000 meters by 6000 meters. In this case, each block in the coarse grid would be 100 meters long and 100 meters wide, a fine grid block 50 meters long and 50 meters wide. The thickness of the domain was represented by 15 layers. The overall thickness of the system was 50 units (meters) and the layers were two, four, or six meters thick. For simulations involving a shallow lake, the domain consisted of 5 two-meter layers overlying 10 four-meter layers; for those involving a deep lake 10 twometer layers overlying 5 six-meter layers were used.

\subsubsection{Lake shape, depth and lake bed slope}

Lake shapes vary widely in nature. Winter (1978) reported that lakes in glacial terrain are mostly circular in plan view. Shaw and Prepas (1990) reported lakes from Alberta with various shapes. To quantify different lake shapes for comparison purposes in selecting a shape for this study, an aspect ratio that is half of the longest horizontal dimension divided by the maximum depth was considered. A list of lakes with different aspect ratios is given in Table 5.1. Some lakes incorporated into this list are model lakes. The table shows a wide range of aspect ratios among real and model lakes in previous studies. A high aspect ratio does not necessarily mean that the lake has more 
Table 5.1. Lake aspect ratios from published studies of lake-groundwater interaction. For lakes reported by Shaw and Prepas (1990), aspect ratios were calculated as the ratio of radius for a circular lake of equivalent area to depth.

\begin{tabular}{|c|c|c|c|c|}
\hline Author(s) & Lake name & Location & Type of study & Aspect ratio \\
\hline $\begin{array}{l}\text { Krabbenhoft et al. } \\
\text { (1990a) }\end{array}$ & Sparkling & Wisconsin & $\begin{array}{l}\text { stable isotope mass } \\
\text { balance method }\end{array}$ & $25.4: 1$ \\
\hline \multirow{9}{*}{$\begin{array}{l}\text { Shaw and Prepas } \\
(1990)\end{array}$} & Island & Alberta, Canada & seepage meter & $101.6: 1$ \\
\hline & Baptiste & Alberta, Canada & seepage meter & $61.1: 1$ \\
\hline & Buffalo & Alberta, Canada & seepage meter & $738.7: 1$ \\
\hline & Jenkins & Alberta, Canada & seepage meter & $42: 1$ \\
\hline & Long & Alberta, Canada & seepage meter & $25.5: 1$ \\
\hline & Narrow & Alberta, Canada & seepage meter & $16.4: 1$ \\
\hline & S-7 & Alberta, Canada & seepage meter & $29.8: 1$ \\
\hline & Spring & Alberta, Canada & seepage meter & $50.5: 1$ \\
\hline & Tucker & Alberta, Canada & seepage meter & $216.3: 1$ \\
\hline $\begin{array}{l}\text { Cherkauer and Zager } \\
\text { (1989b) }\end{array}$ & lower Nashotah & Wisconsin & seepage meter & $53.8: 1$ \\
\hline Winter (1978) & model lake & - & numerical simuation & $160: 1$ \\
\hline Winter (1983) & model lake & - & numerical simulation & $280: 1$ \\
\hline Larson et al. (1975) & Pearl and Sallie & Minnesota & $\begin{array}{l}\text { numerical simulation } \\
\text { and seepage meter }\end{array}$ & $\begin{array}{l}50: 1 \text { (Pearl); } \\
100: 1 \text { (Sallie) }\end{array}$ \\
\hline
\end{tabular}


aerial extent. Aspect ratios of $300: 1$ for shallow lakes and 150:1 for deep lakes were used in the present study.

Lake depth is also a parameter that varies widely in nature. One of the largest lakes in U.S., lake Okeechobee in Florida, has a maximum depth of only 14 meters whereas many smaller lakes are much deeper (Heath and Conover, 1981). In the present study, the shallow lakes were 10 meters deep while the deep lakes were 20 meters deep. Lake bed slope is another parameter that varies from lake to lake. Four lake bed slopes with different lake bed slope gradient were considered in this study; steep slope ( 1 in 50), moderate slope ( 1 in 100) and low slope ( 1 in 150), and asymmetric lake ( 1 in 50 and 1 in 100 on opposite sides of the lake).

\subsubsection{Hydraulic Conductivities and Anisotropy}

Hydraulic conductivities vary due to the variability of the local geology over short distances. To simulate groundwater flow, hydraulic conductivities of the porous medium have to be defined. The hydraulic conductivity in the porous medium surrounding the lakes was taken to be anisotropic $\left(\mathrm{K}_{\mathrm{xx}}=\mathrm{K}_{\mathrm{yy}}\right.$ $=\mathrm{K}_{\mathrm{h}} \neq \mathrm{K}_{\mathrm{zz}}=\mathrm{K}_{\mathrm{v}}$ ) in most simulations, though isotropy was assumed for some simulations. Also, the medium was assumed homogeneous except for those simulations that included a high conductivity zone as an explicit heterogeneity. 
The horizontal hydraulic conductivity of the porous medium was taken to be $1 \mathrm{~m} /$ day, typical of medium to fine sand size material (Freeze and Cherry, 1979). Anisotropy ratios of 1 to 1000 meant that vertical hydraulic conductivity varied between $1 \mathrm{~m} /$ day and $10^{-3} \mathrm{~m} /$ day. The horizontal hydraulic conductivity of the high conductivity zone used in some simulations was 100 $\mathrm{m} /$ day, and that of the lake sediment used in some simulations was three orders of magnitude less than the vertical hydraulic conductivity of the main porous medium.

Anisotropy is the variable that is most difficult to measure, yet it is the most sensitive variable in the simulation of groundwater flow near lakes (Winter, 1976). Reported values of anisotropy vary from nearly one (isotropic) to 500 or more. This study considered anisotropic ratios of $1,10,100$, and 1000. Values of the hydraulic conductivity and anisotropy reported in different studies are compiled in Table 5.2.

\subsubsection{Recharge rates}

Recharge was the sole water source in the simulations of inflow lakes. The model assumes that the recharge is uniformly distributed over the uppermost layer. Recharge was not used for the simulations of flow-through lakes. Refer to section 5.2.5 for the water source in flow-through lakes. Table 
Table 5.2. Hydraulic conductivity $\left(\mathrm{K}_{\mathrm{h}}\right)$ and anisotropy ratio $(\mathrm{R})$ of the porous medium, and hydraulic conductivity of lake sediments $\left(\mathrm{K}_{\mathrm{s}}\right)$, from published studies of lake groundwater interaction. Eckhardt and Eliezer (1983) reported a mean hydraulic conductivity, but did not specify the type of mean (e.g., arithmetic, geometric, or harmonic).

\begin{tabular}{|c|c|c|c|c|c|c|}
\hline \multirow{2}{*}{ Author(s) } & \multirow{2}{*}{ Place of study } & \multirow{2}{*}{ Type of study } & \multirow{2}{*}{$\begin{array}{l}\text { Geology of the } \\
\text { area }\end{array}$} & \multicolumn{2}{|l|}{ Porous medium } & \multirow{2}{*}{$\begin{array}{l}\text { Lake } \\
\text { sediments }\end{array}$} \\
\hline & & & & $\mathrm{K}_{\mathrm{h}}$ (m/day) & $\mathrm{R}$ & \\
\hline $\begin{array}{l}\text { Krabbenhoft et al. } \\
\text { (1990b) }\end{array}$ & Wisconsin & $\begin{array}{l}\text { stable isotope plume } \\
\text { and numerical } \\
\text { analysis }\end{array}$ & glacial deposits & $\begin{array}{l}0.08-6.91 ; \\
\text { geometric mean } \\
=0.6912\end{array}$ & 4 and 100 & 0.00086 \\
\hline Winter (1983) & - & numerical simulation & - & 0.0305 and 4.57 & $\begin{array}{l}100 \text { and } \\
500\end{array}$ & 0.00305 \\
\hline Larson et al. (1975) & $\begin{array}{l}\text { West central } \\
\text { Minnesota }\end{array}$ & numerical simulation & $\begin{array}{l}\text { surficial outwash } \\
\text { aquifer }\end{array}$ & 98 & 10 & 0.000098 \\
\hline Emmons (1990) & $\begin{array}{l}\text { Brown } \\
\text { County, } \\
\text { South Dakota }\end{array}$ & numerical simulation & $\begin{array}{l}\text { glacial aquifer } \\
\text { system }\end{array}$ & $\begin{array}{l}3-106.7 \\
\text { arithmetic mean } \\
=90\end{array}$ & 10 & - \\
\hline $\begin{array}{l}\text { Winter (1976, } \\
1978 \mathrm{a})\end{array}$ & - & numerical simulation & - & 0.06 and 61 & $\begin{array}{l}1,10,100 \\
1000\end{array}$ & $\begin{array}{l}0.00006 \\
\text { and } 0.061\end{array}$ \\
\hline $\begin{array}{l}\text { Eckhardt and } \\
\text { Eliezer (1983) }\end{array}$ & $\begin{array}{l}\text { Long Island, } \\
\text { New York }\end{array}$ & field study & glacial deposits & $\begin{array}{l}43-115 \\
67 \text { (mean) }\end{array}$ & $5-24$ & - \\
\hline $\begin{array}{l}\text { McClymonds and } \\
\text { Franke (1972) }\end{array}$ & $\begin{array}{l}\text { Long Island, } \\
\text { New York }\end{array}$ & field study & glacial deposits & $12-16$ & $30-60$ & - \\
\hline
\end{tabular}


Table 5.2 (contd.)

\begin{tabular}{|c|c|c|c|c|c|c|}
\hline \multirow{2}{*}{ Author(s) } & \multirow{2}{*}{ Place of study } & \multirow{2}{*}{ Type of study } & \multirow{2}{*}{$\begin{array}{l}\text { Geology of the } \\
\text { area }\end{array}$} & \multicolumn{2}{|c|}{ Porous medium } & \multirow{2}{*}{$\begin{array}{l}\text { Lake } \\
\text { sediments }\end{array}$} \\
\hline & & & & $\mathrm{K}_{\mathrm{h}}(\mathrm{m} / \mathrm{day})$ & $\mathrm{R}$ & \\
\hline Getzen (1977) & $\begin{array}{l}\text { Long Island, } \\
\text { New York }\end{array}$ & analog model analysis & $\begin{array}{l}\text { glacial deposits } \\
\text { and surficial } \\
\text { outwash }\end{array}$ & $\begin{array}{l}40-80 \\
12-16\end{array}$ & $\begin{array}{l}10-24 \\
13-13\end{array}$ & - \\
\hline $\begin{array}{l}\text { McBride and } \\
\text { Pfannkuch (1975) }\end{array}$ & $\begin{array}{l}\text { Lake Sallie, } \\
\text { Minnesota }\end{array}$ & $\begin{array}{l}\text { numerical simulation } \\
\text { and seepage meter }\end{array}$ & glacial outwash & 86.4 & $\begin{array}{l}10 \text { (used in } \\
\text { numerical } \\
\text { simulation) }\end{array}$ & $3.5 \times 10^{-5}$ \\
\hline
\end{tabular}

Table 5.3. Recharge rates from published studies.

\begin{tabular}{|l|l|l|l|l|}
\hline Author(s) & Place of study & Type of study & $\begin{array}{l}\text { Recharge rate } \\
\text { (cm/year) }\end{array}$ & Geology of the area \\
\hline $\begin{array}{l}\text { Krabbenhoft et al. } \\
(1990 \mathrm{~b})\end{array}$ & Wisconsin & $\begin{array}{l}\text { stable isotope plume } \\
\text { and numerical analysis }\end{array}$ & 22 and 39 & fine sand and gravel \\
\hline $\begin{array}{l}\text { Cherkauer and } \\
\text { Mckereghan (1991) }\end{array}$ & $\begin{array}{l}\text { Door Peninsula, } \\
\text { Wisconsin }\end{array}$ & seepage meter & $4-45$ & $\begin{array}{l}\text { fractured dolomite } \\
\text { overlain by glacial } \\
\text { sediments }\end{array}$ \\
\hline $\begin{array}{l}\text { Krulikas and Giese } \\
(1995)\end{array}$ & $\begin{array}{l}\text { Lee and Hendry } \\
\text { Counties, Florida }\end{array}$ & $\begin{array}{l}\text { chloride concentration } \\
\text { ratio and flow tube } \\
\text { method }\end{array}$ & $1.5-22$ & glacial aquifer system \\
\hline
\end{tabular}


Table 5.3 (contd.)

\begin{tabular}{|l|l|l|l|l|}
\hline Author(s) & Place of study & Type of study & $\begin{array}{l}\text { Recharge rate } \\
\text { (cm/year })\end{array}$ & Geology of the area \\
\hline Emmons (1990) & $\begin{array}{l}\text { Brown County, South } \\
\text { Dakota }\end{array}$ & numerical simulation & less than 17.5 & glacial aquifer system \\
\hline Vecchioli et al. (1990) & $\begin{array}{l}\text { Okeechobee, Pasco, } \\
\text { and Valusia Counties, } \\
\text { Florida }\end{array}$ & field study & less than 30 & $\begin{array}{l}\text { unconsolidated sand } \\
\text { and gravel }\end{array}$ \\
\hline Bradner (1994) & $\begin{array}{l}\text { Okeechobee County, } \\
\text { Florida }\end{array}$ & field study & $2.5-26.5$ & $\begin{array}{l}\text { unconsolidated sand } \\
\text { and gravel }\end{array}$ \\
\hline Harte et al. (1992) & $\begin{array}{l}\text { Milford - Souhegan, } \\
\text { New Hampshire }\end{array}$ & numerical simulation & $\begin{array}{l}2.5-78.5 \\
55 \text { (average) }\end{array}$ & glacial drift aquifer \\
\hline
\end{tabular}

Table 5.4. Thickness of the surficial aquifer from published studies.

\begin{tabular}{|l|l|l|l|l|}
\hline Author(s) & Location & Type of study & $\begin{array}{l}\text { Aquifer thickness } \\
(\mathrm{m})\end{array}$ & Geology of the area \\
\hline $\begin{array}{l}\text { Krabbenhoft et al. } \\
(1990 \mathrm{~b})\end{array}$ & $\begin{array}{l}\text { Sparkling Lake, } \\
\text { Wisconsin }\end{array}$ & $\begin{array}{l}\text { stable isotope plume and } \\
\text { numerical simulation }\end{array}$ & 50.0 & $\begin{array}{l}\text { layering of fine sand to } \\
\text { gravel }\end{array}$ \\
\hline Winter (1983) & - & numerical simulation & 19.0 & - \\
\hline $\begin{array}{l}\text { Fish and Stewart } \\
(1991)\end{array}$ & Dade County, Florida & field study & $53.34-64.0$ & deep surficial aquifer \\
\hline
\end{tabular}


Table 5.4 (contd.)

\begin{tabular}{|c|c|c|c|c|}
\hline Author(s) & Location & Type of study & Aquifer thickness (m) & Geology of the area \\
\hline Franks (1980) & $\begin{array}{l}\text { US naval station, } \\
\text { Mayport, Florida }\end{array}$ & field study & $7.6-15.2$ & $\begin{array}{l}\text { unconsolidated sand, } \\
\text { clay, shell }\end{array}$ \\
\hline $\begin{array}{l}\text { Causey and Phelps } \\
\text { (1978) }\end{array}$ & $\begin{array}{l}\text { US naval station, } \\
\text { Mayport, Florida }\end{array}$ & field study & 21.33 & $\begin{array}{l}\text { unconsolidated sand, } \\
\text { clay, shell }\end{array}$ \\
\hline Larson et al. (1975) & west central Minnesota & numerical simulation & $0-9.15$ & outwash aquifer \\
\hline Emmons (1990) & $\begin{array}{l}\text { Brown County, South } \\
\text { Dakota }\end{array}$ & numerical simulation & $9.1-15.2$ & $\begin{array}{l}\text { glacial aquilier } \\
\text { system }\end{array}$ \\
\hline Bradner (1994) & $\begin{array}{l}\text { Okeechobee County, } \\
\text { Florida }\end{array}$ & field study & $60-75$ & $\begin{array}{l}\text { unconsolidated sand } \\
\text { and gravel }\end{array}$ \\
\hline $\begin{array}{l}\text { Krulikas and Giese } \\
\text { (1995) }\end{array}$ & $\begin{array}{l}\text { Lee and Hendry } \\
\text { Counties, Florida }\end{array}$ & $\begin{array}{l}\text { chloride concentration } \\
\text { ratio and flow tube } \\
\text { method }\end{array}$ & $30-36$ & glacial aquifer system \\
\hline
\end{tabular}


5.3 shows published data on recharge rates. Though rates vary greatly among sites, recharge rates between 10 and $20 \mathrm{~cm} /$ year are not uncommon. Most simulations for inflow lakes were carried out using a recharge rate of 10 $\mathrm{cm} /$ year, though a few were done with recharge set at $20 \mathrm{~cm} /$ year.

\subsubsection{Hydraulic gradient}

To simulate groundwater flow in flow through lakes, a regional groundwater head was fixed across the model domain. Eckhardt and Eliezer (1985) reported a horizontal hydraulic gradient of 0.0012 in a glacial till aquifer. The vertical gradient measured in that study was equal to 0.0005 and was computed from effective porosity, hydraulic conductivity and anisotropy. A horizontal hydraulic gradient of 0.005 was used in the present study. 


\section{CHAPTER 6}

\section{Results : Comparison Between 2-D and 3-D Simulations}

Two-dimensional models of lake-groundwater interaction may be set up and run more easily and quickly than 3-D models, though 3-D models allow a more realistic treatment of the geometry of lake-groundwater systems. In effect, a 2-D vertical cross-section model through such a system shows the flow patterns that would apply in a vertical cross-section normal to the long axis of a lake of quasi-infinite length. However, in nature most lakes are more round than linear, and groundwater exchange with a round lake may differ considerably from exchange with a linear lake (e.g., Winter, 1978).

Simulations of shallow inflow lakes with moderate slope were run for both 2-D and 3-D model, in order to quantify the differences in lake seepage between the two types of models. The design of the 2-D setting is identical to a vertical cross-section through the center of the 3-D model. The 2-D models were composed of 60 columns and 15 layers with a single row; the 3-D models were $60 \times 60 \times 15$ (Fig. 6.1). In both 2-D and 3-D models, the lake occupied the center portion of the upper 5 layers, and narrowed from 20 cells in width in the top layer to 12 cells in the fifth layer. The horizontal hydraulic conductivity $\left(\mathrm{K}_{\mathrm{h}}\right)$ was $1 \mathrm{~m} /$ day, the recharge rate $(\mathrm{I})$ was $10 \mathrm{~cm} /$ year, and layer thicknesses 

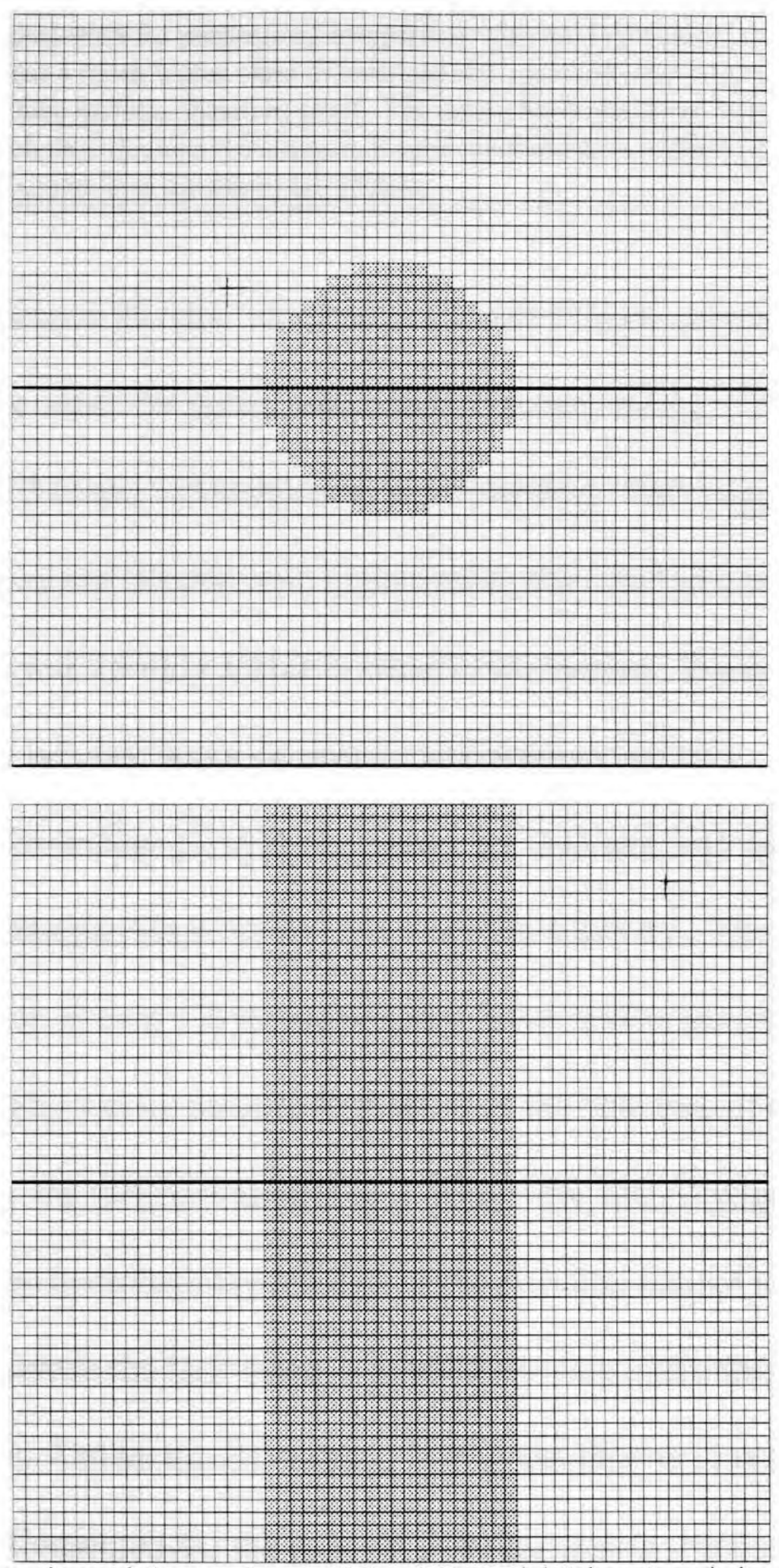

Fig. 6.1. Map view of the top layer of the 3-D model (above) and the top layer of a hypothetical 3-D model that would be equivalent to the 2-D model (below). In reality, the 
2-D model consisted of a single row (from left to right in the figure), but it is shown here as a series of identical rows for purposes of comparison with the 3-D model. It is apparent that the 3-D model has a much higher ratio of recharge area (ground surface shown in white) to discharge area (lake surface, shown in grey). The heavy black line from left to right through the center of each model marks the location of cross-sections along which head and seepage rate are plotted in the later figures in this chapter.

were the same as in all other simulations (the top 5 layers were each 2 meters thick and the other 10 layers were each 4 meters thick). The boundary conditions of 2-D and 3-D simulations were identical. The vertical sides and bottom of the model domain were impermeable, the lake had a constant head, and recharge was the only source of water to the system. The lake behaved as a sink (the lake bed was a constant head discharge surface).

The distribution of hydraulic heads for 2-D and 3-D simulations at different anisotropic ratios $(\mathrm{R})$ are shown in Figs. 6.2 to 6.5. The heads in the porous medium in each $2-\mathrm{D}$ simulation were lower than in the respective $3-\mathrm{D}$ simulation. This can be interpreted in terms of the total area of recharge and discharge for the different models (Fig. 6.1). The 2-D settings assume no changes in any hydrological parameter in the direction normal to the vertical section. Therefore, the lake behaves as infinitely long in the direction normal to the section. Unlike the 2-D setting, in 3-D the lake was made circular in map view. Consequently, the ratio of recharge area to discharge area was 
lower in the 2-D models than in the $3-\mathrm{D}$ models ( 2 versus 10.7$)$. This difference in the proportion of recharge and discharge areas meant that lake beds in the 3-D models would experience much higher seepage, requiring higher heads in the model domain. Table 6.1 summarizes some of the head differences between the 2-D and 3-D simulations. At $\mathrm{R}=1000$, the minimum head below the lake was only 0.47 meter higher than the lake in the 2-D simulation, as opposed to almost 2.5 meters higher than the lake in the $3-\mathrm{D}$ simulation. The maximum head was 66.36 meters at $R=1000$ for the $2-D$ simulation, while it was 81.83 meters in the 3-D simulation.

\begin{tabular}{|c|c|c|c|c|}
\hline Shallow inflow lake & \multicolumn{4}{|c|}{ Anisotropy (R) } \\
\cline { 2 - 5 } with moderate slope & $\mathrm{R}=1$ & $\mathrm{R}=10$ & $\mathrm{R}=100$ & $\mathrm{R}=1000$ \\
\hline 2-D & $50.00,60.32$ & $50.00,60.69$ & $50.02,62.00$ & $50.47,66.36$ \\
\hline 3-D & $50.00,69.17$ & $50.00,70.53$ & $50.12,73.51$ & $52.44,81.83$ \\
\hline
\end{tabular}

Table 6.1. Representative head values for the 2-D and 3-D simulations compared in this chapter. Each of the 8 boxes with 2 numbers gives the minimum head just below the lake (rounded to the nearest $10 \mathrm{~cm}$ ) followed by the highest head along the vertical section shown in Fig. 6.1 (found on the water table at the edge of the model domain).

Seepage rate of each cell at the lake bed was computed by dividing the total volumetric seepage in to the cell by the total area of the cell exposed to the lake bed. Seepage rates were plotted against distance offshore for 2-D and 3-D simulations (Fig. 6.6 and Fig. 6.7). At low anisotropy ratios (e.g., 1 and 
10), the general trend of these plots shows an exponential decrease of seepage rates with distance offshore (Fig. 6.8). At higher anisotropy ratios (i.e., 100 and 1000) the seepage rate diverged somewhat from the exponential trend, especially the high seepage at the shore line (Fig. 6.9).

Other authors have found evidence for an exponential decrease in seepage rate with distance offshore, at least at low anisotropy. Mcbride et al. (1975) simulated a lake-groundwater system through numerical modeling and assumed an anisotropy ratio of 10 for each model. They showed a linear relationship between the logarithm of seepage rate and distance from the shore. They also measured seepage rates in Lake Sallie, Becker County, West Central Minnesota, and found that the results supported the same general conclusion as described from the model (the anisotropy ratio of the site was not mentioned). Cherkauer et al. (1989b) conducted seepage meter studies to investigate the relationship of seepage fluxes to distance from the shore in lower Nashotah lake in Wisconsin. They documented an exponential decrease of seepage rate with distance offshore on the upgradient side of the lake. They also mentioned that the anisotropy ratio for that groundwater system was unknown and had assumed an anisotropy ratio of 20 based on information from Weeks (1960). Shaw et al. (1990) measured the seepage fluxes of lakes 
in Central Alberta and concluded that seepage fluxes decreased "significantly" with distance from shore in five of nine lakes. They did not mention whether the trend was exponential and did not give the ratio of anisotropy of the study sites. Cherkauer et al. (1989a) mentioned an anisotropy ratio on the order of 5000 in Great Lake sites and measured the seepage fluxes at 26 sites on the upper Great Lakes and their connecting channels. They found seepage rate decreased "continually" away from the shore in some sites, but the relevance of anisotropy ratio to seepage patterns was not discussed. Fellows et al. (1980) measured the exponential decay pattern of seepage rates offshore in Floridian lakes. They correlated the deviation from the exponential pattern with variation in sediment hydraulic conductivity. The anisotropy ratio of those sites were not mentioned. As the trend of the seepage pattern is found to be probably related to anisotropy ratio from the present study, a discussion regarding the relationship to anisotropy ratio is included in chapter 10 . At low anisotropy $(\mathrm{R}=1, \mathrm{R}=10)$, seepage rates nearshore in 2-D simulations were less than in the 3-D simulations. Offshore seepage rates at low anisotropy (i.e., $\mathrm{R}=1,10$ ) were almost zero in both 2-D and 3-D simulations. At higher anisotropy ratios $(\mathrm{R}=100,1000)$, the seepage rates were found to be significantly lower both nearshore and offshore in 2-D simulations 
than in the corresponding 3-D simulations. The seepage rate of the fifth cell was anomalously high in the $3-\mathrm{D}$ simulation at $\mathrm{R}=1000$. This cell corresponds to the beginning of the lowermost layer of the lake, where the sloping portion of the lake bed meets the horizontal portion. At higher anisotropies, the vertical gradient was higher and the flow lines started to bend around this "corner" in the lake bed, apparently leading to high seepage at the sharp break in the lake bed slope.

Comparison between 2-D and 3-D simulation shows that the heads were higher everywhere in the porous medium in 3-D simulations. This is similar to Winter's (1978) numerical results concerning heads on the downgradient side of flow-through lakes. Seepage rates were also generally higher in 3-D simulations. These results show important differences between 2-D and more realistic 3-D models. Thus in order to more closely mimic lake-groundwater interactions in real systems, all subsequent simulations were 3-D. 


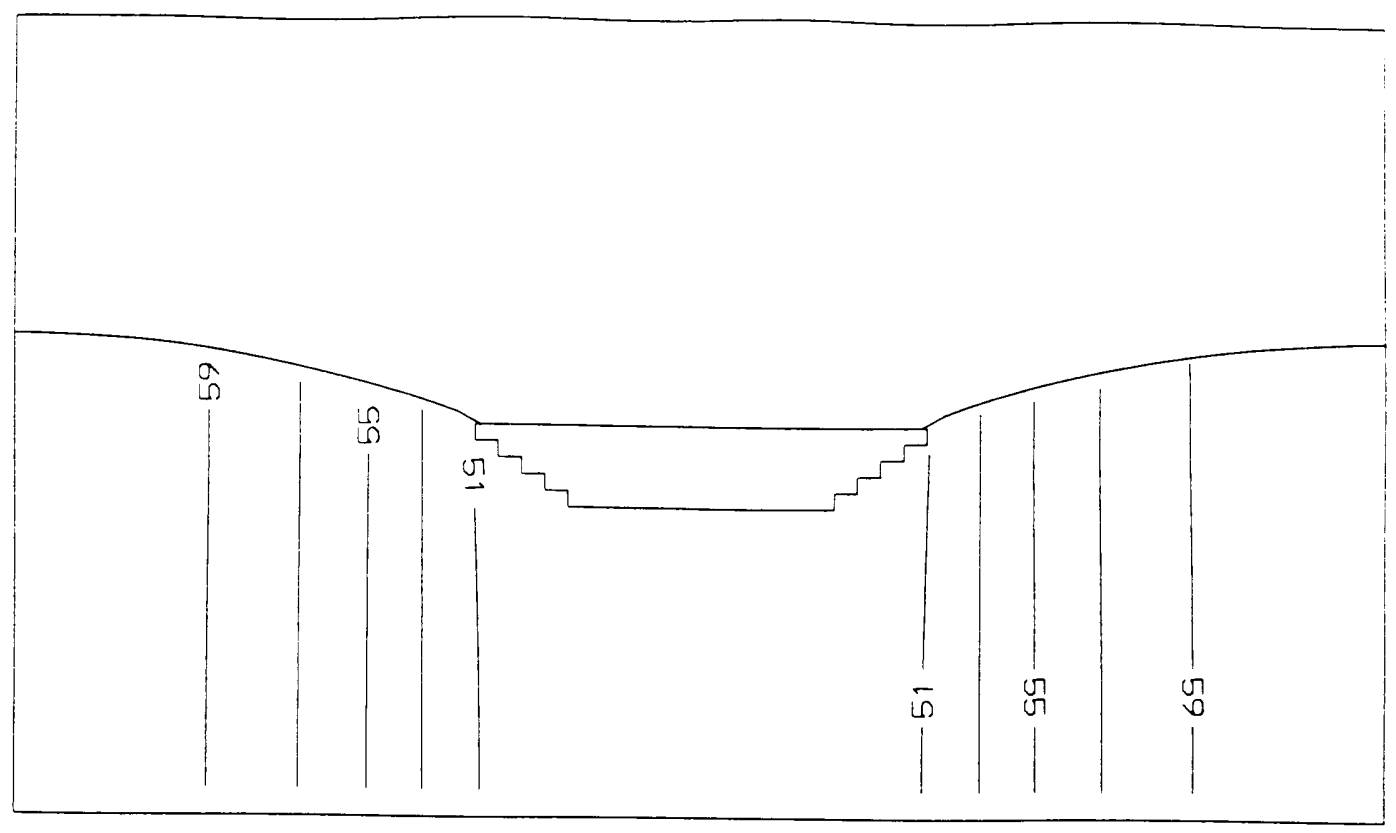

2-D simulation

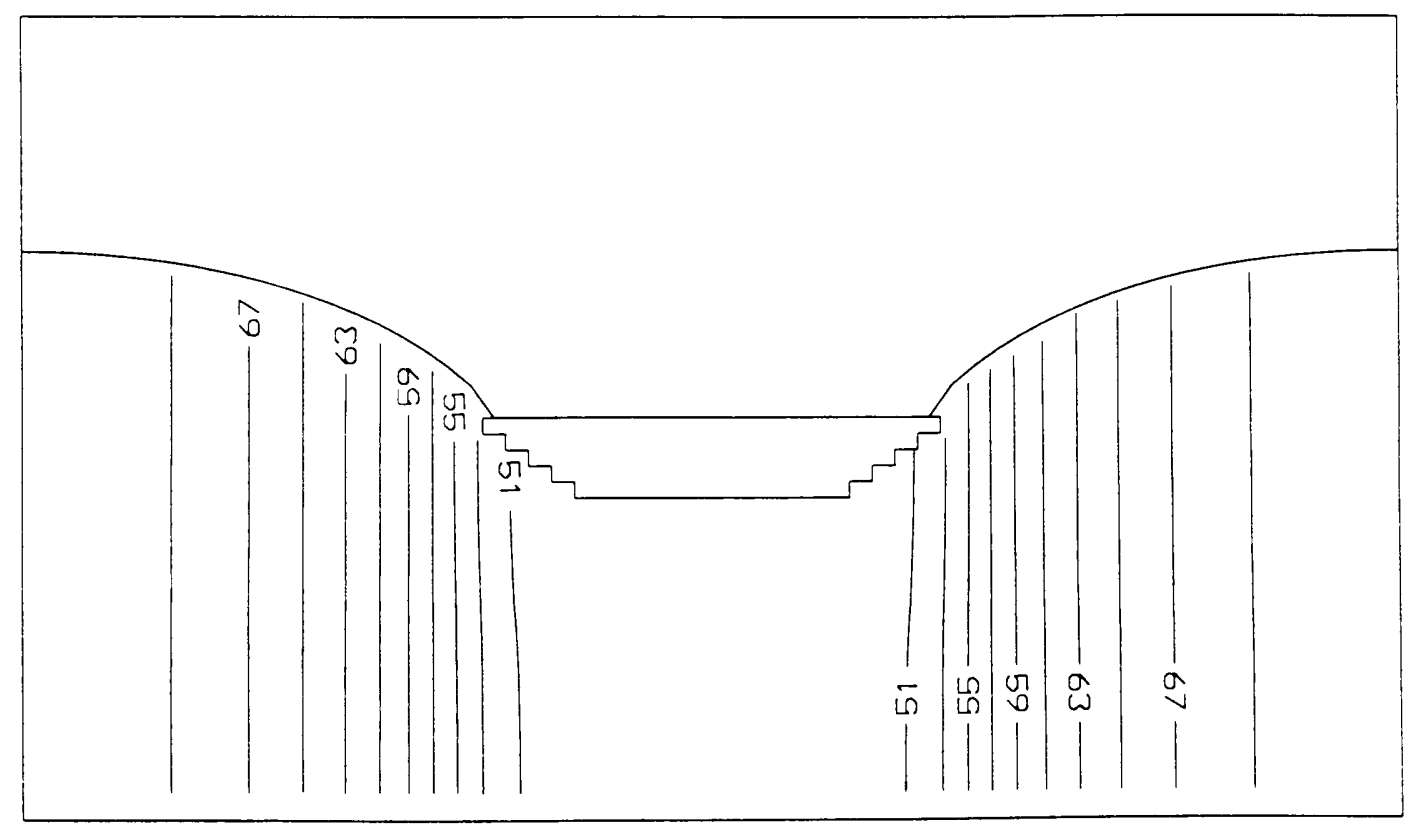

3-D simulation

Fig. 6.2. Distribution of hydraulic heads in the porous medium for 2-D and 3-D simulations of shallow inflow lakes with moderate slope at $R=1$. 


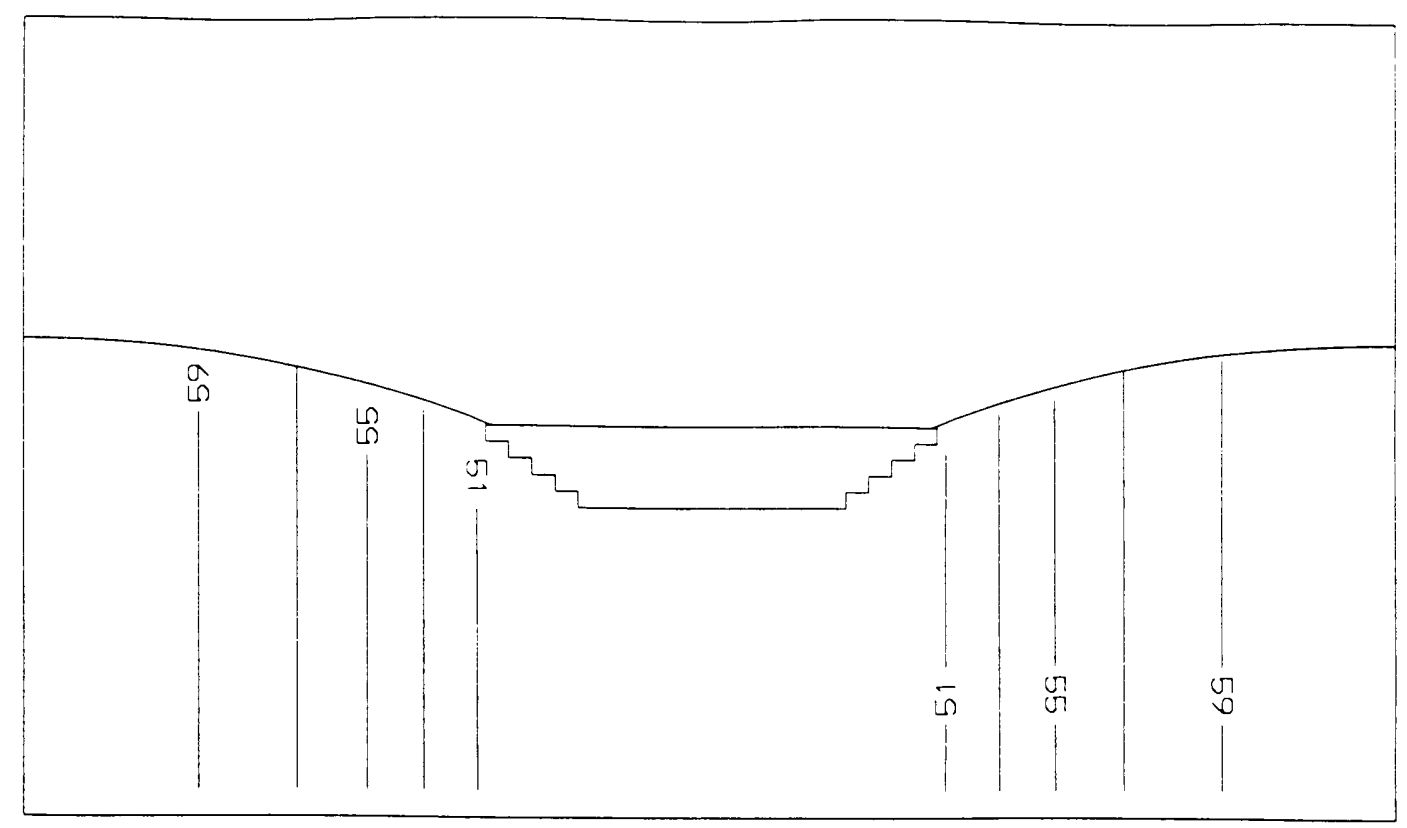

2-D simulation

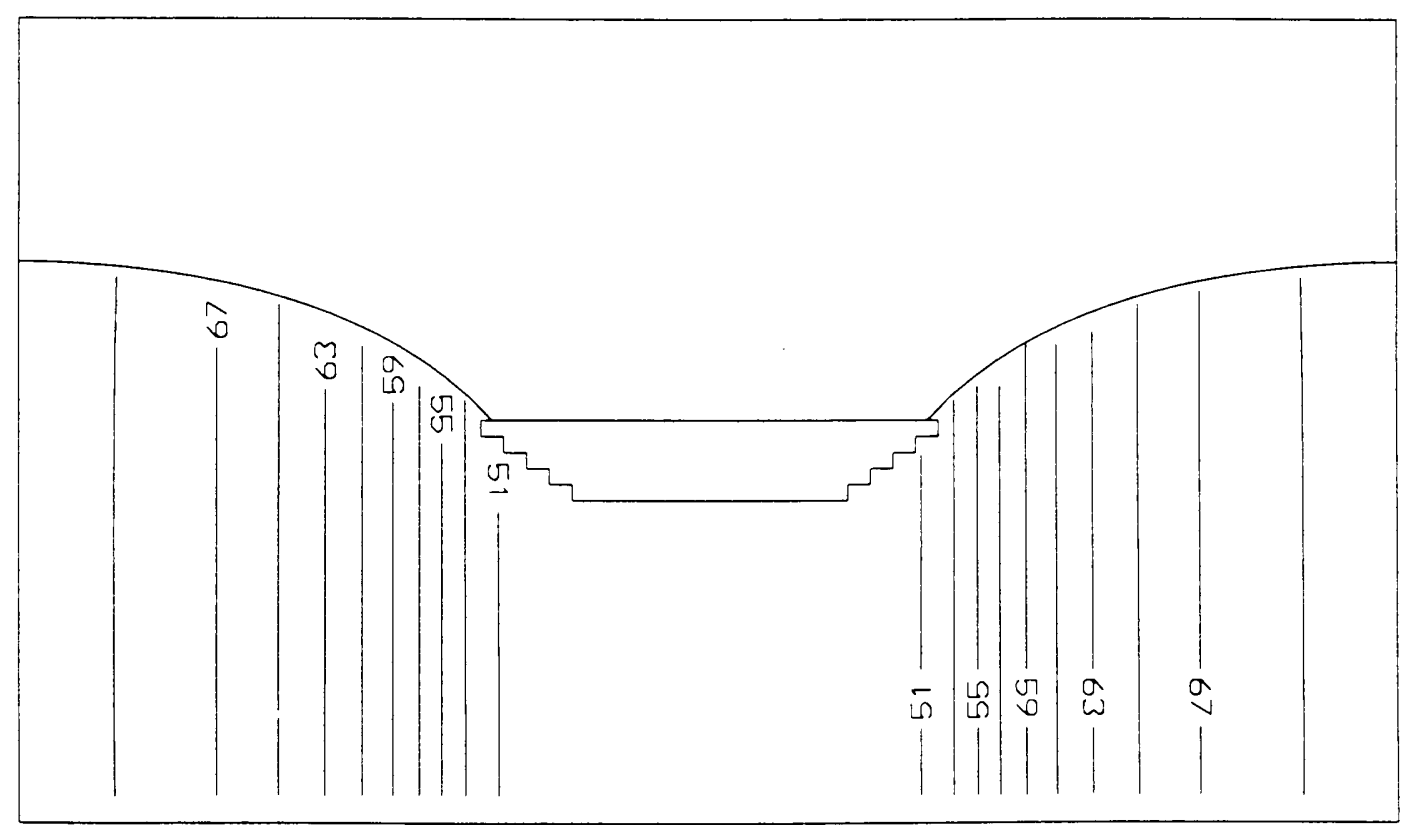

3-D simulation

Fig. 6.3. Distribution of hydraulic heads in the porous medium for 2-D and 3-D simulations of shallow inflow lakes with moderate slope at $\mathrm{R}=10$. 


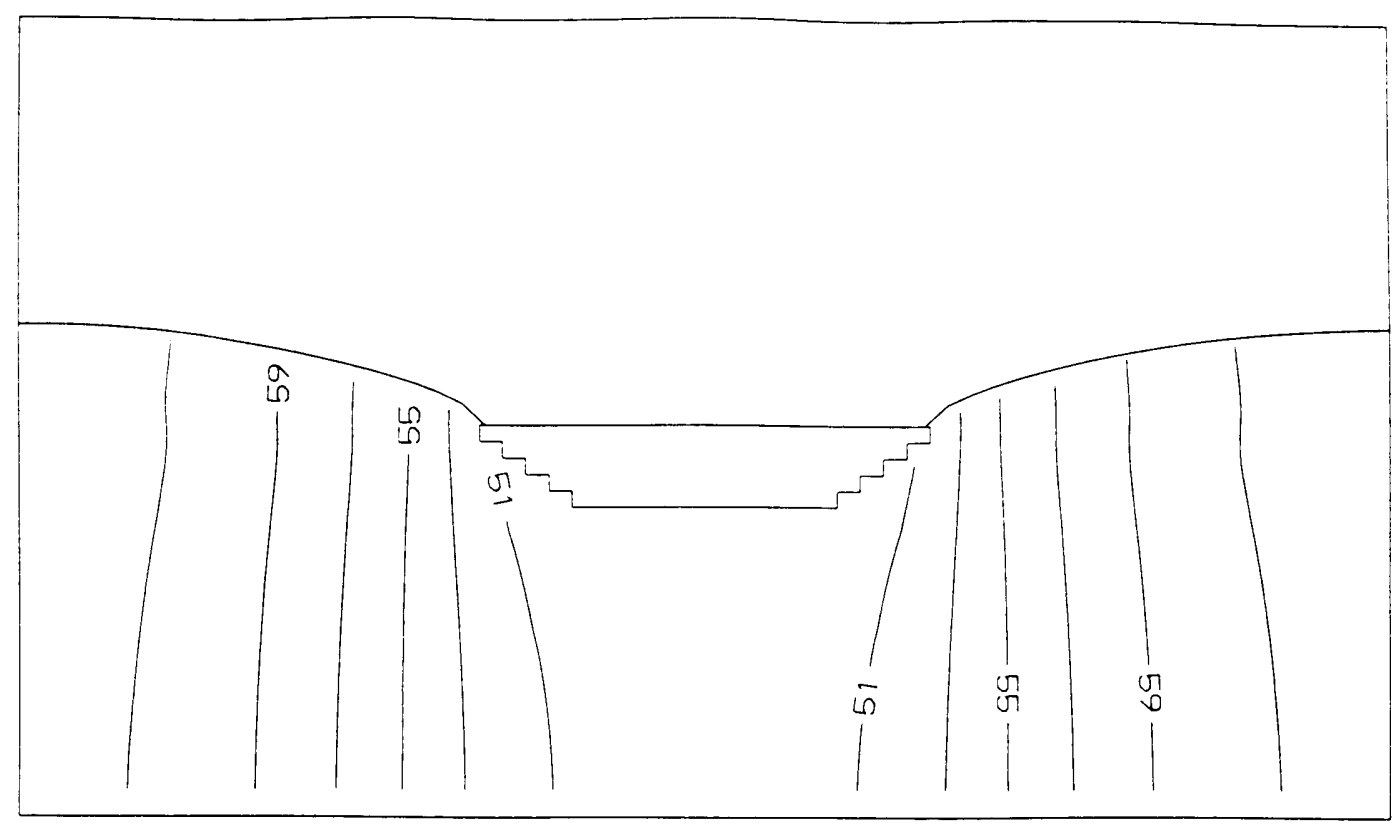

2-D simulation

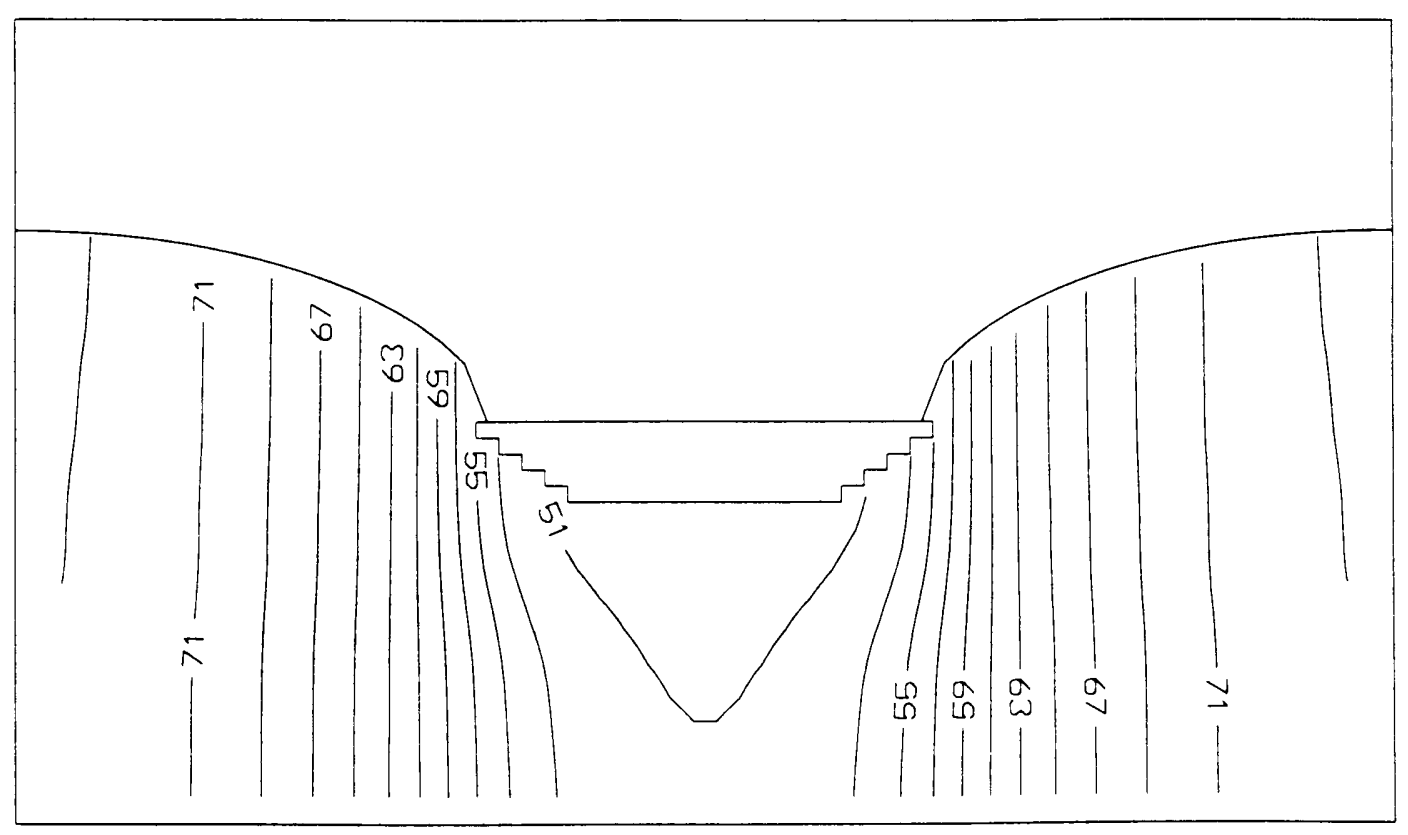

3-D simulation

Fig. 6.4. Distribution of hydraulic heads in the porous medium for 2-D and 3-D simulations of shallow inflow lakes with moderate slope at $R=100$. 


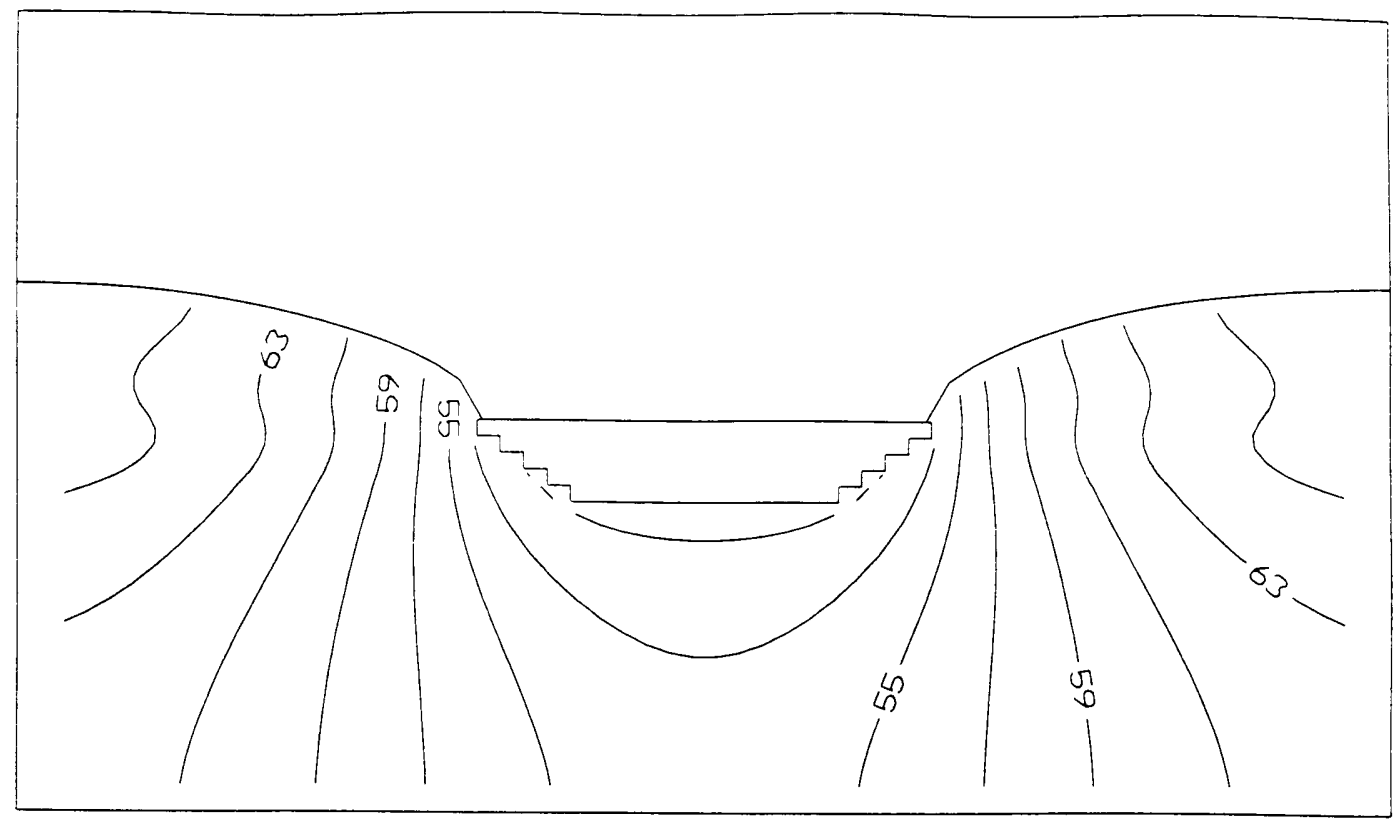

2-D simulation

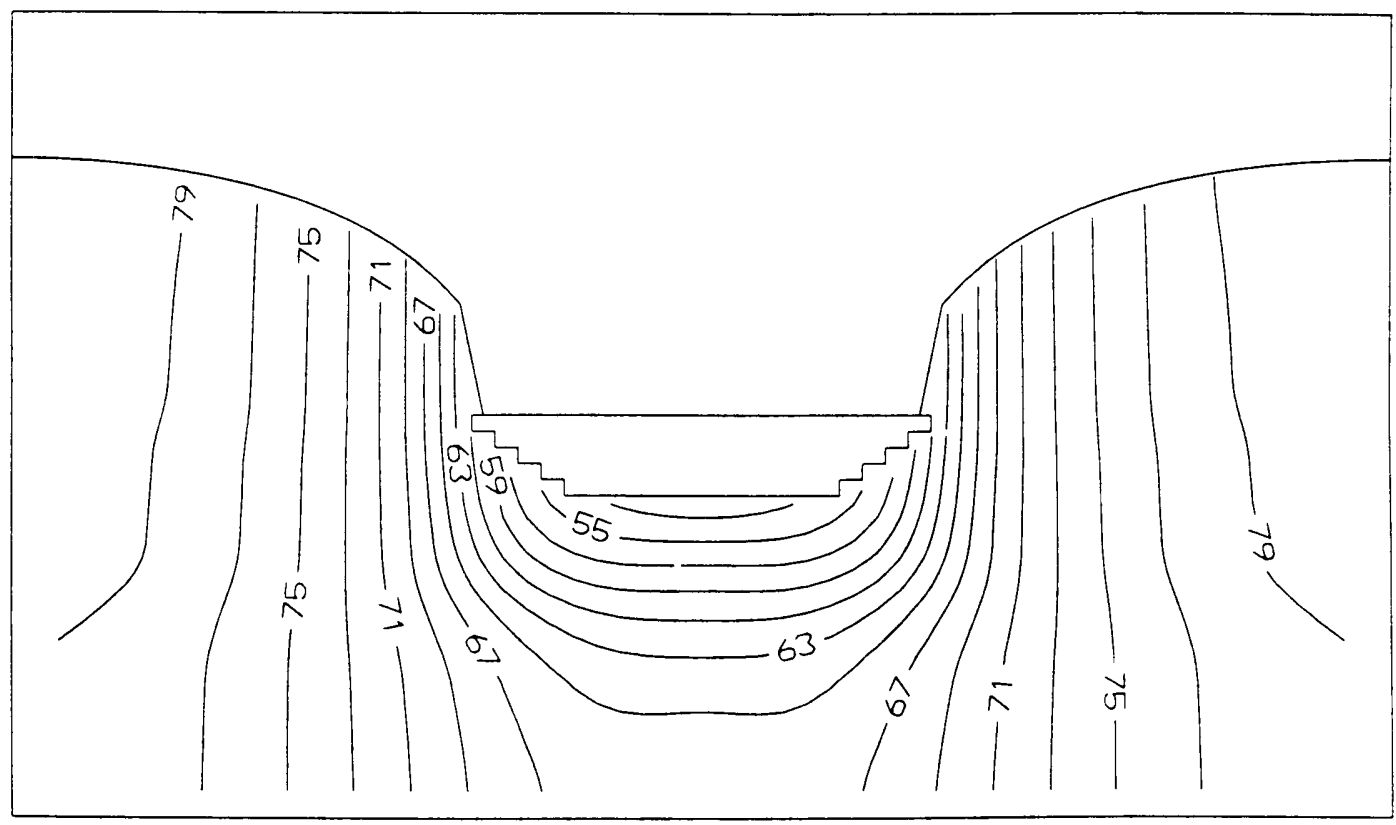

3-D simulation

Fig. 6.5. Distribution of hydraulic heads in the porous medium for 2-D and 3-D simulations of shallow inflow lakes with moderate slope at $R=1000$. 

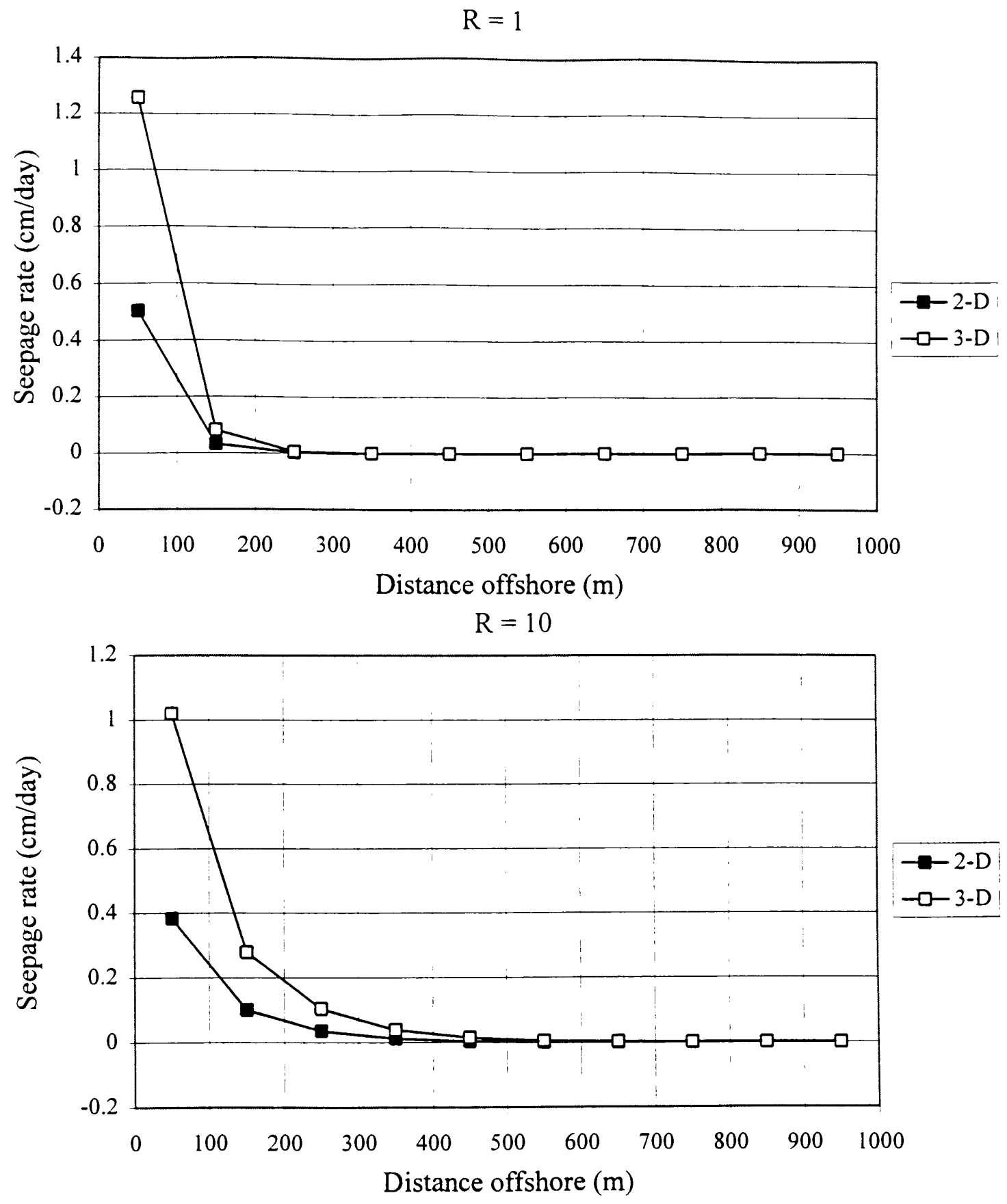

Fig. 6.6. Seepage rate versus distance offshore for 2-D and 3-D simulations of shallow inflow lakes with moderate slope at $R=1$ and $R=10$. 

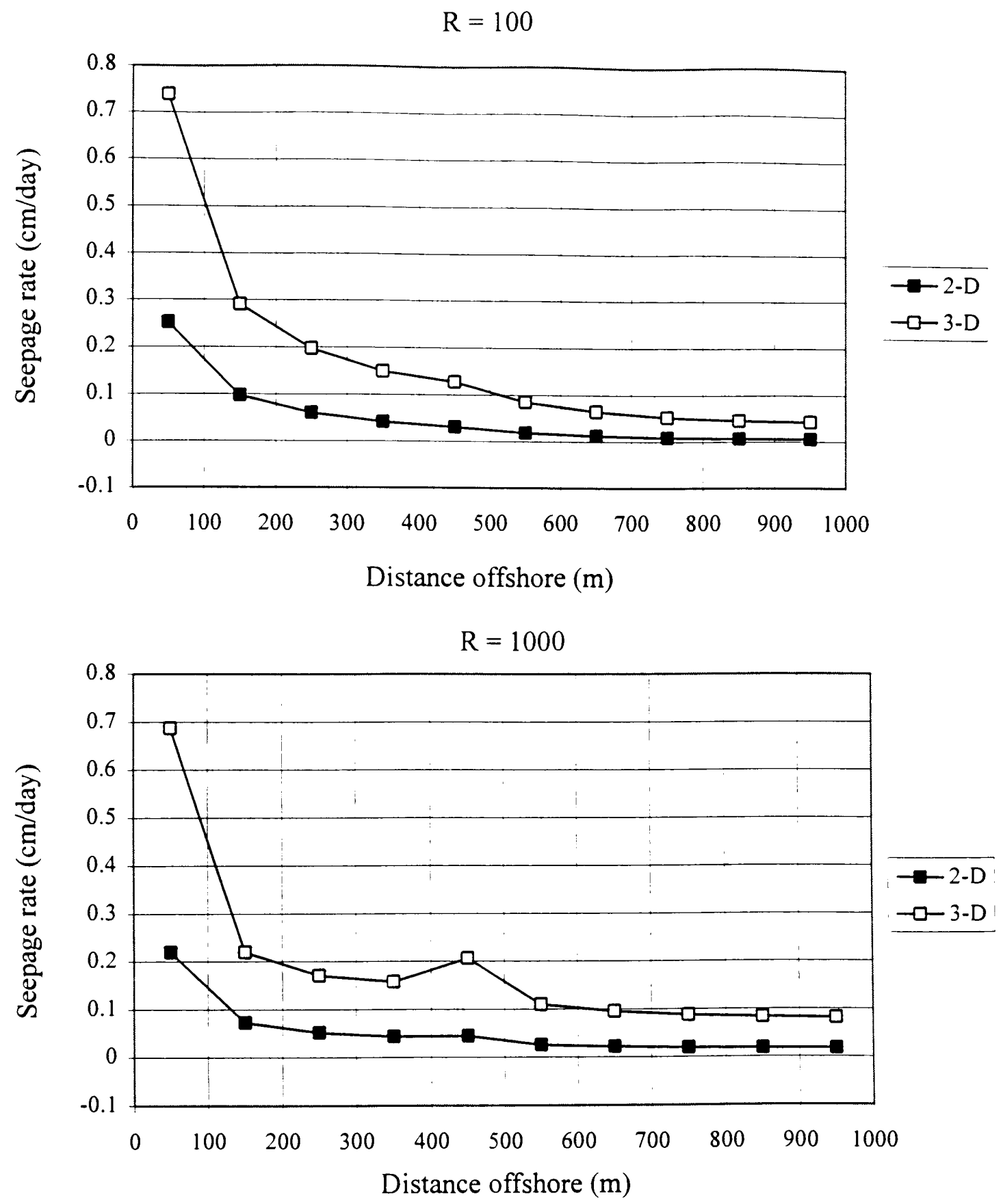

Fig. 6.7. Seepage rate versus distance offshore for $2-D$ and $3-D$ simulations of shallow inflow lakes with moderate slope at $R=100$ and $R=1000$. 


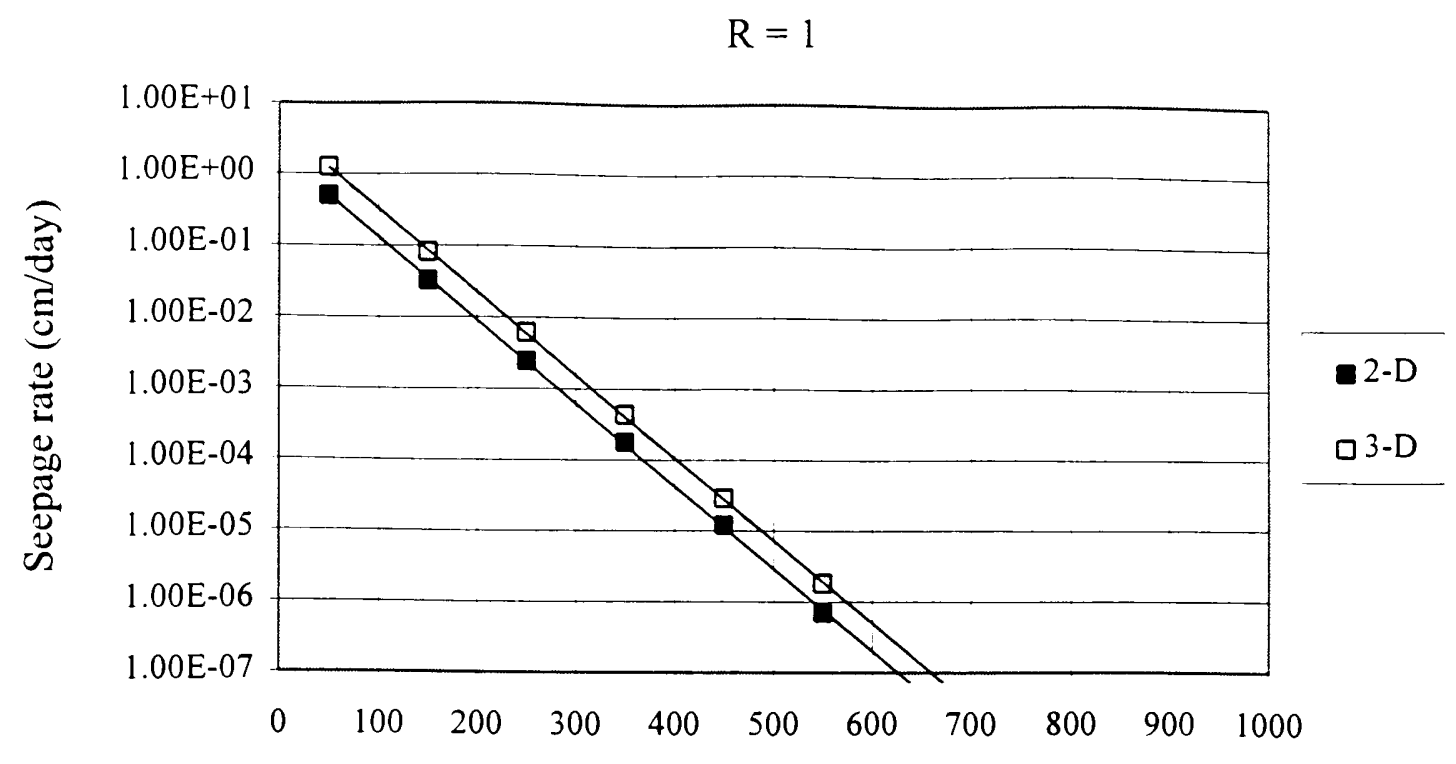

Distance offshore (m)

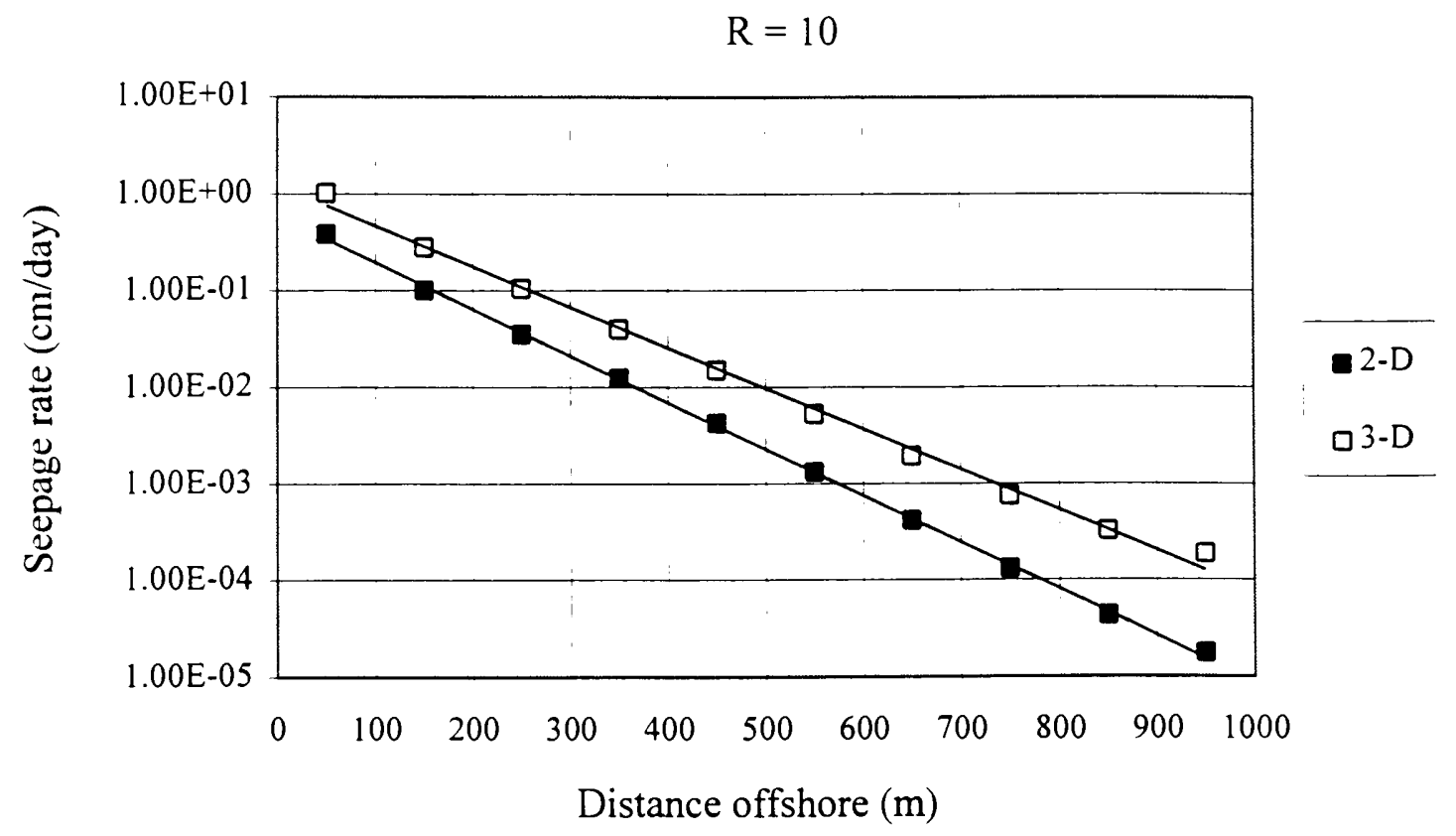

Fig. 6.8. Seepage rate (on log scale) versus distance offshore for 2-D and 3-D simulations of shallow inflow lakes with moderate slope at $R=1$ and $R=10$. The linearity in these plots indicates an exponential decline of seepage rate offshore, with a more rapid decline at $\mathrm{R}=1$. 


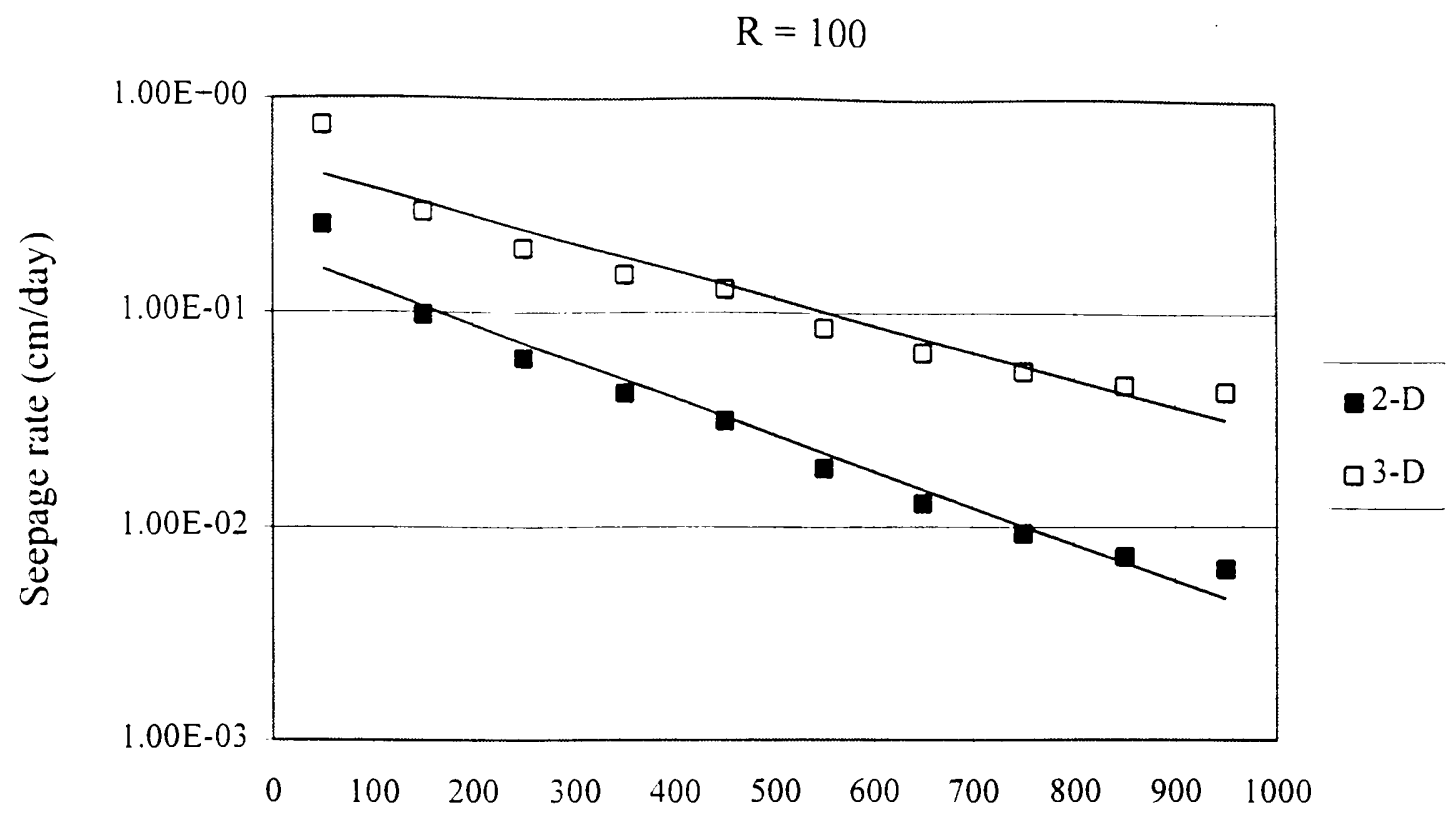

Distance offshore $(\mathrm{m})$

$\mathrm{R}=1000$

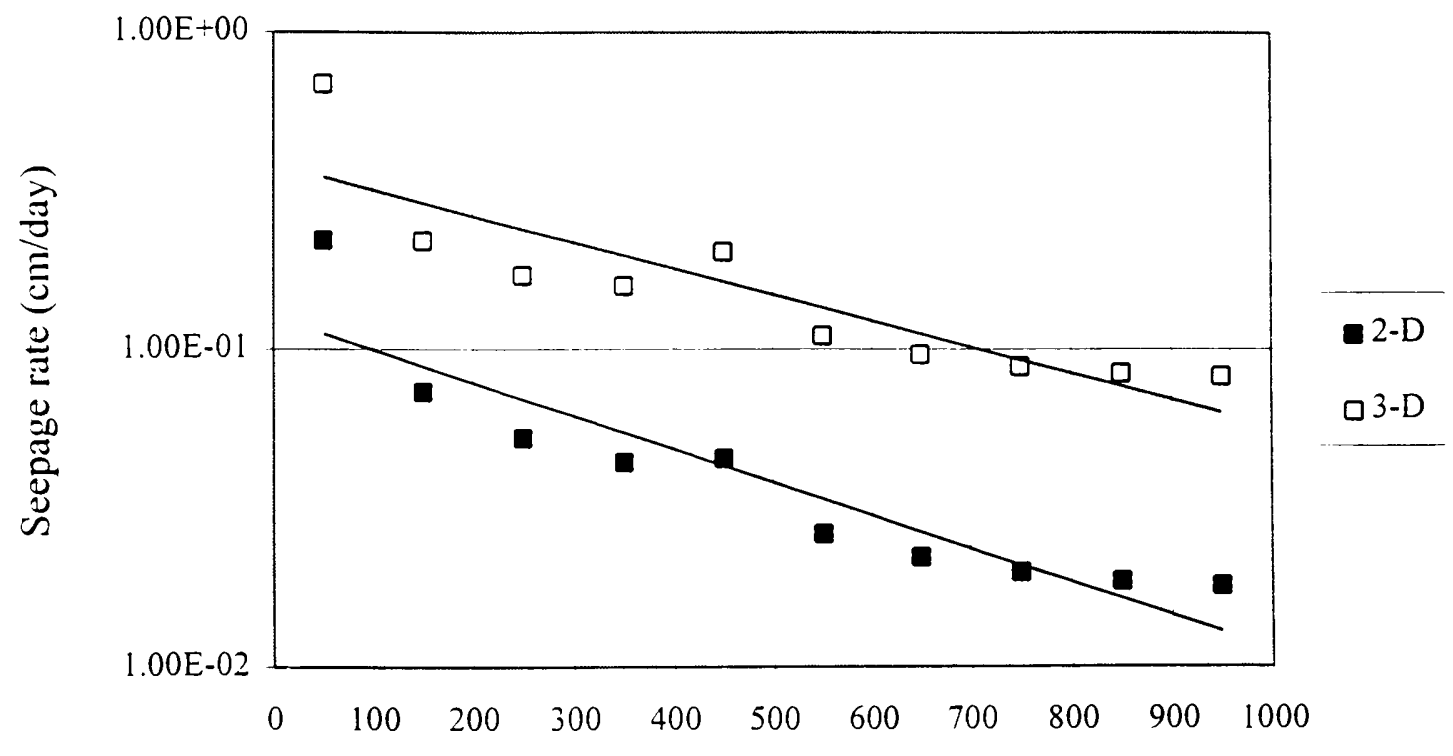

Distance offshore $(\mathrm{m})$

Fig. 6.9. Seepage rate versus distance offshore for 2-D and 3-D simulations of shallow inflow lakes with moderate slope at $R=100$ and $R=1000$. The non-linearity in lognormal plots indicate a deviation from exponential decline of seepage rate offshore at higher anisotropy ratios. especially $\mathrm{R}=1000$. 
Table 6.2. Seepage rate as a function of distance offshore for 2-D and 3-D simulations of shallow inflow lakes with moderate slope at different anisotropy ratios $\left(1,10,100\right.$, and 1000). ${ }^{*}$ denotes when seepage rate is less than $10^{-7} \mathrm{~cm} /$ day.

\begin{tabular}{|c|c|c|c|c|c|c|c|c|}
\hline \multirow{2}{*}{$\begin{array}{c}\text { Distance } \\
(\mathrm{m})\end{array}$} & \multicolumn{9}{|c|}{ Lake bed seepage rate (cm/day) } \\
\cline { 2 - 9 } & \multicolumn{2}{|c|}{$\mathrm{R}=1$} & \multicolumn{2}{c|}{$\mathrm{R}=10$} & \multicolumn{2}{c|}{$\mathrm{R}=100$} & \multicolumn{2}{c|}{$\mathrm{R}=1000$} \\
\cline { 2 - 9 } & $2-\mathrm{D}$ & $3-\mathrm{D}$ & $2-\mathrm{D}$ & $3-\mathrm{D}$ & $2-\mathrm{D}$ & $3-\mathrm{D}$ & $2-\mathrm{D}$ & $3-\mathrm{D}$ \\
\hline 50 & 0.50278 & 1.21878 & 0.38320 & 1.01571 & 0.25258 & 0.73718 & 0.21979 & 0.68651 \\
\hline 150 & 0.03243 & 0.07886 & 0.10070 & 0.27746 & 0.09721 & 0.29045 & 0.07335 & 0.21931 \\
\hline 250 & 0.00243 & 0.00596 & 0.03541 & 0.10401 & 0.06097 & 0.19753 & 0.05233 & 0.17049 \\
\hline 350 & 0.00018 & 0.00042 & 0.01245 & 0.03947 & 0.04202 & 0.14958 & 0.04395 & 0.15804 \\
\hline 450 & $1.20 \mathrm{e}-05$ & $2.84 \mathrm{e}-05$ & 0.00425 & 0.01486 & 0.03124 & 0.12797 & 0.04511 & 0.20254 \\
\hline 550 & $7.01 \mathrm{e}-07$ & $1.76 \mathrm{e}-06$ & 0.00131 & 0.00522 & 0.01886 & 0.08476 & 0.02617 & 0.10992 \\
\hline 650 & $*$ & $1.12 \mathrm{e}-07$ & 0.00041 & 0.00192 & 0.01288 & 0.06485 & 0.02215 & 0.09590 \\
\hline 750 & $*$ & $*$ & 0.00013 & 0.00074 & 0.00932 & 0.05294 & 0.01985 & 0.08797 \\
\hline 850 & $*$ & $*$ & 0.00004 & 0.00032 & 0.00727 & 0.04597 & 0.01856 & 0.08358 \\
\hline 950 & $*$ & $*$ & 0.00002 & 0.00019 & 0.00633 & 0.04272 & 0.01797 & 0.08160 \\
\hline
\end{tabular}




\section{CHAPTER 7}

\section{Results : Grid Size}

\subsection{Effects of grid size}

Groundwater flow equations developed using continuum physics and differential calculus are in principle applicable at the "point scale" (they described head and velocity at individual points, given porous medium properties, and boundary and initial conditions). However, MODFLOW and all other numerical models solve these flow equations at the "grid scale" (computing head and velocity for each rectangular cell in the model grid). In applying numerical models, it is customary to evaluate the effect of grid cell size on the results, in order to separate possible artifacts associated with grid size from true results arising correctly from the physics of the model. Generally, simulations with the same parameters and boundary/initial conditions are run for models with two different grid sizes. If the two simulations give very similar head and velocity distribution, then either grid size likely is adequate for modeling the system without introducing significant numerical artifacts. If the two simulations give significantly different results, additional grids with smaller cells should be investigated (bringing the "grid scale" closer to the "point scale"). 
Simulations of shallow inflow and flow-through lakes with moderate slope were run with different grid spacings, in order to evaluate the effect of grid spacing on hydraulic head distribution in the porous medium and lake bed seepage results. The coarse grid was composed of cells 100 meters long and

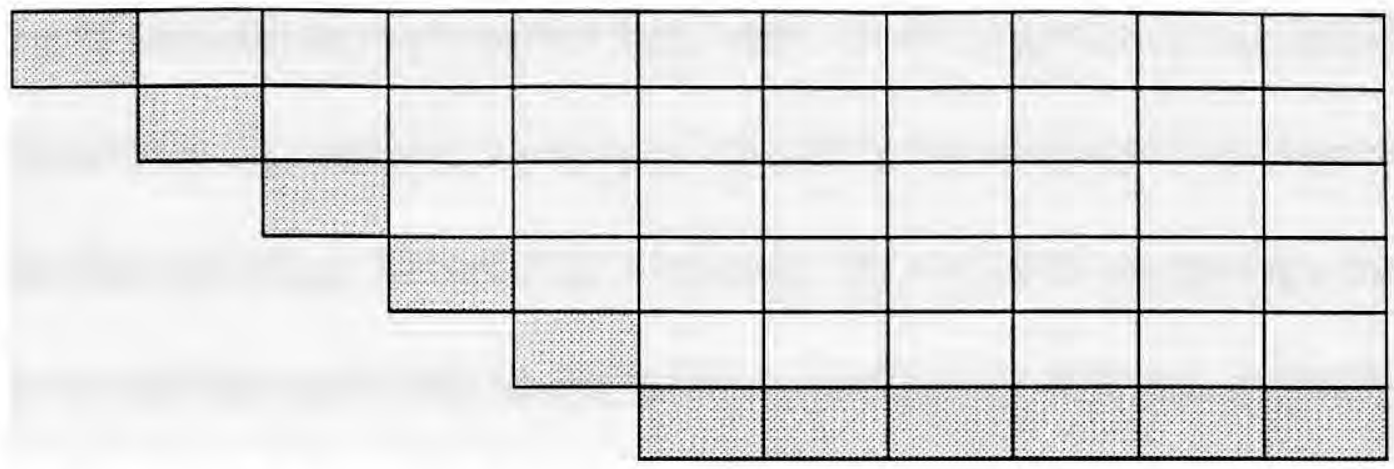

Fig. 7.1. Vertical cross section showing half of a coarse grid lake. Lake cells are white, porous medium cells are shaded.

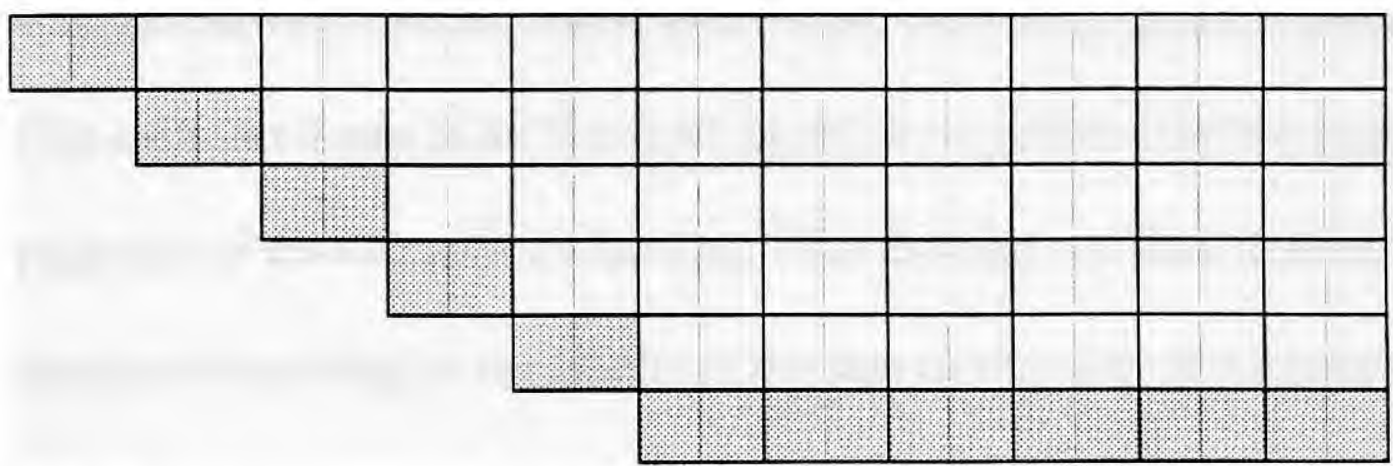

Fig. 7.2. Vertical cross-section showing half of a fine grid lake. Shading as in Fig. 7.1. Note the presence of 2 cells per step (see text).

wide (in the horizontal), while the fine grid was made up of cells 50 meters long and wide. Cell thickness was the same for the fine and coarse grids. Eight simulations were done for each type of lake: one fine grid and one coarse 
grid simulation at each of four anisotropy ratios $(1,10,100$, and 1000). Results are shown in the vertical cross sections, seepage plots and maps on the following pages.

Maintaining the exact same lake size and shape between the coarse and fine grid simulations required that each "step" on the jagged, sloping, stair-step portion of the lake bed was made up of one cell in the coarse grid and two cells in the fine grid (Figs. 7.1 and 7.2). Generally, the two cells occupying a single step in the fine grid lake bed provided significantly different amounts of seepage to the lake, because one of these cells had a horizontal face exposed to the lake bed that the other did not (Fig. 7.2). In order to facilitate comparison between fine and coarse grid results, the average lake bed seepage rate for each 2-cell step in the fine grid models was computed as the average seepage rate of the two cells on the step. This average was then plotted at a distance corresponding to the middle of the step on the plots of seepage rate versus distance offshore (e.g., Figs. 7.5 and 7.6). For the flat portion of the lake bed in the center of the lake, course and fine grid results were plotted and compared directly (no averaging was needed because there were no steps in this portion of the lake bed). 


\subsection{Inflow lake}

Results show very similar heads for both grid sizes at all anisotropy ratios (Table 7.1, Figs. 7.3 and 7.4). A slightly higher seepage rate at the shore line is observed for the fine grid when the seepage rates are plotted with distance from the shore along a central section of the lake (Figs. 7.5 and 7.6).

This higher seepage rate nearshore is balanced by lower seepage offshore for fine grid since the total volumetric seepage into the lake, equal to the recharge to the system, must be the same for both grids. Difference in seepage rates between the two grids were not noticible when the anisotropy ratio was low (i.e., $\mathrm{R}=1$ or 10 ). The difference in seepage rate seems to be slightly higher at $\mathrm{R}=100$ and $\mathrm{R}=1000$, though still minimal. The spatial distribution of seepage rates or the seepage maps of the lake bed between the two grids are comparable and similar at low R (Figs. 7.7 and Fig. 7.8).

Fig. 7.14 shows the alternating high and low seepage rates with distance offshore that arose in the sloping portion of the fine grid lake because of the presence of two cells per "step", as mentioned earlier. As anisotropy increases, horizontal hydraulic gradient near the sloping portion of the lake bed increases (e.g., Figs. 7.3 and 7.4), and the lake bed cells sharing a vertical face as well as a horizontal face with the lake experience progressively higher seepage 
Table 7.1. Grid size comparison, inflow lake. The 4 numbers in each box of the table with results are the minimum and maximum* head along the vertical section through the center of the lake (see Fig. 6.1) (first line in each box), and the minimum and maximum lake bed seepage rate along that section (second line in each box, in parenthesis).

\begin{tabular}{|c|c|c|c|c|}
\hline $\begin{array}{c}\text { Shallow inflow lake with } \\
\text { moderate slope }\end{array}$ & \multicolumn{4}{|c|}{ Anisotropy (R) } \\
\cline { 2 - 5 } & $\mathrm{R}=1$ & $\mathrm{R}=10$ & $\mathrm{R}=100$ & $\mathrm{R}=1000$ \\
\hline Coarse & $\begin{array}{c}50.00,69.17 \\
\left(1.12 \times 10^{-7}, 1.2188\right)\end{array}$ & $\begin{array}{c}50.00,70.53 \\
(0.00019,1.0157)\end{array}$ & $\begin{array}{c}50.12,73.51 \\
(0.0427,0.7372)\end{array}$ & $\begin{array}{c}52.44,81.83 \\
(0.0816,0.6865)\end{array}$ \\
\hline Fine & $\begin{array}{c}50.00,67.74 \\
\left(1.46 \times 10^{-6}, 1.3654\right)\end{array}$ & $\begin{array}{c}50.01,70.21 \\
(0.0004,1.0423)\end{array}$ & $\begin{array}{c}50.09,73.07 \\
(0.0379,0.7591)\end{array}$ & $\begin{array}{c}51.87,81.02 \\
(0.0729,0.722(0)\end{array}$ \\
\hline
\end{tabular}

* the maximum heads along the section are slightly lower than the maximum heads over the entire domain because the distance from the outer boundary of the domain to the lake shore along the section is less than the distance from the lake shore to the corner of the domain. Maximum seepage occurs in cells which are not lying along the section (e.g., see seepage maps, such as Fig. 7.7).

Table 7.2. Grid size comparison, flow-through lake. The 3 numbers in each box with results are the position** of the inseepageoutseepage boundary (first line in each box), and maximum lake bed seepage rate through the downgradient side and upgradient side respectively (second line in each box).

\begin{tabular}{|c|c|c|c|c|}
\hline \multirow{2}{*}{$\begin{array}{c}\text { Shallow flow-through } \\
\text { lake with moderate slope }\end{array}$} & \multicolumn{4}{|c|}{ Anisotropy (R) } \\
\cline { 2 - 5 } & $\mathrm{R}=1$ & $\mathrm{R}=10$ & $\mathrm{R}=100$ & $\mathrm{R}=1000$ \\
\hline Coarse & $*$ & 982 & 963 \\
$\mathbf{9}$ & $(-0.381,0.5158)$ & $(-0.2896,0.3965)$ & $(-0.1454,0.2299)$ & $(-0.0439,0.1164)$ \\
\hline Fine & $*$ & 983 & 961 \\
9 & $(-0.2991,0.4263)$ & $(-0.1536,0.2481)$ & $(-0.0469,0.1262)$ \\
\hline
\end{tabular}

* denotes where the seepage rates are not calculated by MODFI,OW (see text for discussion)

** The position of the inseepage-outseepage boundary is measured as distance $(\mathrm{m})$ from the downgradient side of the lake. 
compared to the adjacent cells that share only a horizontal face with the lake (Fig. 7.2). This behavior does not appear in the seepage plots (Fig. 7.3 and 7.4) because of the averaging described earlier in this chapter. A similar sort of averaging would be more difficult to implement for the seepage maps, and was not used. For this reason, seepage maps at $\mathrm{R}=1000$ (e.g., Fig. 7.14) show alternating bands of high and low seepage on the sloping portion of the lake bed. At $R=1000$, the low seepage $(<0.1 \mathrm{~cm} /$ day $)$ zone has slightly less aerial extent for the course grid than the fine grid (e.g., Figs. 7.13 and 7.14).

\subsection{Flow-through lake}

The effect of grid size was investigated on shallow flow-through lakes with moderate lake bed slope. Eight simulations were run (4 different anisotropy ratios at each of 2 grid sizes), and the results are summarized in Table 7.2 and Figs. 7.15 to 7.28 . Unlike inflow simulations, the heads along 2 of the 4 vertical sides of the model domain were fixed in simulations of flowthrough lakes. This allowed us to impose a regional gradient across the model domain (from 65 meter at the upgradient side, to 35 meter at the down-gradient side, with the lake in the center at a head of 50 meter).

The plots of seepage rate versus distance offshore show that the fine grid and coarse grid results are extremely similar at each value of anisotropy ratio 
(Figs. 7.19 and 7.20). Minor variations were noticed at higher $\mathrm{R}$ near the upgradient shoreline and at places where lake bed slopes met the flat lake bottom. The fine and coarse grid seepage maps look almost identical at $\mathrm{R}=1$, 10, and 100, except in their absolute values at the shore (Figs. 7.21 to 7.26).

As noted earlier in the discussion of inflow lakes, the fine grid lakes contained two grid cells per step, the cell nearer the shore having a higher seepage because it received inflow across both a vertical and horizontal face (as opposed to the adjacent cell further offshore which received inflow over only a horizontal face). While the average inflow per step was approximately the same for coarse and fine grids, the partition of the fine grid inflow into a higher value (nearer shore cell) and lower value (adjacent offshore cell) required higher seepage rates in the cells right at the lake shore in the fine grid simulations. This can be seen in the legends of the seepage maps, in which the range for the highest seepage rate extends to higher values for the fine grid simulations. Averaging seepage rates in the first two cells offshore in the fine grid results would give seepage rates almost identical to those in the cell nearest the shore in the coarse grid simulations (this would be a direct comparison between the step, not cell, nearest the shore on the lake bed). As in the inflow lake simulations, the presence of two cells per step in the fine 
grid lead to alternating cells of low and high seepage at high anisotropy $(\mathrm{R}=1000)$ in the flow-through lake simulation.

Also, as in the inflow lake simulations, higher anisotropy seems to decrease seepage at the shore line and increase seepage further offshore (we return to this in detail in chapter 10). This is reflected by the blank areas in the center of the seepage maps for flow-through lake simulations with $\mathrm{R}=1$. Lake bed seepage rates far offshore were so low in these simulations (less than $10^{-7}$ $\mathrm{cm} /$ day) that they were not computed by MODFLOW. We have left this center area blank in the maps because filling it would necessarily involve assuming a position for the line separating lake outseepage (negative seepage rate on the maps) from lake inseepage. The position of this line moved slightly toward the downgradient side of the lake as anisotropy increased (Table 7.2). Of course, in these simulations each cell on the lake bottom must be inseepage or outseepage (not a mixture), and hence the line between inseepage and outseepage on the lake bed must follow cell boundaries. However, the linear trend of the seepage rate with distance across the lake (Figs. 7.19 and 7.20) allowed estimation of the position the inseepage/outseepage boundary would take were it not constrained by cell boundaries in a discretized medium. As $\mathrm{R}$ changed from 10 to 1000 , the line moved about 50 meters closer to the down- 
gradient boundary of the lake. The position of this line is also suggested by the point where the 50 meter equipotential meets the lake bed in the vertical cross sections of Figs 7.15 to 7.18 . However, this point is controlled by the interpretation of the SURFER contouring package in an area of low hydraulic gradient, and the inseepage/outseepage boundary is more reliably located with the seepage plots.

The results of the above investigations of the inflow and flow through lakes suggest that the seepage rates around the lake or the head distributions in the porous medium are not dependent on grid sizes, especially at low R. At higher R, minor variations were observed which can be correlated to the "step" sizes in the fine grid. Most of our subsequent simulations were made with fine grids. 


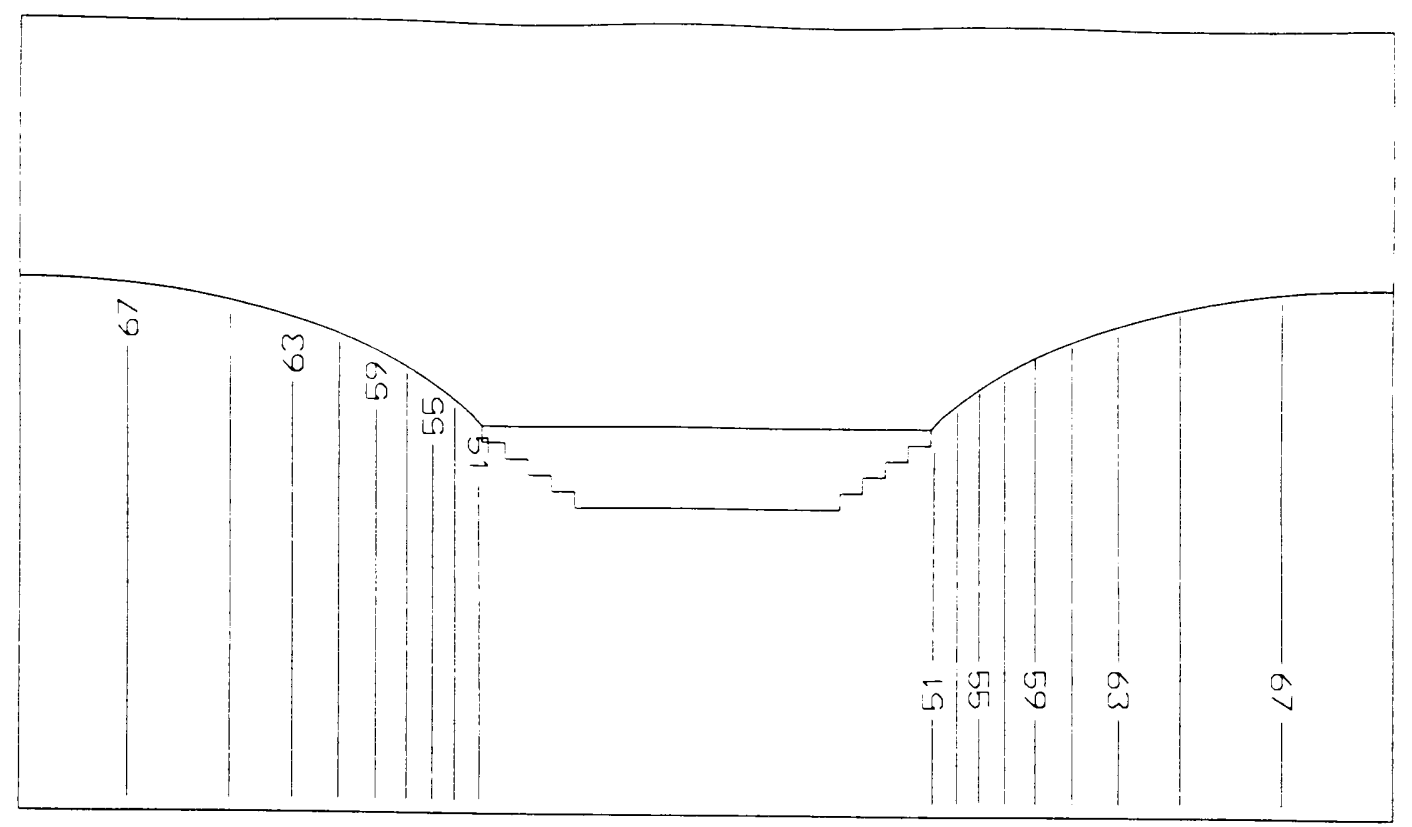

Anisotropy Ratio $=1$

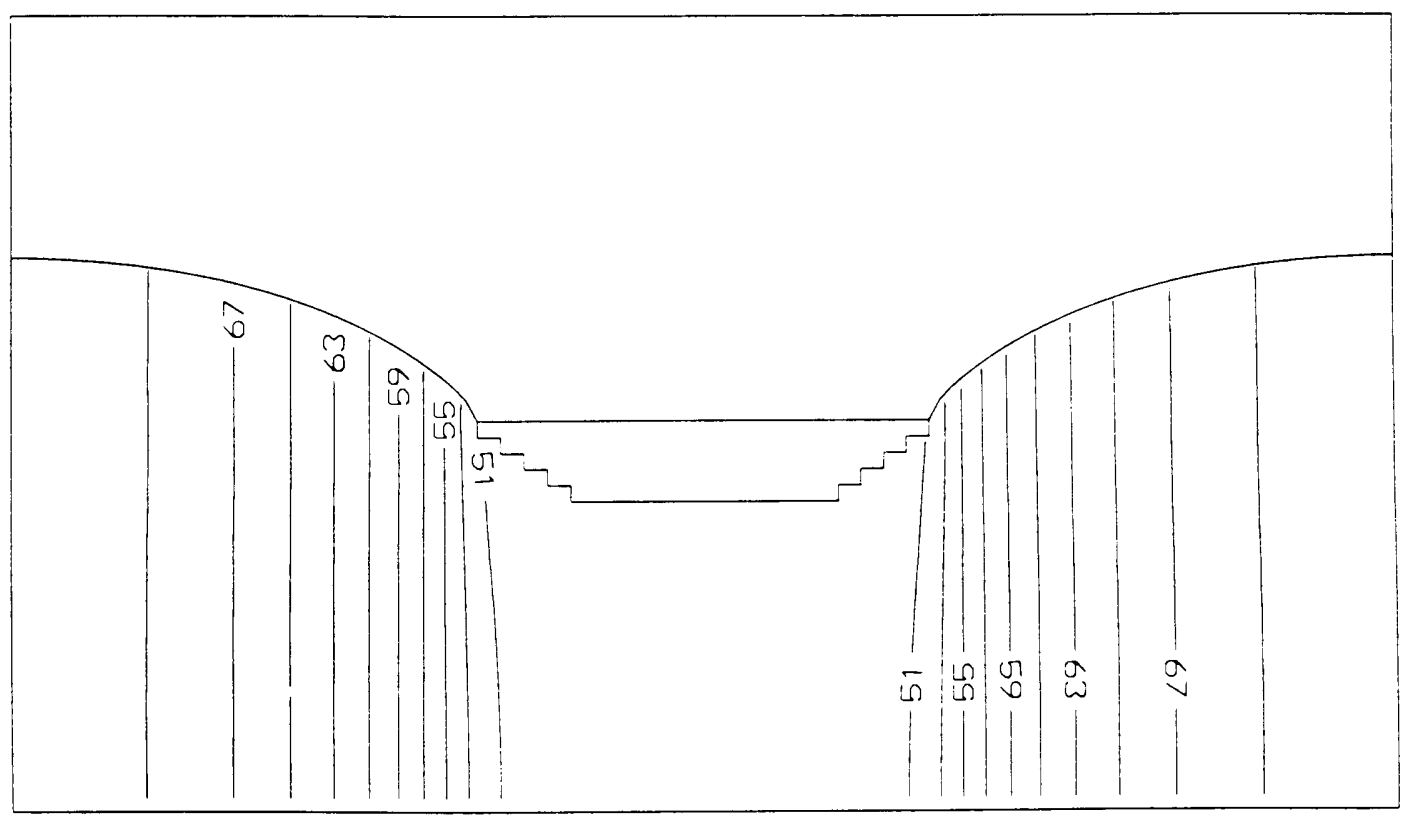

Anisotropy Ratio $=10$

Fig. 7.3. Distribution of hydraulic heads in the porous medium for fine grid simulations of shallow inflow lakes with moderate slope at $R=1$ and $R=10$. Figs. 6.2 and 6.3 give analogous plots for coarse grid simulations. 


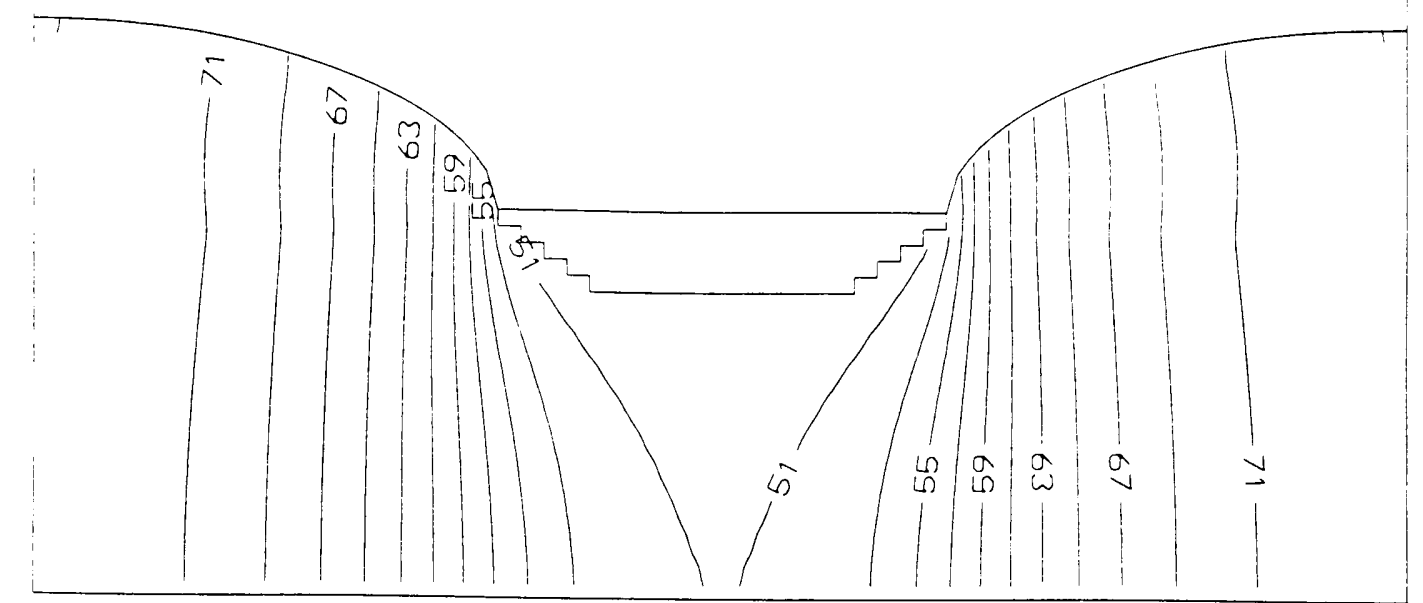

Anisotropy Ratio $=100$

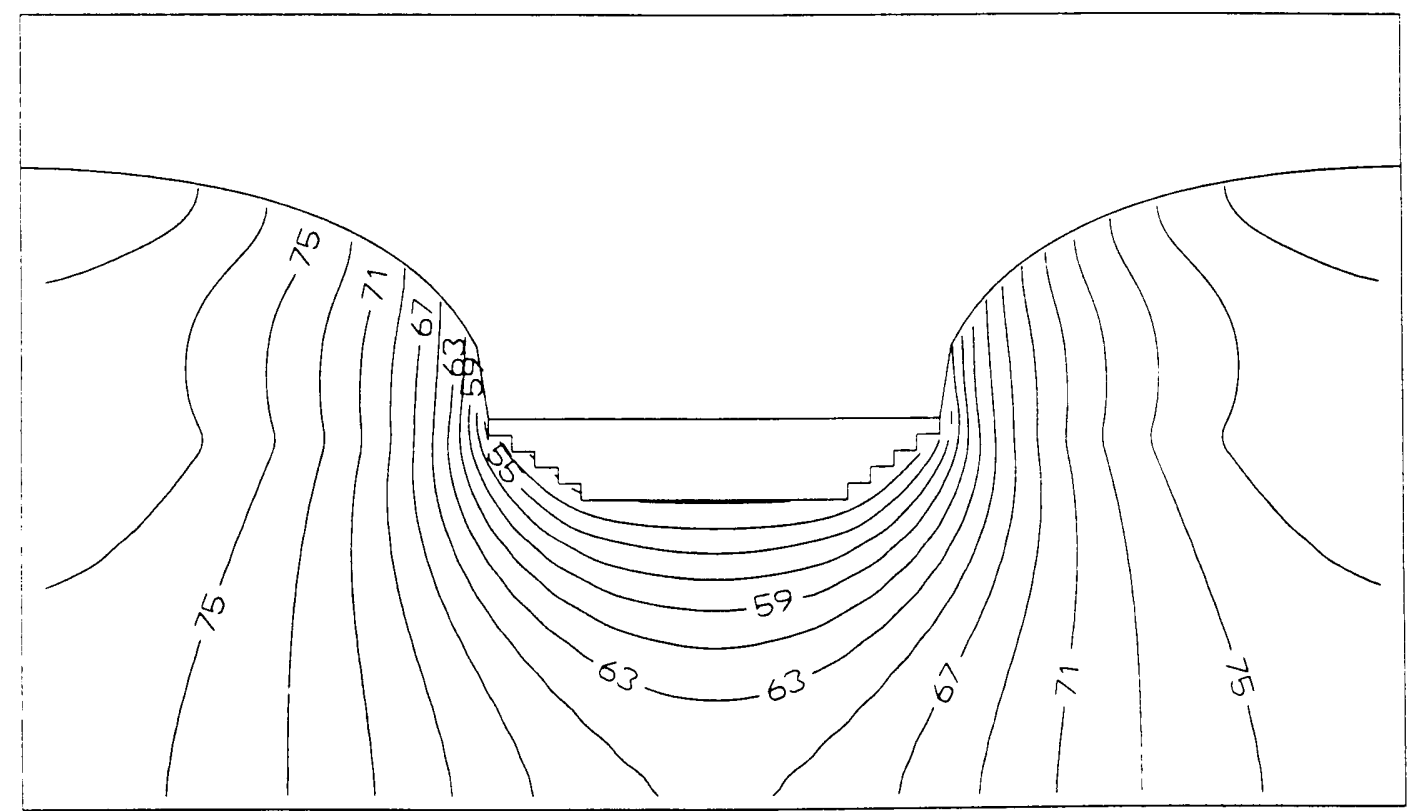

Anisotropy Ratio $=1000$

Fig. 7.4. Distribution of hydraulic heads in the porous medium for fine grid simulations of shallow inflow lakes with moderate lake bed slope at $R=100$ and $R=1000$. Figs. 6.4 and 6.5 give analogous plots for coarse grid simulations. 


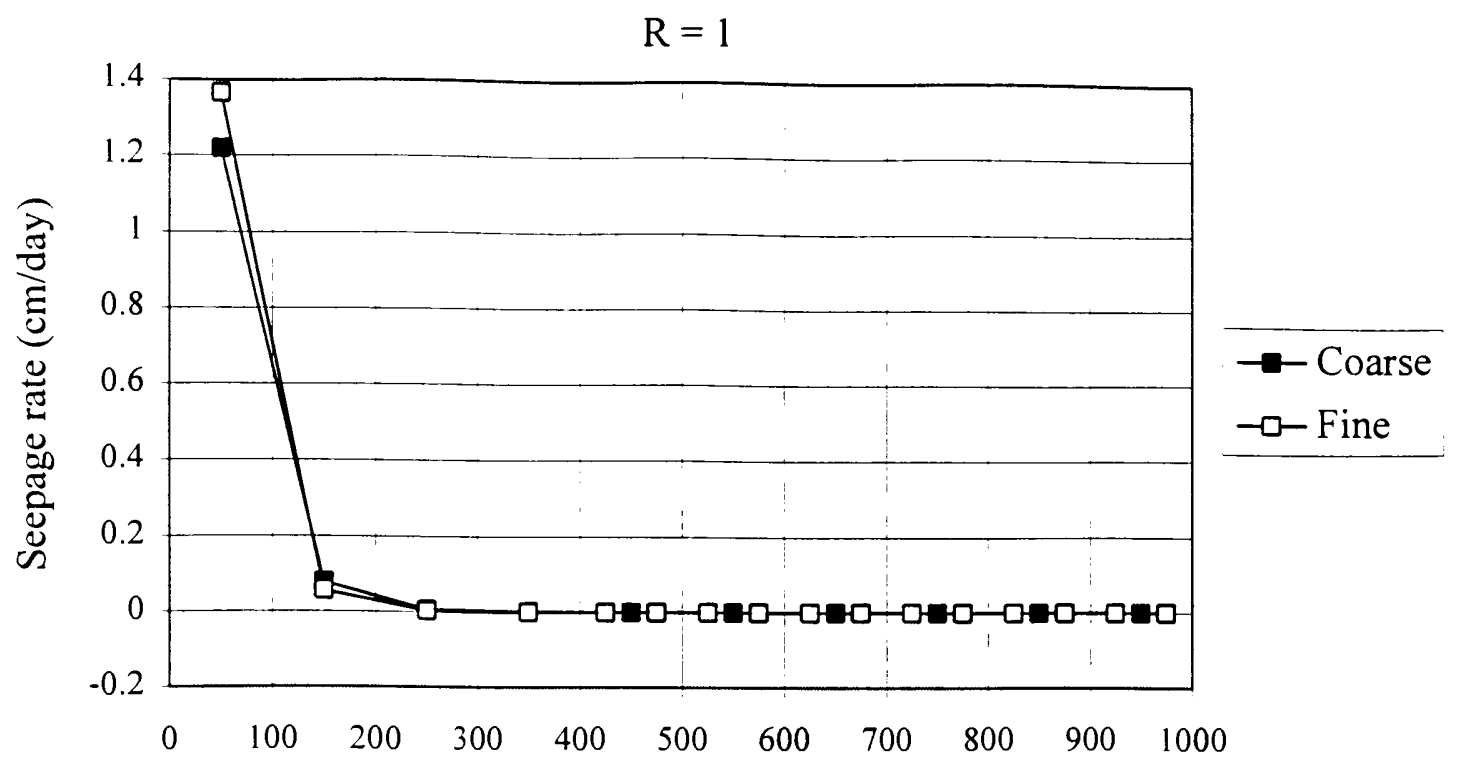

Distance offshore (m)

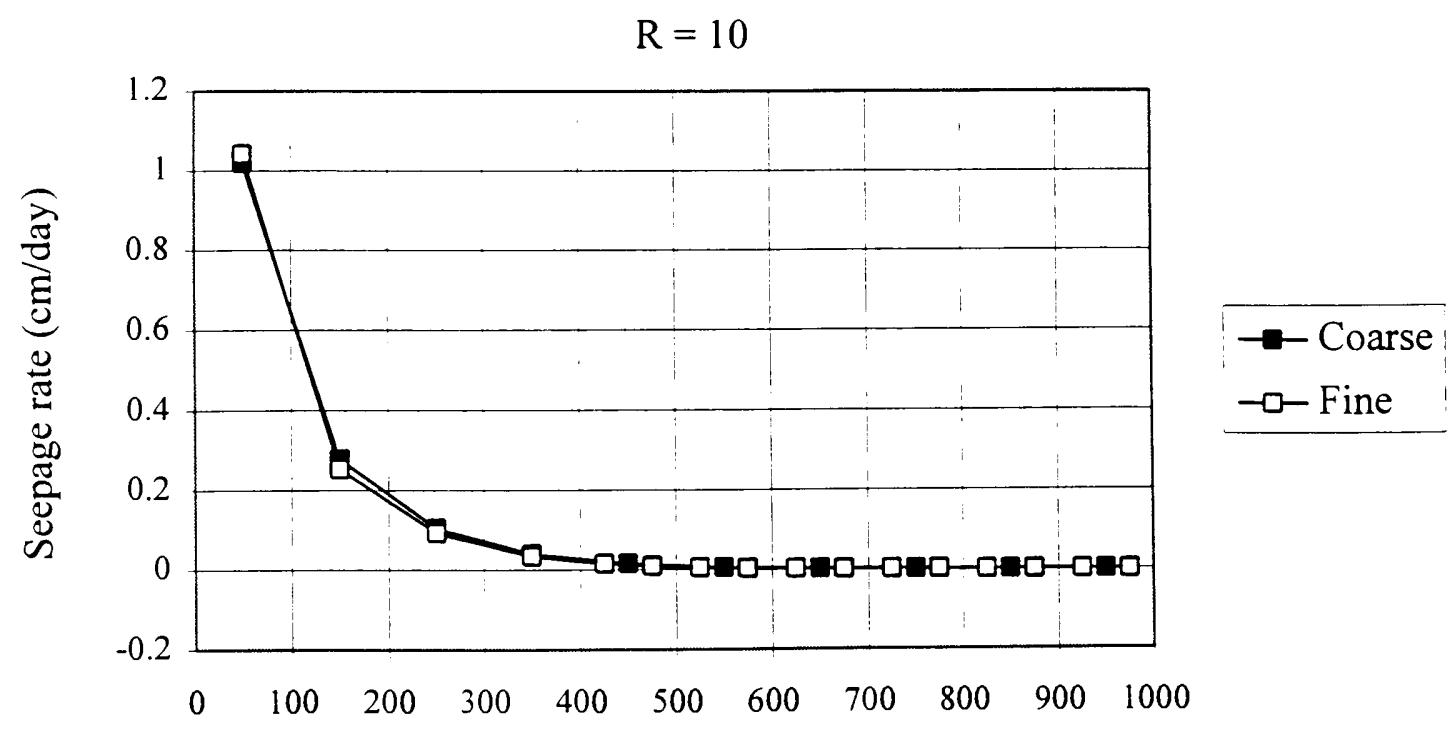

Distance offshore (m)

Fig. 7.5. Seepage rate versus distance offshore for coarse and fine grid simulations of shallow inflow lakes with moderate slope at $R=1$ and $R=10$. 


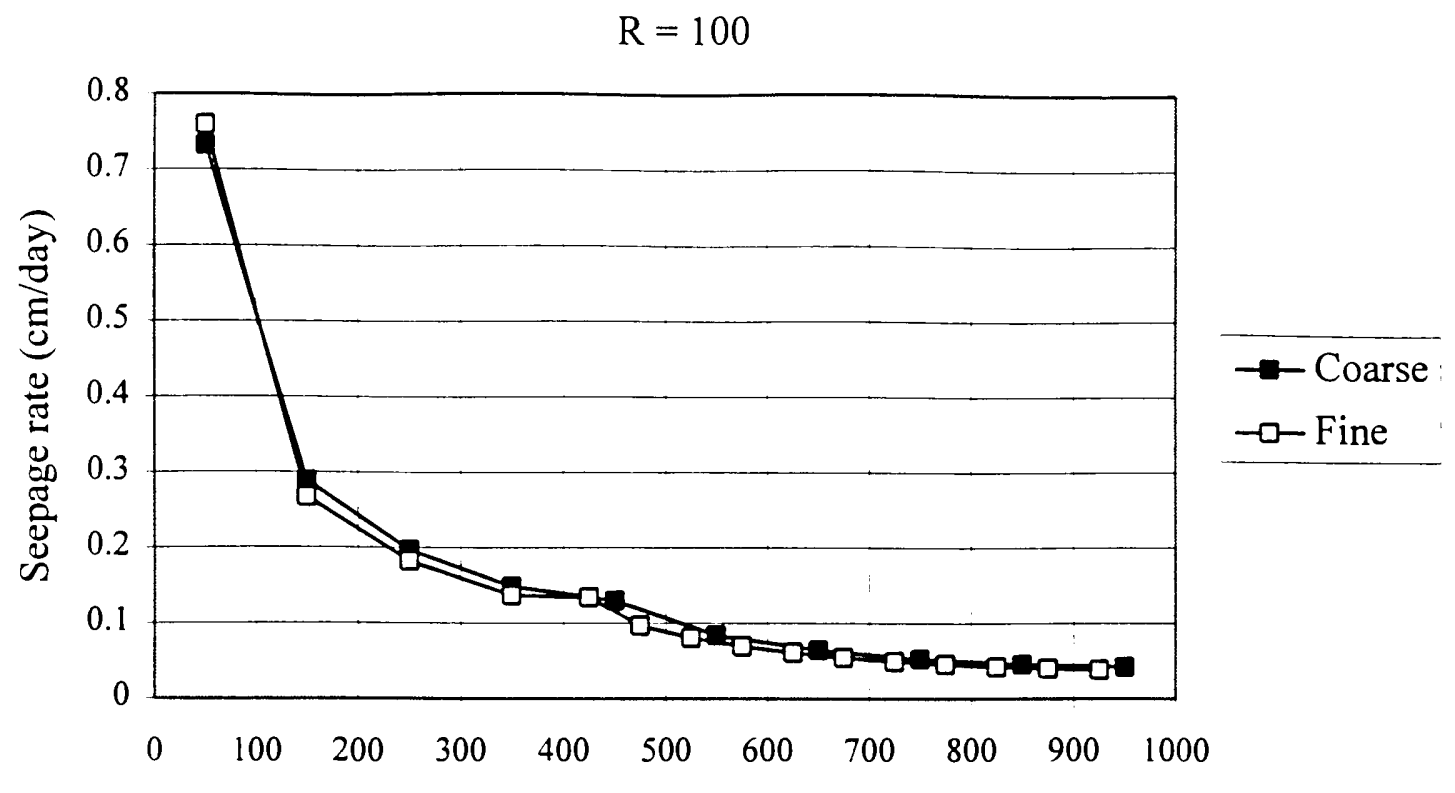

Distance offshore $(\mathrm{m})$

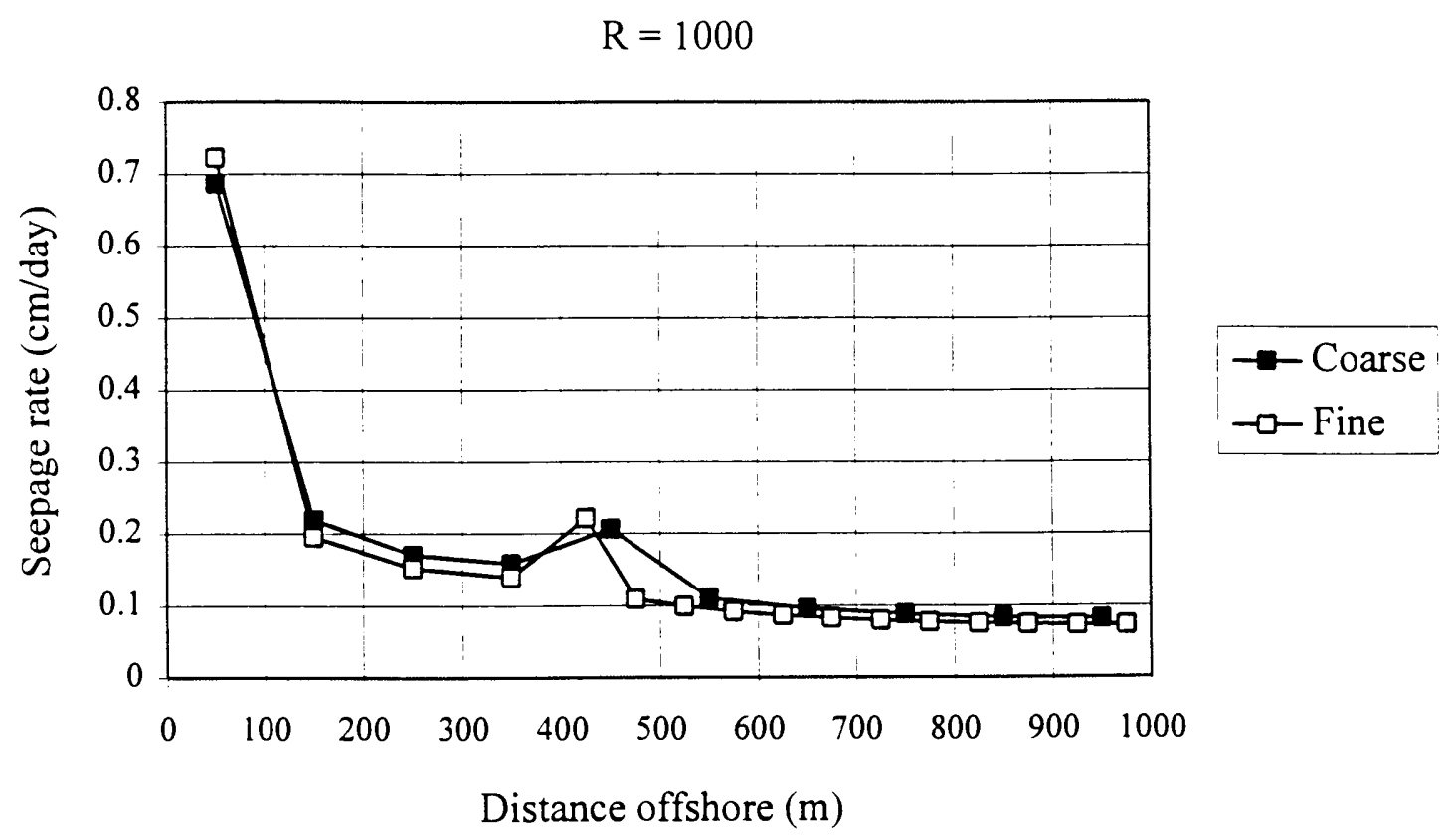

Fig. 7.6. Seepage rate versus distance offshore for coarse and fine grid simulations of shallow inflow lakes with moderate slope at $R=100$ and $R=1000$. 


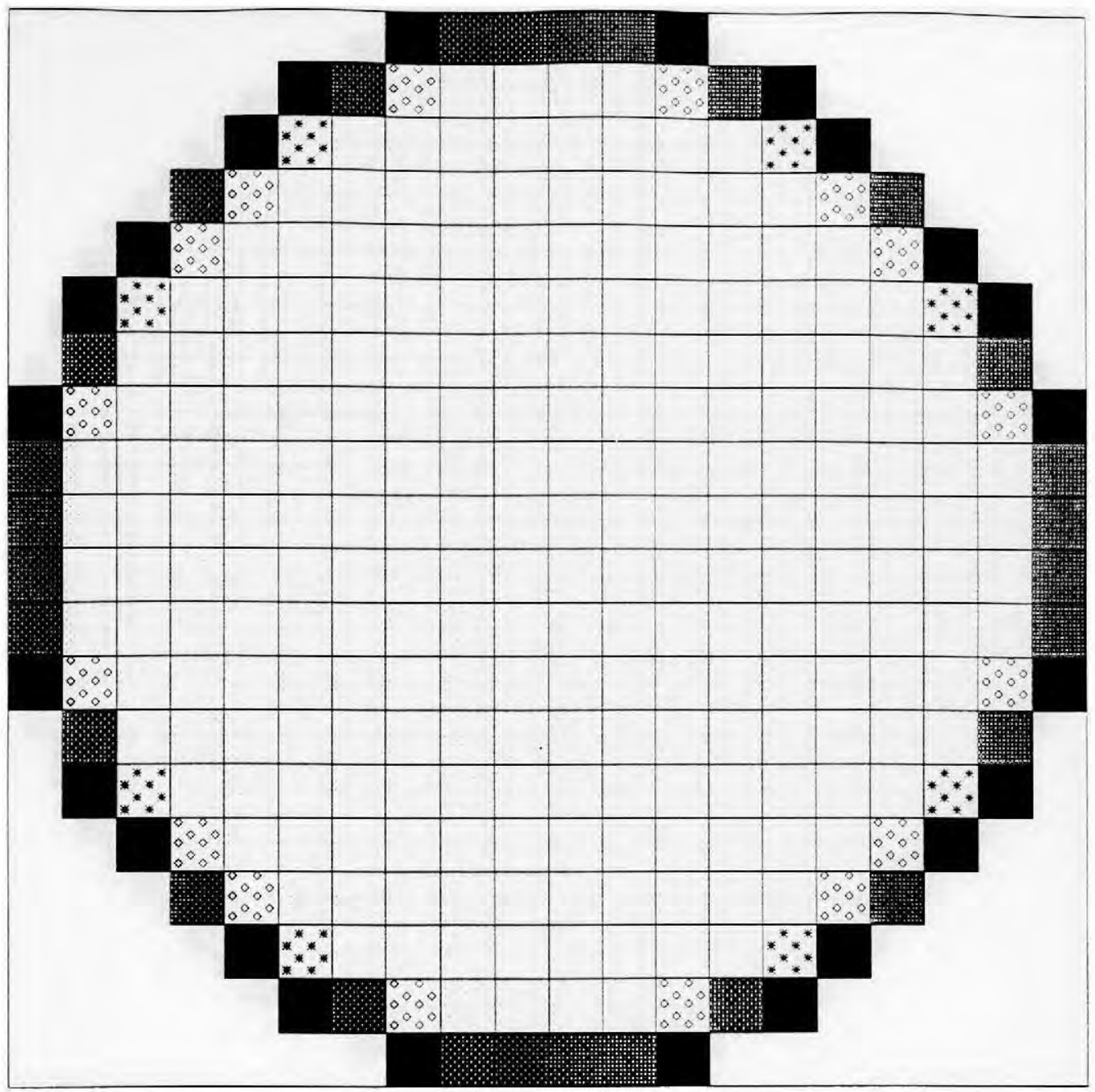

Fig. 7.7. Distribution of seepage rate ( $\mathrm{cm} /$ day) over the

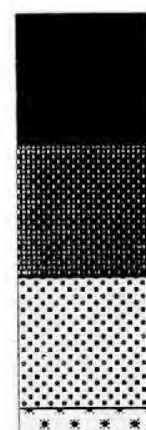

16 to 22

08 to 15

lake bed for the coarse grid simulation of a shallow inflow lake with moderate slope at $\mathrm{R}=1$. 


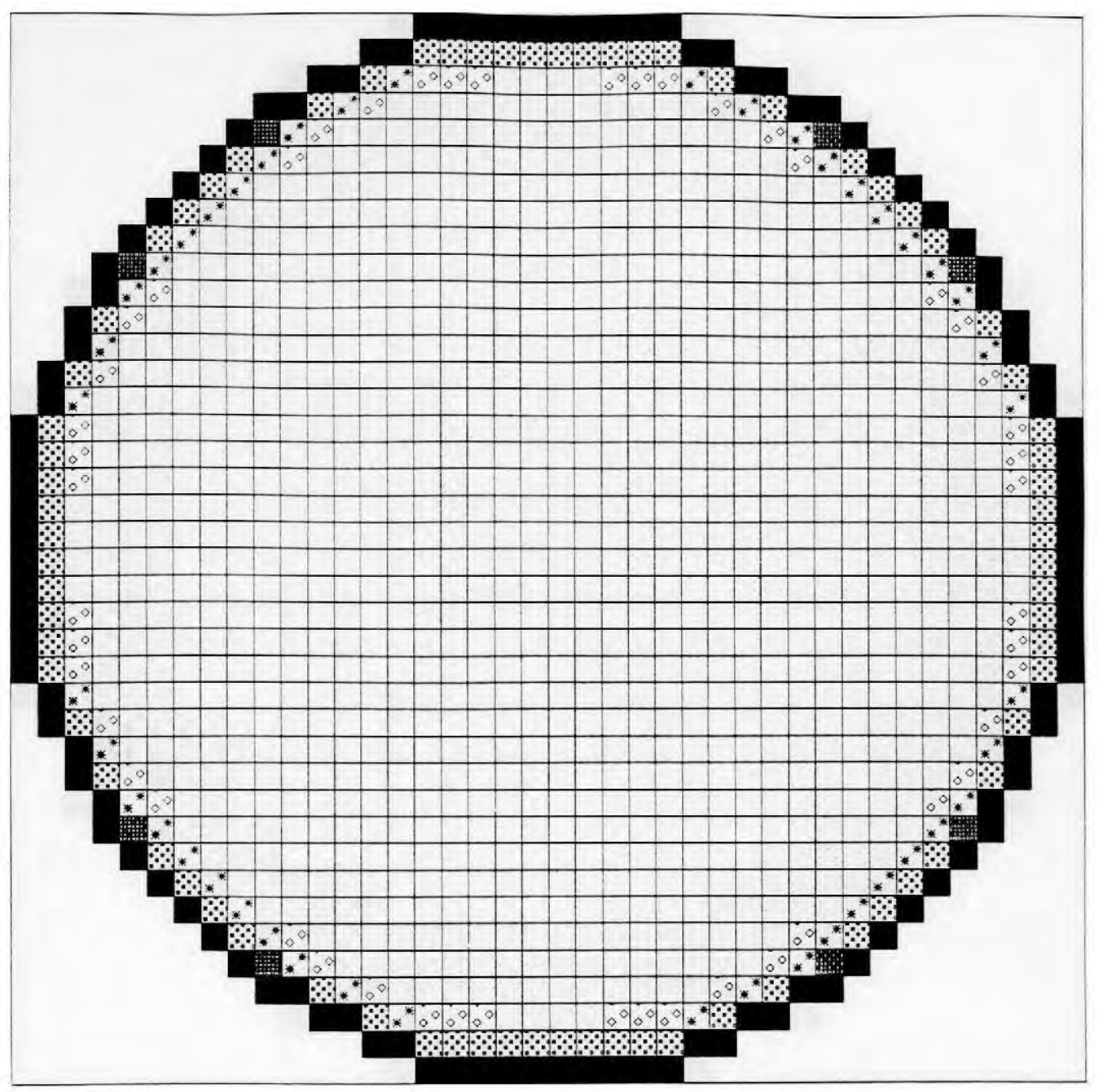

Fig. 7.8. Distribution of seepage rate $(\mathrm{cm} /$ day) over the lake bed for the fine grid simulation of a shallow inflow lake with moderate slope at $\mathrm{R}=1$.

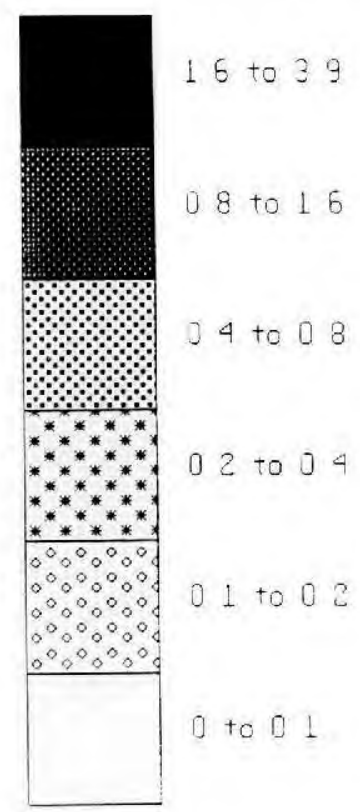



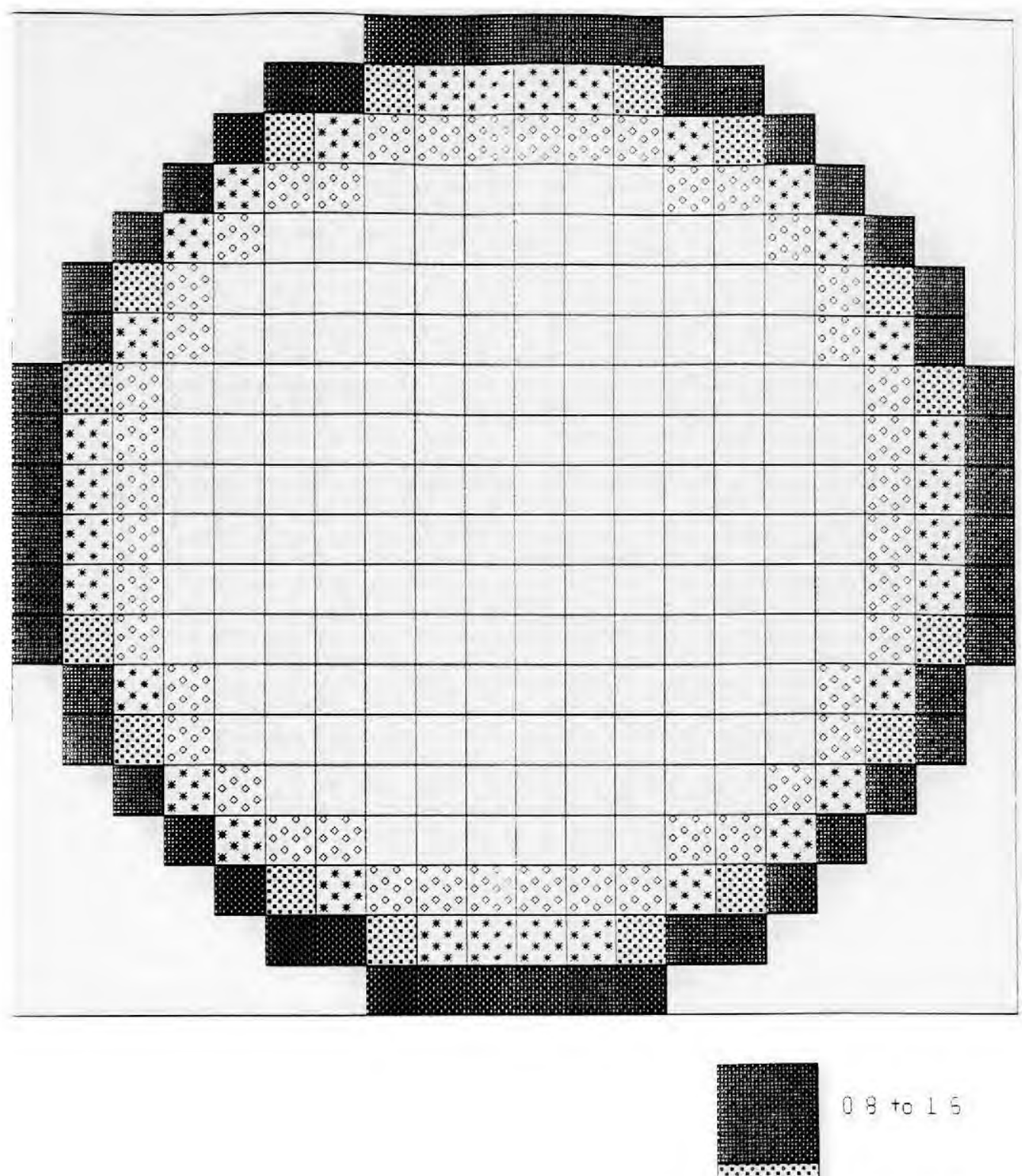

08 to 15

o a to 0.8

Fig. 7.9. Distribution of seepage rate $(\mathrm{cm} /$ day) over the lake bed for the coarse grid simulation of a shallow inflow lake with moderate slope at $R=10$.

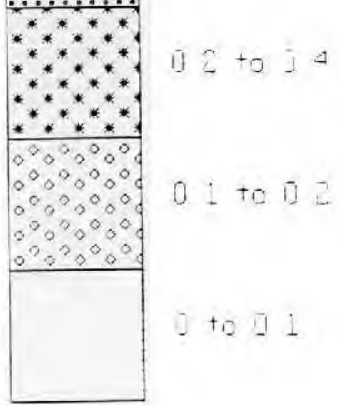




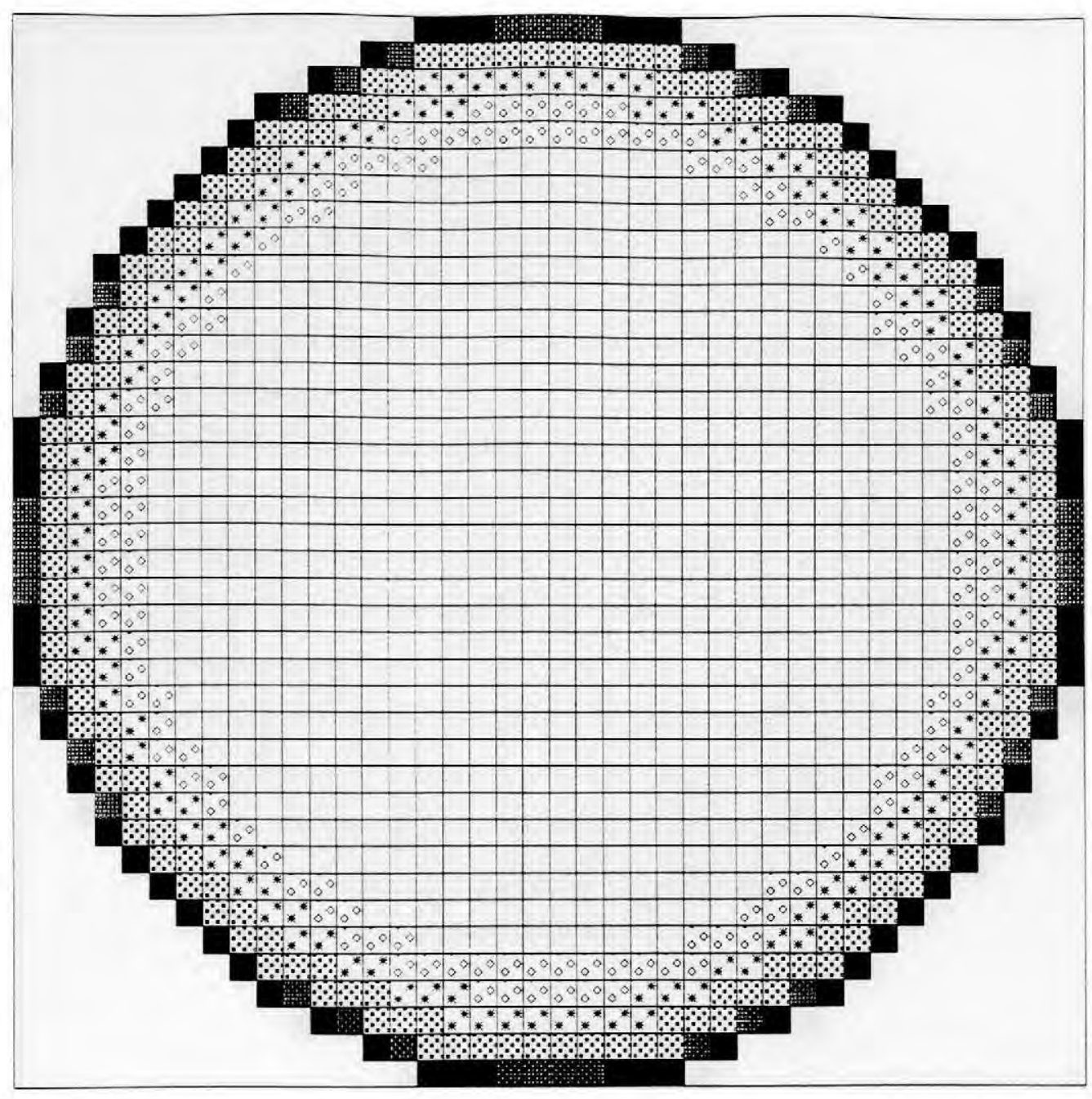

Fig. 7.10. Distribution of seepage rate $(\mathrm{cm} /$ day $)$ over the lake bed for the fine grid simulation of a shallow inflow lake with moderate slope at $\mathrm{R}=10$.

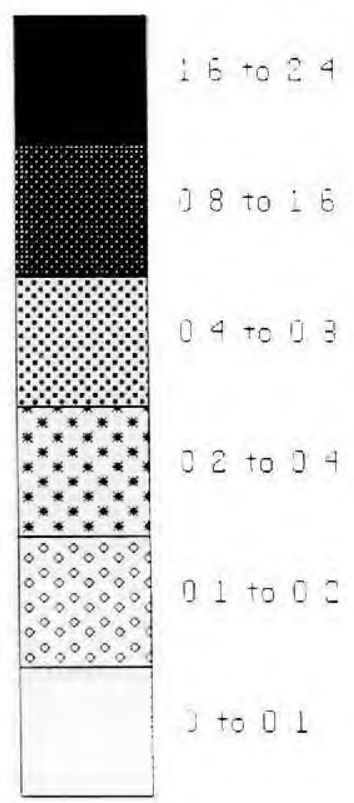




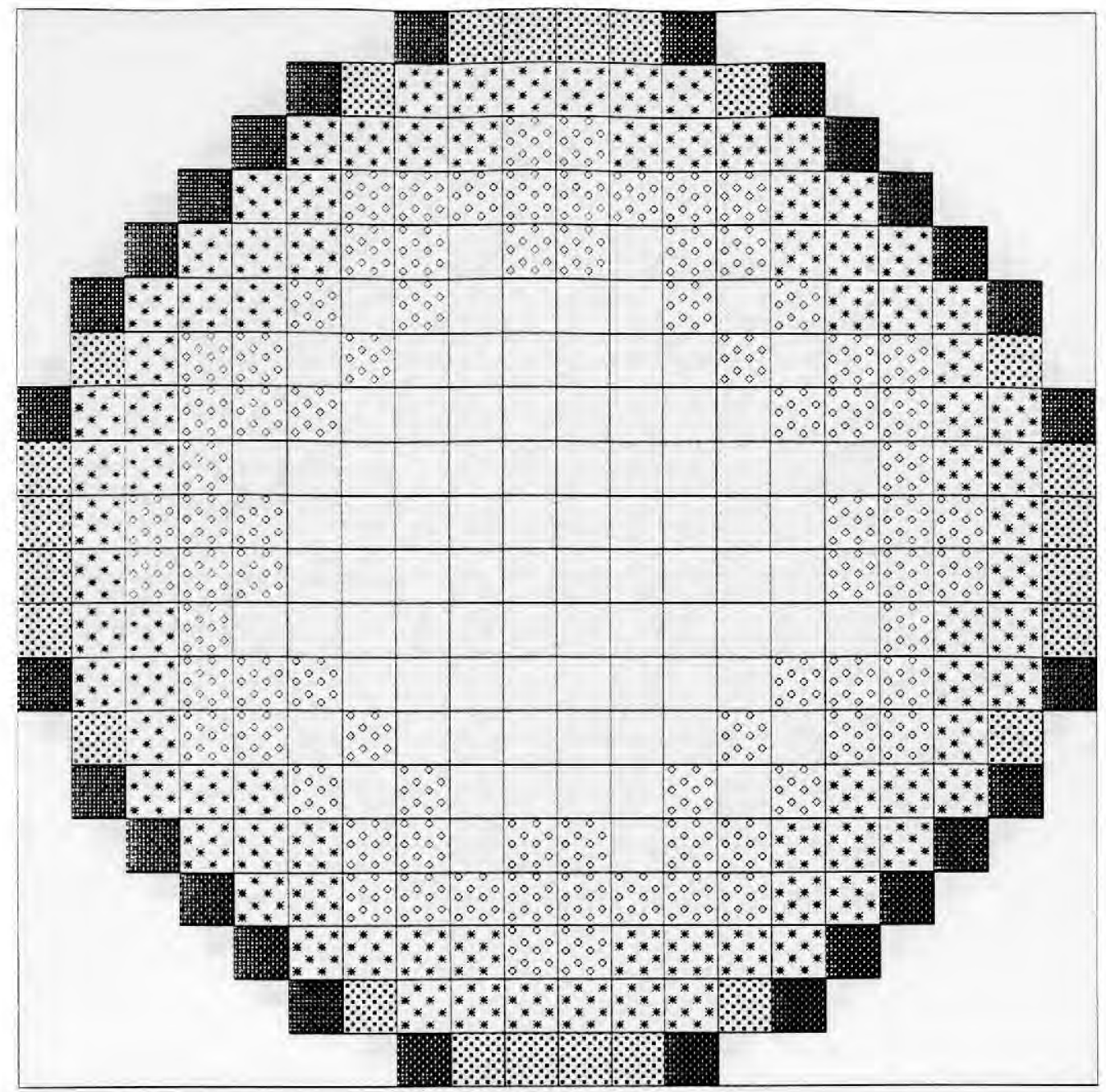

Fig. 7.11. Distribution of seepage rate $(\mathrm{cm} /$ day) over the lake bed for the coarse grid simulation of a shallow inflow lake with moderate slope at $\mathrm{R}=100$.

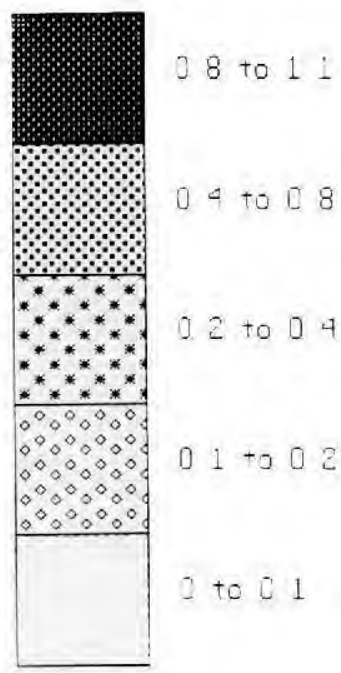




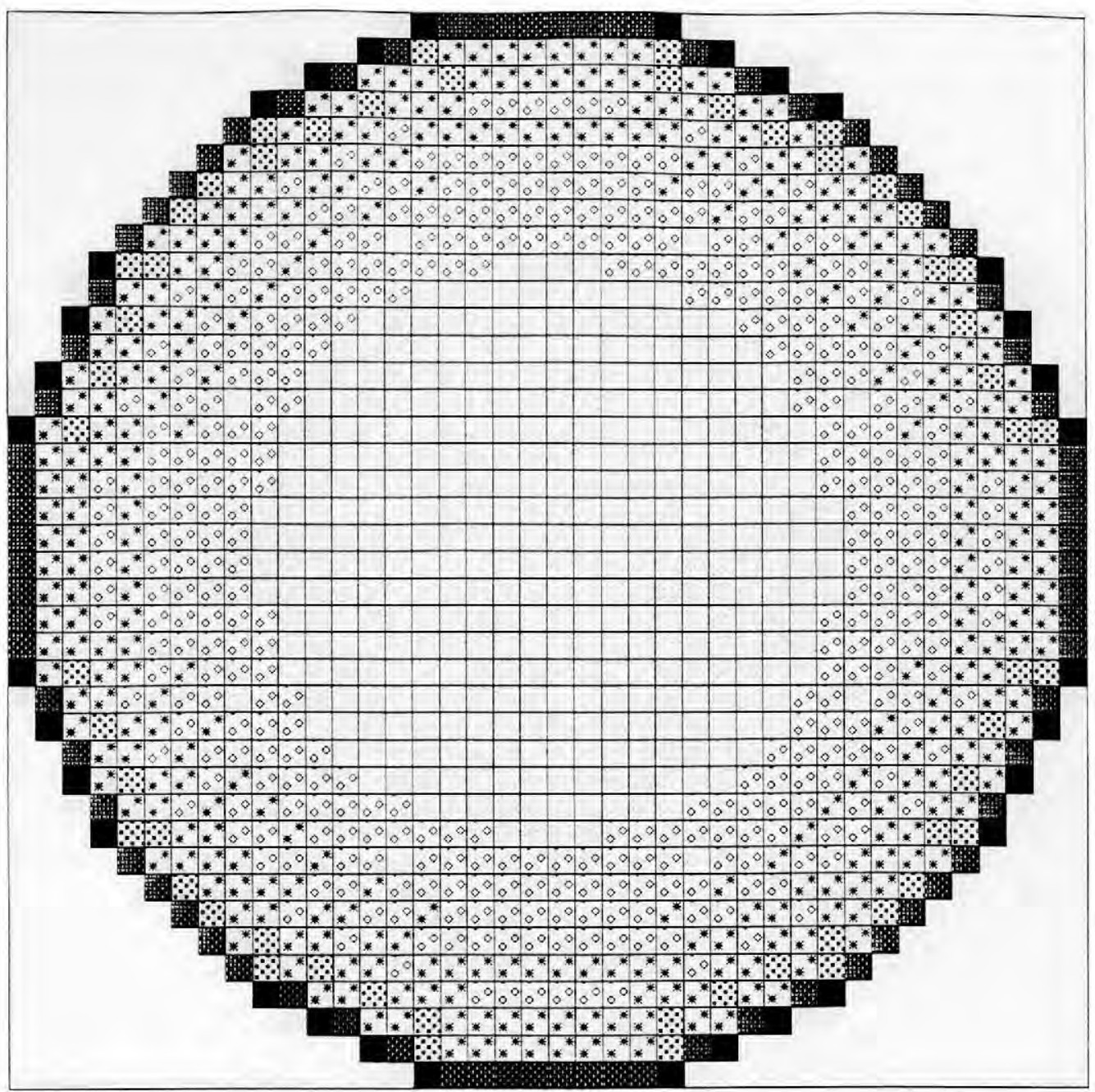

Fig. 7.12. Distribution of seepage rate $(\mathrm{cm} /$ day) over the lake bed for the fine grid simulation of a shallow inflow lake with moderate slope at $\mathrm{R}=100$.

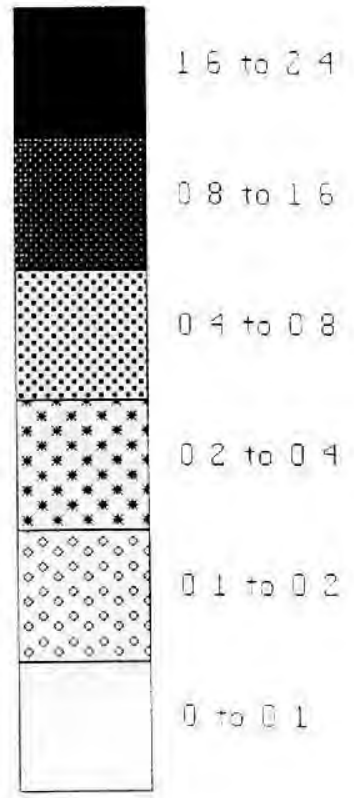



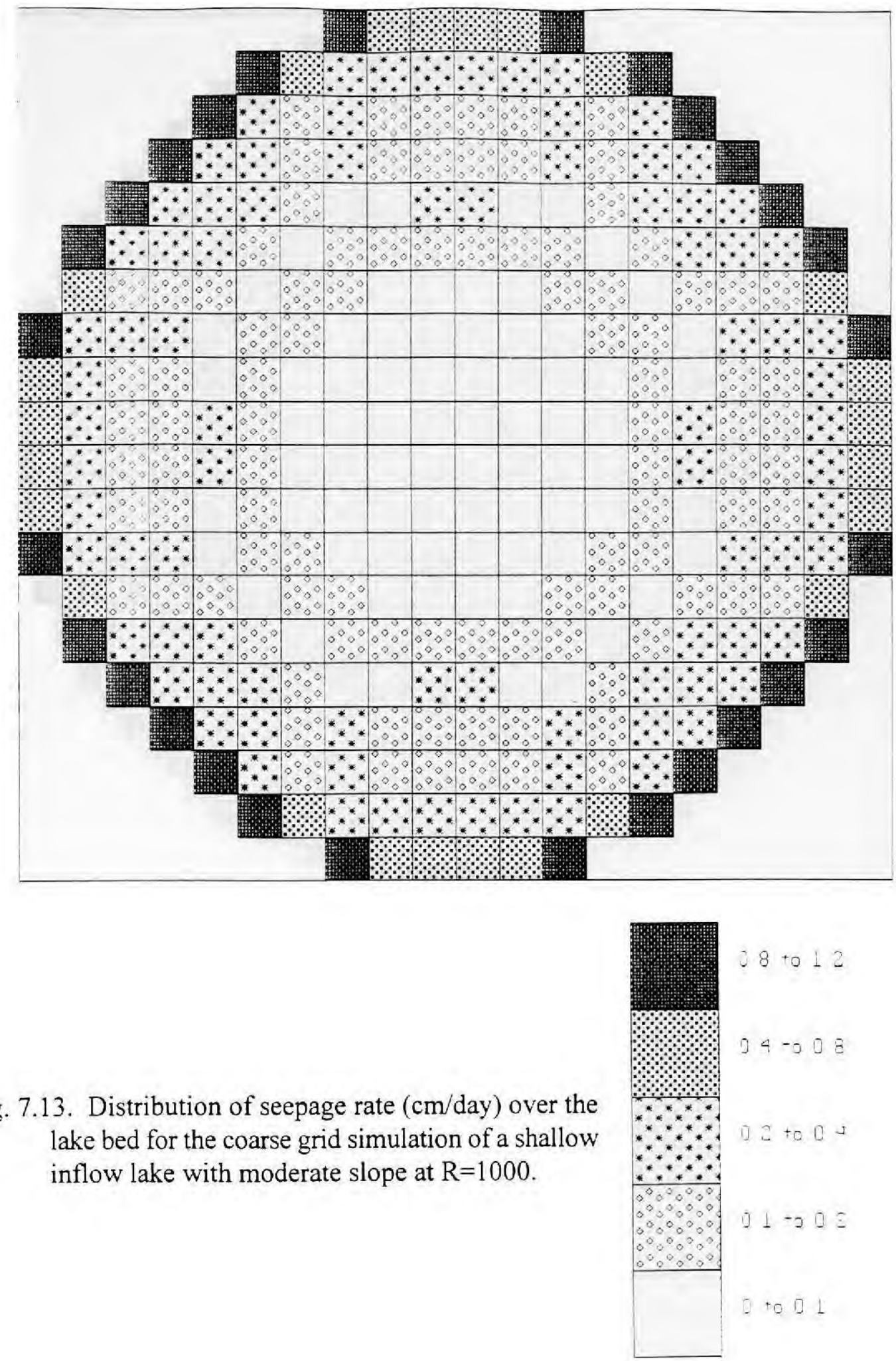

Fig. 7.13. Distribution of seepage rate $(\mathrm{cm} /$ day) over the lake bed for the coarse grid simulation of a shallow inflow lake with moderate slope at $\mathrm{R}=1000$. 


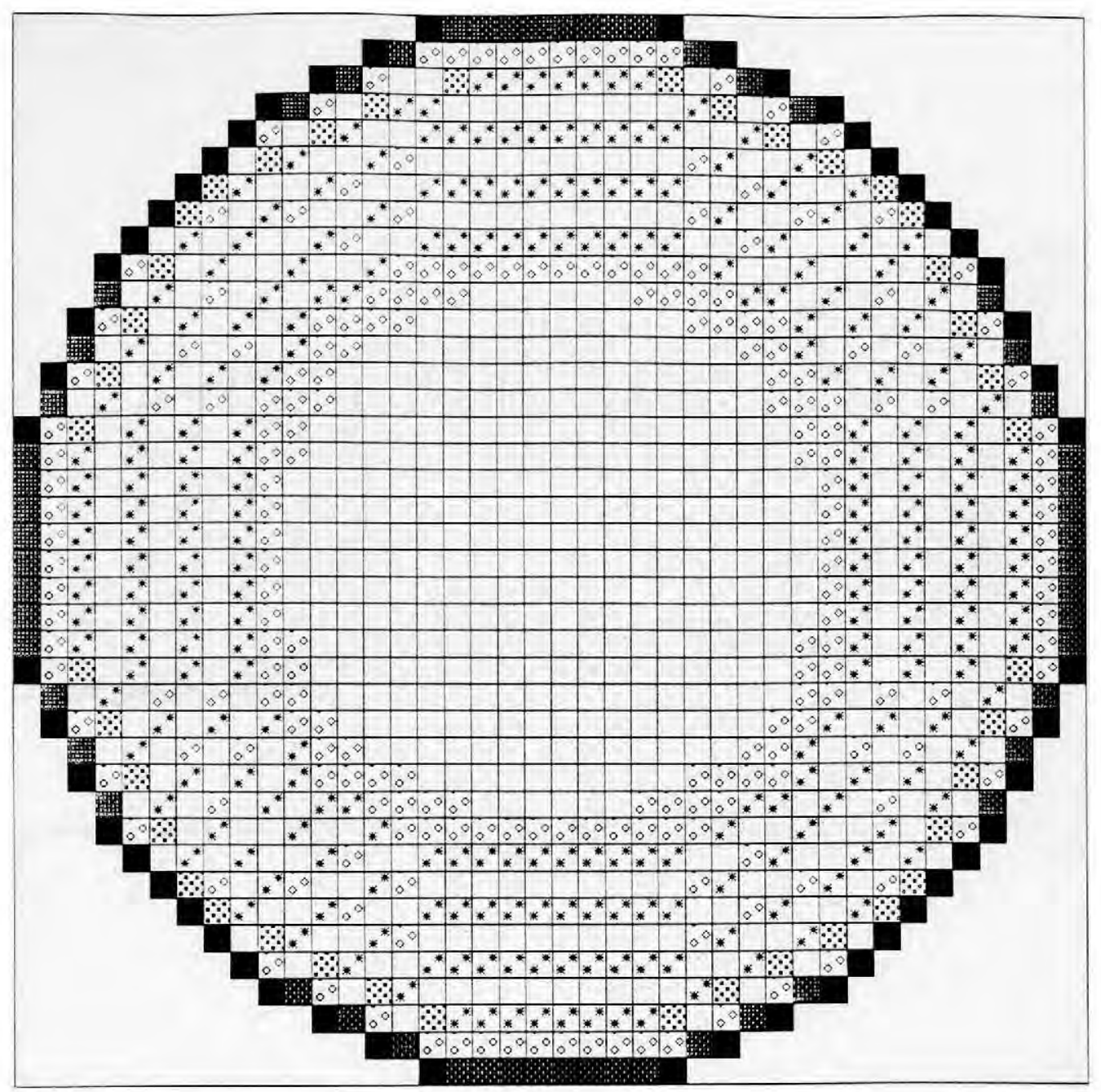

Fig. 7.14. Distribution of seepage rate $(\mathrm{cm} /$ day $)$ over the lake bed for the fine grid simulation of a shallow inflow lake with moderate slope at $\mathrm{R}=1000$.

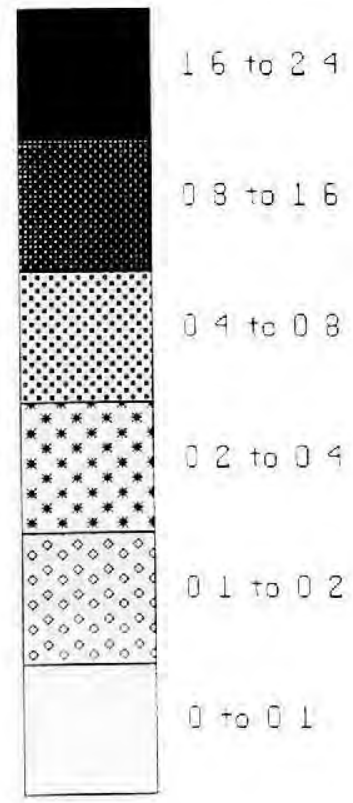




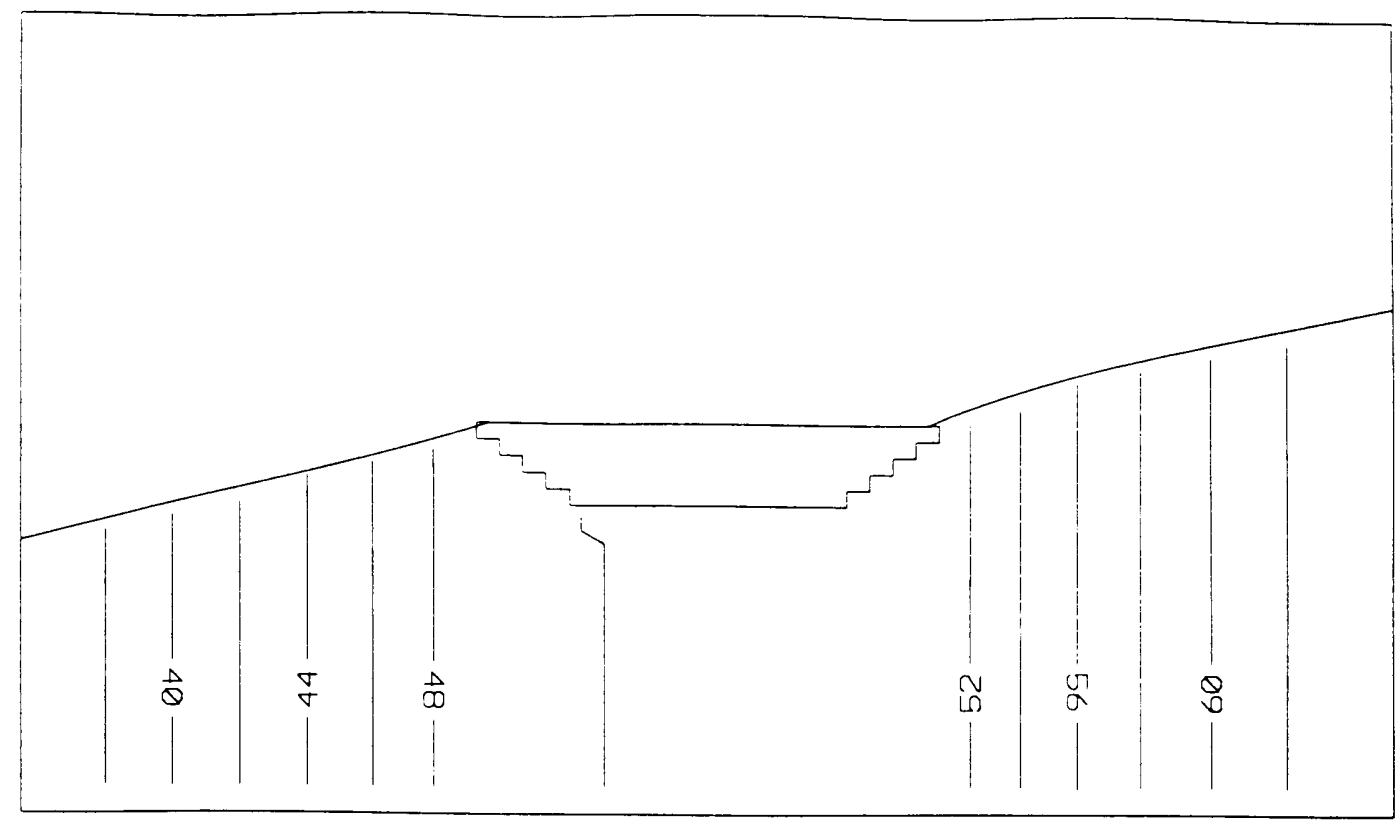

Coarse grid simulation

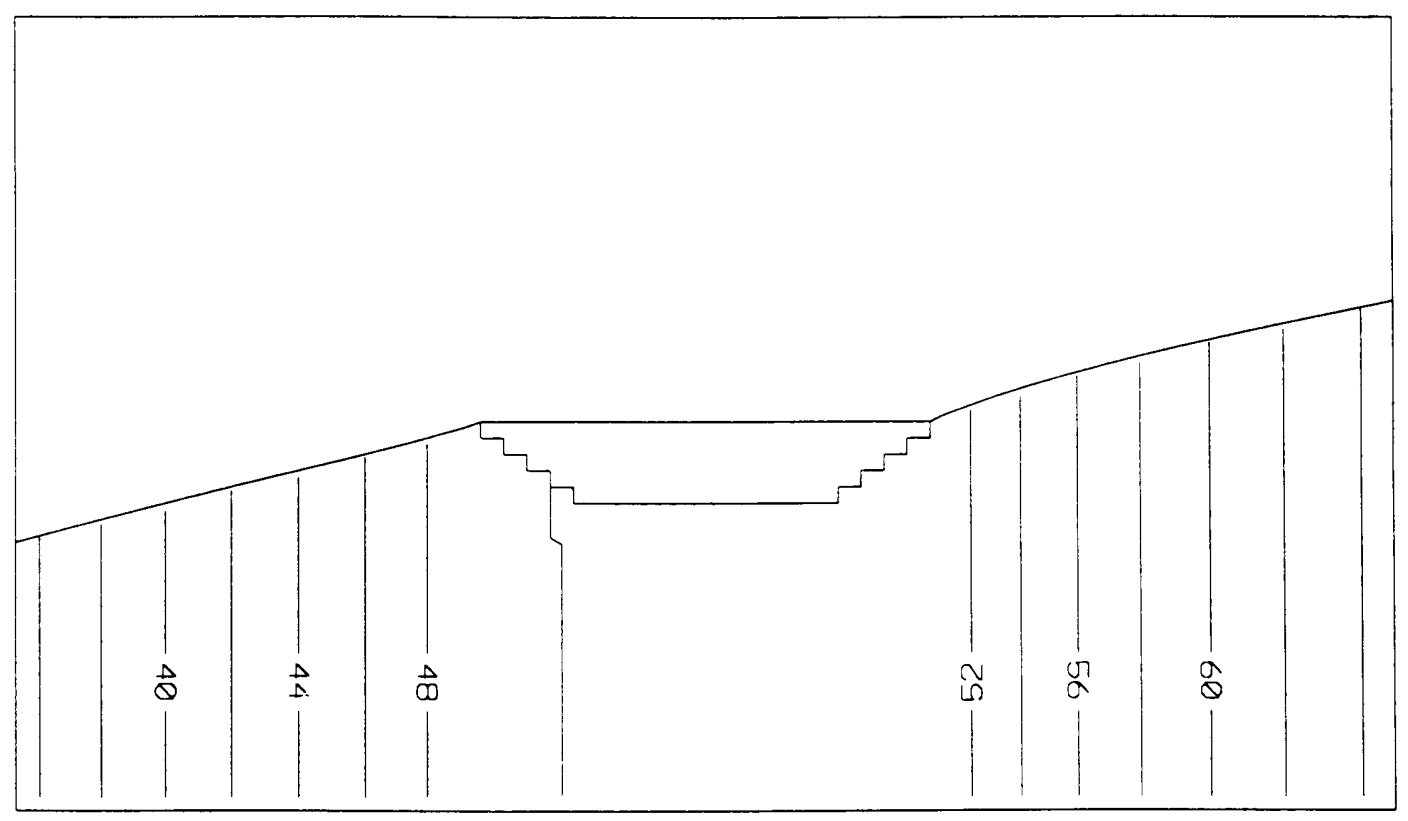

Fine grid simulation

Fig. 7.15. Distribution of hydraulic heads in the porous medium for coarse and fine grid simulations of shallow flow-through lakes with moderate slope at $R=1$. Contour interval is 2 meters. 


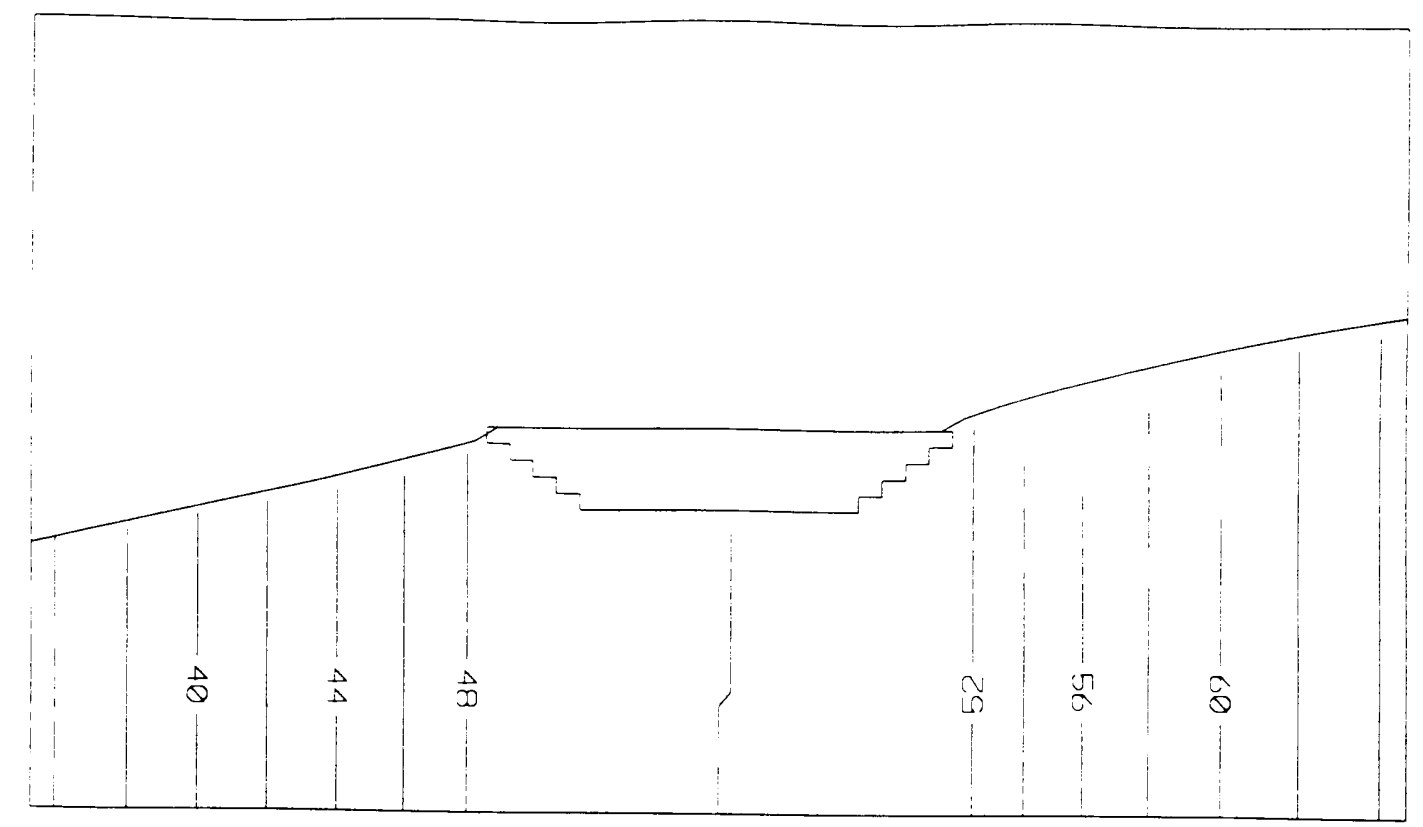

Coarse grid simulation

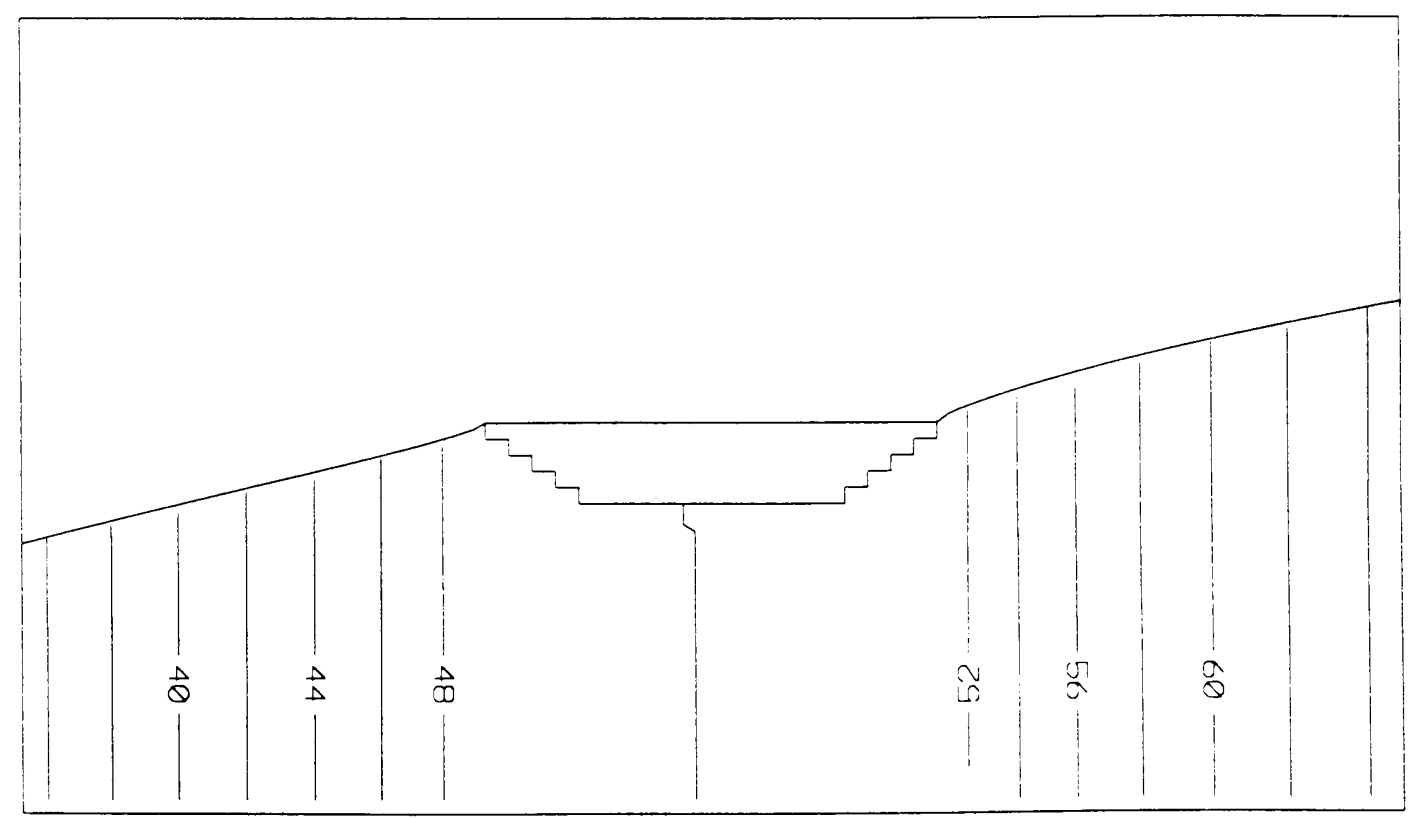

Fine grid simulation

Fig. 7.16. Distribution of hydraulic heads in the porous medium for coarse and fine grid simulations of shallow flow-through lakes with moderate slope at $R=10$. Contour interval is 2 meters. 


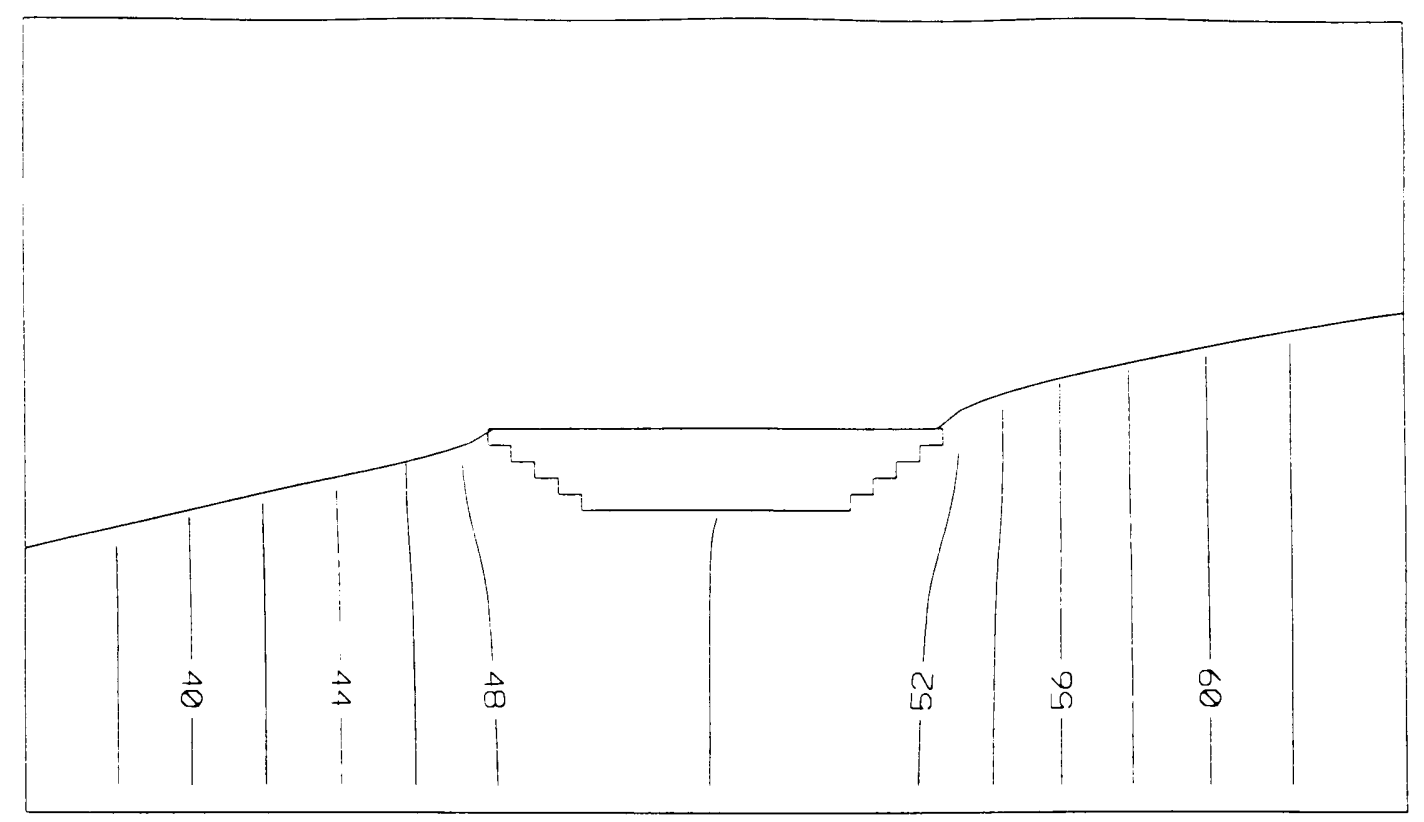

Coarse grid simulation

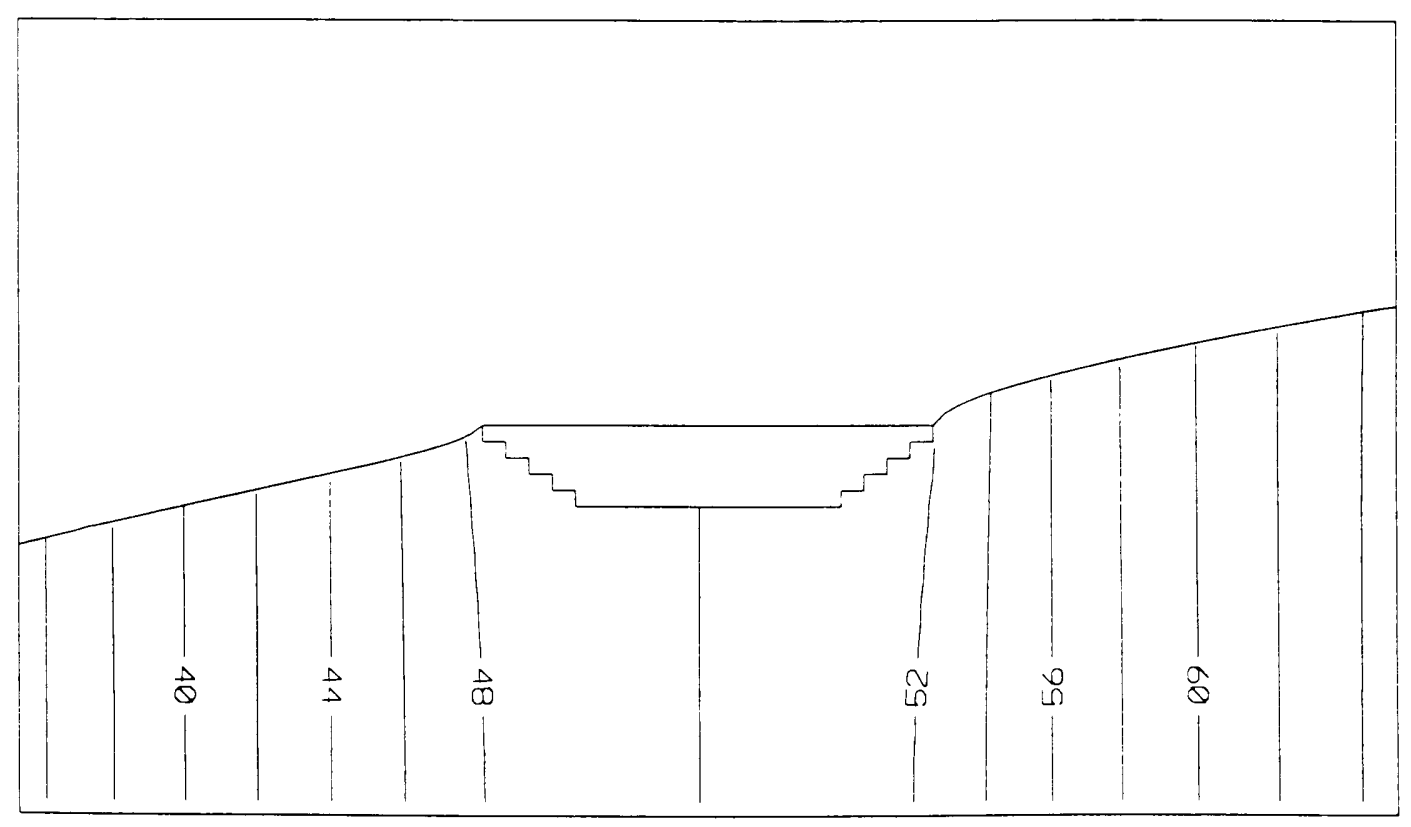

Fine grid simulation

Fig. 7.17. Distribution of hydraulic heads in the porous medium for coarse and fine grid simulations of shallow flow-through lakes with moderate slope at $R=100$. Contour interval is 2 meters. 


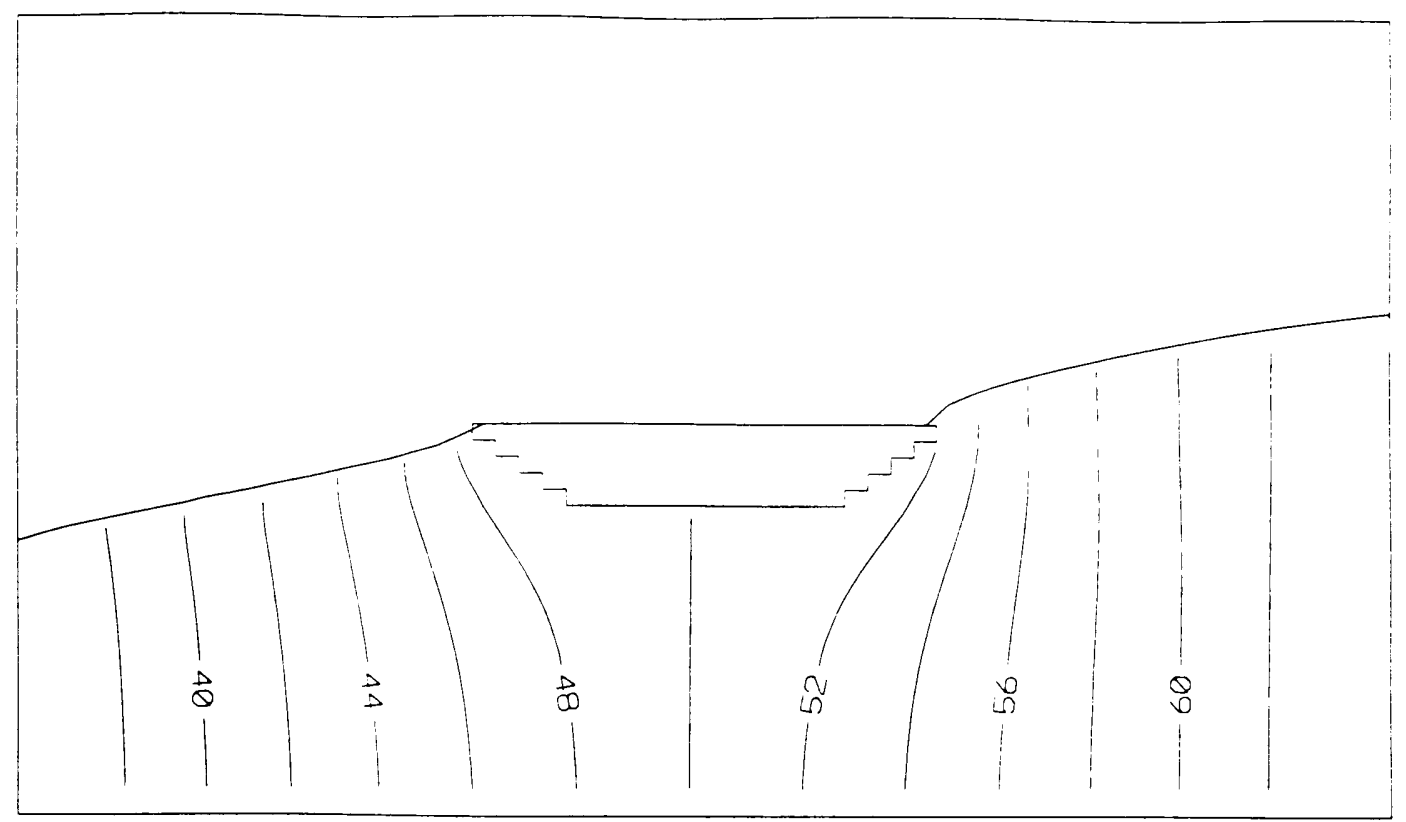

Coarse grid simulation

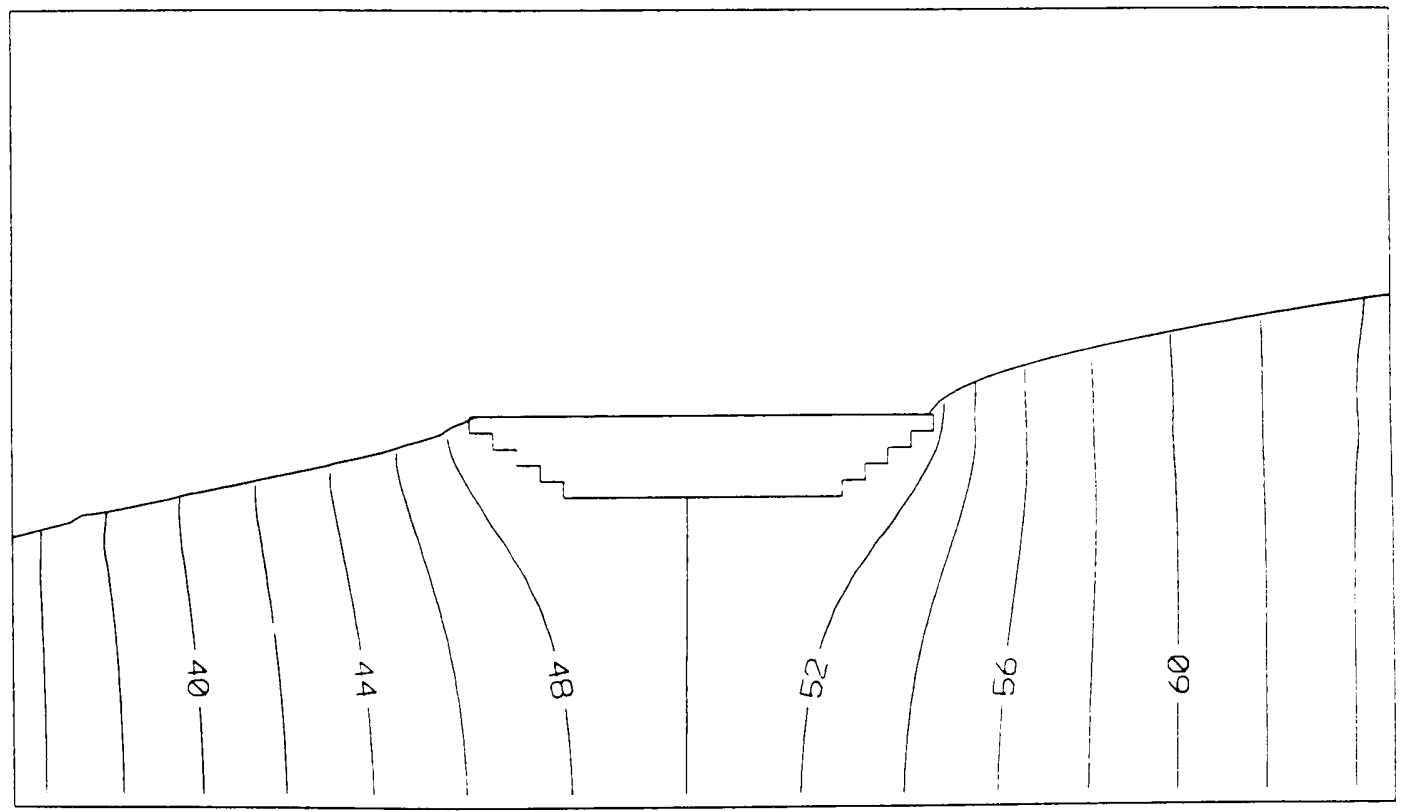

Fine grid simulation

Fig. 7.18. Distribution of hydraulic heads in the porous medium for coarse and fine grid simulations of shallow flow-through lakes with moderate slope at $R=1000$. Contour interval is 2 meters. 


$$
\mathrm{R}=1
$$

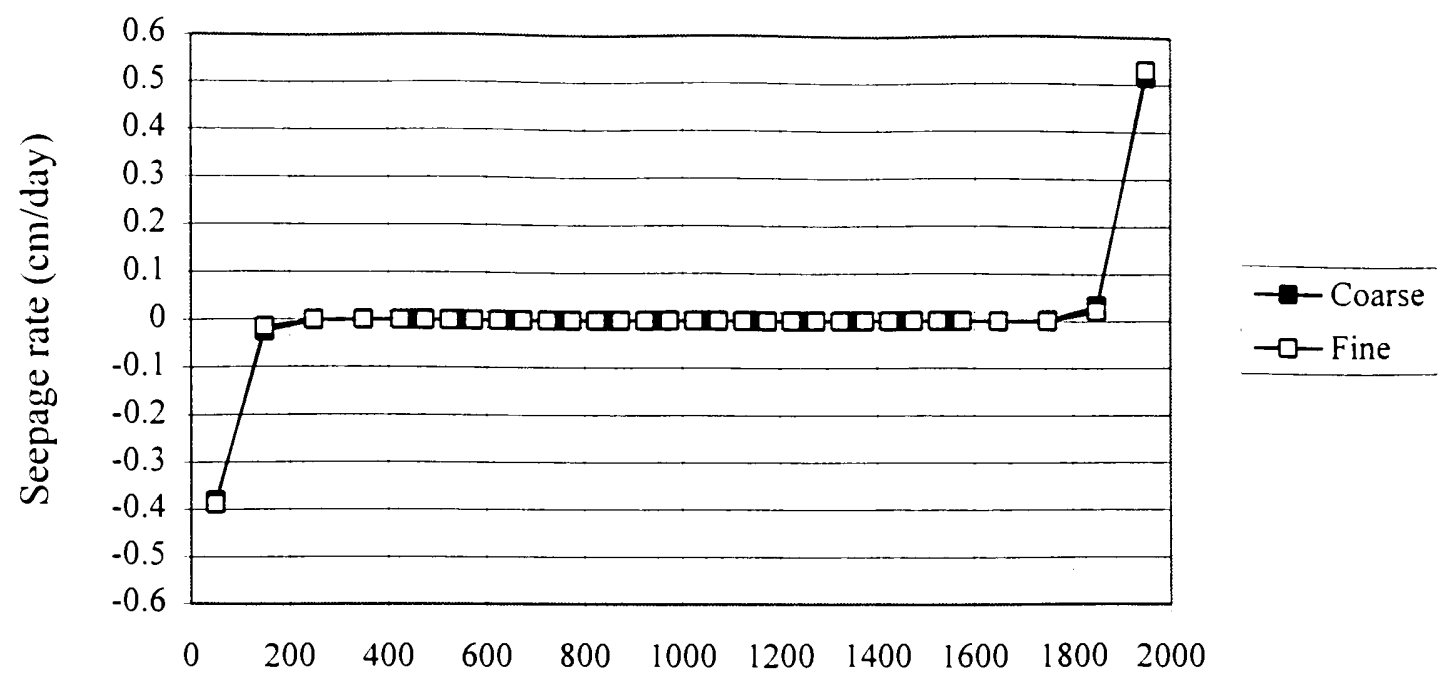

Distance (m)

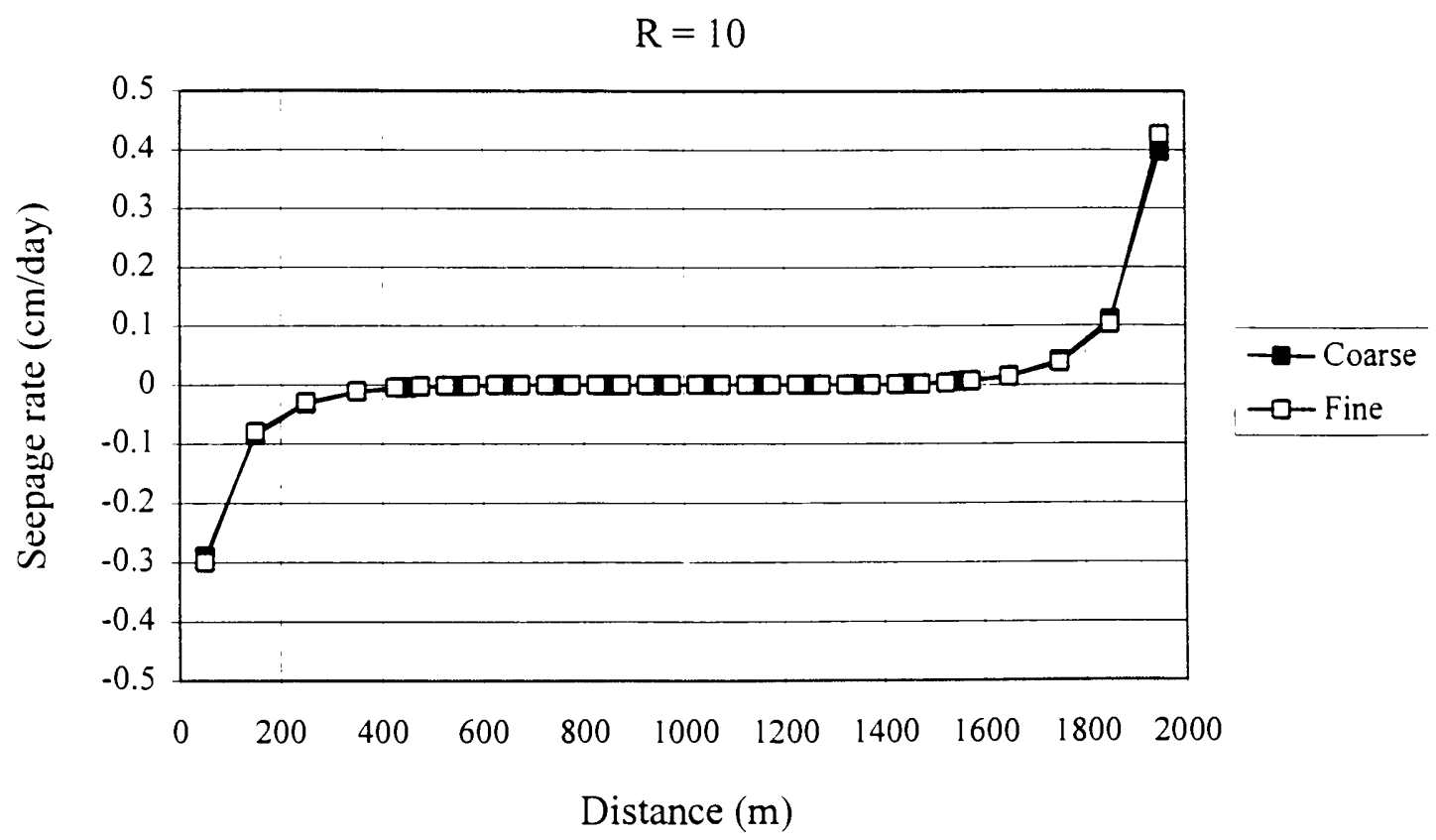

Fig. 7.19. Seepage rate versus distance from the downgradient shoreline for coarse and fine grid simulations of shallow flow-through lakes with moderate lake bed slope at $\mathrm{R}=1$ and $R=10$. 

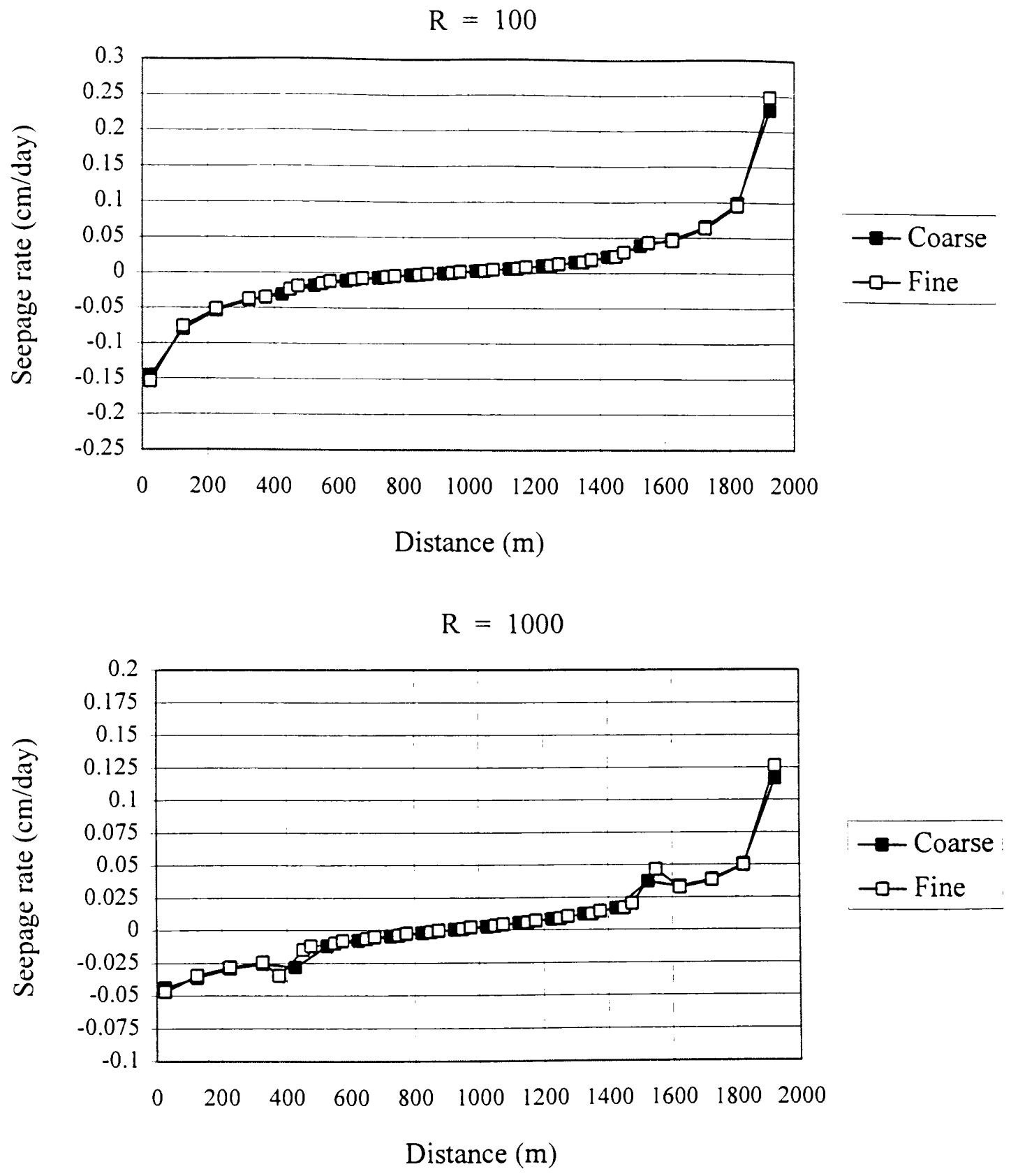

Fig. 7.20. Seepage rate versus distance from the downgradient shoreline for coarse and fine grid simulations of shallow flow-through lakes with moderate lake bed slope at $\mathrm{R}=100$ and $\mathrm{R}=1000$. 


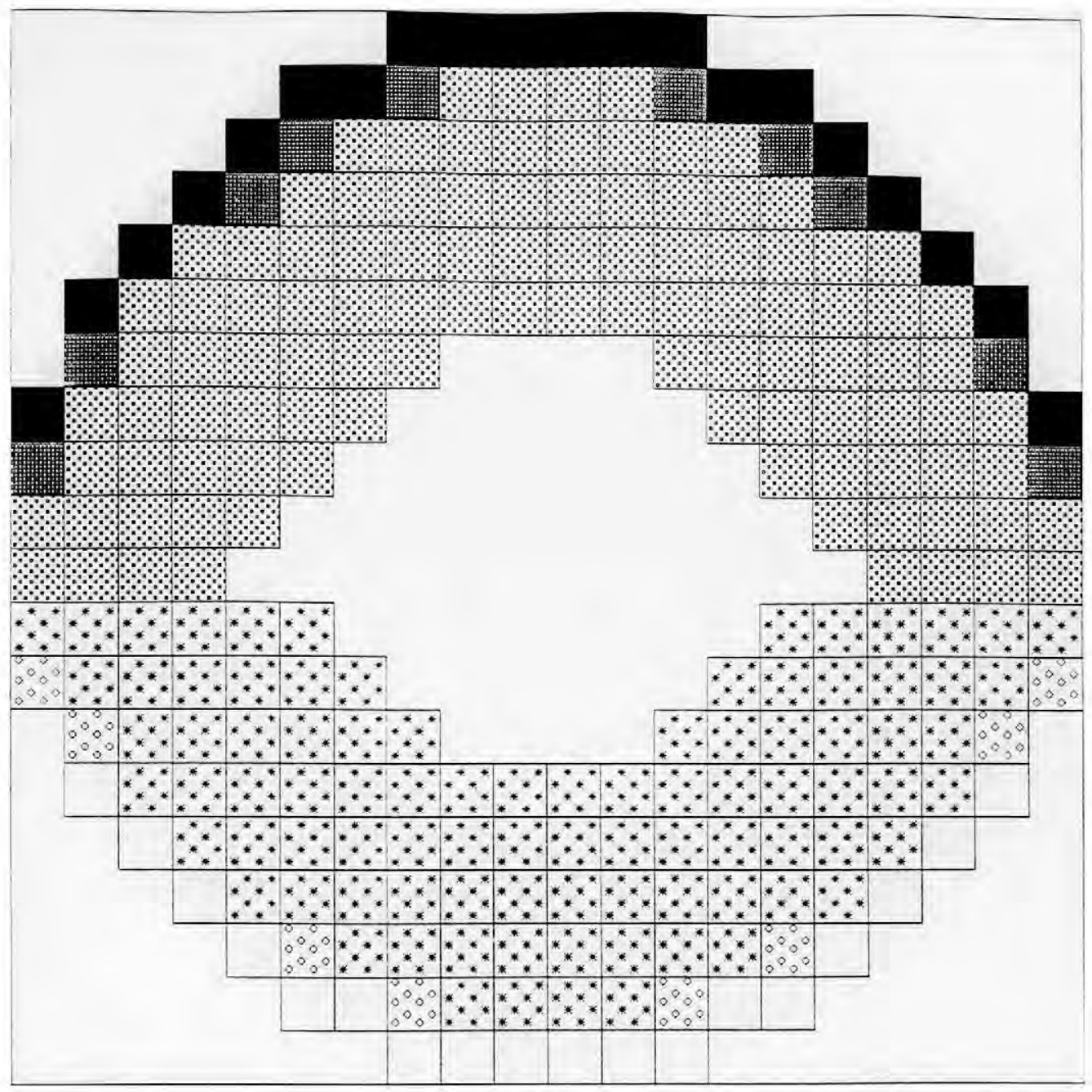

Fig. 7.21. Distribution of seepage rates ( $\mathrm{cm} /$ day) over the lake bed for the coarse grid simulation of a shallow flow-through lake with moderate slope at $\mathrm{R}=1$. The regional groundwater flow is from the top to the bottom of the figure. The white area in the center represents cells having seepage rates with absolute values $<10^{-7} \mathrm{~cm} /$ day.

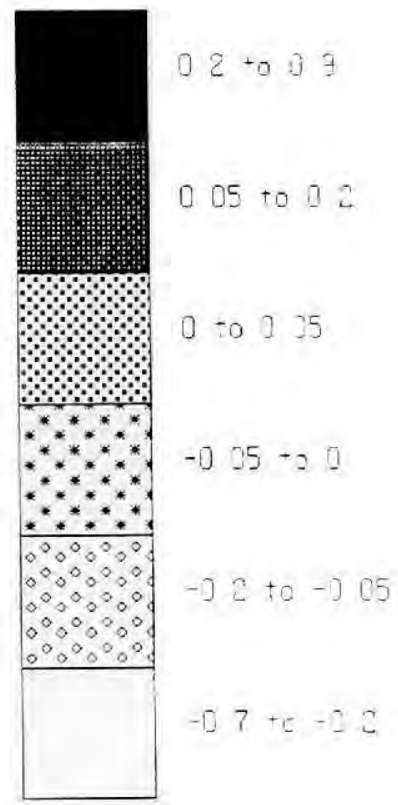




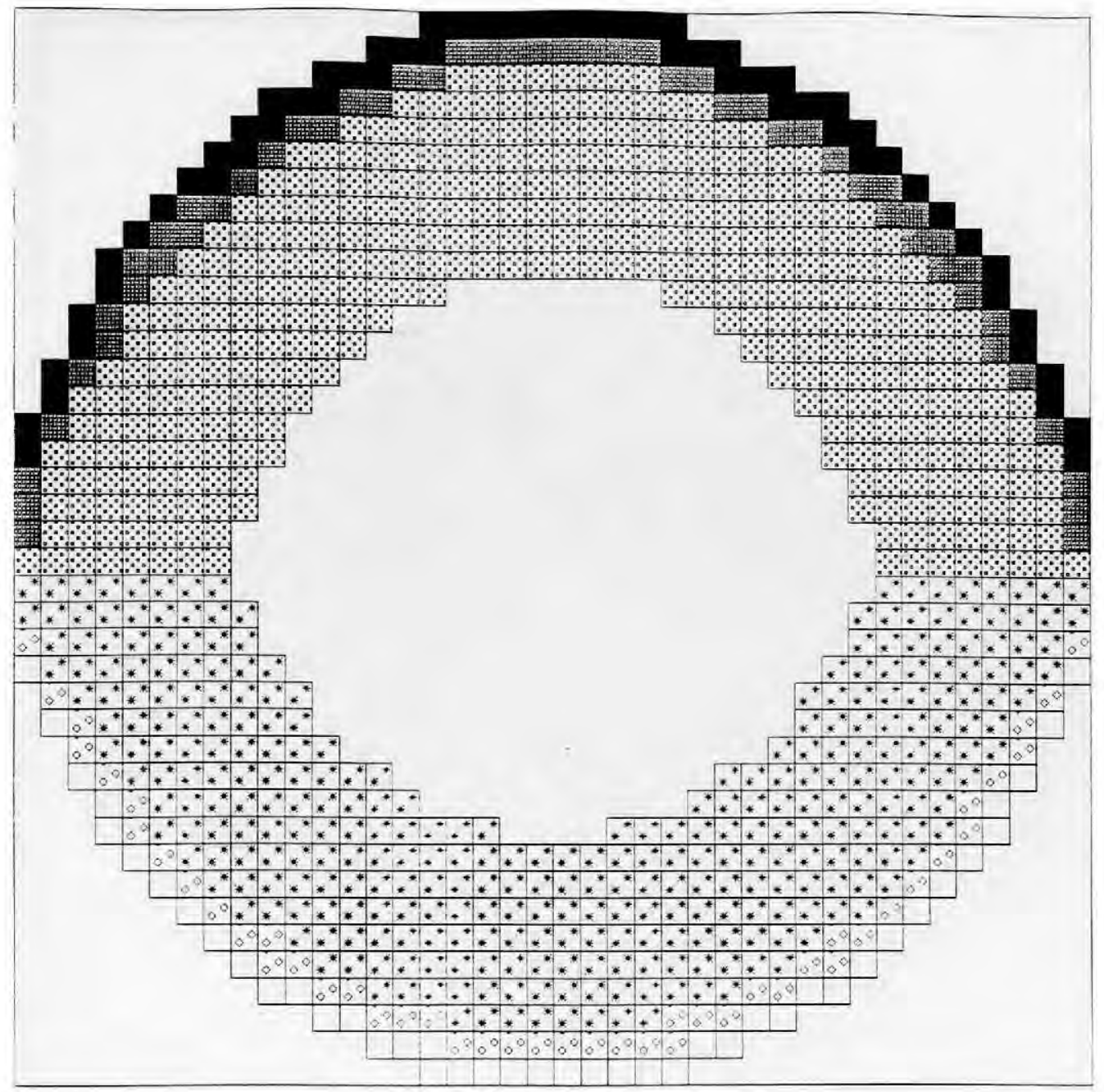

Fig. 7.22. Distribution of seepage rates $(\mathrm{cm} /$ day) over the lake bed for the fine grid simulation of a shallow flow-through lake with moderate slope at $\mathrm{R}=1$. The regional groundwater flow is from the top to the bottom of the figure. The white area in the center represents cells having seepage rates with absolute values $<10^{-7} \mathrm{~cm} /$ day.

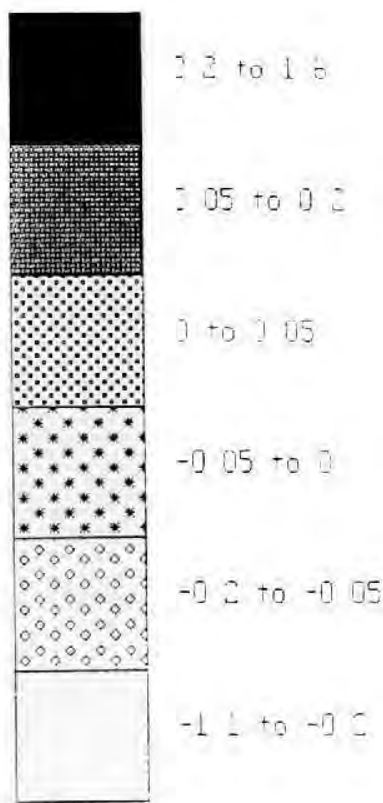



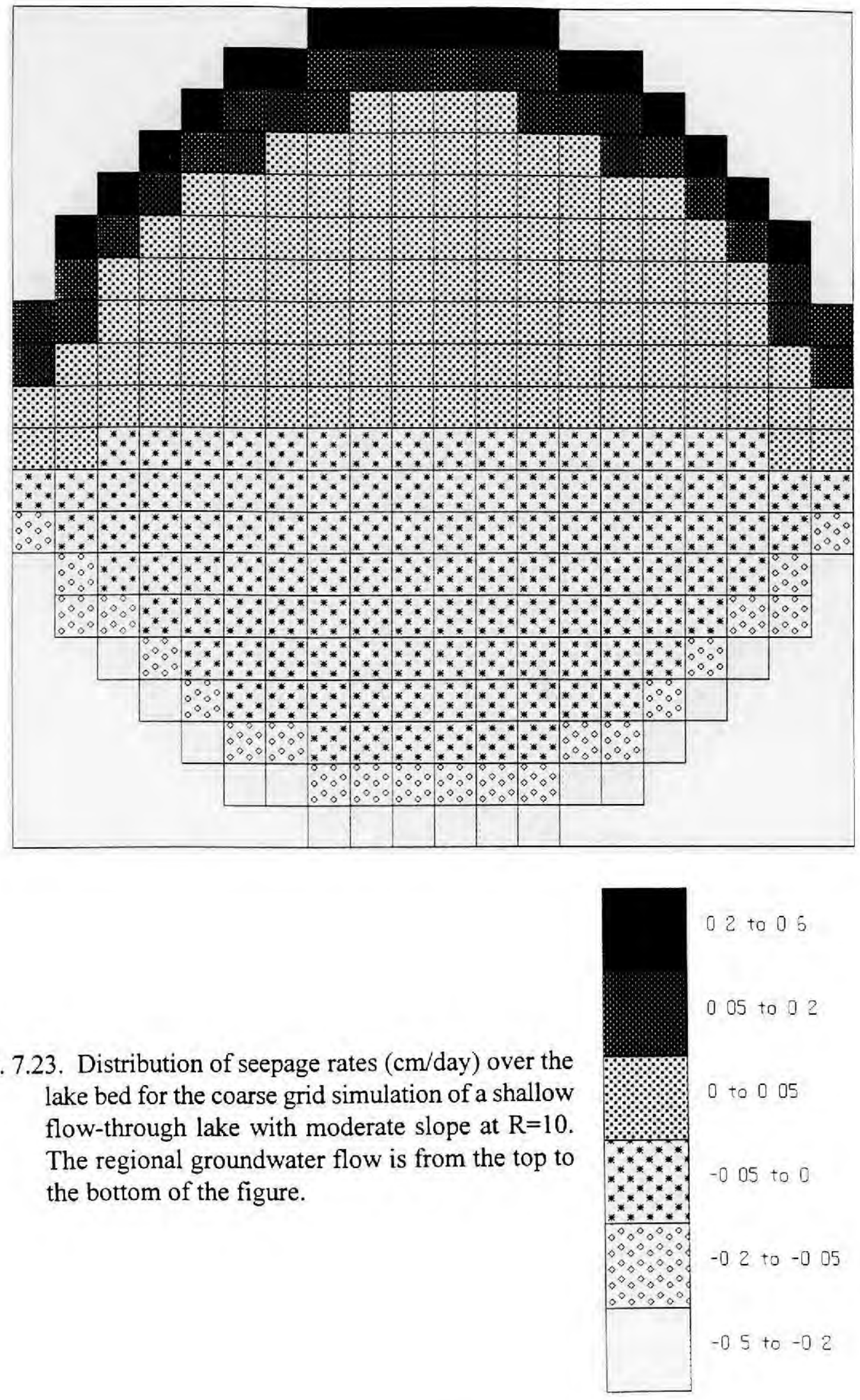

Fig. 7.23. Distribution of seepage rates $(\mathrm{cm} /$ day) over the lake bed for the coarse grid simulation of a shallow flow-through lake with moderate slope at $\mathrm{R}=10$. The regional groundwater flow is from the top to the bottom of the figure. 


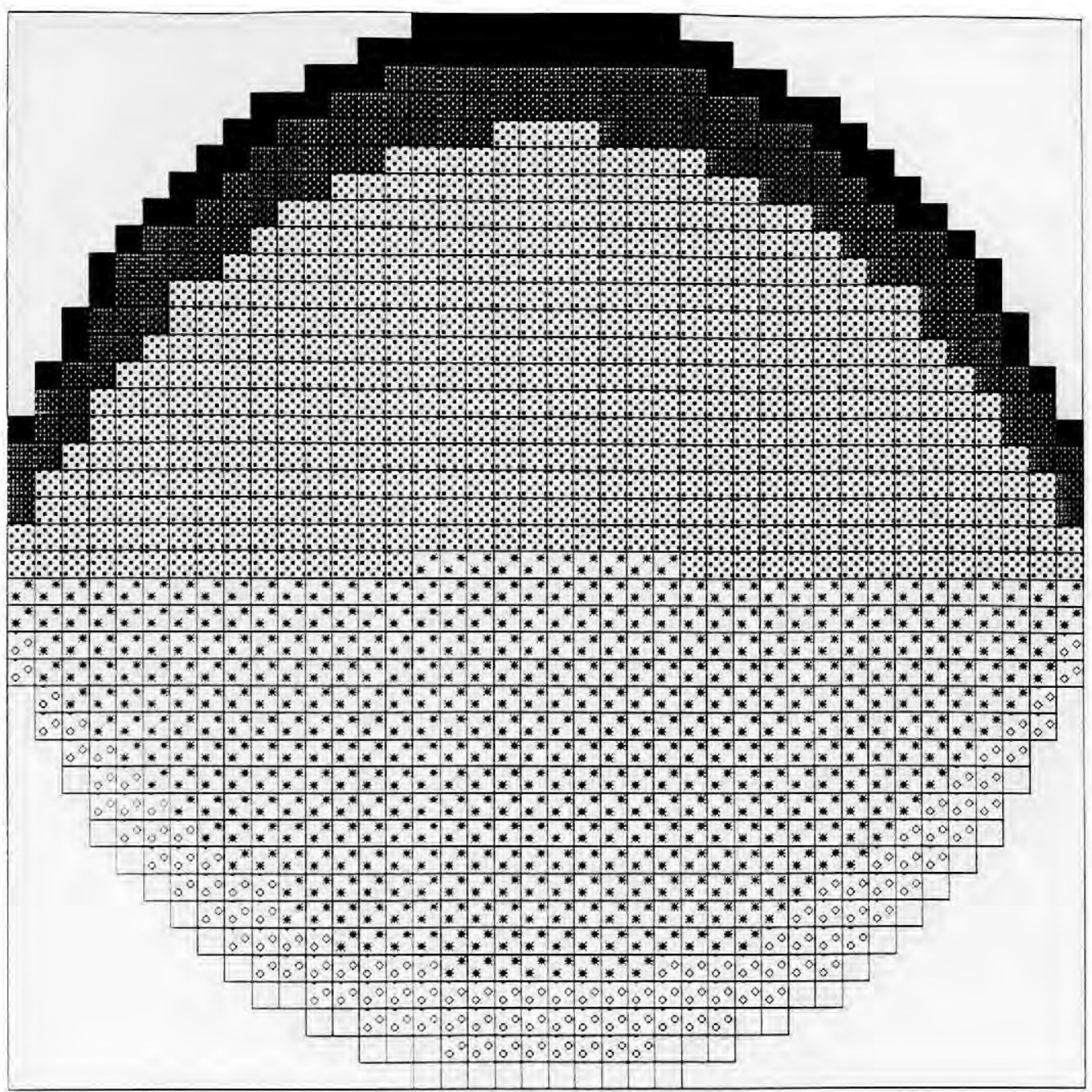

Fig. 7.24. Distribution of seepage rates ( $\mathrm{cm} /$ day) over the lake bed for the fine grid simulation of a shallow flow-through lake with moderate slope at $\mathrm{R}=10$. The regional groundwater flow is from the top to the bottom of the figure.

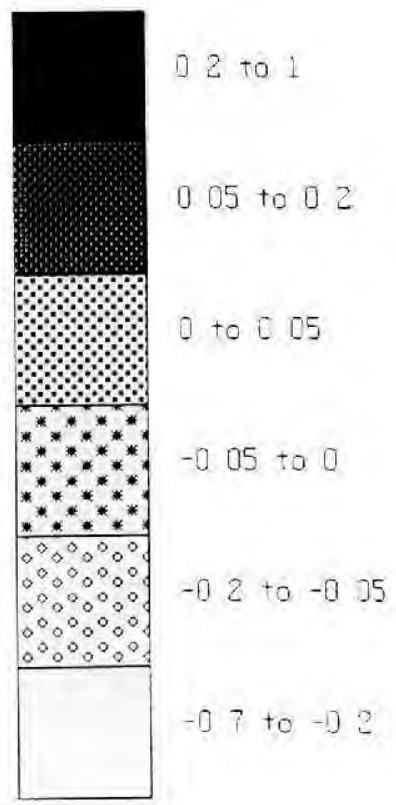




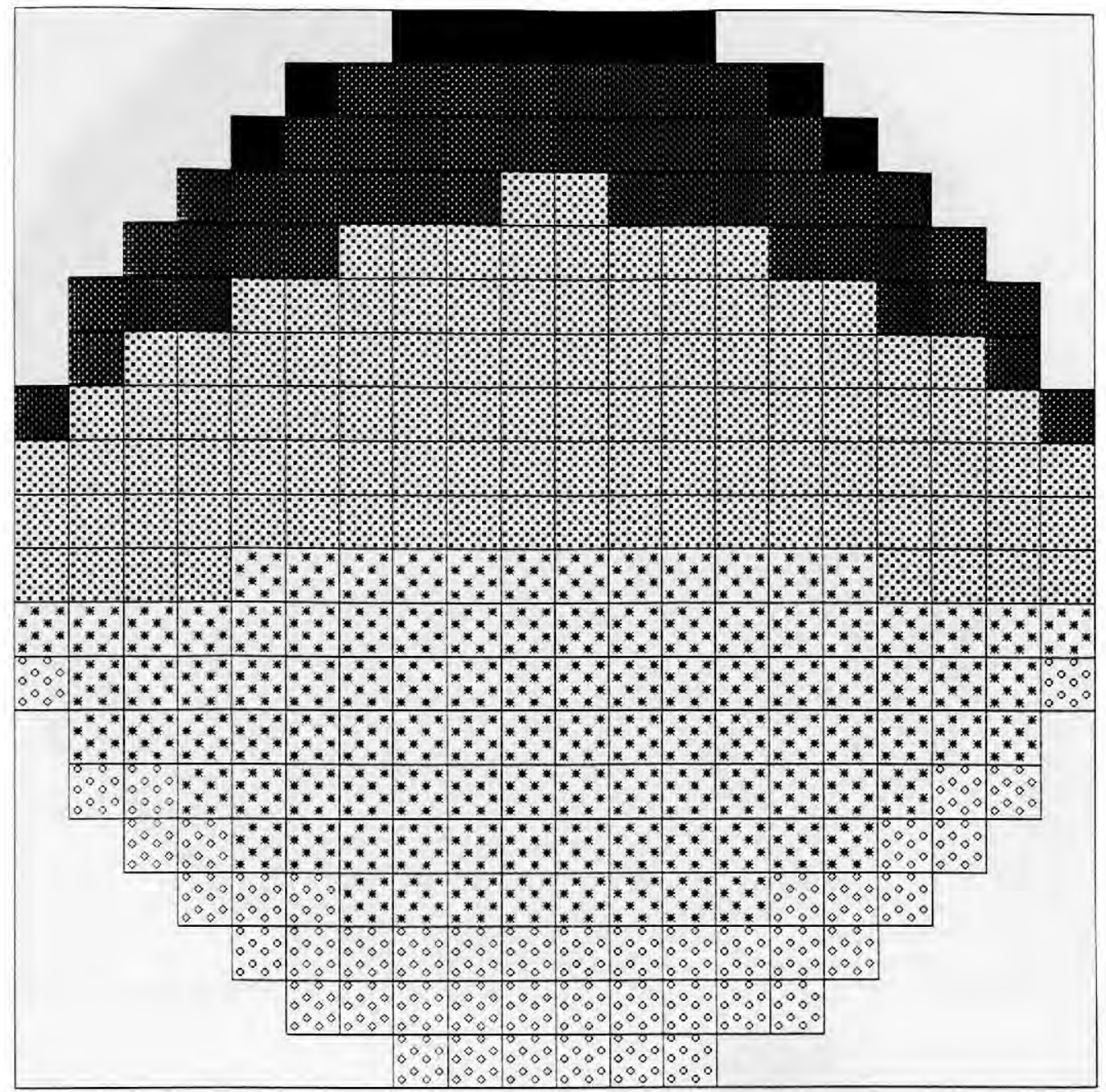

Fig. 7.25. Distribution of seepage rates ( $\mathrm{cm} /$ day) over the lake bed for the coarse grid simulation of a shallow flow-through lake with moderate slope at $\mathrm{R}=100$. The regional groundwater flow is from the top to the bottom of the figure.

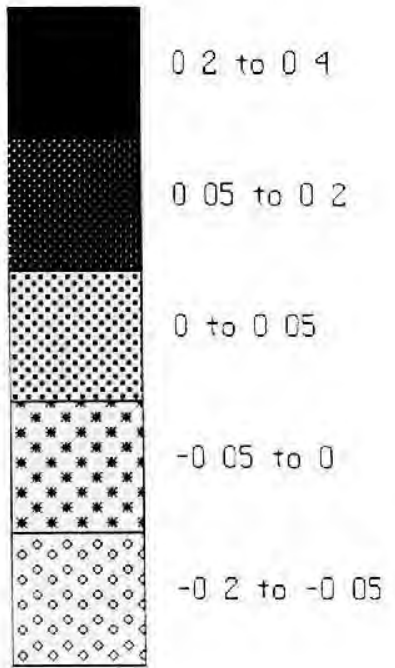




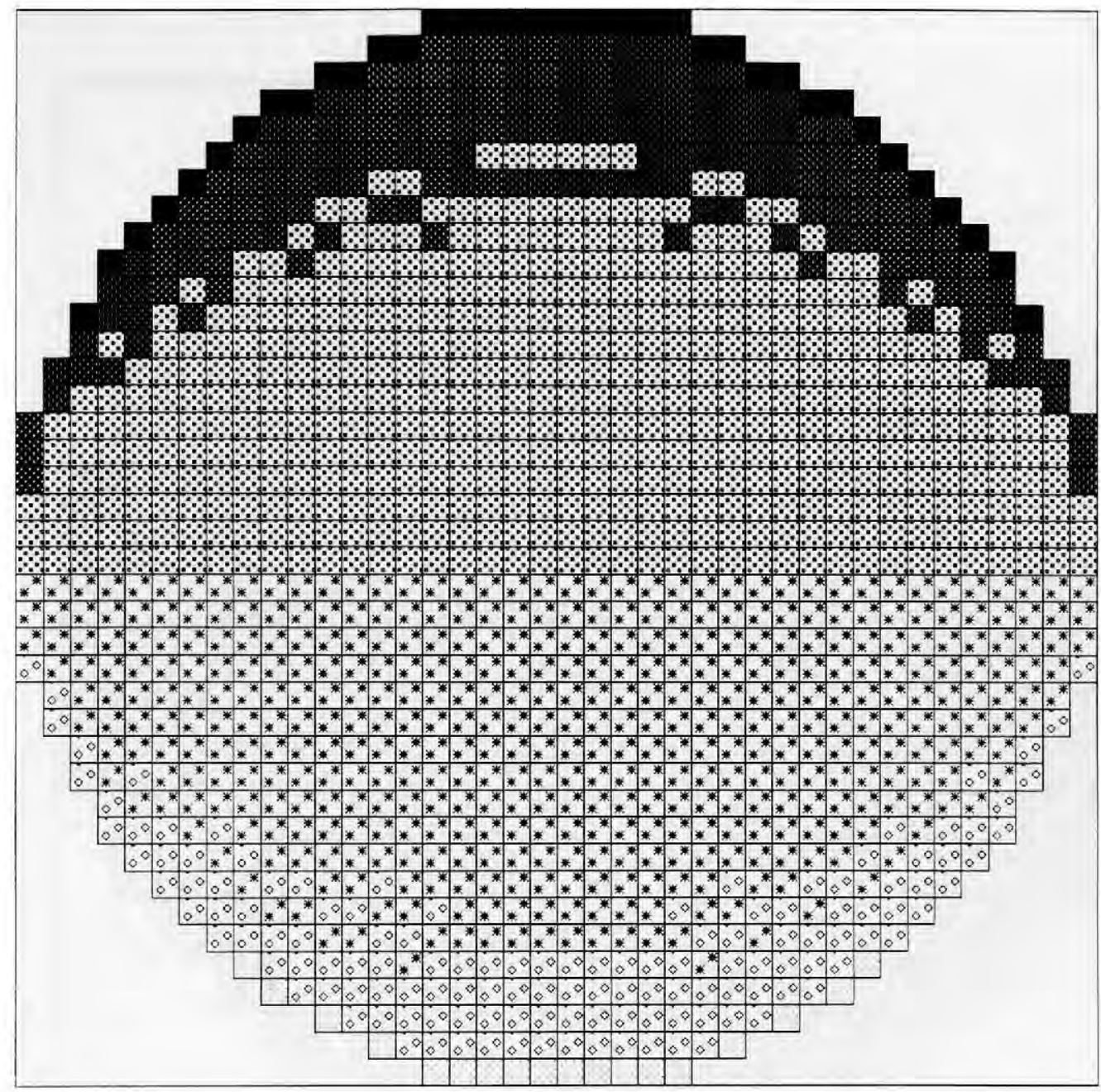

Fig. 7.26. Distribution of seepage rates ( $\mathrm{cm} /$ day) over the lake bed for the fine grid simulation of a shallow flow-through lake with moderate slope at $\mathrm{R}=100$. The regional groundwater flow is from the top to the bottom of the figure.

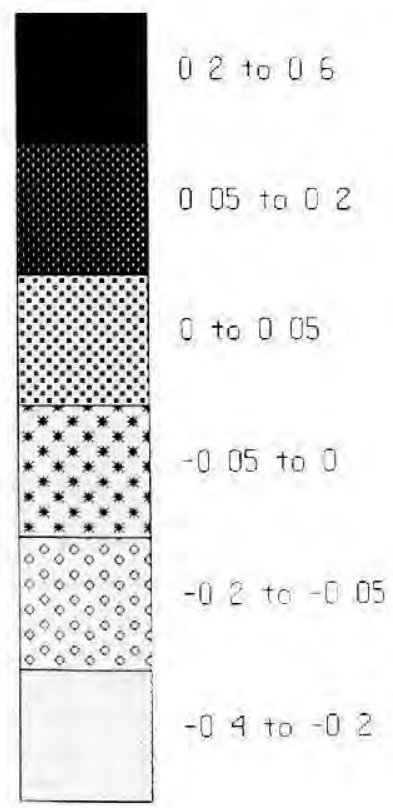




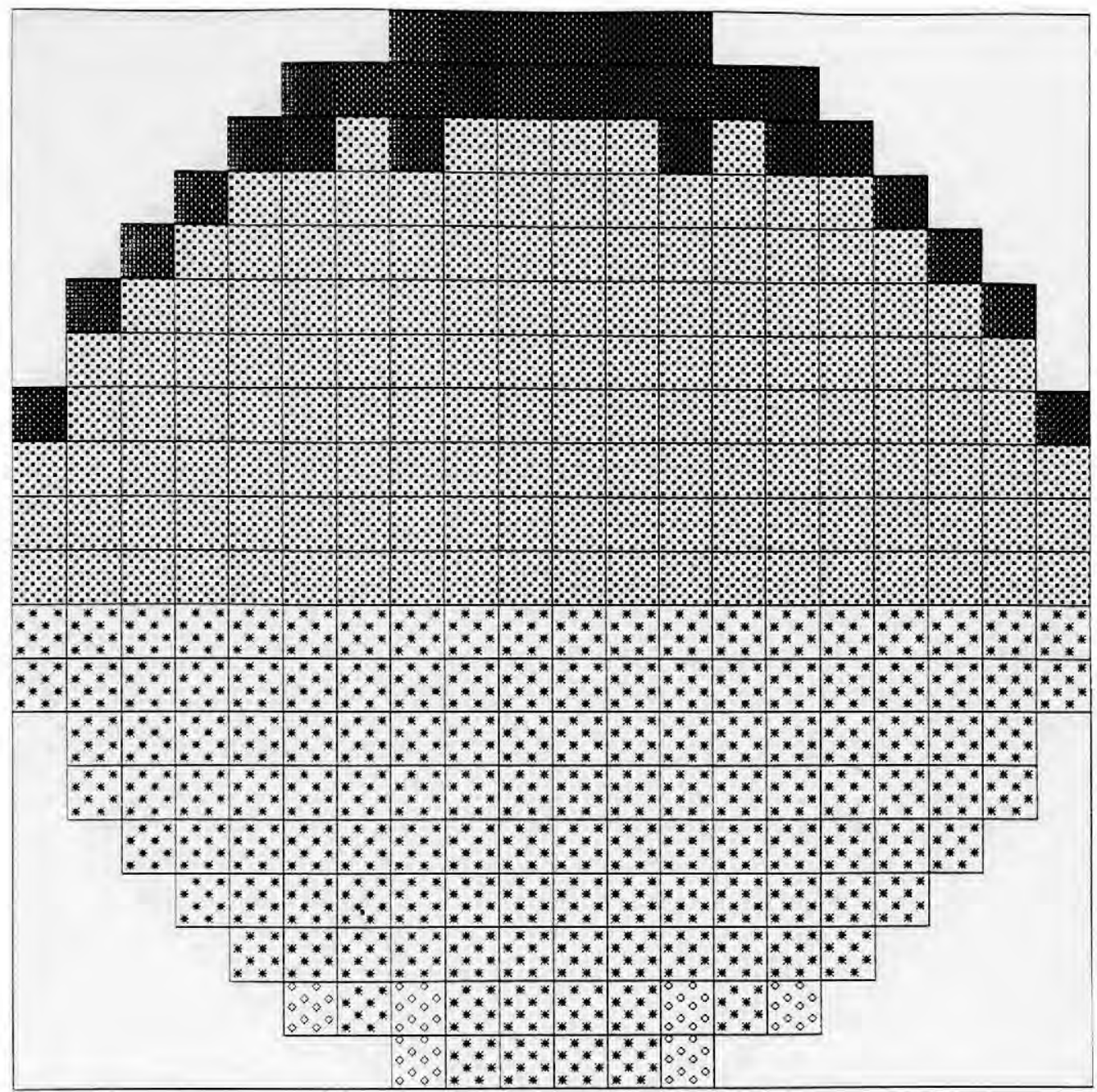

Fig. 7.27. Distribution of seepage rates ( $\mathrm{cm} /$ day) over the lake bed for the coarse grid simulation of a shallow flow-through lake with moderate slope at $\mathrm{R}=1000$. The regional groundwater flow is from the top to the bottom of the figure.

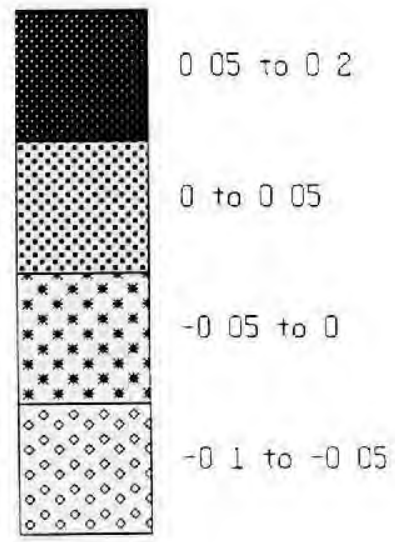




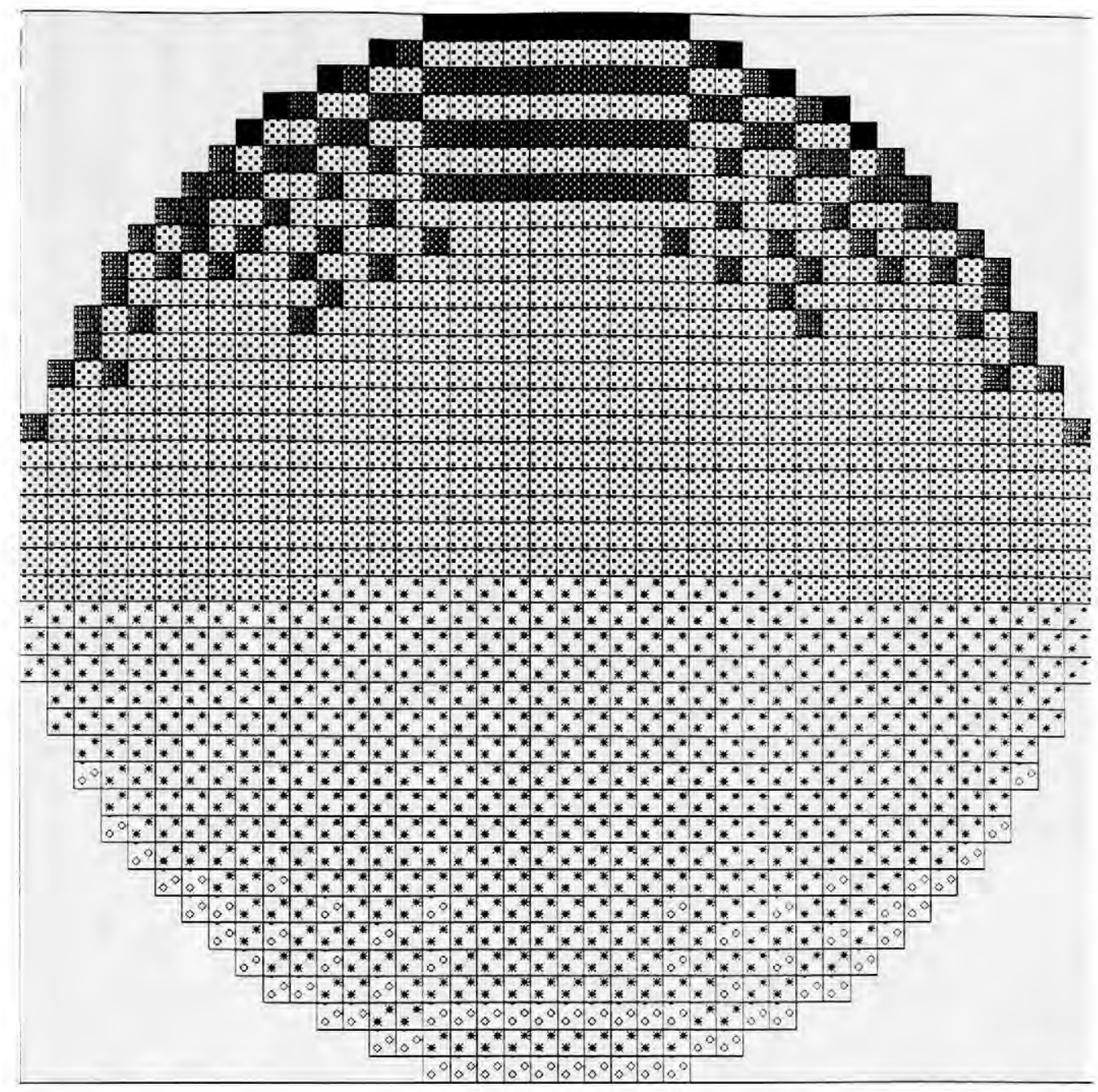

Fig. 7.28. Distribution of seepage rates $(\mathrm{cm} /$ day) over the lake bed for the fine grid simulation of a shallow flow-through lake with moderate slope at $R=1000$. The regional groundwater flow is from the top to the bottom of the figure.

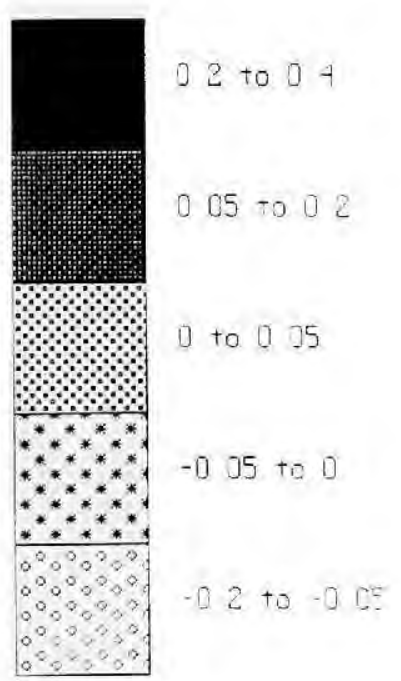


Table 7.3. Seepage rate as a function of distance offshore for shallow inflow lake simulations with different grid sizes (fine and coarse) and anisotropy ratios (1,10,100, and 1000). Two seepage values are given for the sloping portions of the fine grid lake beds: raw model output, and "step averages" (the average seepage rate for the 2 grid cells on a single step; see text for discussion). Distance runs from the lake shore to the center of the lake. A $*$ denotes where the seepage rate was $<10^{-7} \mathrm{~cm} / \mathrm{day}$.

\begin{tabular}{|c|c|c|c|c|c|c|c|c|c|c|c|c|}
\hline \multirow{4}{*}{$\begin{array}{c}\text { Distance } \\
\text { offshore } \\
(\mathrm{m})\end{array}$} & \multicolumn{12}{|c|}{ Lake bed seepage rate $(\mathrm{cm} /$ day $)$} \\
\hline & \multicolumn{3}{|c|}{$\mathrm{R}=1$} & \multicolumn{3}{|c|}{$\mathrm{R}=10$} & \multicolumn{3}{|c|}{$\mathrm{R}=100$} & \multicolumn{3}{|c|}{$\mathrm{R}=1000$} \\
\hline & Coarse & \multicolumn{2}{|c|}{ Fine } & Coarse & \multicolumn{2}{|c|}{ Fine } & Coarse & \multicolumn{2}{|c|}{ Fine } & Coarse & \multicolumn{2}{|c|}{ Fine } \\
\hline & \multicolumn{2}{|c|}{ Raw output } & \multirow[t]{2}{*}{ Average } & \multicolumn{2}{|c|}{ Raw output } & \multirow{2}{*}{ Average } & \multicolumn{2}{|c|}{ Raw output } & \multirow[t]{2}{*}{ Average } & \multicolumn{2}{|c|}{ Raw output } & \multirow[t]{2}{*}{ Average } \\
\hline 25 & & 2.32826 & & & 1.55937 & & & 1.19604 & & & 1.33128 & \\
\hline 50 & 1.21878 & & 1.36537 & 1.01571 & & 1.04233 & 0.73718 & & 0.75918 & 0.68651 & & 0.72204 \\
\hline 75 & & 0.40248 & & & 0.52529 & & & 0.32231 & & & 0.11281 & \\
\hline 125 & & 0.09402 & & & 0.32666 & & & 0.34454 & & & 0.31116 & \\
\hline 150 & 0.07886 & & 0.05748 & 0.27746 & & 0.25284 & 0.29045 & & 0.26690 & 0.21931 & & 0.19514 \\
\hline 175 & & 0.02094 & & & 0.17903 & & & 0.18926 & & & 0.07913 & \\
\hline 225 & & 0.00446 & & & 0.11965 & & & 0.22796 & & & 0.23553 & \\
\hline 250 & 0.00596 & & 0.00270 & 0.10401 & & 0.09312 & 0.19753 & & 0.18164 & 0.17049 & & 0.15175 \\
\hline 275 & & 0.00094 & & & 0.06660 & & & 0.13533 & & & 0.06797 & \\
\hline 325 & & 0.00020 & & & 0.04428 & & & 0.16885 & & & 0.21126 & \\
\hline 350 & 0.00042 & & 0.00012 & 0.03947 & & 0.03432 & 0.14958 & & 0.13663 & 0.15804 & & 0.13897 \\
\hline 375 & & $3.86 \mathrm{e}-05$ & & & 0.02436 & & & 0.10441 & & & 0.06669 & \\
\hline 425 & & $7.63 \mathrm{e}-06$ & & & 0.01599 & & & 0.13405 & & & 0.22166 & \\
\hline 450 & $2.84 \mathrm{e}-05$ & & & 0.01486 & & & 0.12797 & & & 0.20254 & & \\
\hline 475 & & $1.46 \mathrm{e}-06$ & & & 0.00892 & & & 0.09658 & & & 0.10913 & \\
\hline 525 & & $*$ & & & 0.00514 & & & 0.08088 & & & 0.09897 & \\
\hline 550 & $1.76 \mathrm{e}-06$ & & & 0.00522 & & & 0.08476 & & & 0.10992 & & \\
\hline
\end{tabular}


Table 7.3 (contd.)

\begin{tabular}{|c|c|c|c|c|c|c|c|c|c|c|c|c|}
\hline \multirow{4}{*}{$\begin{array}{l}\text { Distance } \\
\text { offshore } \\
\text { (m) }\end{array}$} & \multicolumn{12}{|c|}{ Lake bed seepage rate $(\mathrm{cm} /$ day $)$} \\
\hline & \multicolumn{3}{|c|}{$\mathrm{R}=1$} & \multicolumn{3}{|c|}{$\mathrm{R}=10$} & \multicolumn{3}{|c|}{$\mathrm{R}=100$} & \multicolumn{3}{|c|}{$\mathrm{R}=1000$} \\
\hline & Coarse & \multicolumn{2}{|c|}{ Fine } & Coarse & \multicolumn{2}{|c|}{ Fine } & Coarse & \multicolumn{2}{|c|}{ Fine } & Coarse & \multicolumn{2}{|c|}{ Fine } \\
\hline & \multicolumn{2}{|c|}{ Raw output } & Average & \multicolumn{2}{|c|}{ Raw output } & Average & \multicolumn{2}{|c|}{ Raw output } & Average & \multicolumn{2}{|c|}{ Raw output } & Average \\
\hline 575 & & $*$ & & & 0.00301 & & & 0.06975 & & & 0.09170 & \\
\hline 625 & & * & & & 0.00178 & & & 0.06128 & & & 0.08634 & \\
\hline 650 & $1.12 \mathrm{e}-07$ & & & 0.00192 & & & 0.06485 & & & 0.09590 & & \\
\hline 675 & & $*$ & & & 0.00106 & & & 0.05465 & & & 0.08232 & \\
\hline 725 & & $*$ & & & 0.00064 & & & 0.04944 & & & 0.07928 & \\
\hline 750 & $*$ & & & 0.00074 & & & 0.05294 & & & 0.08797 & & \\
\hline 775 & & $*$ & & & 0.00040 & & & 0.04538 & & & 0.07699 & \\
\hline 825 & & $*$ & & & 0.00026 & & & 0.04230 & & & 0.07528 & \\
\hline 850 & $*$ & & & 0.00032 & & & 0.04597 & & & 0.08358 & & \\
\hline 875 & & $*$ & & & 0.00017 & & & 0.04008 & & & 0.07408 & \\
\hline 925 & & $*$ & & & 0.00013 & & & 0.03864 & & & 0.07330 & \\
\hline 950 & $*$ & & & 0.00019 & & & 0.04272 & & & 0.08160 & & \\
\hline 975 & & $*$ & & & 0.00011 & & & 0.03793 & & & 0.07292 & \\
\hline
\end{tabular}


Table 7.4. Seepage rate as a function of distance offshore for shallow flow-through lake simulations with different grid sizes (fine and coarse) and anisotropy ratios $(1,10,100$, and 1000). Two seepage values are given for the sloping portions of the fine grid lake beds: raw model output, and "step averages" (the average seepage rate for the 2 grid cells on a single step; see text for discussion). Distance runs from the lake shore to the center of the lake. ${ }^{*}$ denotes where the seepage rate was $<10^{-7} \mathrm{~cm} /$ day.

\begin{tabular}{|c|c|c|c|c|c|c|c|c|c|c|c|c|}
\hline \multirow{4}{*}{$\begin{array}{l}\text { Distance } \\
\text { offshore } \\
\text { (m) }\end{array}$} & \multicolumn{12}{|c|}{ Lake bed seepage rate $(\mathrm{cm} /$ day $)$} \\
\hline & \multicolumn{3}{|c|}{$\mathrm{R}=1$} & \multicolumn{3}{|c|}{$\mathrm{R}=10$} & \multicolumn{3}{|c|}{$\mathrm{R}=100$} & \multicolumn{3}{|c|}{$\mathrm{R}=1000$} \\
\hline & Coarse & \multicolumn{2}{|c|}{ Fine } & Coarse & \multicolumn{2}{|c|}{ Fine } & Coarse & \multicolumn{2}{|c|}{ Fine } & Coarse & \multicolumn{2}{|c|}{ Fine } \\
\hline & \multicolumn{2}{|c|}{ Raw output } & \multirow{2}{*}{ Average } & \multicolumn{2}{|c|}{ Raw output } & \multirow[t]{2}{*}{ Average } & \multicolumn{2}{|c|}{ Raw output } & \multirow[t]{2}{*}{ Average } & \multicolumn{2}{|c|}{ Raw output } & \multirow{2}{*}{ Average } \\
\hline 25 & & -0.65818 & & & -0.43978 & & & -0.22134 & & & -0.07580 & \\
\hline 50 & -0.38103 & & -0.38764 & -0.28956 & & -0.29917 & -0.14544 & & -0.15363 & -0.04395 & & -0.04695 \\
\hline 75 & & -0.11710 & & & -0.15856 & & & -0.08591 & & & -0.01811 & \\
\hline 125 & & -0.02655 & & & -0.10285 & & & -0.09737 & & & -0.05449 & \\
\hline 150 & -0.02546 & & -0.01620 & -0.08561 & & -0.07952 & -0.07969 & & -0.07556 & -0.03605 & & -0.03464 \\
\hline 175 & & -0.00585 & & & -0.05619 & & & -0.05374 & & & -0.01479 & \\
\hline 225 & & -0.00129 & & & -0.03743 & & & -0.06429 & & & -0.04403 & \\
\hline 250 & -0.00192 & & -0.00078 & -0.03184 & & -0.02906 & -0.05346 & & -0.05096 & -0.02920 & & -0.02827 \\
\hline 275 & & -0.00027 & & & -0.02070 & & & -0.03763 & & & -0.01250 & \\
\hline 325 & & $-5.70 \mathrm{e}-05$ & & & -0.01367 & & & -0.04607 & & & -0.03783 & \\
\hline 350 & -0.00014 & & $-3.42 \mathrm{e}-05$ & -0.01192 & & -0.01056 & -0.03884 & & -0.03689 & -0.02557 & & -0.02451 \\
\hline 375 & & $-1.13 e-05$ & & & -0.00746 & & & -0.02771 & & & -0.01117 & \\
\hline 425 & & $-2.25 e-06$ & & & -0.00485 & & & -0.03441 & & & -0.03486 & \\
\hline 450 & $-8.92 \mathrm{e}-06$ & & & -0.00440 & & & -0.03089 & & & -0.02821 & & \\
\hline 475 & & $-4.24 \mathrm{e}-07$ & & & -0.00268 & & & -0.02356 & & & -0.01483 & \\
\hline 525 & & $*$ & & & -0.00152 & & & -0.01864 & & & -0.01211 & \\
\hline 550 & $-5.62 e-07$ & & & -0.00150 & & & -0.01823 & & & -0.01203 & & \\
\hline
\end{tabular}


Table 7.4 (Contd.)

\begin{tabular}{|c|c|c|c|c|c|c|c|c|c|c|c|c|}
\hline \multirow{4}{*}{$\begin{array}{l}\text { Distance } \\
\text { offshore } \\
\text { (m) }\end{array}$} & \multicolumn{12}{|c|}{ Lake bed seepage rate $(\mathrm{cm} /$ day $)$} \\
\hline & \multicolumn{3}{|c|}{$\mathrm{R}=1$} & \multicolumn{3}{|c|}{$\mathrm{R}=10$} & \multicolumn{3}{|c|}{$\mathrm{R}=100$} & \multicolumn{3}{|c|}{$\mathrm{R}=1000$} \\
\hline & Coarse & \multicolumn{2}{|c|}{ Fine } & Coarse & \multicolumn{2}{|c|}{ Fine } & Coarse & \multicolumn{2}{|c|}{ Fine } & Coarse & \multicolumn{2}{|c|}{ Fine } \\
\hline & \multicolumn{2}{|c|}{ Raw output } & Average & \multicolumn{2}{|c|}{ Raw output } & \multirow[t]{2}{*}{ Average } & \multicolumn{2}{|c|}{ Raw output } & \multirow{2}{*}{ Average } & \multicolumn{2}{|c|}{ Raw output } & \multirow[t]{2}{*}{ Average } \\
\hline 575 & & $*$ & & & -0.00088 & & & -0.01499 & & & -0.00993 & \\
\hline 625 & & $*$ & & & -0.00051 & & & -0.01206 & & & -0.00810 & \\
\hline 650 & $*$ & & & -0.00053 & & & -0.01169 & & & -0.00794 & & \\
\hline 675 & & $*$ & & & -0.00030 & & & -0.00962 & & & -0.00650 & \\
\hline 725 & & * & & & -0.00017 & & & -0.00752 & & & -0.00506 & \\
\hline 750 & $*$ & & & -0.00019 & & & -0.00711 & & & -0.00480 & & \\
\hline 775 & & $*$ & & & -0.00010 & & & -0.00567 & & & -0.00373 & \\
\hline 825 & & $*$ & & & $-5.77 e-05$ & & & -0.00401 & & & -0.00248 & \\
\hline 850 & * & & & $-6.37 e-05$ & & & -0.00351 & & & -0.00212 & & \\
\hline 875 & & $*$ & & & $-3.17 \mathrm{e}-05$ & & & -0.00248 & & & -0.00129 & \\
\hline 925 & & $*$ & & & $-1.47 \mathrm{e}-05$ & & & -0.00102 & & & -0.00012 & \\
\hline 950 & * & & & $-1.21 \mathrm{e}-05$ & & & -0.00038 & & & 0.00035 & & \\
\hline 975 & & $*$ & & & $-1.90 \mathrm{e}-06$ & & & 0.00039 & & & 0.00104 & \\
\hline 1025 & & $*$ & & & $1.01 \mathrm{e}-05$ & & & 0.00181 & & & 0.00220 & \\
\hline 1050 & $*$ & & & $2.52 \mathrm{e}-05$ & & & 0.00267 & & & 0.00280 & & \\
\hline 1075 & & $*$ & & & $2.47 \mathrm{e}-05$ & & & 0.00328 & & & 0.00337 & \\
\hline 1125 & & $*$ & & & $4.57 \mathrm{e}-05$ & & & 0.00483 & & & \begin{tabular}{|l|}
0.00459 \\
\end{tabular} & \\
\hline 1150 & $*$ & & & $8.80 \mathrm{e}-05$ & & & 0.00601 & & & 0.00537 & & \\
\hline 1175 & & $*$ & & & $7.91 \mathrm{e}-05$ & & & 0.00652 & & & 0.00586 & \\
\hline 1225 & & $*$ & & & 0.00013 & & & 0.00839 & & & 0.00721 & \\
\hline
\end{tabular}


Table 7.4 (Contd.)

\begin{tabular}{|c|c|c|c|c|c|c|c|c|c|c|c|c|}
\hline \multirow{4}{*}{$\begin{array}{c}\text { Distance } \\
\text { offshore } \\
\text { (m) }\end{array}$} & \multicolumn{12}{|c|}{ Lake bed seepage rate $(\mathrm{cm} /$ day $)$} \\
\hline & \multicolumn{3}{|c|}{$\mathrm{R}=1$} & \multicolumn{3}{|c|}{$\mathrm{R}=10$} & \multicolumn{3}{|c|}{$\mathrm{R}=100$} & \multicolumn{3}{|c|}{$\mathrm{R}=1000$} \\
\hline & Coarse & \multicolumn{2}{|c|}{ Fine } & Coarse & \multicolumn{2}{|c|}{ Fine } & Coarse & \multicolumn{2}{|c|}{ Fine } & Coarse & \multicolumn{2}{|c|}{ Fine } \\
\hline & \multicolumn{2}{|c|}{ Raw output } & \multirow[t]{2}{*}{ Average } & \multicolumn{2}{|c|}{ Raw output } & \multirow[t]{2}{*}{ Average } & \multicolumn{2}{|c|}{ Raw output } & \multirow[t]{2}{*}{ Average } & \multicolumn{2}{|c|}{ Raw output } & \multirow[t]{2}{*}{ Average } \\
\hline 1250 & $*$ & & & 0.00025 & & & 0.01004 & & & 0.00827 & & \\
\hline 1275 & & * & & & 0.00023 & & & 0.01052 & & & 0.00867 & \\
\hline 1325 & & * & & & 0.00039 & & & 0.01298 & & & 0.01029 & \\
\hline 1350 & * & & & 0.00069 & & & 0.01537 & & & 0.01182 & & \\
\hline 1375 & & * & & & 0.00067 & & & 0.01588 & & & 0.01213 & \\
\hline 1425 & & * & & & 0.00115 & & & 0.01939 & & & 0.01429 & \\
\hline 1450 & $7.44 \mathrm{e}-07$ & & & 0.00195 & & & 0.02316 & & & 0.01663 & & \\
\hline 1475 & & $*$ & & & 0.00199 & & & 0.02382 & & & 0.01691 & \\
\hline 1525 & & $5.73 e-07$ & & & 0.00350 & & & 0.02983 & & & 0.02023 & \\
\hline 1550 & $1.18 \mathrm{e}-05$ & & & 0.00568 & & & 0.03853 & & & 0.03726 & & \\
\hline 1575 & & $3.05 \mathrm{e}-06$ & & & 0.00633 & & & 0.04324 & & & 0.04647 & \\
\hline 1625 & & $1.53 \mathrm{e}-05$ & & & 0.00971 & & & 0.03468 & & & 0.01479 & \\
\hline 1650 & 0.00018 & & $4.62 \mathrm{e}-05$ & 0.01536 & & 0.01374 & 0.04802 & & 0.04611 & 0.03335 & & 0.03246 \\
\hline 1675 & & $7.71 \mathrm{e}-05$ & & & 0.01778 & & & 0.05753 & & & 0.05013 & \\
\hline 1725 & & 0.00037 & & & 0.02688 & & & 0.04695 & & & 0.01662 & \\
\hline 1750 & 0.00254 & & 0.00106 & 0.04098 & & 0.03771 & 0.06593 & & 0.06365 & 0.03870 & & 0.03816 \\
\hline 1775 & & 0.00175 & & & 0.04853 & & & 0.08034 & & & 0.05969 & \\
\hline 1825 & & 0.00789 & & & 0.07282 & & & 0.06736 & & & 0.02032 & \\
\hline 1850 & 0.03362 & & 0.02182 & 0.11028 & & 0.10311 & 0.09872 & & 0.09523 & 0.05043 & & 0.04985 \\
\hline 1875 & & 0.03576 & & & 0.13339 & & & 0.12309 & & & 0.07937 & \\
\hline
\end{tabular}


Table 7.4 (Contd.)

\begin{tabular}{|c|c|c|c|c|c|c|c|c|c|c|c|c|}
\hline \multirow{4}{*}{$\begin{array}{l}\text { Distance } \\
\text { offshore } \\
\text { (m) }\end{array}$} & \multicolumn{12}{|c|}{ Lake bed seepage rate $(\mathrm{cm} /$ day $)$} \\
\hline & \multicolumn{3}{|c|}{$\mathrm{R}=1$} & \multicolumn{3}{|c|}{$R=10$} & \multicolumn{3}{|c|}{$R=100$} & \multicolumn{3}{|c|}{$\mathrm{R}=1000$} \\
\hline & Coarse & \multicolumn{2}{|c|}{ Fine } & Coarse & \multicolumn{2}{|c|}{ Fine } & Coarse & \multicolumn{2}{|c|}{ Fine } & Coarse & \multicolumn{2}{|c|}{ Fine } \\
\hline & \multicolumn{2}{|c|}{ Raw output } & \multirow[t]{2}{*}{ Average } & \multicolumn{2}{|c|}{ Raw output } & \multirow[t]{2}{*}{ Average } & \multicolumn{2}{|c|}{ Raw output } & \multirow[t]{2}{*}{ Average } & \multicolumn{2}{|c|}{ Raw output } & Average \\
\hline 1925 & & 0.15783 & & & 0.21446 & & & 0.11446 & & & 0.02846 & \\
\hline 1950 & 0.51576 & & 0.53113 & 0.39654 & & 0.42627 & 0.22998 & & 0.24806 & 0.11638 & & 0.12619 \\
\hline 1975 & & 0.90443 & & & 0.63807 & & & 0.38166 & & & 0.22393 & \\
\hline
\end{tabular}




\section{CHAPTER 8}

\section{Results : Recharge Rate}

Two recharge rates of 10 and $20 \mathrm{~cm} /$ year were applied in simulations of both shallow and deep inflow lakes with moderate lake bed slope. Sixteen different simulations were run (two recharge rates at each of four anisotropy ratios, for two different lake depths). Table 8.1 gives some results from the sixteen simulations (all of which were run with the coarse $60 \times 60$ grid).

The effects of the variation of recharge rate can be seen from the change in hydraulic head distribution in the porous medium surrounding the lake (Fig.

8.1 to 8.6 , and 6.2 to 6.5 ). The boundary conditions in all the simulations treated the vertical sides and the base of the porous medium as impermeable and the lake as a constant head. When the recharge rate was changed from 10 $\mathrm{cm} /$ year to $20 \mathrm{~cm} /$ year, twice as much water was moving through the system, causing heads to increase everywhere in the porous medium. Higher heads occurred under the higher recharge rate because of the need for higher gradients (in order to move twice as much water through the system per unit time).

Figs. 8.7 to 8.10 show the variation of seepage rate with distance offshore for both shallow and deep lakes. The total volumetric rate of seepage 
Table 8.1. Summary head and seepage rate results from the sixteen simulations compared in this chapter. Each results box gives the minimum and the maximum heads in meters (first line) and the minimum and maximum seepage rates in $\mathrm{cm} / \mathrm{day}$ (second line within parentheses) for one simulation, along the line of the vertical cross-section as shown in Fig. 6.1.

\begin{tabular}{|c|c|c|c|c|c|}
\hline \multirow{2}{*}{ Type of lake } & \multirow{2}{*}{$\begin{array}{c}\text { Recharge }(\mathrm{I}) \\
(\mathrm{cm} / \text { year })\end{array}$} & \multicolumn{4}{|c|}{ Anisotropy (R) } \\
\cline { 3 - 6 } & $\mathrm{I}=10$ & $\begin{array}{c}50.00,69.17 \\
\left(1.12 \times 10^{-7}, 1.2188\right)\end{array}$ & $\begin{array}{c}50.00,70.53 \\
(0.00019,1.0157)\end{array}$ & $\begin{array}{c}50.12,73.51 \\
(0.0427,0.7372)\end{array}$ & $\begin{array}{c}52.44,81.83 \\
(0.0816,0.6865)\end{array}$ \\
\hline \multirow{2}{*}{$\begin{array}{c}\text { shallow inflow lake } \\
\text { with moderate lake } \\
\text { bed slope }\end{array}$} & $\mathrm{I}=20$ & $\begin{array}{c}50.00,84.71 \\
\left(3.72 \times 10^{-6}, 2.5889\right)\end{array}$ & $\begin{array}{c}50.00,86.21 \\
\left(3.7 \times 10^{-4}, 2.0493\right)\end{array}$ & $\begin{array}{c}50.21,90.87 \\
(0.0799,1.5259)\end{array}$ & $\begin{array}{c}53.39,102.80 \\
(0.1425,1.4468)\end{array}$ \\
\cline { 2 - 6 } & $\mathrm{I}=10$ & $\begin{array}{c}50.00,69.14 \\
\left(1.03 \times 10^{-7}, 1.2158\right)\end{array}$ & $\begin{array}{c}50.00,70.54 \\
(0.00013,1.0162)\end{array}$ & $\begin{array}{c}50.22,73.51 \\
(0.0580,0.7364)\end{array}$ & $\begin{array}{c}56.13,81.44 \\
(0.1441,0.6697)\end{array}$ \\
\hline \multirow{2}{*}{$\begin{array}{c}\text { deep inflow lake with } \\
\text { moderate lake bed } \\
\text { slope }\end{array}$} & $1=20$ & $\begin{array}{c}50.00,84.71 \\
\left(3.59 \times 10^{-6}, 2.5169\right)\end{array}$ & $\begin{array}{c}50.00,86.25 \\
\left(2.5 \times 10^{-4}, 2.0512\right)\end{array}$ & $\begin{array}{c}50.29,90.96 \\
(0.1068,1.5403)\end{array}$ & $\begin{array}{c}53.22,101.00 \\
(0.3795,1.5304)\end{array}$ \\
\cline { 2 - 6 }
\end{tabular}


across the lake bed must obviously be twice as high for the simulations with recharge rate equal to $20 \mathrm{~cm} / \mathrm{year}$, compared to the simulations with a recharge of $10 \mathrm{~cm} /$ year (the lake bed is the only sink for water in the inflow lake simulations). Comparison of results from the simulations at the two recharge rates showed that the additional lake bed seepage created by higher recharge was distributed across the lake bed in much the same pattern as the seepage at the lower recharge rate. In other words, the seepage rate $(\mathrm{cm} /$ day $)$ at each cell on the lake bed was approximately doubled when recharge rate was doubled. There was relatively little change in the distribution of seepage, except at high anisotropy $(\mathrm{R}=1000)$ where doubling the recharge rate increased the seepage rate at the shore line by more than a factor of 2 (e.g., 2.1-2.2) and seepage further offshore by less than a factor of 2 . The same effect was present (though smaller) at $R=100$. Also at $R=1000$, there was an increase in seepage rate offshore for the deep lake.

The basic picture reflected by the seepage maps (Figs. 8.11 to 8.22 ) is a doubling of the lake bed seepage rates in response to doubling recharge, with same exceptions (e.g., the increased focusing of seepage nearshore at high anisotropy, as mentioned above). For example, at $\mathrm{R}=1$, the ring of high seepage $(1.6 \mathrm{~cm} /$ day or higher) near the shore has a greater aerial extent and 
higher seepage values at $\mathrm{I}=20 \mathrm{~cm} /$ year than at $\mathrm{I}=10 \mathrm{~cm} /$ year (Figs. 7.7 and 8.11, Figs. 8.15 and 8.16). At $R=100$ and 1000 , the seepage rates for $I=20$ $\mathrm{cm} /$ day were not exactly twice the seepage rate for $I=10 \mathrm{~cm} /$ day, as mentioned above. The maps show that at $R=100$, the central low seepage zone $(0.1$ $\mathrm{cm} /$ day or lower) in the shallow lake was significantly smaller at higher recharge, and was absent altogether in the deep lake (Figs. 7.9 and 8.13, Figs. 8.19 and 8.20). At high recharge and $\mathrm{R}=1000$, the low seepage zone offshore is absent for the shallow lake (Fig. 8.14) but present locally for the deep lake (Fig. 8.22).

The net effect of the increase in recharge rate is an increase in hydraulic head in the porous medium, with the magnitude of the increase being somewhat larger at higher anisotropy. The heads close to the lake became quite high in some simulations (e.g., those with high recharge and high anisotropy). In many natural settings these high groundwater heads would bring the water table above the ground surface, initiating overland flow. As MODFLOW and many other numerical models do not assume any particular position for the ground surface, this phenomenon was not represented in the simulations presented here. Doubling the recharge rate caused an approximate doubling of seepage rate over the lake bed in both shallow and deep lakes, 
though there was a slight shift in recharge pattern (a slightly larger increase at the shoreline and smaller increase offshore) for the simulations with high anisotropy ( $R=100,1000)$. Apparently, changes in recharge rate may have little or no effect on the relative spatial pattern of lake bed seepage rates (i.e., the ratio of seepage rates at any two points on the lake bed is approximately the same at different recharge rates, with the possible exception of nearshore rates in high anisotropy systems), even though the magnitudes of the seepage rates are altered greatly. 


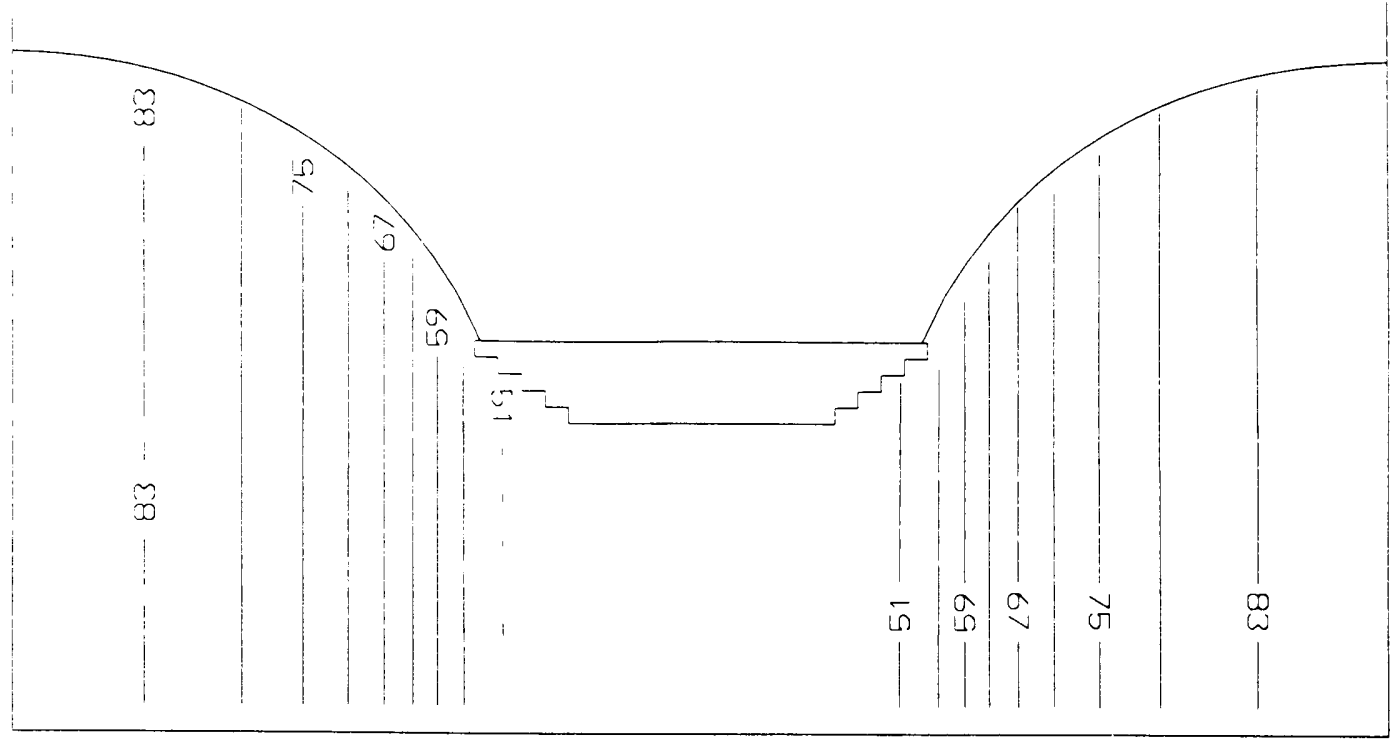

Recharge $=20 \mathrm{~cm} /$ year; Anisotropy Ratio $=1$

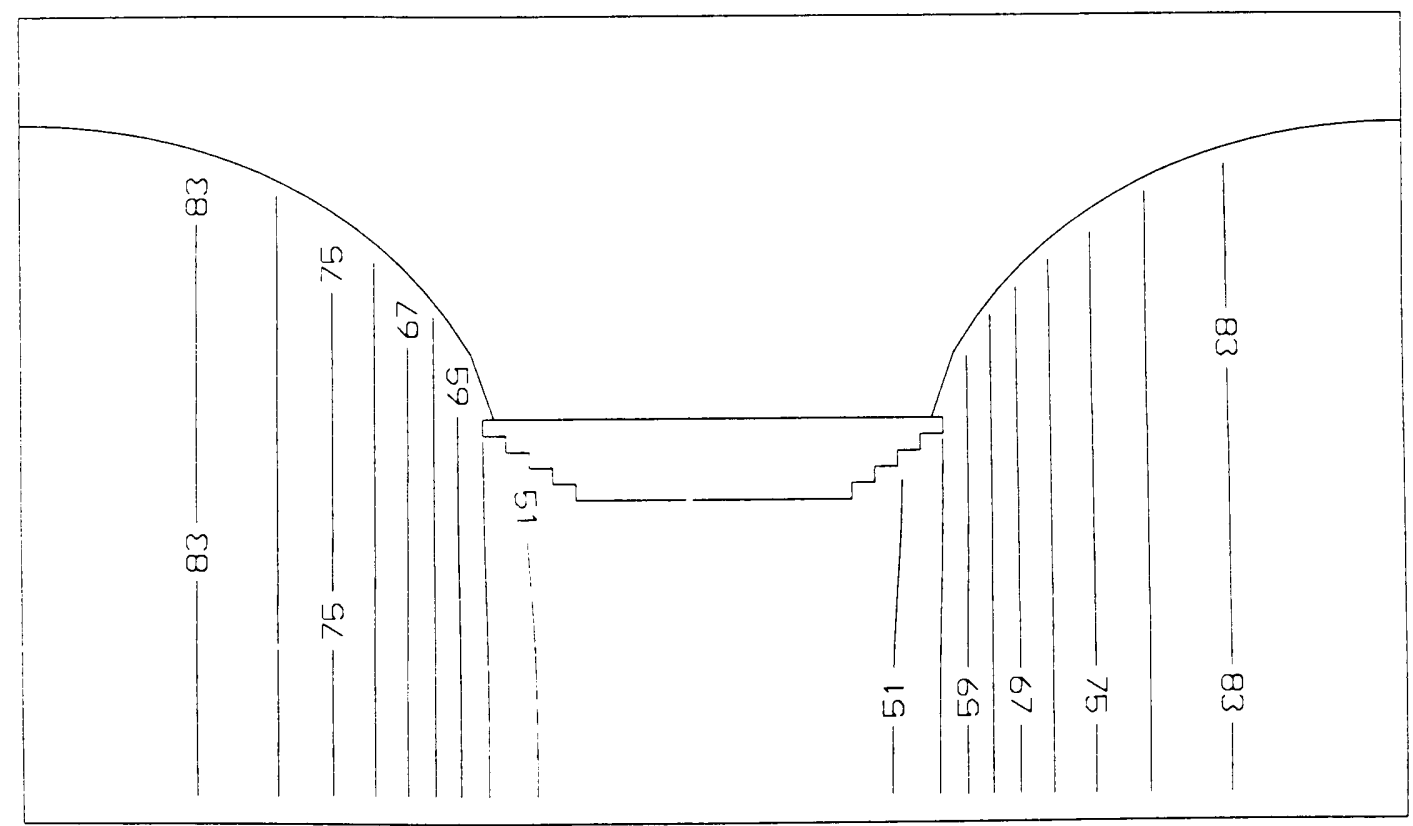

Recharge $=20 \mathrm{~cm} /$ year; Anisotropy Ratio $=10$

Fig. 8.1. Distribution of hydraulic heads in the porous medium surrounding shallow inflow lakes with moderate lake bed slope for a recharge rate of $20 \mathrm{~cm} /$ year at $R=1$ and $R$ $=10$. Figs. 6.2 and 6.3 give analogous cross-sections for the same lake with a recharge rate of $10 \mathrm{~cm} /$ year at $R=1$ and $R=10$ respectively. 


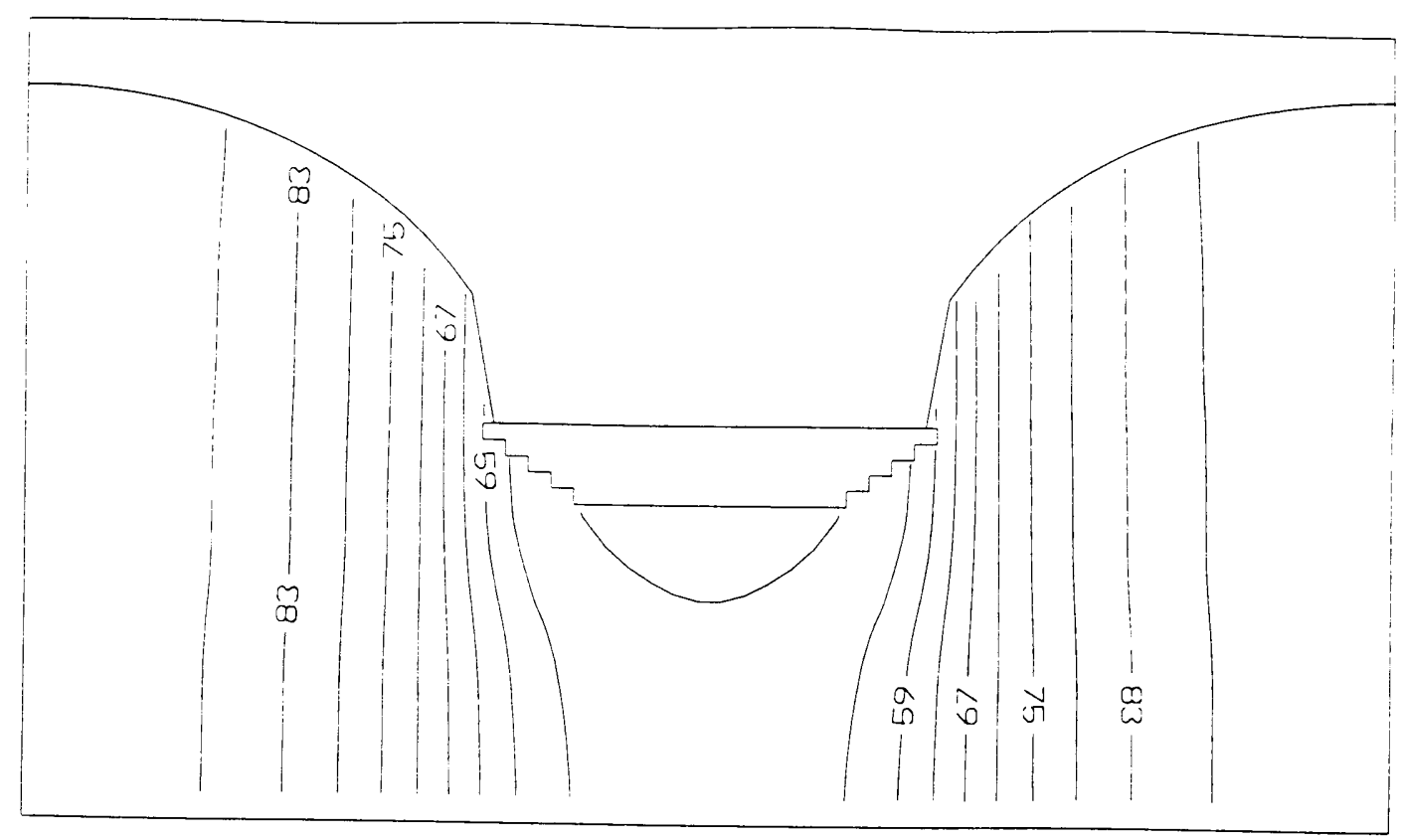

Recharge $=20 \mathrm{~cm} /$ year; Anisotropy Ratio $=100$

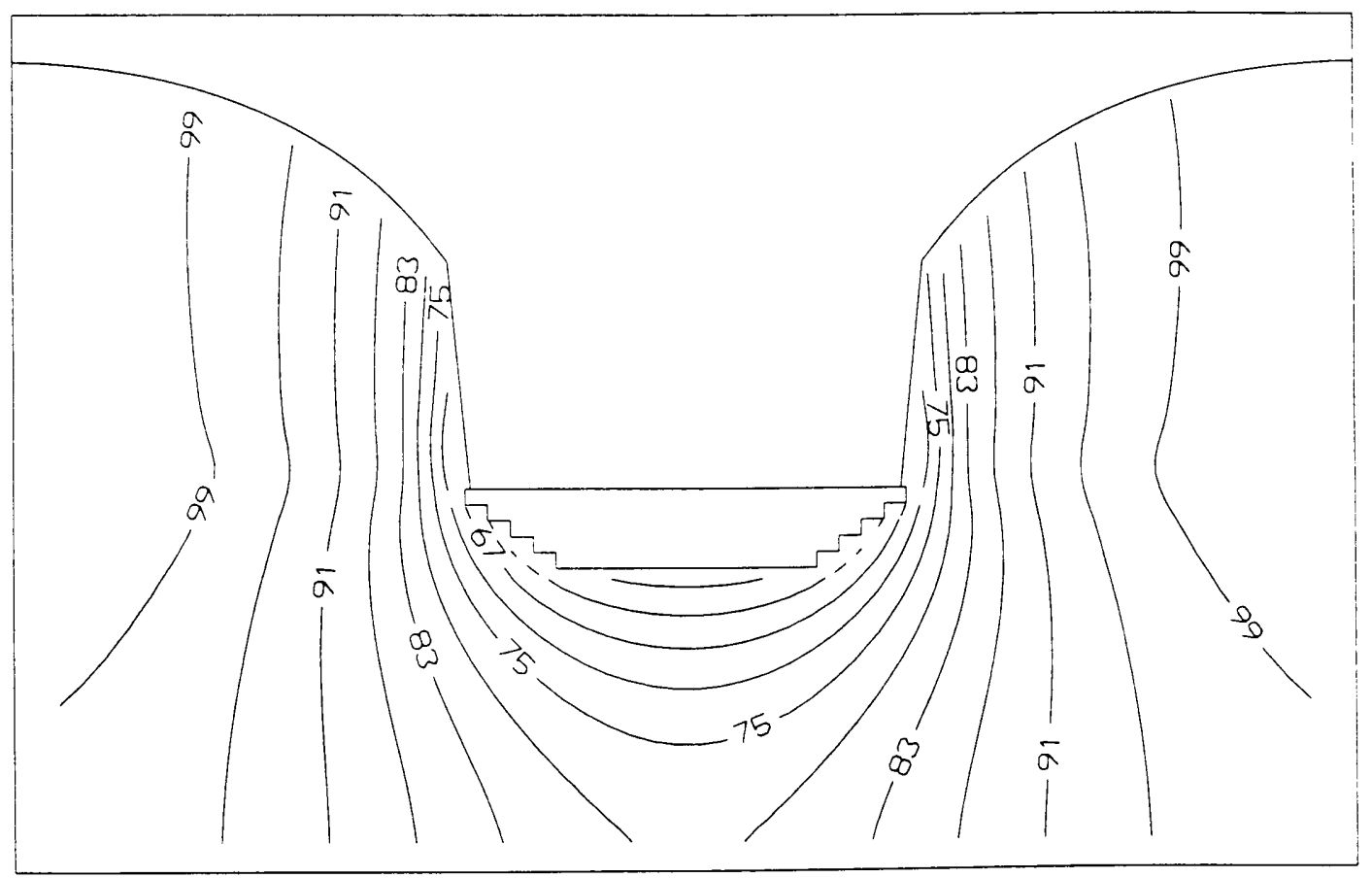

Recharge $=20 \mathrm{~cm} /$ year; Anisotropy Ratio $=1000$

Fig. 8.2. Distribution of hydraulic heads in the porous medium surrounding shallow inflow lakes with moderate lake bed slope for a recharge rate of $20 \mathrm{~cm} /$ year at $R=100$ and $\mathrm{R}=1000$. Figs. 6.4 and 6.5 give analogous cross-sections for the same lake with a recharge rate of $10 \mathrm{~cm} /$ year at $R=100$ and $R=1000$ respectively. 


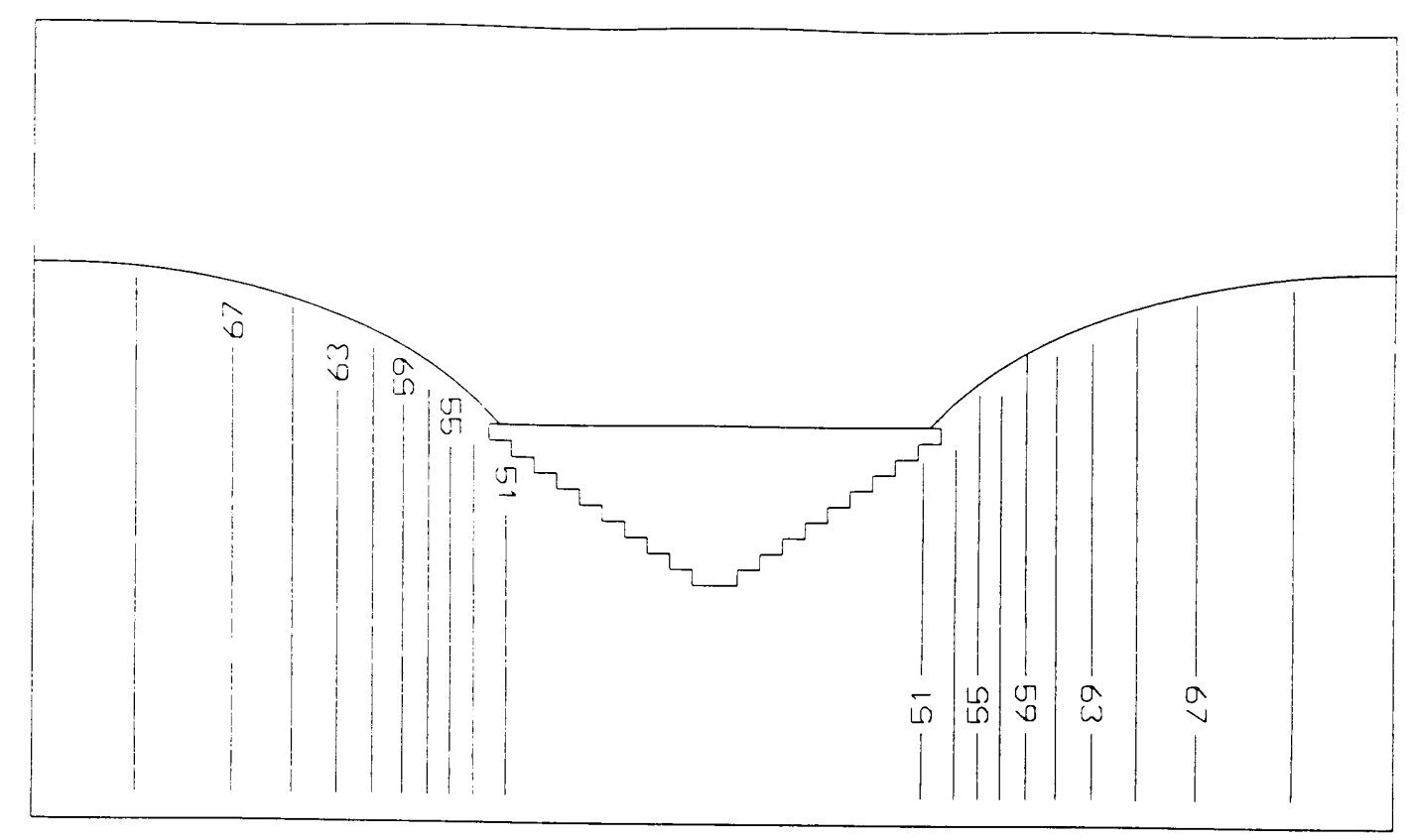

Recharge $=10 \mathrm{~cm} /$ year

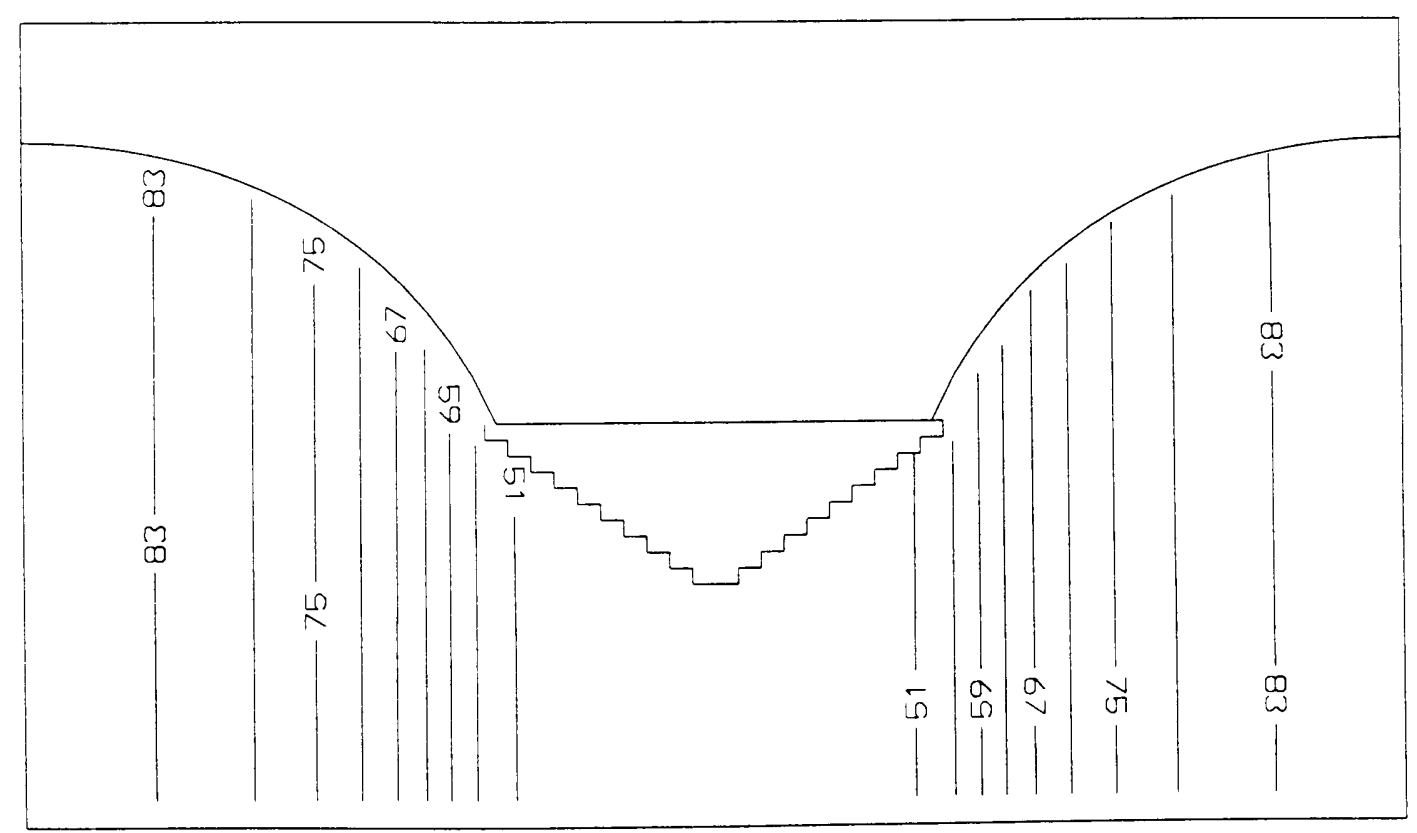

Recharge $=20 \mathrm{~cm} /$ year

Fig. 8.3. Distribution of hydraulic heads in the porous medium surrounding deep inflow lakes with moderate lake bed slope for two different recharge rates at $R=1$. 


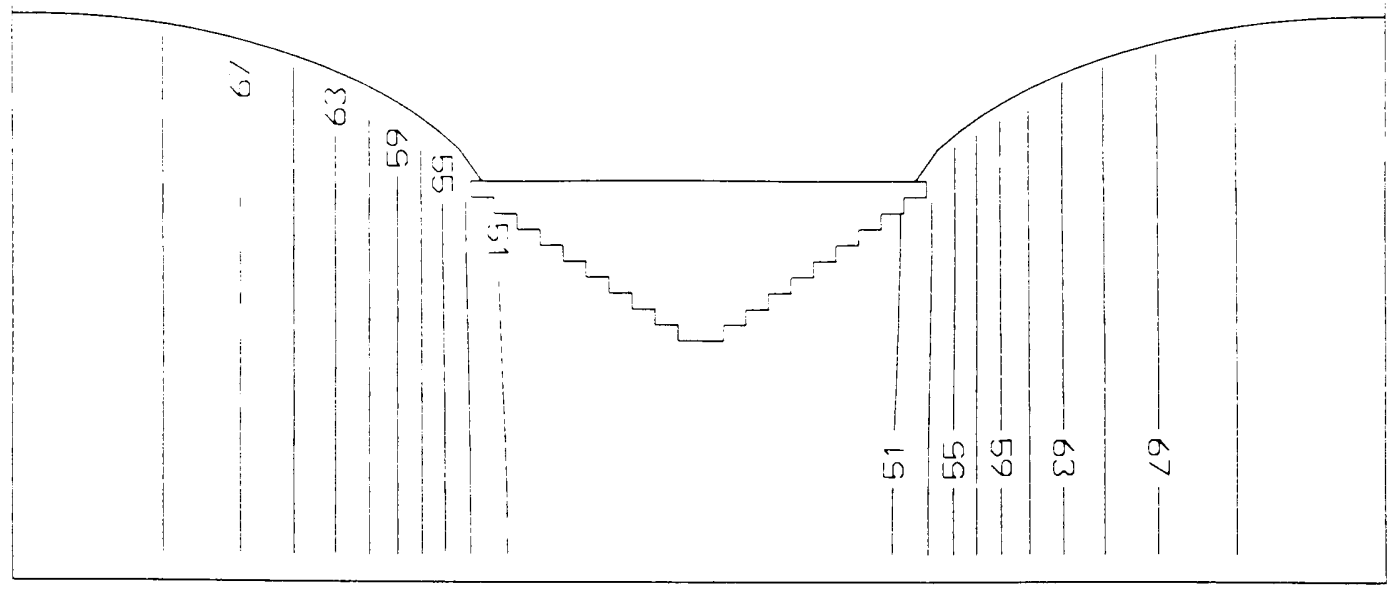

Recharge $=10 \mathrm{~cm} /$ year

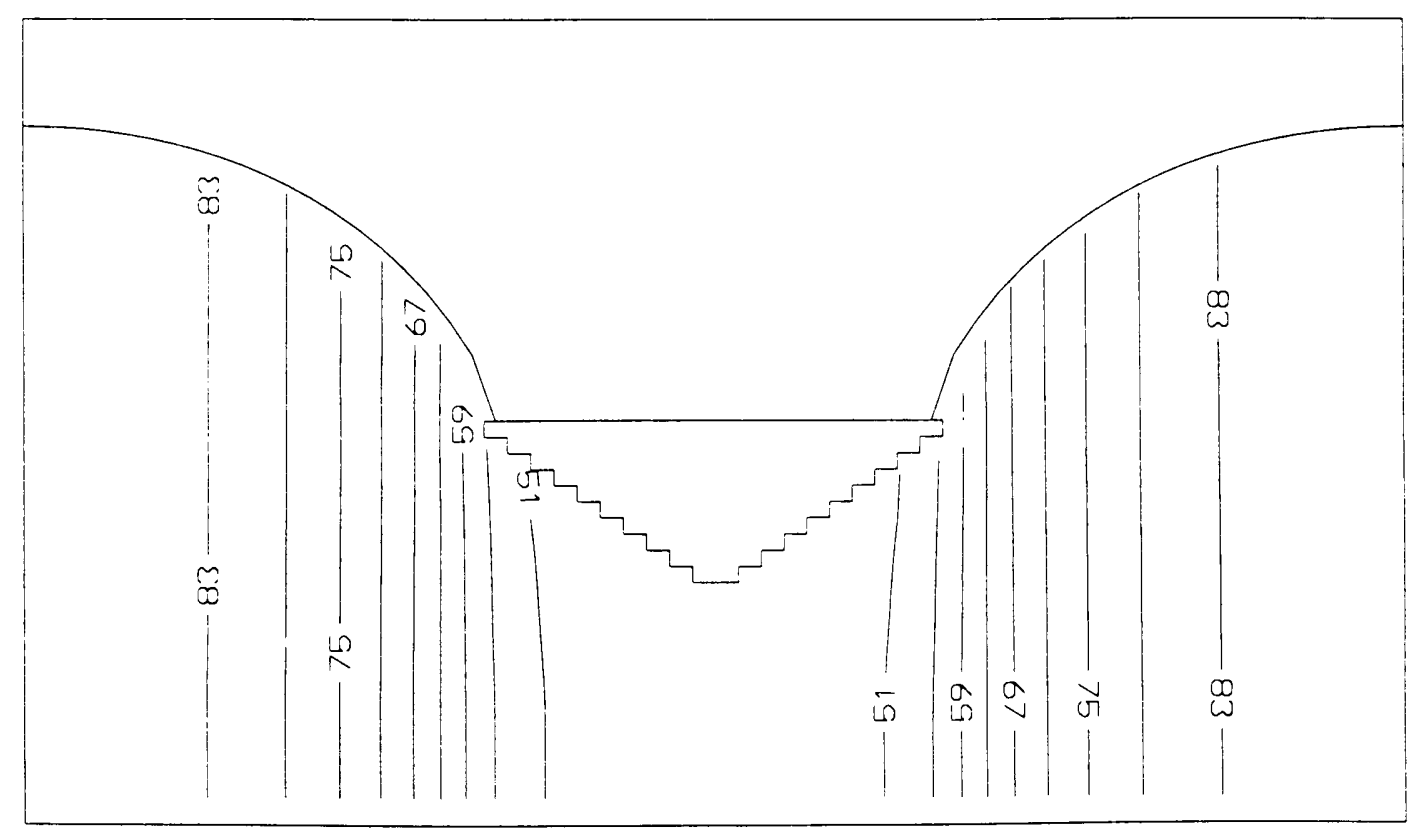

Recharge $=20 \mathrm{~cm} /$ year

Fig. 8.4. Distribution of hydraulic heads in the porous medium surrounding deep inflow lakes with moderate lake bed slope for two different recharge rates at $\mathrm{R}=10$. 


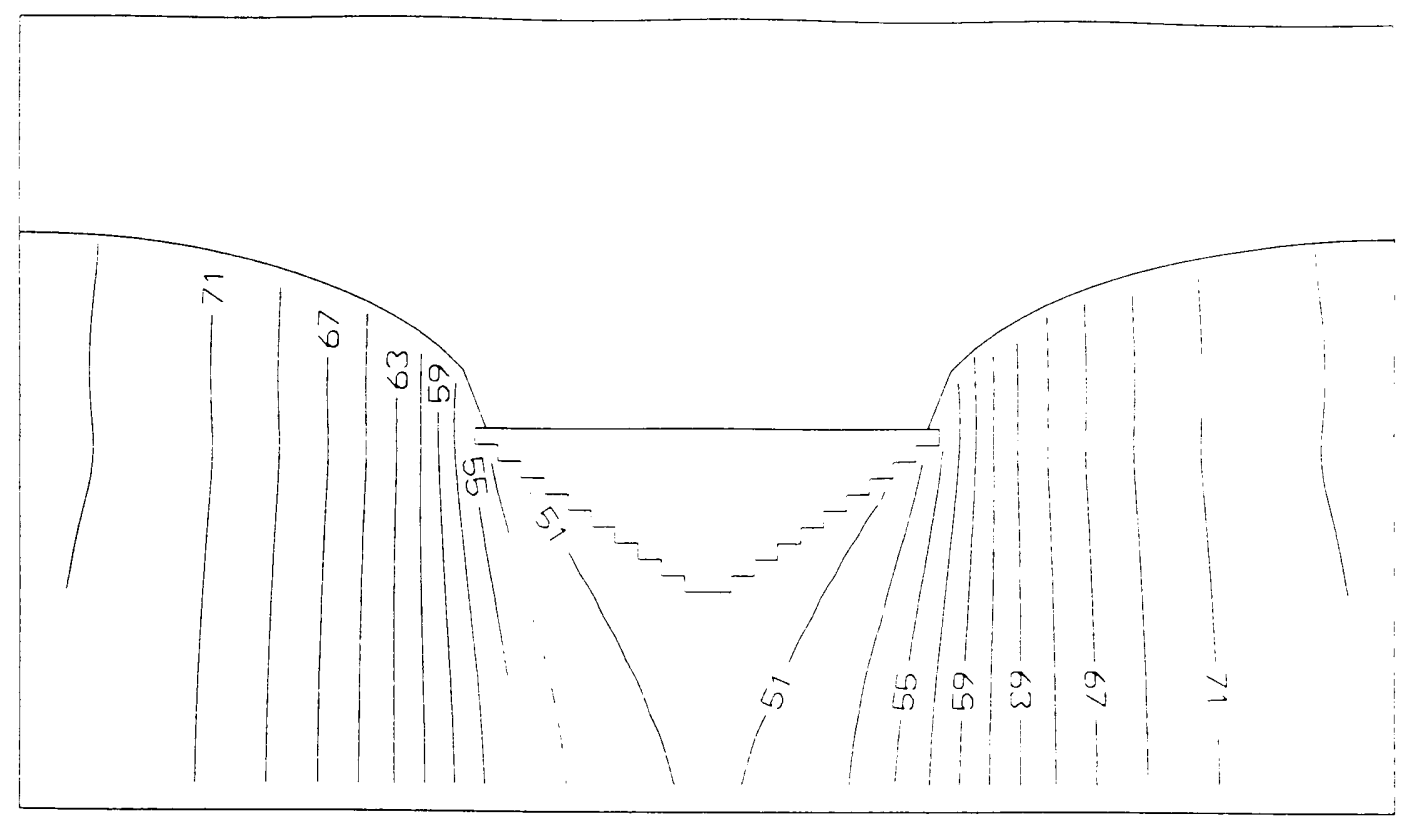

Recharge $=10 \mathrm{~cm} / \mathrm{year}$

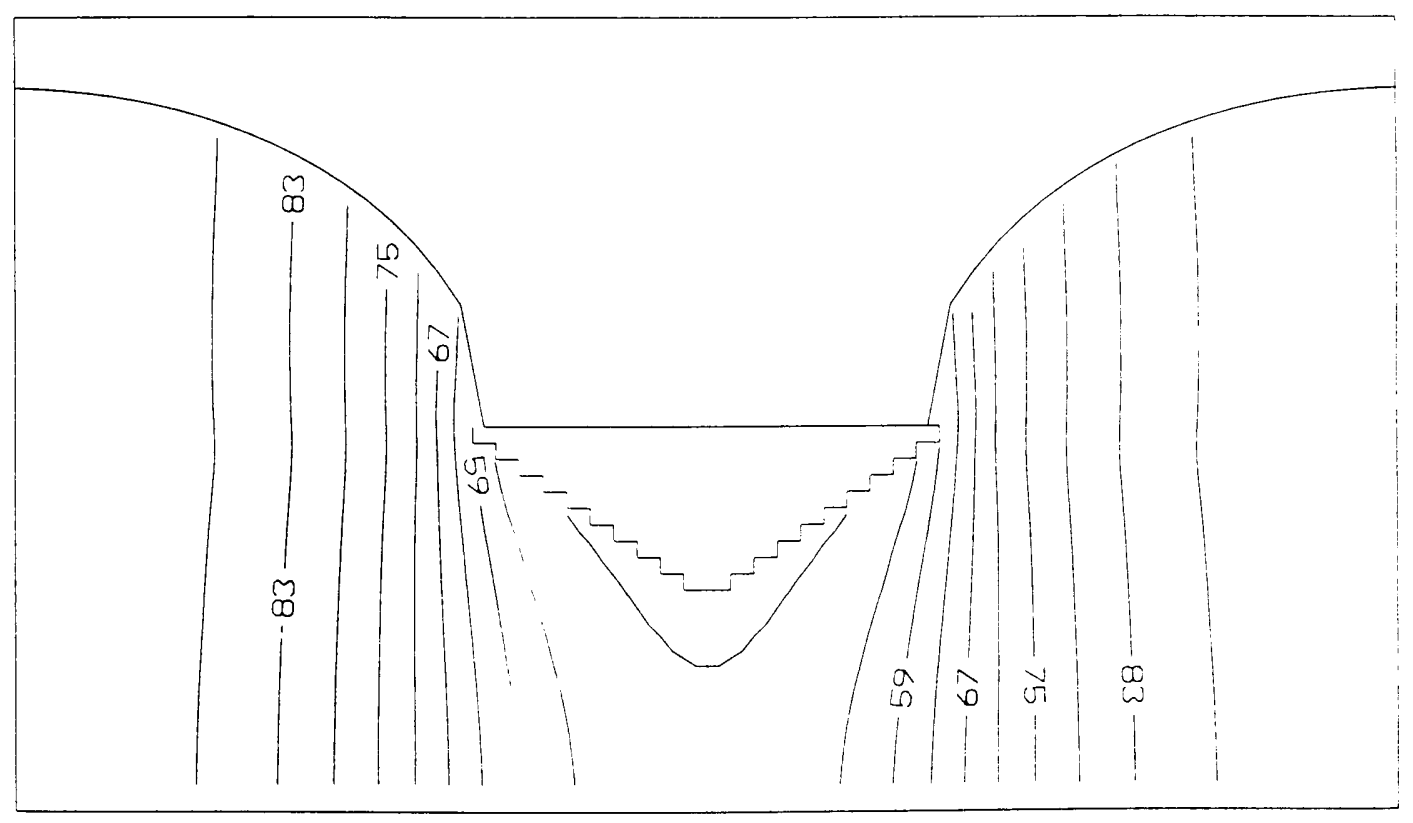

Recharge $=20 \mathrm{~cm} /$ year

Fig. 8.5. Distribution of hydraulic heads in the porous medium surrounding deep inflow lakes with moderate lake bed slope for two different recharge rates at $R=100$. 


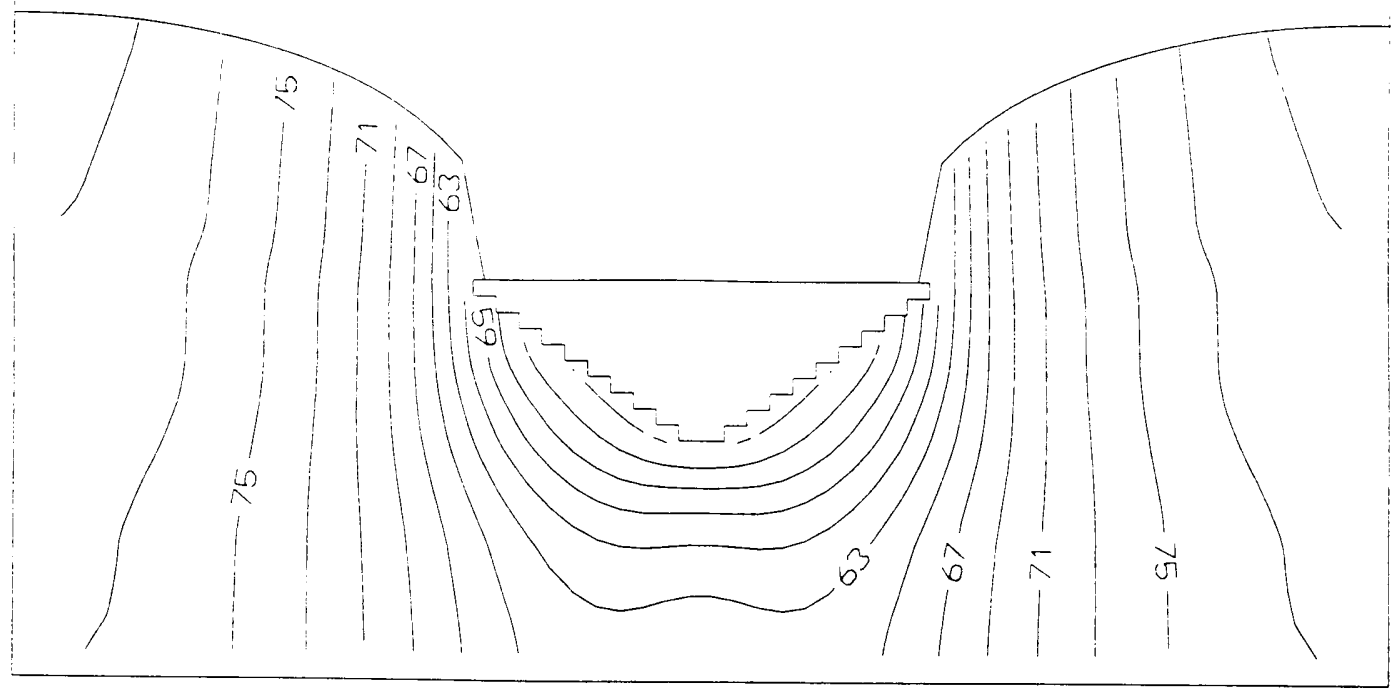

Recharge $=10 \mathrm{~cm} /$ year

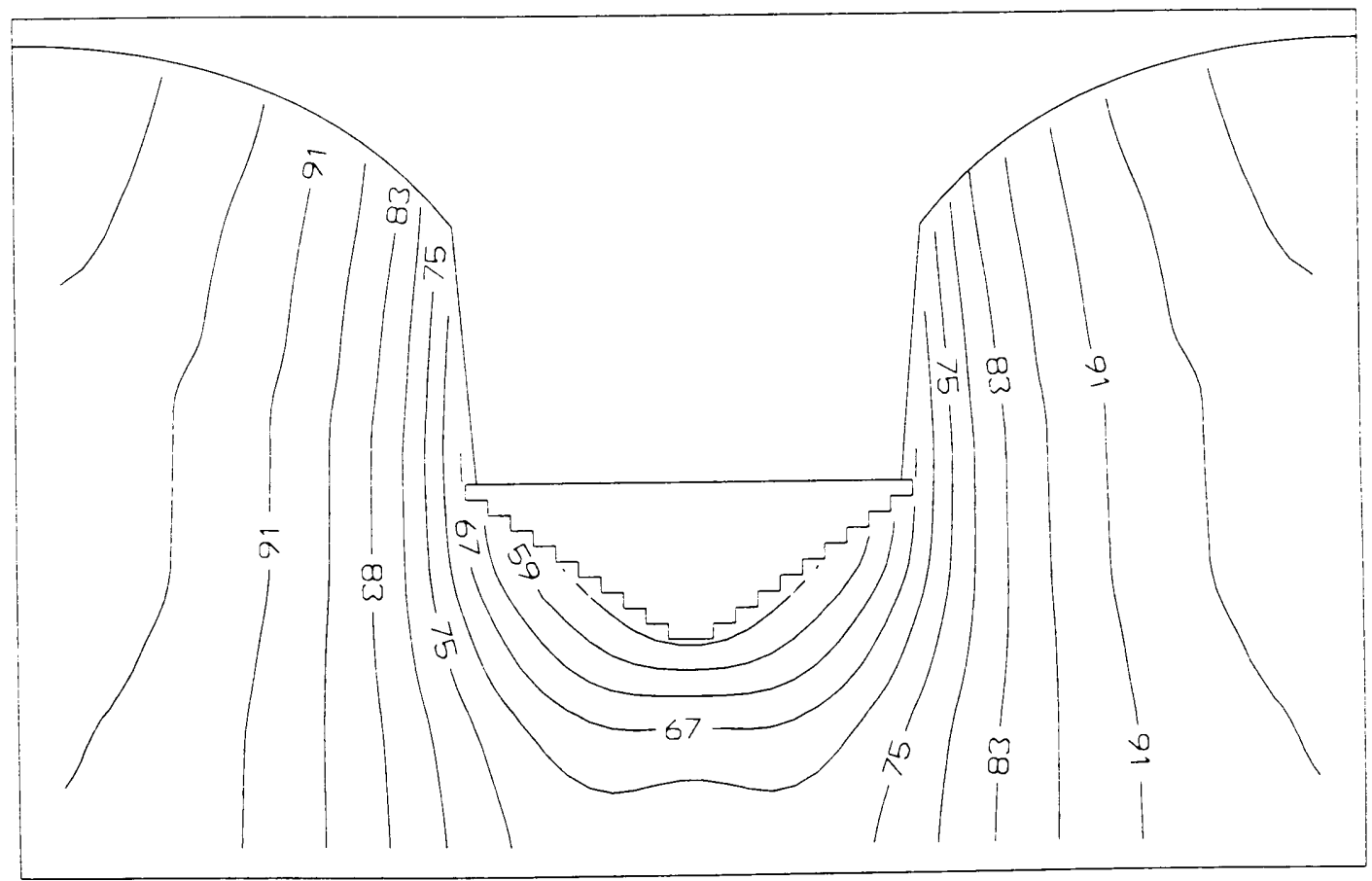

Recharge $=20 \mathrm{~cm} /$ year

Fig. 8.6. Distribution of hydraulic heads in the porous medium surrounding deep inflow lakes with moderate lake bed slope for two different recharge rates at $R=1000$. 


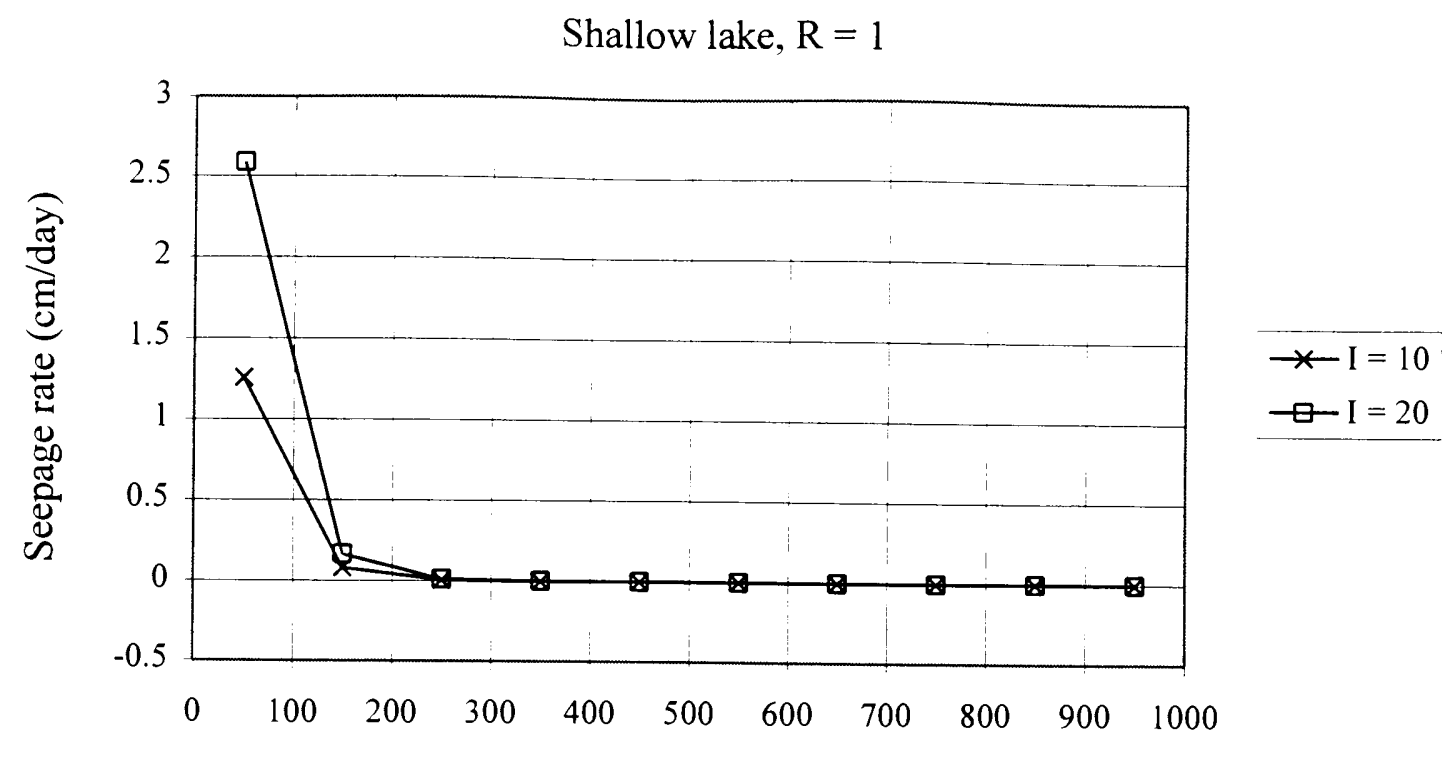

Distance offshore (m)

Deep lake, $\mathrm{R}=1$

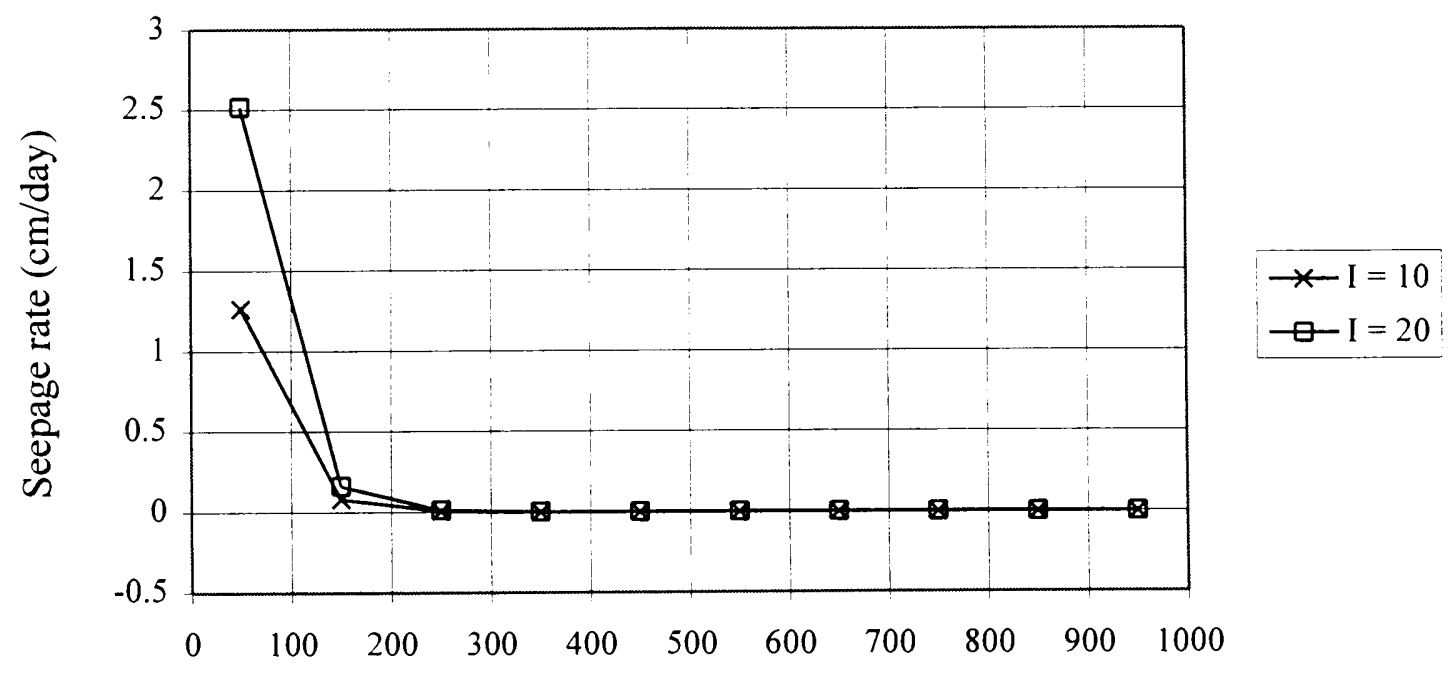

Distance offshore $(\mathrm{m})$

Fig. 8.7. Seepage rate versus distance offshore for two different recharge rates of shallow and deep inflow lakes with moderate lake bed slope at $\mathrm{R}=1$. 
Shallow lake, $R=10$
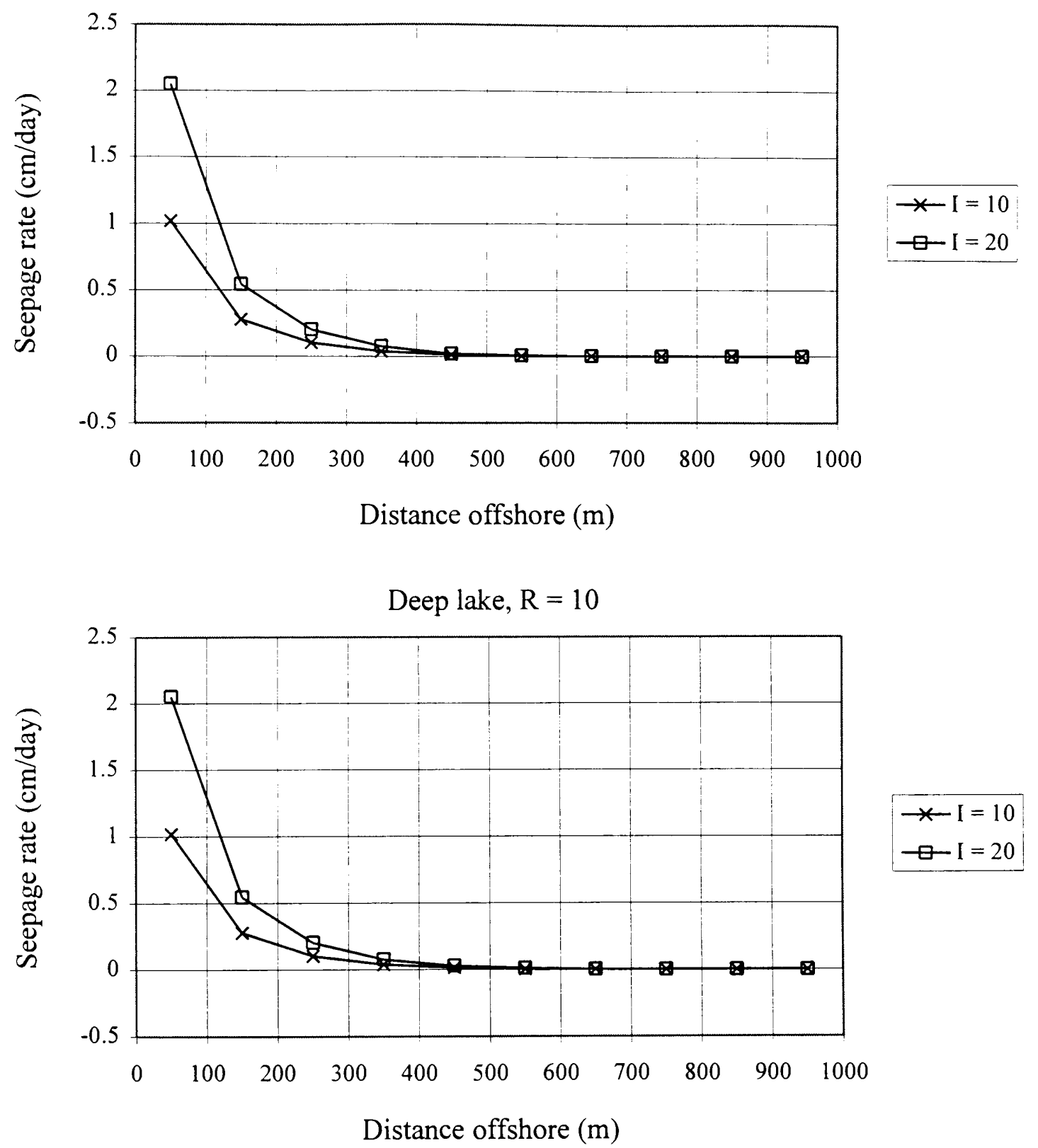

Fig. 8.8. Seepage rate versus distance offshore for two different recharge rates of shallow and deep inflow lakes with moderate lake bed slope at $R=10$. 


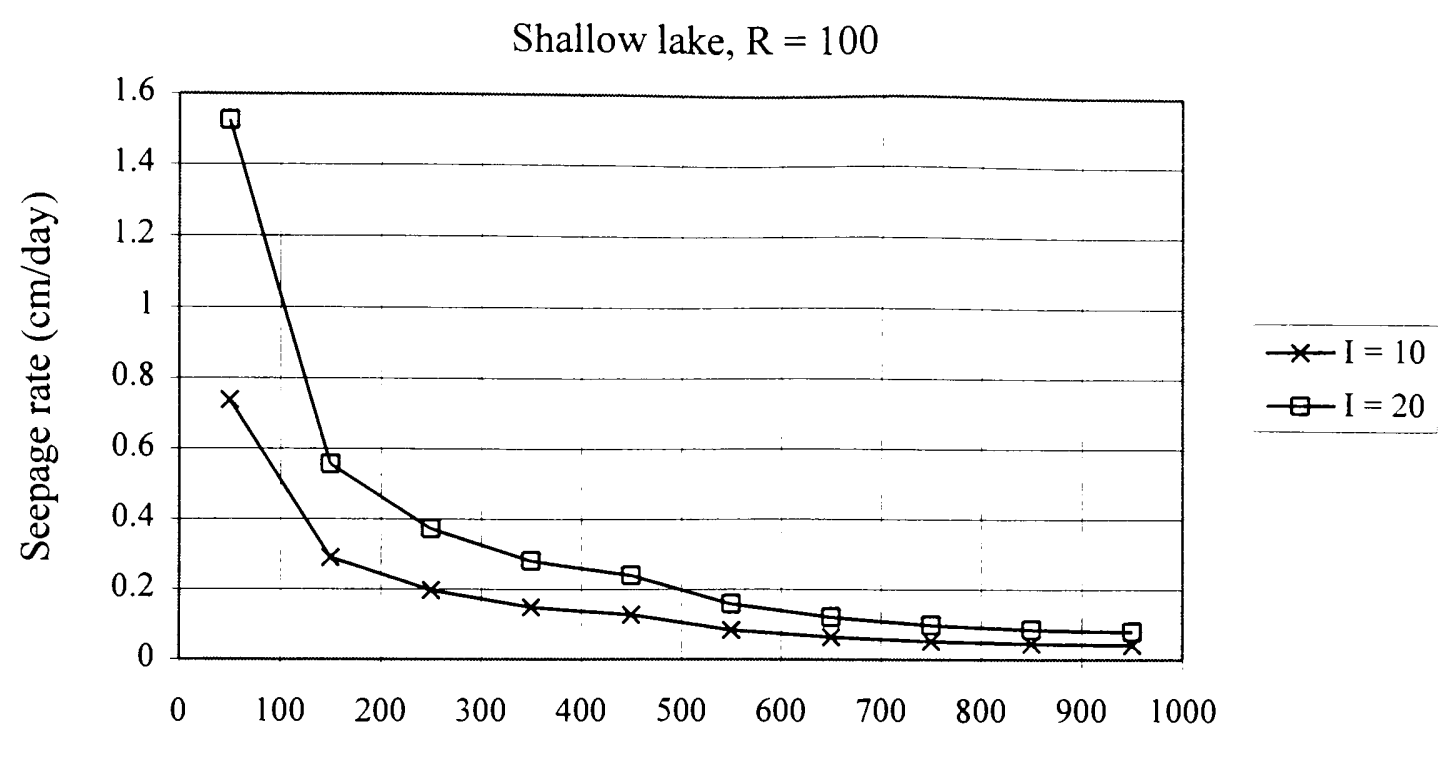

Distance offshore (m)

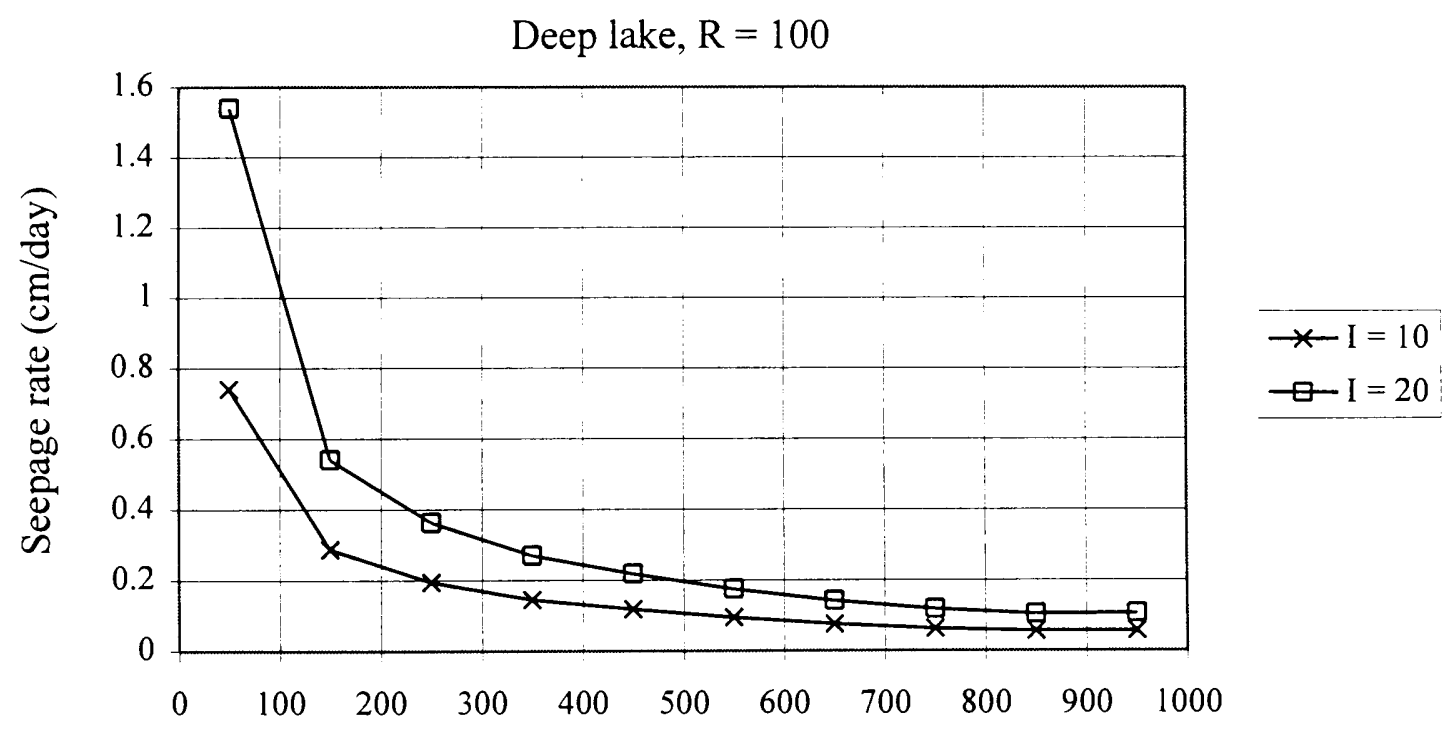

Distance offshore (m)

Fig. 8.9. Seepage rate versus distance offshore for two different recharge rates of shallow and deep inflow lakes with moderate lake bed slope at $\mathrm{R}=100$. 
Shallow lake, $R=1000$

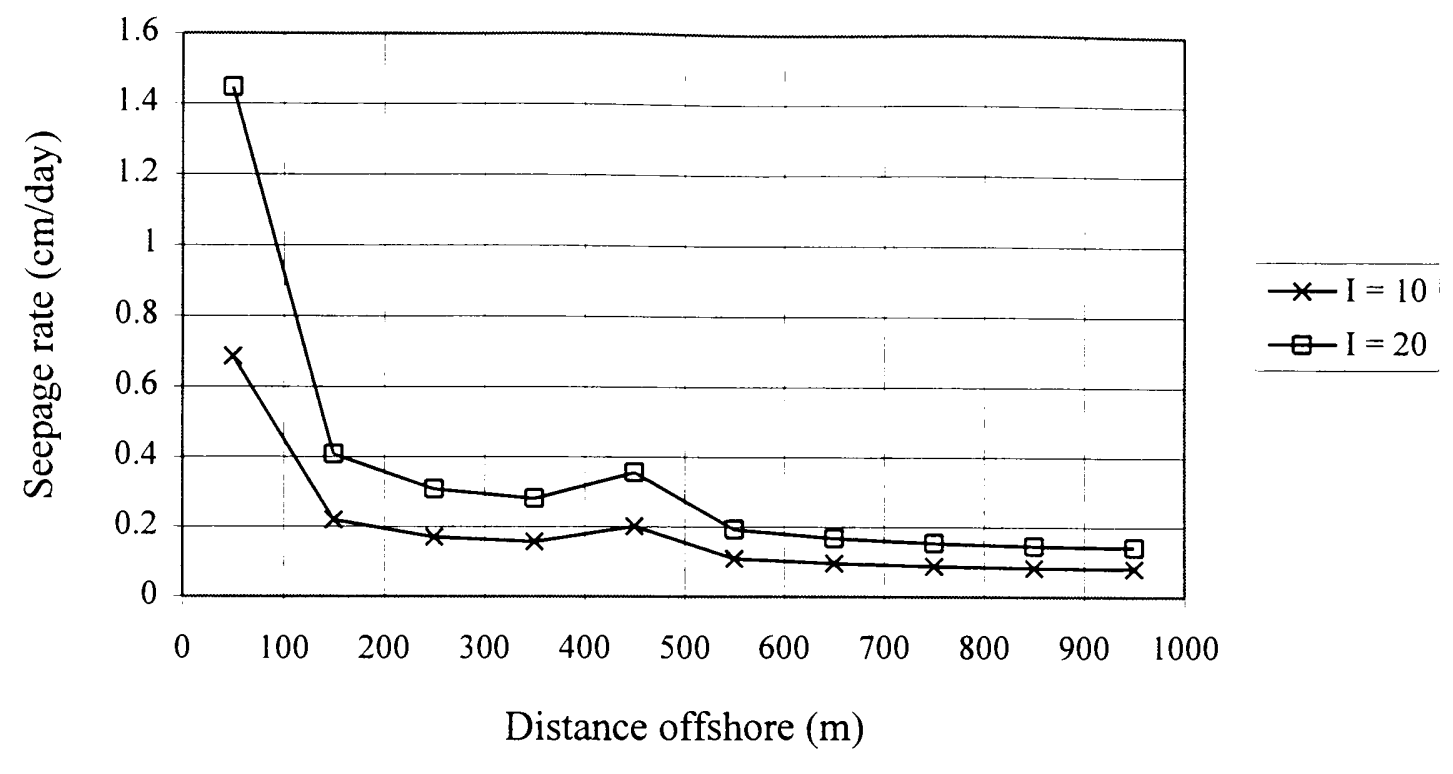

Deep lake, $\mathrm{R}=1000$

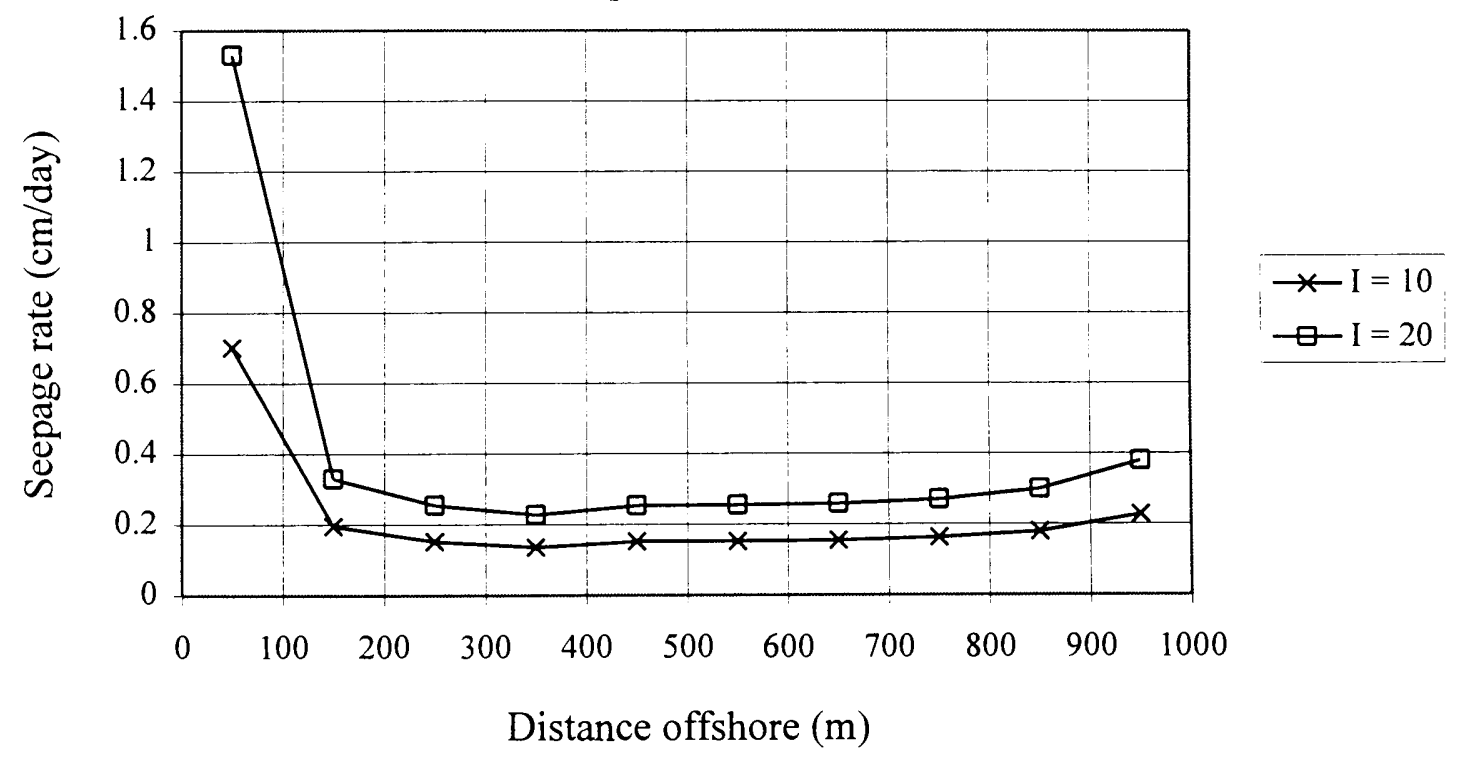

Fig. 8.10. Seepage rate versus distance offshore for two different recharge rates of shallow and deep inflow lakes with moderate lake bed slope at $R=1000$. 


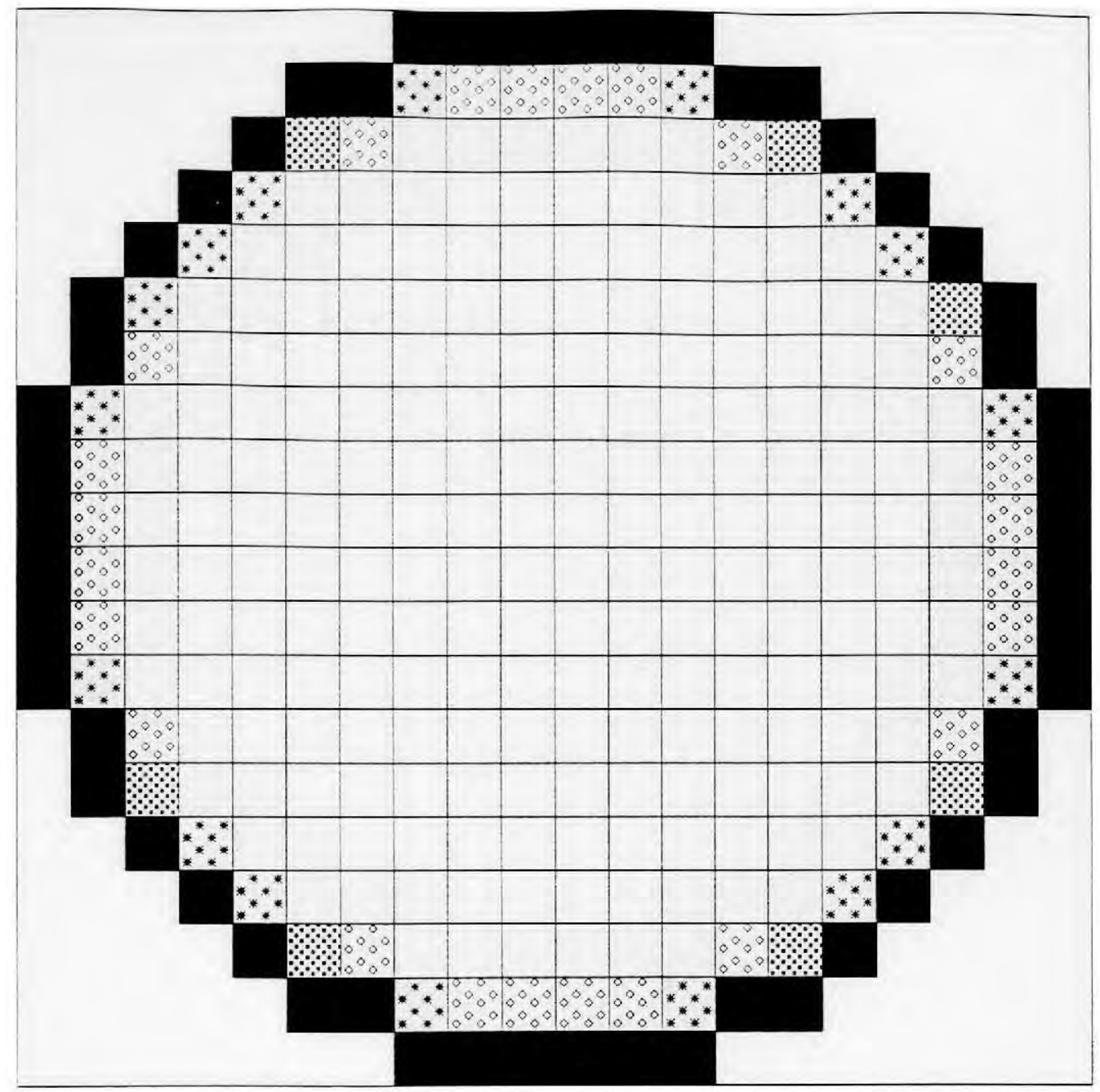

Fig. 8.11. Distribution of seepage rates ( $\mathrm{cm} /$ day) over the lake bed for a shallow inflow lake with moderate

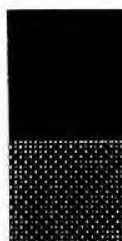

16 to 45 slope at $I=20 \mathrm{~cm} /$ year and $R=1$. Fig. 7.7 gives an analogous map for the same lake with recharge equal to $10 \mathrm{~cm} /$ year.

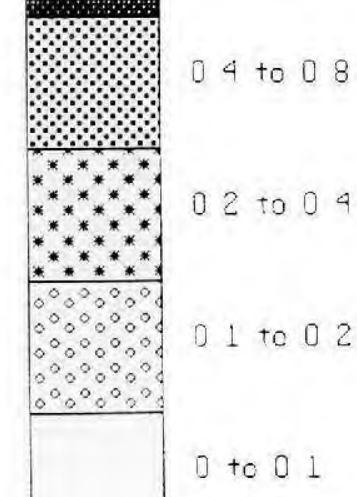




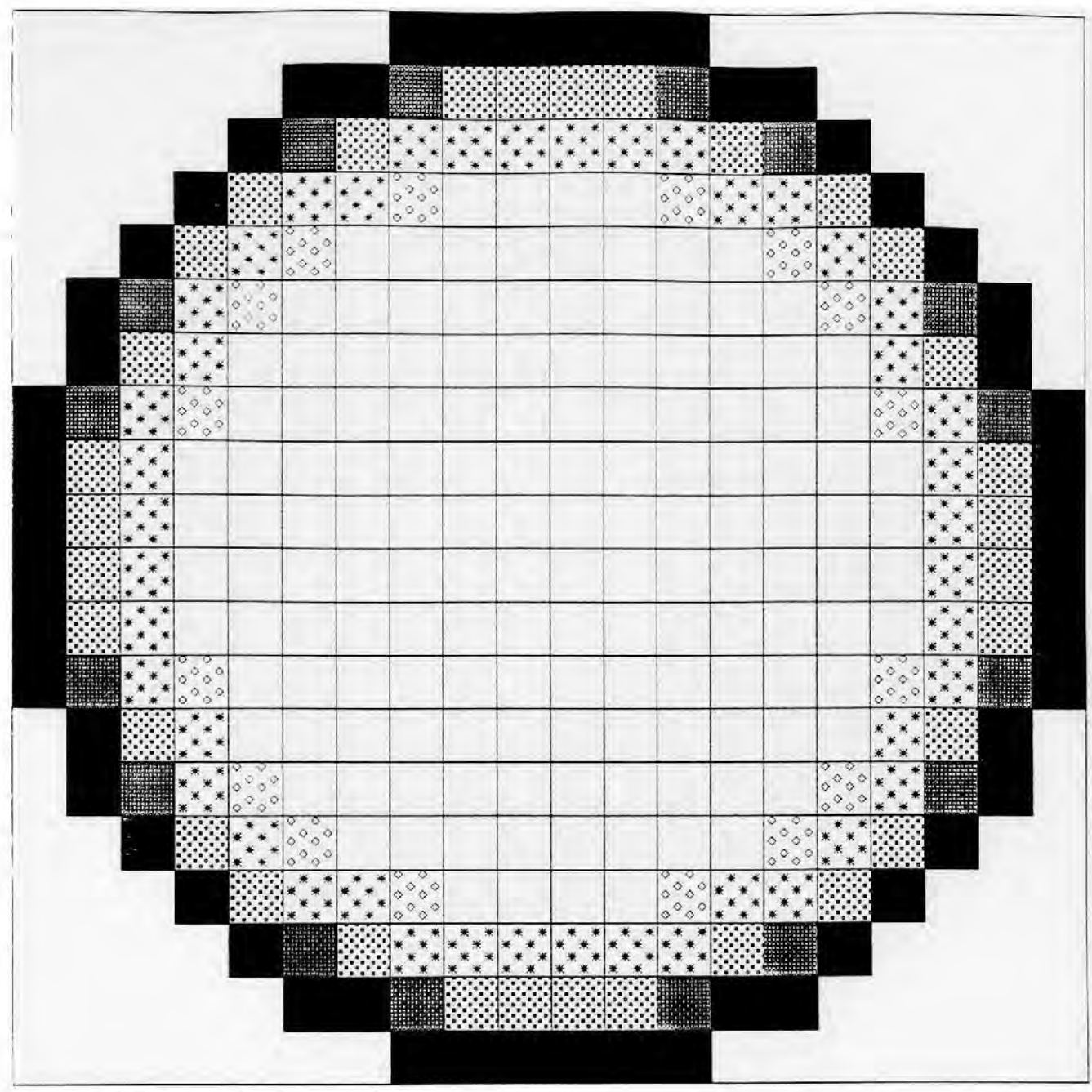

Fig. 8.12. Distribution of seepage rates ( $\mathrm{cm} /$ day) over the lake bed for a shallow inflow lake with moderate slope at $I=20 \mathrm{~cm} /$ year and $R=10$. Fig. 7.9 gives an analogous map for the same lake with recharge equal to $10 \mathrm{~cm} /$ year.

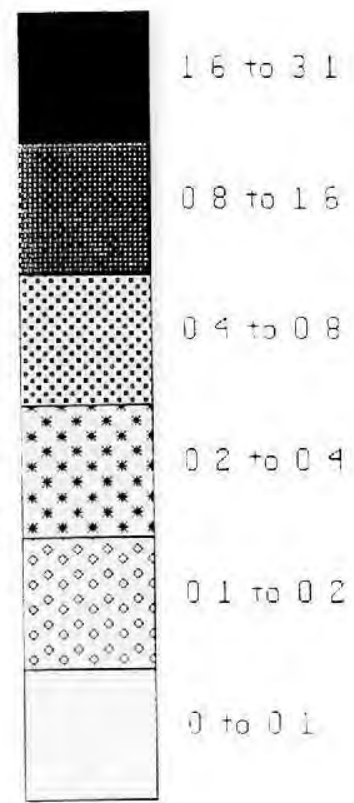




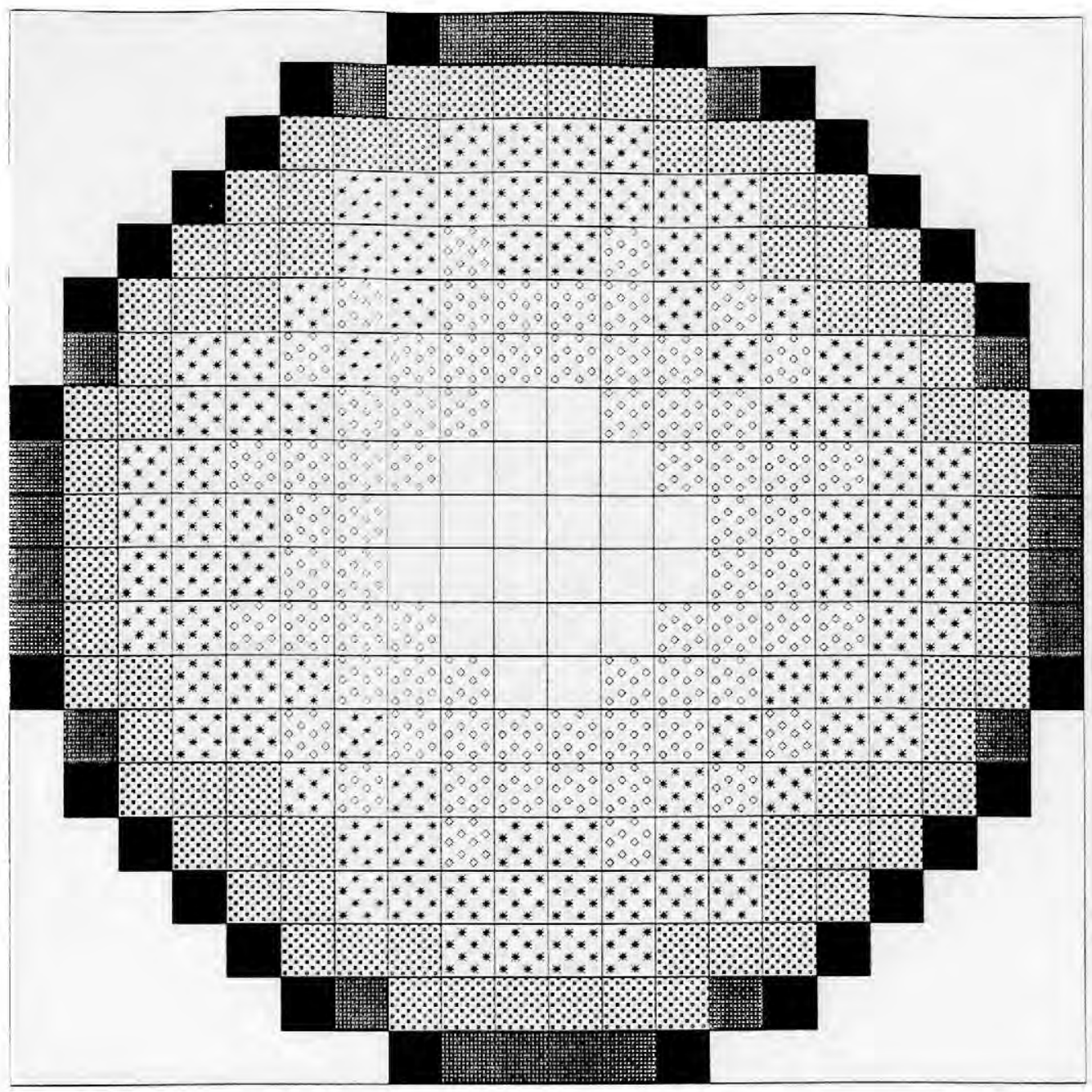

Fig. 8.13. Distribution of seepage rates ( $\mathrm{cm} /$ day) over the lake bed for a shallow inflow lake with moderate slope at $I=20 \mathrm{~cm} /$ year and $R=100$. Fig. 7.11 gives an analogous map for the same lake with recharge equal to $10 \mathrm{~cm} /$ year.

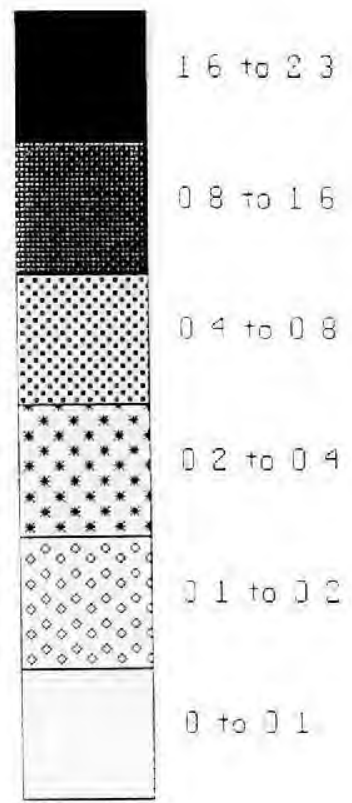




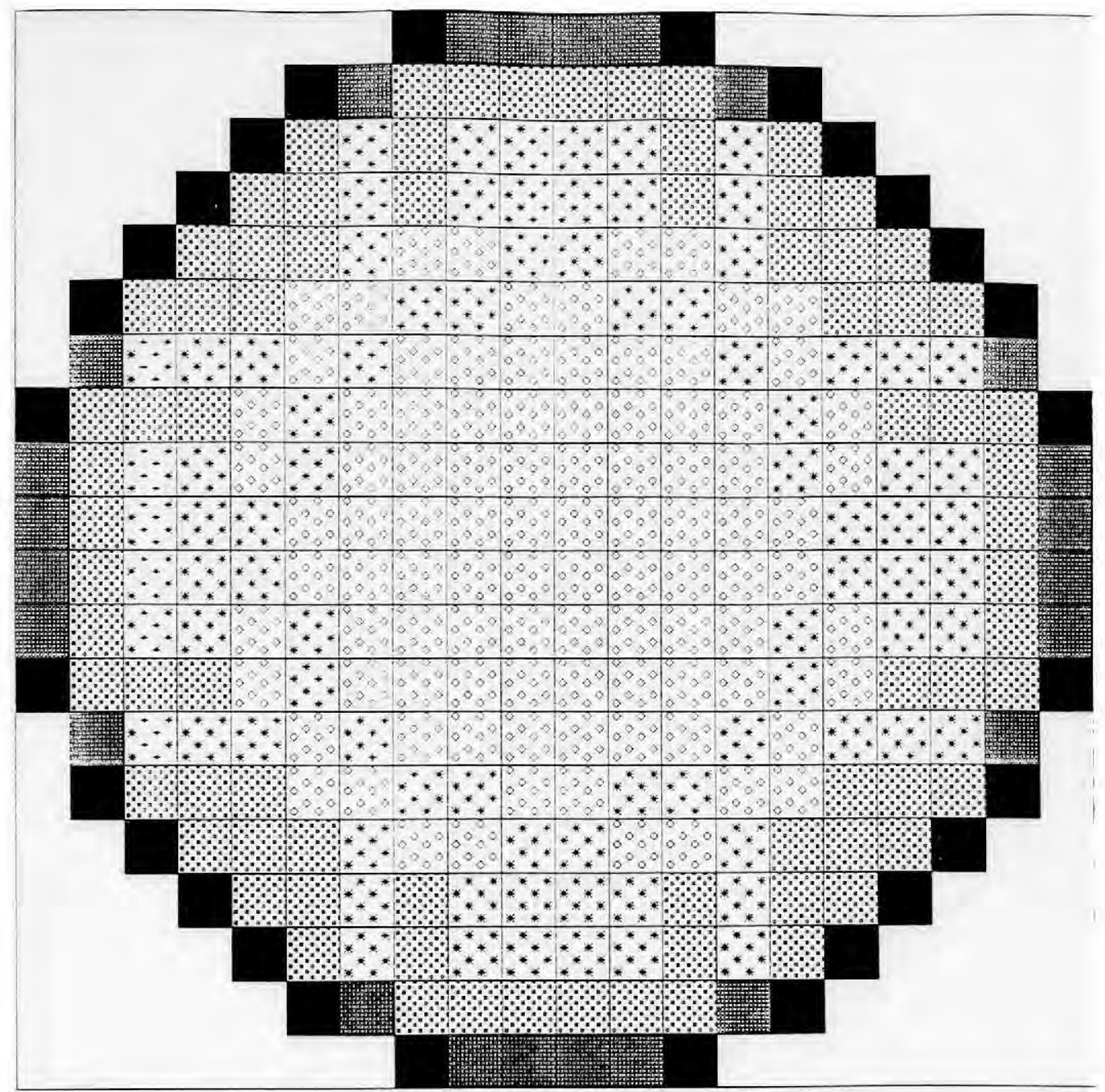

Fig. 8.14. Distribution of seepage rates ( $\mathrm{cm} /$ day) over the lake bed for a shallow inflow lake with moderate slope at $I=20 \mathrm{~cm} /$ year and $R=1000$. Fig. 7.13 gives an analogous map for the same lake with recharge equal to $10 \mathrm{~cm} /$ year.

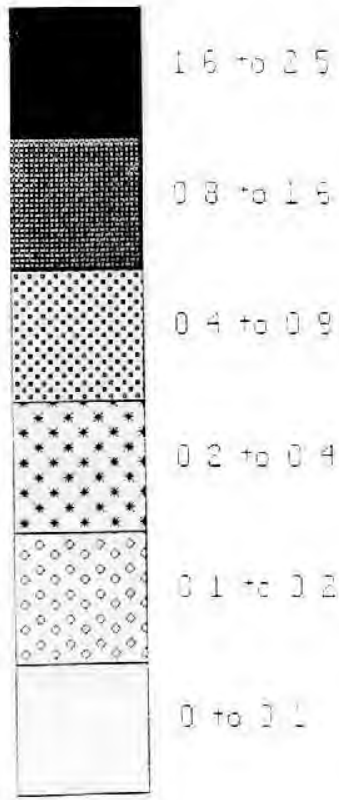




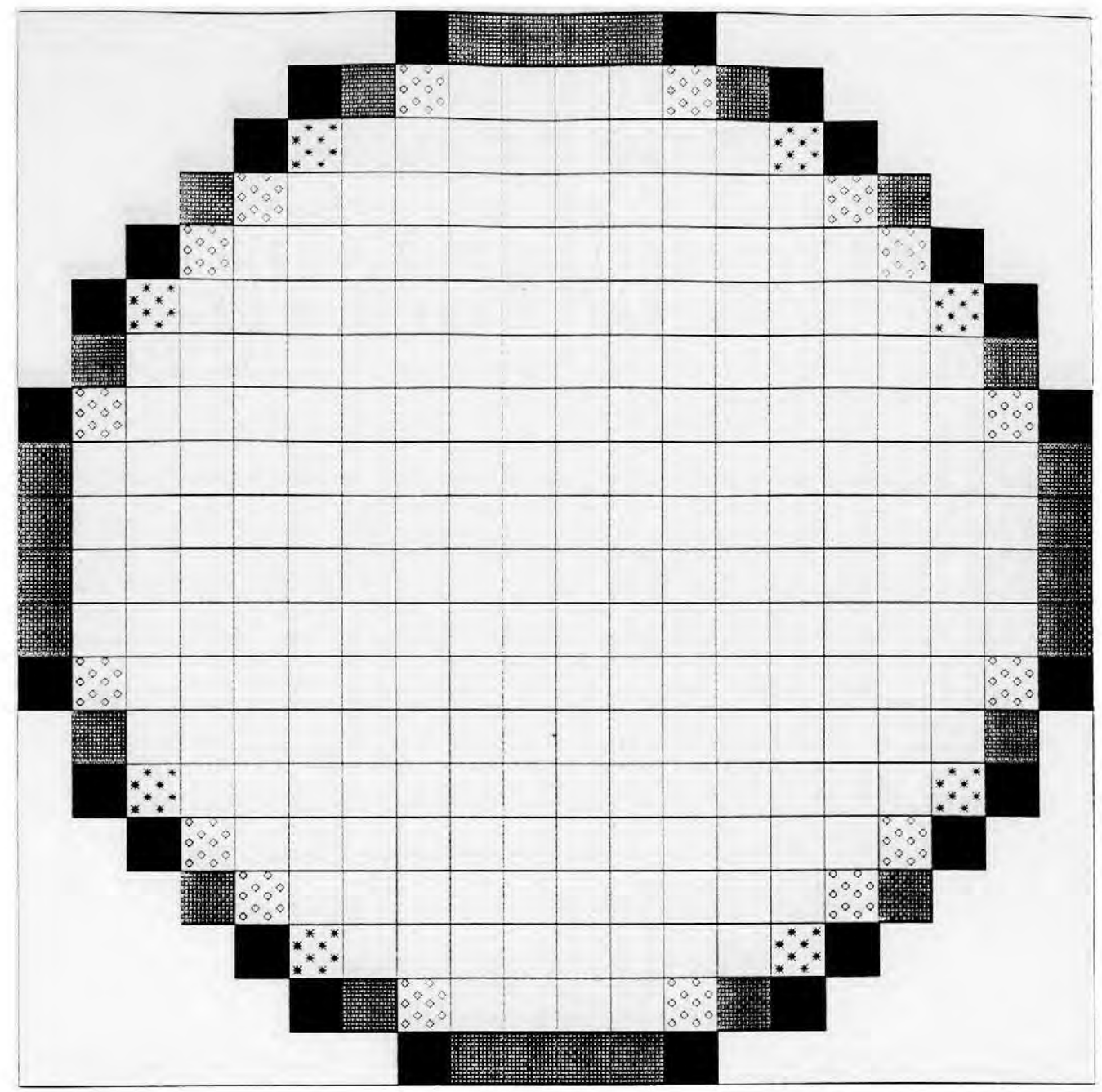

Fig. 8.15. Distribution of seepage rates ( $\mathrm{cm} /$ day) over the lake bed for a deep inflow lake with moderate slope at $\mathrm{I}=10 \mathrm{~cm} /$ year and $\mathrm{R}=1$.

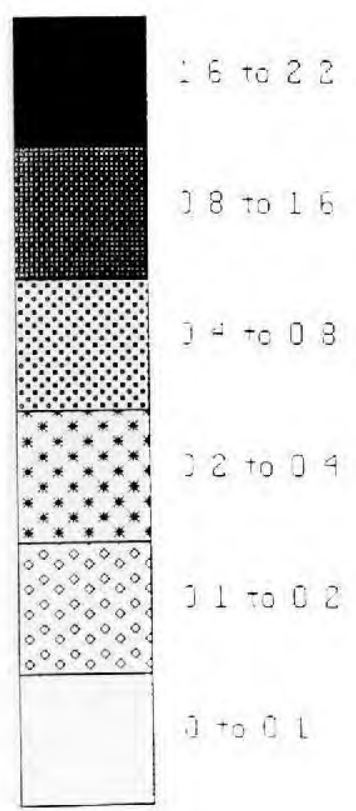




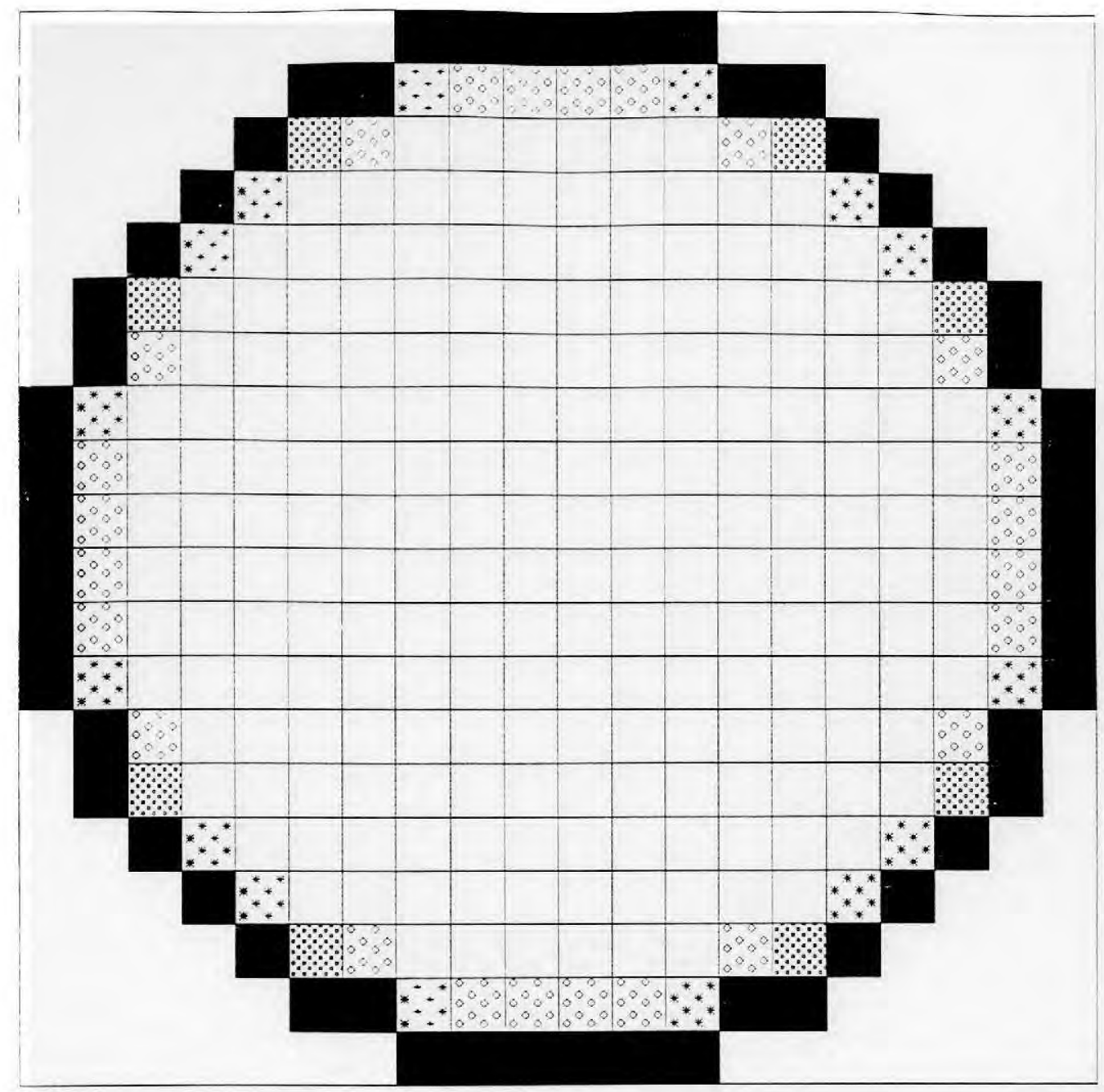

Fig. 8.16. Distribution of seepage rates ( $\mathrm{cm} /$ day) over the lake bed for a deep inflow lake with moderate slope at $\mathrm{I}=20 \mathrm{~cm} /$ year and $\mathrm{R}=1$.

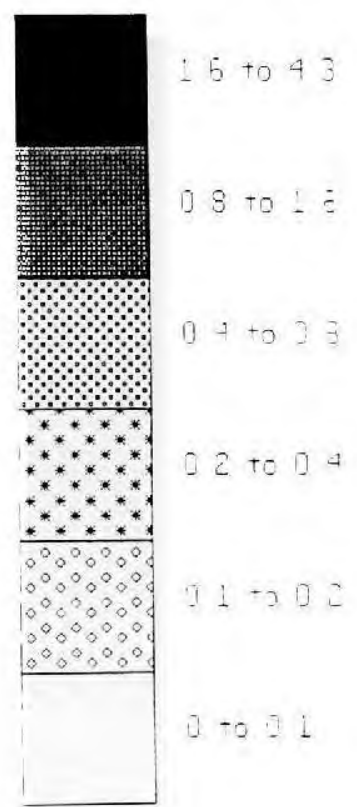



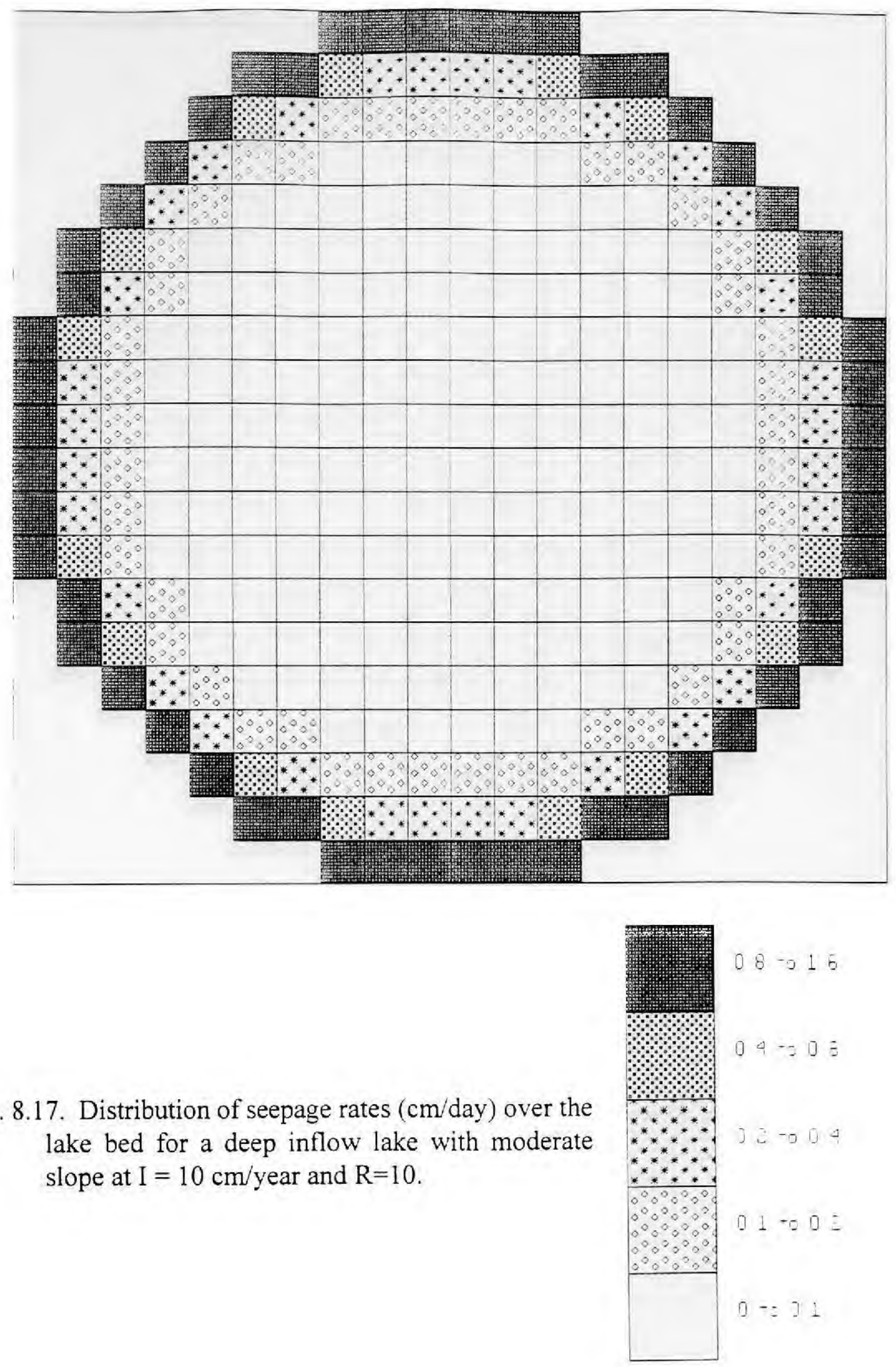


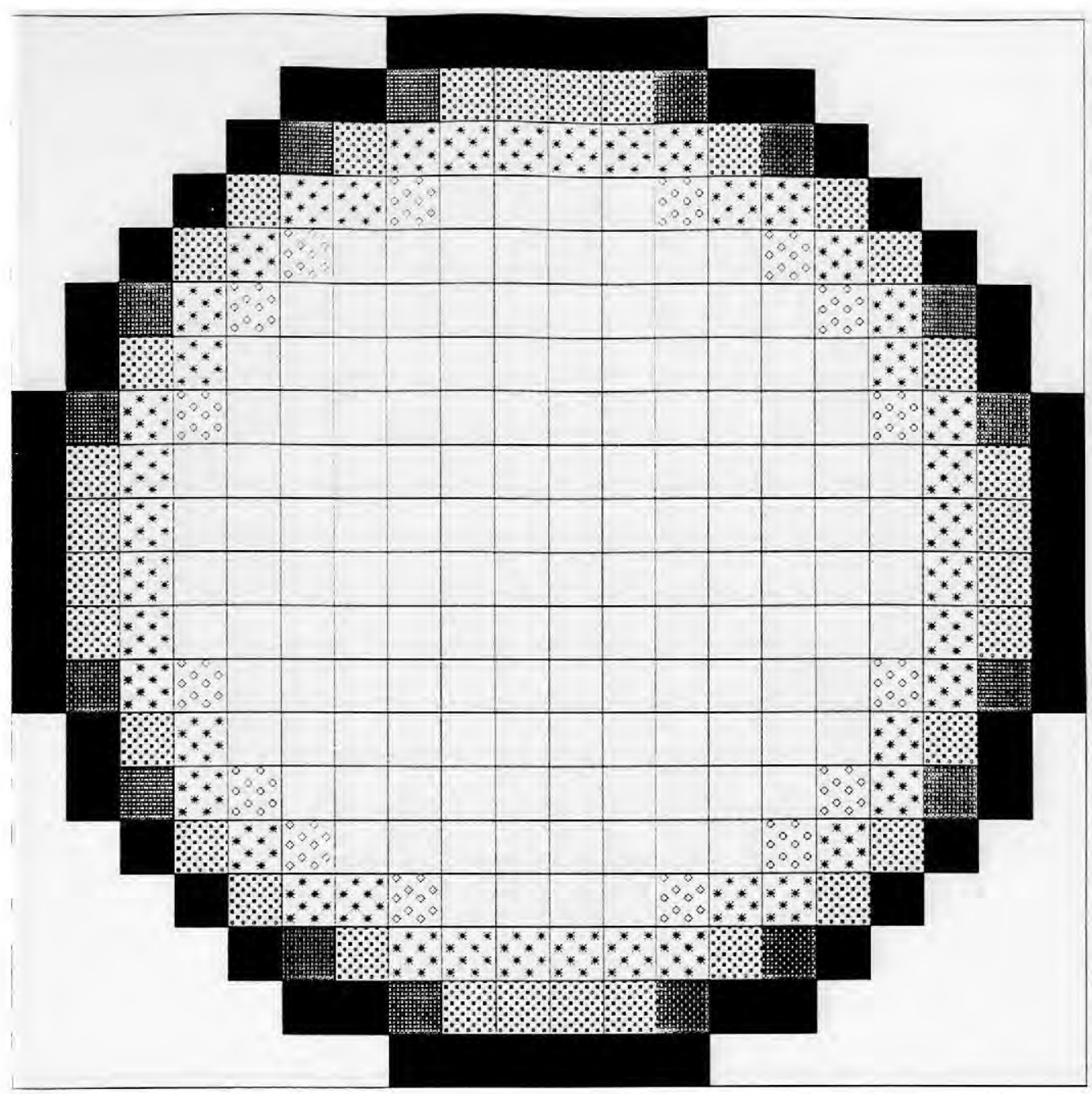

Fig. 8.18. Distribution of seepage rates $(\mathrm{cm} /$ day) over the lake bed for a deep inflow lake with moderate slope at $\mathrm{I}=20 \mathrm{~cm} /$ year and $\mathrm{R}=10$.

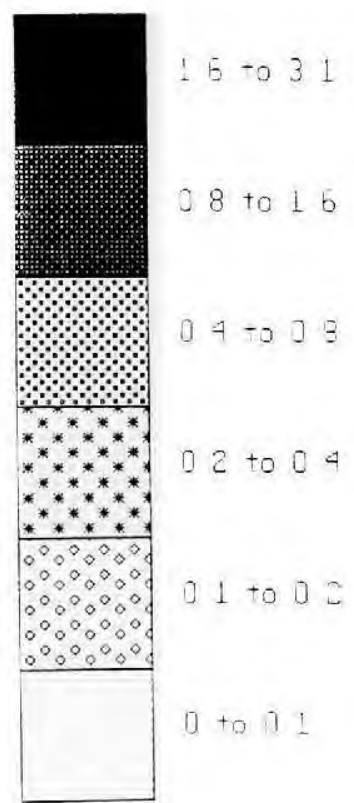




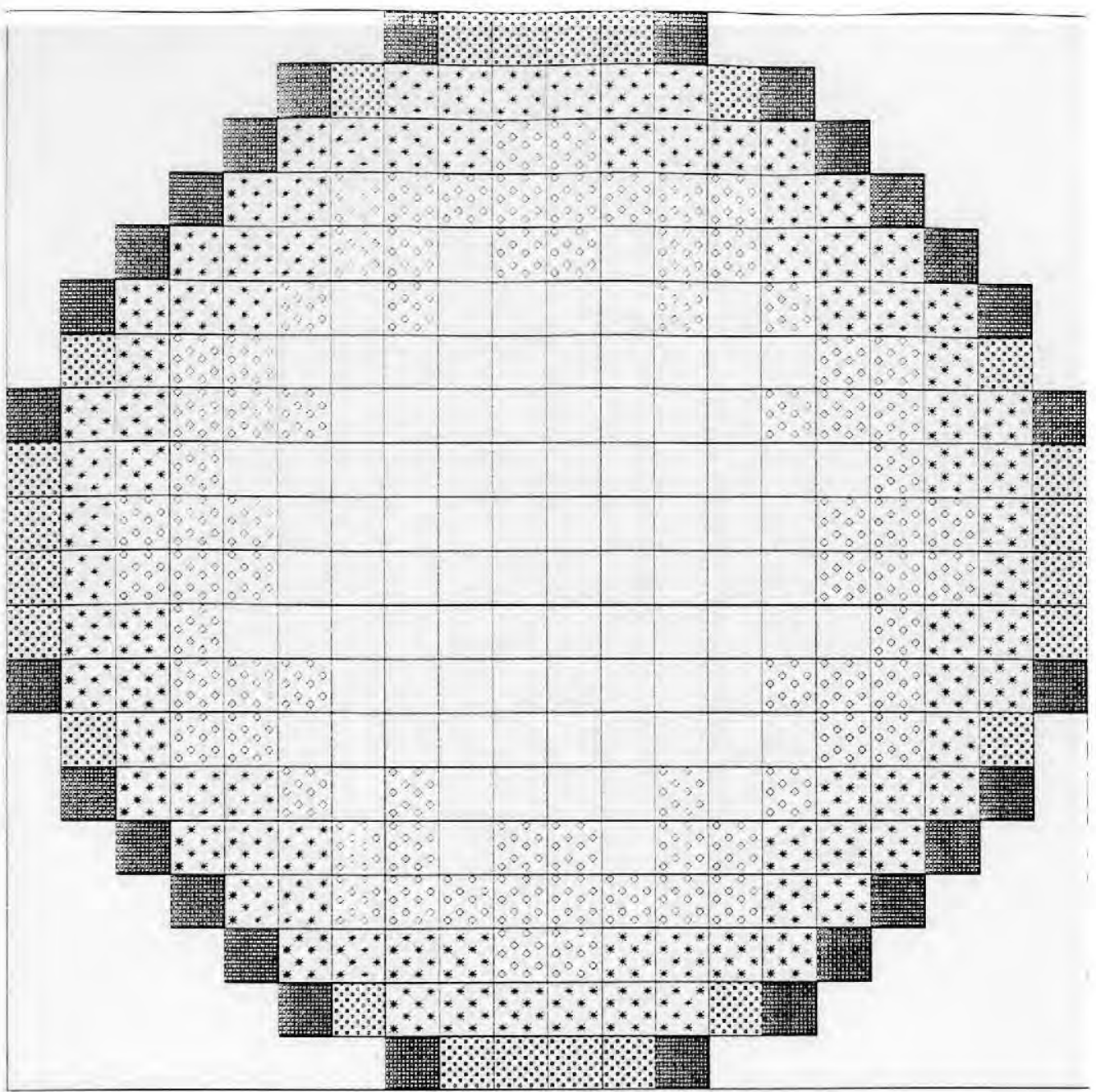

Fig. 8.19. Distribution of seepage rates ( $\mathrm{cm} /$ day) over the lake bed for a deep inflow lake with moderate slope at $\mathrm{I}=10 \mathrm{~cm} /$ year and $\mathrm{R}=100$.

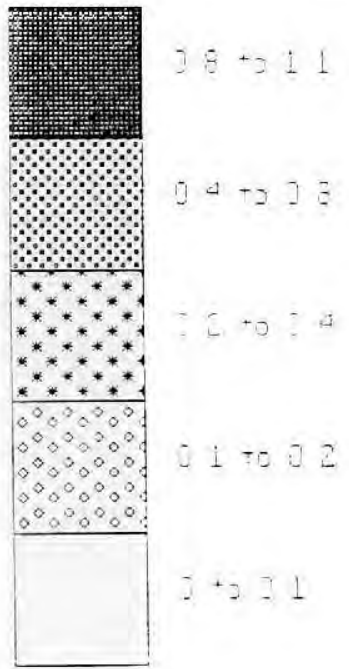




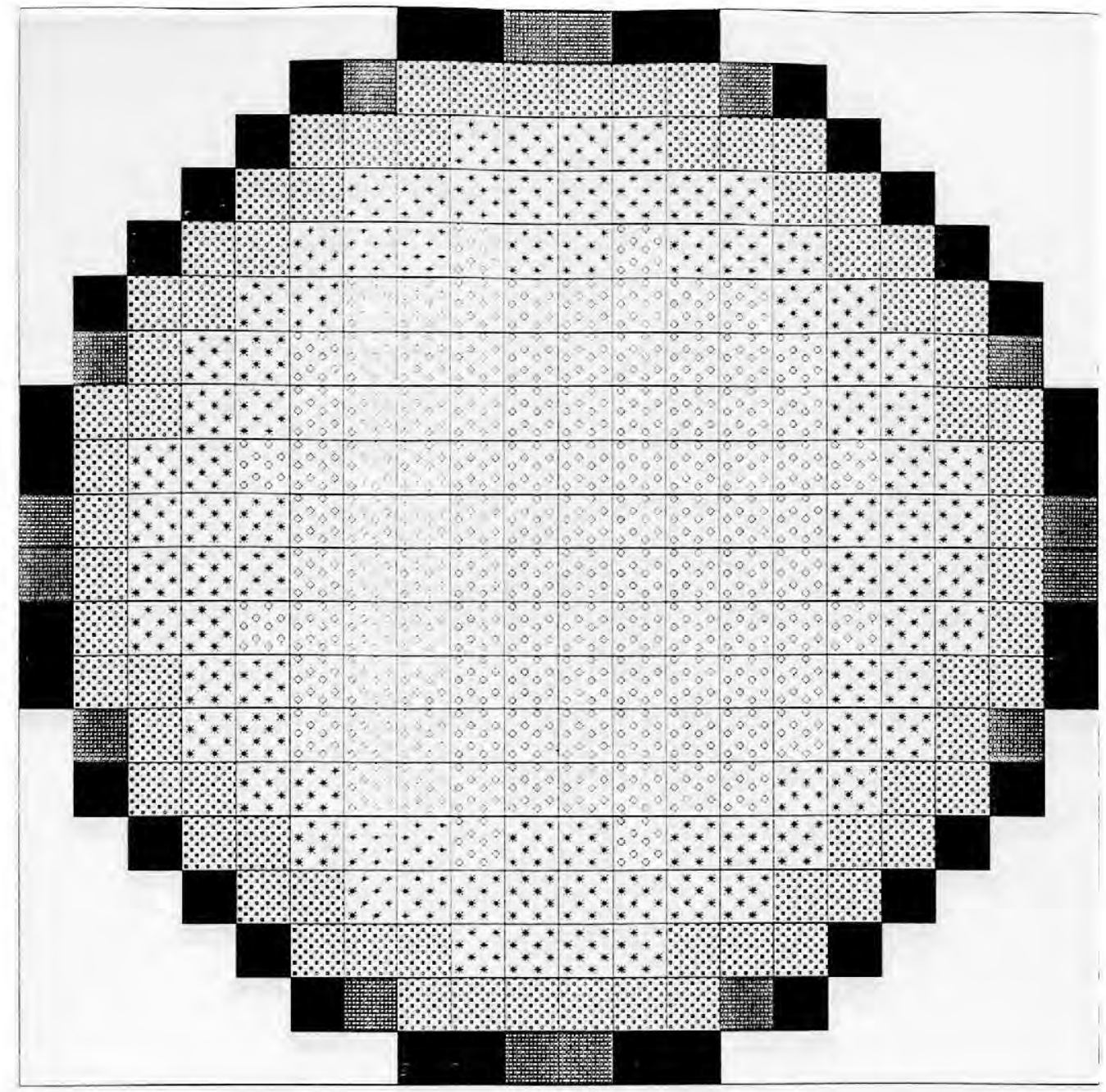

Fig. 8.20. Distribution of seepage rates ( $\mathrm{cm} /$ day) over the lake bed for a deep inflow lake with moderate slope at $\mathrm{I}=20 \mathrm{~cm} /$ year and $\mathrm{R}=100$.

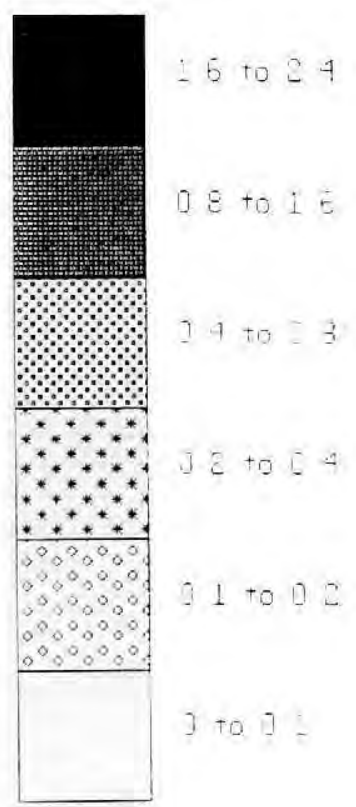



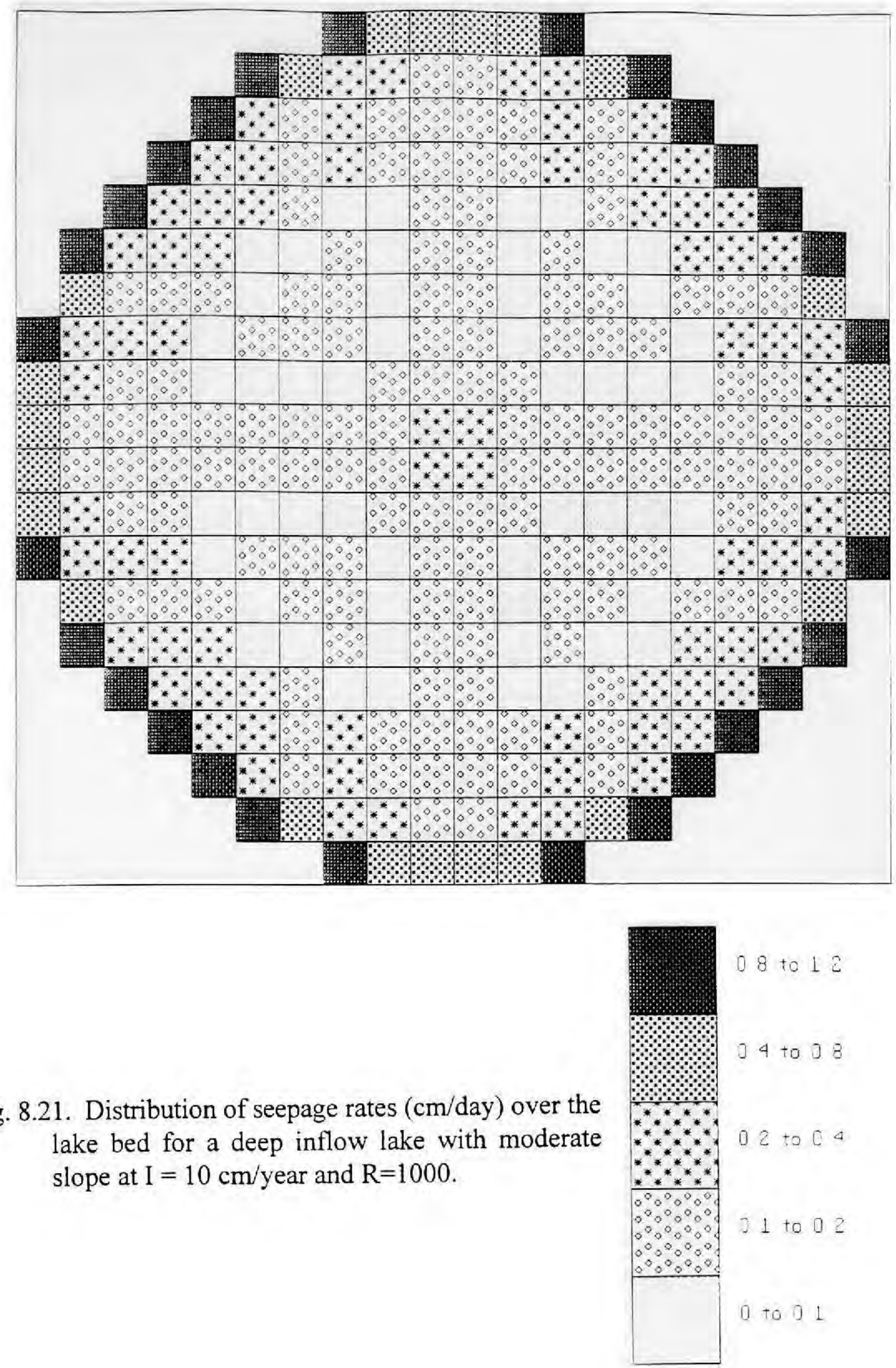

Fig. 8.21. Distribution of seepage rates ( $\mathrm{cm} /$ day) over the lake bed for a deep inflow lake with moderate slope at $\mathrm{I}=10 \mathrm{~cm} /$ year and $\mathrm{R}=1000$. 


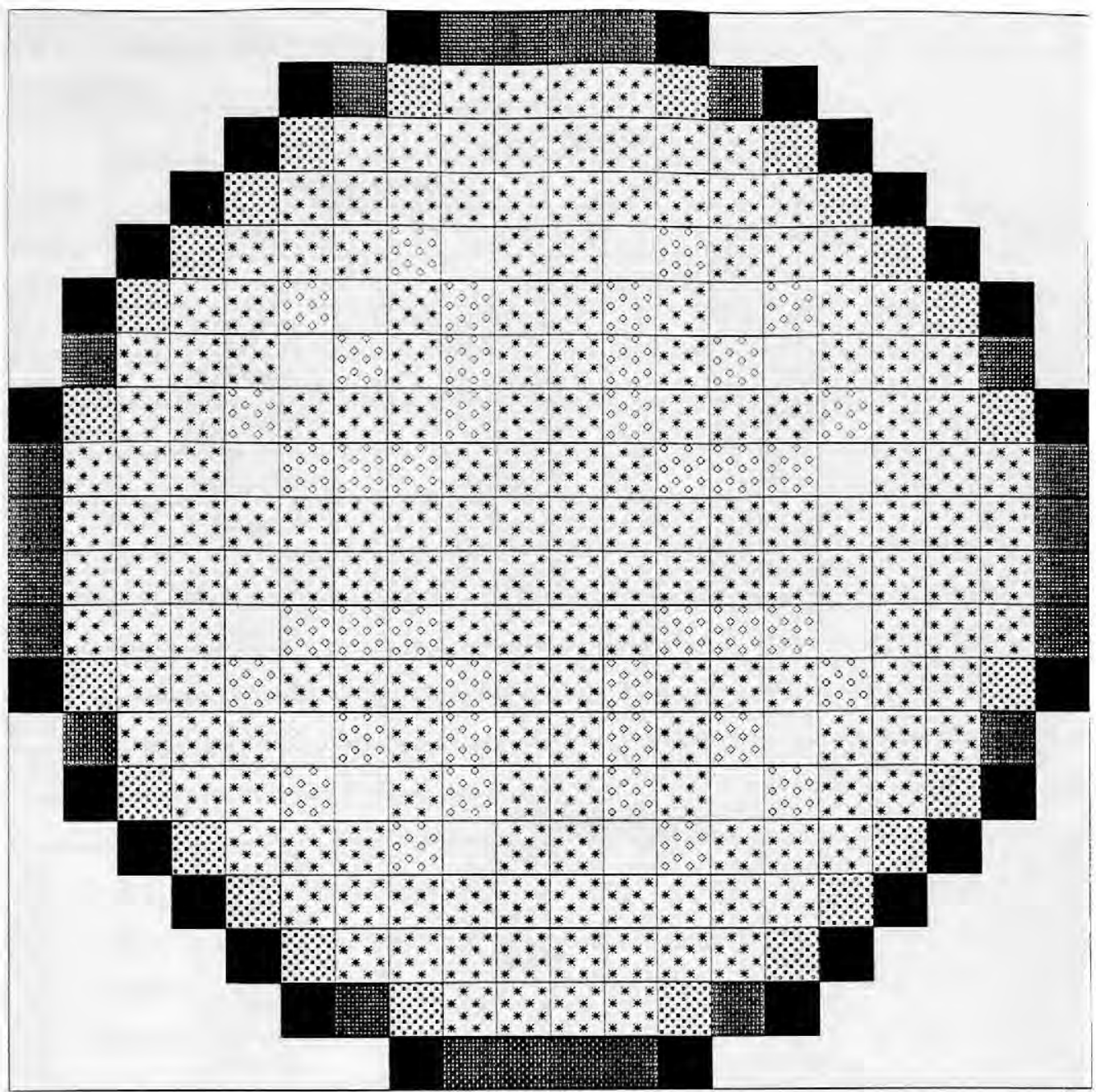

Fig. 8.22. Distribution of seepage rates ( $\mathrm{cm} /$ day) over the lake bed for a deep inflow lake with moderate slope at $\mathrm{I}=20 \mathrm{~cm} /$ year and $\mathrm{R}=1000$.

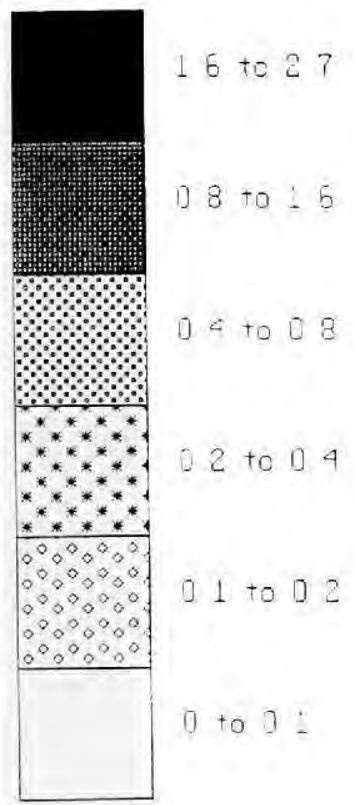


Table 8.2. Seepage rate versus distance offshore. * denotes seepage rates less than $10^{-7}$ $\mathrm{cm} /$ day.

\begin{tabular}{|c|c|c|c|c|}
\hline \multirow{4}{*}{$\begin{array}{c}\text { Distance } \\
\text { offshore } \\
(\mathrm{m})\end{array}$} & \multicolumn{4}{|c|}{ Seepage rate $(\mathrm{cm} /$ day $)$} \\
\hline & \multicolumn{2}{|c|}{ shallow lake } & \multicolumn{2}{|c|}{ deep lake } \\
\hline & $\mathrm{I}=10 \mathrm{~cm} /$ year & $\mathrm{I}=20 \mathrm{~cm} /$ year & $\mathrm{I}=10 \mathrm{~cm} /$ year & $\mathrm{I}=20 \mathrm{~cm} /$ year \\
\hline & \multicolumn{4}{|c|}{ Anisotropy $(\mathrm{R})=1$} \\
\hline 50 & 1.21878 & 2.58891 & 1.21582 & 2.51690 \\
\hline 150 & 0.07886 & 0.16596 & 0.07878 & 0.16155 \\
\hline 250 & 0.00596 & 0.01253 & 0.00597 & 0.01224 \\
\hline 350 & 0.00042 & 0.00089 & 0.00043 & 0.00088 \\
\hline 450 & $2.84 \mathrm{e}-05$ & $5.87 \mathrm{e}-05$ & $2.86 \mathrm{e}-05$ & $5.76 \mathrm{e}-05$ \\
\hline 550 & $1.76 \mathrm{e}-06$ & $3.72 \mathrm{e}-06$ & $1.78 \mathrm{e}-06$ & $3.59 \mathrm{e}-06$ \\
\hline 650 & $1.12 \mathrm{e}-07$ & $*$ & $1.03 \mathrm{e}-07$ & $*$ \\
\hline 750 & $*$ & $*$ & $*$ & * \\
\hline 850 & $*$ & $*$ & * & * \\
\hline \multirow[t]{2}{*}{950} & * & $*$ & $*$ & * \\
\hline & \multicolumn{4}{|c|}{ Anisotropy $(\mathrm{R})=10$} \\
\hline 50 & 1.01571 & 2.04935 & 1.01615 & 2.05124 \\
\hline 150 & 0.27746 & 0.54638 & 0.27738 & 0.54526 \\
\hline 250 & 0.10401 & 0.20445 & 0.10412 & 0.20435 \\
\hline 350 & 0.03947 & 0.07756 & 0.03956 & 0.07764 \\
\hline 450 & 0.01486 & 0.02921 & 0.01480 & 0.02905 \\
\hline 550 & 0.00522 & 0.01026 & 0.00545 & 0.01071 \\
\hline 650 & 0.00192 & 0.00376 & 0.00197 & 0.00386 \\
\hline 750 & 0.00074 & 0.00146 & 0.00070 & 0.00138 \\
\hline 850 & 0.00032 & 0.00064 & 0.00026 & 0.00052 \\
\hline \multirow[t]{2}{*}{950} & 0.00019 & 0.00037 & 0.00013 & 0.00025 \\
\hline & \multicolumn{4}{|c|}{ Anisotropy $(\mathrm{R})=100$} \\
\hline 50 & 0.73718 & 1.52589 & 0.73638 & 1.54027 \\
\hline 150 & 0.29045 & 0.55596 & 0.28952 & 0.54162 \\
\hline 250 & 0.19753 & 0.37319 & 0.19576 & 0.36301 \\
\hline 350 & 0.14958 & 0.28110 & 0.14648 & 0.27065 \\
\hline 450 & 0.12797 & 0.23992 & 0.11876 & 0.21910 \\
\hline 550 & 0.08476 & 0.15873 & 0.09529 & 0.17568 \\
\hline 650 & 0.06485 & 0.12141 & 0.07720 & 0.14229 \\
\hline 750 & 0.05294 & 0.09909 & 0.06433 & 0.11856 \\
\hline 850 & 0.04597 & 0.08603 & 0.05694 & 0.10494 \\
\hline
\end{tabular}


Table 8.2 (contd.)

\begin{tabular}{|c|c|c|c|c|}
\hline \multirow{2}{*}{$\begin{array}{c}\text { Distance } \\
\text { offshore } \\
(\mathrm{m})\end{array}$} & \multicolumn{4}{|c|}{ Seepage rate (cm/day) } \\
\cline { 2 - 5 } & $\mathrm{I}=10 \mathrm{~cm} /$ year & $\mathrm{I}=20 \mathrm{~cm} /$ year & $\mathrm{I}=10 \mathrm{~cm} /$ year & $\mathrm{I}=20 \mathrm{~cm} /$ year \\
\hline 950 & 0.04272 & 0.07994 & 0.05796 & 0.10681 \\
\hline & \multicolumn{4}{|c|}{ Anisotropy $(\mathrm{R})=1000$} \\
\hline 50 & 0.68651 & 1.44681 & 0.66969 & 1.53045 \\
\hline 150 & 0.21931 & 0.40766 & 0.21228 & 0.33007 \\
\hline 250 & 0.17049 & 0.30778 & 0.16215 & 0.25528 \\
\hline 350 & 0.15804 & 0.28100 & 0.14410 & 0.22780 \\
\hline 450 & 0.20254 & 0.35699 & 0.16043 & 0.25403 \\
\hline 550 & 0.10992 & 0.19281 & 0.16119 & 0.25538 \\
\hline 650 & 0.09590 & 0.16788 & 0.16322 & 0.25864 \\
\hline 750 & 0.08797 & 0.15380 & 0.17086 & 0.27074 \\
\hline 850 & 0.08358 & 0.14602 & 0.18901 & 0.29951 \\
\hline 950 & 0.08160 & 0.14250 & 0.23952 & 0.37952 \\
\hline
\end{tabular}




\section{CHAPTER 9}

\section{Results: Lake Bed Sediments}

Many real lakes contain lake bed sediments that are finer grained (and hence less permeable) than the porous medium surrounding the lakes. Such sediments could impede groundwater exchange with a lake, and possibly alter the spatial pattern of lake bed seepage (e.g., Cherkauer et al., 1989a). While the effect of lake sediments was not a primary focus of the present project, a few simulations were done to examine the effect of low permeability lake bed sediments on lake bed seepage and groundwater heads around the simulated lakes. The effect of lake bed sediments was investigated on both inflow and flow-through lakes. In all simulations the anisotropy ratio in the porous medium was 100 , and the ratio of hydraulic conductivity of the lake sediments to the horizontal hydraulic conductivity of the porous medium $\left(\mathrm{K}_{\mathrm{s}} / \mathrm{K}_{\mathrm{h}(\mathrm{pm})}\right)$ was varied between $10^{-2}$ and $10^{-4}$. In each case the sediments were isotropic, and fully covered the lake bed in a layer one grid-cell thick.

\subsection{Inflow lake}

The total volumetric seepage rate through the beds of the simulated inflow lakes was necessarily equal to the amount of recharge, as the lake bed was the only sink for water in the inflow lake simulations, and recharge the 
only source. In comparing two inflow lake simulations identical in every respect except the presence or absence of lake bed sediments, the goal was to evaluate the effect of sediments on groundwater heads, and on the spatial distribution (but not total amount) of lake bed seepage. Simulations with and without lake bed sediments were run for shallow inflow lakes with moderate lake bed slope and recharge rate equal to $10 \mathrm{~cm} /$ year. The presence or absence of low conductivity lake bed sediments has a large effect on the head distribution in the porous medium (Fig. 9.1). The presence of low conductivity lake sediments increased the hydraulic head everywhere in the porous medium, because the lake sediments acted as a barrier to the flow of water from the porous medium to the lake. As the ratio $\mathrm{K}_{\mathrm{s}} / \mathrm{K}_{\mathrm{h}(\mathrm{pm})}$ was reduced, the heads near the lake increased; minimum head below the lake increased to 69.17 meter when the ratio was $10^{-4}$ (Table 9.1). For the simulation with $\mathrm{K}_{\mathrm{s}} / \mathrm{K}_{\mathrm{h}(\mathrm{pm})}=10^{-2}$, head at the outer boundary of the model domain was only 2.66 meters higher than in the simulation with no lake sediments, and head below the lake was only 0.0124 meters higher. At this $\mathrm{K}_{\mathrm{s}} / \mathrm{K}_{\mathrm{h}(\mathrm{pm})}$, the hydraulic conductivity of the lake bed sediments was equal to the vertical hydraulic conductivity of the porous medium. At $\mathrm{K}_{\mathrm{s}} / \mathrm{K}_{\mathrm{h}(\mathrm{pm})}=10^{-3}$, the head at the boundary of the model domain attained 81.93 meters, and the head below the lake was 1.43 meters 
higher than in the simulation without sediments. When $\mathrm{K}_{\mathrm{s}} / \mathrm{K}_{\mathrm{h}(\mathrm{pm})}$ was $10^{-4}$, the head near the domain boundary was 132 meters, showing a very strong vertical gradient. As described in the previous chapter, this high groundwater head in a natural system could bring the water table above the ground surface, causing overland flow.

The presence of lake sediments caused a decrease in nearshore seepage rate and increase in offshore seepage rate. This effect was amplified as the ratio $\mathrm{K}_{\mathrm{s}} / \mathrm{K}_{\mathrm{h}(\mathrm{pm})}$ was reduced. The presence and permeability of lake bed sediments had a strong effect on the spatial distribution of lake bed seepage, even though it could not influence the total amount of seepage in these inflow lake simulations (total volumetric seepage was fixed by the amount of recharge, and was therefore the same in all simulations). This effect was also seen in two inflow lake simulations by Mcbride et al. (1975), one without lake sediments and the other with $\mathrm{K}_{\mathrm{s}} / \mathrm{K}_{\mathrm{h}(\mathrm{pm})}=10^{-3}$. Plots of the logarithm of seepage rate versus distance offshore were prepared for the two simulations, and the slope of the line formed by the results was twice as large for the simulation without sediments. This shows that seepage rates were lower near the shore and higher offshore when lake sediments were present. 


\begin{tabular}{|c|c|c|c|c|}
\hline \multirow{2}{*}{$\begin{array}{c}\text { Type of } \\
\text { lake }\end{array}$} & No Sediment & \multicolumn{3}{|c|}{ Sediment $\left(\mathrm{K}_{\mathrm{s}} / \mathrm{K}_{\mathrm{h}(\mathrm{pm})}\right)$} \\
\cline { 3 - 5 } & $10^{-2}$ & $10^{-3}$ & $10^{-4}$ \\
\hline $\begin{array}{c}\text { shallow } \\
\text { inflow } \\
\text { lake with } \\
\text { moderate } \\
\text { slope }\end{array}$ & 50.11 .73 .24 & $50.14,75.9$ & $51.54,81.93$ & $69.17,132$ \\
\hline
\end{tabular}

Table 9.1. The minimum and the maximum heads in meters (first line of each result box) and the minimum and maximum lake bed seepage rates in $\mathrm{cm} /$ day (second line of each result box in parentheses) along the vertical section through the center of the lake for simulations pertaining to lake bed sediments.

When comparing seepage maps, the high seepage zone defined by a seepage rate of $0.8 \mathrm{~cm} /$ day or higher had less aerial extent at $\mathrm{K}_{\mathrm{s}} / \mathrm{K}_{\mathrm{h}(\mathrm{pm})}=10^{-2}$ compared to the simulation without lake sediments (Figs. 9.3 and 7.11). Similarly, the area of low seepage rate (i.e., $0.1 \mathrm{~cm} /$ day or lower) was larger when lake sediments were absent. At $\mathrm{K}_{\mathrm{s}} / \mathrm{K}_{\mathrm{h}(\mathrm{pm})}=10^{-3}$, nearshore seepage rates fell between 0.4 to $0.8 \mathrm{~cm} /$ day, and seepage rates offshore were all $>0.1$ $\mathrm{cm} /$ day (Fig. 9.4). At $\mathrm{K}_{\mathrm{s}} / \mathrm{K}_{\mathrm{h}(\mathrm{pm})}=10^{-4}$, nearshore and offshore seepage rates were very similar (Fig. 9.5).

\subsection{Flow-through lake}

Similar to inflow lakes, flow-through lake simulations were done with lake sediments at $\mathrm{K}_{\mathrm{s}} / \mathrm{K}_{\mathrm{h}(\mathrm{pm})}=10^{-2}, 10^{-3}$, and $10^{-4}$. As mentioned earlier, the overall hydraulic head gradient in flow-through lake simulations was fixed; head on the upgradient side of the model domain was set at $65 \mathrm{~m}$, while head 
on the downgradient side was $35 \mathrm{~m}$. Figs 9.6 and 9.7 shows the distribution of hydraulic heads in the porous medium for these simulations.

When $\mathrm{K}_{\mathrm{s}} / \mathrm{K}_{\mathrm{h}(\mathrm{pm})}$ was $10^{-2}$, heads close to the upgradient side of the lake were higher, and the heads near the downgradient side lower, compared to an identical simulation without lake sediments (Fig. 7.17). As $\mathrm{K}_{\mathrm{s}} / \mathrm{K}_{\mathrm{h}(\mathrm{pm})}$ decreased, this effect was more pronounced. This indicated an impedance of

\begin{tabular}{|c|c|c|c|c|}
\hline \multirow{2}{*}{$\begin{array}{c}\text { Type of } \\
\text { Lake }\end{array}$} & \multirow{2}{*}{ No Sediment } & \multicolumn{3}{|c|}{ Sediment $\left(\mathrm{K}_{\mathrm{s}} / \mathrm{K}_{\mathrm{h}(\mathrm{pm})}\right)$} \\
\cline { 3 - 5 } & & $10^{-2}$ & $10^{-3}$ & $10^{-4}$ \\
\hline $\begin{array}{c}\text { shallow } \\
\text { flow- }\end{array}$ & 963 & 952 & 932 & 858 \\
$\begin{array}{c}\text { through } \\
\text { lake with } \\
\text { moderate } \\
\text { slope }\end{array}$ & $(-0.1454$, & $(-0.1373$, & $(-0.0810$, & $(-0.0175$. \\
& $0.2300)$ & $0.1867)$ & $0.1098)$ & $0.0256)$ \\
\hline
\end{tabular}

Table 9.2. The location of the seepage boundary in meters from the downgradient shore of the lake (first line of each result box) and the minimum and maximum seepage rates in $\mathrm{cm} /$ day (second line of the result box, in parentheses) along the vertical crosssection parallel the regional gradient and through the center of the lake.

flow of groundwater to and from the lake because of the low conductivity lake sediments.

The effect of lake sediments on the amount of groundwater inseepage and lake water outseepage was calculated for the four flow-through lake simulations (three with sediments and one without). Adding lake sediments, and decreasing the conductivity of the sediments, decreased the amounts of 
inseepage and outseepage (Table 9.3). The total amount of groundwater seepage into the lake was highest (about $1.6 \%$ of the lake volume per year) when lake sediment was absent, and decreased to $0.35 \%$ at $\mathrm{K}_{\mathrm{s}} / \mathrm{K}_{\mathrm{h}(\mathrm{pm})}$ equal to $10^{-4}$. Similarly, the total amount of seepage from the lake ranged from $1.09 \%$ when no sediment was present to $0.17 \%$ when $\mathrm{K}_{\mathrm{s}} / \mathrm{K}_{\mathrm{h}(\mathrm{pm})}=10^{-4}$.

\begin{tabular}{|c|c|c|c|c|}
\hline $\mathrm{K}_{\mathrm{s}} / \mathrm{K}_{\mathrm{h}(\mathrm{pm})}$ & $\begin{array}{c}\text { Total } \\
\text { volumetric } \\
\text { groundwater } \\
\text { inseepage } \\
\left(\mathrm{m}^{3} / \text { year }\right)\end{array}$ & $\begin{array}{c}\text { Total } \\
\text { volumetric } \\
\text { lake water } \\
\text { outseepage } \\
\left(\mathrm{m}^{3} / \text { year }\right)\end{array}$ & $\begin{array}{c}\text { Groundwater } \\
\text { inseepage per } \\
\text { year as a } \\
\text { percentage of } \\
\text { lake volume }\end{array}$ & $\begin{array}{c}\text { Lake water } \\
\text { outseepage per } \\
\text { year as a } \\
\text { percentage of } \\
\text { lake volume }\end{array}$ \\
\hline $\begin{array}{c}\text { lake sediment } \\
\text { absent }\end{array}$ & $3.34 \times 10^{5}$ & $2.26 \times 10^{5}$ & 1.62 & 1.09 \\
\hline $10^{-2}$ & $3.12 \times 10^{5}$ & $2.12 \times 10^{5}$ & 1.51 & 1.03 \\
\hline $10^{-3}$ & $2.34 \times 10^{5}$ & $1.5 \times 10^{5}$ & 1.13 & 0.73 \\
\hline $10^{-4}$ & $7.3 \times 10^{4}$ & $3.54 \times 10^{4}$ & 0.35 & 0.17 \\
\hline
\end{tabular}

Table 9.3. Groundwater inflow for coarse grid simulations of shallow flow-through lakes with moderate slope (three with lake sediment and one without). Lake volume was $2.064 \times 10^{7} \mathrm{~m}^{3}$.

Lake sediments had a significant effect on the position of the seepage boundary. The boundary moved slightly toward to the downgradient side when $\mathrm{K}_{\mathrm{s}} / \mathrm{K}_{\mathrm{h}(\mathrm{pm})}$ was $10^{-2}$, compared to a simulation without lake sediments. As the ratio was decreased, the boundary moved more toward the downgradient side and a maximum movement of 105 meters was observed. The precise location of the seepage boundary can be interpolated from the 
seepage data along the section plotted in Fig. 9.8 (Table 9.2).

When seepage rates were plotted against distance offshore, it was found that the seepage rates into and out of the lake were significantly lower in the presence of lake sediments (Fig. 9.8). Similar to inflow lakes, sediments in flow-through lakes also acted as a barrier in the exchange of water between the porous medium and the lake. The seepage rates decreased both in the upgradient and downgradient side of the lake as $\mathrm{K}_{\mathrm{s}} / \mathrm{K}_{\mathrm{h}(\mathrm{pm})}$ was lowered. The seepage maps clearly demonstrate the effect of the lake sediments (Figs. 7.25; 9.9 to 9.11 ). The high seepage rate area in the upgradient side of the lake (defined by seepage of $0.2 \mathrm{~cm} /$ day or higher) had less aerial extent in presence of lake sediments with $\mathrm{K}_{\mathrm{s}} / \mathrm{K}_{\mathrm{h}(\mathrm{pm})}=10^{-2}$ compared a simulation without lake sediments. At $\mathrm{K}_{\mathrm{s}} / \mathrm{K}_{\mathrm{h}(\mathrm{pm})}=10^{-4}$ the entire lake bed experienced seepage rates within $\pm 0.05 \mathrm{~cm} /$ day, much lower rates than in absence of sediments.

The introduction of the low conductivity lake sediments strongly influenced the head distribution and seepage through the lake beds by acting as a barrier to the flow between the lake and the porous medium. This in effect increased the heads in the porous medium in inflow lakes. As the water table was essentially fixed by the boundary conditions in flow-through lake simulations, the main response to lake sediments in these simulations was to 
decrease seepage rather than increase groundwater heads, though lake sediments did increase the head close to the upgradient side and decrease the head close to the downgradient side of the lake. In both types of lakes, adding sediments and lowering the conductivity of existing sediments spread seepage more evenly over the lake bed, reducing the contrast between nearshore and offshore seepage rates. A significant movement of the seepage boundary was also observed in flow-through lakes, and seepage rates were significantly lower in the presence of lake sediments. Flow-through lakes showed a decrease in seepage rate in both upgradient and downgradient sides of the lake in the presence of lake sediments. 


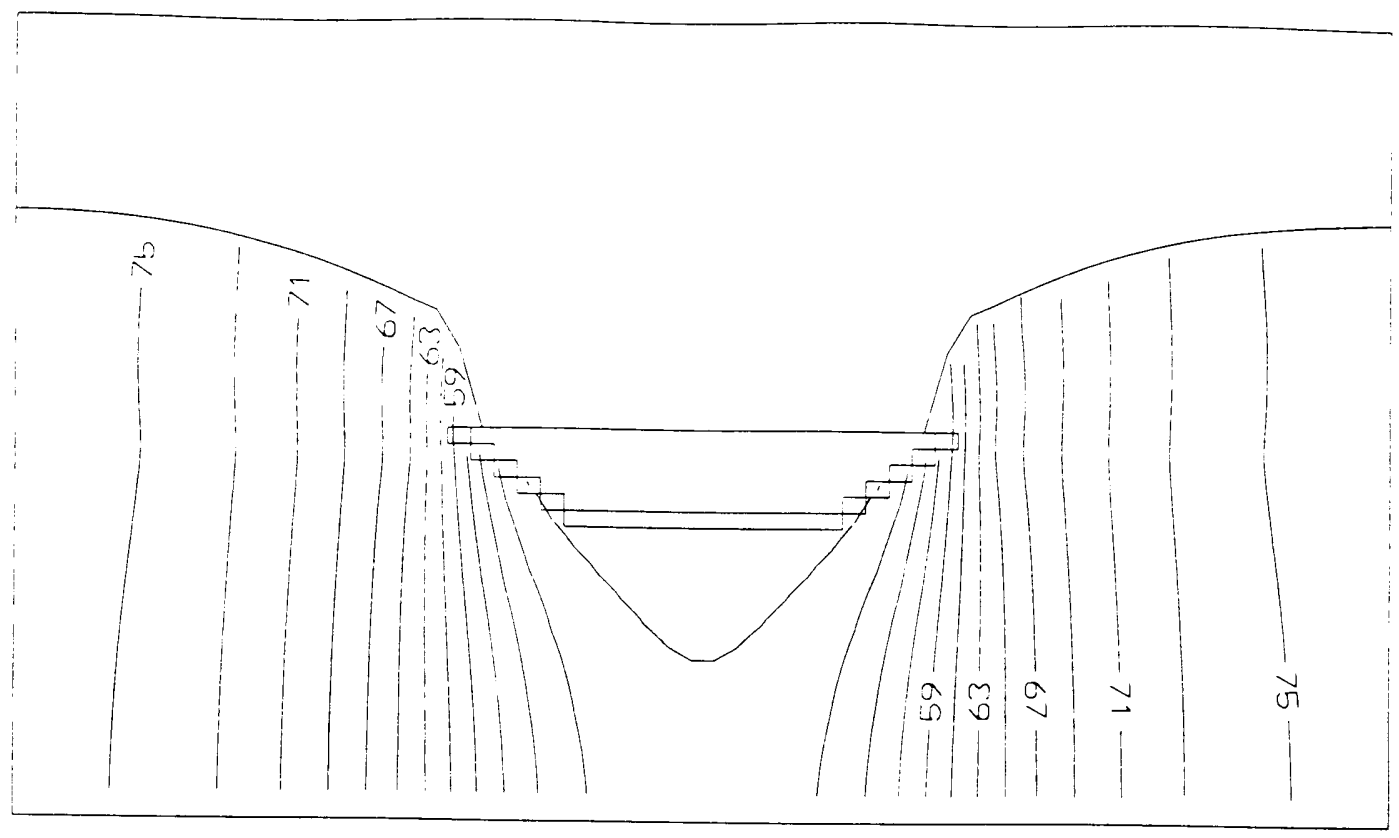

Lake sediment present $\left(\mathrm{K}_{\mathrm{s}} / \mathrm{K}_{\mathrm{h}(\mathrm{pm})}\right)=10^{-2}$

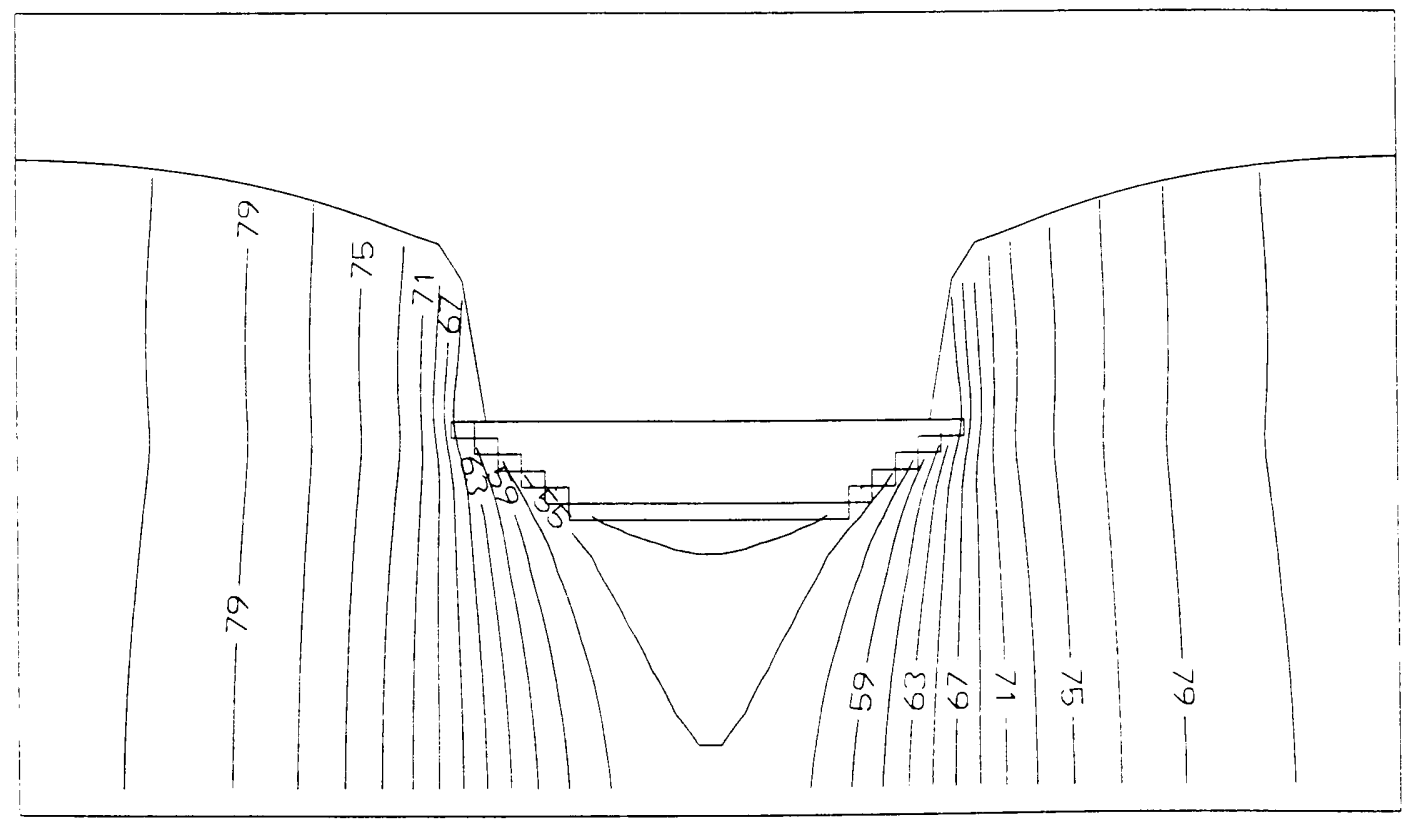

Lake sediment present $\left(\mathrm{K}_{\mathrm{s}} / \mathrm{K}_{\mathrm{h}(\mathrm{pm})}\right)=10^{-3}$

Fig. 9.1. Distribution of hydraulic heads in the porous medium surrounding shallow inflow lakes with moderate slope and lake sediments. Fig. 6.4 gives an analogous figure for a simulation without lake sediments. 


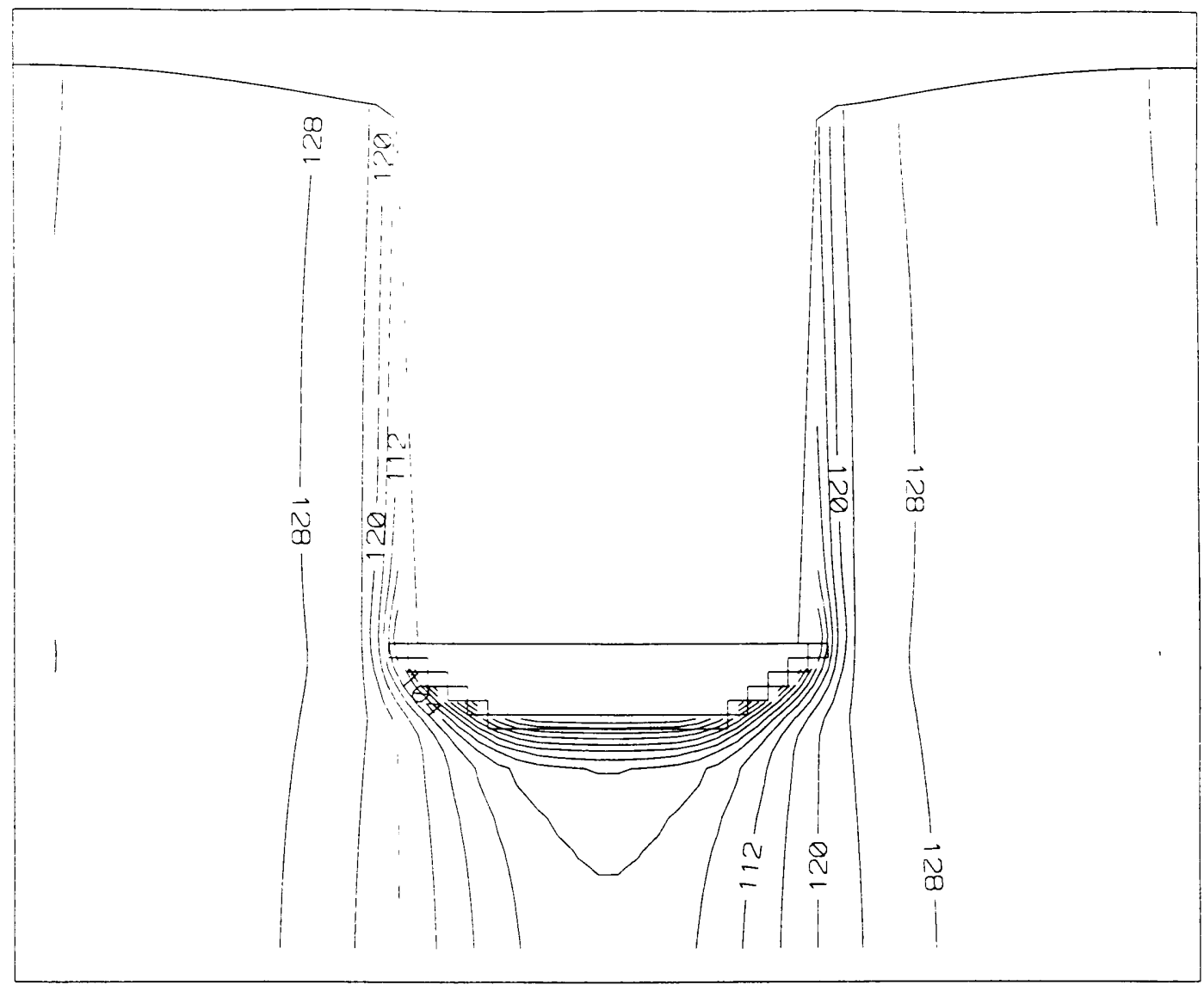

Lake sediment present $\left(\mathrm{K}_{\mathrm{s}} / \mathrm{K}_{\mathrm{h}(\mathrm{pm})}\right)=10^{-4}$

Fig. 9.2. Distribution of hydraulic heads in the porous medium surrounding shallow inflow lakes with moderate slope and lake sediments. Fig. 6.4 gives an analogous figure for a simulation without lake sediments. 


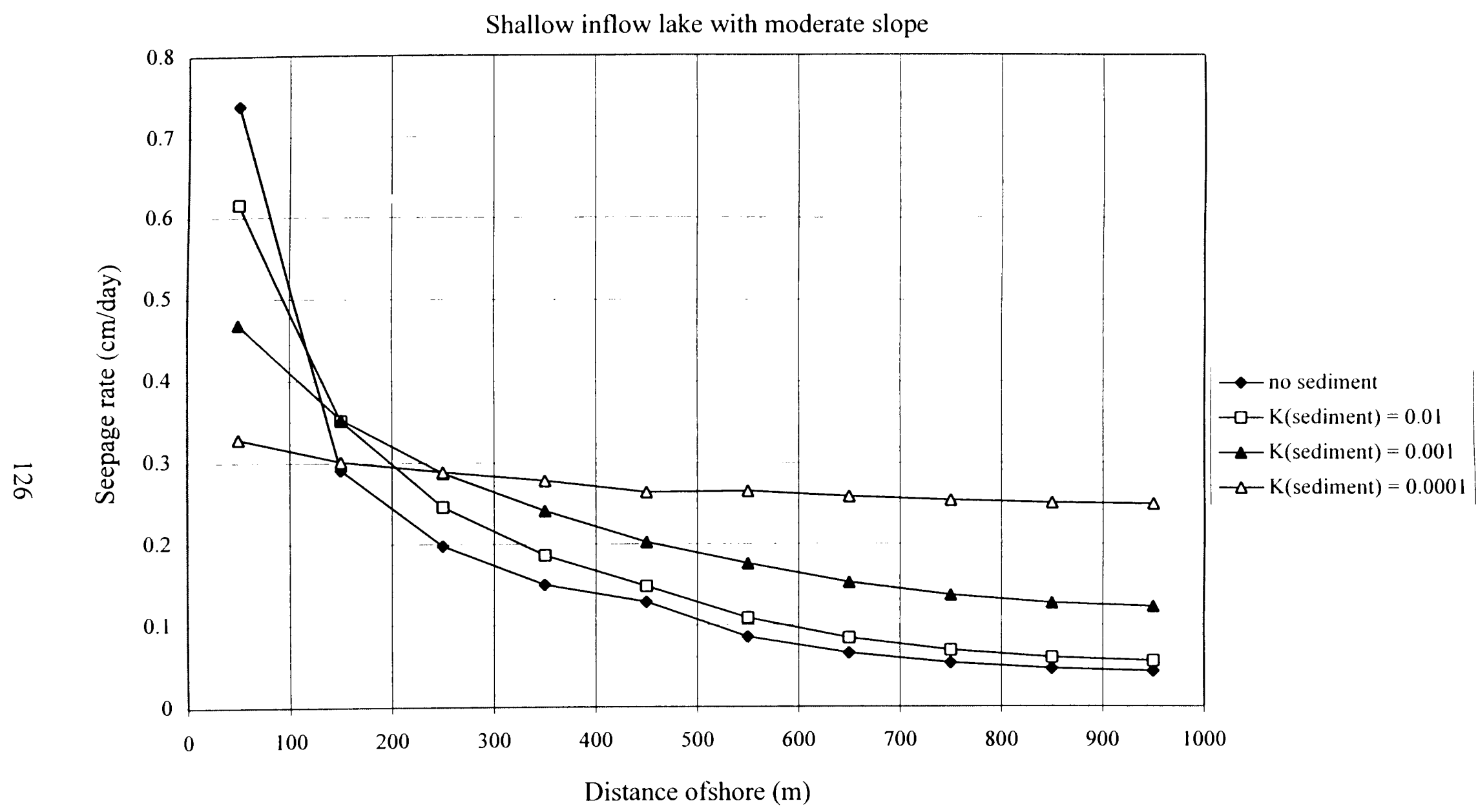

Fig. 9.3. Seepage rate versus distance offshore for simulations of shallow inflow lakes having moderate lake bed slope, with and without lake sediments. 

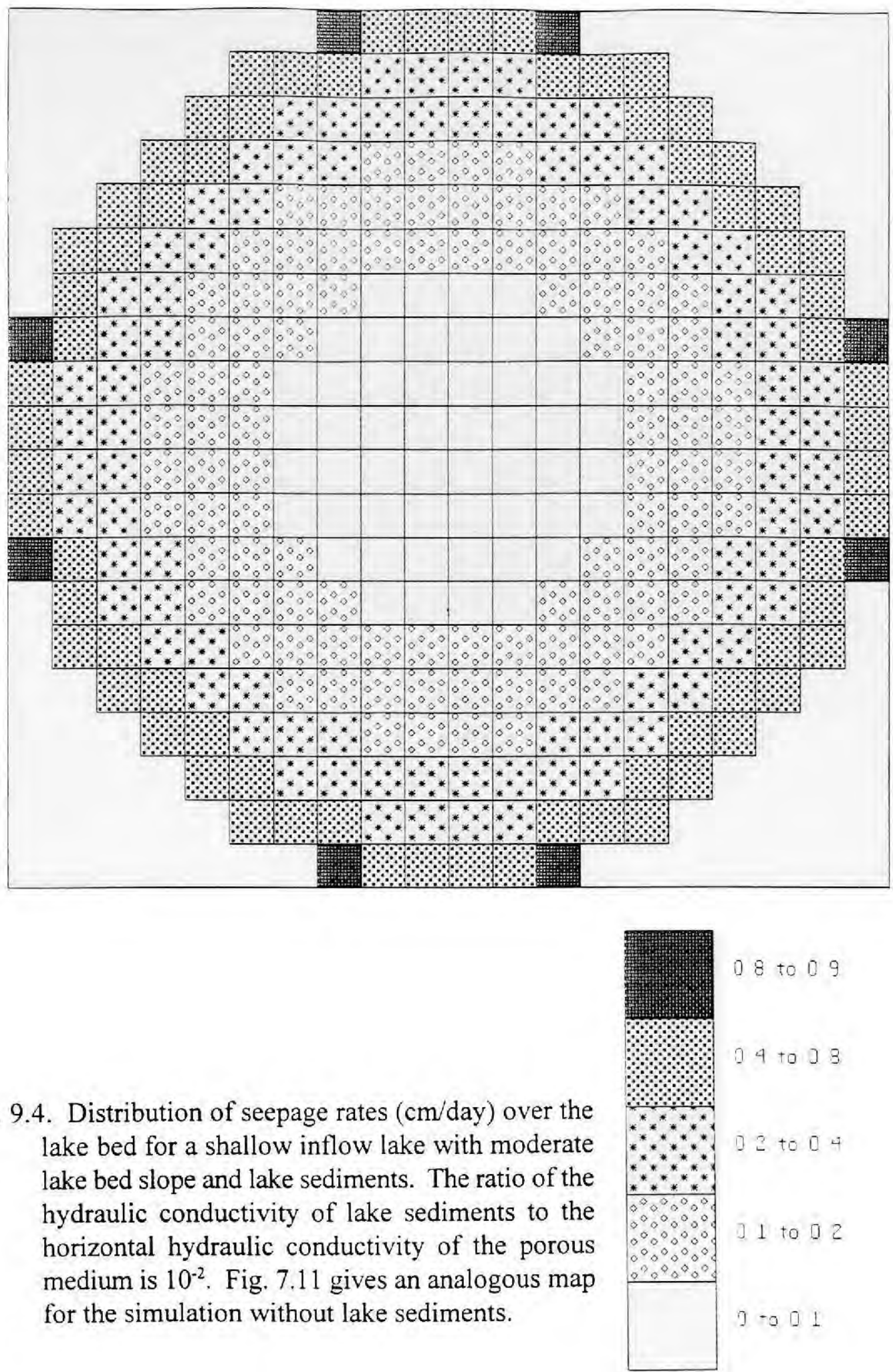

Fig. 9.4. Distribution of seepage rates ( $\mathrm{cm} /$ day) over the lake bed for a shallow inflow lake with moderate lake bed slope and lake sediments. The ratio of the hydraulic conductivity of lake sediments to the horizontal hydraulic conductivity of the porous medium is $10^{-2}$. Fig. 7.11 gives an analogous map for the simulation without lake sediments. 


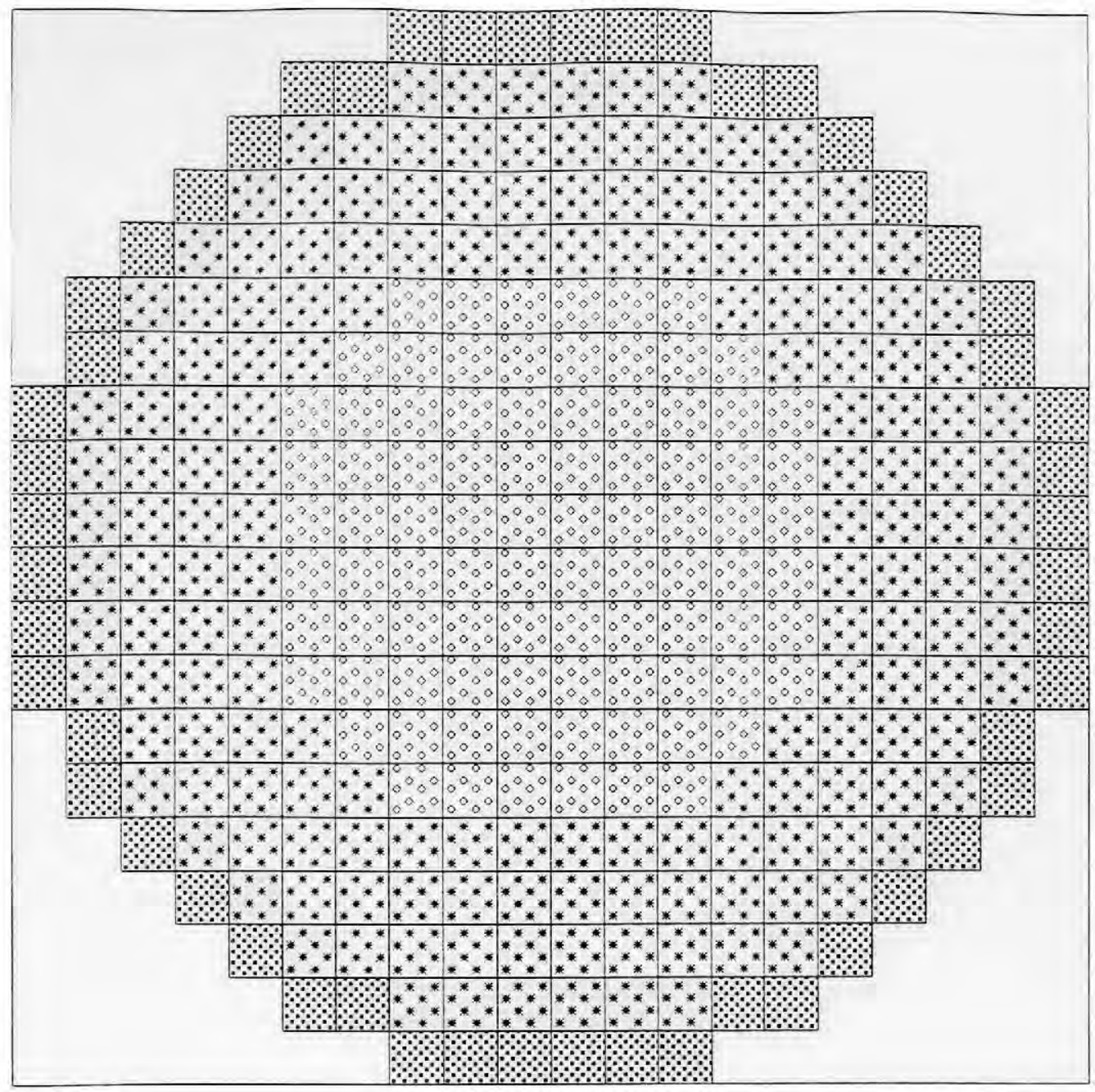

Fig. 9.5. Distribution of seepage rates ( $\mathrm{cm} /$ day) over the lake bed for a shallow inflow lake with moderate lake bed slope and lake sediments. The ratio of the

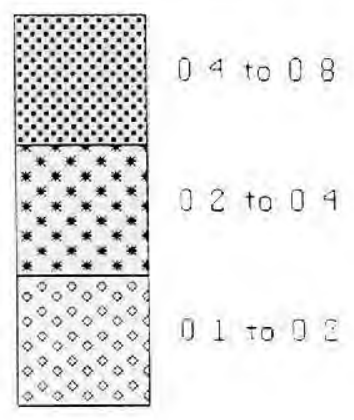
hydraulic conductivity of lake sediments to the horizontal hydraulic conductivity of the porous medium is $10^{-3}$. Fig. 7.11 gives an analogous map for the simulation without lake sediments. 


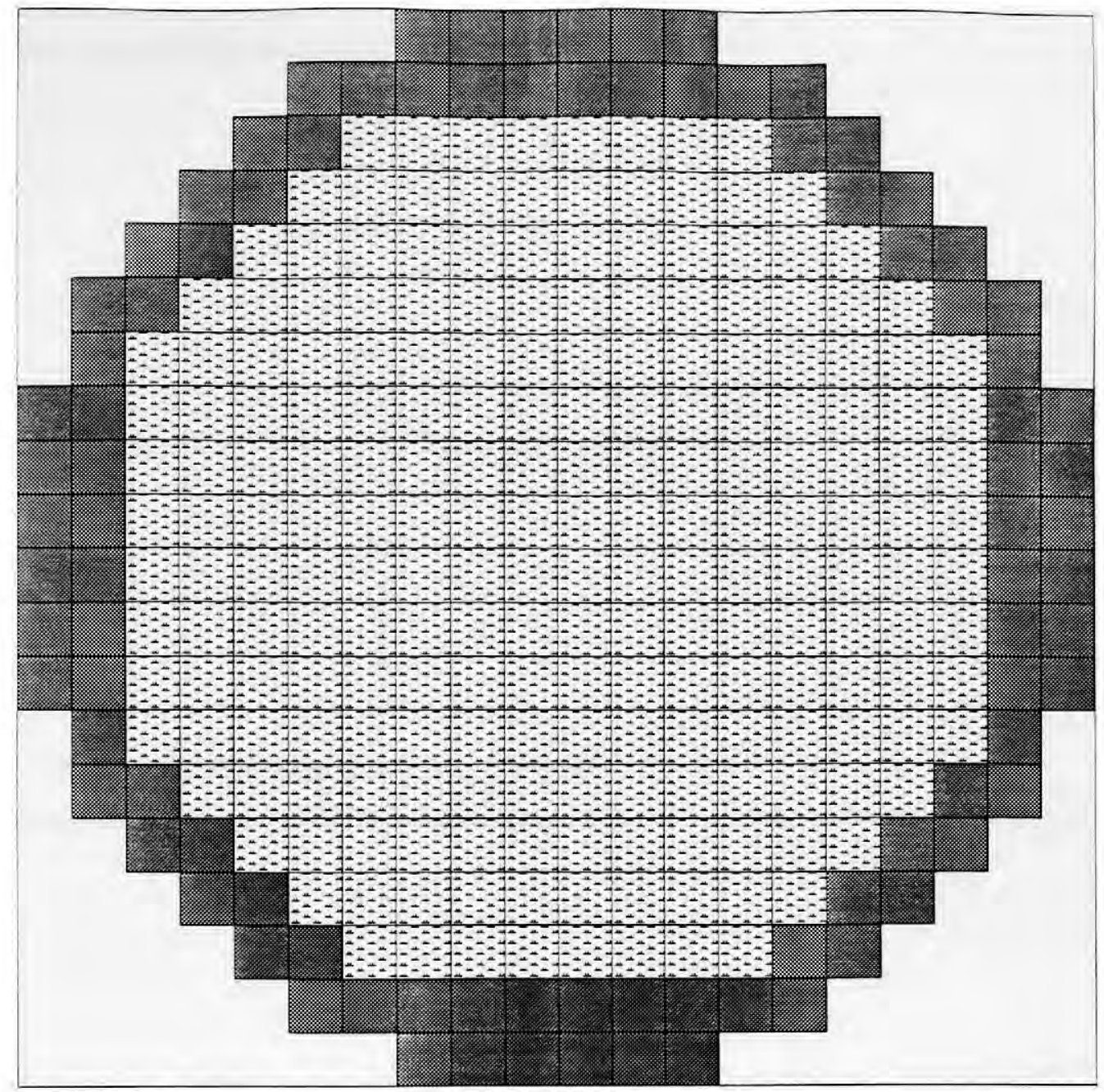

Fig. 9.6. Distribution of seepage rates $(\mathrm{cm} /$ day) over the

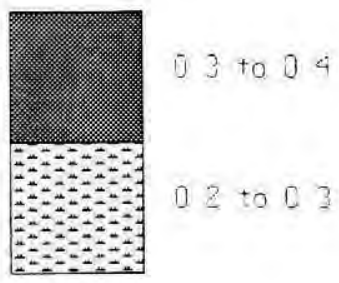
lake bed for a shallow inflow lake with moderate lake bed slope and lake sediments. The ratio of the hydraulic conductivity of lake sediments to the horizontal hydraulic conductivity of the porous medium is $10^{-4}$. Fig. 7.11 gives an analogous map for the simulation without lake sediments. 


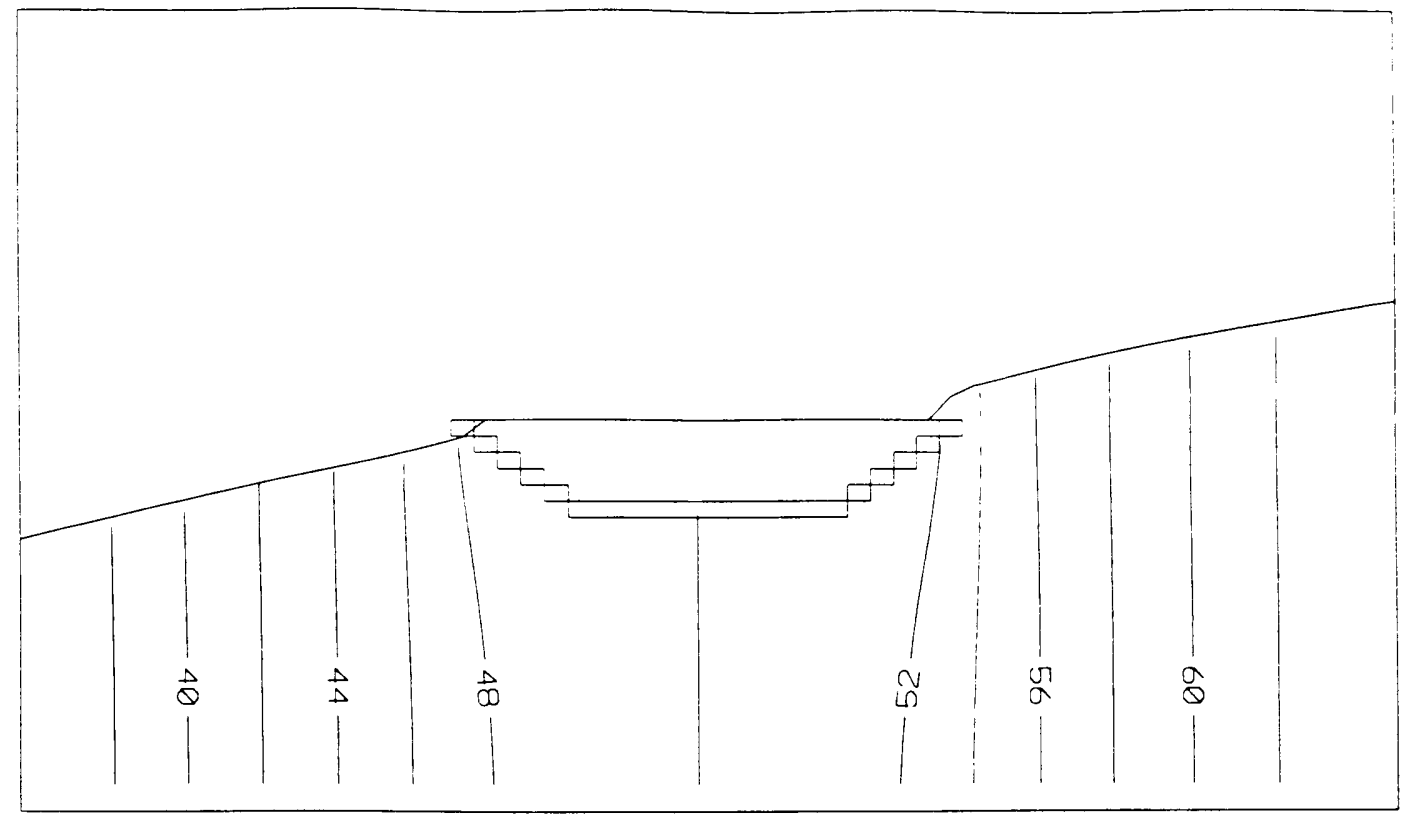

Lake sediment present $\left(\mathrm{K}_{\mathrm{s}} / \mathrm{K}_{\mathrm{h}(\mathrm{pm})}\right)=10^{-2}$

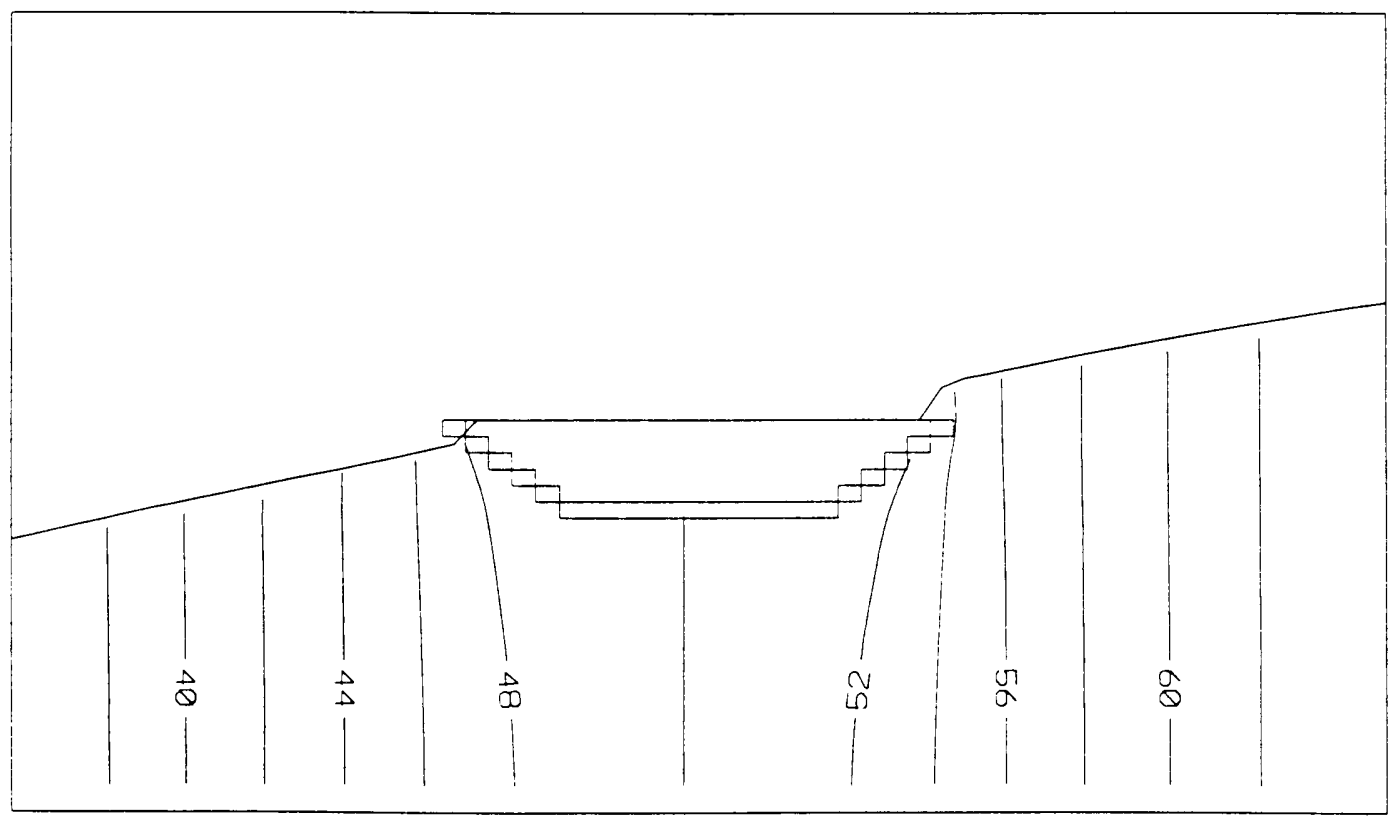

Lake sediment present $\left(\mathrm{K}_{\mathrm{s}} / \mathrm{K}_{\mathrm{h}(\mathrm{pm})}\right)=10^{-3}$

Fig. 9.7. Distribution of hydraulic heads in the porous medium surrounding shallow flowthrough lakes with moderate lake bed slope and lake sediments. Fig. 7.17 gives an analogous cross-section for a simulation without lake sediments. The uppermost cell containing lake sediments on the downgradient side lies above the water table and is therefore "dry". 


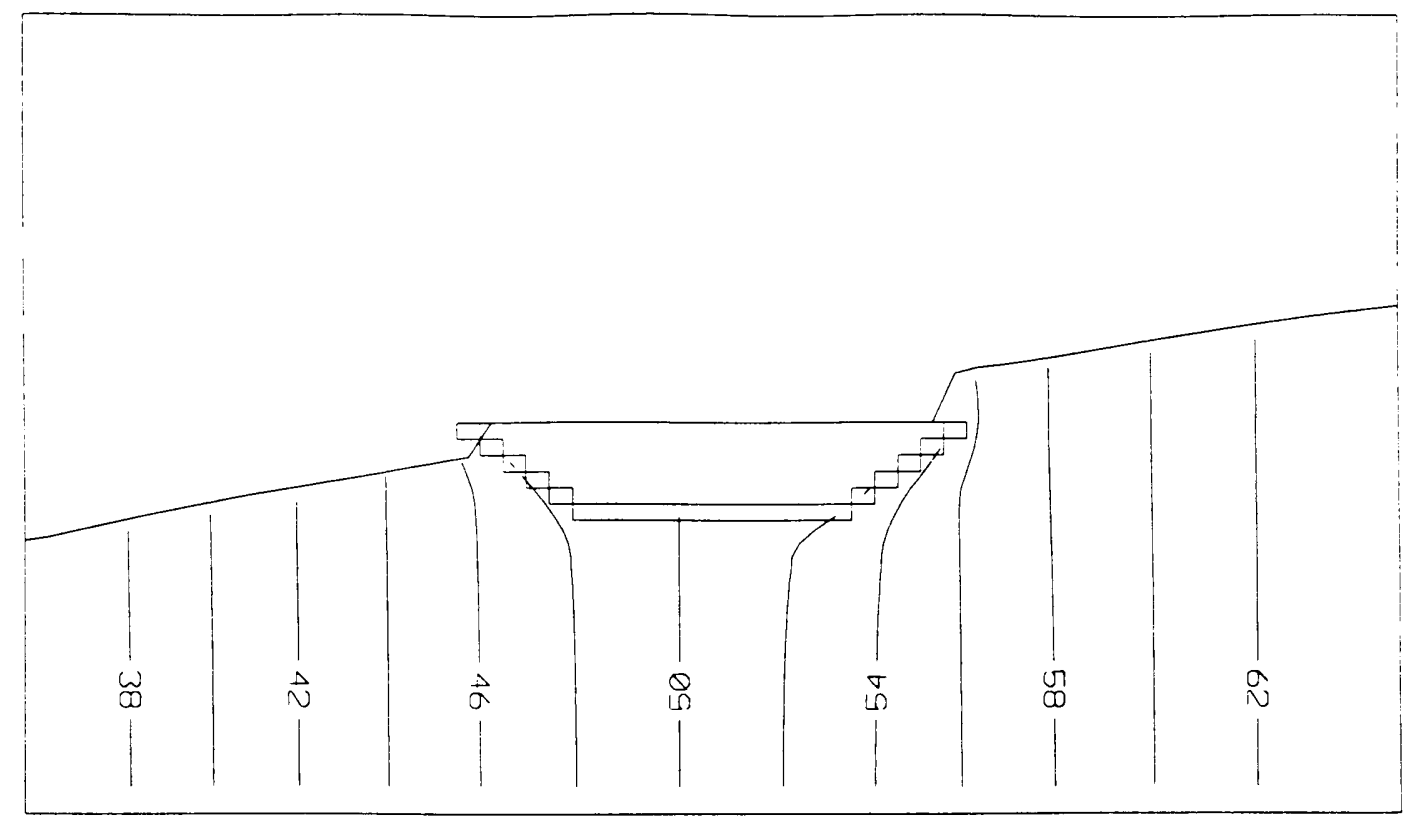

Lake sediment present $\left(\mathrm{K}_{\mathrm{s}} / \mathrm{K}_{\mathrm{h}(\mathrm{pm})}\right)=10^{-4}$

Fig. 9.8. Distribution of hydraulic heads in the porous medium surrounding shallow flowthrough lakes with moderate lake bed slope and lake sediments. Fig. 7.17 gives an analogous cross-section for a simulation without lake sediments. The uppermost cell containing lake sediments on the downgradient side lies above the water table and is therefore "dry". 
Shallow flow-through lake with moderate slope

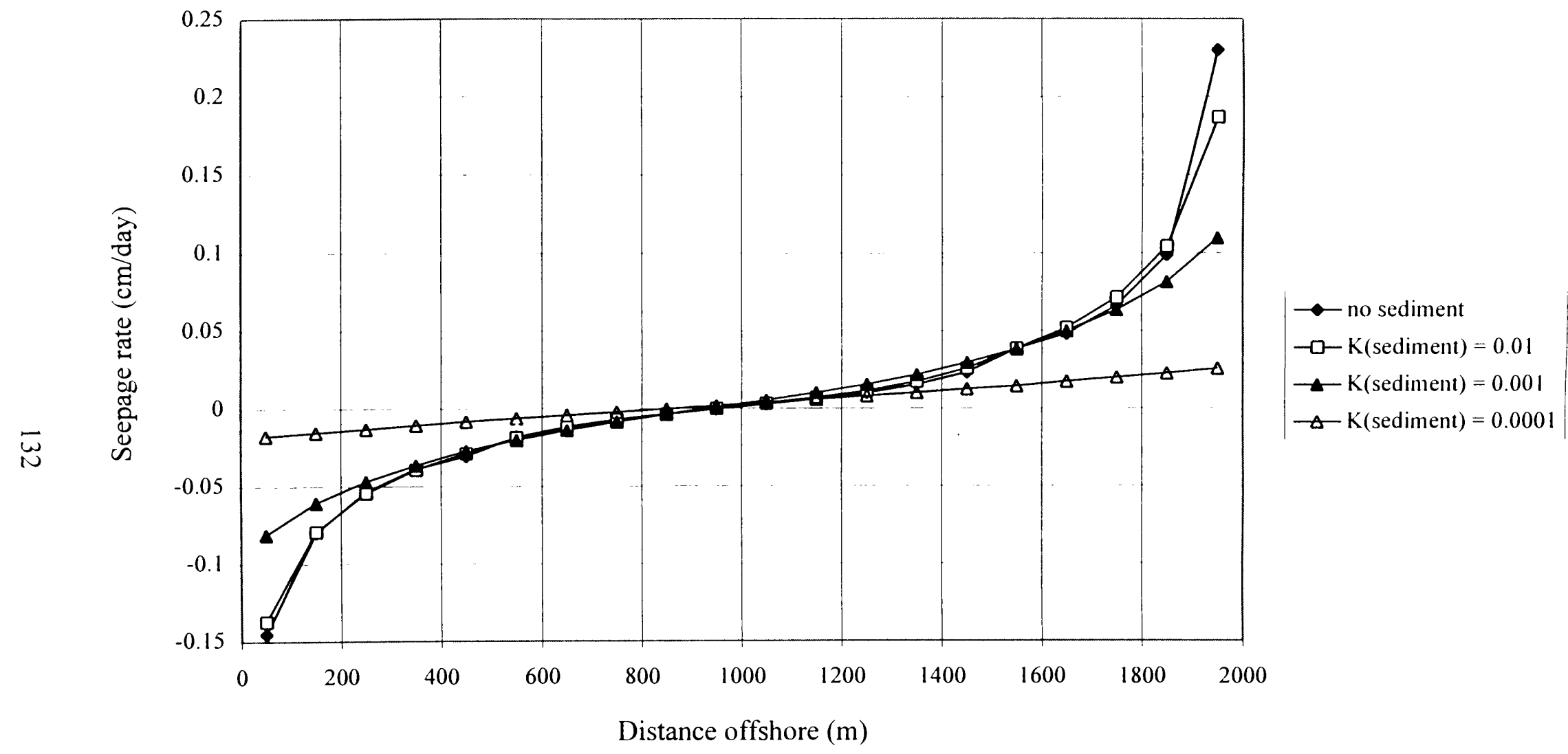

Fig. 9.9. Seepage rate versus distance offshore for simulations of shallow flow-through lakes having moderate lake bed slope, with and without lake sediments. 


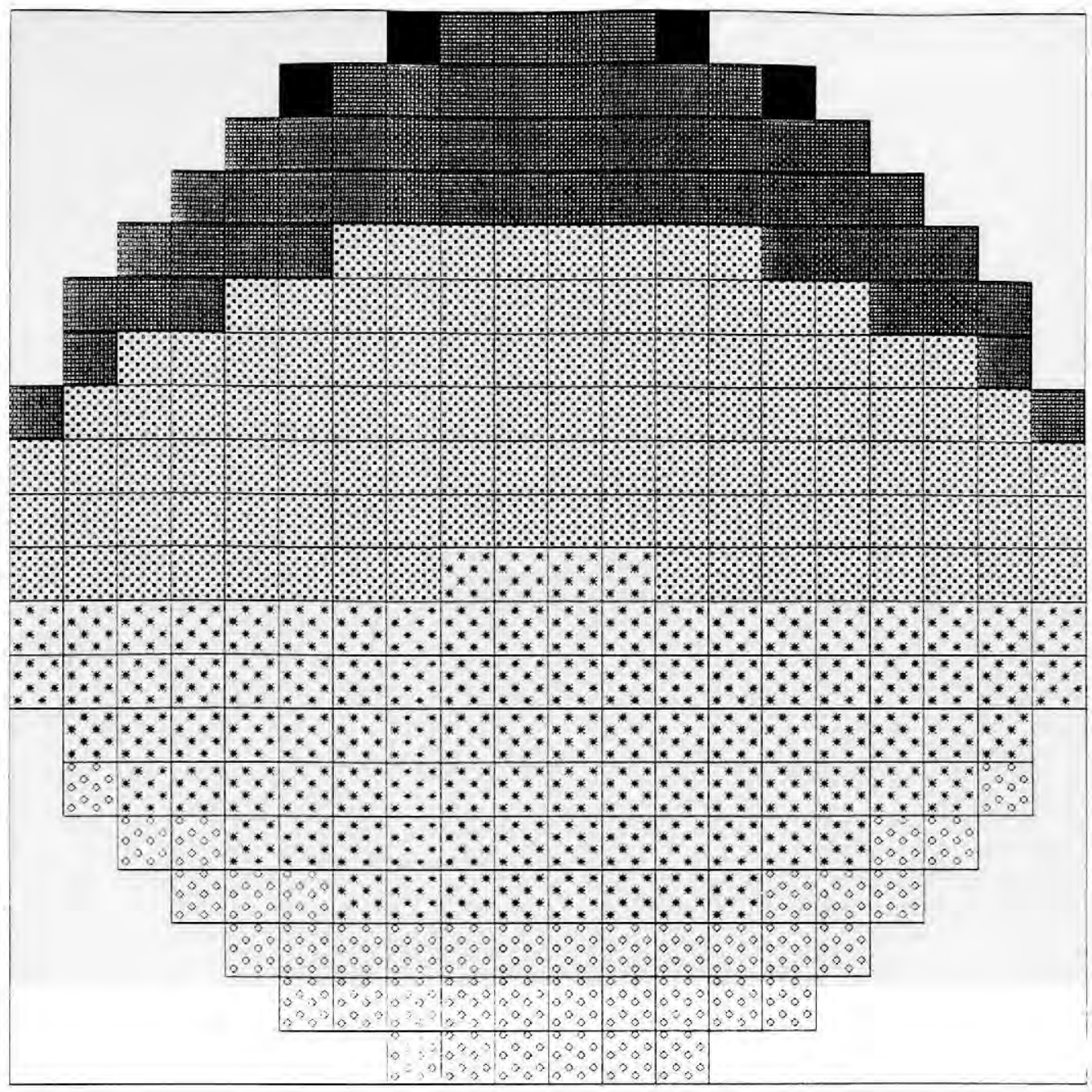

Fig. 9.10. Distribution of seepage rates ( $\mathrm{cm} /$ day) over the lake bed for a shallow flow-through lake with moderate lake bed slope and lake sediments. The ratio of the hydraulic conductivity of lake sediments to the horizontal hydraulic conductivity of the porous medium is $10^{-2}$. The regional groundwater flow is from the top to the bottom of the figure. Fig. 7.25 gives an analogous map for the simulation without lake sediments.

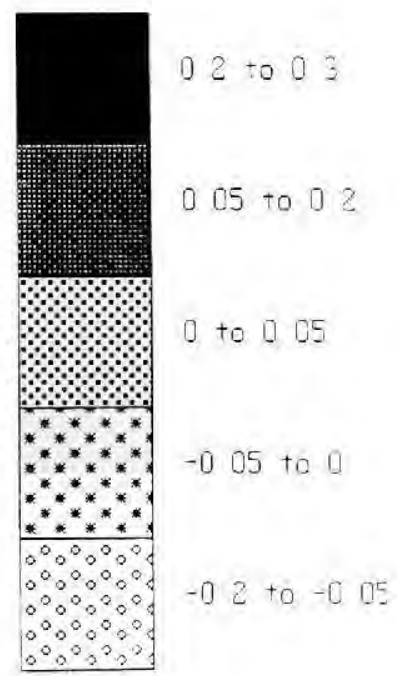




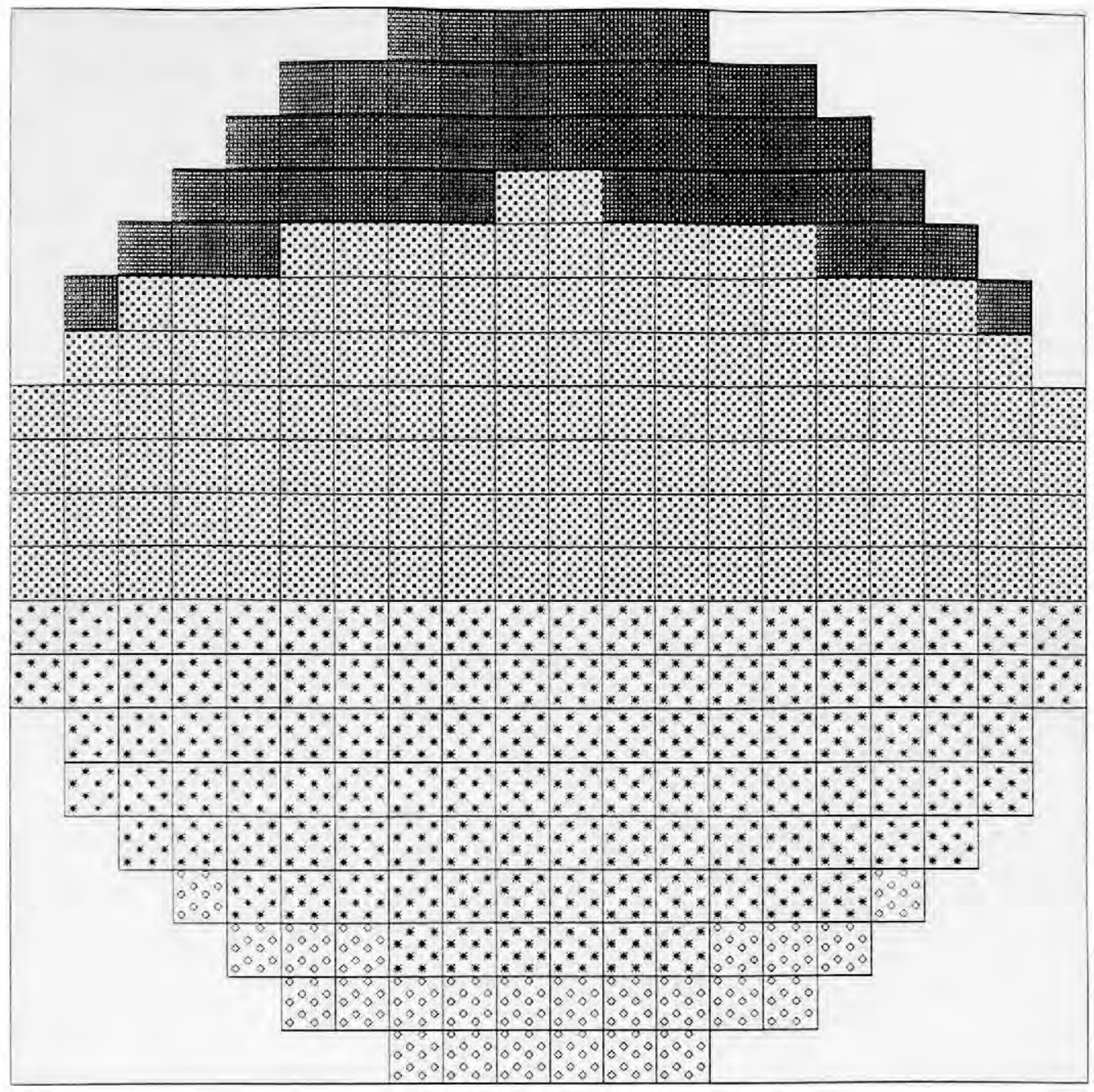

Fig. 9.11. Distribution of seepage rates ( $\mathrm{cm} /$ day) over the lake bed for a shallow flow-through lake with moderate lake bed slope and lake sediments. The ratio of the hydraulic conductivity of lake sediments to the horizontal hydraulic conductivity of the porous medium is $10^{-3}$. The regional

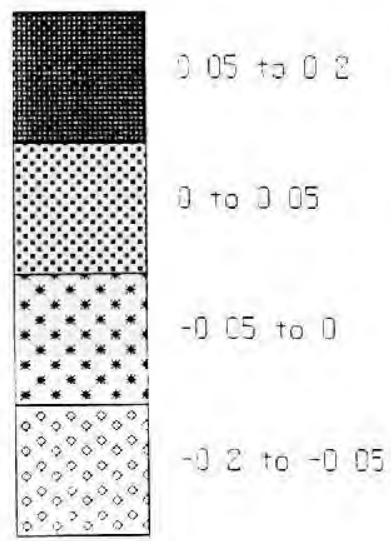
groundwater flow is from the top to the bottom of the figure. Fig. 7.25 gives an analogous map for the simulation without lake sediments. 


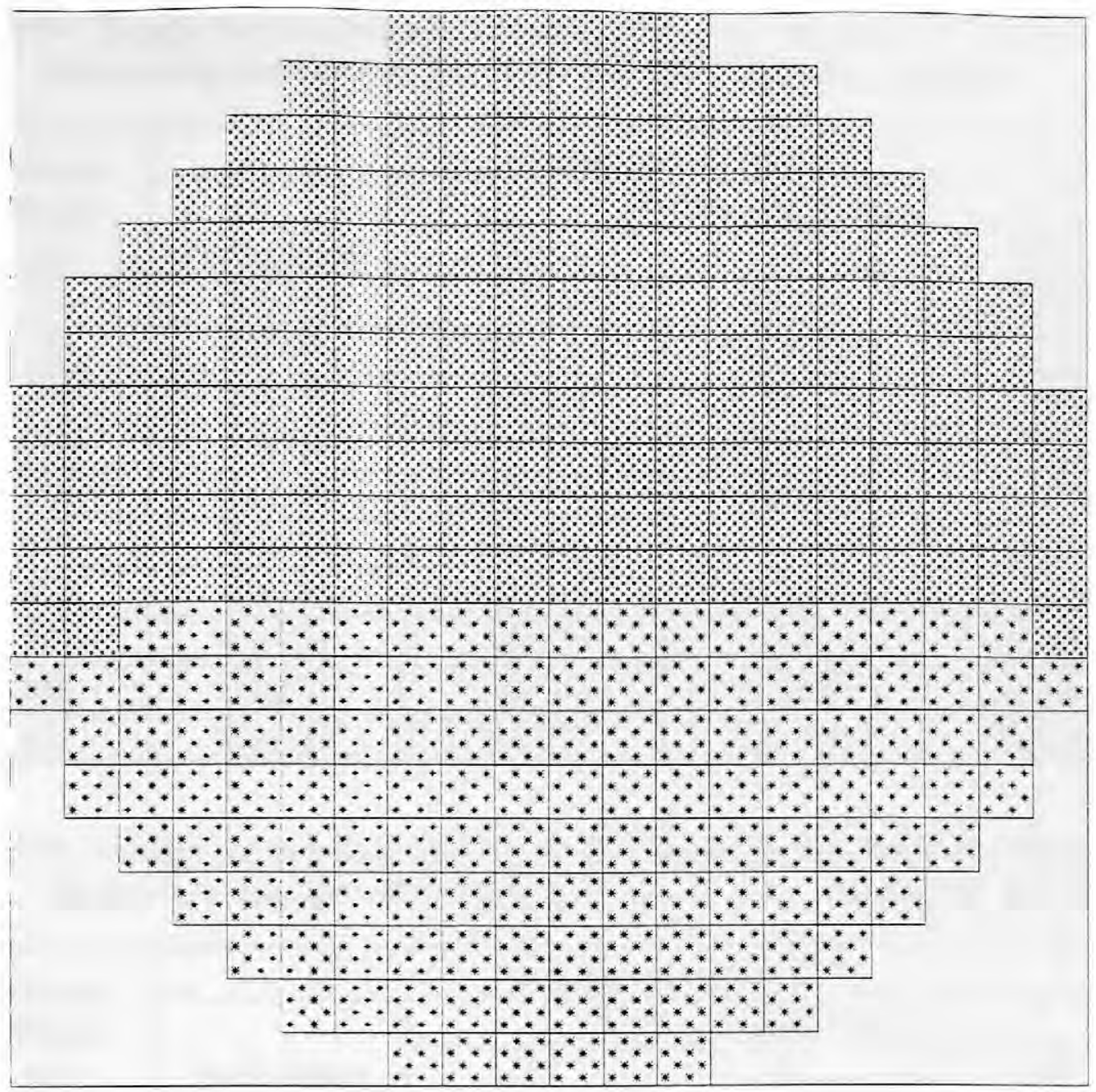

Fig. 9.12. Distribution of seepage rates (cm/day) over the lake bed for a shallow flow-through lake with moderate lake bed slope and lake sediments. The

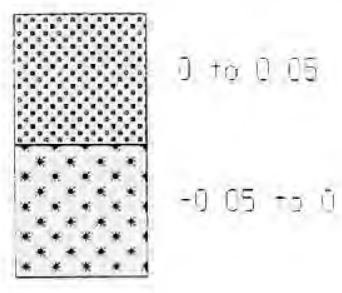
ratio of the hydraulic conductivity of lake sediments to the horizontal hydraulic conductivity of the porous medium is $10^{-4}$. The regional groundwater flow is from the top to the bottom of the figure. Fig. 7.25 gives an analogous map for the simulation without lake sediments. 
Table 9.4. Seepage rate as a function of distance offshore for simulations of shallow inflow lakes having moderate lake bed slope, with and without lake sediments.

\begin{tabular}{|c|c|c|c|c|}
\hline \multirow{2}{*}{$\begin{array}{c}\text { Distance } \\
\text { offshore } \\
(\mathrm{m})\end{array}$} & \multirow{4}{|c|}{ Seepage rate $(\mathrm{cm} /$ day $)$} \\
\cline { 2 - 5 } & No Sediment & $10^{-2}$ & $10^{-3}$ & $10^{-4}$ \\
\cline { 2 - 5 } & 0.73718 & 0.61520 & 0.46818 & 0.32872 \\
\hline 50 & 0.29045 & 0.35146 & 0.35301 & 0.30115 \\
\hline 150 & 0.19753 & 0.24564 & 0.28718 & 0.28847 \\
\hline 250 & 0.14958 & 0.18613 & 0.24088 & 0.27788 \\
\hline 350 & 0.12797 & 0.14777 & 0.20244 & 0.26379 \\
\hline 450 & 0.08476 & 0.10850 & 0.17590 & 0.26522 \\
\hline 550 & 0.06485 & 0.08357 & 0.15251 & 0.25862 \\
\hline 650 & 0.05294 & 0.06834 & 0.13666 & 0.25381 \\
\hline 750 & 0.04597 & 0.05936 & 0.12676 & 0.25065 \\
\hline 850 & 0.04272 & 0.05517 & 0.12199 & 0.24909 \\
\hline 950 & & & & \\
\hline
\end{tabular}

Table 9.5. Seepage rate as a function of distance offshore for simulations of shallow flowthrough lakes having moderate lake bed slope, with and without lake sediments.

\begin{tabular}{|c|c|c|c|c|}
\hline \multirow{2}{*}{$\begin{array}{c}\text { Distance } \\
\text { offshore } \\
(\mathrm{m})\end{array}$} & \multirow{4}{|c|}{ Seepage rate $(\mathrm{cm} /$ day $)$} \\
\cline { 2 - 5 } & No Sediment & $10^{-2}$ & $10^{-3}$ & $10^{-4}$ \\
\cline { 2 - 5 } & -0.14544 & -0.13728 & -0.08099 & -0.01754 \\
\hline 50 & -0.07969 & -0.07918 & -0.06055 & -0.01525 \\
\hline 150 & -0.05346 & -0.05420 & -0.04696 & -0.01301 \\
\hline 250 & -0.03884 & -0.03928 & -0.03654 & -0.01076 \\
\hline 350 & -0.03089 & -0.02896 & -0.02732 & -0.00824 \\
\hline 450 & -0.01823 & -0.01889 & -0.02021 & -0.00634 \\
\hline 550 & -0.01169 & -0.01212 & -0.01382 & -0.00423 \\
\hline 650 & -0.00711 & -0.00728 & -0.00845 & -0.00218 \\
\hline 750 & -0.00351 & -0.00344 & -0.00368 & -0.00016 \\
\hline 850 & -0.00038 & -0.00006 & 0.00081 & 0.00185 \\
\hline 950 & 0.00267 & 0.00327 & 0.00531 & 0.00387 \\
\hline 1050 & 0.00601 & 0.00693 & 0.01009 & 0.00592 \\
\hline 1150 & 0.01004 & 0.01138 & 0.01544 & 0.00803 \\
\hline 1250 & 0.01537 & 0.01726 & 0.02173 & 0.01021 \\
\hline 1350 & & & & \\
\hline
\end{tabular}


Table 9.5 (contd.)

\begin{tabular}{|c|c|c|c|c|}
\hline \multirow{2}{*}{$\begin{array}{c}\text { Distance } \\
\text { offshore } \\
(\mathrm{m})\end{array}$} & \multirow{4}{|c|}{ Seepage rate $(\mathrm{cm} /$ day $)$} \\
\cline { 3 - 5 } & No Sediment & $10^{-2}$ & $10^{-3}$ & $10^{-4}$ \\
\cline { 3 - 5 } & 0.02316 & 0.02574 & 0.02950 & 0.01251 \\
\hline 1450 & 0.03853 & 0.03855 & 0.03822 & 0.01442 \\
\hline 1550 & 0.04802 & 0.05167 & 0.04982 & 0.01734 \\
\hline 1650 & 0.06593 & 0.07104 & 0.06319 & 0.01992 \\
\hline 1750 & 0.09872 & 0.10428 & 0.08118 & 0.02258 \\
\hline 1850 & 0.22998 & 0.18666 & 0.10978 & 0.02559 \\
\hline 1950 & & & & \\
\hline
\end{tabular}




\section{CHAPTER 10}

\section{Results: Anisotropy Ratio}

One of the strongest factors that influences the interaction of lakes and groundwater is the anisotropy ratio (ratio of horizontal to vertical hydraulic conductivity) in the porous medium surrounding the lake (Winter, 1976). Anisotropy is also one of the most difficult things to measure in the field and the ratio can vary from 1 (isotropic medium) to 1000 in field situations (Winter et al., 1984). To quantify the effect of anisotropy ratio (R) on spatial patterns of lake bed seepage two sets of simulations (inflow lakes and flowthrough lakes) were run at four different anisotropy ratios $(1,10,100$, and 1000). When $\mathrm{R}$ was varied, all other parameters were held constant. $\mathrm{R}$ was increased by decreasing the vertical hydraulic conductivity $\left(\mathrm{K}_{\mathrm{v}}\right)$ while the horizontal hydraulic conductivity $\left(\mathrm{K}_{\mathrm{h}}\right)$ was the same. In other words, $\mathrm{K}_{\mathrm{h}}$ was held constant at $1 \mathrm{~m} /$ day for all simulations, while $\mathrm{K}_{\mathrm{v}}$ ranged from $1 \mathrm{~m} /$ day $(\mathrm{R}=1)$ to $10^{-3} \mathrm{~m} /$ day $(\mathrm{R}=1000)$ in different simulations. Lower $\mathrm{K}_{\mathrm{v}}$ made the vertical movement of water more difficult and increased the vertical gradient. The horizontal gradient also changed, and the resultant effect was the bending of equipotential lines as anisotropy was increased. Inflow lakes and flow- 
through lakes were not directly compared to each other, as their boundary conditions were different.

\subsection{Inflow lakes}

Some inflow lake results are summarized in Table 10.1. The effect of the variation of anisotropy was seen both in the porous medium surrounding the lake and in the lake bed seepage. The equipotential lines at $R=1$ were virtually vertical and suggest no vertical gradient (Fig. 10.1). The increase in horizontal gradient towards the lake represented an increase in the gradient of the water table near the lake. The head below the lake bottom was almost the same as the lake head $(50 \mathrm{~m})$, and there was very little seepage into the center of the lake. As $\mathrm{R}$ was increased to 10 , the equipotential lines close to the lake show a slight bending toward the lake and vertical gradients developed (Fig. 10.1). Most of the cells below the lake had head values only slightly above the head in the lake. The equipotential lines near the boundary of the porous medium were still vertical. Also the heads near the boundary increased when anisotropy was increased from 1 to 10 (Table 10.1). At $R=100$, equipotential lines were no longer vertical because the vertical gradient was more significant (Fig. 10.2). Increase in $\mathrm{R}$ led to an increase in hydraulic head below the lake (Table 10.1), and an increase in the maximum head near the boundary of the 
Table 10.1. Summary of the head and seepage rate results along the line of the vertical cross-section for the twenty simulations compared in the inflow lake section of this chapter. Each result box gives the minimum and the maximum heads in meters (first line) and the minimum and the maximum seepage rates in $\mathrm{cm} /$ day (second line within parentheses) for one simulation.

\begin{tabular}{|c|c|c|c|c|c|}
\hline \multirow{2}{*}{ Type of lake } & \multicolumn{4}{|c|}{ Anisotropy Ratio (R) } & $\begin{array}{c}\text { Chapter where } \\
\text { figures are } \\
\text { located }\end{array}$ \\
\cline { 2 - 6 } & $\mathrm{R}=1$ & $\mathrm{R}=10$ & $\mathrm{R}=100$ & $\mathrm{R}=1000$ & 10 \\
\hline $\begin{array}{c}\text { shallow lake with } \\
\text { steep lake bed } \\
\text { slope }\end{array}$ & $\begin{array}{c}50.00,69.19 \\
\left(6.85 \times 10^{-7}, 1.9715\right)\end{array}$ & $\begin{array}{c}50.00,70.09 \\
\left(8.57 \times 10^{-5}, 1.5069\right)\end{array}$ & $\begin{array}{c}50.09,72.03 \\
(0.0334,1.0926)\end{array}$ & $\begin{array}{c}51.81,79.61 \\
(0.0635,1.1294)\end{array}$ & \\
\hline $\begin{array}{c}\text { deep lake with } \\
\text { steep lake bed } \\
\text { slope }\end{array}$ & $\begin{array}{c}50.00,67.76 \\
\left(2.31 \times 10^{-6}, 1.9775\right)\end{array}$ & $\begin{array}{c}50.00,70.11 \\
\left(1.12 \times 10^{-5}, 1.5017\right)\end{array}$ & $\begin{array}{c}50.13,72.02 \\
(0.0207,1.0219)\end{array}$ & $\begin{array}{c}51.72,78.47 \\
(0.0599,1.0587)\end{array}$ & 11 \\
\hline $\begin{array}{c}\text { shallow lake with } \\
\text { moderate lake bed } \\
\text { slope }\end{array}$ & $\begin{array}{c}50.00,69.17 \\
\left(1.12 \times 10^{-7}, 1.2188\right)\end{array}$ & $\begin{array}{c}50.00,70.53 \\
(0.00019,1.0157)\end{array}$ & $\begin{array}{c}50.12,73.51 \\
(0.0427,0.7372)\end{array}$ & $\begin{array}{c}52.44,81.83 \\
(0.0816,0.6865)\end{array}$ & 6 \\
\hline $\begin{array}{c}\text { deep lake with } \\
\text { moderate lake bed } \\
\text { slope }\end{array}$ & $\begin{array}{c}50.00,69.14 \\
\left(1.03 \times 10^{-7}, 1.2158\right)\end{array}$ & $\begin{array}{c}50.00,70.54 \\
(0.00013,1.0162)\end{array}$ & $\begin{array}{c}50.22,73.51 \\
(0.0580,0.7364)\end{array}$ & $\begin{array}{c}56.13,81.44 \\
(0.2395,0.6697)\end{array}$ & 11 \\
\hline $\begin{array}{c}\text { shallow lake with } \\
\text { low lake bed } \\
\text { slope }\end{array}$ & $\begin{array}{c}50.00,68.17 \\
\left(5.19 \times 10^{-7}, 2.155\right)\end{array}$ & $\begin{array}{c}\left(7.81 \times 10^{-5}, 1.9554\right) \\
(0.0383,1.4392)\end{array}$ & $(0.0839,1.5136)$ & \\
\hline
\end{tabular}


model domain. The minimum head below the shallow inflow lake with moderate slope was 0.12 meters greater than the lake head at $R=100$. The steepness of the water table also increased with $\mathrm{R}$, along with the increase in maximum head at the domain boundary. At $R=1000$, the equipotential lines close to the lake encircle the lake bed, and there is a strong vertical gradient below the lake (Fig. 10.2). The lowest head just below the shallow inflow lake with moderate slope is 2.44 meters above the lake head (Table 10.1). The equipotential lines near the boundary are curved in such a way so as to direct the flow toward the lake. The closeness of the equipotential lines near the shore implies the convergence of the flow lines.

The effect of anisotropy was also seen from the variation in seepage rate with distance from the shore. As mentioned in Chapter 6, seepage rate declined at an exponential rate as a function of distance from the shore. When the log of seepage rate was plotted against the distance offshore, the slope of the line decreased as anisotropy was increased (Fig. 10.3). The slopes were nearly the same at higher anisotropy (i.e., $R=100$ and 1000). Seepage rates decreased near the shore and increased offshore as anisotropy was changed from 1 to 1000 (Figs. 10.3 to 10.5 ). Seepage rates near the shore at $R=1000$ are slightly higher than the respective seepage rate at $\mathrm{R}=100$ for lakes with 
steep and low lake bed slope. When the seepage maps were considered (Figs. 10.6 to 10.10), the high seepage zone nearshore defined by a seepage of 1.6 $\mathrm{cm} /$ day or higher gradually decreased in aerial extent as $\mathrm{R}$ was increased from 1 to 100 , and again increased from $R=100$ to $R=1000$. Similarly, the offshore low seepage zone defined by a seepage of $0.1 \mathrm{~cm} /$ day or lower decreased in aerial extent as $\mathrm{R}$ was increased from 1 to 100 , and increased again between $R=100$ and $R=1000$. The low seepage rates near the shore at $R=1000$ were compensated by high seepage rates offshore and vice versa at low $R$. At $R=$ 1, most of the cells offshore have practically no seepage (Figs. 10.1, 10.6). Some of these cells had seepage rates less than $10^{-7} \mathrm{~cm} /$ day, the threshold below which MODFLOW does not report seepage rates.

For the deep inflow lake with moderate lake bed slope, seepage rates increased offshore at $\mathrm{R}=1000$, at distances of $400 \mathrm{~m}$ or more offshore (Fig. 10.4). This increasing seepage offshore was not observed in any other simulations, at any anisotropy. The reason for this behavior seems to be the result of a particular combination of anisotropy, lake shape, and lake depth that focuses flow lines onto the narrowing conical lake bed which, in this simulation, extends deep into the porous medium. This phenomenon is similar to the unusually high seepage which occurs at high $\mathrm{R}$ at breaks in the lake bed 
slopes (Chapter 6). Another phenomenon observed in lakes with low lake bed slope was the oscillating patterns of seepage rate along the sloping portion of the lake bed at $R=1000$ (Fig. 10.5). This oscillation is due to the presence of three cells per step along the lake bed slope. Among three cells in each step, the one nearest to the shore has the highest seepage and the one farthest from the shore has the lowest seepage rate. This phenomenon was discussed for lake beds with two cells per "step" in Chapter 7. In order to get an overall estimation of the seepage rate for each step, for use in later chapters, an average of the seepage rates for the three cells along each step was taken.

\subsection{Flow-through lakes}

Flow-through lake simulations, with a regional groundwater head gradient across the model domain, had a "seepage boundary" running across the lake bed normal to the regional groundwater flow. This seepage boundary was a line of zero seepage, separating the upgradient portion of the lake bed which experienced inseepage of groundwater, from the downgradient portion which experienced outseepage of lake water. As a line of zero seepage, the seepage boundary was also the intersection of the $50 \mathrm{~m}$ equipotential plane with the lake bed (lake head was $50 \mathrm{~m}$, so a spot on the lake bed with head equal to $50 \mathrm{~m}$ would experience no inseepage or outseepage). We took 
Table 10.2. Summary of the position of the seepage boundary (in meters upgradient from the downgradient shore of the lake; see text) and seepage rate along the line of the vertical cross-section for the twenty simulations compared in the flow-through lake section of this chapter. Each result box gives the location of the seepage boundary (first line) and the minimum and the maximum seepage rates in $\mathrm{cm} /$ day (second line within parentheses) for one simulation.

\begin{tabular}{|c|c|c|c|c|c|}
\hline \multirow{2}{*}{ Type of lakes } & \multicolumn{4}{|c|}{ Anisotropy Ratio (R) } & $\begin{array}{c}\text { Chapter where } \\
\text { figures are located }\end{array}$ \\
\cline { 2 - 6 } & $\mathrm{R}=1$ & $\mathrm{R}=10$ & $\mathrm{R}=100$ & $\mathrm{R}=1000$ & 10 \\
\hline $\begin{array}{c}\text { shallow lake with } \\
\text { steep lake bed } \\
\text { slope }\end{array}$ & $(-0.6448,0.8889)$ & $(-0.4214,0.5909)$ & $(-0.1961,0.3300)$ & $(-0.0605,0.1812)$ & \\
\hline $\begin{array}{c}\text { deep lake with } \\
\text { steep lake bed } \\
\text { slope }\end{array}$ & $(-0.6699,0.9188)$ & $(-0.4288,0.5949)$ & $(-0.1925,0.3227)$ & $(-0.0588,0.1751)$ & 11 \\
\hline $\begin{array}{c}\text { shallow lake with } \\
\text { moderate lake bed } \\
\text { slope }\end{array}$ & $(-0.3810,0.5158)$ & $(-0.2896,0.3965)$ & $(-0.1454,0.2299)$ & $(-0.0437,0.1164)$ & 7 \\
\hline $\begin{array}{c}\text { deep lake with } \\
\text { moderate lake bed } \\
\text { slope }\end{array}$ & $(-0.3786,0.5135)$ & $(-0.2873,0.3950)$ & $(-0.1446,0.2293)$ & $(-0.0437,0.1158)$ & 11 \\
\hline $\begin{array}{c}\text { shallow lake with } \\
\text { low lake bed } \\
\text { slope }\end{array}$ & $(-0.2895,0.3934)$ & $(-0.2497,0.3393)$ & $(-0.1373,0.2051)$ & $(-0.0431,0.1011)$ & \\
\hline
\end{tabular}

* indicates position of seepage boundary unknown, as seepage rates over a significant portion of the center of the lake were too low to be reported by MODFLOW $\left(<10^{-7} \mathrm{~cm} /\right.$ day $)$. 
advantage of the highly linear (at least in the center of the lakes, off the lake slope) variation of seepage rate with distance from shore (e.g., Fig. 10.12) in these lakes to estimate the position of the seepage boundary in the vertical cross-section parallel to the regional flow (e.g., Fig. 10.10). Using seepage rate results from several cells near the center of the lake, the position of the seepage boundary was linearly interpolated between the two cells bracketing the boundary (one upgradient, one downgradient). Of course, for purposes of plotting seepage maps based on a space filling finite difference model grid (e.g., Fig. 10.15), the seepage boundary is constrained to lie along boundaries between cells of the grid. But in real systems, and in computations involving MODFLOW output, no such restriction exists. Thus, one aspect of groundwater interaction we were able to evaluate for flow-through lakes was the movement of seepage boundary as other parameters (in this chapter, anisotropy ratio) were varied (Table 10.2).

In principle, the position of the seepage boundary should also be shown by the intersection of the $50 \mathrm{~m}$ equipotential with the lake bed on a vertical cross-section such as Fig. 10.10. In practice though this is a less accurate means of locating the boundary than the method described in the previous paragraph. This is particularly true in the isotropic case $(\mathrm{R}=1)$, where heads 
are very close to the lake head over a large region of the porous medium under the lake; thus the contouring program (SURFER) has only weak guidance in placing the $50 \mathrm{~m}$ equipotential in this region. (The other means of locating the seepage boundary was also ineffective at $R=1$ though, because heads under the lake bed were very close to $50 \mathrm{~m}$, and seepage rates over a large portion of the center of the lake bed were therefore below $10^{-7} \mathrm{~cm} /$ day and were not reported by MODFLOW). Even at higher anisotropy, the method described earlier is more accurate, as it does not rely on contouring. At $R=10,100$ or 1000 the position of the seepage boundary is always near halfway into the lake. Winter (1978) mentioned that in the absence of a water table mound on the downgradient side of the lake arising from focused recharge, the potential for inseepage and outseepage will be same. This suggests that the inseepageoutseepage boundary will lie about halfway across the lake.

As $\mathrm{R}$ increased, the seepage boundary migrated towards the downgradient side of the lake. The maximum movement between $R=10$ and $\mathrm{R}=1000$ is found to be about 50 meter except the simulation of a deep lake with moderate slope. A plot of seepage rate versus distance offshore across the regional gradient and through the center of the lake shows that the offshore seepages becomes more significant as $R$ was increased (Fig. 10.13). The 
shifting of the seepage boundary resulted in a smaller area of outseepage compared to the area of inseepage. Also, the equipotential lines started to bend toward the lake in response to the higher vertical gradient. The bending of equipotential lines was pronounced at $R=100$ and $R=1000$ (Fig. 10.11) similar to inflow lakes. The head below the downgradient side of the lake decreased and the head below the upgradient side increased as $\mathrm{R}$ increased.

The variation of seepage rate along the lake bed from the downgradient side to the upgradient side is a reflection of hydraulic heads in the porous medium. As anisotropy increased, the inseepage as well as the outseepage rates decreased near the shore in all the simulations even though head under the downgradient lake shore decreased and head under the upgradient lake shore increased as $\mathrm{R}$ increased (Fig. 10.12). It is observed from the seepage maps that the maximum seepage near the shore decreases with an increase in R. For example, for a shallow flow-through lake with steep slope the maximum outseepage and inseepage rates were -1.1 and $1.5 \mathrm{~cm} /$ day, respectively, at $R=1$ and -0.2 and $0.5 \mathrm{~cm} /$ day, respectively, at $R=1000$. The ring of high seepage rate (both inseepage and outseepage) near the shore decreased in aerial extent as $\mathrm{R}$ was increased. Similarly, the area of low seepage (i.e., an area occupied by $-0.5 \mathrm{~cm} /$ day to $0.5 \mathrm{~cm} /$ day seepage) 
decreased as anisotropy was increased. The fifth cell of the shallow lakes and the tenth cell of the deep lake show slightly elevated inseepage rate and outseepage rate at $\mathrm{R}=1000$ similar to inflow lakes.

Total groundwater inseepage and outseepage decreased with an increase in anisotropy ratio (Table 10.3). At low anisotropy ratio, most of the flow enters through the sloping portion of the lake bed, and vertical flow through the horizontal portion was minimum. The total amount of groundwater seepage into the lake was highest ( $2.1 \%$ of the lake volume per year) at $R=1$,

\begin{tabular}{|c|c|c|c|c|}
\hline $\begin{array}{c}\text { Anisotropy } \\
\text { Ratio (R) }\end{array}$ & $\begin{array}{c}\text { Total } \\
\text { volumetric } \\
\text { groundwater } \\
\text { inseepage } \\
\left(\mathrm{m}^{3} / \text { year }\right)\end{array}$ & $\begin{array}{c}\text { Total } \\
\text { volumetric } \\
\text { lake water } \\
\text { outseepage } \\
\left(\mathrm{m}^{3} / \text { year }\right)\end{array}$ & $\begin{array}{c}\text { Groundwater } \\
\text { inseepage per } \\
\text { year as a } \\
\text { percentage of } \\
\text { lake volume }\end{array}$ & $\begin{array}{c}\text { Lake water } \\
\text { outseepage per } \\
\text { year as a } \\
\text { percentage of } \\
\text { lake volume }\end{array}$ \\
\hline 1 & $4.34 \times 10^{5}$ & $3.09 \times 10^{5}$ & 2.10 & 1.50 \\
\hline 10 & $4.14 \times 10^{5}$ & $2.94 \times 10^{5}$ & 2.00 & 1.42 \\
\hline 100 & $3.34 \times 10^{5}$ & $2.26 \times 10^{5}$ & 1.62 & 1.09 \\
\hline 1000 & $1.94 \times 10^{5}$ & $1.02 \times 10^{5}$ & 0.94 & 0.49 \\
\hline
\end{tabular}

Table 10.3. Groundwater inseepage and lake water outseepage per year as a percentage of lake volume in coarse grid shallow flow-through lake with moderate slope at different anisotropy ratio. Lake volume was $2.064 \times 10^{7} \mathrm{~m}^{3}$.

and decreased to $0.94 \%$ at $\mathrm{R}=1000$. Likewise, the total annual lake water outseepage was reduced from $1.5 \%$ of the lake volume per year at $\mathrm{R}=1$ to about $0.5 \%$ at $\mathrm{R}=1000$. 
It can be concluded from the above discussions, that anisotropy ratio plays an important role in the spatial patterns of lake bed seepage, distribution of hydraulic heads in the porous medium, and the location of the seepage boundary in flow-through lakes. In inflow lakes the increase in anisotropy results in higher heads in the porous medium (at least, when the higher anisotropy is created by lowering $K_{v}$ relative to $K_{h}$, as it was in this study). Increases in anisotropy were associated with lower seepage rates nearshore and higher seepage rates offshore. The seepage boundary in flow-through lakes moves toward the downgradient side of the lake with increasing anisotropy, resulting in more area of inseepage than outseepage. Also, the total amount of water exchange between the lake and surrounding porous medium decreased as $\mathrm{R}$ increased. 


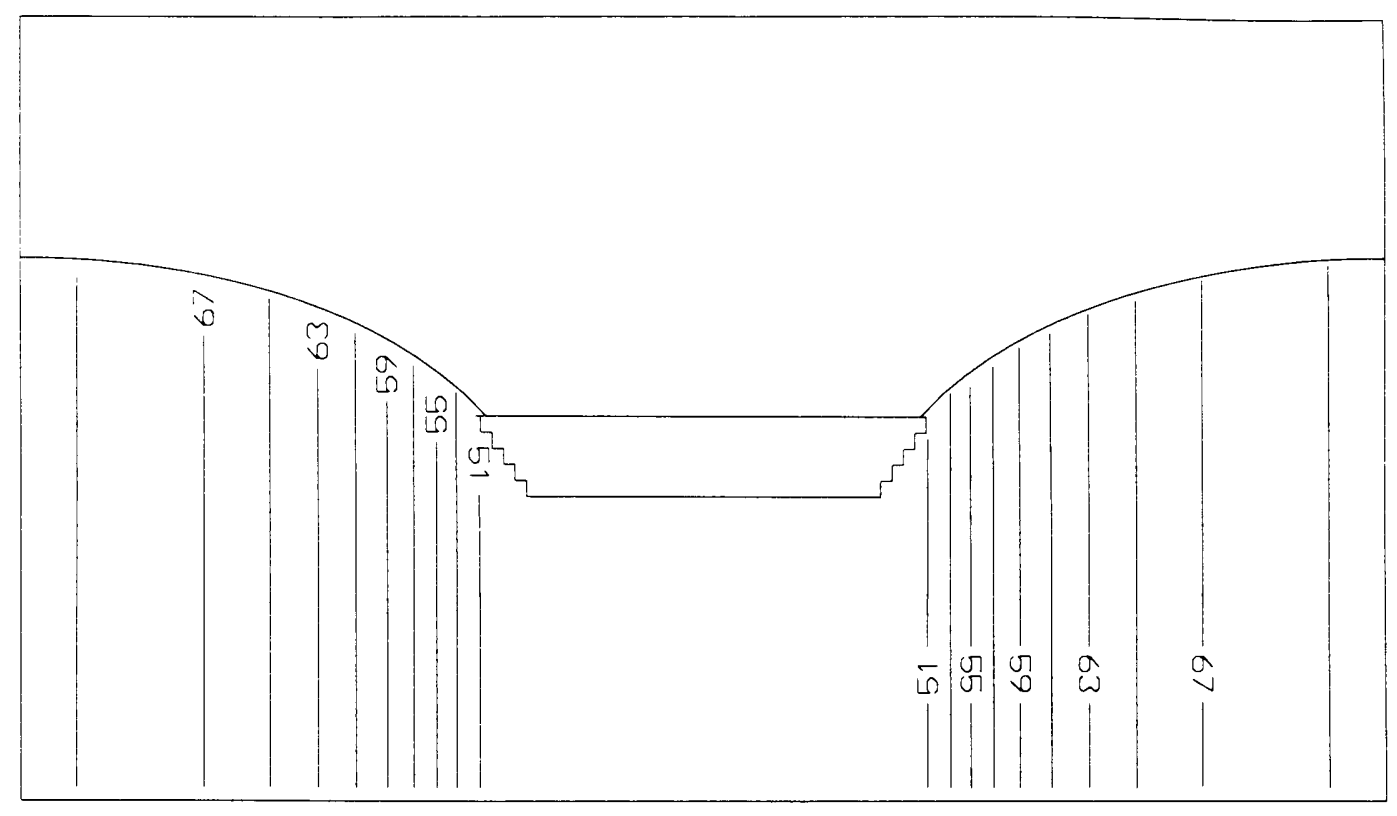

Anisotropy Ratio $=1$

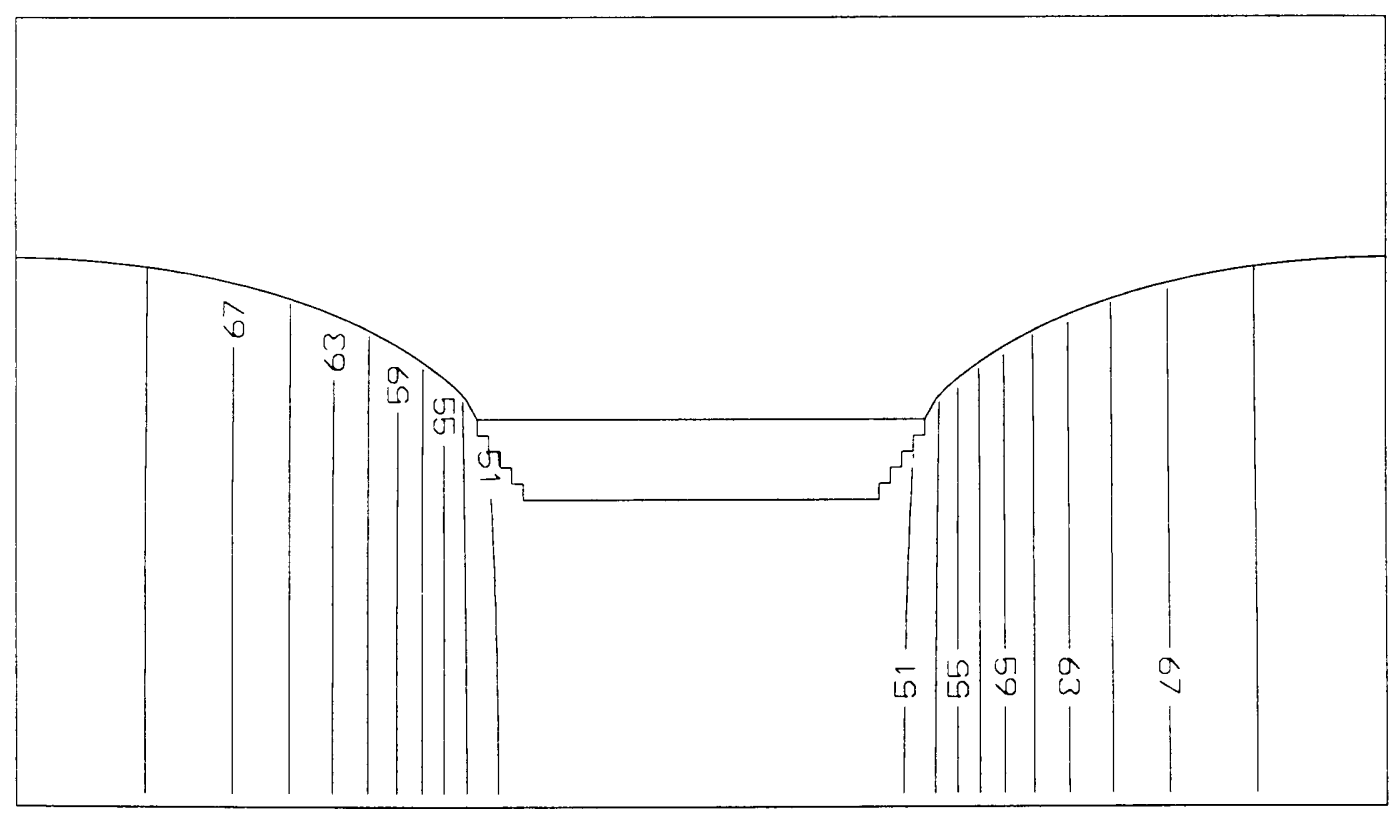

Anisotropy Ratio $=10$

Fig. 10.1. Distribution of hydraulic heads in the porous medium surrounding shallow inflow lakes with steep lake bed slope at $R=1$ and $R=10$. Figs. 6.2 and 6.3 give analogous cross-sections of shallow inflow lakes with moderate lake bed slope at $R=1$ and $R$ $=10$ respectively. 


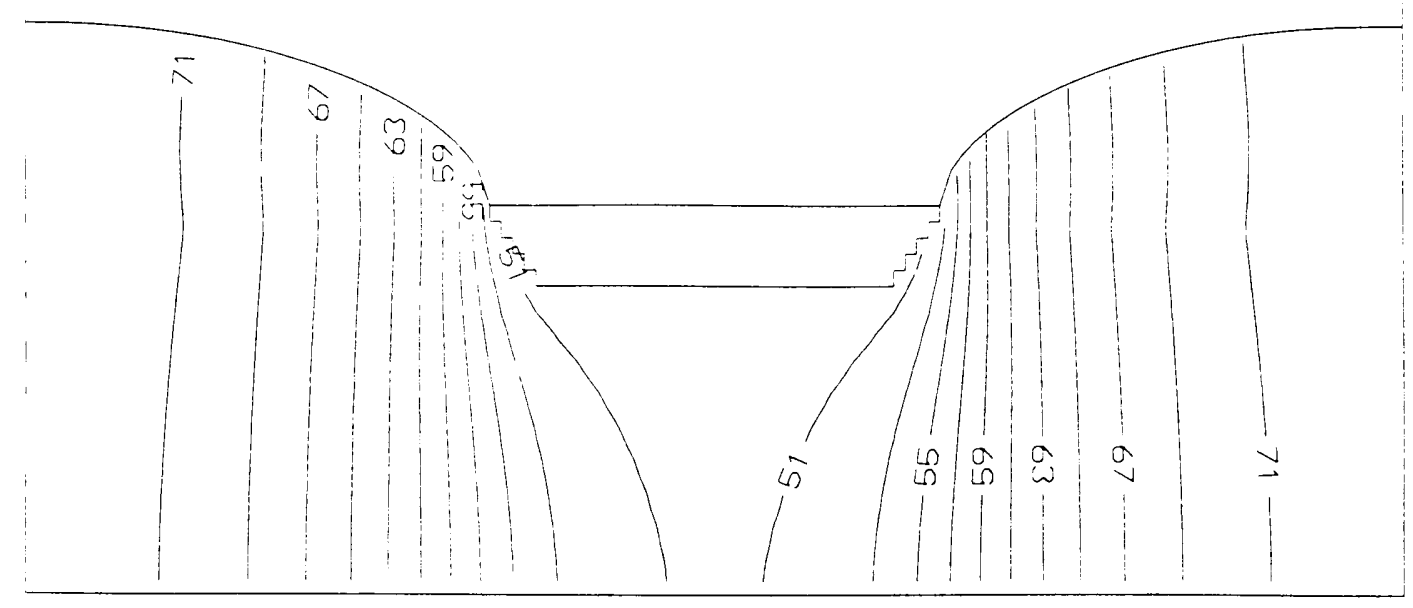

Anisotropy Ratio $=100$

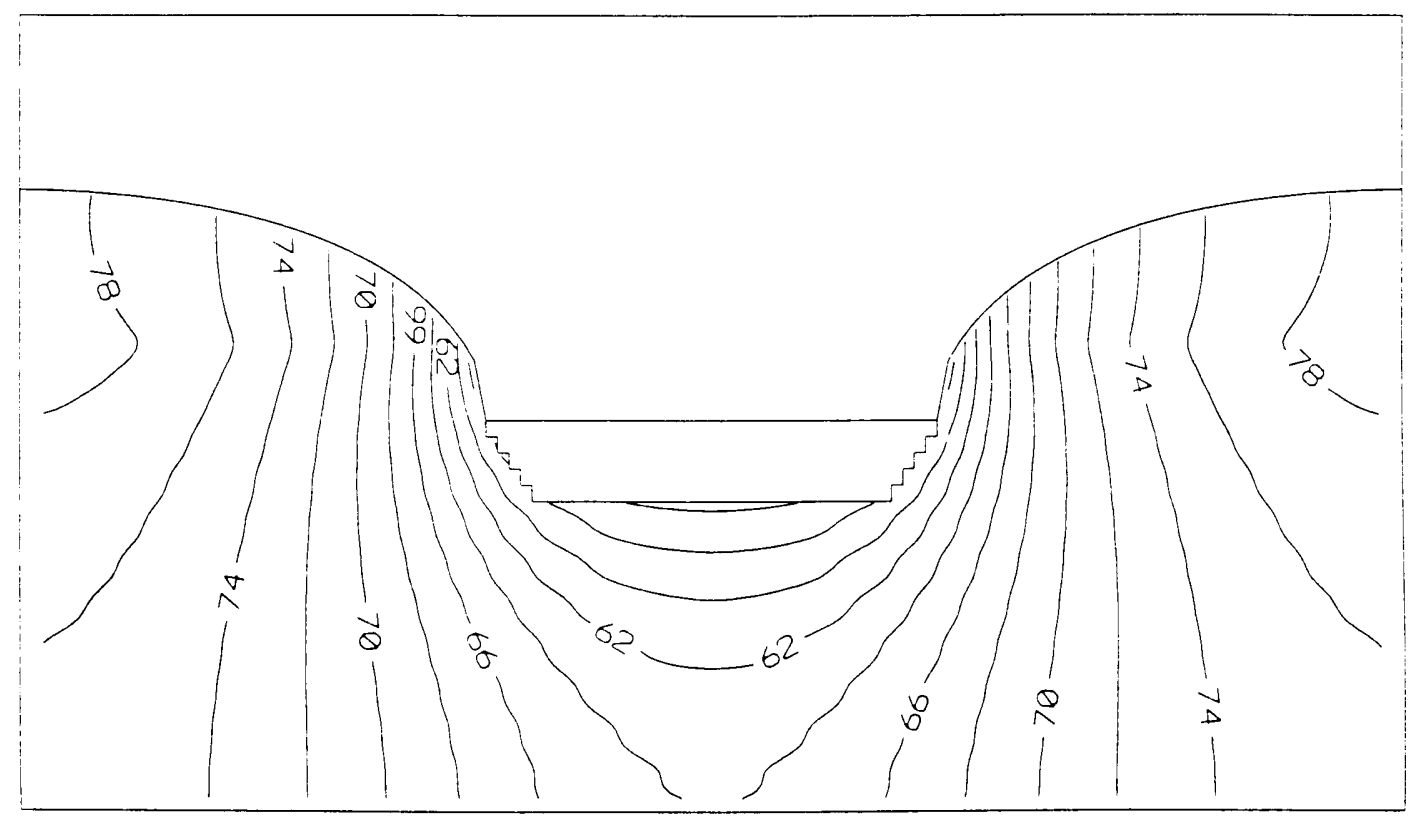

Anisotropy Ratio $=1000$

Fig. 10.2. Distribution of hydraulic heads in the porous medium surrounding shallow inflow lakes with steep lake bed slope at $R=100$ and $R=1000$. Figs. 6.4 and 6.5 give analogous cross-sections of shallow inflow lakes with moderate lake bed slope at $R$ $=100$ and $\mathrm{R}=1000$ respectively. 
Shallow inflow lake with moderate slope

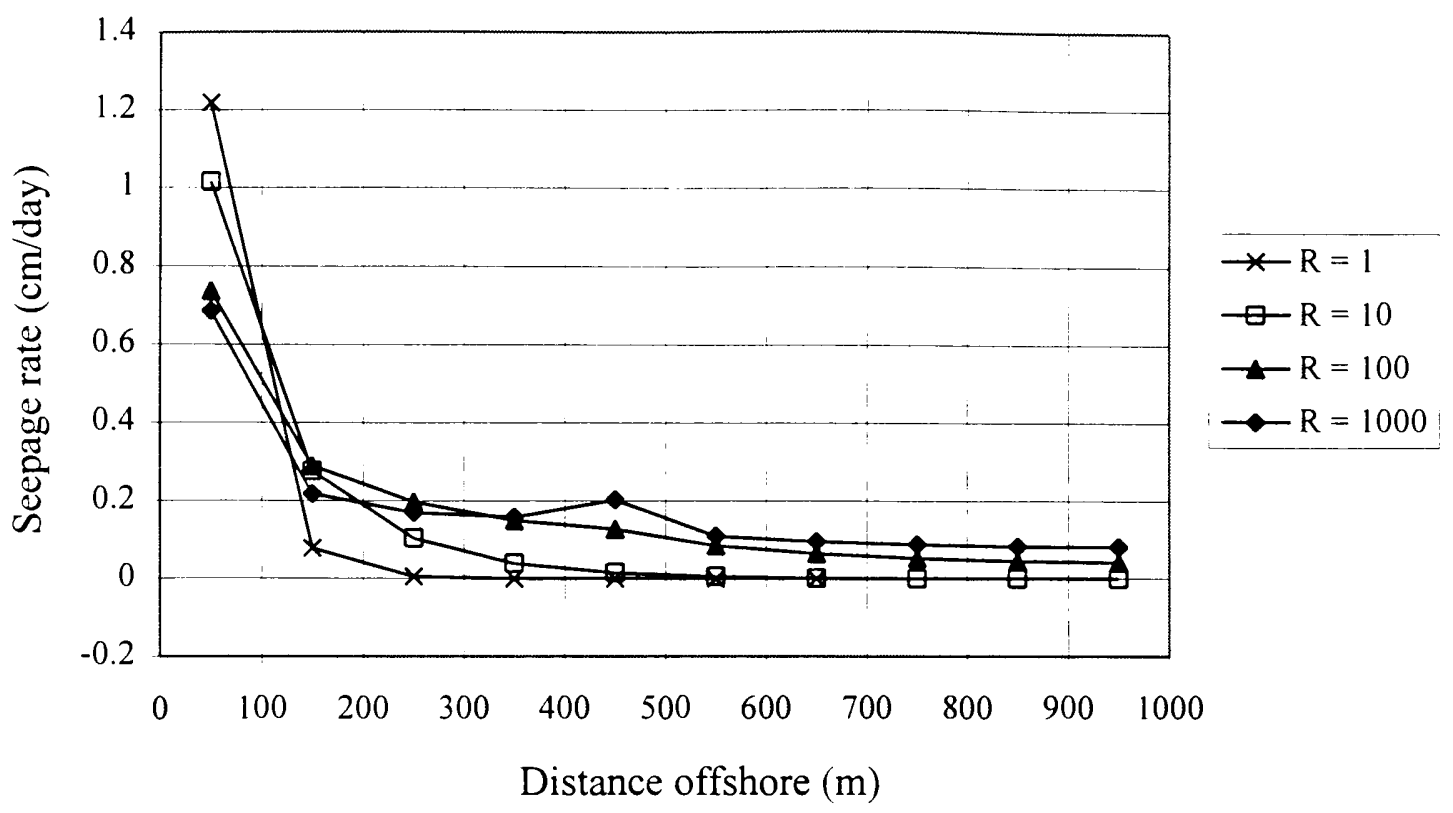

Shallow inflow lake with moderate slope

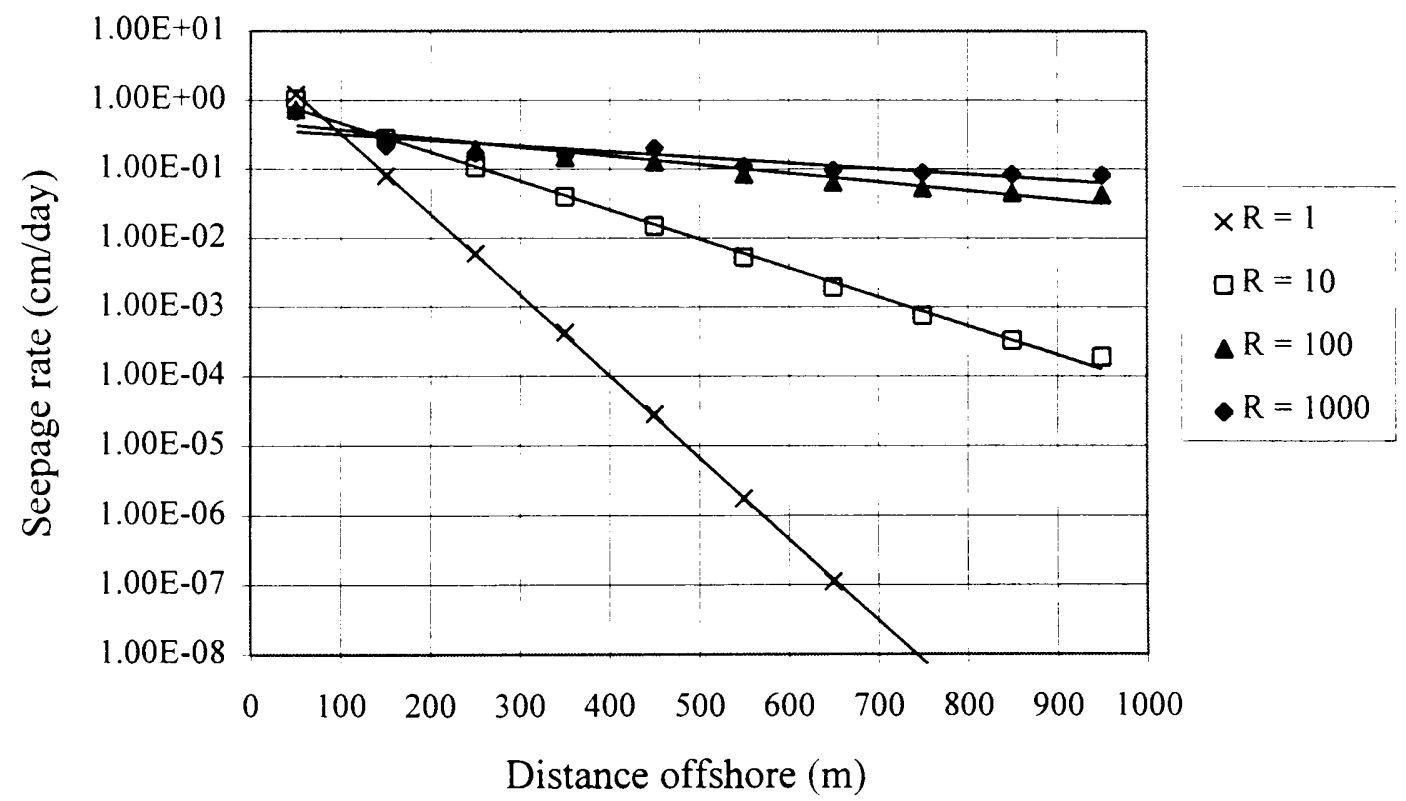

Fig. 10.3. Seepage rate versus distance offshore for simulations of shallow inflow lakes with moderate lake bed slope at different anisotropy ratios. The figure above indicates the exponential decrease of seepage rate with distance offshore. The semilogarithmic plot of seepage rate versus distance offshore in the bottom figure confirms the true exponential nature only at low anisotropy (i.e., $R=1,10$ ). 


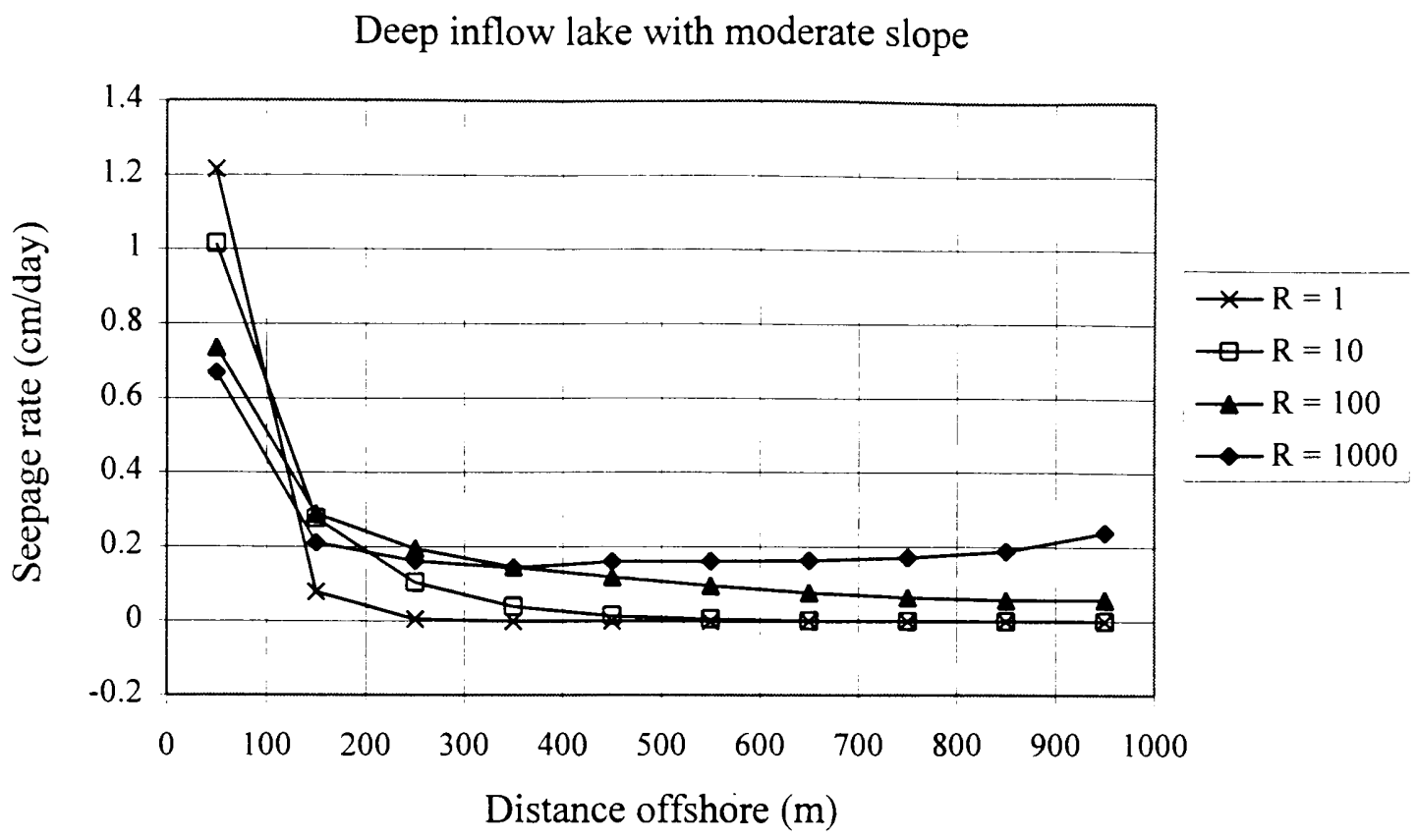

Shallow inflow lake with steep slope

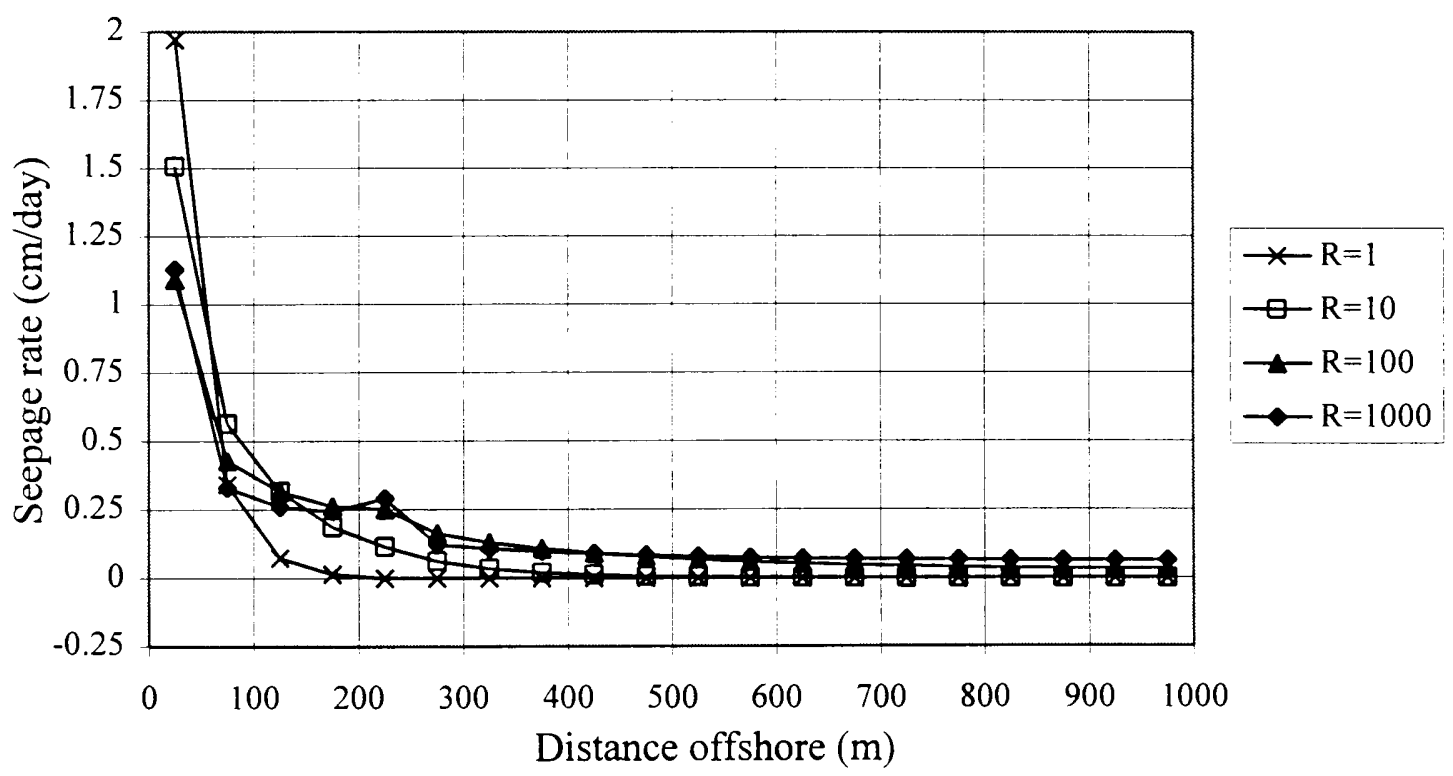

Fig. 10.4. Seepage rate versus distance offshore for simulations of deep inflow lakes with moderate lake bed slope (above) and shallow inflow lakes with steep lake bed slope (below) at different anisotropy ratios. 


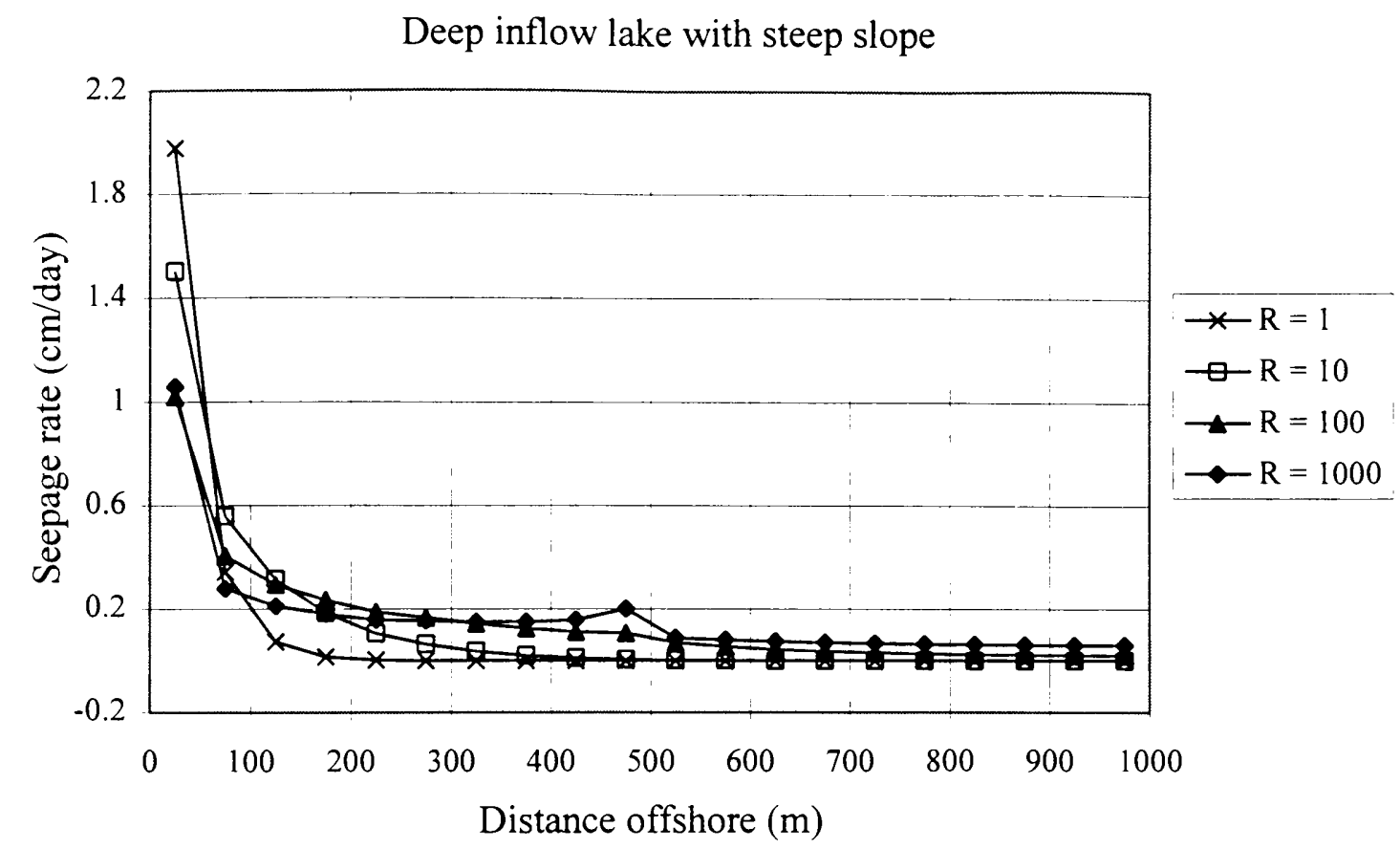

Shallow inflow lake with low slope

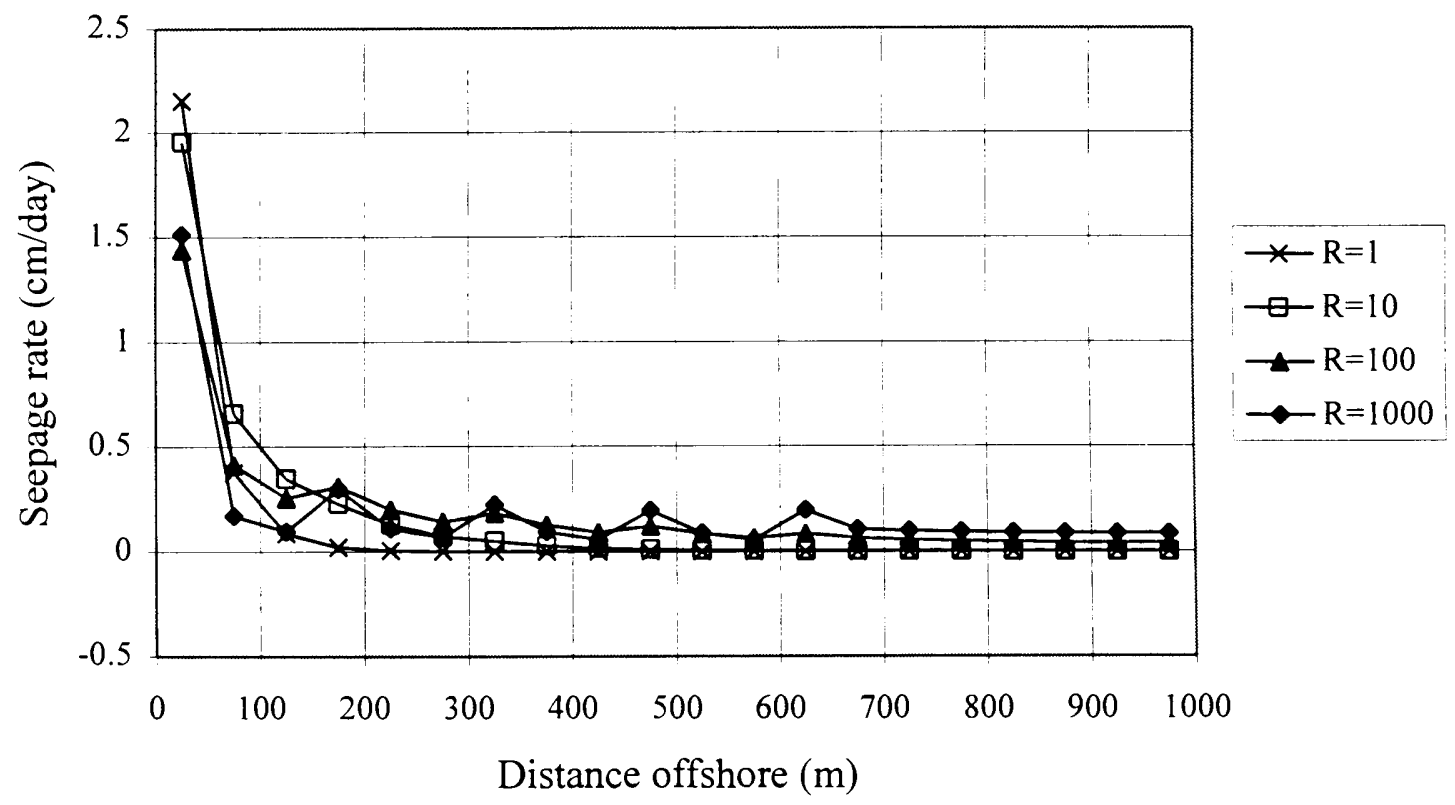

Fig. 10.5. Seepage rate versus distance offshore for simulations of deep inflow lakes with steep lake bed slope (above) and shallow inflow lakes with low lake bed slope (below) at different anisotropy ratios. 


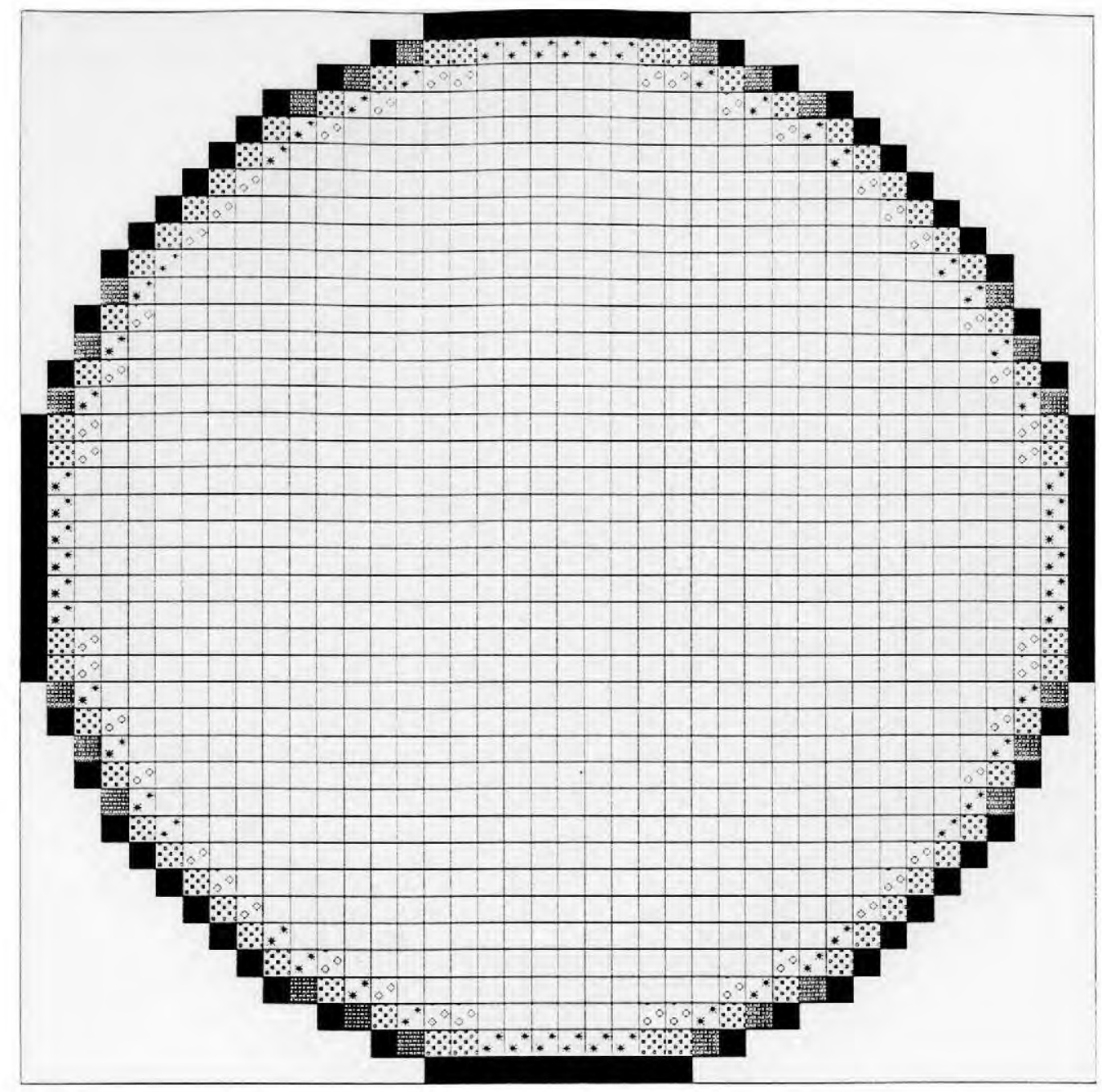

Fig. 10.6. Distribution of seepage rates ( $\mathrm{cm} /$ day) over the lake bed for a shallow inflow lake with steep lake bed slope at $\mathrm{R}=1$. Fig. 7.8 gives an analogous map for the simulation of a shallow inflow lake with moderate lake bed slope at $\mathrm{R}=1$.

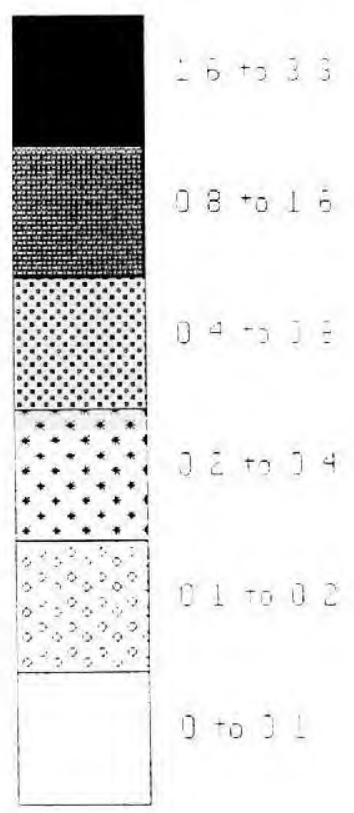




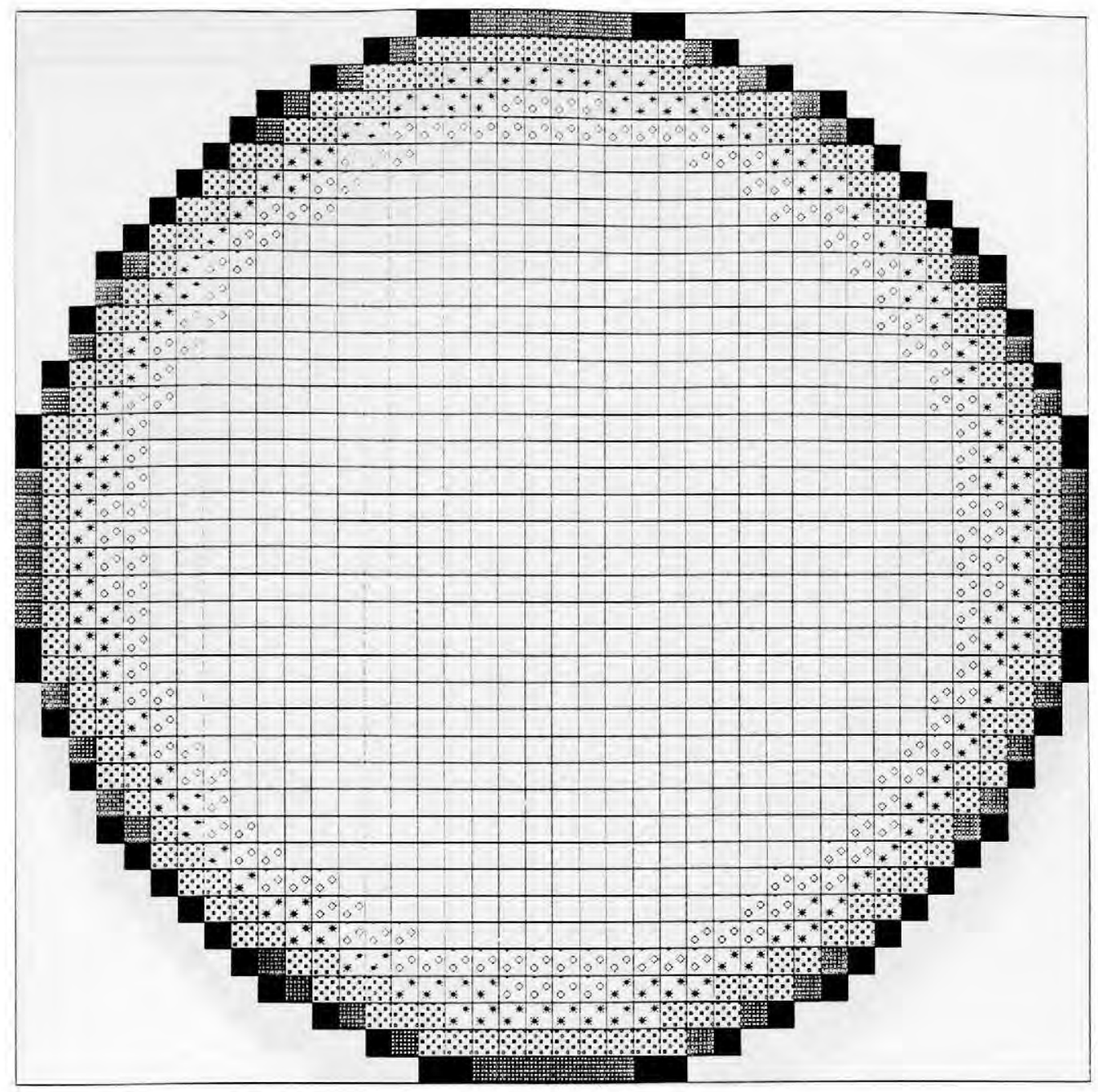

Fig. 10.7. Distribution of seepage rates (cm/day) over the lake bed for a shallow inflow lake with steep lake bed slope at $\mathrm{R}=10$. Fig. 7.10 gives an analogous map for the simulation of a shallow inflow lake with moderate lake bed slope at $\mathrm{R}=10$.

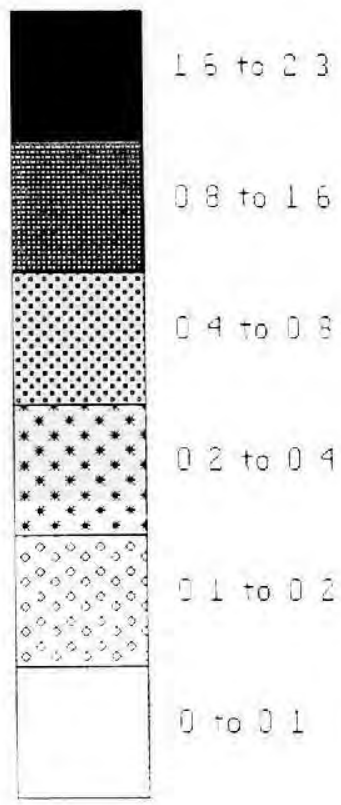




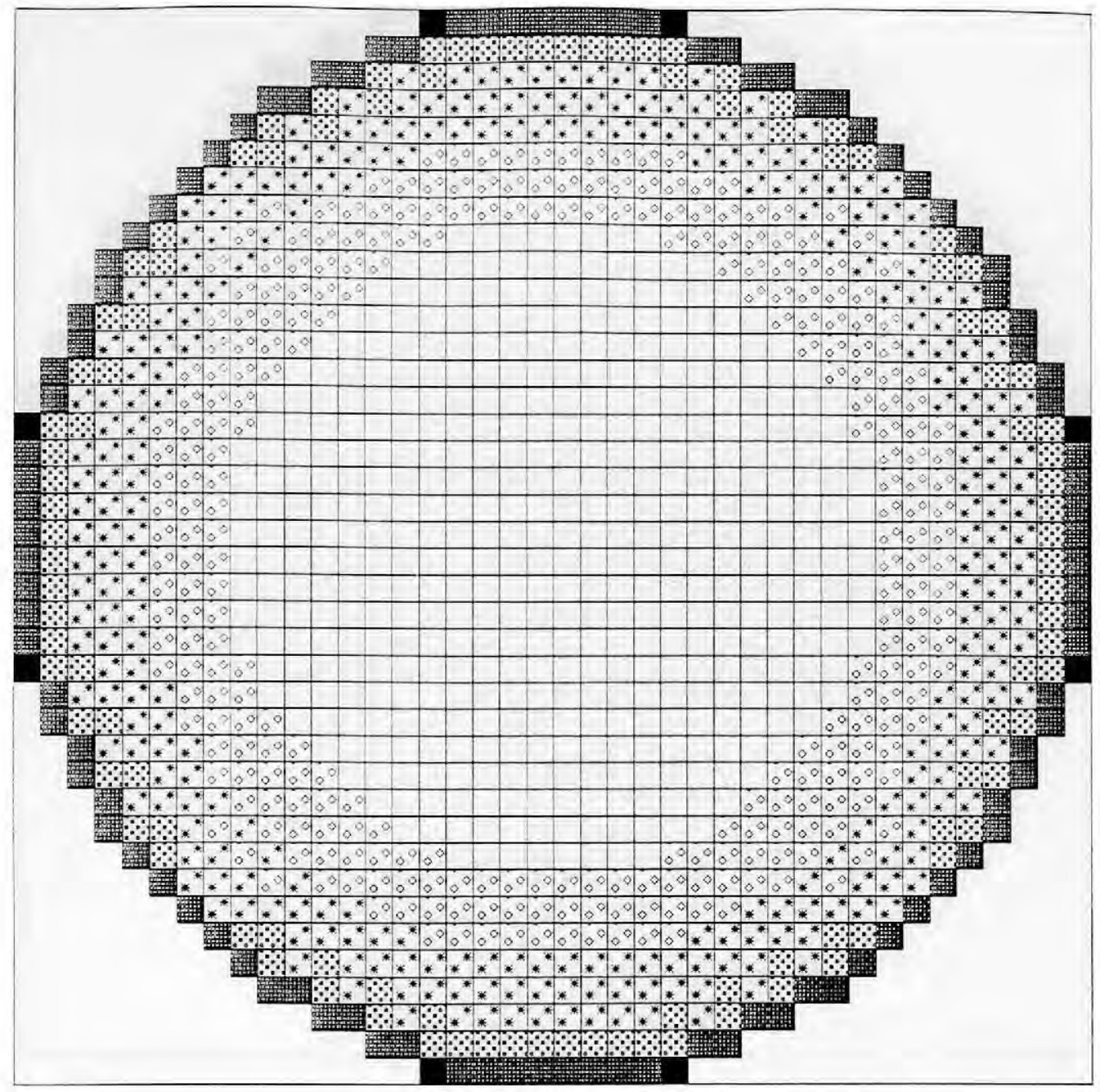

Fig. 10.8. Distribution of seepage rates (cm/day) over the lake bed for a shallow inflow lake with steep lake bed slope at $R=100$. Fig. 7.12 gives an analogous map for the simulation of a shallow inflow lake with moderate lake bed slope at $\mathrm{R}=100$.

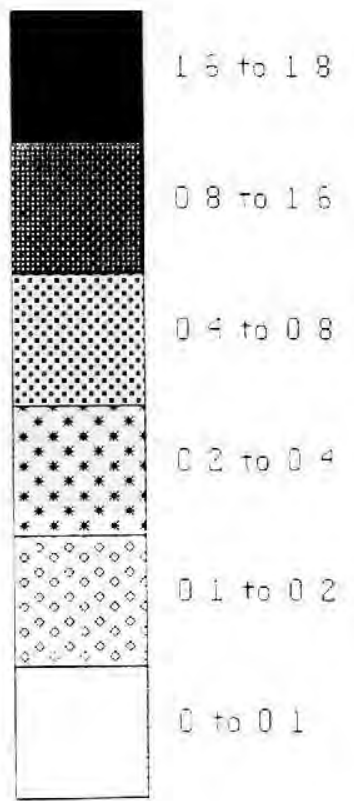




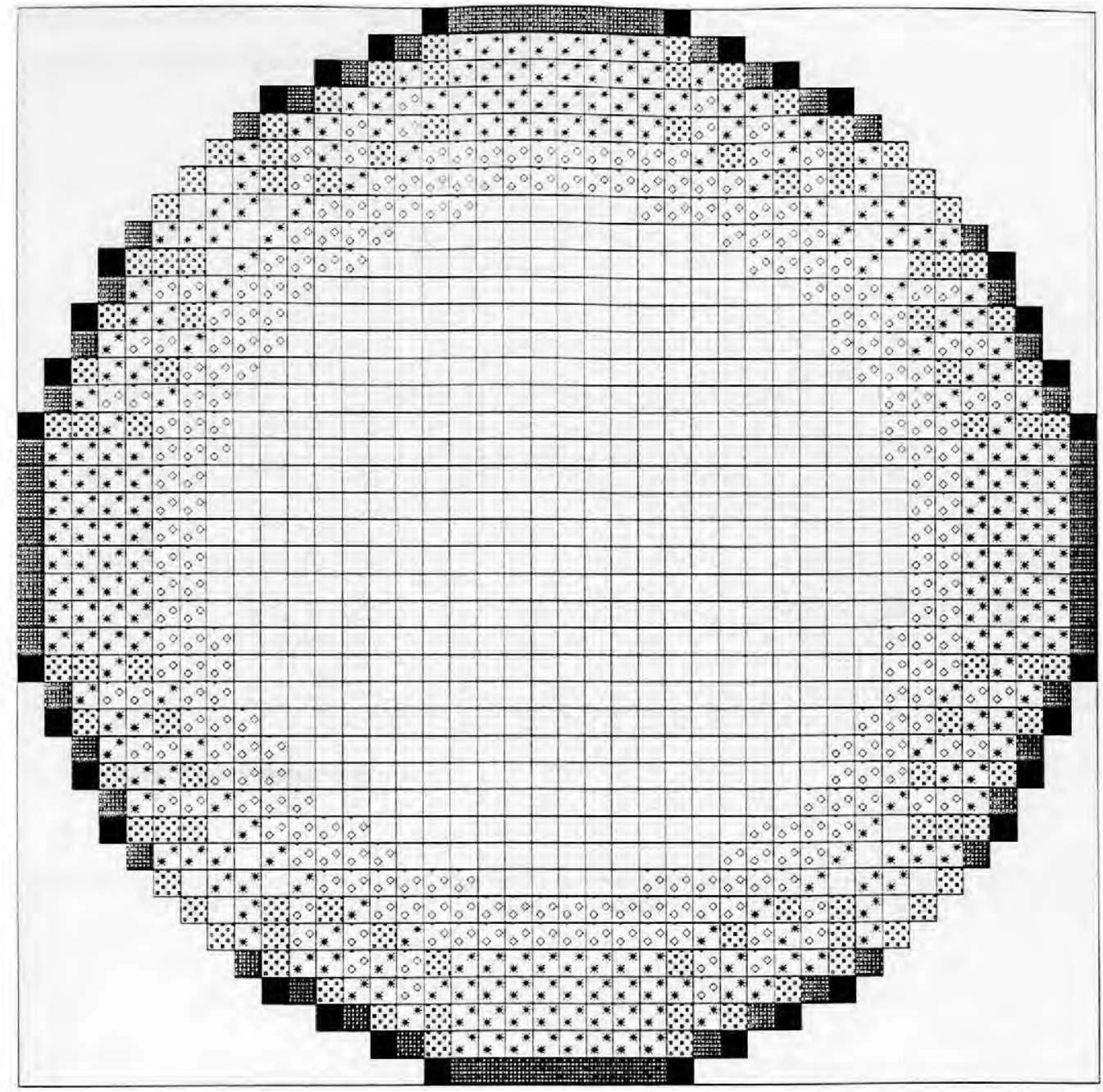

Fig. 10.9. Distribution of seepage rates ( $\mathrm{cm} /$ day) over the lake bed for a shallow inflow lake with steep lake bed slope at $\mathrm{R}=1000$. Fig. 7.14 gives an analogous map for the simulation of a shallow inflow lake with moderate lake bed slope at $\mathrm{R}=1000$.

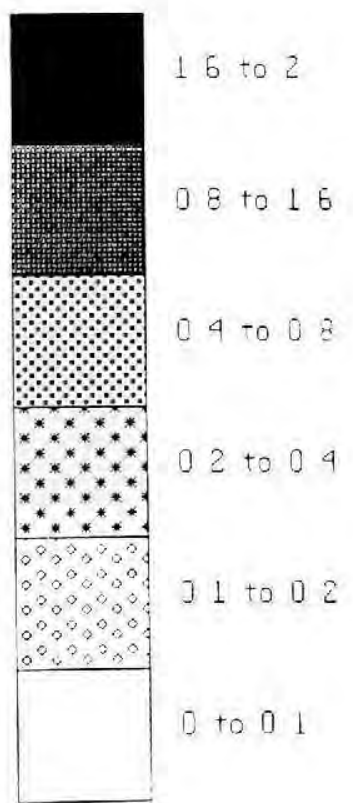




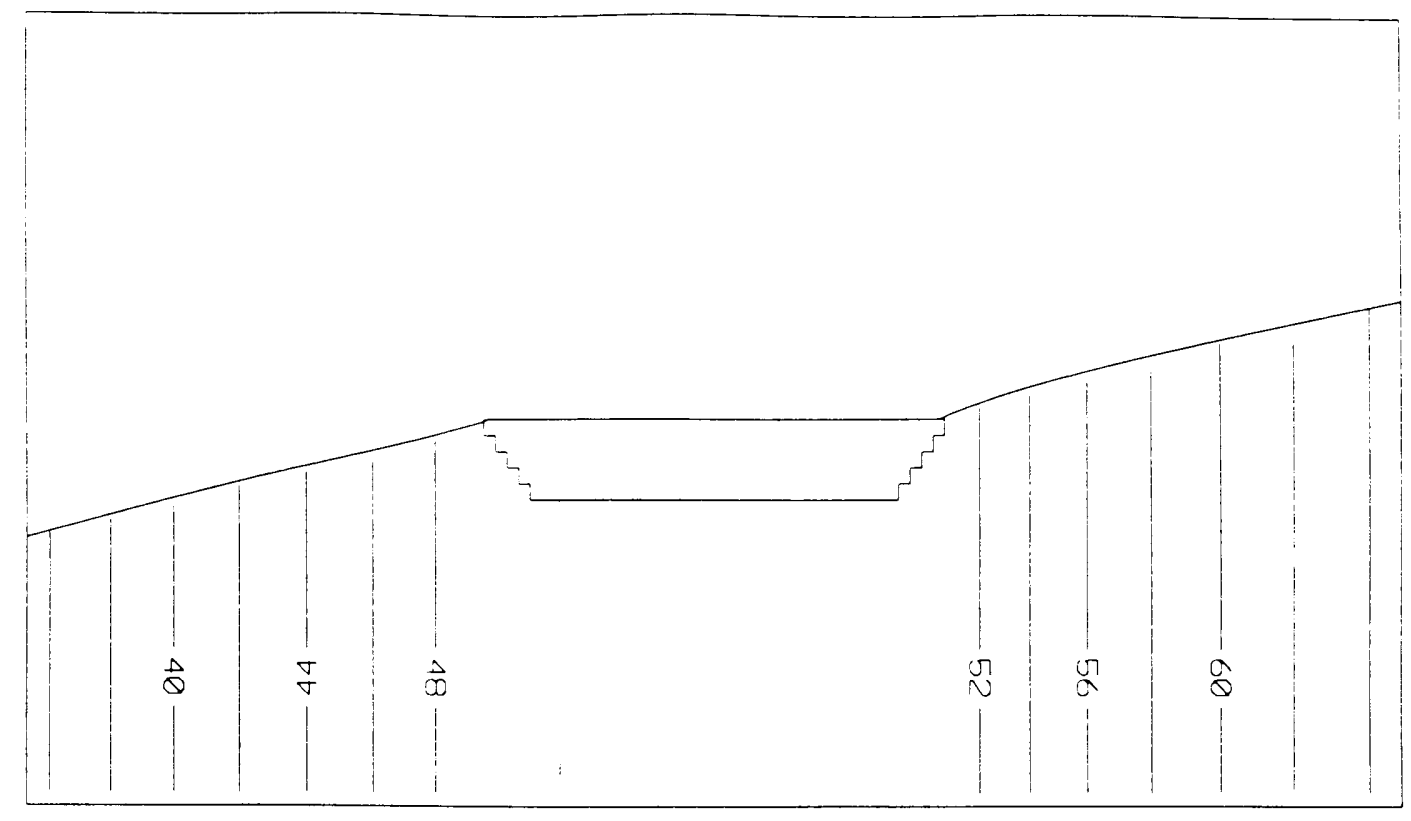

Anisotropy Ratio $=1$

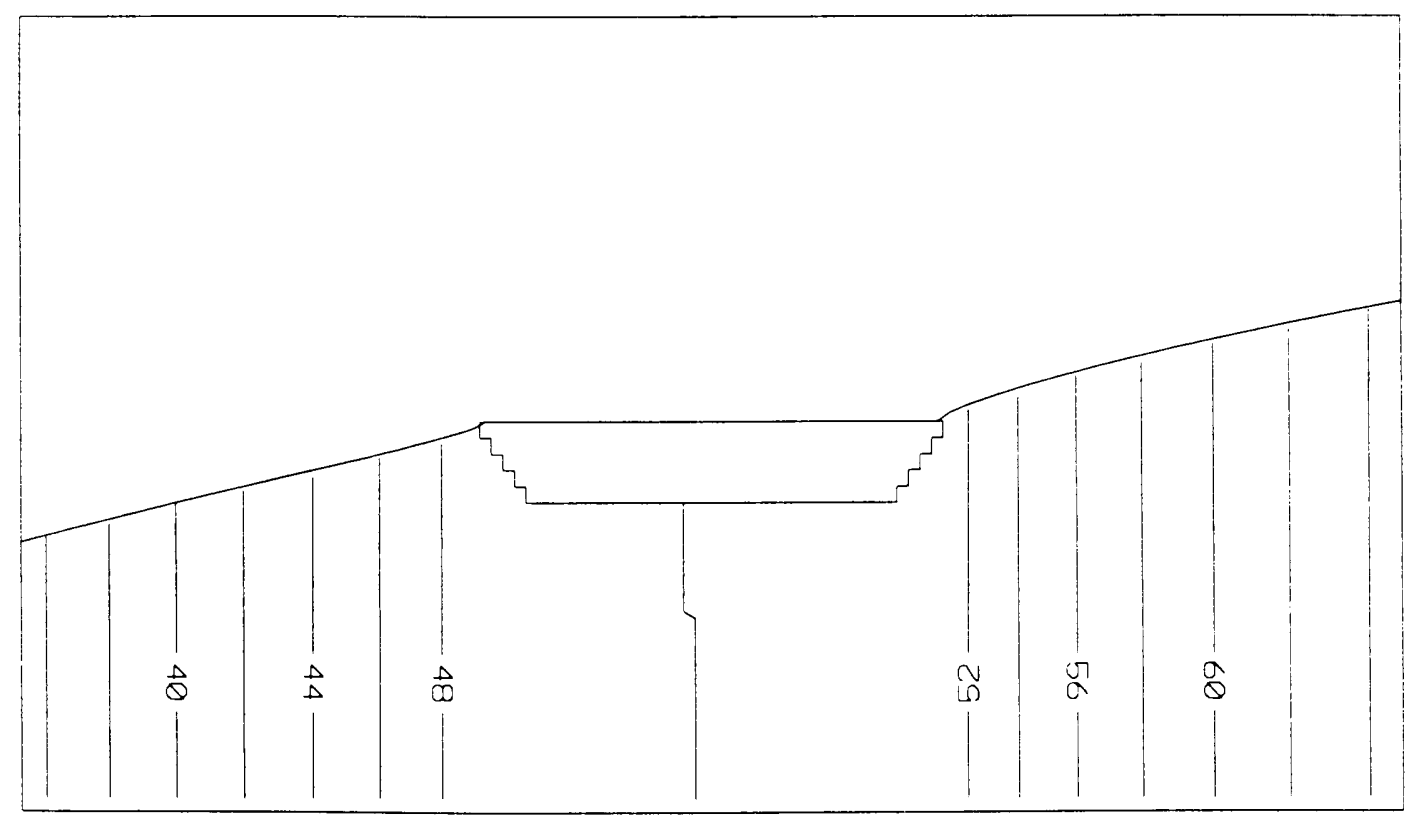

Anisotropy Ratio $=10$

Fig. 10.10. Distribution of hydraulic heads in the porous medium surrounding shallow flowthrough lakes with steep lake bed slope at $R=1$ and $R=10$. Figs. 7.15 and 7.16 give analogous cross-sections of shallow flow-through lakes with moderate lake bed slope at $\mathrm{R}=1$ and $\mathrm{R}=10$ respectively. 


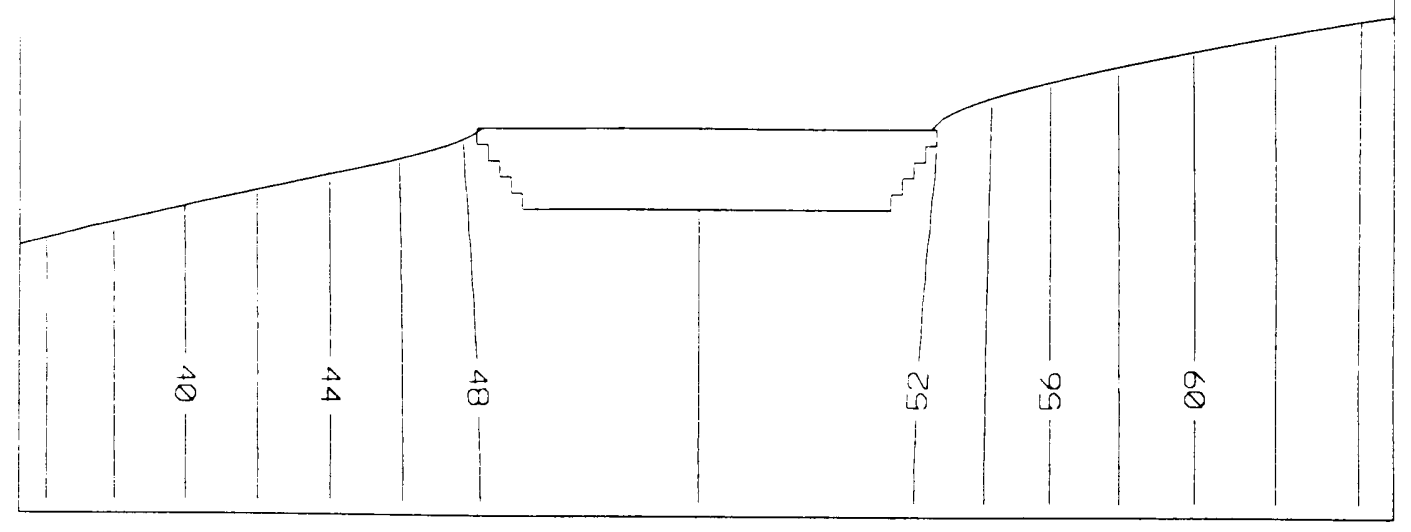

Anisotropy Ratio $=100$

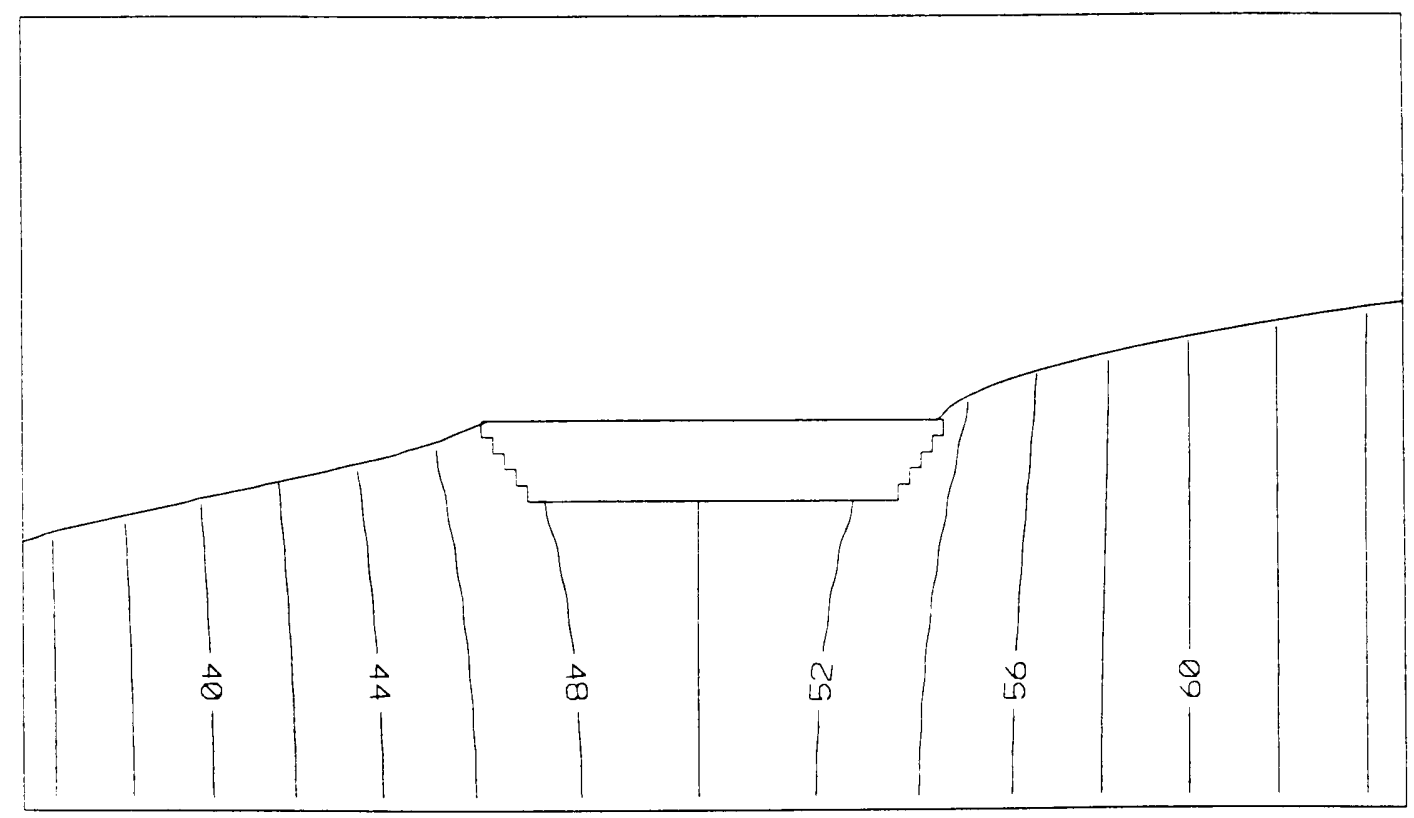

Anisotropy Ratio $=1000$

Fig. 10.11. Distribution of hydraulic heads in the porous medium surrounding shallow flowthrough lakes with steep lake bed slope at $R=100$ and $R=1000$. Figs. 7.17 and 7.18 give analogous cross-sections of shallow flow-through lakes with moderate lake bed slope at $R=100$ and $R=1000$ respectively. 
Shallow flow-through lake with steep lake bed slope

(section parallel to the flow gradient)

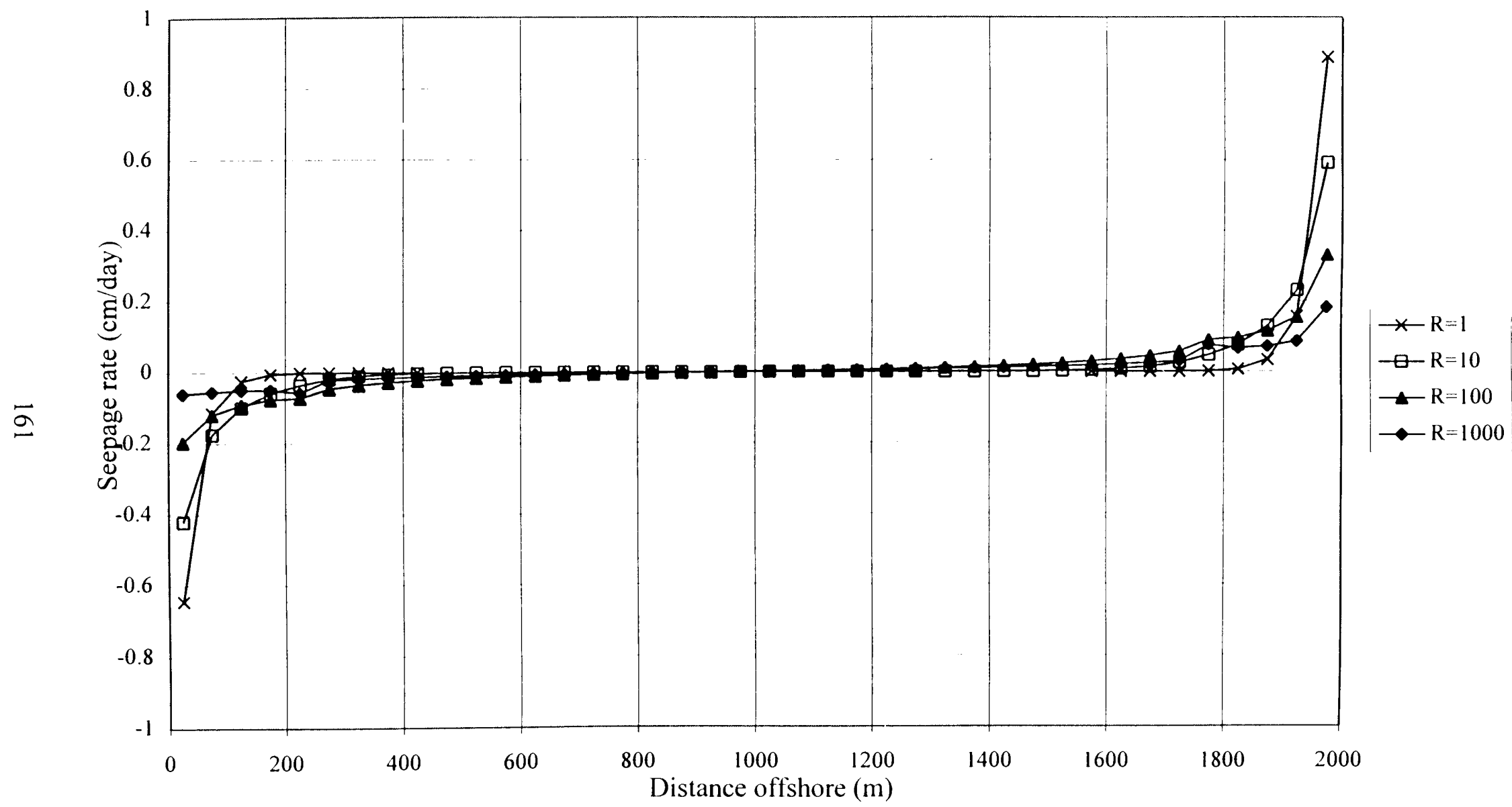

Fig. 10.12. Seepage rate versus distance offshore for the simulations of shallow flow-through lakes with steep lake bed slope at different anisotropy ratios. 
Shallow flow-through lake with steep lake bed slope (section normal to the flow gradient)

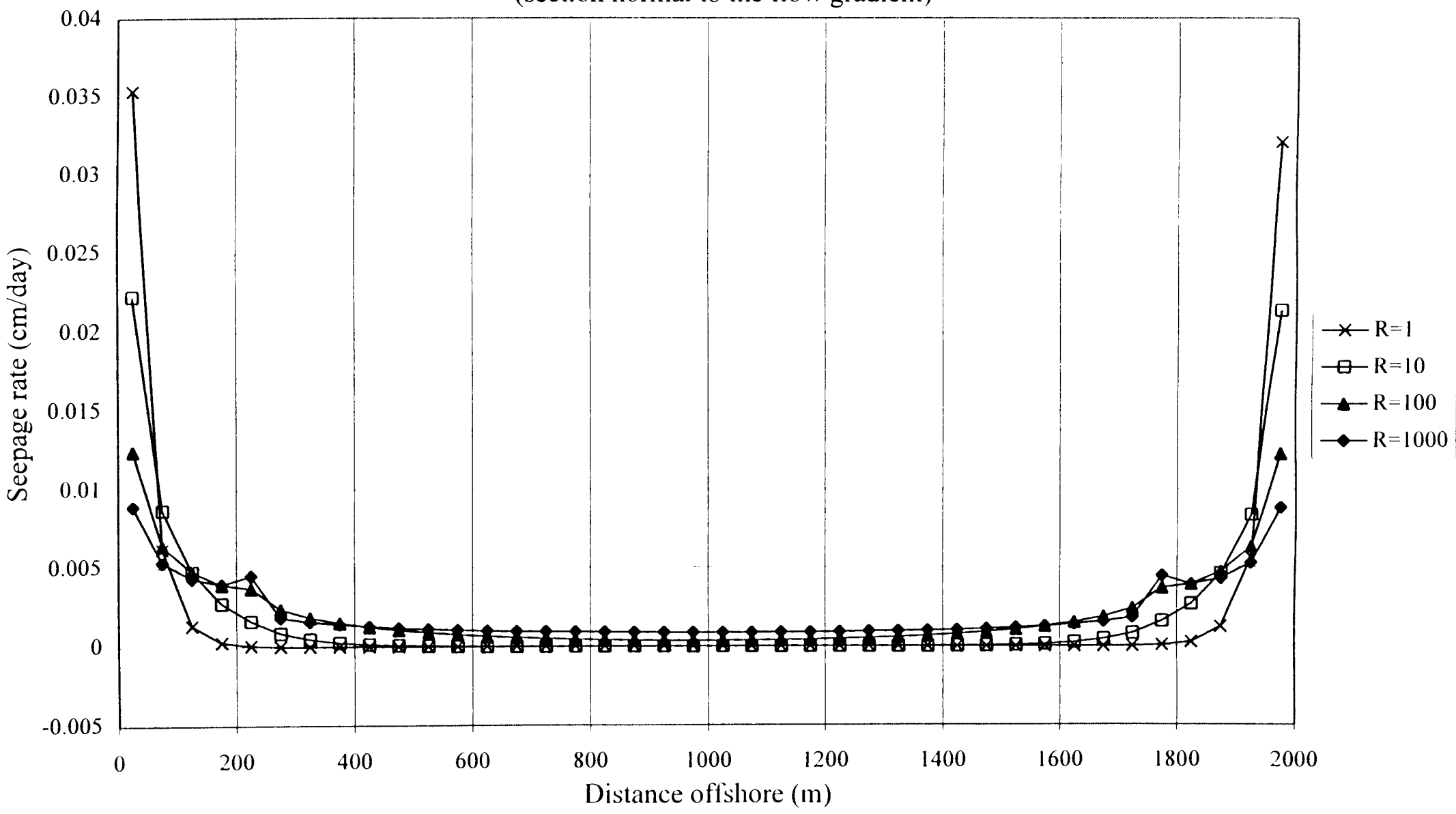

Fig. 10.13. Seepage rate versus distance oftshore for the simulations of shallow flow-through lakes with steep lake bed slope at different anisotropy ratios. This section is normal to the direction of groundwater flow. 


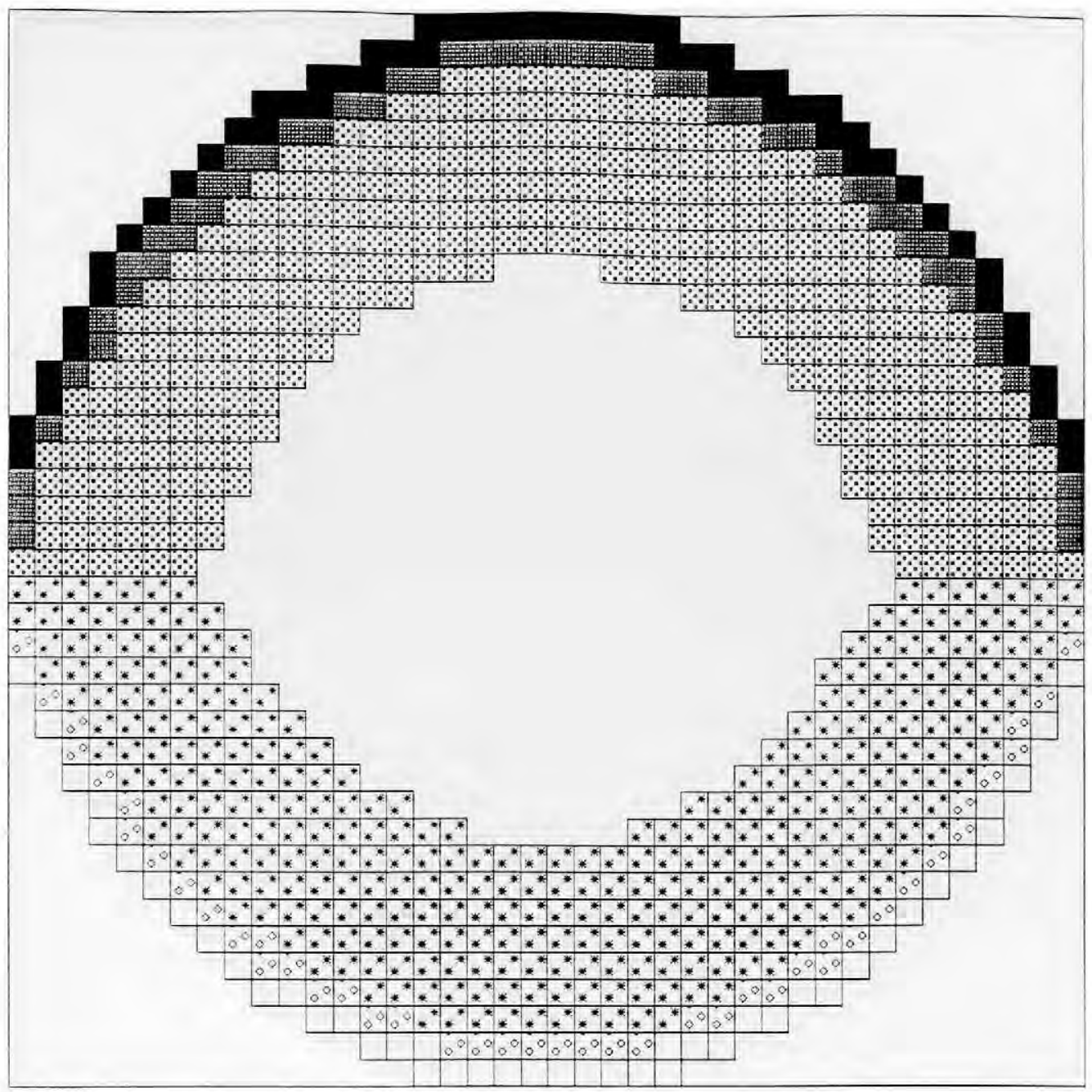

Fig. 10.14. Distribution of seepage rates ( $\mathrm{cm} /$ day) over the lake bed for a shallow flow-through lake with steep lake bed slope at $\mathrm{R}=1$. The regional gradient of groundwater flow is from the top to the bottom of the figure. Fig. 7.22 gives an analogous map for the simulation of a shallow flow-through lake with moderate lake bed slope at $\mathrm{R}=1$. The white area in the center represents cells having seepage rates with absolute values $<10^{-7} \mathrm{~cm} /$ day.

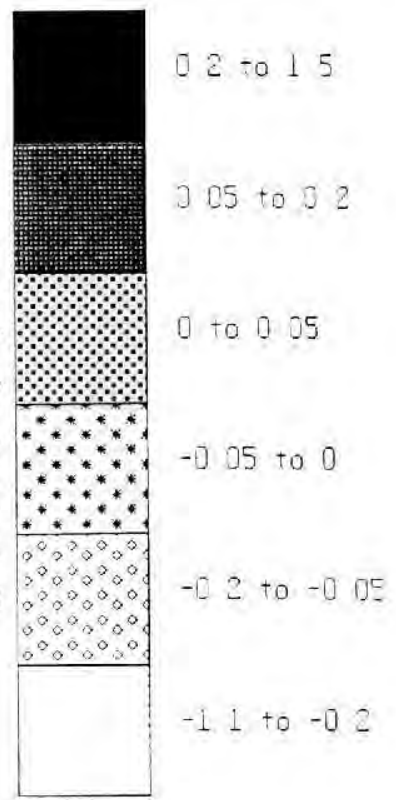




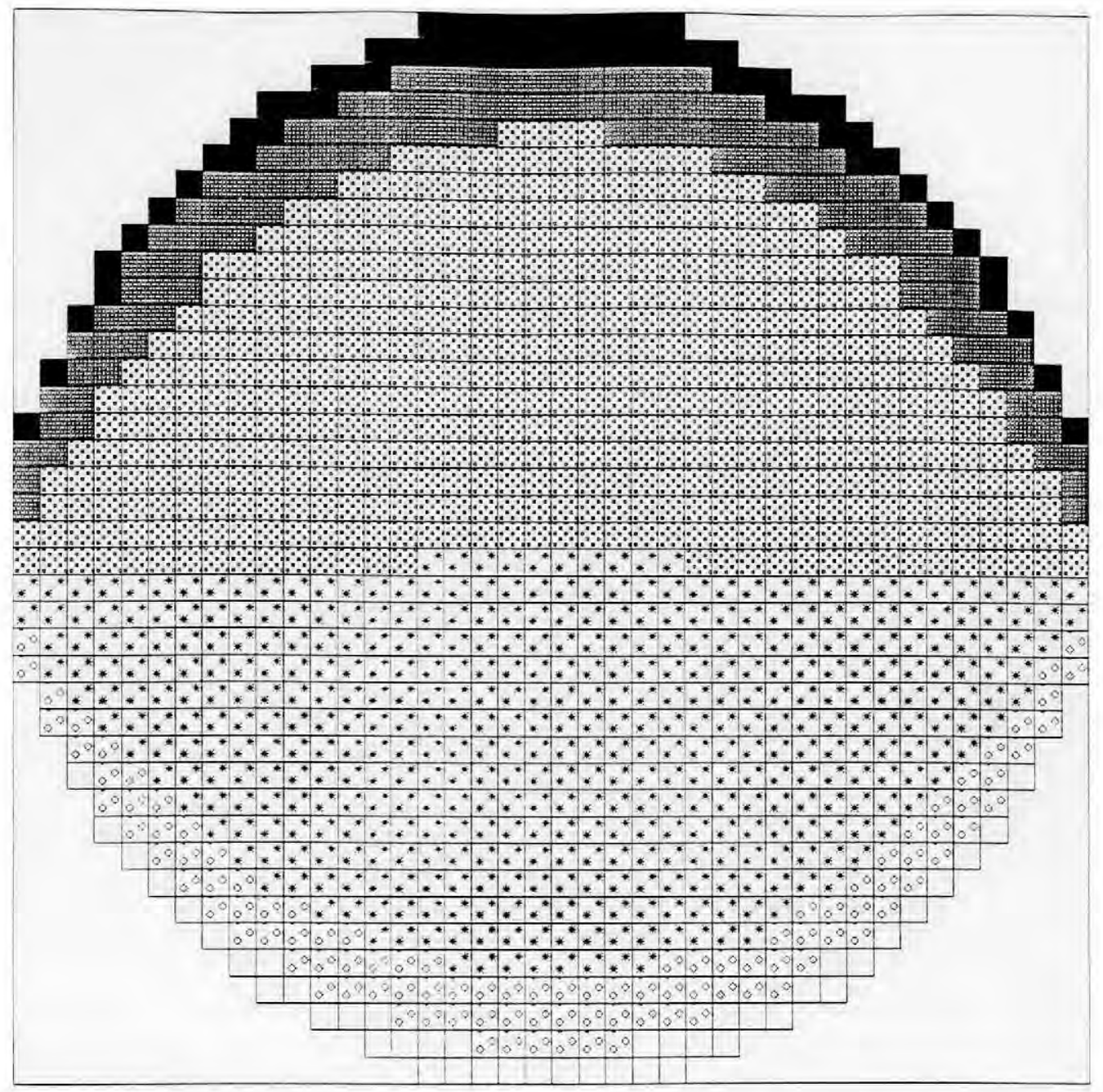

Fig. 10.15. Distribution of seepage rates ( $\mathrm{cm} /$ day) over the lake bed for a shallow flow-through lake with steep lake bed slope at $R=10$. The regional gradient of groundwater flow is from the top to the bottom of the figure. Fig. 7.24 gives an analogous map for the simulation of a shallow flow-through lake with moderate lake bed slope at $\mathrm{R}=10$.

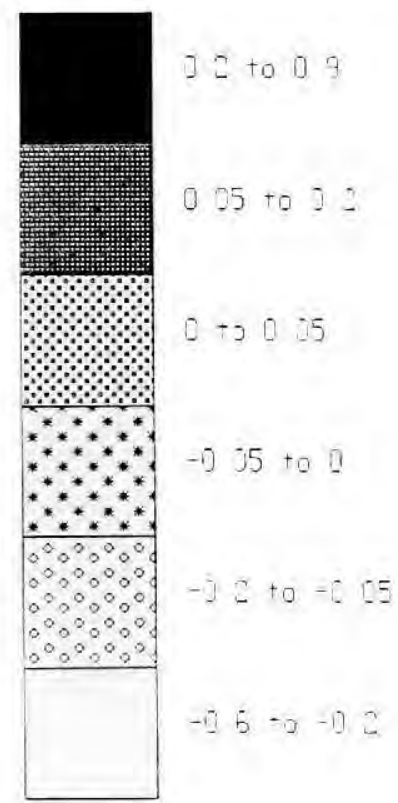




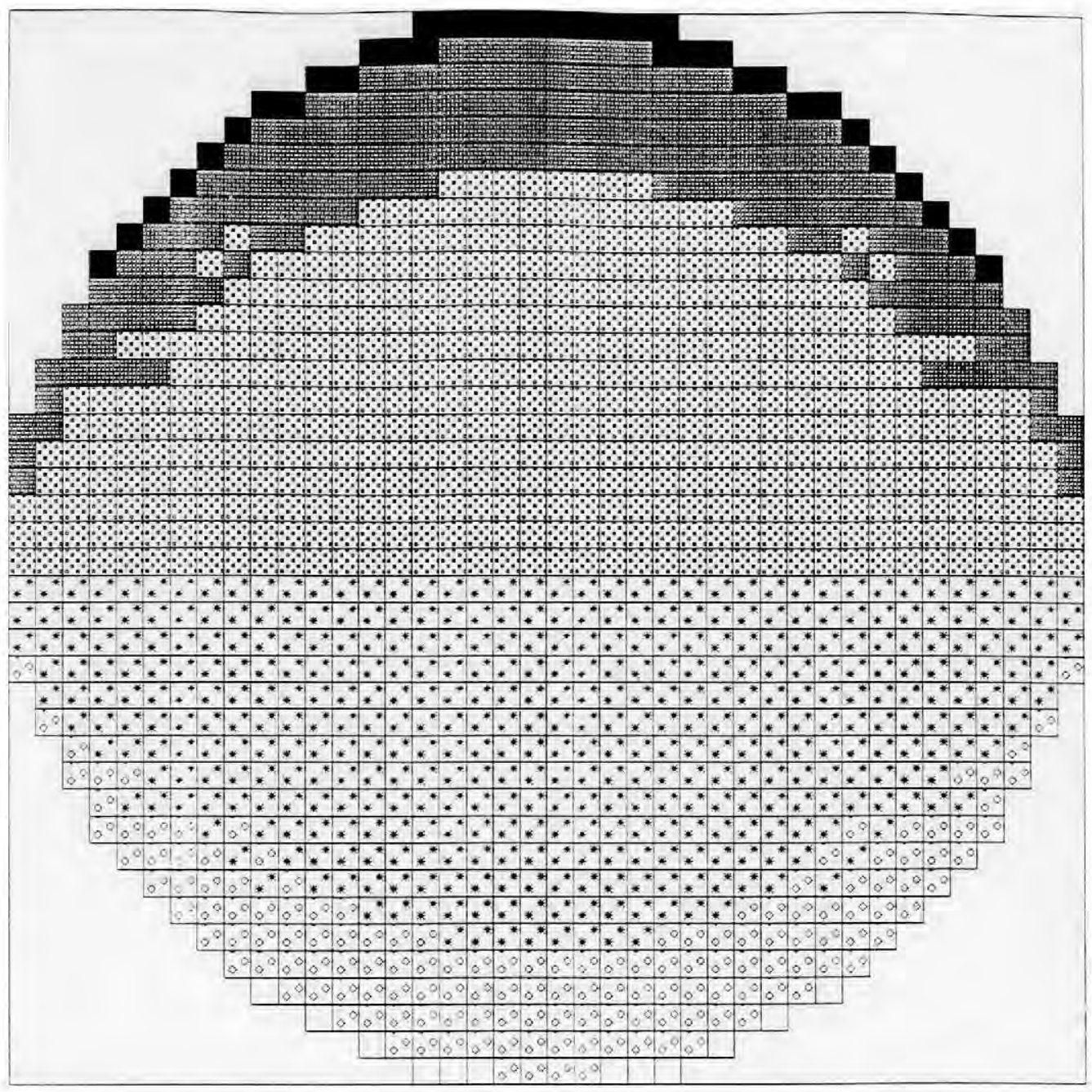

Fig. 10.16. Distribution of seepage rates ( $\mathrm{cm} /$ day) over the lake bed for a shallow flow-through lake with steep lake bed slope at $\mathrm{R}=100$. The regional gradient of groundwater flow is from the top to the bottom of the figure. Fig. 7.26 gives an analogous map for the simulation of a shallow flow-through lake with moderate lake bed slope at $\mathrm{R}=100$.

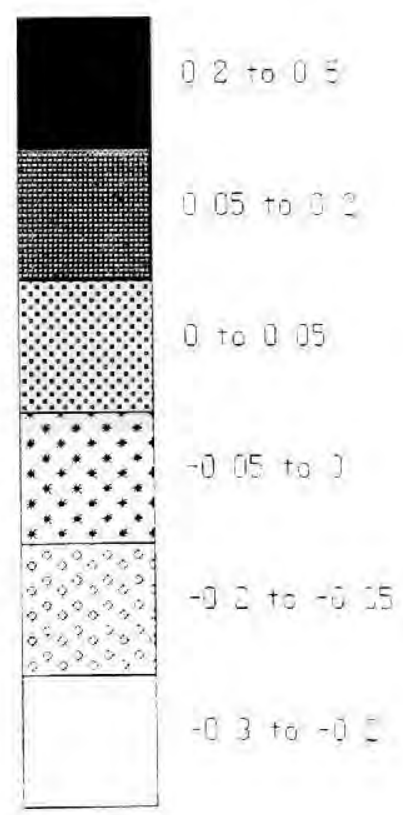




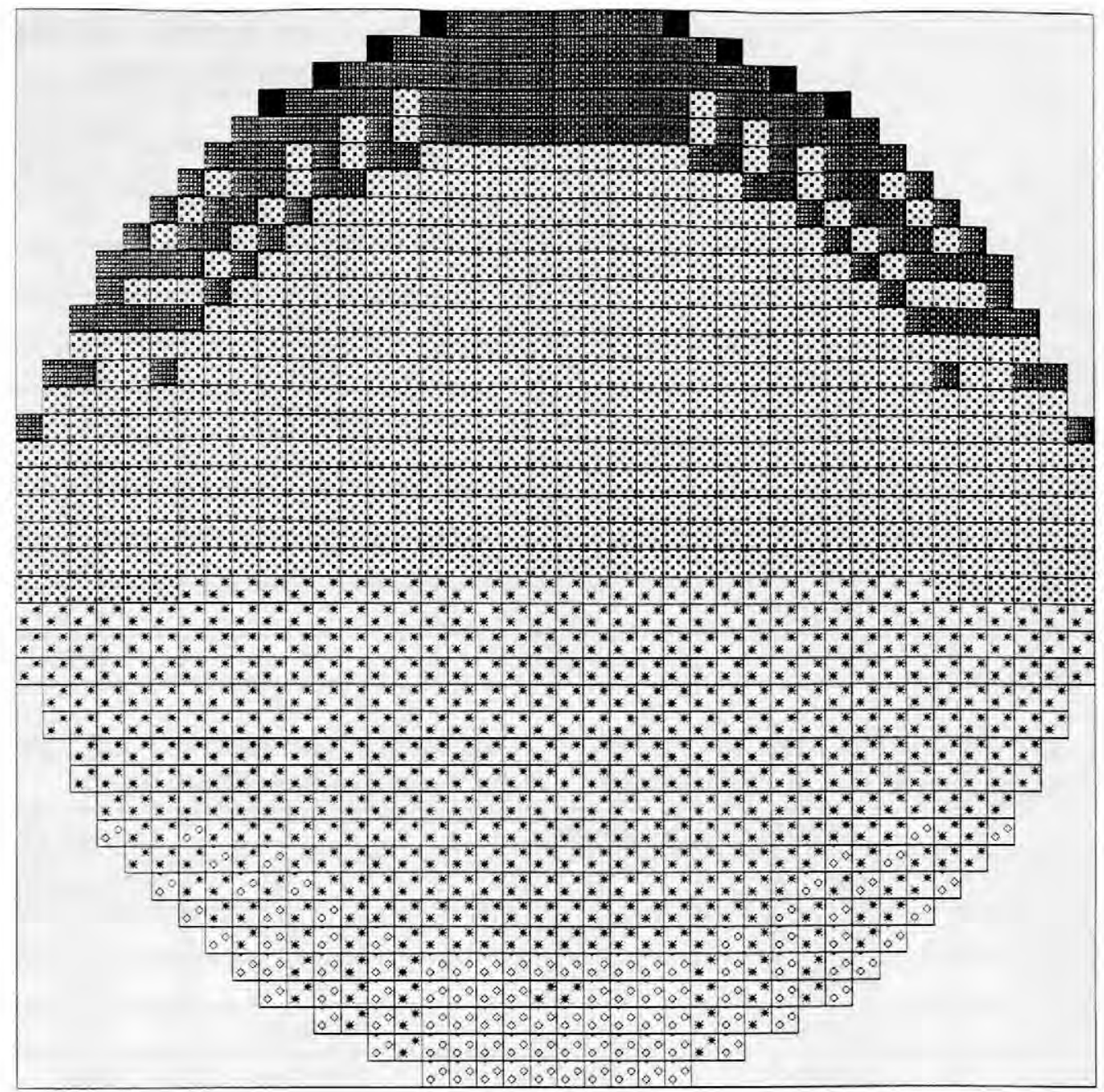

Fig. 10.17. Distribution of seepage rates (cm/day) over the lake bed for a shallow flow-through lake with steep lake bed slope at $\mathrm{R}=1000$. The regional gradient of groundwater flow is from the top to the bottom of the figure. Fig. 7.28 gives an analogous map for the simulation of a shallow flow-through lake with moderate lake bed slope at $\mathrm{R}=1000$.

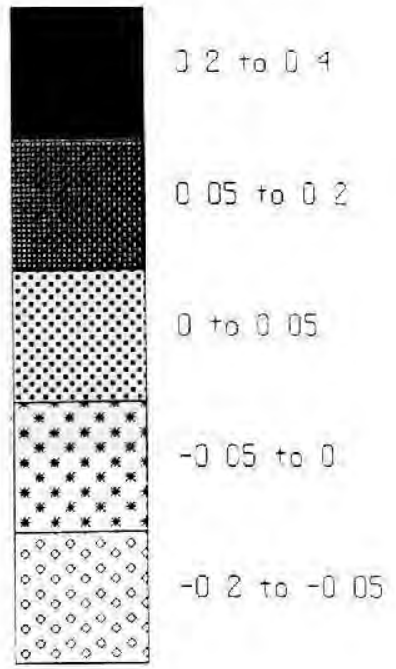


Table 10.4. Seepage rate versus distance offshore for shallow inflow lake with moderate slope at different anisotropy ratios. ${ }^{*}$ denotes seepage rate $<10^{-7} \mathrm{~cm} /$ day.

\begin{tabular}{|c|c|c|c|c|}
\hline Distance & \multicolumn{4}{|c|}{ Seepage rate $(\mathrm{cm} /$ day $)$} \\
\hline offshore $(\mathrm{m})$ & $\mathrm{R}=1$ & $\mathrm{R}=10$ & $\mathrm{R}=100$ & $\mathrm{R}=1000$ \\
\hline 50 & 1.21878 & 1.01571 & 0.73718 & 0.68651 \\
\hline 150 & 0.07886 & 0.27746 & 0.29045 & 0.21931 \\
\hline 250 & 0.00596 & 0.10401 & 0.19753 & 0.17049 \\
\hline 350 & 0.00042 & 0.03947 & 0.14958 & 0.15804 \\
\hline 450 & $2.84 \mathrm{e}-05$ & 0.01486 & 0.12797 & 0.20254 \\
\hline 550 & $1.76 \mathrm{e}-06$ & 0.00522 & 0.08476 & 0.10992 \\
\hline 650 & $1.12 \mathrm{e}-07$ & 0.00192 & 0.06485 & 0.09590 \\
\hline 750 & $*$ & 0.00074 & 0.05294 & 0.08797 \\
\hline 850 & $*$ & 0.00032 & 0.04597 & 0.08358 \\
\hline 950 & $*$ & 0.00019 & 0.04272 & 0.08160 \\
\hline
\end{tabular}

Table 10.5. Seepage rate versus distance offshore for deep inflow lake with moderate slope at different anisotropy ratios. ${ }^{*}$ denotes seepage rate $<10^{-7} \mathrm{~cm} /$ day.

\begin{tabular}{|c|c|c|c|c|}
\hline Distance & \multicolumn{4}{|c|}{ Seepage rate $(\mathrm{cm} /$ day $)$} \\
\hline offshore $(\mathrm{m})$ & $\mathrm{R}=1$ & $\mathrm{R}=10$ & $\mathrm{R}=100$ & $\mathrm{R}=1000$ \\
\hline 50 & 1.21582 & 1.01615 & 0.73638 & 0.66969 \\
\hline 150 & 0.07878 & 0.27738 & 0.28952 & 0.21228 \\
\hline 250 & 0.00597 & 0.10412 & 0.19576 & 0.16215 \\
\hline 350 & 0.00043 & 0.03956 & 0.14648 & 0.14410 \\
\hline 450 & $2.86 \mathrm{e}-05$ & 0.01480 & 0.11876 & 0.16043 \\
\hline 550 & $1.78 \mathrm{e}-06$ & 0.00545 & 0.09529 & 0.16119 \\
\hline 650 & $1.03 \mathrm{e}-07$ & 0.00197 & 0.07720 & 0.16322 \\
\hline 750 & $*$ & 0.00070 & 0.06433 & 0.17086 \\
\hline 850 & $*$ & 0.00026 & 0.05694 & 0.18901 \\
\hline 950 & $*$ & 0.00013 & 0.05796 & 0.23952 \\
\hline
\end{tabular}

Table 10.6. Seepage rate versus distance offshore for shallow inflow lake with steep slope at different anisotropy ratios. ${ }^{*}$ denotes seepage rate $<10^{-7} \mathrm{~cm} /$ day.

\begin{tabular}{|c|c|c|c|c|}
\hline Distance & \multicolumn{4}{|c|}{ Seepage rate $(\mathrm{cm} /$ day $)$} \\
\hline offshore $(\mathrm{m})$ & $\mathrm{R}=1$ & $\mathrm{R}=10$ & $\mathrm{R}=100$ & $\mathrm{R}=1000$ \\
\hline 25 & 1.97153 & 1.50688 & 1.09265 & 1.12945 \\
\hline 75 & 0.34260 & 0.56290 & 0.42907 & 0.33101 \\
\hline 125 & 0.07383 & 0.31618 & 0.31599 & 0.26009 \\
\hline
\end{tabular}


Table 10.6. (Contd.)

\begin{tabular}{|c|c|c|c|c|}
\hline Distance & \multicolumn{5}{|c|}{ Seepage rate (cm/day) } \\
\hline offshore $(\mathrm{m})$ & $\mathrm{R}=1$ & $\mathrm{R}=10$ & $\mathrm{R}=100$ & $\mathrm{R}=1000$ \\
\hline 175 & 0.01540 & 0.18819 & 0.26286 & 0.24331 \\
\hline 225 & 0.00010 & 0.11545 & 0.25079 & 0.29031 \\
\hline 275 & $1.93 \mathrm{e}-05$ & 0.06233 & 0.16387 & 0.12253 \\
\hline 325 & $3.61 \mathrm{e}-06$ & 0.03512 & 0.13041 & 0.10756 \\
\hline 375 & $6.85 \mathrm{e}-07$ & 0.02010 & 0.10795 & 0.09689 \\
\hline 425 & $*$ & 0.01159 & 0.09133 & 0.08902 \\
\hline 475 & $*$ & 0.00672 & 0.07843 & 0.08305 \\
\hline 525 & $*$ & 0.00392 & 0.06814 & 0.07841 \\
\hline 575 & $*$ & 0.00231 & 0.05983 & 0.07475 \\
\hline 625 & $*$ & 0.00137 & 0.05308 & 0.07183 \\
\hline 675 & $*$ & 0.00082 & 0.04762 & 0.06950 \\
\hline 725 & $*$ & 0.00050 & 0.04323 & 0.06764 \\
\hline 775 & $*$ & 0.00031 & 0.03977 & 0.06618 \\
\hline 825 & $*$ & 0.00020 & 0.03712 & 0.06506 \\
\hline 875 & $*$ & 0.00014 & 0.03519 & 0.06426 \\
\hline 925 & $*$ & 0.00010 & 0.03394 & 0.06373 \\
\hline 975 & $*$ & $8.57 \mathrm{e}-05$ & 0.03333 & 0.06347 \\
\hline
\end{tabular}

Table 10.7. Seepage rate versus distance offshore for deep inflow lake with steep slope at different anisotropy ratios. ${ }^{*}$ denotes seepage rate $<10^{-7} \mathrm{~cm} /$ day.

\begin{tabular}{|c|c|c|c|c|}
\hline Distance & \multicolumn{4}{|c|}{ Seepage rate (cm/day) } \\
\hline offshore $(\mathrm{m})$ & $\mathrm{R}=1$ & $\mathrm{R}=10$ & $\mathrm{R}=100$ & $\mathrm{R}=1000$ \\
\hline 25 & 1.97752 & 1.50174 & 1.02188 & 1.05875 \\
\hline 75 & 0.34370 & 0.55985 & 0.40578 & 0.27875 \\
\hline 125 & 0.07421 & 0.31396 & 0.29381 & 0.21107 \\
\hline 175 & 0.01551 & 0.18601 & 0.23516 & 0.18136 \\
\hline 225 & 0.00295 & 0.10627 & 0.18896 & 0.15873 \\
\hline 275 & 0.00057 & 0.06443 & 0.16719 & 0.15505 \\
\hline 325 & $9.78 \mathrm{e}-05$ & 0.03673 & 0.14420 & 0.15003 \\
\hline 375 & $1.57 \mathrm{e}-05$ & 0.02035 & 0.12564 & 0.14995 \\
\hline 425 & $2.31 \mathrm{e}-06$ & 0.01095 & 0.11153 & 0.15842 \\
\hline 475 & $*$ & 0.00581 & 0.10698 & 0.20026 \\
\hline 525 & $*$ & 0.00267 & 0.07064 & 0.08960 \\
\hline
\end{tabular}


Table 10.7. (Contd.)

\begin{tabular}{|c|c|c|c|c|}
\hline Distance & \multicolumn{4}{|c|}{ Seepage rate $(\mathrm{cm} /$ day $)$} \\
\hline offshore $(\mathrm{m})$ & $\mathrm{R}=1$ & $\mathrm{R}=10$ & $\mathrm{R}=100$ & $\mathrm{R}=1000$ \\
\hline 575 & ${ }^{*}$ & 0.00128 & 0.05549 & 0.08154 \\
\hline 625 & $*$ & 0.00062 & 0.04516 & 0.07545 \\
\hline 675 & $*$ & 0.00031 & 0.03768 & 0.07082 \\
\hline 725 & $*$ & 0.00015 & 0.03211 & 0.06729 \\
\hline 775 & $*$ & $7.90 \mathrm{e}-05$ & 0.02795 & 0.06462 \\
\hline 825 & $*$ & $4.19 \mathrm{e}-05$ & 0.02490 & 0.06264 \\
\hline 875 & $*$ & $2.35 \mathrm{e}-05$ & 0.02275 & 0.06125 \\
\hline 925 & $*$ & $1.47 \mathrm{e}-05$ & 0.02138 & 0.06036 \\
\hline 975 & $*$ & $1.12 \mathrm{e}-05$ & 0.02071 & 0.05992 \\
\hline
\end{tabular}

Table 10.8. Seepage rate versus distance offshore for shallow inflow lake with low slope at different anisotropy ratios. ${ }^{*}$ denotes seepage rate $<10^{-7} \mathrm{~cm} /$ day.

\begin{tabular}{|c|c|c|c|c|}
\hline Distance & \multicolumn{4}{|c|}{ Seepage rate $(\mathrm{cm} /$ day $)$} \\
\hline offshore $(\mathrm{m})$ & $\mathrm{R}=1$ & $\mathrm{R}=10$ & $\mathrm{R}=100$ & $\mathrm{R}=1000$ \\
\hline 25 & 2.15507 & 1.95545 & 1.43922 & 1.51365 \\
\hline 75 & 0.37721 & 0.65806 & 0.41428 & 0.17117 \\
\hline 125 & 0.08576 & 0.34678 & 0.25654 & 0.09622 \\
\hline 175 & 0.02022 & 0.22763 & 0.30952 & 0.29709 \\
\hline 225 & 0.00458 & 0.12795 & 0.20069 & 0.11048 \\
\hline 275 & 0.00103 & 0.07247 & 0.14128 & 0.06688 \\
\hline 325 & $1.11 \mathrm{e}-05$ & 0.04817 & 0.18343 & 0.22156 \\
\hline 375 & $2.54 \mathrm{e}-06$ & 0.02692 & 0.12564 & 0.09151 \\
\hline 425 & $5.19 e-07$ & 0.01506 & 0.09093 & 0.05705 \\
\hline 475 & $*$ & 0.00986 & 0.12022 & 0.19555 \\
\hline 525 & $*$ & 0.00543 & 0.08441 & 0.08604 \\
\hline 575 & $*$ & 0.00300 & 0.06253 & 0.05548 \\
\hline 625 & $*$ & 0.00194 & 0.08382 & 0.19575 \\
\hline 675 & $*$ & 0.00106 & 0.06269 & 0.10416 \\
\hline 725 & $*$ & 0.00061 & 0.05410 & 0.09692 \\
\hline 775 & $*$ & 0.00036 & 0.04821 & 0.09190 \\
\hline 825 & $*$ & 0.00021 & 0.04401 & 0.08842 \\
\hline 875 & $*$ & 0.00014 & 0.04108 & 0.08607 \\
\hline 925 & $*$ & $9.59 \mathrm{e}-05$ & 0.03921 & 0.08462 \\
\hline 975 & * & $7.81 \mathrm{e}-05$ & 0.03830 & 0.08393 \\
\hline
\end{tabular}


Table 10.9. Seepage rate versus distance offshore for shallow flow-through lake with steep slope at different anisotropy ratios when the section is parallel to regional groundwater flow gradient. ${ }^{*}$ denotes absolute value of seepage rate $<10^{-7} \mathrm{~cm} /$ day.

\begin{tabular}{|c|c|c|c|c|}
\hline Distance & \multicolumn{4}{|c|}{ Seepage rate $(\mathrm{cm} /$ day $)$} \\
\hline offshore $(\mathrm{m})$ & $\mathrm{R}=1$ & $\mathrm{R}=10$ & $R=100$ & $\mathrm{R}=1000$ \\
\hline 25 & -0.64488 & -0.42141 & -0.19613 & -0.06053 \\
\hline 75 & -0.11509 & -0.17543 & -0.11970 & -0.05479 \\
\hline 125 & -0.02476 & -0.09890 & -0.09106 & -0.05052 \\
\hline 175 & -0.00516 & -0.05876 & -0.07624 & -0.04975 \\
\hline 225 & -0.00102 & -0.03588 & -0.07213 & -0.05838 \\
\hline 275 & -0.00019 & -0.01925 & -0.04621 & -0.02287 \\
\hline 325 & $-3.47 e-05$ & -0.01077 & -0.03590 & -0.01893 \\
\hline 375 & $-6.43 e-06$ & -0.00611 & -0.02884 & -0.01592 \\
\hline 425 & $-1.20 \mathrm{e}-06$ & -0.00349 & -0.02353 & -0.01352 \\
\hline 475 & $*$ & -0.00200 & -0.01932 & -0.01151 \\
\hline 525 & $*$ & -0.00115 & -0.01588 & -0.00979 \\
\hline 575 & $*$ & -0.00067 & -0.01302 & -0.00827 \\
\hline 625 & $*$ & -0.00039 & -0.01059 & -0.00690 \\
\hline 675 & $*$ & -0.00023 & -0.00850 & -0.00564 \\
\hline 725 & $*$ & -0.00013 & -0.00667 & -0.00445 \\
\hline 775 & $*$ & $-7.69 e-05$ & -0.00505 & -0.00333 \\
\hline 825 & * & $-4.43 e-05$ & -0.00358 & -0.00225 \\
\hline 875 & $*$ & $-2.43 e-05$ & -0.00221 & -0.00120 \\
\hline 925 & $*$ & $-1.12 e-05$ & -0.00092 & -0.00017 \\
\hline 975 & $*$ & $-1.28 \mathrm{e}-06$ & 0.00035 & 0.00086 \\
\hline 1025 & $*$ & $8.05 e-06$ & 0.00161 & 0.00189 \\
\hline 1075 & $*$ & $1.93 \mathrm{e}-05$ & 0.00292 & 0.00293 \\
\hline 1125 & $*$ & $3.56 e-05$ & 0.00430 & 0.00399 \\
\hline 1175 & $*$ & $6.15 e-05$ & 0.00580 & 0.00509 \\
\hline 1225 & $*$ & 0.00010 & 0.00746 & 0.00624 \\
\hline 1275 & $*$ & 0.00018 & 0.00933 & 0.00745 \\
\hline 1325 & $*$ & 0.00030 & 0.01147 & 0.00875 \\
\hline 1375 & $*$ & 0.00051 & 0.01394 & 0.01016 \\
\hline 1425 & $*$ & 0.00088 & 0.01685 & 0.01171 \\
\hline 1475 & $*$ & 0.00152 & 0.02031 & 0.01347 \\
\hline 1525 & $*$ & 0.00264 & 0.02448 & 0.01548 \\
\hline 1575 & $1.62 \mathrm{e}-06$ & 0.00459 & 0.02963 & 0.01788 \\
\hline
\end{tabular}


Table 10.9. (Contd.)

\begin{tabular}{|c|c|c|c|c|}
\hline Distance & \multicolumn{4}{|c|}{ Seepage rate (cm/day) } \\
\hline offshore $(\mathrm{m})$ & $\mathrm{R}=1$ & $\mathrm{R}=10$ & $\mathrm{R}=100$ & $\mathrm{R}=1000$ \\
\hline 1625 & $8.72 \mathrm{e}-06$ & 0.00801 & 0.03616 & 0.02080 \\
\hline 1675 & $4.71 \mathrm{e}-05$ & 0.01409 & 0.04488 & 0.02452 \\
\hline 1725 & 0.00026 & 0.02514 & 0.05769 & 0.02946 \\
\hline 1775 & 0.00138 & 0.04680 & 0.09015 & 0.07577 \\
\hline 1825 & 0.00698 & 0.07657 & 0.09571 & 0.06652 \\
\hline 1875 & 0.03349 & 0.12894 & 0.11537 & 0.07123 \\
\hline 1925 & 0.15570 & 0.22939 & 0.15468 & 0.08583 \\
\hline 1975 & 0.88894 & 0.59099 & 0.33006 & 0.18127 \\
\hline
\end{tabular}

Table 10.10. Seepage rate versus distance offshore for shallow flow-through lake with steep slope at different anisotropy ratios when the section is normal to regional groundwater flow gradient. ${ }^{*}$ denotes absolute value of seepage rate $<10^{-7} \mathrm{~cm} /$ day.

\begin{tabular}{|c|c|c|c|c|}
\hline Distance & \multicolumn{4}{|c|}{ Seepage rate $(\mathrm{cm} /$ day $)$} \\
\hline offshore (m) & $\mathrm{R}=1$ & $\mathrm{R}=10$ & $R=100$ & $\mathrm{R}=1000$ \\
\hline 25 & 0.03534 & 0.02226 & 0.01248 & 0.00893 \\
\hline 75 & 0.00619 & 0.00869 & 0.00642 & 0.00535 \\
\hline 125 & 0.00132 & 0.00476 & 0.00477 & 0.00434 \\
\hline 175 & 0.00027 & 0.00274 & 0.00394 & 0.00395 \\
\hline 225 & $5.26 \mathrm{e}-05$ & 0.00162 & 0.00370 & 0.00451 \\
\hline 275 & $9.48 \mathrm{e}-06$ & 0.00084 & 0.00236 & 0.00182 \\
\hline 325 & $1.69 \mathrm{e}-06$ & 0.00045 & 0.00184 & 0.00157 \\
\hline 375 & $*$ & 0.00024 & 0.00149 & 0.00139 \\
\hline 425 & $*$ & 0.00013 & 0.00123 & 0.00126 \\
\hline 475 & $*$ & $6.88 e-05$ & 0.00103 & 0.00117 \\
\hline 525 & $*$ & $3.56 e-05$ & 0.00087 & 0.00109 \\
\hline 575 & * & $1.77 e-05$ & 0.00075 & 0.00104 \\
\hline 625 & $*$ & $8.26 \mathrm{e}-06$ & 0.00064 & 0.00099 \\
\hline 675 & * & $3.31 \mathrm{e}-06$ & 0.00056 & 0.00095 \\
\hline 725 & * & $7.98 \mathrm{e}-07$ & 0.00049 & 0.00092 \\
\hline 775 & $*$ & $-1.00 \mathrm{e}-06$ & 0.00044 & 0.00090 \\
\hline 825 & $*$ & $-9.85 e-07$ & 0.00040 & 0.00088 \\
\hline 875 & $*$ & $-1.21 e-06$ & 0.00037 & 0.00087 \\
\hline 925 & $*$ & $-1.28 \mathrm{e}-06$ & 0.00036 & 0.00086 \\
\hline 975 & $*$ & $-1.28 \mathrm{e}-06$ & 0.00035 & 0.00086 \\
\hline
\end{tabular}


Table 10.10. (Contd.)

\begin{tabular}{|c|c|c|c|c|}
\hline Distance & \multicolumn{5}{|c|}{ Seepage rate $(\mathrm{cm} /$ day $)$} \\
\hline offshore $(\mathrm{m})$ & $\mathrm{R}=1$ & $\mathrm{R}=10$ & $\mathrm{R}=100$ & $\mathrm{R}=1000$ \\
\hline 1025 & $*$ & $-1.24 \mathrm{e}-06$ & 0.00035 & 0.00086 \\
\hline 1075 & $*$ & $-1.17 \mathrm{e}-06$ & 0.00036 & 0.00086 \\
\hline 1125 & $*$ & $-1.02 \mathrm{e}-06$ & 0.00038 & 0.00087 \\
\hline 1175 & $*$ & $-7.27 \mathrm{e}-07$ & 0.00041 & 0.00088 \\
\hline 1225 & $*$ & $-1.00 \mathrm{e}-06$ & 0.00045 & 0.00090 \\
\hline 1275 & $*$ & $1.14 \mathrm{e}-06$ & 0.00050 & 0.00092 \\
\hline 1325 & $*$ & $3.61 \mathrm{e}-06$ & 0.00057 & 0.00095 \\
\hline 1375 & $*$ & $8.36 \mathrm{e}-06$ & 0.00066 & 0.00098 \\
\hline 1425 & $*$ & $1.74 \mathrm{e}-05$ & 0.00076 & 0.00103 \\
\hline 1475 & $*$ & $3.43 \mathrm{e}-05$ & 0.00089 & 0.00108 \\
\hline 1525 & $*$ & $6.58 \mathrm{e}-05$ & 0.00105 & 0.00115 \\
\hline 1575 & $*$ & 0.00012 & 0.00125 & 0.00125 \\
\hline 1625 & $*$ & 0.00023 & 0.00151 & 0.00137 \\
\hline 1675 & $1.51 \mathrm{e}-06$ & 0.00043 & 0.00185 & 0.00155 \\
\hline 1725 & $8.52 \mathrm{e}-06$ & 0.00080 & 0.00237 & 0.00179 \\
\hline 1775 & $4.74 \mathrm{e}-05$ & 0.00156 & 0.00368 & 0.00444 \\
\hline 1825 & 0.00025 & 0.00265 & 0.00390 & 0.00390 \\
\hline 1875 & 0.00120 & 0.00459 & 0.00471 & 0.00427 \\
\hline 1925 & 0.00563 & 0.00837 & 0.00632 & 0.00528 \\
\hline 1975 & 0.03210 & 0.02138 & 0.01227 & 0.00882 \\
\hline & & & & \\
\hline
\end{tabular}

Table 10.11. Seepage rate versus distance offshore for deep flow-through lake with steep slope at different anisotropy ratios when the section is parallel to regional groundwater flow gradient. ${ }^{*}$ denotes absolute value of seepage rate $<10^{-7} \mathrm{~cm} /$ day.

\begin{tabular}{|c|c|c|c|c|}
\hline Distance & \multicolumn{4}{|c|}{ Seepage rate $(\mathrm{cm} /$ day $)$} \\
\hline offshore $(\mathrm{m})$ & $\mathrm{R}=1$ & $\mathrm{R}=10$ & $\mathrm{R}=100$ & $\mathrm{R}=1000$ \\
\hline 25 & -0.66991 & -0.42478 & -0.19252 & -0.05880 \\
\hline 75 & -0.11981 & -0.17647 & -0.11646 & -0.05209 \\
\hline 125 & -0.02589 & -0.09924 & -0.08739 & -0.04678 \\
\hline 175 & -0.00542 & -0.05867 & -0.07076 & -0.04336 \\
\hline 225 & -0.00103 & -0.03340 & -0.05689 & -0.03926 \\
\hline 275 & -0.00020 & -0.02016 & -0.05003 & -0.03869 \\
\hline 325 & $-3.40 \mathrm{e}-05$ & -0.01144 & -0.04266 & -0.03701 \\
\hline
\end{tabular}


Table 10.11 (Contd.)

\begin{tabular}{|c|c|c|c|c|}
\hline Distance & \multicolumn{4}{|c|}{ Seepage rate $(\mathrm{cm} /$ day $)$} \\
\hline offshore $(\mathrm{m})$ & $\mathrm{R}=1$ & $\mathrm{R}=10$ & $\mathrm{R}=100$ & $\mathrm{R}=1000$ \\
\hline 375 & $-5.43 e-06$ & -0.00631 & -0.03658 & -0.03582 \\
\hline 425 & $-8.02 \mathrm{e}-07$ & -0.00337 & -0.03176 & -0.03566 \\
\hline 475 & * & -0.00178 & -0.02948 & -0.04006 \\
\hline 525 & $*$ & -0.00081 & -0.01860 & -0.01508 \\
\hline 575 & $*$ & -0.00038 & -0.01387 & -0.01231 \\
\hline 625 & $*$ & -0.00018 & -0.01056 & -0.01000 \\
\hline 675 & $*$ & $-8.94 \mathrm{e}-05$ & -0.00806 & -0.00803 \\
\hline 725 & $*$ & $-4.37 e-05$ & -0.00609 & -0.00629 \\
\hline 775 & $*$ & $-2.15 e-05$ & -0.00449 & -0.00472 \\
\hline 825 & $*$ & $-1.06 \mathrm{e}-05$ & -0.00313 & -0.00327 \\
\hline 875 & $*$ & $-5.09 e-06$ & -0.00195 & -0.00190 \\
\hline 925 & $*$ & $-2.19 e-06$ & -0.00088 & -0.00059 \\
\hline 975 & $*$ & $-1.00 e-06$ & 0.00015 & 0.00071 \\
\hline 1025 & $*$ & $1.19 \mathrm{e}-06$ & 0.00117 & 0.00200 \\
\hline 1075 & $*$ & $3.30 \mathrm{e}-06$ & 0.00224 & 0.00331 \\
\hline 1125 & $*$ & $6.97 \mathrm{e}-06$ & 0.00341 & 0.00468 \\
\hline 1175 & $*$ & $1.41 \mathrm{e}-05$ & 0.00475 & 0.00612 \\
\hline 1225 & $*$ & $2.83 e-05$ & 0.00632 & 0.00768 \\
\hline 1275 & $*$ & $5.74 \mathrm{e}-05$ & 0.00823 & 0.00939 \\
\hline 1325 & $*$ & 0.00012 & 0.01060 & 0.01132 \\
\hline 1375 & $*$ & 0.00024 & 0.01363 & 0.01355 \\
\hline 1425 & $*$ & 0.00050 & 0.01770 & 0.01620 \\
\hline 1475 & $*$ & 0.00106 & 0.02353 & 0.01941 \\
\hline 1525 & $*$ & 0.00232 & 0.03704 & 0.05021 \\
\hline 1575 & $1.07 e-06$ & 0.00440 & 0.03973 & 0.04422 \\
\hline 1625 & $7.26 \mathrm{e}-06$ & 0.00823 & 0.04565 & 0.04448 \\
\hline 1675 & $4.54 \mathrm{e}-05$ & 0.01492 & 0.05320 & 0.04631 \\
\hline 1725 & 0.00026 & 0.02628 & 0.06240 & 0.04910 \\
\hline 1775 & 0.00148 & 0.04701 & 0.07679 & 0.05501 \\
\hline 1825 & 0.00719 & 0.07644 & 0.08885 & 0.05818 \\
\hline 1875 & 0.03443 & 0.12931 & 0.11074 & 0.06632 \\
\hline 1925 & 0.15973 & 0.23046 & 0.15052 & 0.08215 \\
\hline 1975 & 0.91183 & 0.59495 & 0.32266 & 0.17511 \\
\hline
\end{tabular}


Table 10.12. Seepage rate versus distance offshore for deep flow-through lake with steep slope at different anisotropy ratios when the section is normal to regional groundwater flow gradient. ${ }^{*}$ denotes absolute value of seepage rate $<10^{-7} \mathrm{~cm} /$ day.

\begin{tabular}{|c|c|c|c|c|}
\hline Distance & \multicolumn{4}{|c|}{ Seepage rate $(\mathrm{cm} /$ day $)$} \\
\hline offshore $(\mathrm{m})$ & $\mathrm{R}=1$ & $\mathrm{R}=10$ & $\mathrm{R}=100$ & $\mathrm{R}=1000$ \\
\hline 25 & 0.03381 & 0.02674 & 0.01185 & 0.00826 \\
\hline 75 & 0.00588 & 0.01062 & 0.00605 & 0.00485 \\
\hline 125 & 0.00124 & 0.00580 & 0.00442 & 0.00377 \\
\hline 175 & 0.00025 & 0.00329 & 0.00352 & 0.00314 \\
\hline 225 & $4.90 \mathrm{e}-05$ & 0.00186 & 0.00290 & 0.00273 \\
\hline 275 & $8.91 \mathrm{e}-06$ & 0.00103 & 0.00244 & 0.00243 \\
\hline 325 & $1.51 \mathrm{e}-06$ & 0.00056 & 0.00206 & 0.00223 \\
\hline 375 & $*$ & 0.00029 & 0.00175 & 0.00212 \\
\hline 425 & * & 0.00015 & 0.00151 & 0.00215 \\
\hline 475 & $*$ & $7.24 \mathrm{e}-05$ & 0.00139 & 0.00261 \\
\hline 525 & $*$ & $2.96 \mathrm{e}-05$ & 0.00087 & 0.00112 \\
\hline 575 & $*$ & $1.21 \mathrm{e}-05$ & 0.00065 & 0.00101 \\
\hline 625 & $*$ & $4.66 \mathrm{e}-06$ & 0.00050 & 0.00092 \\
\hline 675 & $*$ & $1.53 \mathrm{e}-06$ & 0.00039 & 0.00086 \\
\hline 725 & $*$ & $-1.00 \mathrm{e}-06$ & 0.00031 & 0.00081 \\
\hline 775 & $*$ & $-1.00 e-06$ & 0.00025 & 0.00077 \\
\hline 825 & $*$ & $-1.00 \mathrm{e}-06$ & 0.00020 & 0.00074 \\
\hline 875 & $*$ & $-1.00 \mathrm{e}-06$ & 0.00017 & 0.00072 \\
\hline 925 & $*$ & $-1.00 \mathrm{e}-06$ & 0.00015 & 0.00071 \\
\hline 975 & $*$ & $-1.00 \mathrm{e}-06$ & 0.00015 & 0.00071 \\
\hline 1025 & $*$ & $-1.00 \mathrm{e}-06$ & 0.00015 & 0.00071 \\
\hline 1075 & $*$ & $-1.00 \mathrm{e}-06$ & 0.00016 & 0.00071 \\
\hline 1125 & $*$ & $-1.20 \mathrm{e}-06$ & 0.00018 & 0.00072 \\
\hline 1175 & $*$ & $-1.20 \mathrm{e}-06$ & 0.00021 & 0.00074 \\
\hline 1225 & * & $-1.20 \mathrm{e}-06$ & 0.00025 & 0.00077 \\
\hline 1275 & $*$ & $-1.00 \mathrm{e}-06$ & 0.00031 & 0.00081 \\
\hline 1325 & * & $-1.00 e-06$ & 0.00040 & 0.00086 \\
\hline 1375 & $*$ & $2.00 \mathrm{e}-06$ & 0.00051 & 0.00092 \\
\hline 1425 & $*$ & $6.66 \mathrm{e}-06$ & 0.00066 & 0.00101 \\
\hline 1475 & $*$ & $1.82 \mathrm{e}-05$ & 0.00088 & 0.00113 \\
\hline 1525 & $*$ & $4.78 \mathrm{e}-05$ & 0.00141 & 0.00261 \\
\hline 1575 & $*$ & 0.00010 & 0.00152 & 0.00215 \\
\hline
\end{tabular}


Table 10.12. (Contd.)

\begin{tabular}{|c|c|c|c|c|}
\hline Distance & \multicolumn{4}{|c|}{ Seepage rate $(\mathrm{cm} /$ day $)$} \\
\hline offshore $(\mathrm{m})$ & $\mathrm{R}=1$ & $\mathrm{R}=10$ & $\mathrm{R}=100$ & $\mathrm{R}=1000$ \\
\hline 1625 & $*$ & 0.00021 & 0.00177 & 0.00213 \\
\hline 1675 & $1.39 \mathrm{e}-06$ & 0.00040 & 0.00208 & 0.00224 \\
\hline 1725 & $8.33 \mathrm{e}-06$ & 0.00075 & 0.00245 & 0.00244 \\
\hline 1775 & $4.82 \mathrm{e}-05$ & 0.00141 & 0.00304 & 0.00284 \\
\hline 1825 & 0.00024 & 0.00239 & 0.00354 & 0.00315 \\
\hline 1875 & 0.00117 & 0.00419 & 0.00443 & 0.00377 \\
\hline 1925 & 0.00552 & 0.00769 & 0.00606 & 0.00486 \\
\hline 1975 & 0.03154 & 0.01976 & 0.01186 & 0.00827 \\
\hline
\end{tabular}

Table 10.13. Seepage rate versus distance offshore for shallow flow-through lake with moderate slope at different anisotropy ratios when the section is parallel to regional groundwater flow gradient. ${ }^{*}$ denotes absolute value of seepage rate $<10^{-7} \mathrm{~cm} /$ day.

\begin{tabular}{|c|c|c|c|c|}
\hline Distance & \multicolumn{5}{|c|}{ Seepage rate (cm/day) } \\
\hline offshore $(\mathrm{m})$ & $\mathrm{R}=1$ & $\mathrm{R}=10$ & $\mathrm{R}=100$ & $\mathrm{R}=1000$ \\
\hline 50 & -0.38103 & -0.28956 & -0.14544 & -0.04395 \\
\hline 150 & -0.02546 & -0.08561 & -0.07969 & -0.03605 \\
\hline 250 & -0.00192 & -0.03184 & -0.05346 & -0.02920 \\
\hline 350 & -0.00014 & -0.01192 & -0.03884 & -0.02557 \\
\hline 450 & $-8.92 \mathrm{e}-06$ & -0.00440 & -0.03089 & -0.02821 \\
\hline 550 & $-5.62 \mathrm{e}-07$ & -0.00150 & -0.01823 & -0.01203 \\
\hline 650 & $*$ & -0.00053 & -0.01169 & -0.00794 \\
\hline 750 & $*$ & -0.00019 & -0.00711 & -0.00480 \\
\hline 850 & $*$ & $-6.37 \mathrm{e}-05$ & -0.00351 & -0.00212 \\
\hline 950 & $*$ & $-1.21 \mathrm{e}-05$ & -0.00038 & 0.00035 \\
\hline 1050 & $*$ & $2.52 \mathrm{e}-05$ & 0.00267 & 0.00280 \\
\hline 1150 & $*$ & $8.80 \mathrm{e}-05$ & 0.00601 & 0.00537 \\
\hline 1250 & $*$ & 0.00025 & 0.01004 & 0.00827 \\
\hline 1350 & $*$ & 0.00069 & 0.01537 & 0.01182 \\
\hline 1450 & $7.44 \mathrm{e}-07$ & 0.00195 & 0.02316 & 0.01663 \\
\hline 1550 & $1.18 \mathrm{e}-05$ & 0.00568 & 0.03853 & 0.03726 \\
\hline 1650 & 0.00018 & 0.01536 & 0.04802 & 0.03335 \\
\hline 1750 & 0.00254 & 0.04098 & 0.06593 & 0.03870 \\
\hline 1850 & 0.03362 & 0.11028 & 0.09872 & 0.05043 \\
\hline 1950 & 0.51576 & 0.39654 & 0.22998 & 0.11638 \\
\hline
\end{tabular}


Table 10.14. Seepage rate versus distance offshore for shallow flow-through lake with moderate slope at different anisotropy ratios when the section is normal to regional groundwater flow gradient. ${ }^{*}$ denotes absolute value of seepage rate $<10^{-7} \mathrm{~cm} /$ day.

\begin{tabular}{|c|c|c|c|c|}
\hline Distance & \multicolumn{4}{|c|}{ Seepage rate $(\mathrm{cm} /$ day $)$} \\
\hline offshore $(\mathrm{m})$ & $\mathrm{R}=1$ & $\mathrm{R}=10$ & $\mathrm{R}=100$ & $\mathrm{R}=1000$ \\
\hline 50 & 0.00733 & 0.00484 & 0.00405 & 0.00446 \\
\hline 150 & 0.00042 & 0.00072 & 0.00141 & 0.00202 \\
\hline 250 & $2.49 \mathrm{e}-05$ & -0.00002 & 0.00065 & 0.00136 \\
\hline 350 & $1.13 \mathrm{e}-06$ & -0.00014 & 0.00021 & 0.00102 \\
\hline 450 & $*$ & -0.00014 & -0.00038 & 0.00016 \\
\hline 550 & $*$ & $-7.37 \mathrm{e}-05$ & -0.00024 & 0.00052 \\
\hline 650 & $*$ & $-4.14 \mathrm{e}-05$ & -0.00030 & 0.00044 \\
\hline 750 & $*$ & $-2.42 \mathrm{e}-05$ & -0.00034 & 0.00039 \\
\hline 850 & $*$ & $-1.56 \mathrm{e}-05$ & -0.00037 & 0.00036 \\
\hline 950 & $*$ & $-1.21 \mathrm{e}-05$ & -0.00038 & 0.00035 \\
\hline 1050 & $*$ & $-1.22 \mathrm{e}-05$ & -0.00038 & 0.00035 \\
\hline 1150 & $*$ & $-1.57 \mathrm{e}-05$ & -0.00036 & 0.00036 \\
\hline 1250 & $*$ & $-2.45 e-05$ & -0.00034 & 0.00039 \\
\hline 1350 & $*$ & $-4.21 \mathrm{e}-05$ & -0.00029 & 0.00043 \\
\hline 1450 & * & $-7.52 \mathrm{e}-05$ & -0.00023 & 0.00052 \\
\hline 1550 & $*$ & -0.00014 & -0.00037 & 0.00015 \\
\hline 1650 & $8.02 \mathrm{e}-07$ & -0.00015 & 0.00021 & 0.00100 \\
\hline 1750 & $2.05 \mathrm{e}-05$ & -0.00004 & 0.00062 & 0.00134 \\
\hline 1850 & 0.00036 & 0.00066 & 0.00133 & 0.00200 \\
\hline 1950 & 0.00643 & 0.00456 & 0.00385 & 0.00443 \\
\hline
\end{tabular}

Table 10.15. Seepage rate versus distance offshore for deep flow-through lake with moderate slope at different anisotropy ratios when the section is parallel to regional groundwater flow gradient. ${ }^{*}$ denotes absolute value of seepage rate $<10^{-7} \mathrm{~cm} /$ day.

\begin{tabular}{|c|c|c|c|c|}
\hline Distance & \multicolumn{4}{|c|}{ Seepage rate $(\mathrm{cm} /$ day $)$} \\
\hline offshore $(\mathrm{m})$ & $\mathrm{R}=1$ & $\mathrm{R}=10$ & $\mathrm{R}=100$ & $\mathrm{R}=1000$ \\
\hline 50 & -0.37860 & -0.28727 & -0.14462 & -0.04373 \\
\hline 150 & -0.02533 & -0.08485 & -0.07892 & -0.03562 \\
\hline 250 & -0.00192 & -0.03160 & -0.05276 & -0.02873 \\
\hline 350 & -0.00014 & -0.01184 & -0.03806 & -0.02477 \\
\hline 450 & $-9.14 \mathrm{e}-06$ & -0.00434 & -0.02908 & -0.02530 \\
\hline
\end{tabular}


Table 10.15. (Contd.)

\begin{tabular}{|c|c|c|c|c|}
\hline Distance & \multicolumn{4}{|c|}{ Seepage rate $(\mathrm{cm} /$ day $)$} \\
\hline offshore $(\mathrm{m})$ & $\mathrm{R}=1$ & $\mathrm{R}=10$ & $\mathrm{R}=100$ & $\mathrm{R}=1000$ \\
\hline 550 & $-5.55 \mathrm{e}-07$ & -0.00156 & -0.02141 & -0.02241 \\
\hline 650 & $*$ & -0.00054 & -0.01517 & -0.01882 \\
\hline 750 & $*$ & -0.00018 & -0.01007 & -0.01476 \\
\hline 850 & $*$ & $-5.56 \mathrm{e}-05$ & -0.00566 & -0.00978 \\
\hline 950 & $*$ & $-1.06 \mathrm{e}-05$ & -0.00112 & -0.00175 \\
\hline 1050 & $*$ & $1.96 \mathrm{e}-05$ & 0.00444 & 0.01128 \\
\hline 1150 & $*$ & $7.58 \mathrm{e}-05$ & 0.00897 & 0.01742 \\
\hline 1250 & $*$ & 0.00024 & 0.01388 & 0.02185 \\
\hline 1350 & $*$ & 0.00070 & 0.01983 & 0.02585 \\
\hline 1450 & $7.36 \mathrm{e}-07$ & 0.00203 & 0.02727 & 0.02969 \\
\hline 1550 & $1.19 \mathrm{e}-05$ & 0.00563 & 0.03651 & 0.03302 \\
\hline 1650 & 0.00018 & 0.01533 & 0.04740 & 0.03231 \\
\hline 1750 & 0.00253 & 0.04085 & 0.06550 & 0.03823 \\
\hline 1850 & 0.03353 & 0.10979 & 0.09835 & 0.05009 \\
\hline 1950 & 0.51350 & 0.39498 & 0.22926 & 0.11575 \\
\hline
\end{tabular}

Table 10.16. Seepage rate versus distance offshore for deep flow-through lake with moderate slope at different anisotropy ratios when the section is normal to regional ground- water flow gradient. ${ }^{*}$ denotes absolute value of seepage rate $<10^{-7} \mathrm{~cm} /$ day.

\begin{tabular}{|c|c|c|c|c|}
\hline Distance & \multicolumn{5}{|c|}{ Seepage rate $(\mathrm{cm} /$ day $)$} \\
\hline offshore $(\mathrm{m})$ & $\mathrm{R}=1$ & $\mathrm{R}=10$ & $\mathrm{R}=100$ & $\mathrm{R}=1000$ \\
\hline 50 & 0.00836 & 0.00590 & 0.00473 & 0.00462 \\
\hline 150 & 0.00049 & 0.00103 & 0.00176 & 0.00209 \\
\hline 250 & $3.01 \mathrm{e}-05$ & 0.00010 & 0.00091 & 0.00137 \\
\hline 350 & $1.50 \mathrm{e}-06$ & -0.00010 & 0.00040 & 0.00095 \\
\hline 450 & $*$ & -0.00012 & -0.00026 & -0.00016 \\
\hline 550 & $*$ & $-7.93 \mathrm{e}-05$ & -0.00053 & -0.00057 \\
\hline 650 & $*$ & $-4.56 \mathrm{e}-05$ & -0.00070 & -0.00088 \\
\hline 750 & $*$ & $-2.53 \mathrm{e}-05$ & -0.00083 & -0.00121 \\
\hline 850 & $*$ & $-1.50 \mathrm{e}-05$ & -0.00097 & -0.00158 \\
\hline 950 & $*$ & $-1.06 \mathrm{e}-05$ & -0.00112 & -0.00175 \\
\hline 1050 & $*$ & $-1.06 \mathrm{e}-05$ & -0.00112 & -0.00175 \\
\hline 1150 & $*$ & $-1.50 \mathrm{e}-05$ & -0.00098 & -0.00157 \\
\hline
\end{tabular}


Table 10.16 (Contd.)

\begin{tabular}{|c|c|c|c|c|}
\hline Distance & \multicolumn{4}{|c|}{ Seepage rate $(\mathrm{cm} /$ day $)$} \\
\hline offshore $(\mathrm{m})$ & $\mathrm{R}=1$ & $\mathrm{R}=10$ & $\mathrm{R}=100$ & $\mathrm{R}=1000$ \\
\hline 1250 & $*$ & $-2.53 \mathrm{e}-05$ & -0.00084 & -0.00119 \\
\hline 1350 & $*$ & $-4.56 \mathrm{e}-05$ & -0.00071 & -0.00086 \\
\hline 1450 & $*$ & $-7.89 \mathrm{e}-05$ & -0.00054 & -0.00055 \\
\hline 1550 & $*$ & -0.00012 & -0.00028 & -0.00013 \\
\hline 1650 & $1.38 \mathrm{e}-06$ & -0.00009 & 0.00038 & 0.00097 \\
\hline 1750 & $2.86 \mathrm{e}-05$ & 0.00011 & 0.00087 & 0.00140 \\
\hline 1850 & 0.00047 & 0.00106 & 0.00170 & 0.00213 \\
\hline 1950 & 0.00805 & 0.00597 & 0.00462 & 0.00470 \\
\hline
\end{tabular}

Table 10.17. Seepage rate versus distance offshore for shallow flow-through lake with low slope at different anisotropy ratios when the section is parallel to regional groundwater flow gradient. ${ }^{*}$ denotes absolute value of seepage rate $<10^{-7} \mathrm{~cm} /$ day.

\begin{tabular}{|c|c|c|c|c|}
\hline Distance & \multicolumn{4}{|c|}{ Seepage rate $(\mathrm{cm} /$ day $)$} \\
\hline offshore (m) & $\mathrm{R}=1$ & $\mathrm{R}=10$ & $R=100$ & $\mathrm{R}=1000$ \\
\hline 25 & -0.71098 & -0.46690 & -0.23645 & -0.08498 \\
\hline 75 & -0.12834 & -0.18260 & -0.10748 & -0.02801 \\
\hline 125 & -0.02925 & -0.09967 & -0.06798 & -0.01625 \\
\hline 175 & -0.00690 & -0.06777 & -0.08274 & -0.05124 \\
\hline 225 & -0.00156 & -0.03959 & -0.05368 & -0.01929 \\
\hline 275 & -0.00035 & -0.02325 & -0.03760 & -0.01153 \\
\hline 325 & $-7.87 e-05$ & -0.01605 & -0.04838 & -0.03730 \\
\hline 375 & $-1.71 \mathrm{e}-05$ & -0.00934 & -0.03260 & -0.01452 \\
\hline 425 & $-3.70 e-06$ & -0.00543 & -0.02318 & -0.00872 \\
\hline 475 & $-8.12 e-07$ & -0.00370 & -0.02988 & -0.02826 \\
\hline 525 & $*$ & -0.00212 & -0.02015 & -0.01101 \\
\hline 575 & $*$ & -0.00122 & -0.01429 & -0.00660 \\
\hline 625 & $*$ & -0.00082 & -0.01798 & -0.02078 \\
\hline 675 & $*$ & -0.00046 & -0.01210 & -0.00850 \\
\hline 725 & $*$ & -0.00027 & -0.00915 & -0.00643 \\
\hline 775 & $*$ & -0.00016 & -0.00679 & -0.00465 \\
\hline 825 & * & $-9.15 e-05$ & -0.00475 & -0.00306 \\
\hline 875 & $*$ & $-5.05 e-05$ & -0.00290 & -0.00159 \\
\hline 925 & * & $-2.35 e-05$ & -0.00117 & -0.00019 \\
\hline 975 & * & $-3.00 e-06$ & 0.00051 & 0.00119 \\
\hline
\end{tabular}


Table 10.17. (Contd.)

\begin{tabular}{|c|c|c|c|c|}
\hline Distance & \multicolumn{4}{|c|}{ Seepage rate $(\mathrm{cm} /$ day $)$} \\
\hline offshore $(\mathrm{m})$ & $\mathrm{R}=1$ & $\mathrm{R}=10$ & $\mathrm{R}=100$ & $\mathrm{R}=1000$ \\
\hline 1025 & $*$ & $1.64 \mathrm{e}-05$ & 0.00219 & 0.00256 \\
\hline 1075 & $*$ & $3.96 e-05$ & 0.00393 & 0.00397 \\
\hline 1125 & * & $7.30 e-05$ & 0.00578 & 0.00546 \\
\hline 1175 & $*$ & 0.00013 & 0.00781 & 0.00706 \\
\hline 1225 & $*$ & 0.00021 & 0.01013 & 0.00883 \\
\hline 1275 & $*$ & 0.00036 & 0.01288 & 0.01088 \\
\hline 1325 & * & 0.00061 & 0.01640 & 0.01335 \\
\hline 1375 & * & 0.00107 & 0.02367 & 0.03018 \\
\hline 1425 & $*$ & 0.00160 & 0.01851 & 0.00932 \\
\hline 1475 & * & 0.00278 & 0.02581 & 0.01529 \\
\hline 1525 & $1.08 \mathrm{e}-06$ & 0.00483 & 0.03788 & 0.03842 \\
\hline 1575 & $4.94 \mathrm{e}-06$ & 0.00708 & 0.02919 & 0.01176 \\
\hline 1625 & $2.29 \mathrm{e}-05$ & 0.01216 & 0.04088 & 0.01952 \\
\hline 1675 & 0.00011 & 0.02085 & 0.06044 & 0.05022 \\
\hline 1725 & 0.00046 & 0.03015 & 0.04690 & 0.01559 \\
\hline 1775 & 0.00207 & 0.05127 & 0.06694 & 0.02624 \\
\hline 1825 & 0.00914 & 0.08770 & 0.10344 & 0.07209 \\
\hline 1875 & 0.03883 & 0.12903 & 0.08545 & 0.02343 \\
\hline 1925 & 0.17117 & 0.23703 & 0.13656 & 0.04151 \\
\hline 1975 & 0.97035 & 0.65204 & 0.39317 & 0.23835 \\
\hline
\end{tabular}

Table 10.18. Seepage rate versus distance offshore for shallow flow-through lake with low slope at different anisotropy ratios when the section is normal to regional groundwater flow gradient. ${ }^{*}$ denotes absolute value of seepage rate $<10^{-7} \mathrm{~cm} /$ day.

\begin{tabular}{|c|c|c|c|c|}
\hline Distance & \multicolumn{4}{|c|}{ Seepage rate $(\mathrm{cm} /$ day $)$} \\
\hline offshore $(\mathrm{m})$ & $\mathrm{R}=1$ & $\mathrm{R}=10$ & $\mathrm{R}=100$ & $\mathrm{R}=1000$ \\
\hline 25 & 0.03672 & 0.02308 & 0.01475 & 0.01372 \\
\hline 75 & 0.00627 & 0.00828 & 0.00560 & 0.00298 \\
\hline 125 & 0.00134 & 0.00432 & 0.00350 & 0.00168 \\
\hline 175 & 0.00030 & 0.00282 & 0.00425 & 0.00516 \\
\hline 225 & $6.36 \mathrm{e}-05$ & 0.00157 & 0.00276 & 0.00188 \\
\hline 275 & $1.34 \mathrm{e}-05$ & 0.00088 & 0.00195 & 0.00112 \\
\hline 325 & $2.80 \mathrm{e}-06$ & 0.00058 & 0.00253 & 0.00367 \\
\hline 375 & $5.33 \mathrm{e}-07$ & 0.00032 & 0.00174 & 0.00147 \\
\hline
\end{tabular}


Table 10.18. (Contd.)

\begin{tabular}{|c|c|c|c|c|}
\hline Distance & \multicolumn{4}{|c|}{ Seepage rate $(\mathrm{cm} /$ day $)$} \\
\hline offshore $(\mathrm{m})$ & $\mathrm{R}=1$ & $\mathrm{R}=10$ & $\mathrm{R}=100$ & $\mathrm{R}=1000$ \\
\hline 425 & $*$ & 0.00017 & 0.00125 & 0.00090 \\
\hline 475 & $*$ & 0.00011 & 0.00166 & 0.00306 \\
\hline 525 & $*$ & $5.27 \mathrm{e}-05$ & 0.00116 & 0.00132 \\
\hline 575 & $*$ & $2.49 \mathrm{e}-05$ & 0.00085 & 0.00084 \\
\hline 625 & * & $1.25 \mathrm{e}-05$ & 0.00114 & 0.00294 \\
\hline 675 & $*$ & $3.74 \mathrm{e}-06$ & 0.00085 & 0.00154 \\
\hline 725 & $*$ & $-6.88 \mathrm{e}-07$ & 0.00073 & 0.00142 \\
\hline 775 & * & $-2.00 e-06$ & 0.00065 & 0.00133 \\
\hline 825 & * & $-2.72 e-06$ & 0.00059 & 0.00127 \\
\hline 875 & $*$ & $-2.96 \mathrm{e}-06$ & 0.00055 & 0.00123 \\
\hline 925 & $*$ & $-3.01 e-06$ & 0.00052 & 0.00120 \\
\hline 975 & $*$ & $-3.00 e-06$ & 0.00051 & 0.00119 \\
\hline 1025 & * & $-3.01 \mathrm{e}-06$ & 0.00051 & 0.00118 \\
\hline 1075 & $*$ & $-3.02 \mathrm{e}-06$ & 0.00052 & 0.00119 \\
\hline 1125 & $*$ & $-3.00 e-06$ & 0.00055 & 0.00120 \\
\hline 1175 & $*$ & $-2.82 e-06$ & 0.00059 & 0.00123 \\
\hline 1225 & $*$ & $-2.22 e-06$ & 0.00065 & 0.00128 \\
\hline 1275 & $*$ & $-6.88 e-07$ & 0.00073 & 0.00135 \\
\hline 1325 & $*$ & $2.82 \mathrm{e}-06$ & 0.00085 & 0.00145 \\
\hline 1375 & * & $1.07 \mathrm{e}-05$ & 0.00115 & 0.00275 \\
\hline 1425 & $*$ & $2.22 \mathrm{e}-05$ & 0.00086 & 0.00078 \\
\hline 1475 & $*$ & $4.79 e-05$ & 0.00116 & 0.00122 \\
\hline 1525 & $*$ & 0.000102 & 0.00173 & 0.00294 \\
\hline 1575 & $*$ & 0.000161 & 0.00126 & 0.00083 \\
\hline 1625 & $4.12 \mathrm{e}-07$ & 0.000302 & 0.00175 & 0.00135 \\
\hline 1675 & $2.29 \mathrm{e}-06$ & 0.000559 & 0.00255 & 0.00336 \\
\hline 1725 & $1.15 \mathrm{e}-05$ & 0.000858 & 0.00196 & 0.00103 \\
\hline 1775 & $5.72 \mathrm{e}-05$ & 0.001536 & 0.00278 & 0.00172 \\
\hline 1825 & 0.00027 & 0.002758 & 0.00427 & 0.00474 \\
\hline 1875 & 0.00124 & 0.004222 & 0.00351 & 0.00154 \\
\hline 1925 & 0.00570 & 0.008050 & 0.00561 & 0.00275 \\
\hline 1975 & 0.03297 & 0.022318 & 0.01475 & 0.01272 \\
\hline
\end{tabular}




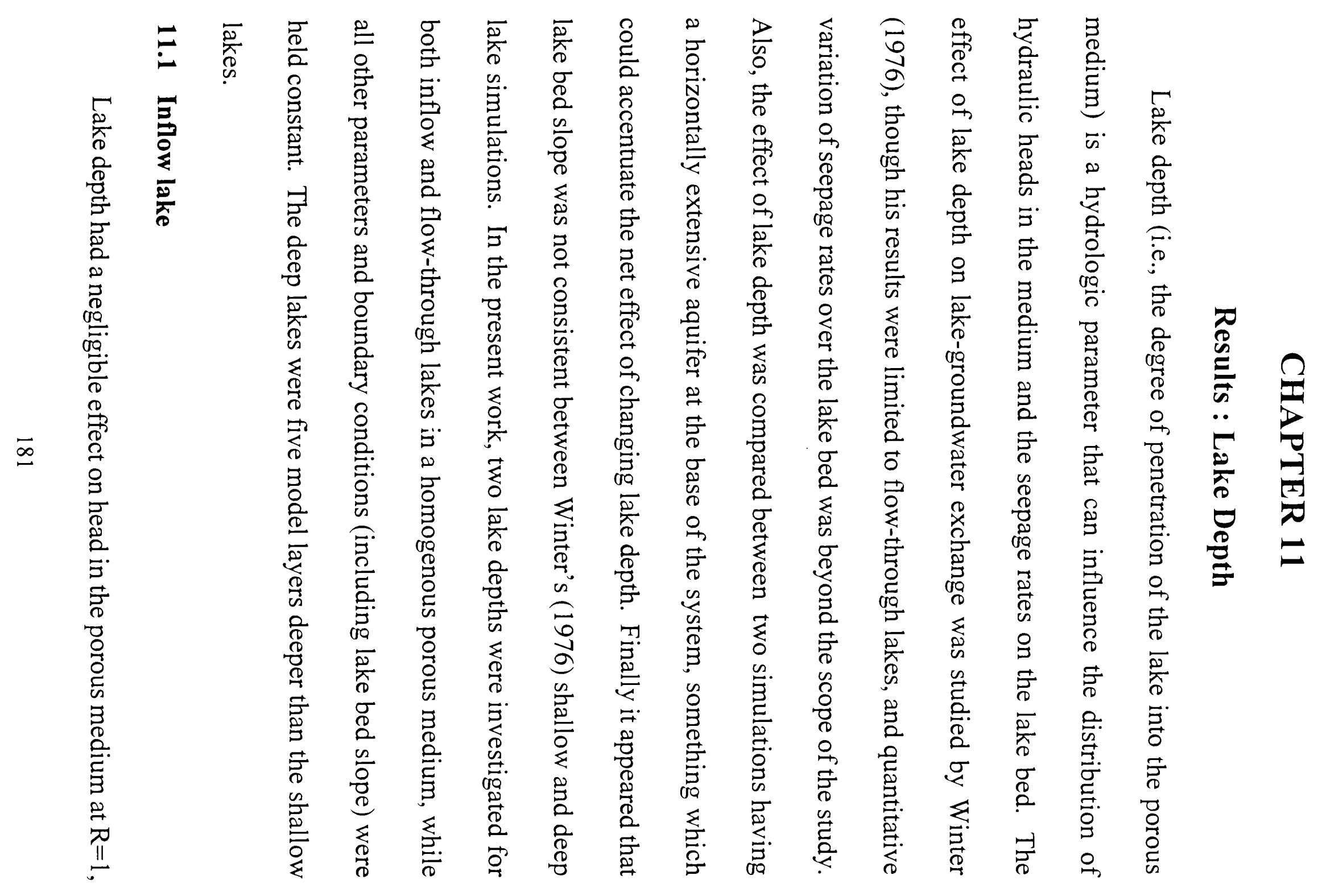




\begin{tabular}{|c|c|c|c|c|c|c|}
\hline 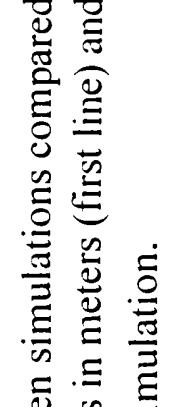 & & 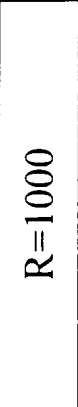 & 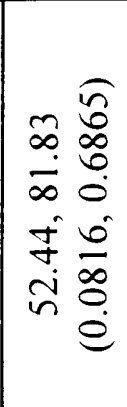 & 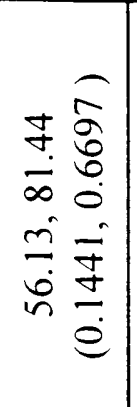 & 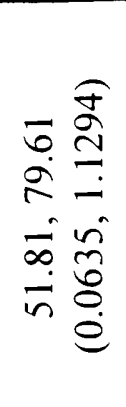 & 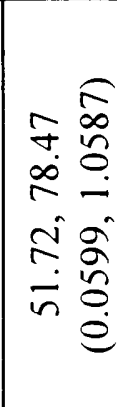 \\
\hline 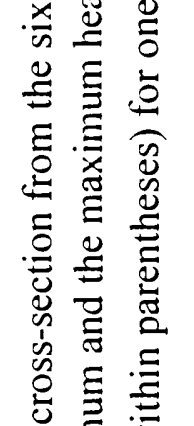 & $\begin{array}{l}\widehat{\widetilde{\Omega}} \\
\stackrel{0}{\bar{\Xi}} \\
\simeq\end{array}$ & $\frac{8}{\simeq}$ & 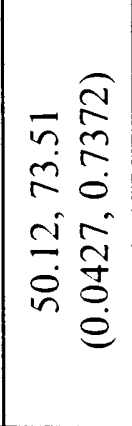 & 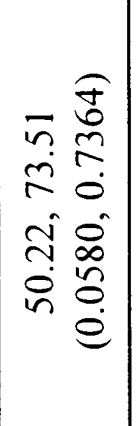 & 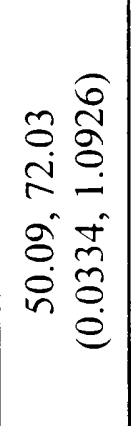 & 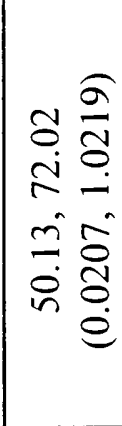 \\
\hline 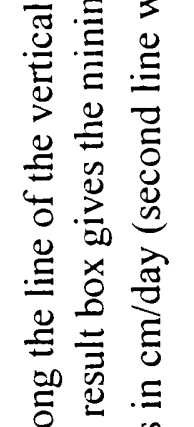 & 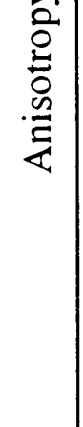 & $\frac{0}{\Perp 1}$ & 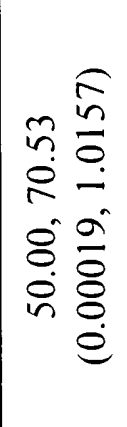 & 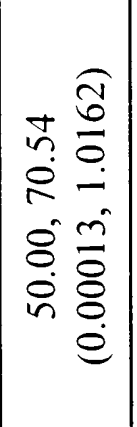 & 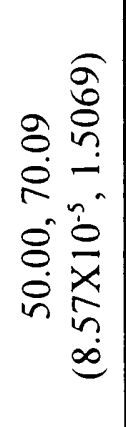 & 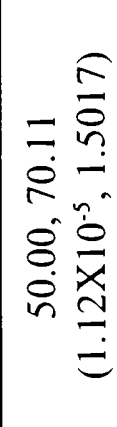 \\
\hline 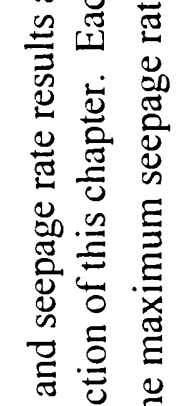 & & $\mathbb{\pi}$ & 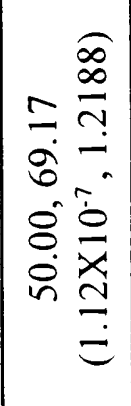 & 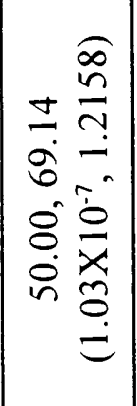 & 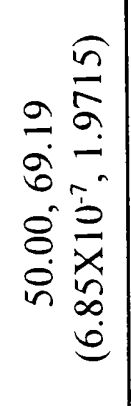 & 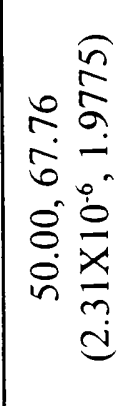 \\
\hline 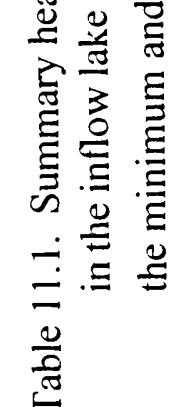 & 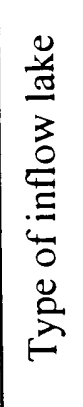 & & 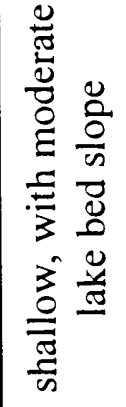 & 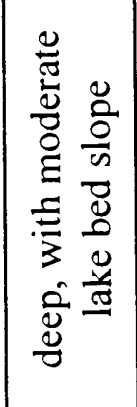 & 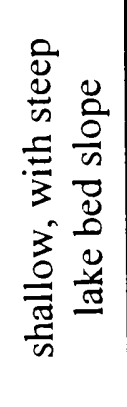 & 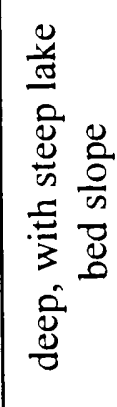 \\
\hline
\end{tabular}


10, and 100, and a small effect at $\mathrm{R}=1000$ (Table 11.1; Figs. 6.2 to 6.5; Fig.

11.1 and 11.2). At $\mathrm{R}=1000$, the maximum head was 0.39 meter lower for the deep lake, compared to the shallow lake, for lakes with moderate lake bed slope; the difference was 0.74 meter for lakes with steep lake bed slope (Table 11.1). The minimum heads below the center of the lakes were very similar between shallow and deep lakes for all simulations (except for lakes with moderate lake bed slope at $\mathrm{R}=1000$, where the minimum head below the lake was 3.7 meters higher for the deep lake).

As the heads in the porous medium were almost identical at all anisotropy ratios for shallow and deep lakes, the seepage rates into the lake were expected to be similar. At $R=1$ and 10 , the seepage rates of the deep lakes and shallow lakes perfectly coincide with each other (Figs. 11.3 and 11.4). The seepage maps were also identical for shallow and deep lakes at $R$ $=1$ (Figs. 7.7, 8.15, 10.6, and 11.7) and $\mathrm{R}=10$ (Figs. 7.9, 8.17, 10.7, and 11.8). At $R=100$, the seepage rate near the shore of the shallow lake was slightly higher than that for the deep lake when the lake bed slope was steep. Also, the high seepage zone near the shore of the shallow lake with steep slope had a larger aerial extent than in the corresponding deep lake simulation at $\mathrm{R}=100$.

Nearshore seepage rates were very similar for the shallow and deep lakes with 
moderate lake bed slope (Fig. 11.5). The deep lake had slightly higher seepage rates offshore in the simulations with moderate lake bed slope, but lower seepage rate offshore in the simulations with steep lake bed slope. When the seepage maps were considered, the aerial extent of the low seepage zone defined by a seepage of $0.1 \mathrm{~cm} /$ day or lower was slightly larger for the shallow lake with steep slope than for the corresponding deep lake at $\mathrm{R}=100$ (Figs. 10.8 and 11.7).

At $R=1000$, the seepage rate near the shore was always higher for the shallow lake (Fig. 11.6) though the seepage rates offshore were very different for shallow and deep lakes when different lake bed slopes were considered. The seepage rate of the deep lake with moderate slope increased with distance offshore. As noted in chapter 10, this effect was observed in simulations where there was no flat (horizontal) area in the center of the lake bed; the deep lakes with moderate lake bed slope are conical in shape, and seepage is focused around their bottom "tips", leading to an increase in seepage rate from midslope to lake center. Also, as discussed in chapter 6, the presence of a break in lake bed slope leads to a local maximum in seepage at about 450 meters offshore in the shallow lake. The seepage rates of the shallow and the deep lakes were very similar in the simulations with steep lake bed slope. The 


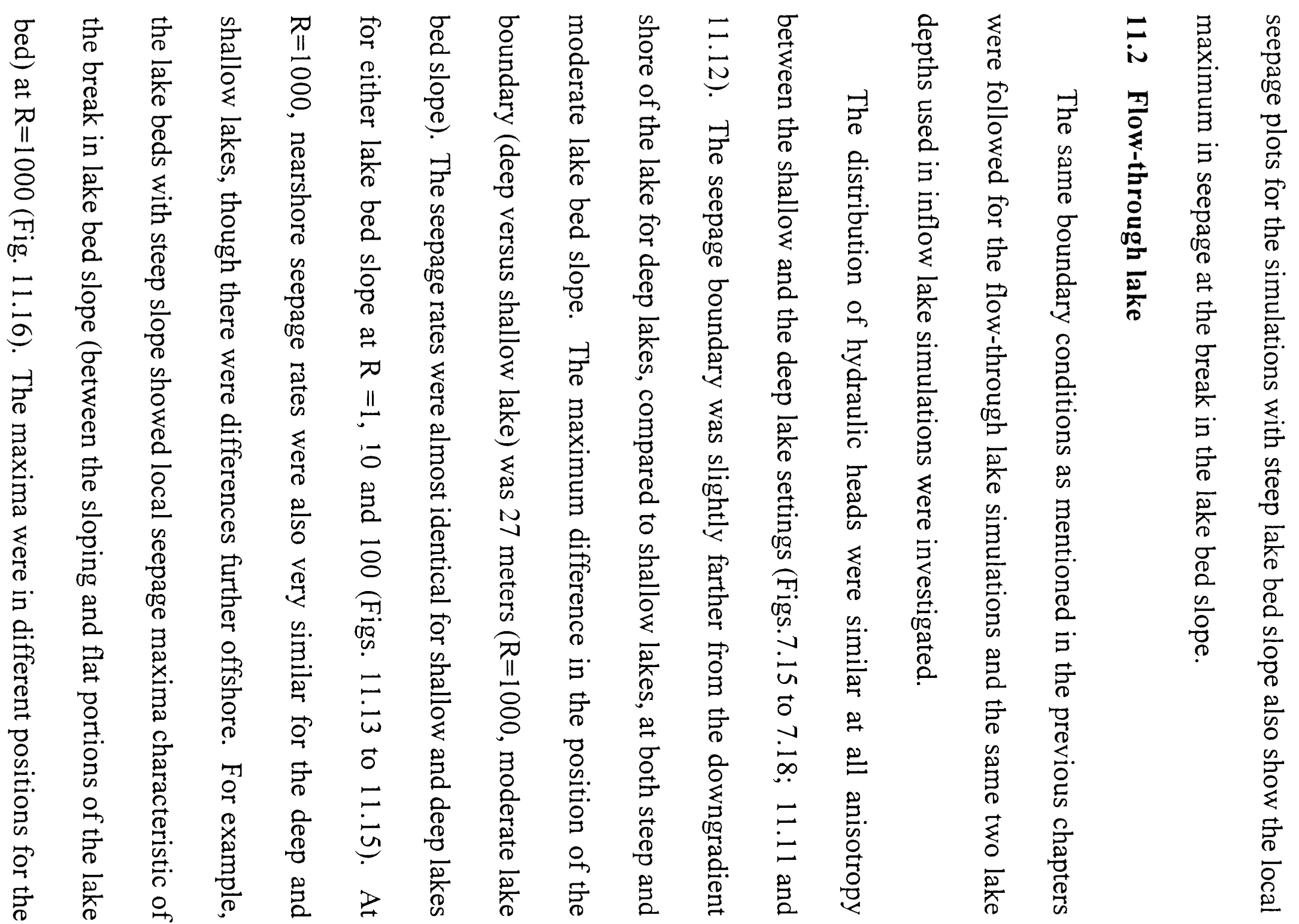




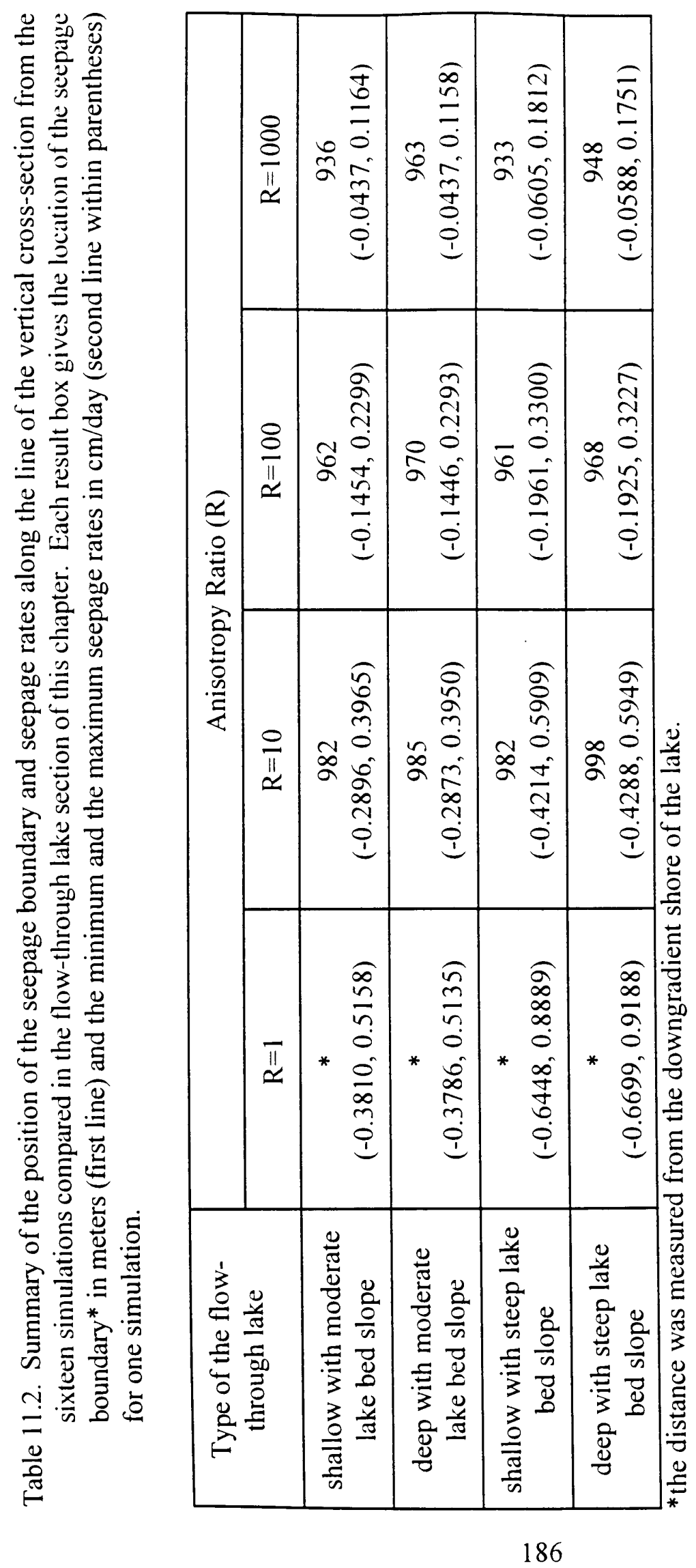


deep and shallow lakes, since the break in slope occurred farther offshore for the deep lake. This effect was present on both the inseepage (upgradient) and outseepage (downgradient) sides of the lake bed. For the lakes with moderate bed slope, the focussing of seepage around the tip of the conical deep lake resulted in higher seepage rates in the center of this lake, compared to the shallow lake (Fig. 11.16). As the seepage rates were very similar, so were the seepage maps at all $\mathrm{R}$ (Figs. 7.21, 7.23, 7.25, 7.27; 11.17 to 11.20). Changing lake depth does not appear to have a large effect on spatial patterns of lake bed seepage in flow-through lakes, unless there is high anisotropy in the surrounding porous medium.

In addition, changing lake depth did not affect the overall amount of groundwater exchange with lakes. The total groundwater inseepage and lake water outseepage were very similar, at all anisotropy ratios, for shallow and deep lakes (Table 11.3). The deep lake had slightly higher outseepage and inseepage than the shallow lake at $\mathrm{R}=1000$. Because the lake volume was larger in deep lakes, annual inseepage and outseepage as a percentage of lake volume were slightly lower. Krabbenhoft et al.(1990) estimated groundwater exchange with Sparkling lake with a numerical model, and the average annual inseepage and outseepage from initial simulations were $1.4 \times 10^{5}$ and $4.1 \times 10^{5}$ 
$\mathrm{m}^{3} /$ year, respectively. From Krabbenhoft et al.(1990a), the lake volume was $8.84 \times 10^{6} \mathrm{~m}^{3}$; thus annual groundwater inseepage and lake water outseepage constituted $1.58 \%$ and $4.64 \%$ of the lake volume.

\begin{tabular}{|c|c|c|c|c|}
\hline \multirow{2}{*}{$\begin{array}{c}\text { Anisotropy } \\
\text { Ratio (R) }\end{array}$} & $\begin{array}{c}\text { Total } \\
\text { volumetric } \\
\text { groundwater } \\
\text { inseepage } \\
\left(\mathrm{m}^{3} / \text { year }\right)\end{array}$ & $\begin{array}{c}\text { Groundwater } \\
\text { inseepage per } \\
\text { year as a } \\
\text { percentage of } \\
\text { lake volume }\end{array}$ & $\begin{array}{c}\text { Total } \\
\text { volumetric } \\
\text { groundwater } \\
\text { inseepage } \\
\left(\mathrm{m}^{3} / \text { year }\right)\end{array}$ & $\begin{array}{c}\text { Groundwater } \\
\text { inseepage per } \\
\text { year as a } \\
\text { percentage of } \\
\text { lake volume }\end{array}$ \\
\hline 1 & \multicolumn{2}{|c|}{ Shallow } & \multicolumn{2}{c|}{ Deep } \\
\hline 10 & $4.34 \times 10^{5}$ & 2.10 & $4.34 \times 10^{5}$ & 1.83 \\
\hline 100 & $3.14 \times 10^{5}$ & 2.00 & $4.14 \times 10^{5}$ & 1.75 \\
\hline 1000 & $1.94 \times 10^{5}$ & 1.62 & $3.36 \times 10^{5}$ & 1.42 \\
\hline
\end{tabular}

\begin{tabular}{|c|c|c|c|c|}
\hline \multirow{2}{*}{$\begin{array}{c}\text { Anisotropy } \\
\text { Ratio (R) }\end{array}$} & $\begin{array}{c}\text { Total } \\
\text { volumetric } \\
\text { lake water } \\
\text { outseepage } \\
\left(\mathrm{m}^{3} / \text { year }\right)\end{array}$ & $\begin{array}{c}\text { Lake water } \\
\text { outseepage per } \\
\text { year as a } \\
\text { percentage of } \\
\text { lake volume }\end{array}$ & $\begin{array}{c}\text { Total } \\
\text { volumetric } \\
\text { lake water } \\
\text { outseepage } \\
\left(\mathrm{m}^{3} / \text { year }\right)\end{array}$ & $\begin{array}{c}\text { Lake water } \\
\text { outseepage per } \\
\text { year as a } \\
\text { percentage of } \\
\text { lake volume }\end{array}$ \\
\hline 1 & \multicolumn{2}{|c|}{ Shallow } & \multicolumn{2}{|c|}{ Deep } \\
\hline 10 & $3.09 \times 10^{5}$ & 1.50 & $3.07 \times 10^{5}$ & 1.30 \\
\hline 100 & $2.94 \times 10^{5}$ & 1.42 & $2.91 \times 10^{5}$ & 1.23 \\
\hline 1000 & $1.02 \times 10^{5}$ & 0.49 & $2.25 \times 10^{5}$ & 0.95 \\
\hline
\end{tabular}

Table 11.3. Groundwater inseepage (above) and lake water outseepage (below) per year as a percentage of lake volume in coarse grid shallow (lake volume $=2.064 \times 10^{7} \mathrm{~m}^{3}$ ) and deep (lake volume $=2.368 \times 10^{7} \mathrm{~m}^{3}$ ) flow-through lakes with moderate bed slope at different anisotropy ratios. 


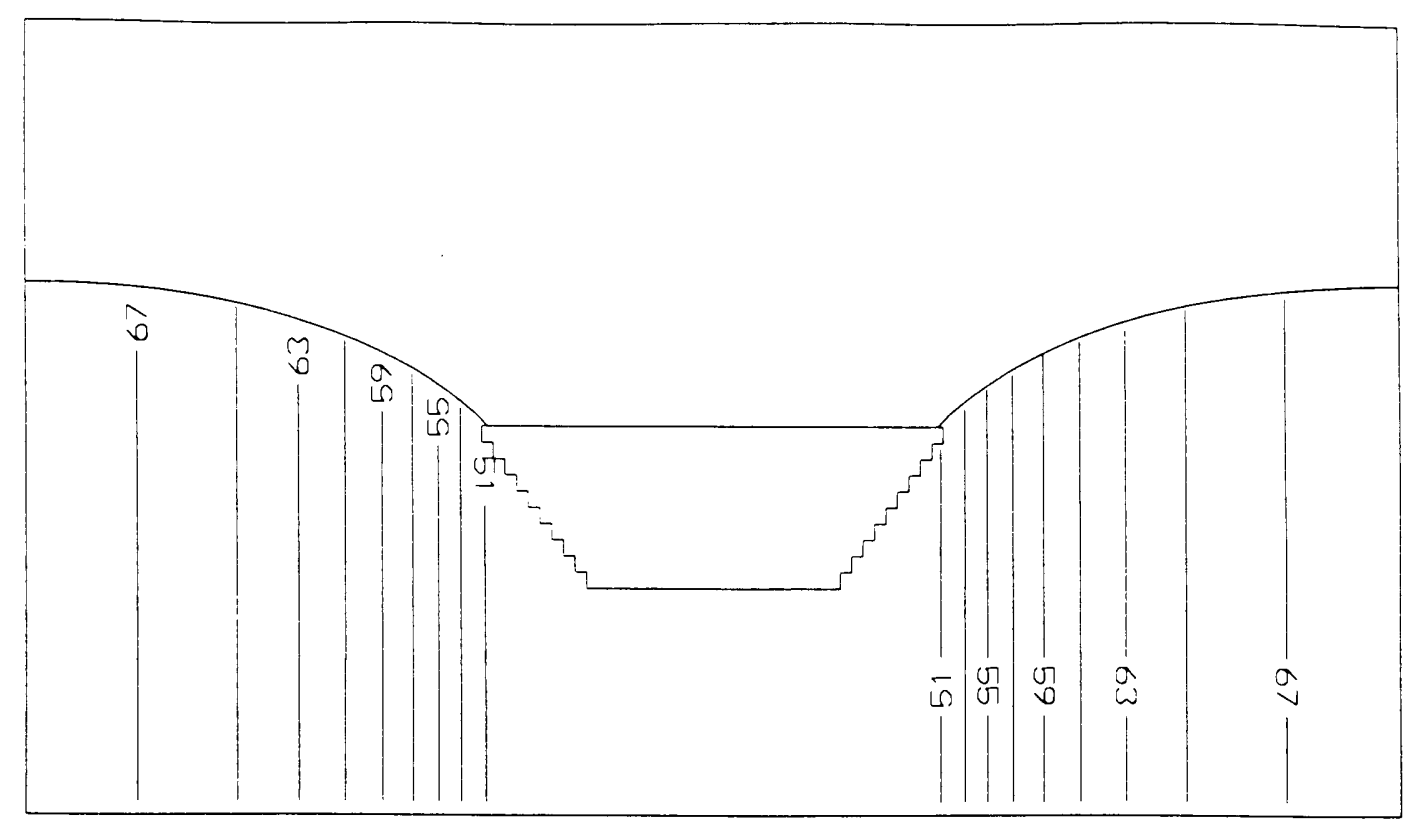

Anisotropy Ratio $=1$

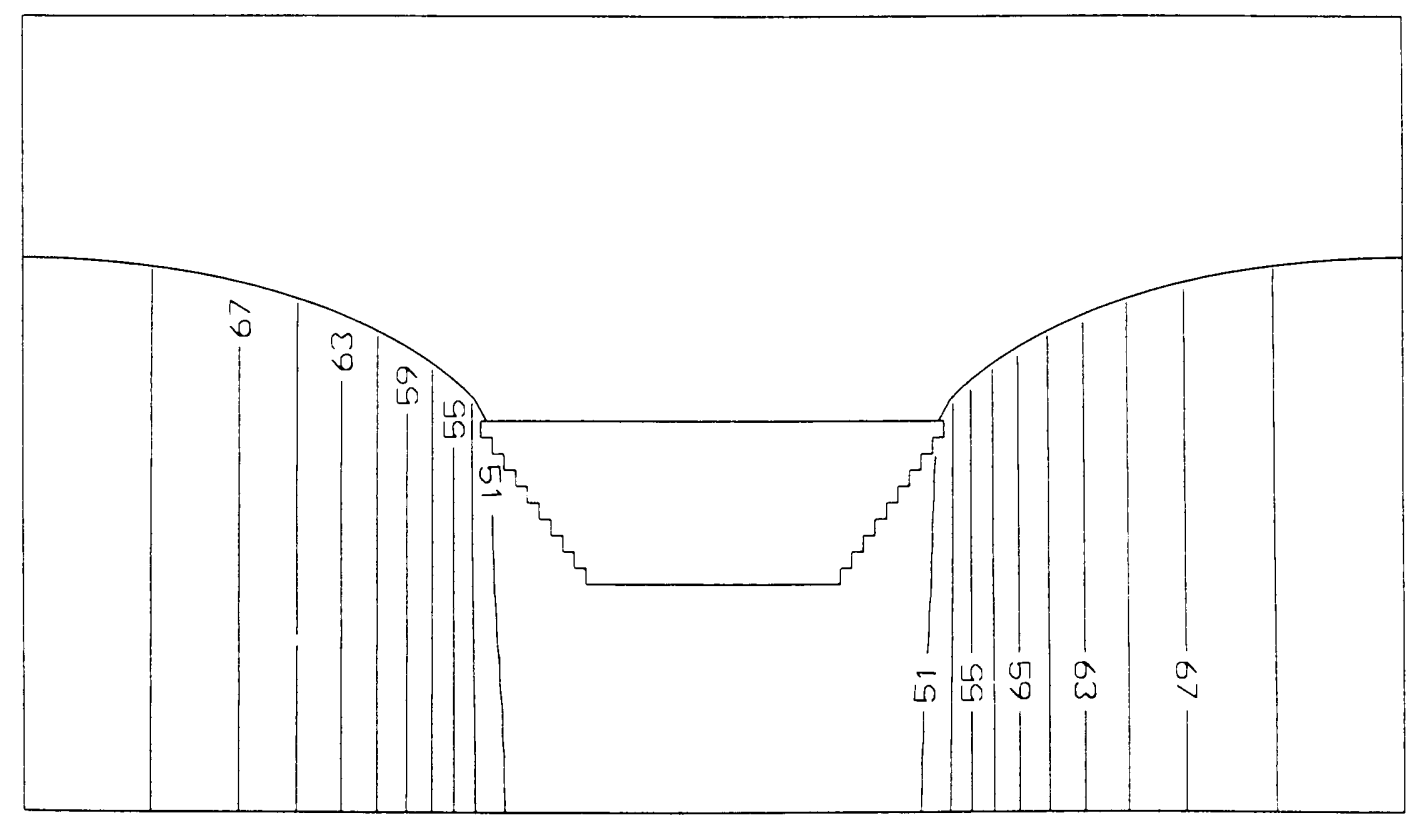

Anisotropy Ratio $=10$

Fig. 11.1. Distribution of hydraulic heads in the porous medium surrounding deep inflow lakes with steep lake bed slope at $R=1$ and $R=10$. Fig. 10.1 gives analogous crosssections of shallow inflow lakes with steep lake bed slope at $R=1$ and $R=10$. 


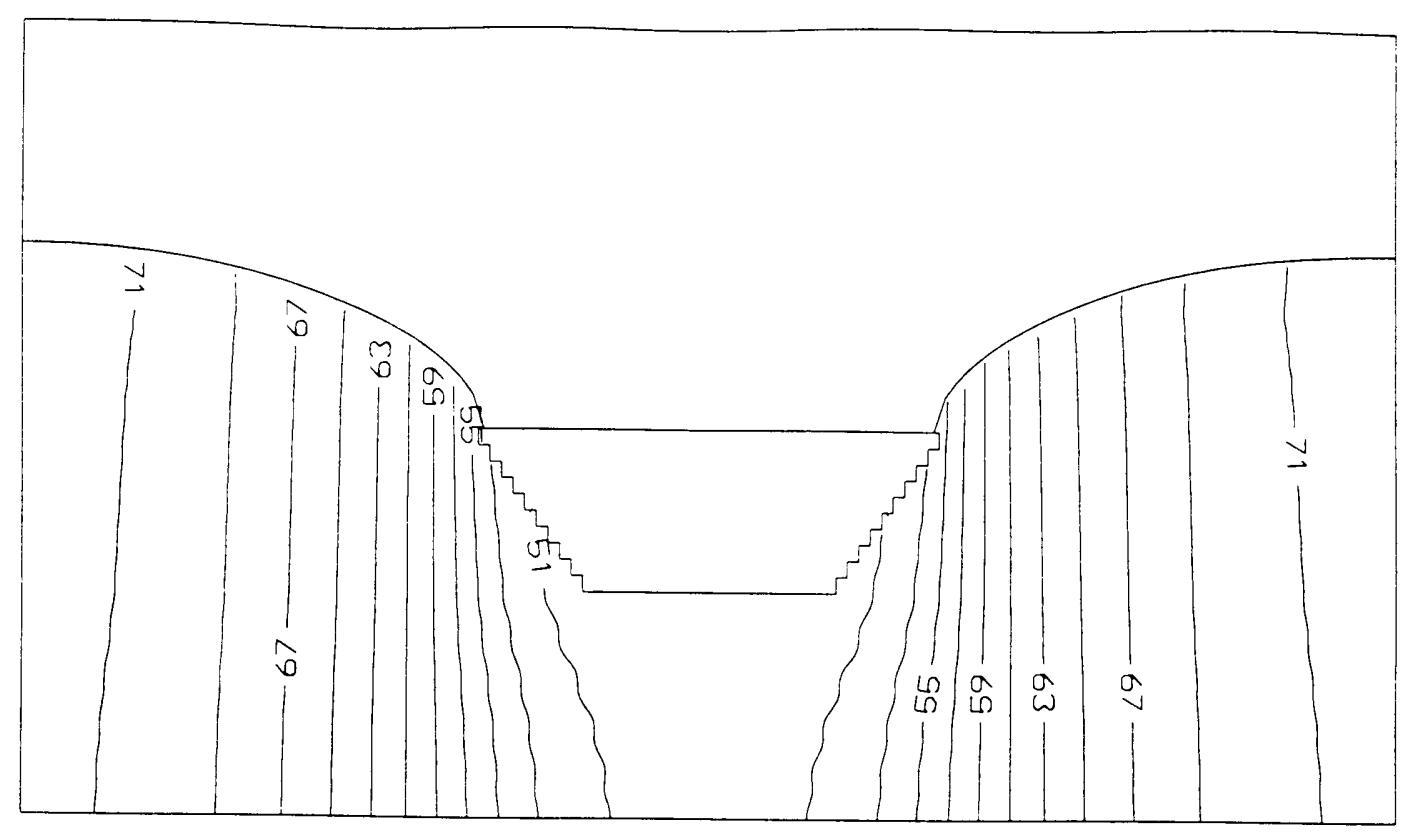

Anisotropy Ratio $=100$

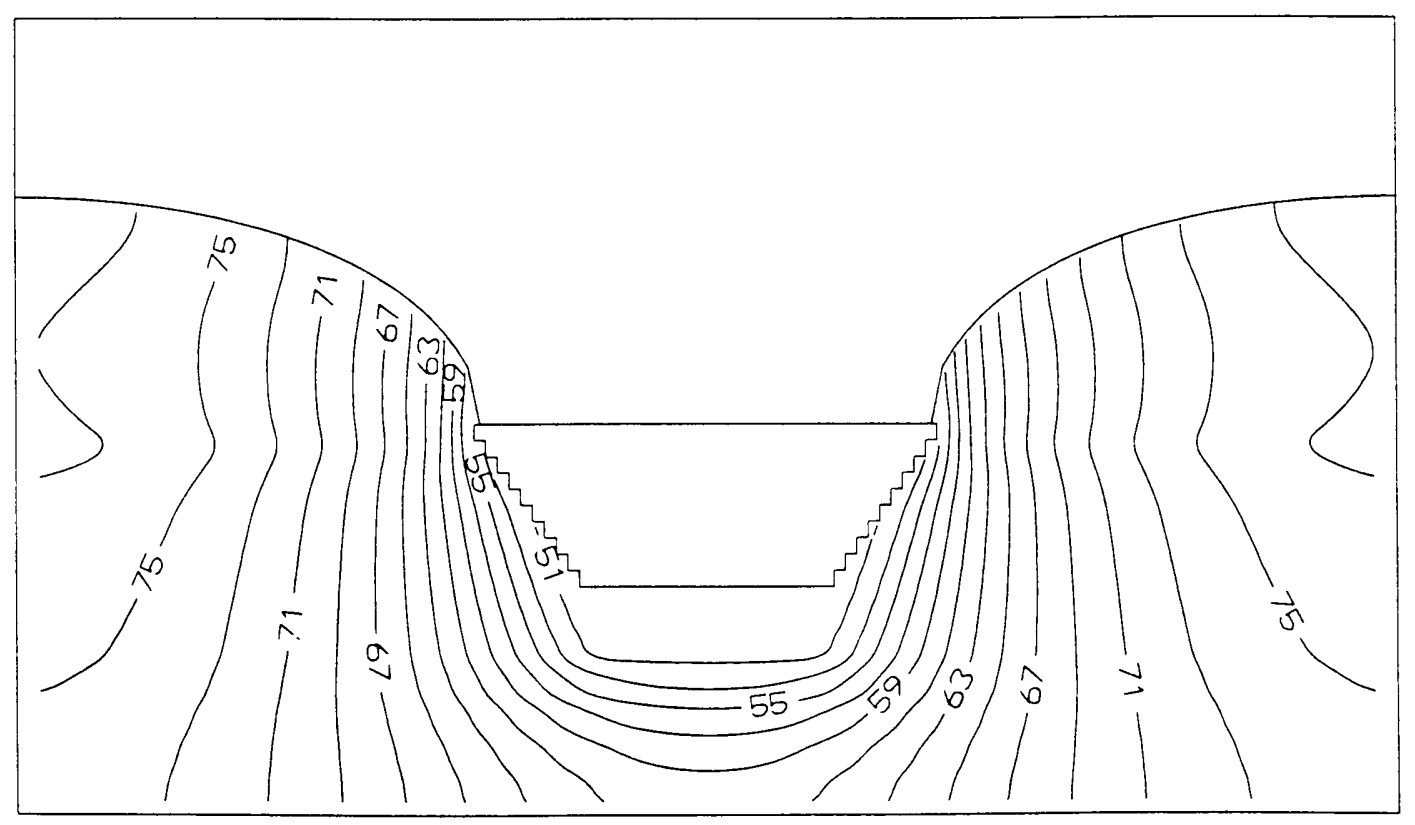

Anisotropy Ratio $=1000$

Fig. 11.2. Distribution of hydraulic heads in the porous medium surrounding deep inflow lakes with steep lake bed slope at $R=100$ and $R=1000$. Fig. 10.2 gives analogous cross-sections of shallow inflow lakes with steep lake bed slope at $R=100$ and $\mathrm{R}=1000$. 
Shallow and deep inflow lakes with moderate lake bed slope

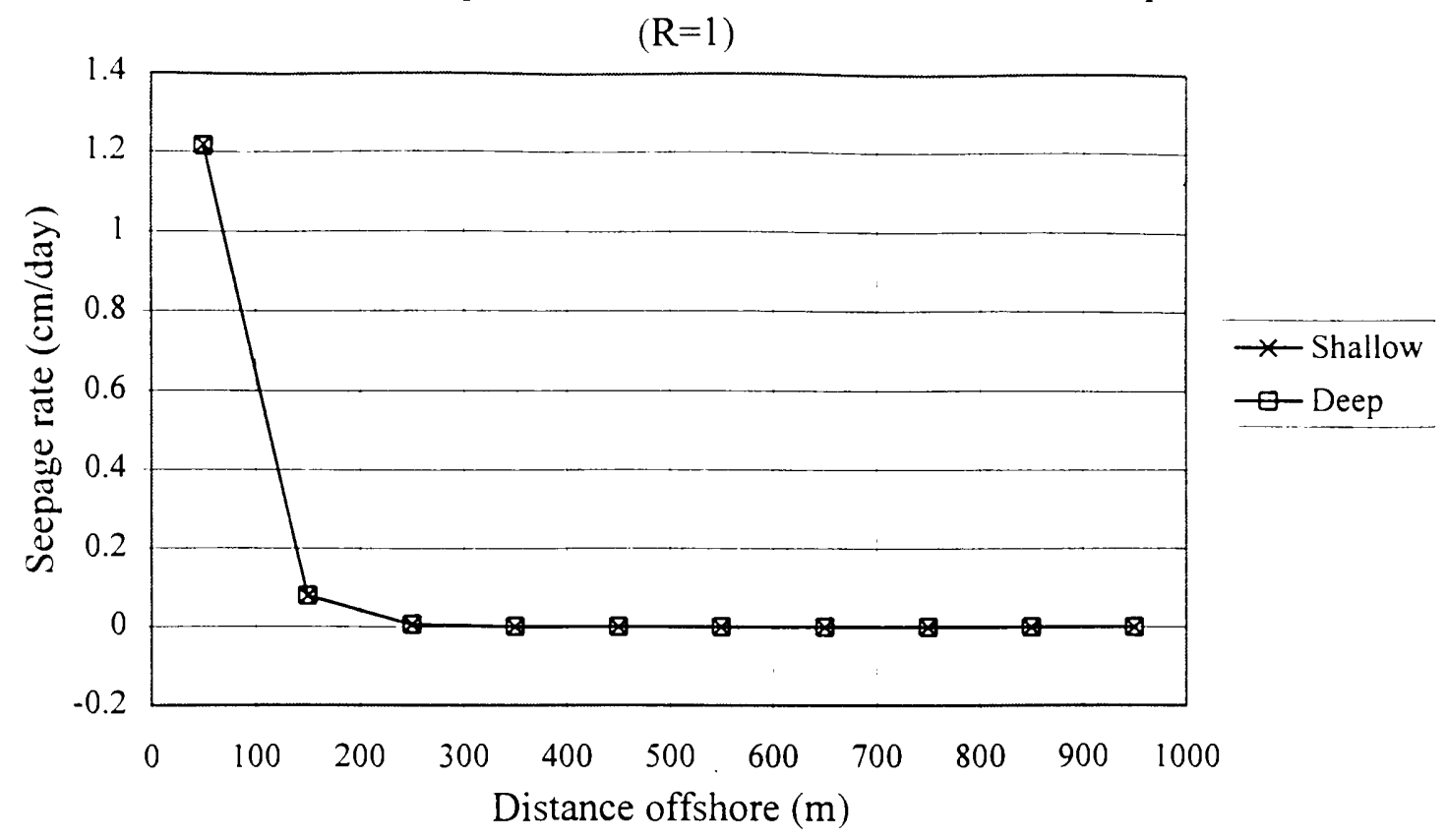

Shallow and deep inflow lakes with steep lake bed slope

$(\mathrm{R}=1)$

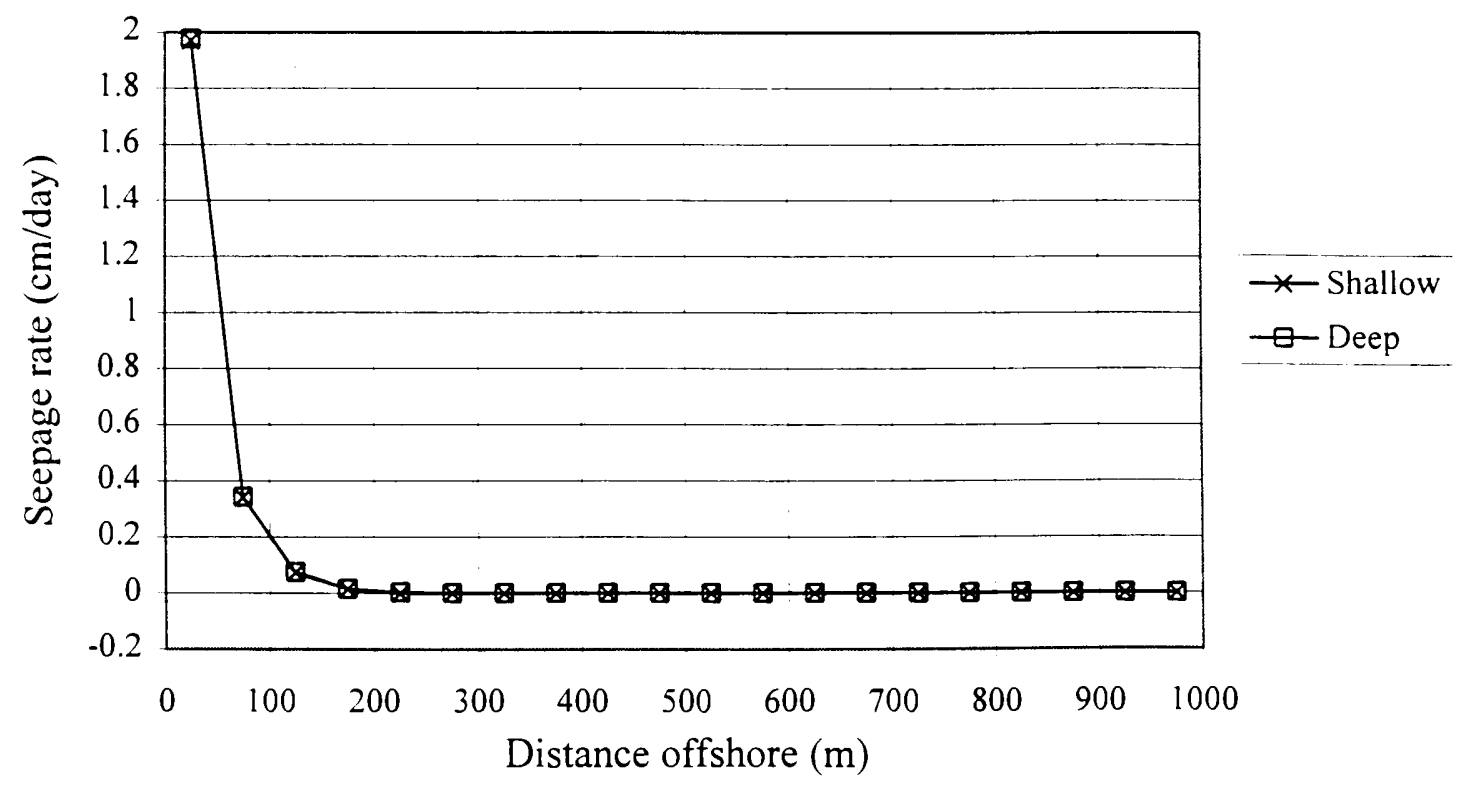

Fig. 11.3. Seepage rate versus distance offshore for the simulations of shallow and deep inflow lakes with moderate and steep lake bed slopes at $R=1$. 
Shallow and deep inflow lakes with moderate lake bed slope

$$
(\mathrm{R}=10)
$$

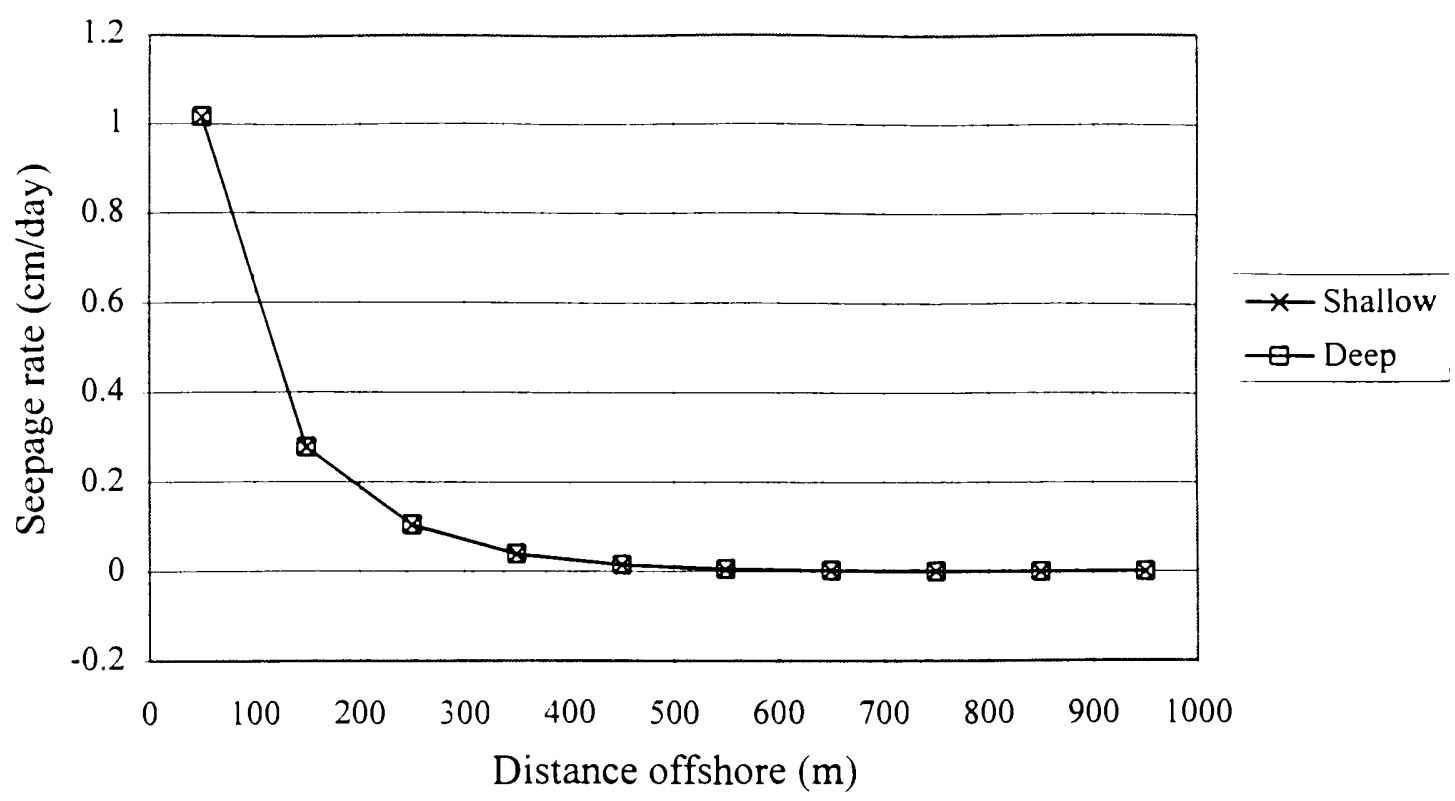

Shallow and deep inflow lakes with steep lake bed slope $(\mathrm{R}=10)$

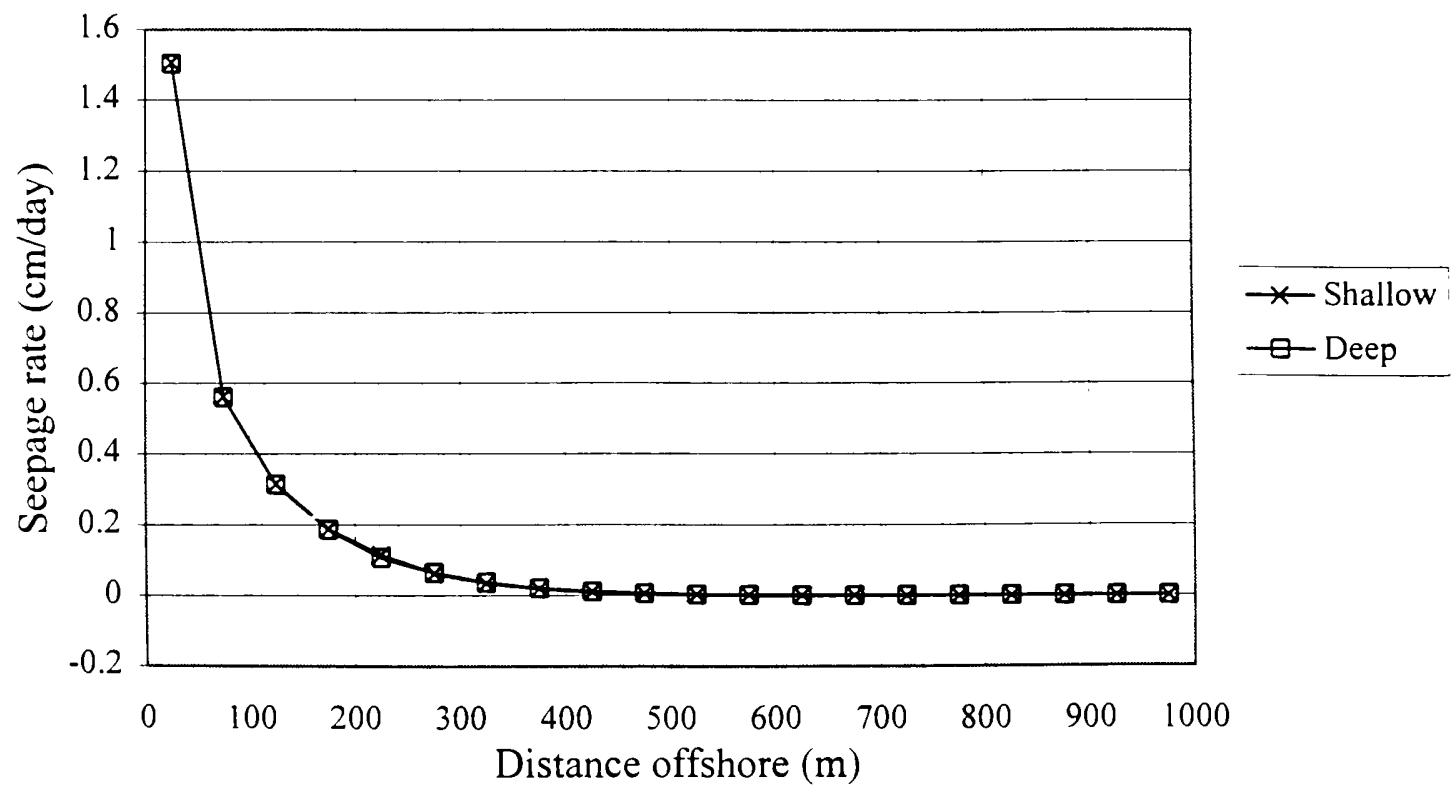

Fig. 11.4. Seepage rate versus distance offshore for the simulations of shallow and deep inflow lakes with moderate and steep lake bed slopes at $R=10$. 
Shallow and deep inflow lakes with moderate lake bed slope

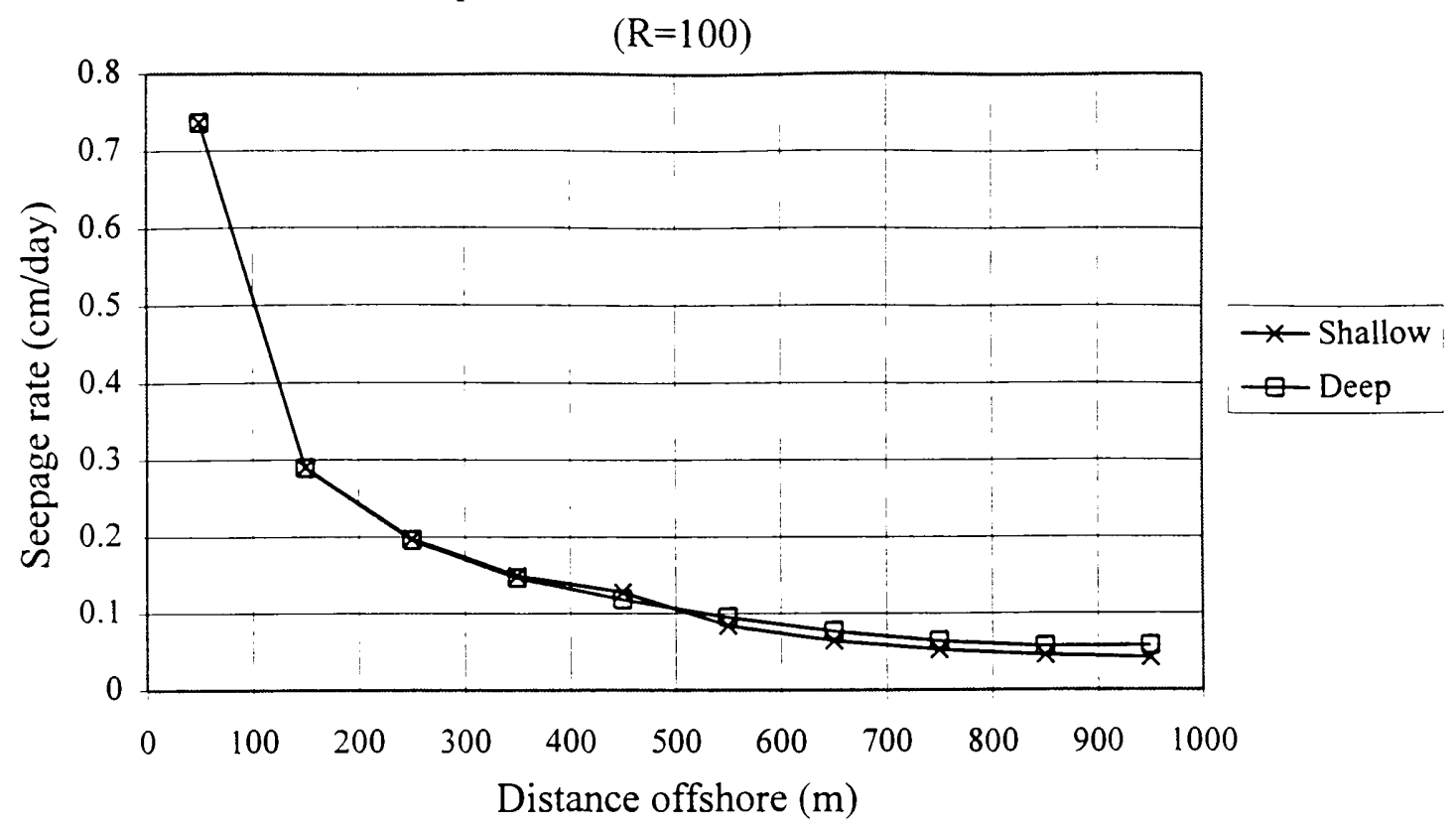

Shallow and deep inflow lakes with steep lake bed slope $(\mathrm{R}=100)$

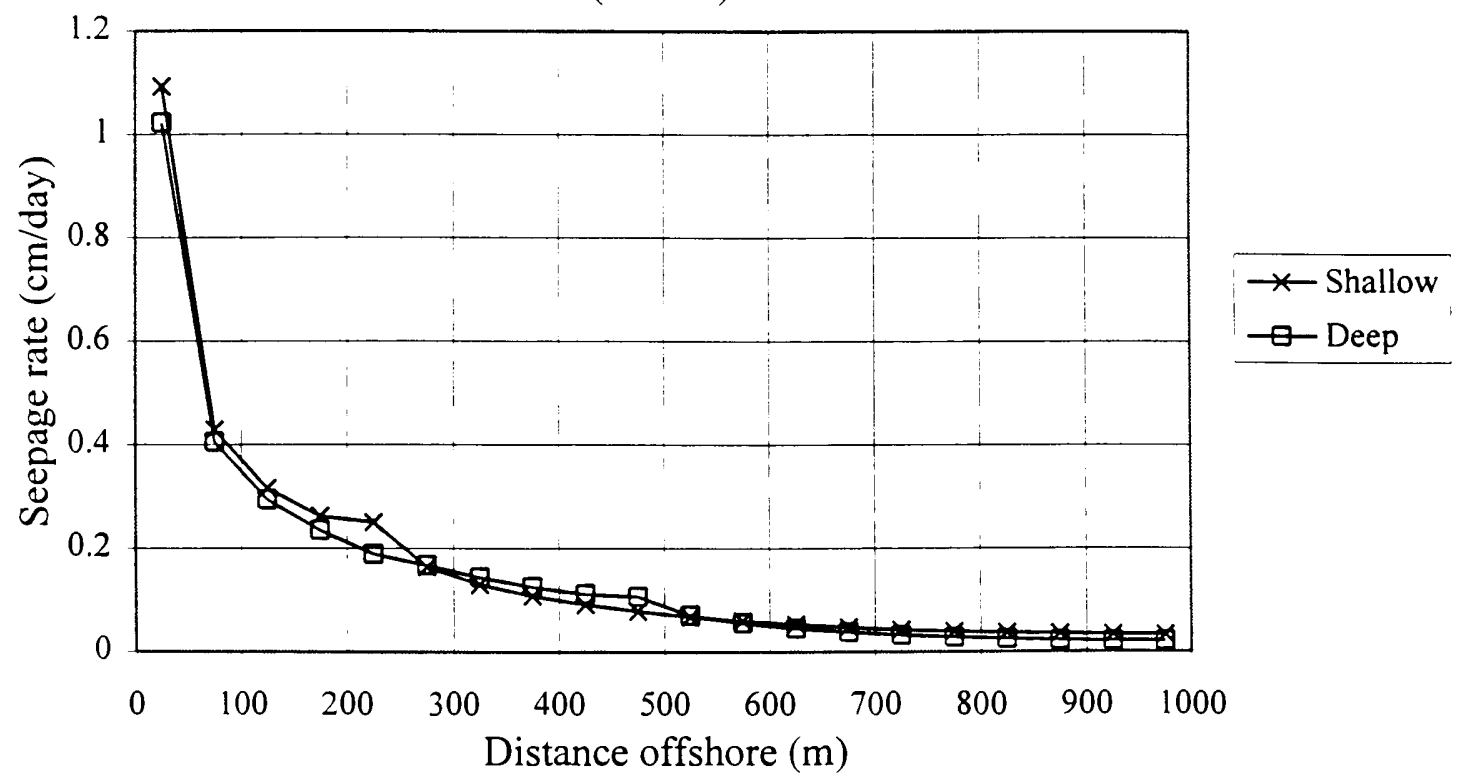

Fig. 11.5. Seepage rate versus distance offshore for the simulations of shallow and deep inflow lakes with moderate and steep lake bed slopes at $R=100$. 
Shallow and deep inflow lakes with moderate lake bed slope $(\mathrm{R}=1000)$

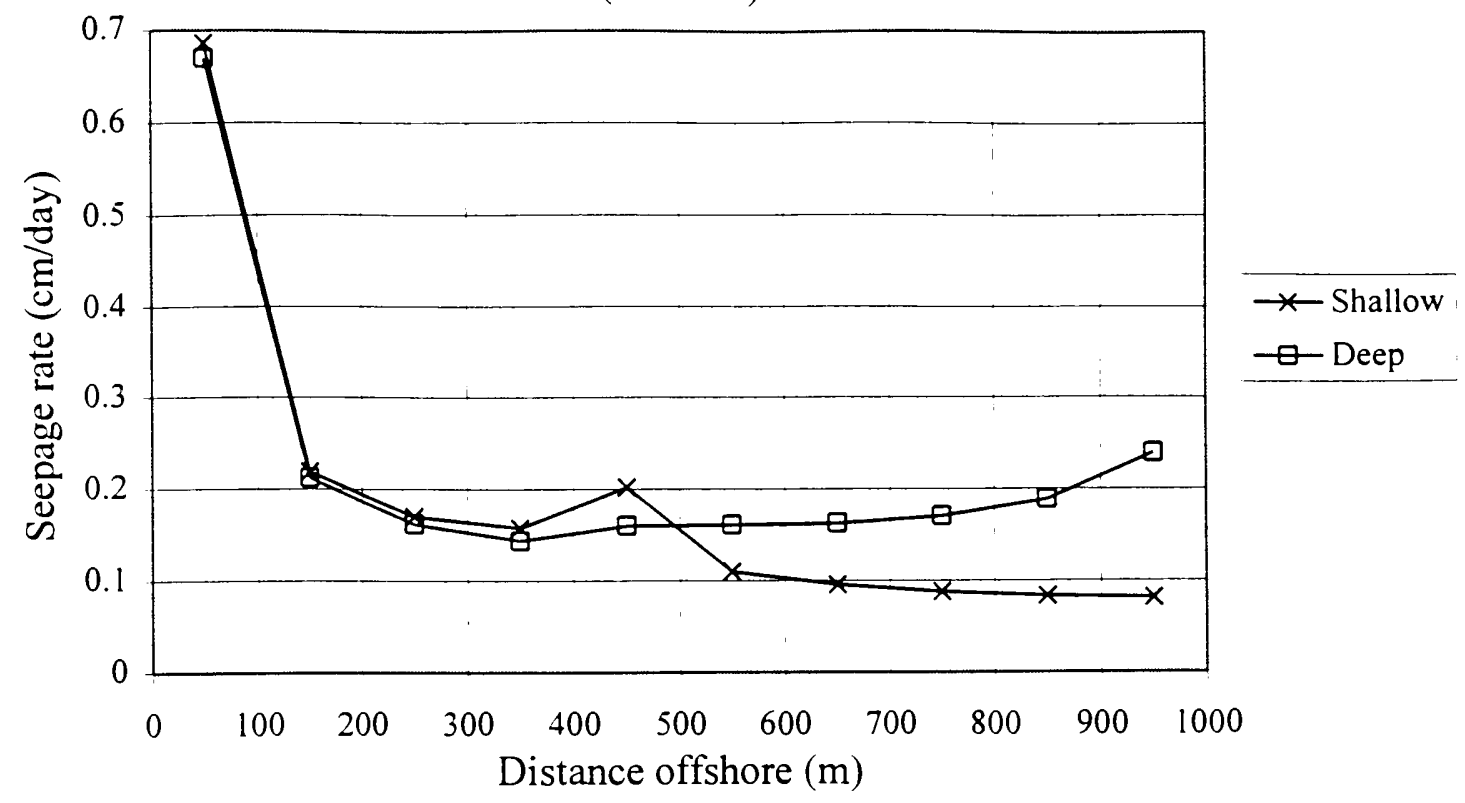

Shallow and deep inflow lakes with steep lake bed slope

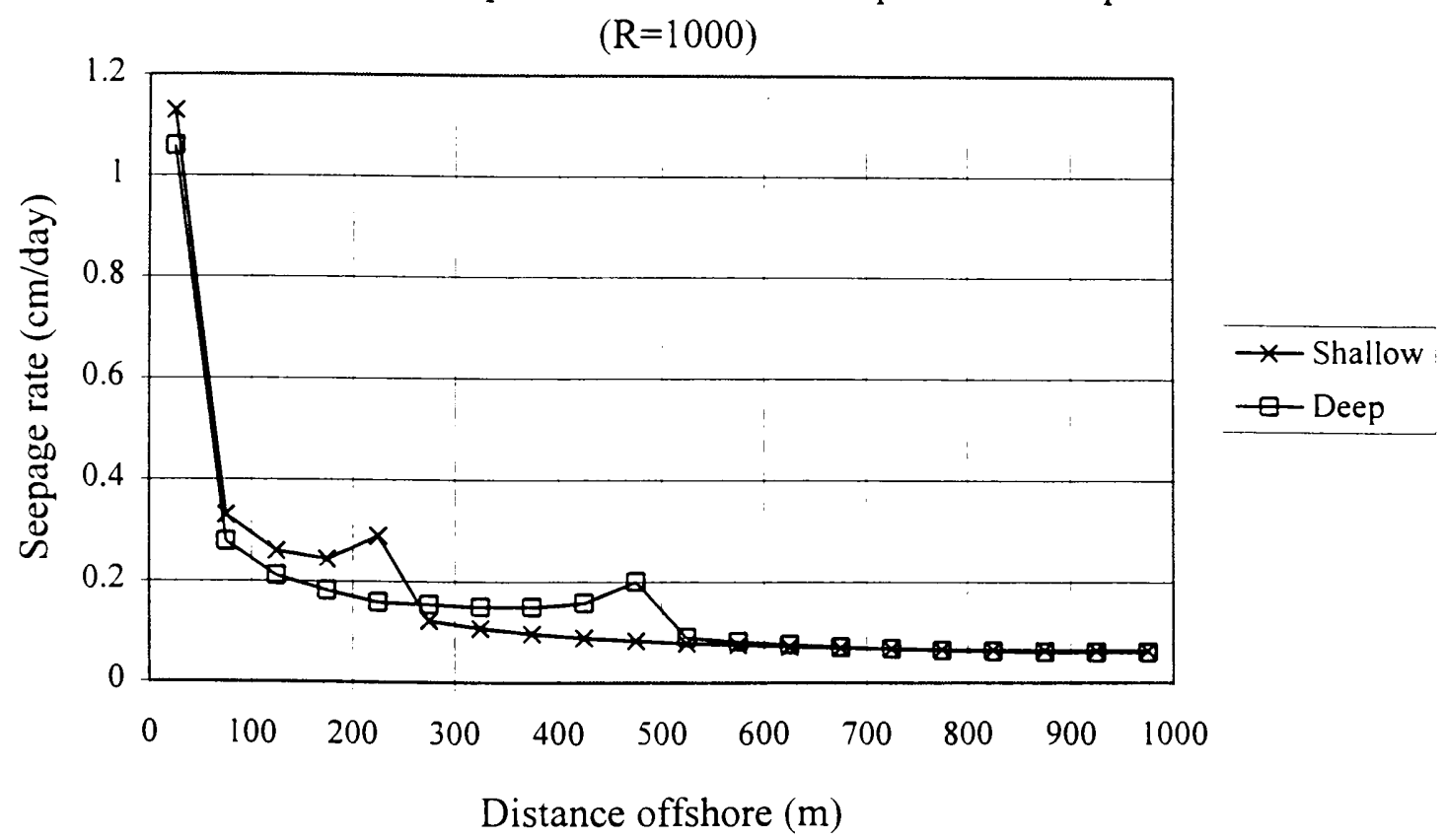

Fig. 11.6. Seepage rate versus distance offshore for the simulations of shallow and deep inflow lakes with moderate and steep lake bed slopes at $R=1000$. 


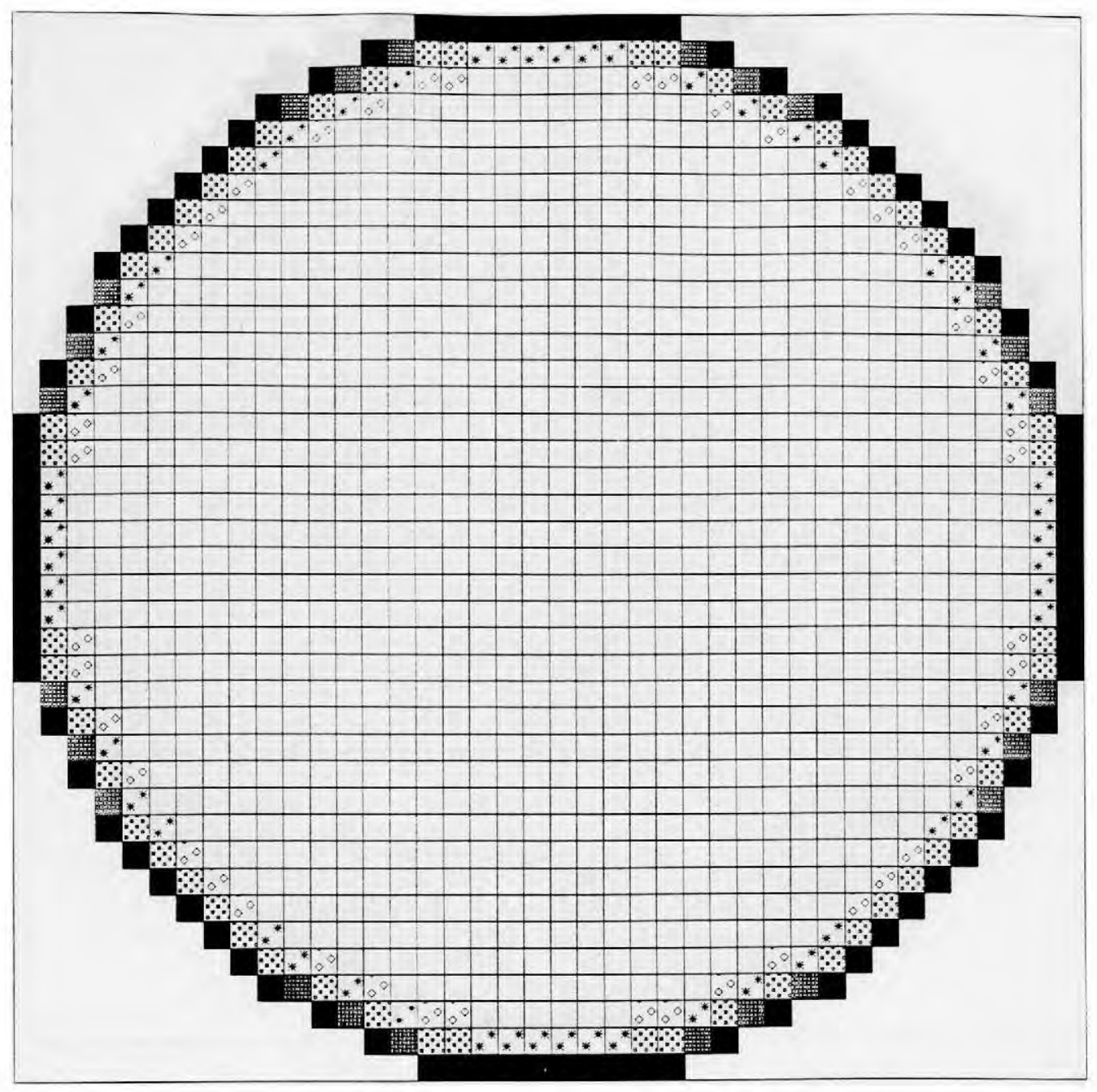

Fig. 11.7. Distribution of seepage rates ( $\mathrm{cm} /$ day) over the lake bed for a deep inflow lake with steep lake bed slope at $\mathrm{R}=1$. Fig. 10.6 gives an analogous map for the simulation of a shallow inflow lake with steep lake bed slope at $\mathrm{R}=1$.

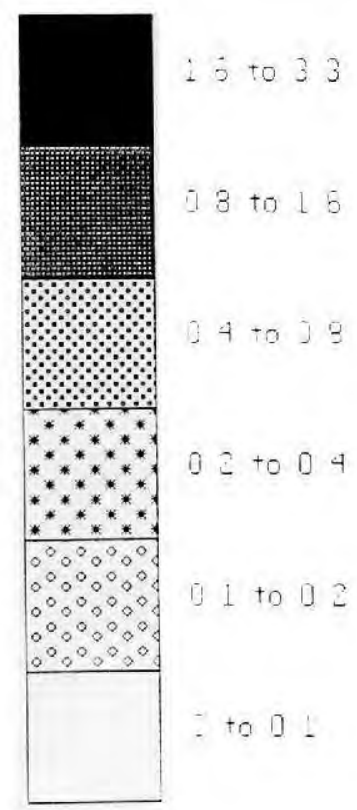




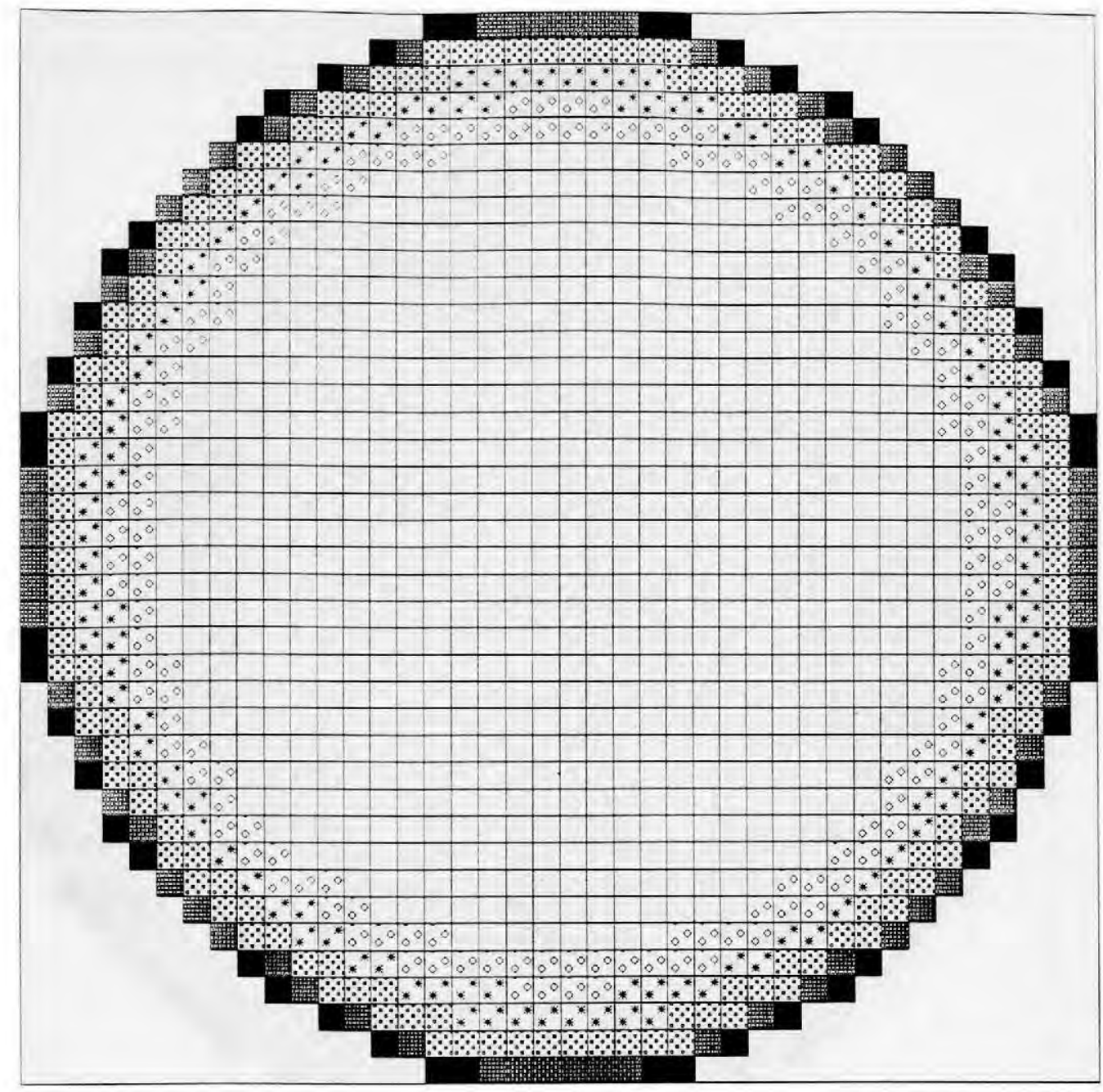

Fig. 11.8. Distribution of seepage rates ( $\mathrm{cm} /$ day) over the lake bed for a deep inflow lake with steep lake bed slope at $\mathrm{R}=10$. Fig. 10.7 gives an analogous map for the simulation of a shallow inflow lake with steep lake bed slope at $\mathrm{R}=10$.

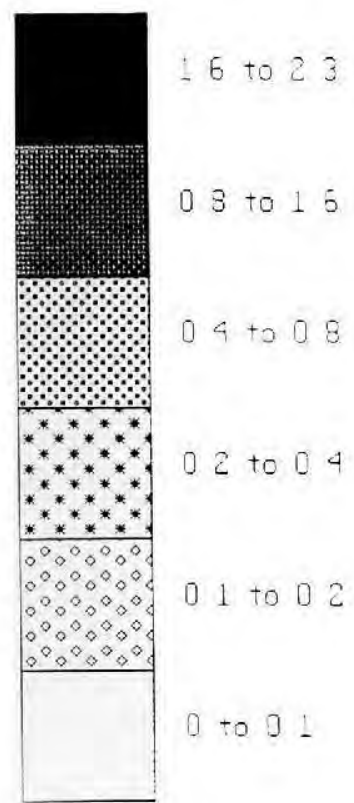




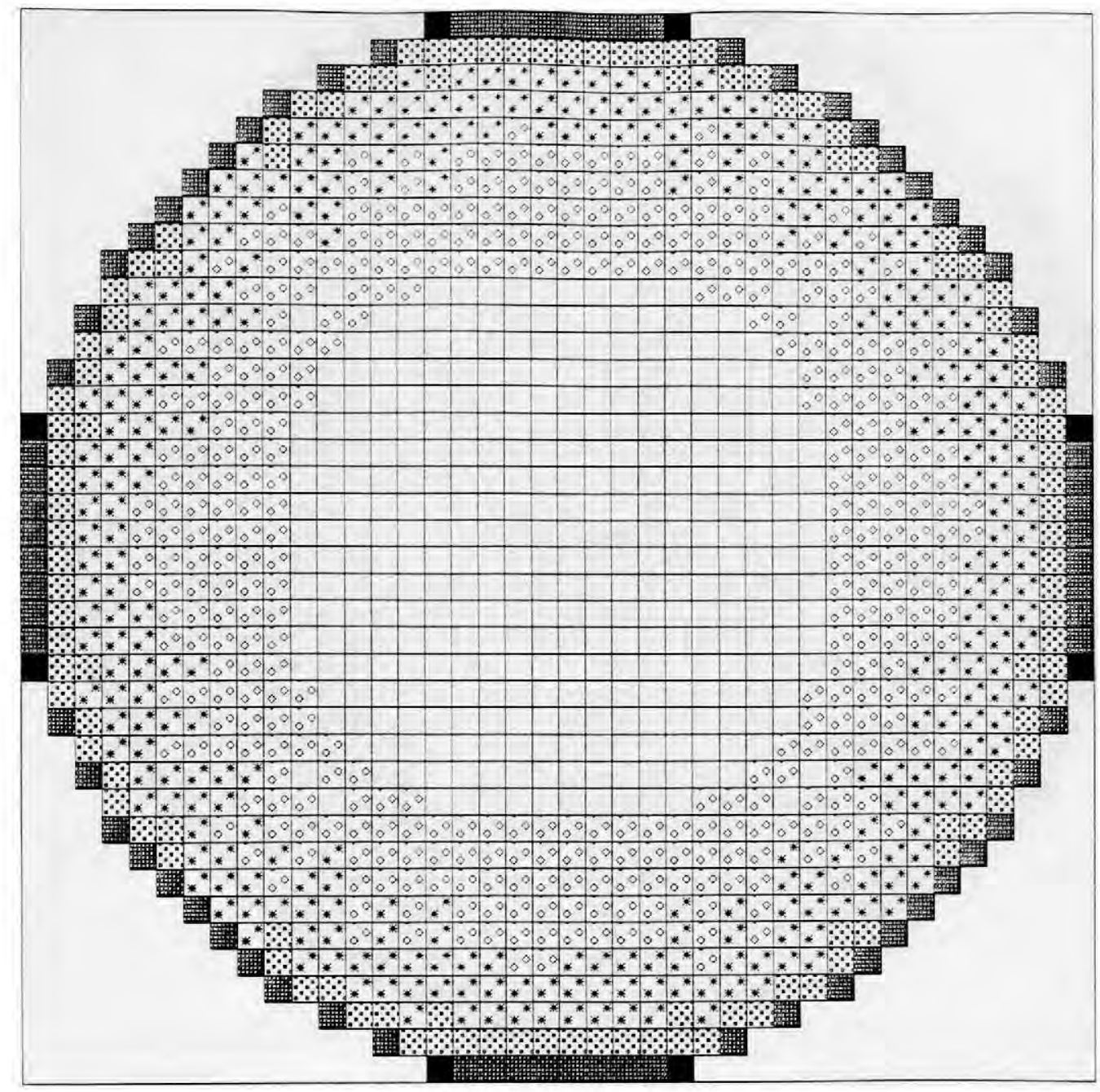

Fig. 11.9. Distribution of seepage rates ( $\mathrm{cm} /$ day) over the lake bed for a deep inflow lake with steep lake bed slope at $R=100$. Fig. 10.8 gives an analogous map for the simulation of a shallow inflow lake with steep lake bed slope at $\mathrm{R}=100$.

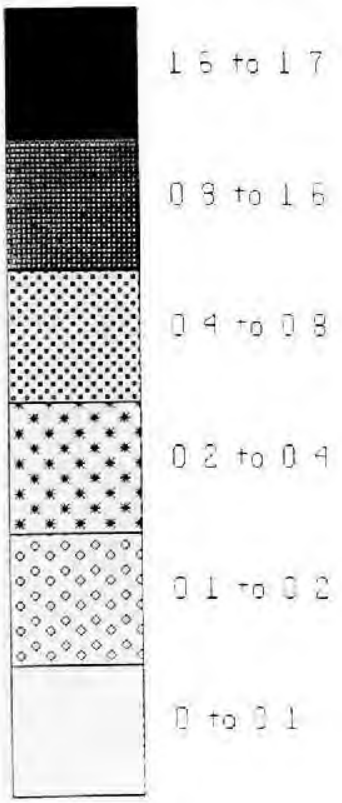




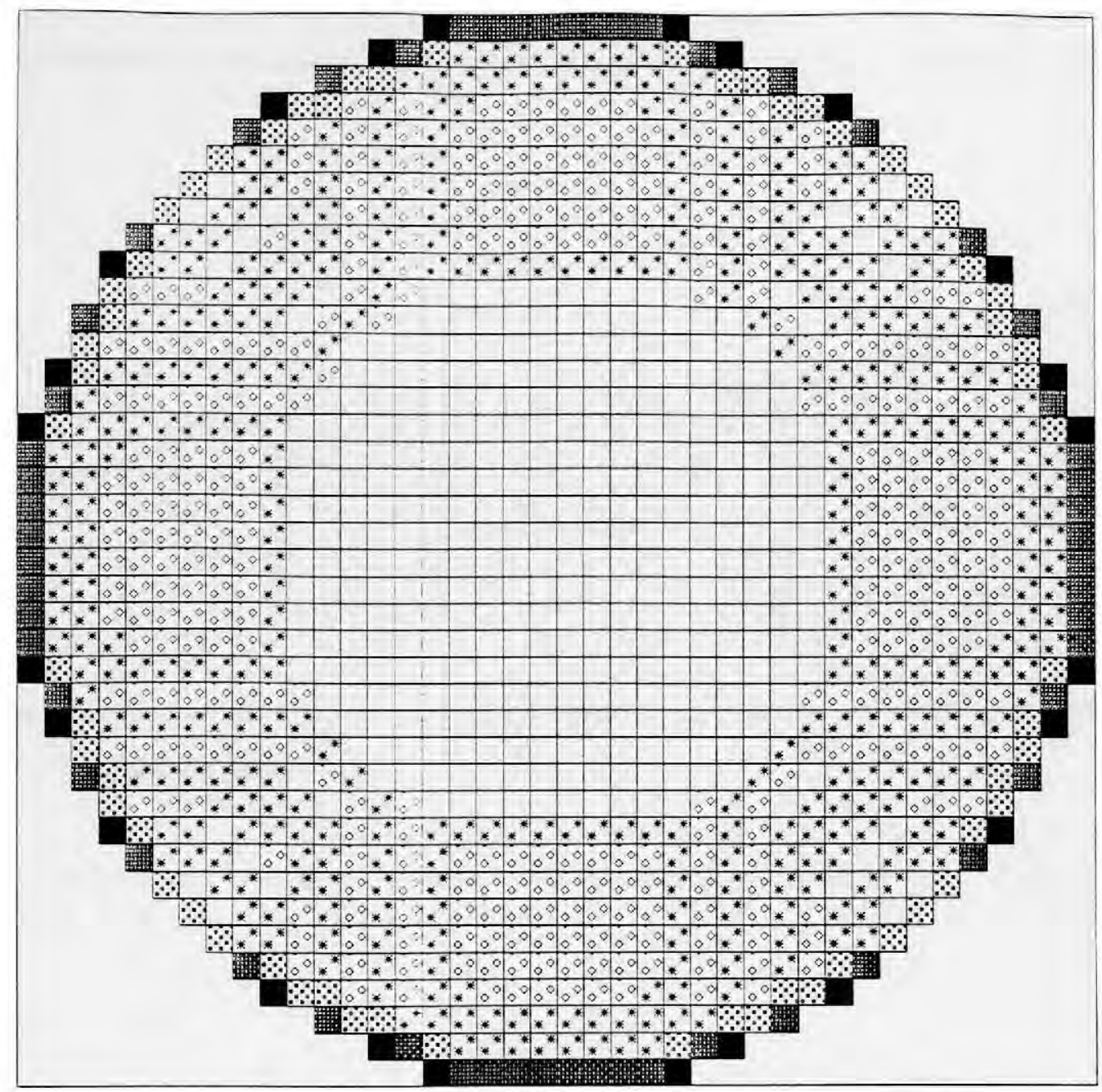

Fig. 11.10. Distribution of seepage rates ( $\mathrm{cm} /$ day) over the lake bed for a deep inflow lake with steep lake bed slope at $\mathrm{R}=1000$. Fig. 10.9 gives an analogous map for the simulation of a shallow inflow lake with steep lake bed slope at $\mathrm{R}=1000$.

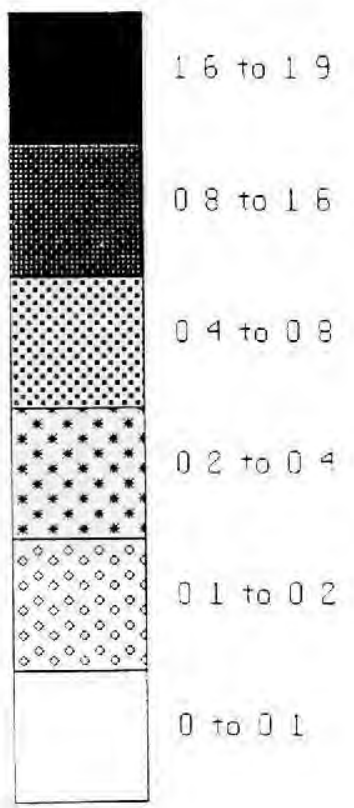




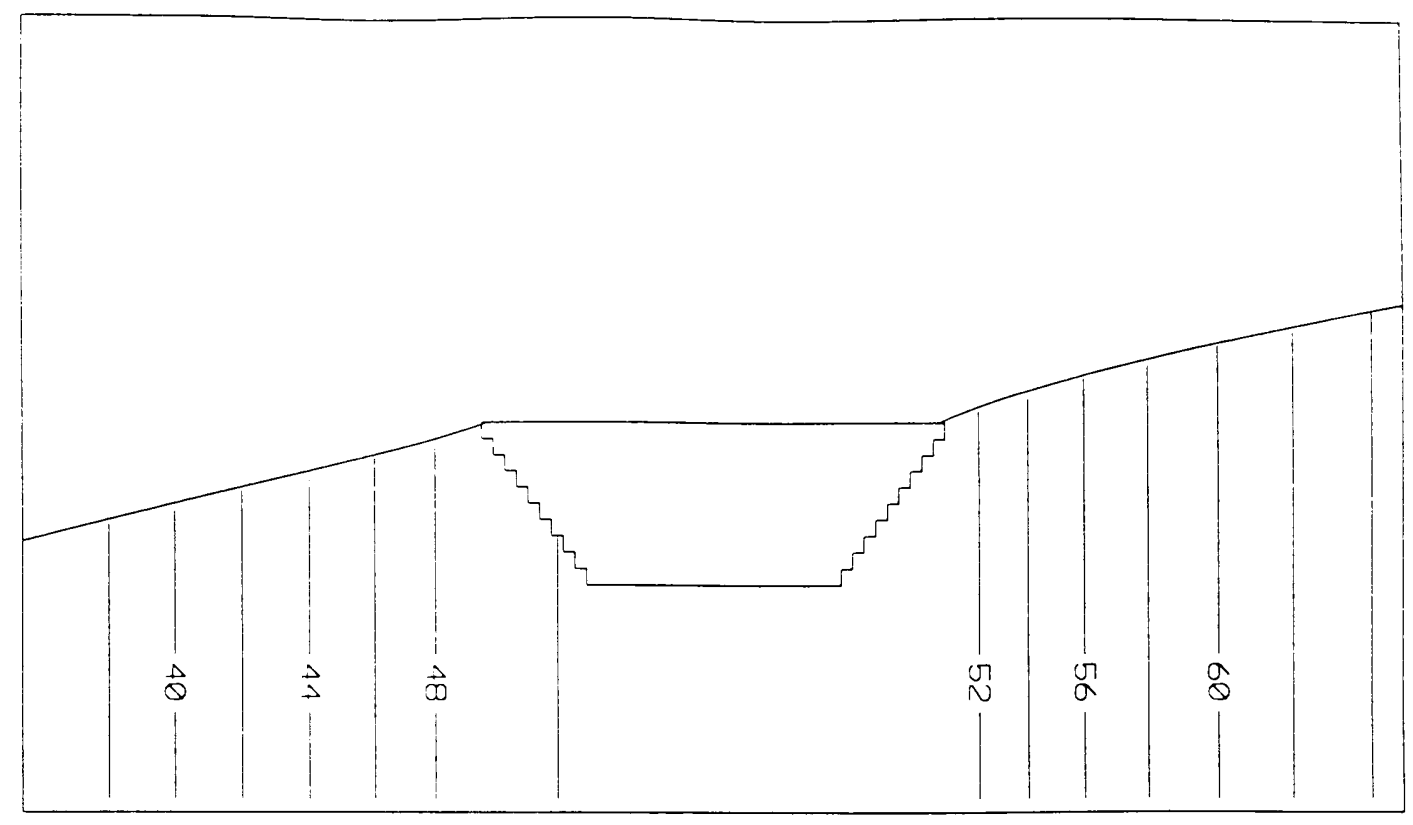

Anisotropy Ratio $=1$

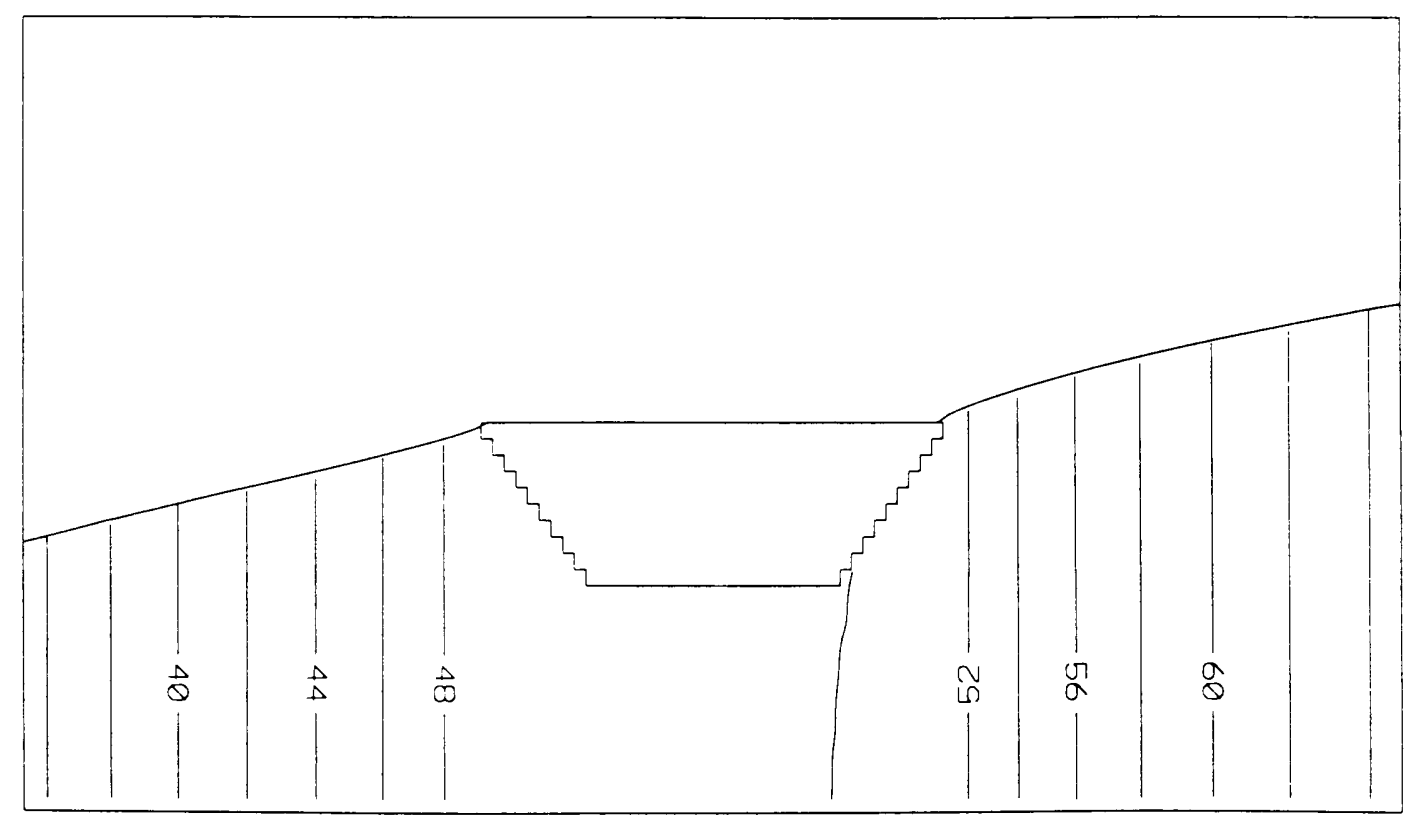

Anisotropy Ratio $=10$

Fig. 11.11. Distribution of hydraulic heads in the porous medium surrounding deep flowthrough lakes with steep lake bed slope at $R=1$ and $R=10$. Fig. 10.10 gives analogous cross-sections of shallow flow-through lakes with steep lake bed slope at $\mathrm{R}=1$ and $\mathrm{R}=10$. 


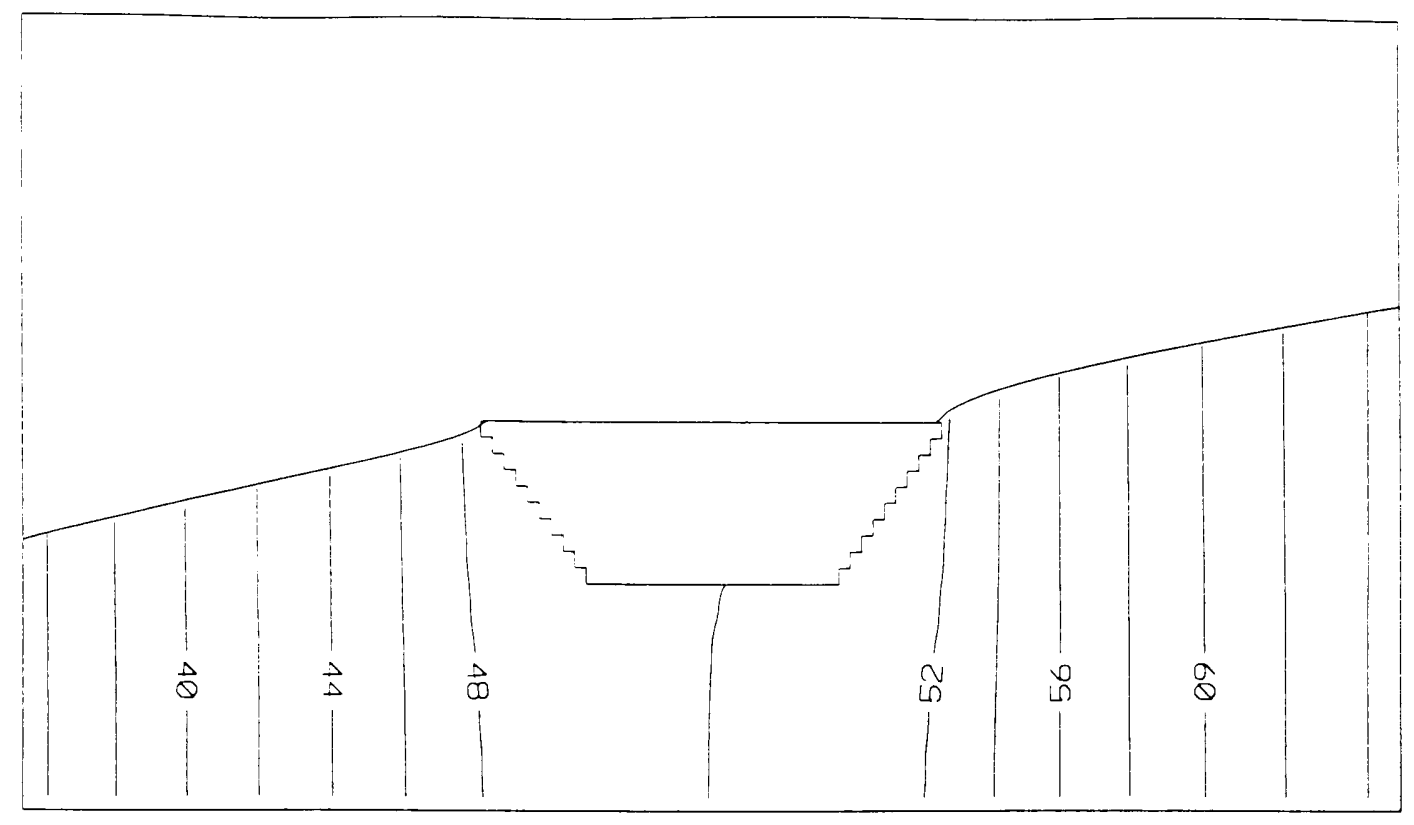

Anisotropy Ratio $=100$

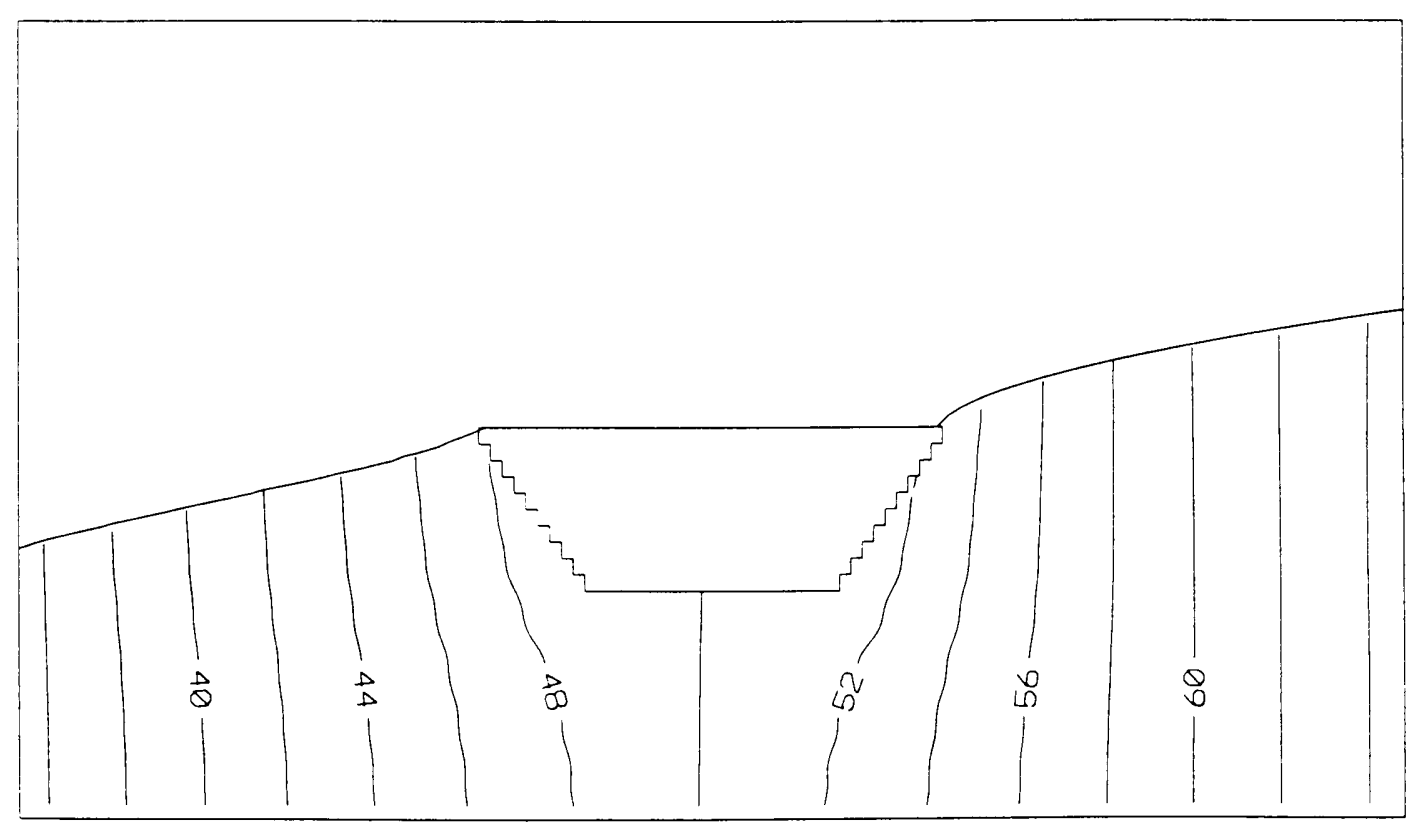

Anisotropy Ratio $=1000$

Fig. 11.12. Distribution of hydraulic heads in the porous medium surrounding deep flowthrough lakes with steep lake bed slope at $R=100$ and $R=1000$. Fig. 10.11 gives analogous cross-sections of shallow flow-through lakes with steep lake bed slope at $\mathrm{R}=100$ and $\mathrm{R}=1000$. 
Shallow and deep flow-through lakes with moderate slope

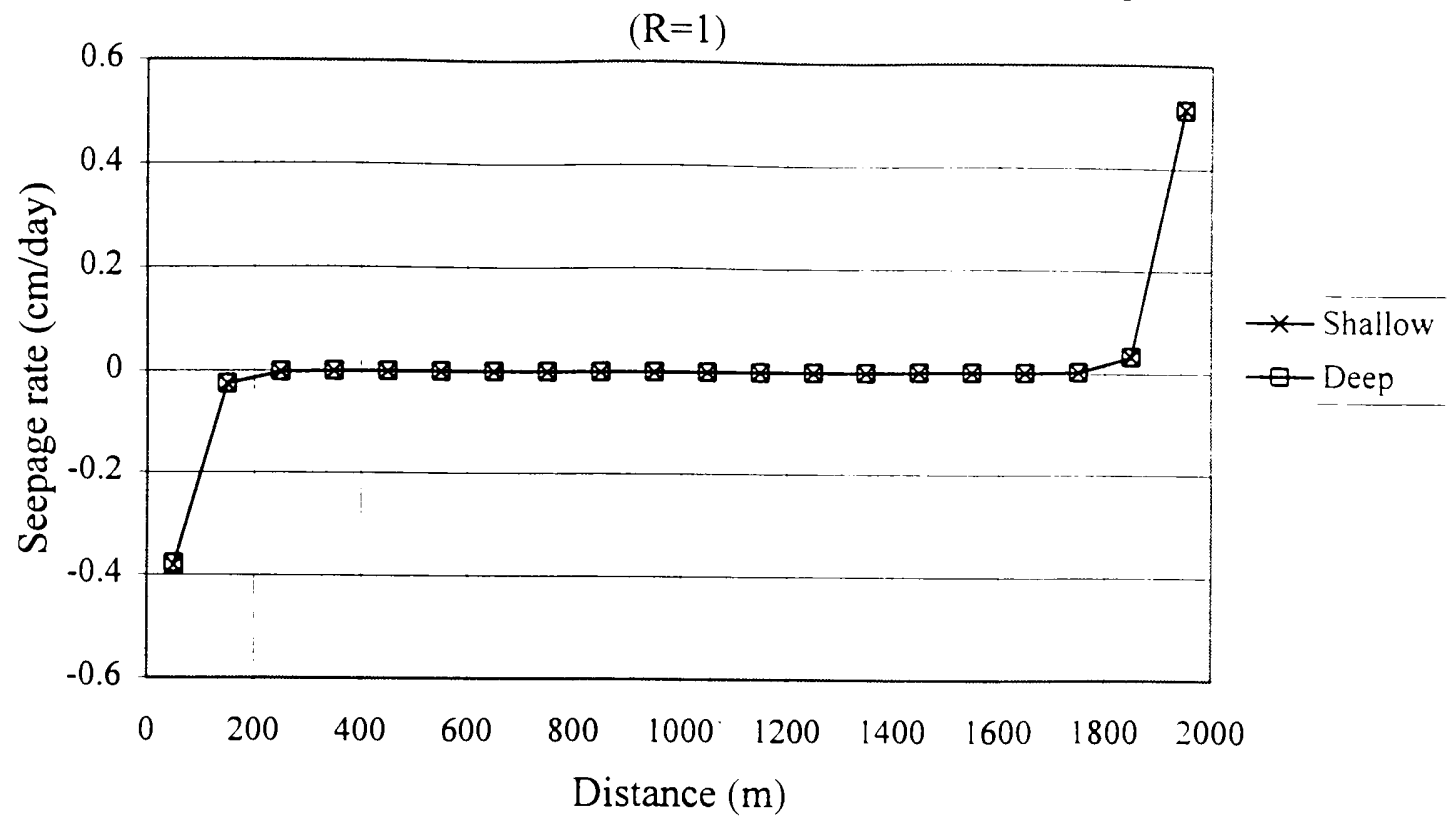

Shallow and deep flow-through lakes with steep slope

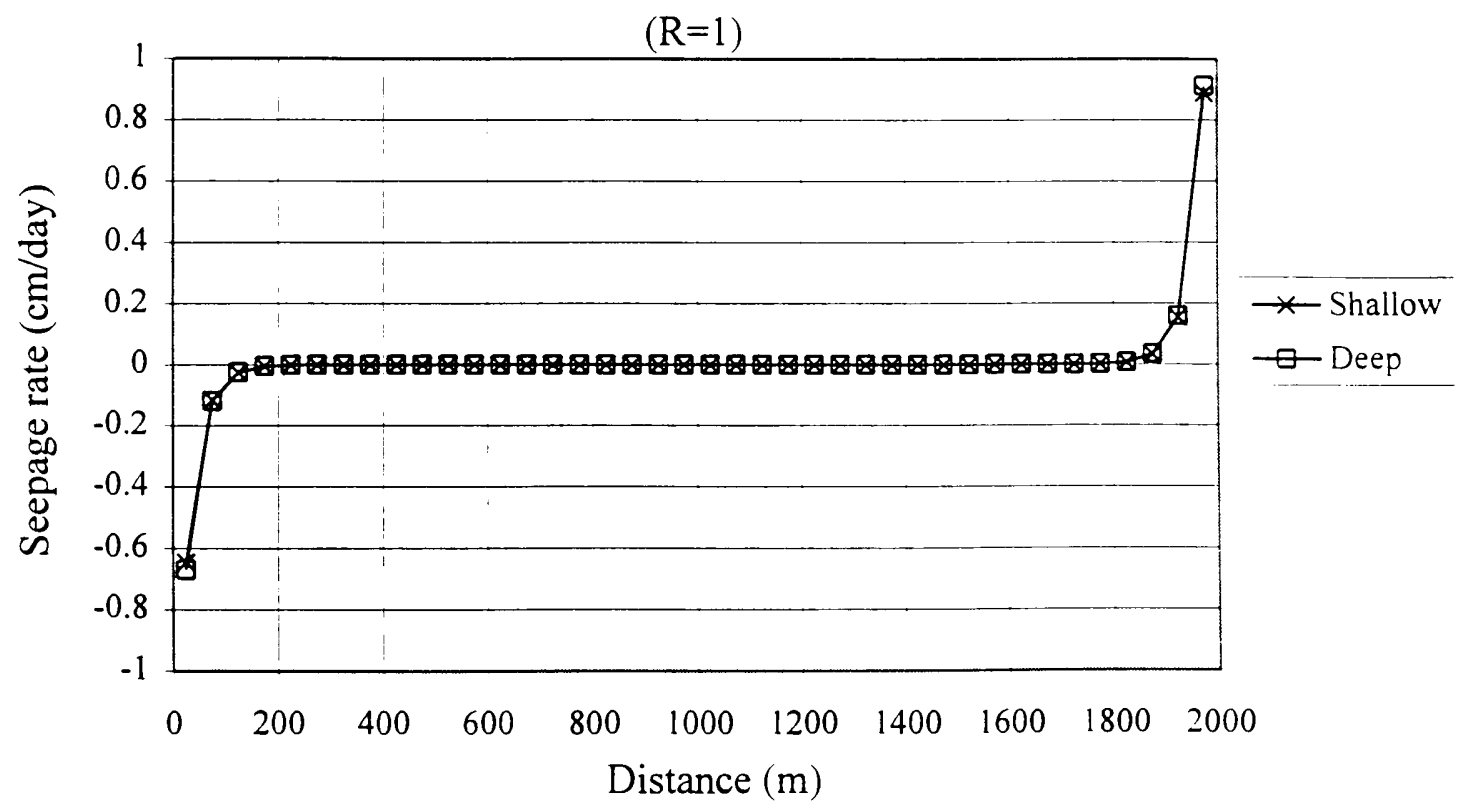

Fig. 11.13. Seepage rate versus distance from the downgradient shoreline for simulations of shallow and deep flow-through lakes with moderate and steep lake bed slopes at $\mathrm{R}=1$. 
Shallow and deep flow-through lakes with moderate slope

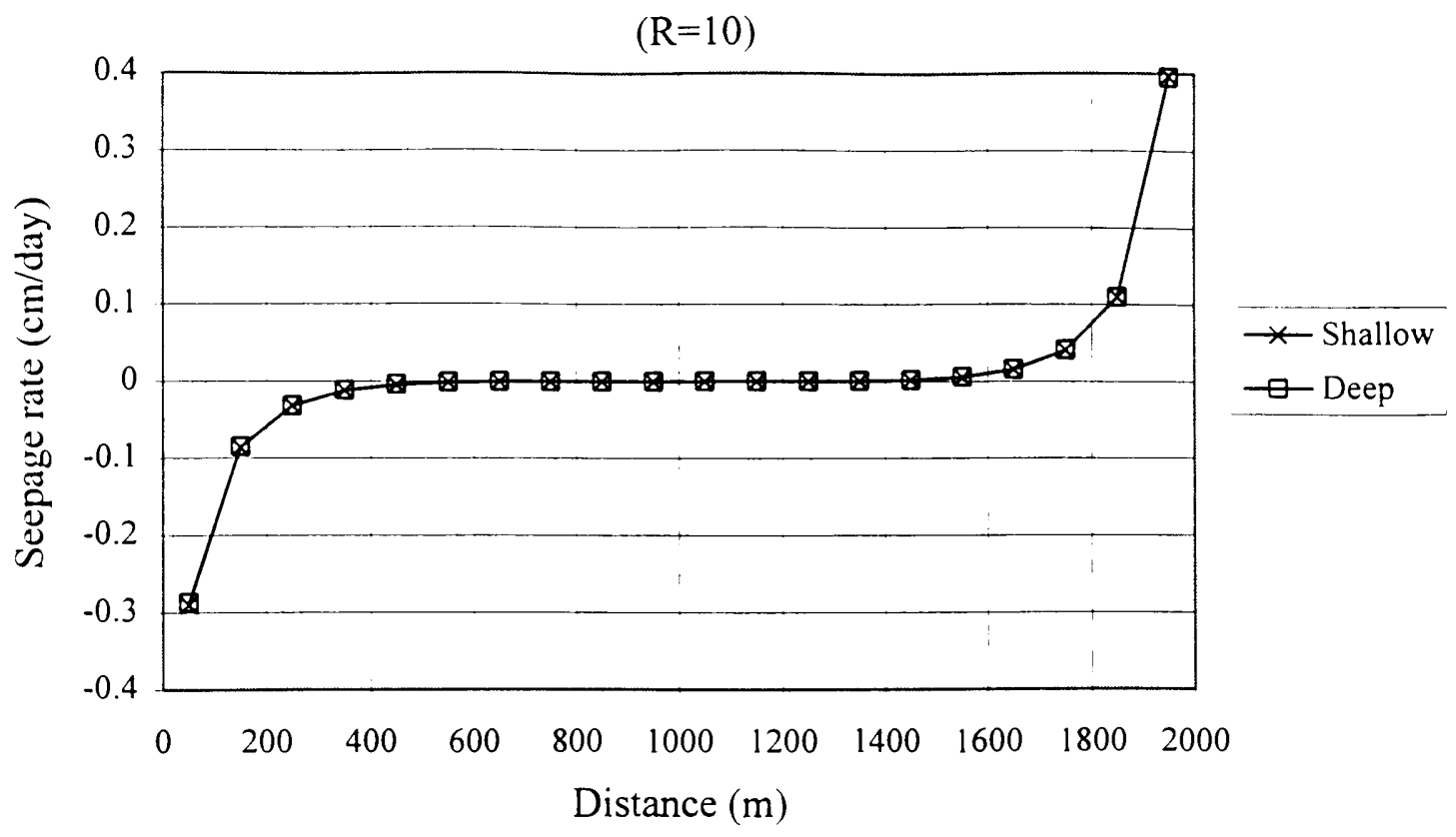

Shallow and deep flow-through lakes with steep slope

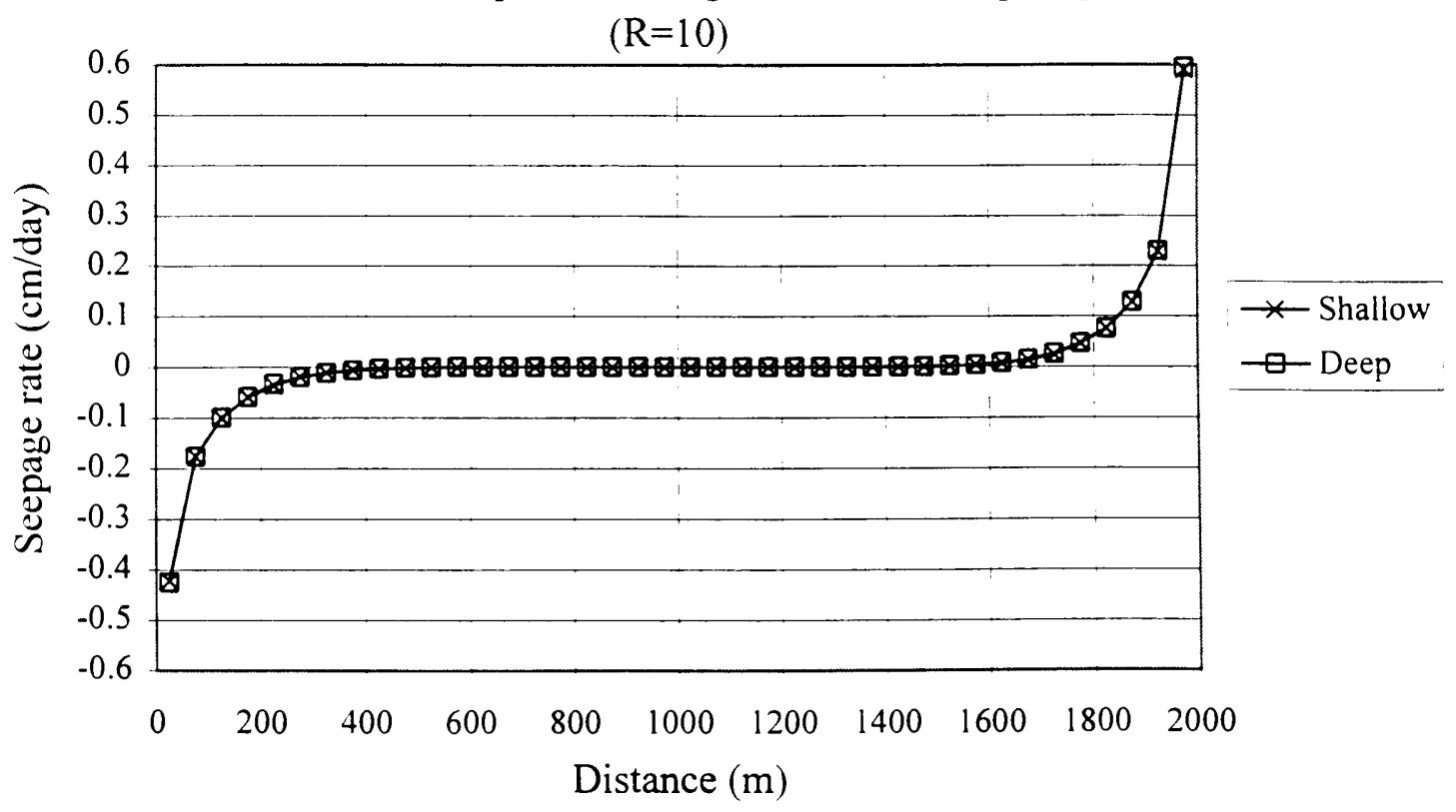

Fig. 11.14. Seepage rate versus distance from the downgradient lake shore for the simulations of shallow and deep flow-through lakes with moderate and steep lake bed slopes at $\mathrm{R}=10$. 
Shallow and deep flow-through lakes with moderate slope

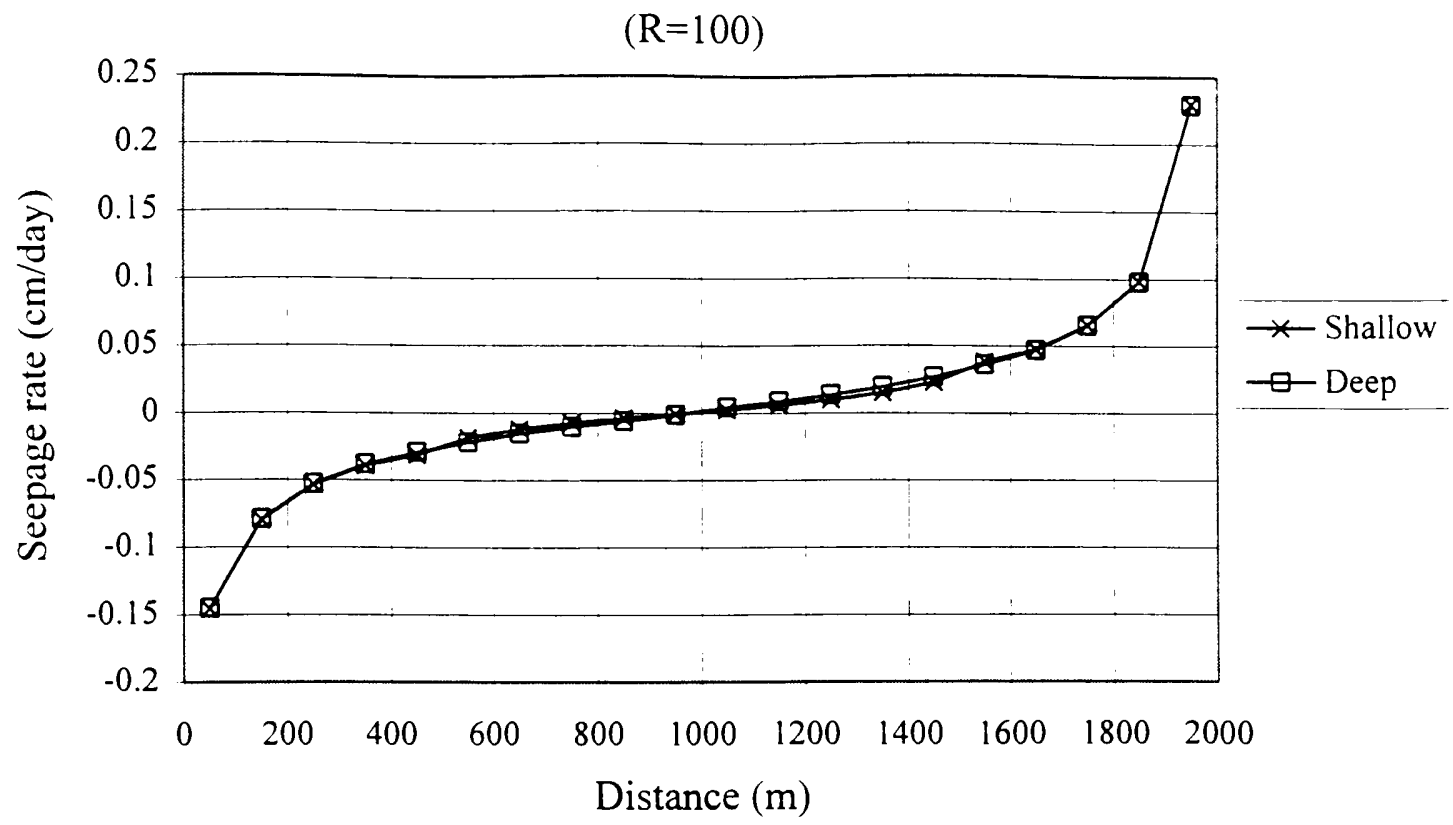

Shallow and deep flow-through lakes with steep slope

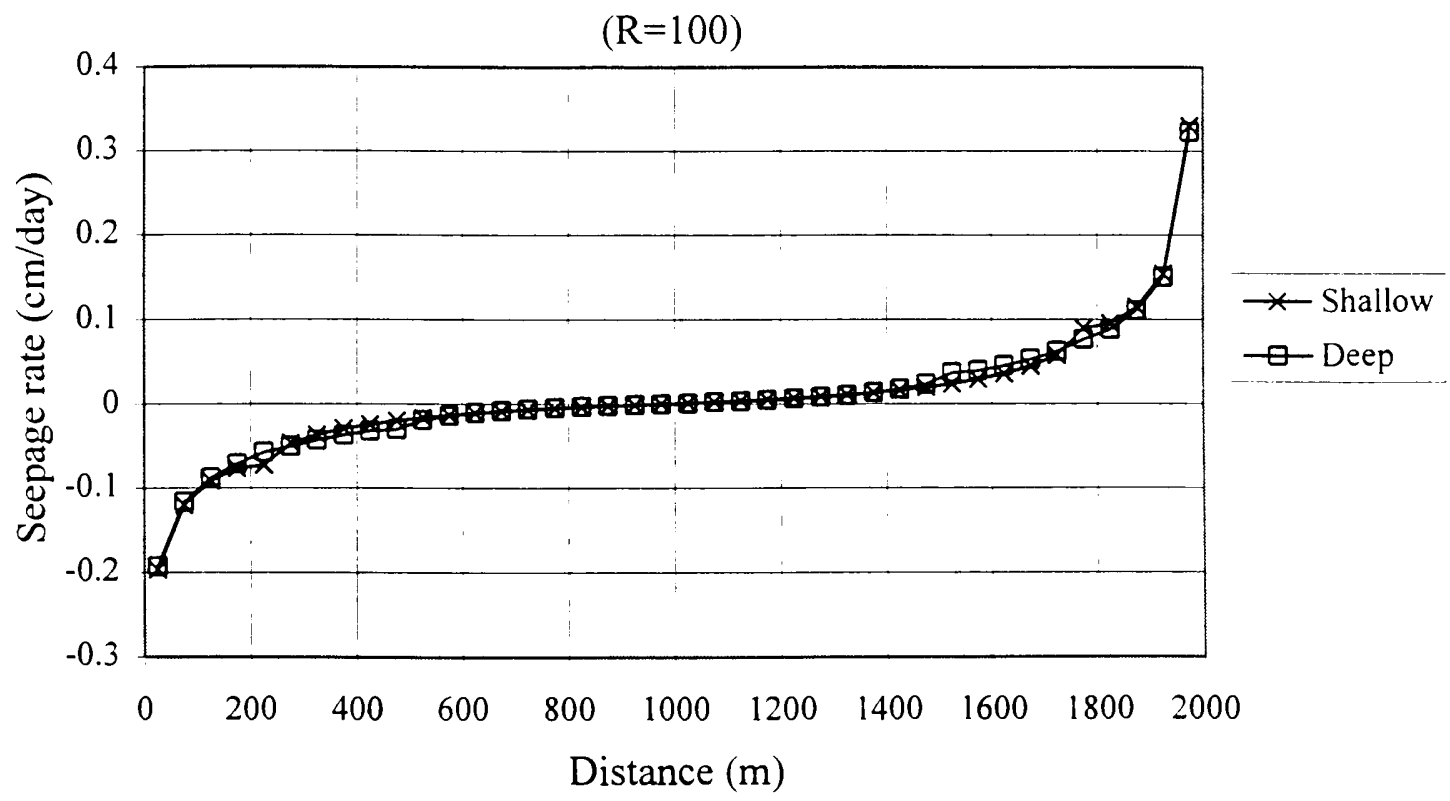

Fig. 11.15. Seepage rate versus distance from the downgradient lake shore for the simulations of shallow and deep flow-through lakes with moderate and steep lake bed slopes at $\mathrm{R}=100$. 
Shallow and deep flow-through lakes with moderate slope

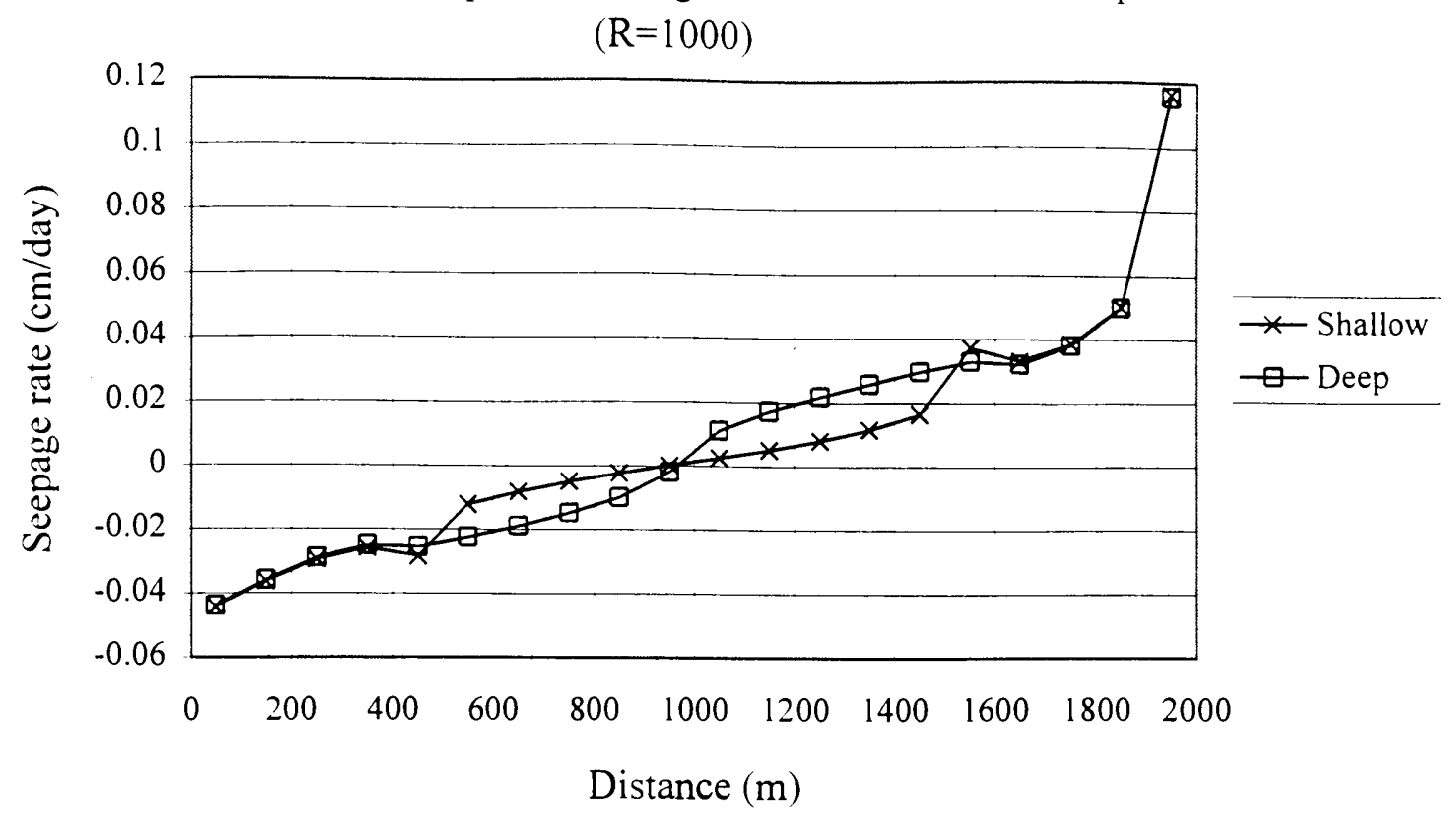

Shallow and deep flow-through lakes with steep slope

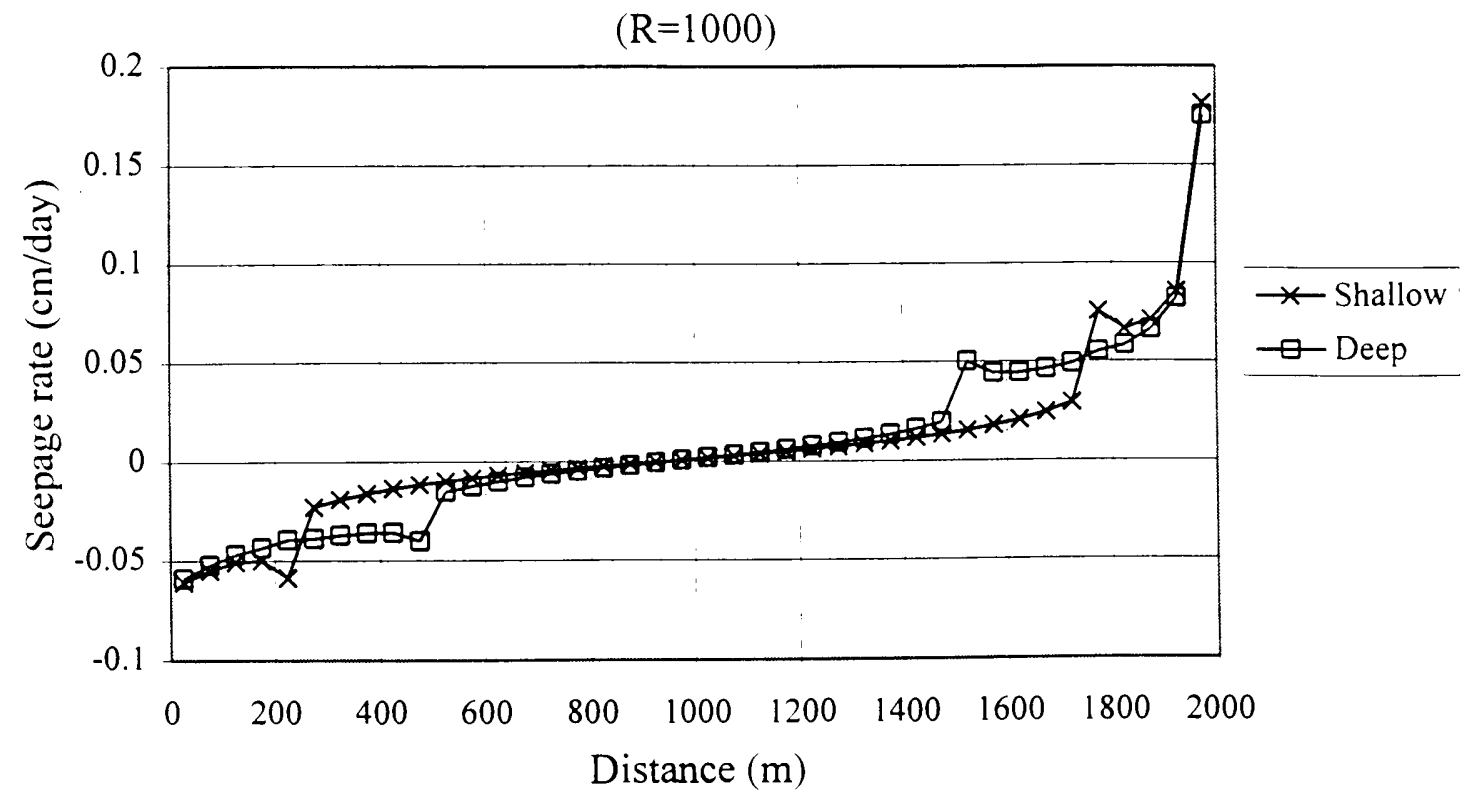

Fig. 11.16. Seepage rate versus distance from the downgradient shoreline for simulations of shallow and deep flow-through lakes with moderate and steep lake bed slopes at $\mathrm{R}=1000$. 


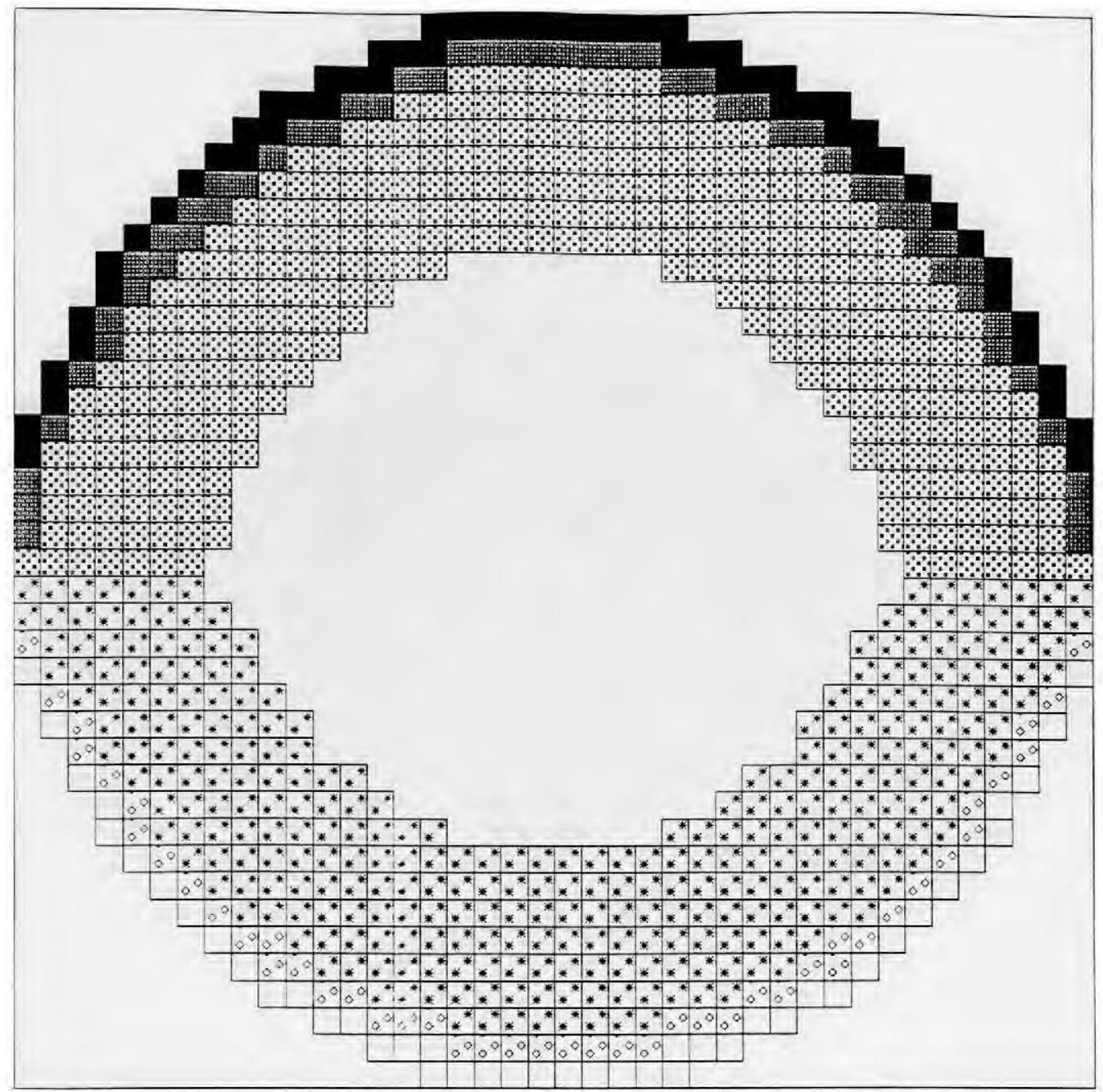

Fig. 11.17. Distribution of seepage rates (cm/day) over the lake bed for a deep flow-through lake with steep lake bed slope at $\mathrm{R}=1$. The regional gradient of groundwater flow is from the top to the bottom of the figure. Fig. 10.14 gives an analogous map for the simulation of a shallow flow-through lake with steep lake bed slope at $\mathrm{R}=1$. The white area in the center represents cells having seepage rates with absolute values $<10^{-7}$ $\mathrm{cm} /$ day.

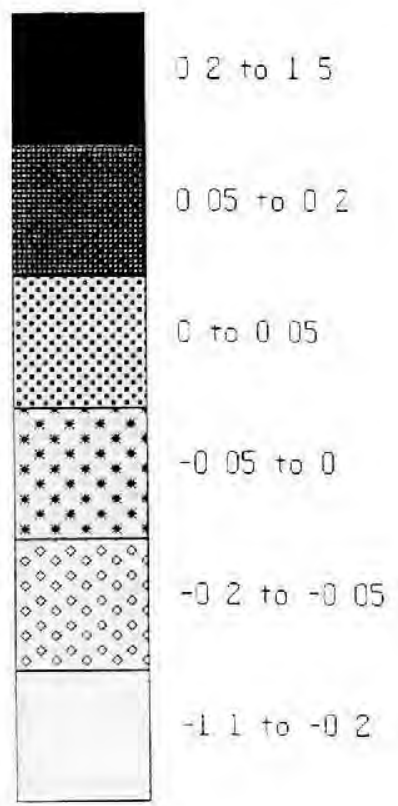




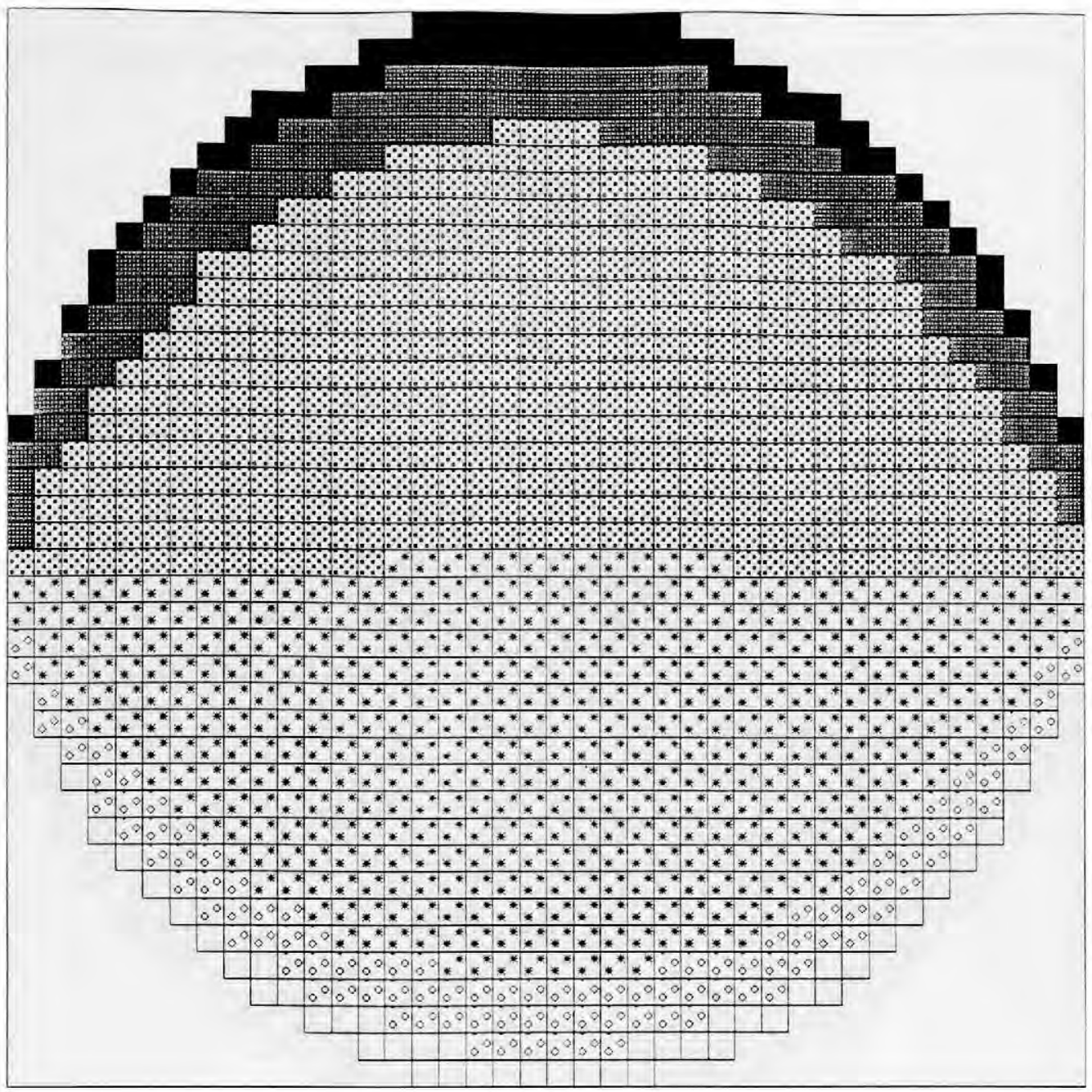

Fig. 11.18. Distribution of seepage rates ( $\mathrm{cm} /$ day) over the lake bed for a deep flow-through lake with steep lake bed slope at $\mathrm{R}=10$. The regional gradient of groundwater flow is from the top to the bottom of the figure. Fig. 10.15 gives an analogous map for the simulation of a shallow flow-through lake with steep lake bed slope at $\mathrm{R}=10$.

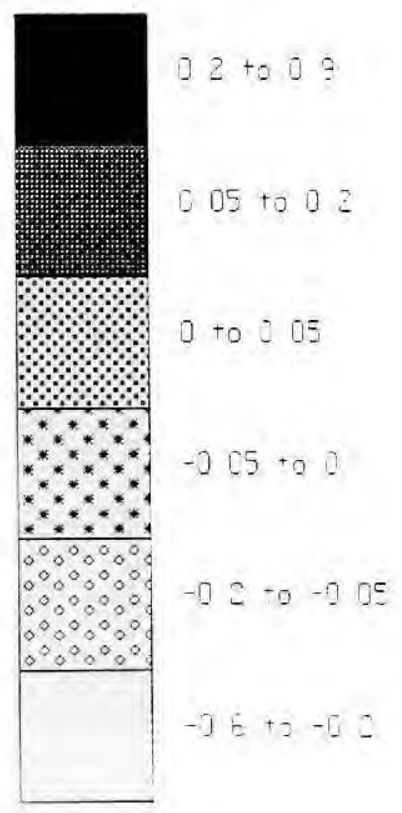




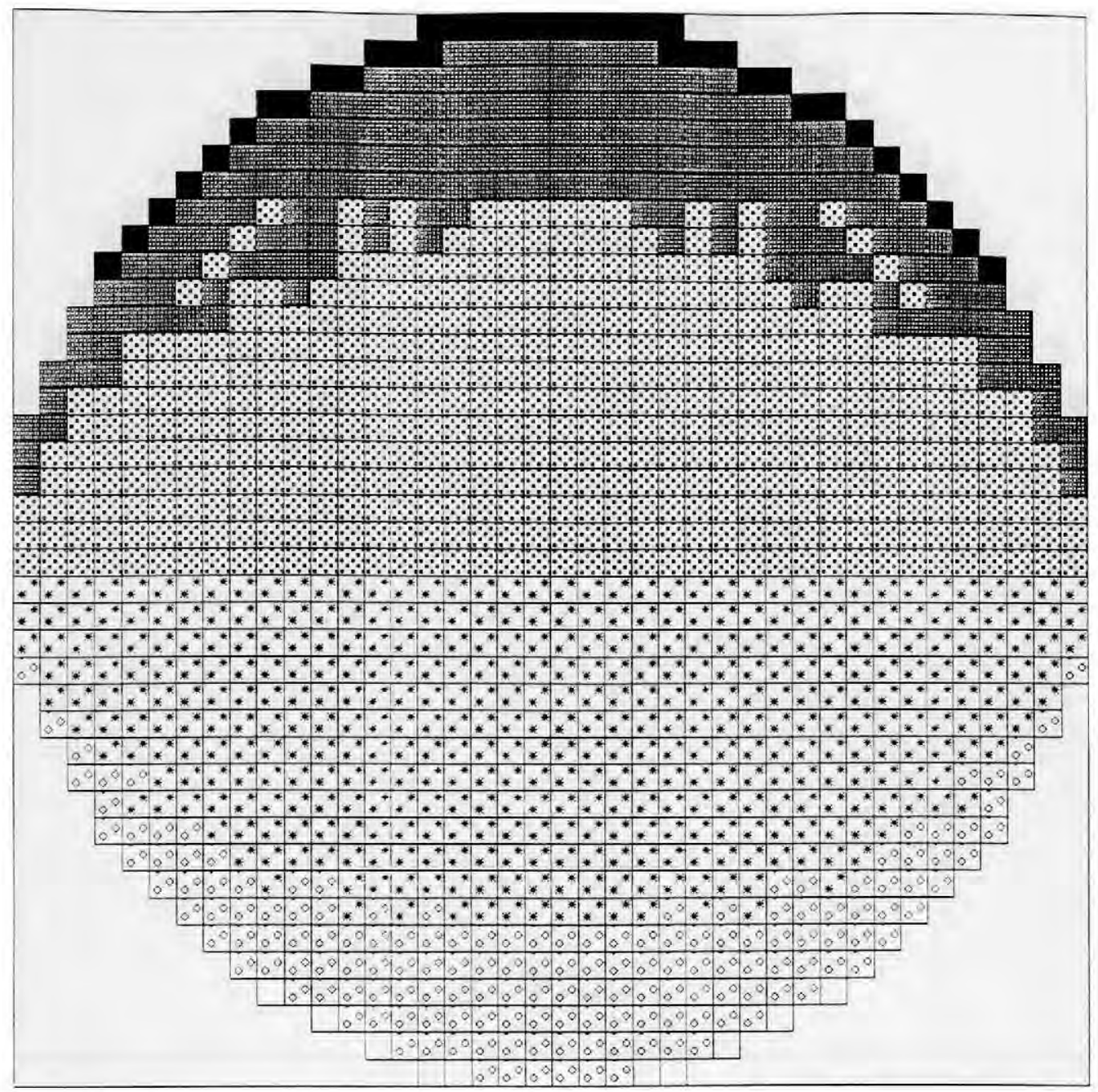

Fig. 11.19. Distribution of seepage rates ( $\mathrm{cm} /$ day) over the lake bed for a deep flow-through lake with steep lake bed slope at $\mathrm{R}=100$. The regional gradient of groundwater flow is from the top to the bottom of the figure. Fig. 10.16 gives an analogous map for the simulation of a shallow flow-through lake with steep lake bed slope at $\mathrm{R}=100$.

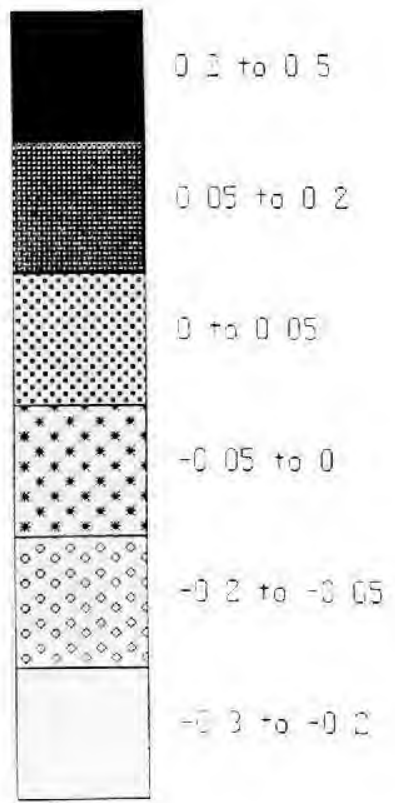




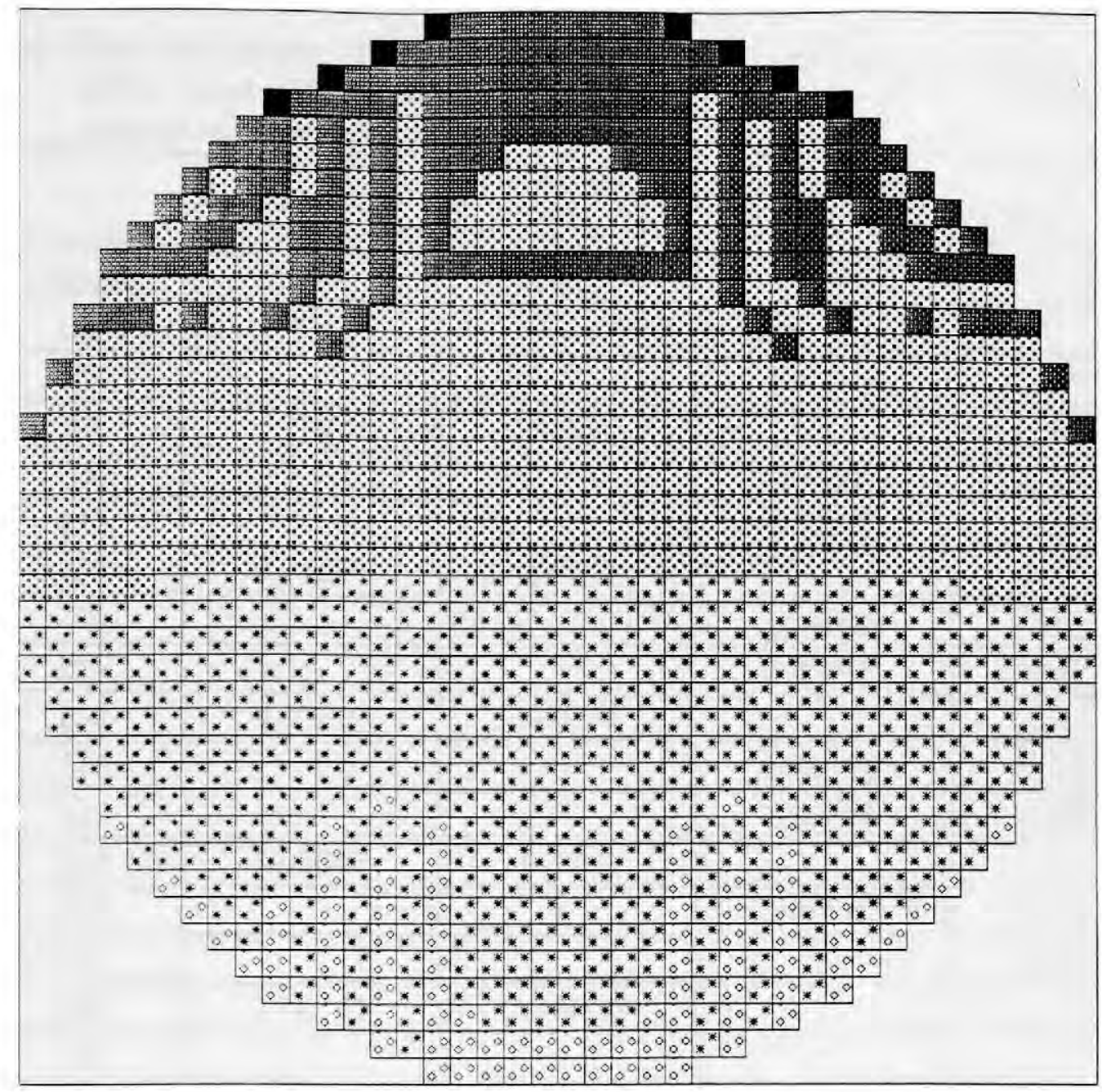

Fig. 11.20. Distribution of seepage rates ( $\mathrm{cm} /$ day) over the lake bed for a deep flow-through lake with steep lake bed slope at $\mathrm{R}=1000$. The regional gradient of groundwater flow is from the top to the bottom of the figure. Fig. 10.17 gives an analogous map for the simulation of a shallow flow-through lake with steep lake bed slope at $\mathrm{R}=1000$.

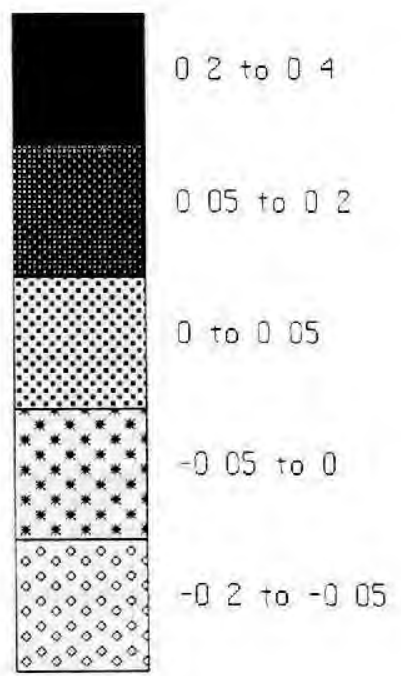


Table 11.4. Seepage rate versus distance offshore for the simulations of shallow and deep inflow lakes with moderate and steep lake bed slope at $\mathrm{R}=1$. ${ }^{*}$ denotes where seepage rates are less than $10^{-7} \mathrm{~cm} /$ day.

\begin{tabular}{|c|c|c|c|c|}
\hline \multirow{4}{*}{$\begin{array}{c}\text { Distance } \\
\text { offshore } \\
(\mathrm{m})\end{array}$} & \multicolumn{4}{|c|}{ Seepage rate $(\mathrm{cm} /$ day $)$} \\
\hline & \multicolumn{2}{|c|}{ lake with moderate slope } & \multicolumn{2}{|c|}{ lake with steep slope } \\
\hline & shallow & deep & shallow & deep \\
\hline & \multicolumn{4}{|c|}{ Anisotropy $(\mathrm{R})=1$} \\
\hline 25 & & & 1.97153 & 1.97752 \\
\hline 50 & 1.21878 & 1.21582 & & \\
\hline 75 & & & 0.34260 & 0.34370 \\
\hline 125 & & & 0.07383 & 0.07421 \\
\hline 150 & 0.07886 & 0.07878 & & \\
\hline 175 & & & 0.01540 & 0.01551 \\
\hline 225 & & & 0.00010 & 0.00295 \\
\hline 250 & 0.00596 & 0.00597 & & \\
\hline 275 & & & $1.93 \mathrm{e}-05$ & 0.00057 \\
\hline 325 & & & $3.61 \mathrm{e}-06$ & $9.78 \mathrm{e}-05$ \\
\hline 350 & 0.00042 & 0.00043 & & \\
\hline 375 & & & $6.85 e-07$ & $1.57 \mathrm{e}-05$ \\
\hline 425 & & & * & $2.31 \mathrm{e}-06$ \\
\hline 450 & $2.84 \mathrm{e}-05$ & $2.86 \mathrm{e}-05$ & & \\
\hline 475 & & & $*$ & * \\
\hline 525 & & & * & $*$ \\
\hline 550 & $1.76 \mathrm{e}-06$ & $1.78 \mathrm{e}-06$ & & \\
\hline 575 & & & $*$ & * \\
\hline 625 & & & $*$ & $*$ \\
\hline 650 & $1.12 \mathrm{e}-07$ & $1.03 e-07$ & & \\
\hline 675 & & & * & * \\
\hline 725 & & & $*$ & $*$ \\
\hline 750 & * & * & & \\
\hline 775 & & & $*$ & $*$ \\
\hline 825 & & & * & $*$ \\
\hline 850 & $*$ & $*$ & & \\
\hline 875 & & & $*$ & $*$ \\
\hline 925 & & & $*$ & $*$ \\
\hline 950 & * & $*$ & & \\
\hline 975 & & & $*$ & * \\
\hline
\end{tabular}


Table 11.5. Seepage rate versus distance offshore for the simulations of shallow and deep inflow lakes with moderate and steep lake bed slope at $R=10$.

\begin{tabular}{|c|c|c|c|c|}
\hline \multirow{4}{*}{$\begin{array}{c}\text { Distance } \\
\text { offshore } \\
(\mathrm{m})\end{array}$} & \multicolumn{4}{|c|}{ Seepage rate $(\mathrm{cm} /$ day $)$} \\
\hline & \multicolumn{2}{|c|}{ lake with moderate slope } & \multicolumn{2}{|c|}{ lake with steep slope } \\
\hline & shallow & deep & shallow & deep \\
\hline & \multicolumn{4}{|c|}{ Anisotropy $(\mathrm{R})=10$} \\
\hline 25 & & & 1.50688 & 1.50174 \\
\hline 50 & 1.01571 & 1.01615 & & \\
\hline 75 & & & 0.56290 & 0.55985 \\
\hline 125 & & & 0.31618 & 0.31396 \\
\hline 150 & 0.27746 & 0.27738 & & \\
\hline 175 & & & 0.18819 & 0.18601 \\
\hline 225 & & & 0.11545 & 0.10627 \\
\hline 250 & 0.10401 & 0.10412 & & \\
\hline 275 & & & 0.06233 & 0.06443 \\
\hline 325 & & & 0.03512 & 0.03673 \\
\hline 350 & 0.03947 & 0.03956 & & \\
\hline 375 & & & 0.02010 & 0.02035 \\
\hline 425 & & & 0.01159 & 0.01095 \\
\hline 450 & 0.01486 & 0.01480 & & \\
\hline 475 & & & 0.00672 & 0.00581 \\
\hline 525 & & & 0.00392 & 0.00267 \\
\hline 550 & 0.00522 & 0.00545 & & \\
\hline 575 & & & 0.00231 & 0.00128 \\
\hline 625 & & & 0.00137 & 0.00062 \\
\hline 650 & 0.00192 & 0.00197 & & \\
\hline 675 & & & 0.00082 & 0.00031 \\
\hline 725 & & & 0.00050 & 0.00015 \\
\hline 750 & 0.00074 & 0.00070 & & \\
\hline 775 & & & 0.00031 & $7.90 \mathrm{e}-05$ \\
\hline 825 & & & 0.00020 & $4.19 \mathrm{e}-05$ \\
\hline 850 & 0.00032 & 0.00026 & & \\
\hline 875 & & & 0.00014 & $2.35 e-05$ \\
\hline 925 & & & 0.00010 & $1.47 \mathrm{e}-05$ \\
\hline 950 & 0.00019 & 0.00013 & & \\
\hline 975 & & & $8.57 e-05$ & $1.12 \mathrm{e}-05$ \\
\hline
\end{tabular}


Table 11.6. Seepage rate versus distance offshore for the simulations of shallow and deep inflow lakes with moderate and steep lake bed slope at $R=100$.

\begin{tabular}{|c|c|c|c|c|}
\hline \multirow{4}{*}{$\begin{array}{c}\text { Distance } \\
\text { offshore } \\
(\mathrm{m})\end{array}$} & \multicolumn{4}{|c|}{ Seepage rate $(\mathrm{cm} /$ day $)$} \\
\hline & \multicolumn{2}{|c|}{ lake with moderate slope } & \multicolumn{2}{|c|}{ lake with steep slope } \\
\hline & shallow & deep & shallow & deep \\
\hline & \multicolumn{4}{|c|}{ Anisotropy $(\mathrm{R})=100$} \\
\hline 25 & & & 1.09265 & 1.02188 \\
\hline 50 & 0.73718 & 0.73638 & & \\
\hline 75 & & & 0.42907 & 0.40578 \\
\hline 125 & & & 0.31599 & 0.29381 \\
\hline 150 & 0.29045 & 0.28952 & & \\
\hline 175 & & & 0.26286 & 0.23516 \\
\hline 225 & & & 0.25079 & 0.18896 \\
\hline 250 & 0.19753 & 0.19576 & & \\
\hline 275 & & & 0.16387 & 0.16719 \\
\hline 325 & & & 0.13041 & 0.14420 \\
\hline 350 & 0.14958 & 0.14648 & & \\
\hline 375 & & & 0.10795 & 0.12564 \\
\hline 425 & & & 0.09133 & 0.11153 \\
\hline 450 & 0.12797 & 0.11876 & & \\
\hline 475 & & & 0.07843 & 0.10698 \\
\hline 525 & & & 0.06814 & 0.07064 \\
\hline 550 & 0.08476 & 0.09529 & & \\
\hline 575 & & & 0.05983 & 0.05549 \\
\hline 625 & & & 0.05308 & 0.04516 \\
\hline 650 & 0.06485 & 0.07720 & & \\
\hline 675 & & & 0.04762 & 0.03768 \\
\hline 725 & & & 0.04323 & 0.03211 \\
\hline 750 & 0.05294 & 0.06433 & & \\
\hline 775 & & & 0.03977 & 0.02795 \\
\hline 825 & & & 0.03712 & 0.02490 \\
\hline 850 & 0.04597 & 0.05694 & & \\
\hline 875 & & & 0.03519 & 0.02275 \\
\hline 925 & & & 0.03394 & 0.02138 \\
\hline 950 & 0.04272 & 0.05796 & & \\
\hline 975 & & & 0.03333 & 0.02071 \\
\hline
\end{tabular}


Table 11.7. Seepage rate versus distance offshore for the simulations of shallow and deep inflow lakes with moderate and steep lake bed slope at $R=1000$.

\begin{tabular}{|c|c|c|c|c|}
\hline \multirow{4}{*}{$\begin{array}{c}\text { Distance } \\
\text { offshore } \\
(\mathrm{m})\end{array}$} & \multicolumn{4}{|c|}{ Seepage rate $(\mathrm{cm} /$ day $)$} \\
\hline & \multicolumn{2}{|c|}{ lake with moderate slope } & \multicolumn{2}{|c|}{ lake with steep slope } \\
\hline & shallow & deep & shallow & deep \\
\hline & \multicolumn{4}{|c|}{ Anisotropy $(R)=1000$} \\
\hline 25 & & & 1.12945 & 1.05875 \\
\hline 50 & 0.68651 & 0.66969 & & \\
\hline 75 & & & 0.33101 & 0.27875 \\
\hline 125 & & & 0.26009 & 0.21107 \\
\hline 150 & 0.21931 & 0.21228 & & \\
\hline 175 & & & 0.24331 & 0.18136 \\
\hline 225 & & & 0.29031 & 0.15873 \\
\hline 250 & 0.17049 & 0.16215 & & \\
\hline 275 & & & 0.12253 & 0.15505 \\
\hline 325 & & & 0.10756 & 0.15003 \\
\hline 350 & 0.15804 & 0.14410 & & \\
\hline 375 & & & 0.09689 & 0.14995 \\
\hline 425 & & & 0.08902 & 0.15842 \\
\hline 450 & 0.20254 & 0.16043 & & \\
\hline 475 & & & 0.08305 & 0.20026 \\
\hline 525 & & & 0.07841 & 0.08960 \\
\hline 550 & 0.10992 & 0.16119 & & \\
\hline 575 & & & 0.07475 & 0.08154 \\
\hline 625 & & & 0.07183 & 0.07545 \\
\hline 650 & 0.09590 & 0.16322 & & \\
\hline 675 & & & 0.06950 & 0.07082 \\
\hline 725 & & & 0.06764 & 0.06729 \\
\hline 750 & 0.08797 & 0.17086 & & \\
\hline 775 & & & 0.06618 & 0.06462 \\
\hline 825 & & & 0.06506 & 0.06264 \\
\hline 850 & 0.08358 & 0.18901 & & \\
\hline 875 & & & 0.06426 & 0.06125 \\
\hline 925 & & & 0.06373 & 0.06036 \\
\hline 950 & 0.08160 & 0.23952 & & \\
\hline 975 & & & 0.06347 & 0.05992 \\
\hline
\end{tabular}


Table 11.8. Seepage rate versus distance from the downgradient lake shore for the simulations of shallow and deep flow-through lakes with moderate and steep lake bed slope at $\mathrm{R}=1 .^{*}$ denotes where the absolute value of seepage rate was $<10^{-7} \mathrm{~cm} /$ day.

\begin{tabular}{|c|c|c|c|c|}
\hline \multirow{4}{*}{$\begin{array}{l}\text { Distance } \\
\text { offshore } \\
\text { (m) }\end{array}$} & \multicolumn{4}{|c|}{ Seepage rate $(\mathrm{cm} /$ day $)$} \\
\hline & \multicolumn{2}{|c|}{ lake with moderate slope } & \multicolumn{2}{|c|}{ lake with steep slope } \\
\hline & shallow & deep & shallow & deep \\
\hline & \multicolumn{4}{|c|}{ Anisotropy $(\mathrm{R})=1$} \\
\hline 25 & & & -0.64488 & -0.66991 \\
\hline 50 & -0.38103 & -0.37860 & & \\
\hline 75 & & & -0.11509 & -0.11981 \\
\hline 125 & & & -0.02476 & -0.02589 \\
\hline 150 & -0.02546 & -0.02533 & & \\
\hline 175 & & & -0.00516 & -0.00542 \\
\hline 225 & & & -0.00102 & -0.00103 \\
\hline 250 & -0.00192 & -0.00192 & & \\
\hline 275 & & & -0.00019 & -0.00020 \\
\hline 325 & & & $-3.47 e-05$ & $-3.40 \mathrm{e}-05$ \\
\hline 350 & -0.00014 & -0.00014 & & \\
\hline 375 & & & $-6.43 e-06$ & $-5.43 e-06$ \\
\hline 425 & & & $-1.20 \mathrm{e}-06$ & $-8.02 \mathrm{e}-07$ \\
\hline 450 & $-8.92 e-06$ & $-9.14 e-06$ & & \\
\hline 475 & & & * & $*$ \\
\hline 525 & & & $*$ & * \\
\hline 550 & $-5.62 e-07$ & $-5.55 e-07$ & & \\
\hline 575 & & & * & $*$ \\
\hline 625 & & & * & $*$ \\
\hline 650 & $*$ & $\star$ & & \\
\hline 675 & & & * & $*$ \\
\hline 725 & & & * & $*$ \\
\hline 750 & $*$ & $*$ & & \\
\hline 775 & & & $*$ & * \\
\hline 825 & & & $*$ & * \\
\hline 850 & $*$ & $*$ & & \\
\hline 875 & & & $*$ & $*$ \\
\hline 925 & & & $*$ & * \\
\hline 950 & $*$ & $*$ & & \\
\hline 975 & & & * & * \\
\hline
\end{tabular}


Table 11.8. (Contd.)

\begin{tabular}{|c|c|c|c|c|}
\hline \multirow{4}{*}{$\begin{array}{c}\text { Distance } \\
\text { offshore } \\
(\mathrm{m})\end{array}$} & \multicolumn{4}{|c|}{ Seepage rate $(\mathrm{cm} /$ day $)$} \\
\hline & \multicolumn{2}{|c|}{ lake with moderate slope } & \multicolumn{2}{|c|}{ lake with steep slope } \\
\hline & shallow & deep & shallow & deep \\
\hline & \multicolumn{4}{|c|}{ Anisotropy $(\mathrm{R})=1$} \\
\hline 1025 & & & $*$ & * \\
\hline 1050 & * & * & & \\
\hline 1075 & & & * & * \\
\hline 1125 & & & * & * \\
\hline 1150 & * & * & & \\
\hline 1175 & & & * & * \\
\hline 1225 & & & $*$ & $*$ \\
\hline 1250 & * & * & & \\
\hline 1275 & & & * & * \\
\hline 1325 & & & * & * \\
\hline 1350 & * & $*$ & & \\
\hline 1375 & & & $*$ & $*$ \\
\hline 1425 & & & $*$ & $*$ \\
\hline 1450 & $7.44 \mathrm{e}-07$ & $7.36 \mathrm{e}-07$ & & \\
\hline 1475 & & & $*$ & * \\
\hline 1525 & & & $*$ & $*$ \\
\hline 1550 & $1.18 \mathrm{e}-05$ & $1.19 e-05$ & & \\
\hline 1575 & & & $1.62 \mathrm{e}-06$ & $1.07 \mathrm{e}-06$ \\
\hline 1625 & & & $8.72 \mathrm{e}-06$ & $7.26 \mathrm{e}-06$ \\
\hline 1650 & 0.00018 & 0.00018 & & \\
\hline 1675 & & & $4.71 \mathrm{e}-05$ & $4.54 e-05$ \\
\hline 1725 & & & 0.00026 & 0.00026 \\
\hline 1750 & 0.00254 & 0.00253 & & \\
\hline 1775 & & & 0.00138 & 0.00148 \\
\hline 1825 & & & 0.00698 & 0.00719 \\
\hline 1850 & 0.03362 & 0.03353 & & \\
\hline 1875 & & & 0.03349 & 0.03443 \\
\hline 1925 & & & 0.15570 & 0.15973 \\
\hline 1950 & 0.51576 & 0.51350 & & \\
\hline 1975 & & & 0.88894 & 0.91183 \\
\hline
\end{tabular}


Table 11.9. Seepage rate versus distance from the downgradient lake shore for the simulations of shallow and deep flow-through lakes with moderate and steep lake bed slope at $R=10$.

\begin{tabular}{|c|c|c|c|c|}
\hline \multirow{4}{*}{$\begin{array}{c}\text { Distance } \\
\text { offshore } \\
(\mathrm{m})\end{array}$} & \multicolumn{4}{|c|}{ Seepage rate $(\mathrm{cm} /$ day $)$} \\
\hline & \multicolumn{2}{|c|}{ lake with moderate slope } & \multicolumn{2}{|c|}{ lake with steep slope } \\
\hline & shallow & deep & shallow & deep \\
\hline & \multicolumn{4}{|c|}{ Anisotropy $(R)=10$} \\
\hline 25 & & & -0.42141 & -0.42478 \\
\hline 50 & -0.28956 & -0.28727 & & \\
\hline 75 & & & -0.17543 & -0.17647 \\
\hline 125 & & & -0.09890 & -0.09924 \\
\hline 150 & -0.08561 & -0.08485 & & \\
\hline 175 & & & -0.05876 & -0.05867 \\
\hline 225 & & & -0.03588 & -0.03340 \\
\hline 250 & -0.03184 & -0.03160 & & \\
\hline 275 & & & -0.01925 & -0.02016 \\
\hline 325 & & & -0.01077 & -0.01144 \\
\hline 350 & -0.01192 & -0.01184 & & \\
\hline 375 & & & -0.00611 & -0.00631 \\
\hline 425 & & & -0.00349 & -0.00337 \\
\hline 450 & -0.00440 & -0.00434 & & \\
\hline 475 & & & -0.00200 & -0.00178 \\
\hline 525 & & & -0.00115 & -0.00081 \\
\hline 550 & -0.00150 & -0.00156 & & \\
\hline 575 & & & -0.00067 & -0.00038 \\
\hline 625 & & & -0.00039 & -0.00018 \\
\hline 650 & -0.00053 & -0.00054 & & \\
\hline 675 & & & -0.00023 & $-8.94 \mathrm{e}-05$ \\
\hline 725 & & & -0.00013 & $-4.37 e-05$ \\
\hline 750 & -0.00019 & -0.00018 & & \\
\hline 775 & & & $-7.69 e-05$ & $-2.15 e-05$ \\
\hline 825 & & & $-4.43 e-05$ & $-1.06 \mathrm{e}-05$ \\
\hline 850 & $-6.37 e-05$ & $-5.56 e-05$ & & \\
\hline 875 & & & $-2.43 e-05$ & $-5.09 e-06$ \\
\hline 925 & & & $-1.12 e-05$ & $-2.19 \mathrm{e}-06$ \\
\hline 950 & $-1.21 \mathrm{e}-05$ & $-1.06 e-05$ & & \\
\hline 975 & & & $-1.28 e-06$ & $-1.00 e-06$ \\
\hline
\end{tabular}


Table 11.9. (Contd.)

\begin{tabular}{|c|c|c|c|c|}
\hline \multirow{4}{*}{$\begin{array}{c}\text { Distance } \\
\text { offshore } \\
(\mathrm{m})\end{array}$} & \multicolumn{4}{|c|}{ Seepage rate $(\mathrm{cm} /$ day $)$} \\
\hline & \multicolumn{2}{|c|}{ lake with moderate slope } & \multicolumn{2}{|c|}{ lake with steep slope } \\
\hline & shallow & deep & shallow & deep \\
\hline & \multicolumn{4}{|c|}{ Anisotropy $(\mathrm{R})=10$} \\
\hline 1025 & & & $8.05 \mathrm{e}-06$ & $1.19 e-06$ \\
\hline 1050 & $2.52 \mathrm{e}-05$ & $1.96 \mathrm{e}-05$ & & \\
\hline 1075 & & & $1.93 \mathrm{e}-05$ & $3.30 \mathrm{e}-06$ \\
\hline 1125 & & & $3.56 e-05$ & $6.97 e-06$ \\
\hline 1150 & $8.80 e-05$ & $7.58 e-05$ & & \\
\hline 1175 & & & $6.15 e-05$ & $1.41 \mathrm{e}-05$ \\
\hline 1225 & & & 0.00010 & $2.83 e-05$ \\
\hline 1250 & 0.00025 & 0.00024 & & \\
\hline 1275 & & & 0.00018 & $5.74 e-05$ \\
\hline 1325 & & & 0.00030 & 0.00012 \\
\hline 1350 & 0.00069 & 0.00070 & & \\
\hline 1375 & & & 0.00051 & 0.00024 \\
\hline 1425 & & & 0.00088 & 0.00050 \\
\hline 1450 & 0.00195 & 0.00203 & & \\
\hline 1475 & & & 0.00152 & 0.00106 \\
\hline 1525 & & & 0.00264 & 0.00232 \\
\hline 1550 & 0.00568 & 0.00563 & & \\
\hline 1575 & & & 0.00459 & 0.00440 \\
\hline 1625 & & & 0.00801 & 0.00823 \\
\hline 1650 & 0.01536 & 0.01533 & & \\
\hline 1675 & & & 0.01409 & 0.01492 \\
\hline 1725 & & & 0.02514 & 0.02628 \\
\hline 1750 & 0.04098 & 0.04085 & & \\
\hline 1775 & & & 0.04680 & 0.04701 \\
\hline 1825 & & & 0.07657 & 0.07644 \\
\hline 1850 & 0.11028 & 0.10979 & & \\
\hline 1875 & & & 0.12894 & 0.12931 \\
\hline 1925 & & & 0.22939 & 0.23046 \\
\hline 1950 & 0.39654 & 0.39498 & & \\
\hline 1975 & & & 0.59099 & 0.59495 \\
\hline
\end{tabular}


Table 11.10. Seepage rate versus distance from the downgradient lake shore for the simulations of shallow and deep flow-through lakes with moderate and steep lake bed slope at $R=100$.

\begin{tabular}{|c|c|c|c|c|}
\hline \multirow{4}{*}{$\begin{array}{c}\text { Distance } \\
\text { offshore } \\
(\mathrm{m})\end{array}$} & \multicolumn{4}{|c|}{ Seepage rate $(\mathrm{cm} /$ day $)$} \\
\hline & \multicolumn{2}{|c|}{ lake with moderate slope } & \multicolumn{2}{|c|}{ lake with steep slope } \\
\hline & shallow & deep & shallow & deep \\
\hline & \multicolumn{4}{|c|}{ Anisotropy $(\mathrm{R})=100$} \\
\hline 25 & & & -0.19613 & -0.19252 \\
\hline 50 & -0.14544 & -0.14462 & & \\
\hline 75 & & & -0.11970 & -0.11646 \\
\hline 125 & & & -0.09106 & -0.08739 \\
\hline 150 & -0.07969 & -0.07892 & & \\
\hline 175 & & & -0.07624 & -0.07076 \\
\hline 225 & & & -0.07213 & -0.05689 \\
\hline 250 & -0.05346 & -0.05276 & & \\
\hline 275 & & & -0.04621 & -0.05003 \\
\hline 325 & & & -0.03590 & -0.04266 \\
\hline 350 & -0.03884 & -0.03806 & & \\
\hline 375 & & & -0.02884 & -0.03658 \\
\hline 425 & & & -0.02353 & -0.03176 \\
\hline 450 & -0.03089 & -0.02908 & & \\
\hline 475 & & & -0.01932 & -0.02948 \\
\hline 525 & & & -0.01588 & -0.01860 \\
\hline 550 & -0.01823 & -0.02141 & & \\
\hline 575 & & & -0.01302 & -0.01387 \\
\hline 625 & & & -0.01059 & -0.01056 \\
\hline 650 & -0.01169 & $-0.0 i 517$ & & \\
\hline 675 & & & -0.00850 & -0.00806 \\
\hline 725 & & & -0.00667 & -0.00609 \\
\hline 750 & -0.00711 & -0.01007 & & \\
\hline 775 & & & -0.00505 & -0.00449 \\
\hline 825 & & & -0.00358 & -0.00313 \\
\hline 850 & -0.00351 & -0.00566 & & \\
\hline 875 & & & -0.00221 & -0.00195 \\
\hline 925 & & & -0.00092 & -0.00088 \\
\hline 950 & -0.00038 & -0.00112 & & \\
\hline 975 & & & 0.00035 & 0.00015 \\
\hline
\end{tabular}


Table 11.10. (Contd.)

\begin{tabular}{|c|c|c|c|c|}
\hline \multirow{4}{*}{$\begin{array}{c}\text { Distance } \\
\text { offshore } \\
(\mathrm{m})\end{array}$} & \multicolumn{4}{|c|}{ Seepage rate $(\mathrm{cm} /$ day $)$} \\
\hline & \multicolumn{2}{|c|}{ lake with moderate slope } & \multicolumn{2}{|c|}{ lake with steep slope } \\
\hline & shallow & deep & shallow & deep \\
\hline & \multicolumn{4}{|c|}{ Anisotropy $(\mathrm{R})=100$} \\
\hline 1025 & & & 0.00161 & 0.00117 \\
\hline 1050 & 0.00267 & 0.00444 & & \\
\hline 1075 & & & 0.00292 & 0.00224 \\
\hline 1125 & & & 0.00430 & 0.00341 \\
\hline 1150 & 0.00601 & 0.00897 & & \\
\hline 1175 & & & 0.00580 & 0.00475 \\
\hline 1225 & & & 0.00746 & 0.00632 \\
\hline 1250 & 0.01004 & 0.01388 & & \\
\hline 1275 & & & 0.00933 & 0.00823 \\
\hline 1325 & & & 0.01147 & 0.01060 \\
\hline 1350 & 0.01537 & 0.01983 & & \\
\hline 1375 & & & 0.01394 & 0.01363 \\
\hline 1425 & & & 0.01685 & 0.01770 \\
\hline 1450 & 0.02316 & 0.02727 & & \\
\hline 1475 & & & 0.02031 & 0.02353 \\
\hline 1525 & & & 0.02448 & 0.03704 \\
\hline 1550 & 0.03853 & 0.03651 & & \\
\hline 1575 & & & 0.02963 & 0.03973 \\
\hline 1625 & & & 0.03616 & 0.04565 \\
\hline 1650 & 0.04802 & 0.04740 & & \\
\hline 1675 & & & 0.04488 & 0.05320 \\
\hline 1725 & & & 0.05769 & 0.06240 \\
\hline 1750 & 0.06593 & 0.06550 & & \\
\hline 1775 & & & 0.09015 & 0.07679 \\
\hline 1825 & & & 0.09571 & 0.08885 \\
\hline 1850 & 0.09872 & 0.09835 & & \\
\hline 1875 & & & 0.11537 & 0.11074 \\
\hline 1925 & & & 0.15468 & 0.15052 \\
\hline 1950 & 0.22998 & 0.22926 & & \\
\hline 1975 & & & 0.33006 & 0.32266 \\
\hline
\end{tabular}


Table 11.11. Seepage rate versus distance from the downgradient lake shore for the simulations of shallow and deep flow-through lakes with moderate and steep lake bed slope at $\mathrm{R}=1000$.

\begin{tabular}{|c|c|c|c|c|}
\hline \multirow{4}{*}{$\begin{array}{c}\text { Distance } \\
\text { offshore } \\
(\mathrm{m})\end{array}$} & \multicolumn{4}{|c|}{ Seepage rate $(\mathrm{cm} /$ day $)$} \\
\hline & \multicolumn{2}{|c|}{ lake with moderate slope } & \multicolumn{2}{|c|}{ lake with steep slope } \\
\hline & shallow & deep & shallow & deep \\
\hline & \multicolumn{4}{|c|}{ Anisotropy $(R)=1000$} \\
\hline 25 & & & -0.06053 & -0.05880 \\
\hline 50 & -0.04395 & -0.04373 & & \\
\hline 75 & & & -0.05479 & -0.05209 \\
\hline 125 & & & -0.05052 & -0.04678 \\
\hline 150 & -0.03605 & -0.03562 & & \\
\hline 175 & & & -0.04975 & -0.04336 \\
\hline 225 & & & -0.05838 & -0.03926 \\
\hline 250 & -0.02920 & -0.02873 & & \\
\hline 275 & & & -0.02287 & -0.03869 \\
\hline 325 & & & -0.01893 & -0.03701 \\
\hline 350 & -0.02557 & -0.02477 & & \\
\hline 375 & & & -0.01592 & -0.03582 \\
\hline 425 & & & -0.01352 & -0.03566 \\
\hline 450 & -0.02821 & -0.02530 & & \\
\hline 475 & & & -0.01151 & -0.04006 \\
\hline 525 & & & -0.00979 & -0.01508 \\
\hline 550 & -0.01203 & -0.02241 & & \\
\hline 575 & & & -0.00827 & -0.01231 \\
\hline 625 & & & -0.00690 & -0.01000 \\
\hline 650 & -0.00794 & -0.01882 & & \\
\hline 675 & & & -0.00564 & -0.00803 \\
\hline 725 & & & -0.00445 & -0.00629 \\
\hline 750 & -0.00480 & -0.01476 & & \\
\hline 775 & & & -0.00333 & -0.00472 \\
\hline 825 & & & -0.00225 & -0.00327 \\
\hline 850 & -0.00212 & -0.00978 & & \\
\hline 875 & & & -0.00120 & -0.00190 \\
\hline 925 & & & -0.00017 & -0.00059 \\
\hline 950 & 0.00035 & -0.00175 & & \\
\hline 975 & & & 0.00086 & 0.00071 \\
\hline
\end{tabular}


Table 11.11. (Contd.)

\begin{tabular}{|c|c|c|c|c|}
\hline \multirow{4}{*}{$\begin{array}{c}\text { Distance } \\
\text { offshore } \\
(\mathrm{m})\end{array}$} & \multicolumn{4}{|c|}{ Seepage rate $(\mathrm{cm} /$ day $)$} \\
\hline & \multicolumn{2}{|c|}{ lake with moderate slope } & \multicolumn{2}{|c|}{ lake with steep slope } \\
\hline & shallow & deep & shallow & deep \\
\hline & \multicolumn{4}{|c|}{ Anisotropy $(R)=1000$} \\
\hline 1025 & & & 0.00189 & 0.00200 \\
\hline 1050 & 0.00280 & 0.01128 & & \\
\hline 1075 & & & 0.00293 & 0.00331 \\
\hline 1125 & & & 0.00399 & 0.00468 \\
\hline 1150 & 0.00537 & 0.01742 & & \\
\hline 1175 & & & 0.00509 & 0.00612 \\
\hline 1225 & & & 0.00624 & 0.00768 \\
\hline 1250 & 0.00827 & 0.02185 & & \\
\hline 1275 & & & 0.00745 & 0.00939 \\
\hline 1325 & & & 0.00875 & 0.01132 \\
\hline 1350 & 0.01182 & 0.02585 & & \\
\hline 1375 & & & 0.01016 & 0.01355 \\
\hline 1425 & & & 0.01171 & 0.01620 \\
\hline 1450 & 0.01663 & 0.02969 & & \\
\hline 1475 & & & 0.01347 & 0.01941 \\
\hline 1525 & & & 0.01548 & 0.05021 \\
\hline 1550 & 0.03726 & 0.03302 & & \\
\hline 1575 & & & 0.01788 & 0.04422 \\
\hline 1625 & & & 0.02080 & 0.04448 \\
\hline 1650 & 0.03335 & 0.03231 & & \\
\hline 1675 & & & 0.02452 & 0.04631 \\
\hline 1725 & & & 0.02946 & 0.04910 \\
\hline 1750 & 0.03870 & 0.03823 & & \\
\hline 1775 & & & 0.07577 & 0.05501 \\
\hline 1825 & & & 0.06652 & 0.05818 \\
\hline 1850 & 0.05043 & 0.05009 & & \\
\hline 1875 & & & 0.07123 & 0.06632 \\
\hline 1925 & & & 0.08583 & 0.08215 \\
\hline 1950 & 0.11638 & 0.11575 & & \\
\hline 1975 & & & 0.18127 & 0.17511 \\
\hline
\end{tabular}




\section{CHAPTER 12}

\section{Results : Lake Bed Slope}

Lake bed slope is another hydrologic parameter which could influence the groundwater head distribution in the vicinity of a lake, or groundwater exchange with a lake. However, the effect of lake bed slope has not yet been investigated in studies of lake-groundwater interaction. In the present study the effect of lake bed slope was investigated in both inflow lakes and flowthrough lakes. The lake bed slope was varied by changing the number of cells per "step" in the lake from the top layer downward (Fig. 12.1). In all simulations, lake bed sediment was absent and the lakes were shallow in depth. The porous medium was homogeneous and anisotropy ratio was varied from 1 to 1000 in the same way as in previous chapters. In order to facilitate comparison of seepage results among lakes with different slope, "step average" seepage rates (with two cells per step in lakes with moderate slope and three cells per step in lakes with low slope) were calculated, and the average seepage rates were plotted against distance offshore. This was discussed previously in chapter 7.

\subsection{Inflow lake}

Inflow lake simulations were run with three different lake bed slopes: 


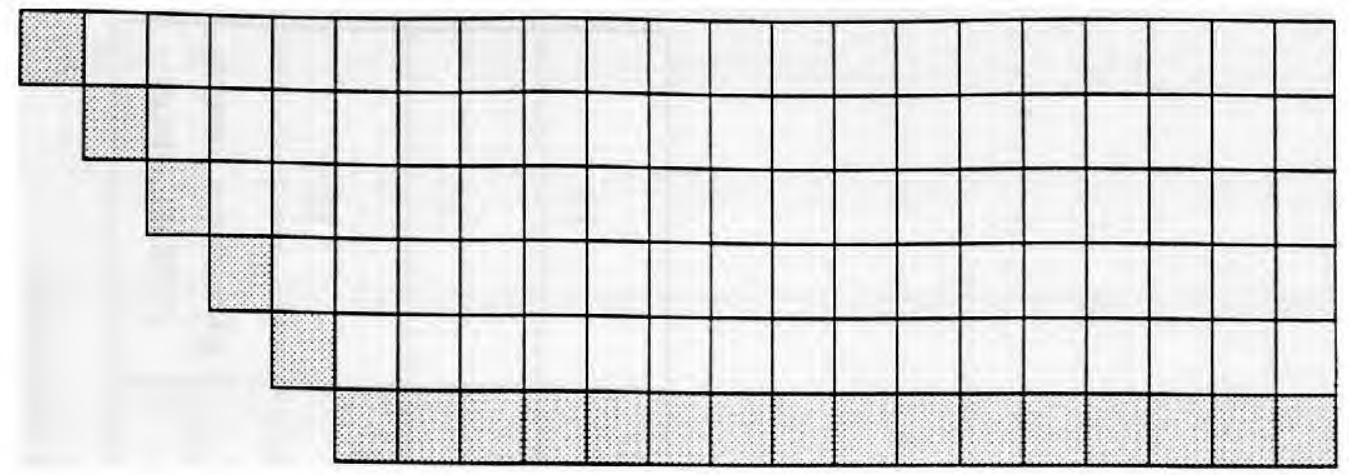

shallow lake with steep lake bed slope

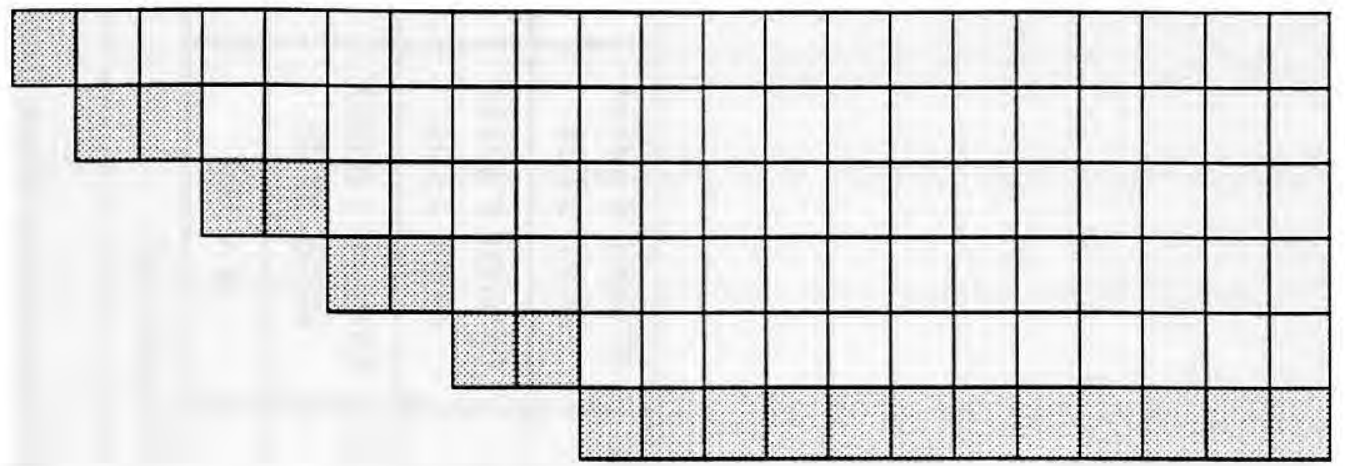

shallow lake with moderate lake bed slope

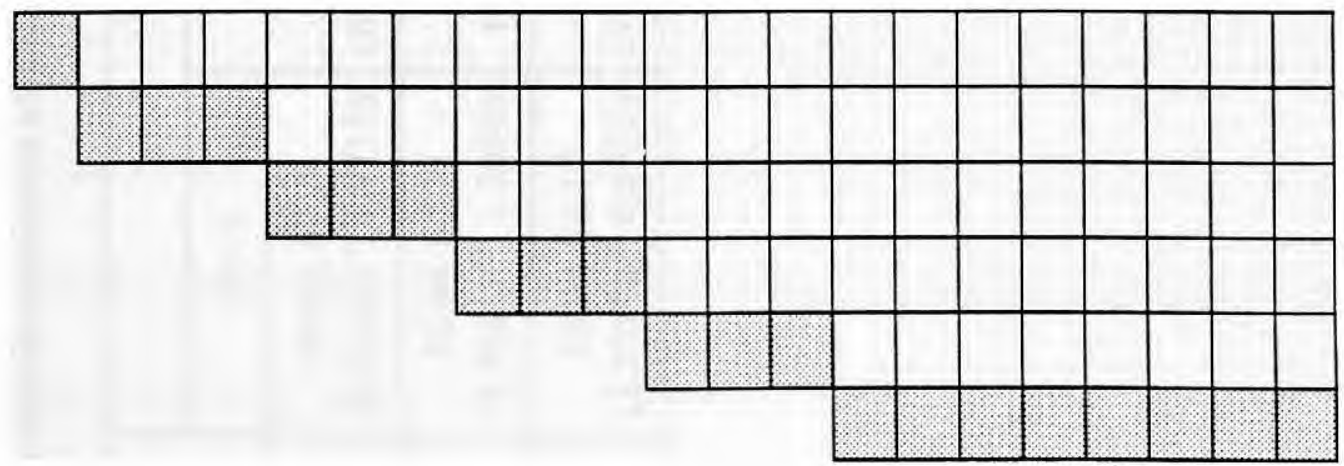

shallow lake with low lake bed slope

Fig. 12.1. Vertical cross-sections showing halves of three shallow lakes with different lake bed slope. The grey area represents cells of the porous medium. 
Table 12.1. Summary of head and seepage rates along the line of the vertical cross-section from the twelve simulations compared in the inflow lake section of this chapter. Each result box gives the minimum and the maximum heads in meters (first line) and the minimum and the maximum seepage rates in $\mathrm{cm} / \mathrm{day}$ (second line within parentheses) for one simulation.

\begin{tabular}{|c|c|c|c|c|c|}
\hline \multirow[t]{2}{*}{ Type of the lake } & \multicolumn{4}{|c|}{ Anisotropy Ratio (R) } & \multirow{2}{*}{$\begin{array}{l}\text { Chapter where } \\
\text { figures are located }\end{array}$} \\
\hline & $\mathrm{R}=1$ & $\mathrm{R}=10$ & $R=100$ & $\mathrm{R}=1000$ & \\
\hline $\begin{array}{l}\text { steep lake bed } \\
\text { slope }\end{array}$ & $\begin{array}{c}50.00,67.74 \\
\left(6.85 \times 10^{-7}, 1.9715\right)\end{array}$ & $\begin{array}{c}50.00,70.09 \\
\left(8.57 \times 10^{-5}, 1.5069\right)\end{array}$ & $\begin{array}{c}50.09,72.03 \\
(0.0334,1.0926)\end{array}$ & $\begin{array}{c}51.81,79.61 \\
(0.0635,1.1294)\end{array}$ & 10 \\
\hline $\begin{array}{l}\text { moderate lake bed } \\
\text { slope }\end{array}$ & $\begin{array}{c}50.00,67.74 \\
\left(1.46 \times 10^{-6}, 1.3654\right)\end{array}$ & $\begin{array}{c}50.00,70.21 \\
(0.0001,1.0423)\end{array}$ & $\begin{array}{c}50.09,73.07 \\
(0.0380,0.7651)\end{array}$ & $\begin{array}{c}51.87,81.02 \\
(0.0708,0.7401)\end{array}$ & 7 \\
\hline $\begin{array}{c}\text { low lake bed } \\
\text { slope }\end{array}$ & $\begin{array}{c}50.00,68.17 \\
\left(1.53 \times 10^{-6}, 0.8727\right)\end{array}$ & $\begin{array}{c}50.00,73.85 \\
\left(7.81 \times 10^{-5}, 0.9868\right)\end{array}$ & $\begin{array}{c}50.11,75.34 \\
(0.0383,0.7033)\end{array}$ & $\begin{array}{c}52.62,81.49 \\
(0.0839,0.5937)\end{array}$ & 12 \\
\hline
\end{tabular}


steep, moderate and low. The steep, moderate and low slopes lake bed had one, two and three cells per step, respectively (Fig.12.1). The lake with low bed slope always had the highest water table head at the boundary of the model domain, while the lake with steep bed slope had the lowest water table head at the boundary, at all anisotropy ratios.

The variation in lake bed slope resulted in little change in seepage rate along the lake bed. Seepage plots for the simulations (Figs. 12.3 and 12.4) show generally the same trend at all lake bed slopes, with small exceptions. For example, the nearest-shore seepage value for the lakes with low bed slope fell slightly above the trend defined by the near shore seepage rates in the lakes with moderate and steep bed slope. At higher anisotropy values $(R=100$, and especially $R=1000$ ), seepage rates further offshore did show same dependance on lake bed slope (rates being highest at low slope, and lowest at steep slope). As discussed for previous simulations, seepage plots at $\mathrm{R}=1000$, showed a local maximum in seepage at the break between the sloping and horizontal portions of the lake bed.

The seepage maps for all three lake bed slopes looked almost identical at $R=1$ and 10 (Figs.10.6, 10.7, and 12.5; 7.8, 7.10, and 12.6), though the maximum seepage rates in the highest seepage zone were different. At $\mathrm{R}=$ 
100 , the low seepage zone defined by a seepage of $0.1 \mathrm{~cm} /$ day or lower had more aerial extent in the steep lake than the lakes with moderate and low slope (Figs.10.8, 7.12 and 12.7). This decrease in aerial extent of low seepage zone indicated that the offshore seepage was lowest for the lake with steep slope and highest for the lake with low slope. At $\mathrm{R}=1000$, the lakes with moderate and low slope (Figs. 7.14 and 12.8) had "oscillating" patterns of seepage as described earlier in chapter 7. The low seepage zone had again the largest aerial extent for the lake with steep slope (Fig. 10.9). The high seepage zone defined by a seepage of $1.6 \mathrm{~cm} /$ day or higher was largest for the lake with low slope at $R=100$ and 1000 . Overall, it can be concluded that lake bed slope has a small effect on the distribution of hydraulic heads in the porous medium surrounding a lake and seepage through the lake bed, and the effect on seepage is larger at high anisotropy.

\subsection{Flow-through lake}

At all anisotropy ratios (Fig. 10.11, 10.12; 7.15 to $7.18 ; 12.9,12.10$ ), the heads on both upgradient and downgradient side of the lake were identical for all three lake bed slopes. The seepage boundary shifted about 50 meters to the downgradient side when $\mathrm{R}$ was increased from 10 to 1000 , but showed no dependance on lake bed slope (Table 12.2). 
Table 12.2. Summary of the position of the seepage boundary and seepage rate along the line of the vertical cross-section from the twelve simulations compared in the flow-through lake section of this chapter. Each result box gives the position of the seepage boundary* (first line) and the minimum and the maximum seepage rates in $\mathrm{cm} /$ day (second line within parentheses) for one simulation.

\begin{tabular}{|c|c|c|c|c|c|}
\hline \multirow[t]{2}{*}{ Type of the lake } & \multicolumn{4}{|c|}{ Anisotropy Ratio (R) } & \multirow{2}{*}{$\begin{array}{l}\text { Chapter where } \\
\text { figures are located }\end{array}$} \\
\hline & $\mathrm{R}=1$ & $\mathrm{R}=10$ & $\mathrm{R}=100$ & $\mathrm{R}=1000$ & \\
\hline $\begin{array}{l}\text { steep lake bed } \\
\text { slope }\end{array}$ & $\begin{array}{c}* \\
(-0.6448,0.8889)\end{array}$ & $\begin{array}{c}982 \\
(-0.4214,0.5909)\end{array}$ & $\begin{array}{c}961 \\
(-0.1961,0.3300)\end{array}$ & $\begin{array}{c}933 \\
(-0.0605,0.1812)\end{array}$ & 10 \\
\hline $\begin{array}{l}\text { moderate lake bed } \\
\text { slope }\end{array}$ & $\begin{array}{c}* \\
(-0.3876,0.5311)\end{array}$ & $\begin{array}{c}983 \\
(-0.2991,0.4263)\end{array}$ & $\begin{array}{c}961 \\
(-0.1536,0.2481)\end{array}$ & $\begin{array}{c}930 \\
(-0.0469,0.1262)\end{array}$ & 7 \\
\hline $\begin{array}{l}\text { low lake bed } \\
\text { slope }\end{array}$ & $\begin{array}{c}* \\
(-0.2895,0.3934)\end{array}$ & $\begin{array}{c}983 \\
(-0.2497,0.3393)\end{array}$ & $\begin{array}{c}960 \\
(-0.1373,0.2051)\end{array}$ & $\begin{array}{c}932 \\
(-0.0431,0.1011)\end{array}$ & 12 \\
\hline
\end{tabular}

${ }^{*}$ the distances are measured from the downgradient shore of the lake. 
The seepage rate distribution along the lake bed in all lake bed slopes was almost identical at $\mathrm{R}=1,10$ and 100 (Figs. 12.11 and 12.12). As with inflow lakes, the seepage value closest to shore for the lake with low lake bed slope had a larger magnitude than the seepage in this area for lakes with moderate and steep slopes. At $\mathrm{R}=1000$, the lake with steep slope had slightly higher outseepage on the downgradient side compared to the lake with low slope (Table 12.8). When the seepage maps were considered the distribution of seepage rates around the lake did not show any variation between lakes of steep and low bed slope at lower anisotropy (Figs. 10.15 to $10.17 ; 7.22,7.24$, $7.26 ; 12.13$ to 12.15 ). At $\mathrm{R}=1000$, the lowest outseepage zone (i.e., 0.2 $\mathrm{cm} /$ day or lower) had more aerial extent in lakes with steep slope than in the analogous lake with moderate slope.

In addition, changing lake bed slope did not affect the overall amount of groundwater exchange with lakes. The total groundwater inseepage and lake water outseepage were very similar, at all anisotropy ratios, for lakes with three different bed slopes (Table 12.3). Lakes with steep bed slope had the highest total annual inseepage and outseepage at all $\mathrm{R}$ while lakes with low bed slope had the least annual inseepage and outseepage.

In conclusion it can be inferred from the above discussion that the lake 


\begin{tabular}{|c|c|c|c|c|c|c|}
\hline \multirow{2}{*}{$\begin{array}{c}\text { Anisotropy } \\
\text { Ratio (R) }\end{array}$} & \multicolumn{2}{|c|}{ Steep } & \multicolumn{2}{c|}{ Moderate } & \multicolumn{3}{c|}{ Low } \\
\cline { 2 - 7 } & $\begin{array}{c}\text { net inseepage } \\
\left(\mathrm{m}^{3} / \text { year }\right)\end{array}$ & $\%$ of lake volume & $\begin{array}{c}\text { net inseepage } \\
\left(\mathrm{m}^{3} / \text { year }\right)\end{array}$ & $\%$ of lake volume & $\begin{array}{c}\text { net inseepage } \\
\left(\mathrm{m}^{3} / \text { year }\right)\end{array}$ & $\%$ of lake volume \\
\hline 1 & $4.34 \times 10^{5}$ & 2.10 & $4.34 \times 10^{5}$ & 2.10 & $4.29 \times 10^{5}$ & 2.08 \\
\hline 10 & $4.22 \times 10^{5}$ & 2.04 & $4.14 \times 10^{5}$ & 2.00 & $4.12 \times 10^{5}$ & 1.99 \\
\hline 100 & $3.51 \times 10^{5}$ & 1.70 & $3.34 \times 10^{5}$ & 1.62 & $3.19 \times 10^{5}$ & 1.55 \\
\hline 1000 & $2.18 \times 10^{5}$ & 1.06 & $1.94 \times 10^{5}$ & 0.94 & $1.83 \times 10^{5}$ & 0.88 \\
\hline
\end{tabular}

\begin{tabular}{|c|c|c|c|c|c|c|}
\hline \multirow{2}{*}{$\begin{array}{c}\text { Anisotropy } \\
\text { Ratio (R) }\end{array}$} & \multicolumn{2}{|c|}{ Steep } & \multicolumn{2}{c|}{ Moderate } & \multicolumn{2}{c|}{ Low } \\
\cline { 2 - 7 } & $\begin{array}{c}\text { net outseepage } \\
\left(\mathrm{m}^{3} / \text { year }\right)\end{array}$ & $\%$ of lake volume & $\begin{array}{c}\text { net outseepage } \\
\left(\mathrm{m}^{3} / \text { year }\right)\end{array}$ & $\%$ of lake volume & $\begin{array}{c}\text { net outseepage } \\
\left(\mathrm{m}^{3} / \text { year }\right)\end{array}$ & \% of lake volume \\
\hline 1 & $3.02 \times 10^{5}$ & 1.46 & $3.01 \times 10^{5}$ & 1.46 & $2.99 \times 10^{5}$ & 1.49 \\
\hline 10 & $2.96 \times 10^{5}$ & 1.43 & $2.94 \times 10^{5}$ & 1.42 & $2.90 \times 10^{5}$ & 1.41 \\
\hline 100 & $2.38 \times 10^{5}$ & 1.15 & $2.26 \times 10^{5}$ & 1.09 & $2.09 \times 10^{5}$ & 1.01 \\
\hline 1000 & $1.21 \times 10^{5}$ & 0.58 & $1.02 \times 10^{5}$ & 0.49 & $9.20 \times 10^{4}$ & 0.44 \\
\hline
\end{tabular}

Table 12.3. Groundwater inseepage (above) and lake water outseepage (below) per year as a percentage of lake volume in shallow flow-through lakes with different lake bed slopes at different anisotropy ratio. Lake volume was $2.064 \times 10^{7} \mathrm{~m}^{3}$. 
bed slope in flow-through lakes has very little effect on the position of the seepage boundary separating inseepage and outseepage portions of the lake bed and on spatial patterns of seepage through the lake beds. Also, the annual groundwater inseepage and lake water outseepage were very similar for lakes with different bed slope. 


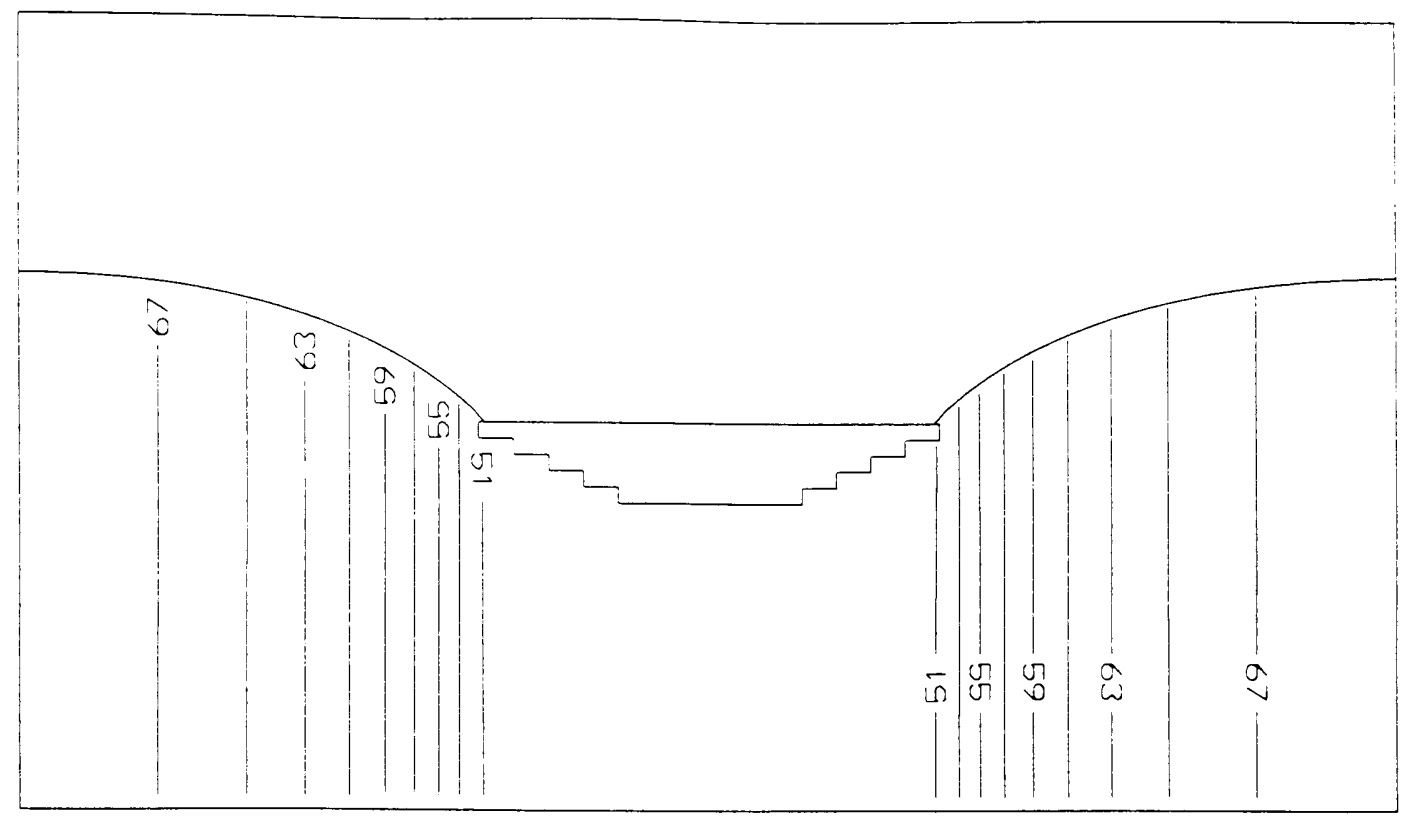

Anisotropy Ratio $=1$

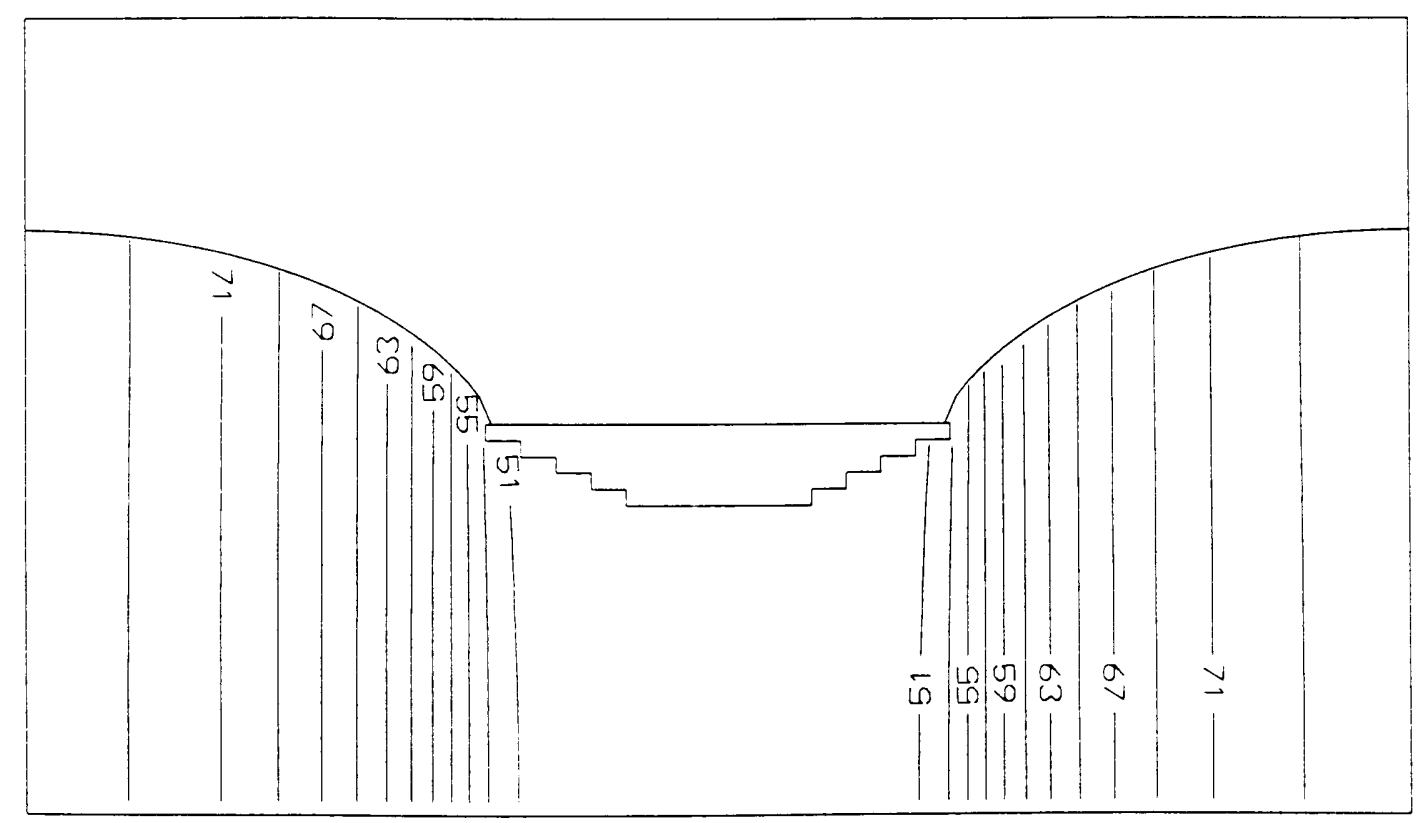

Anisotropy Ratio $=10$

Fig. 12.1. Distribution of hydraulic heads in the porous medium surrounding shallow inflow lakes with low lake bed slope at $R=1$ and $R=10$. Figs. 10.1 and 7.3 give analogous cross-sections of shallow inflow lakes with steep and moderate lake bed slopes at $\mathrm{R}=1$ and $\mathrm{R}=10$ respectively. 


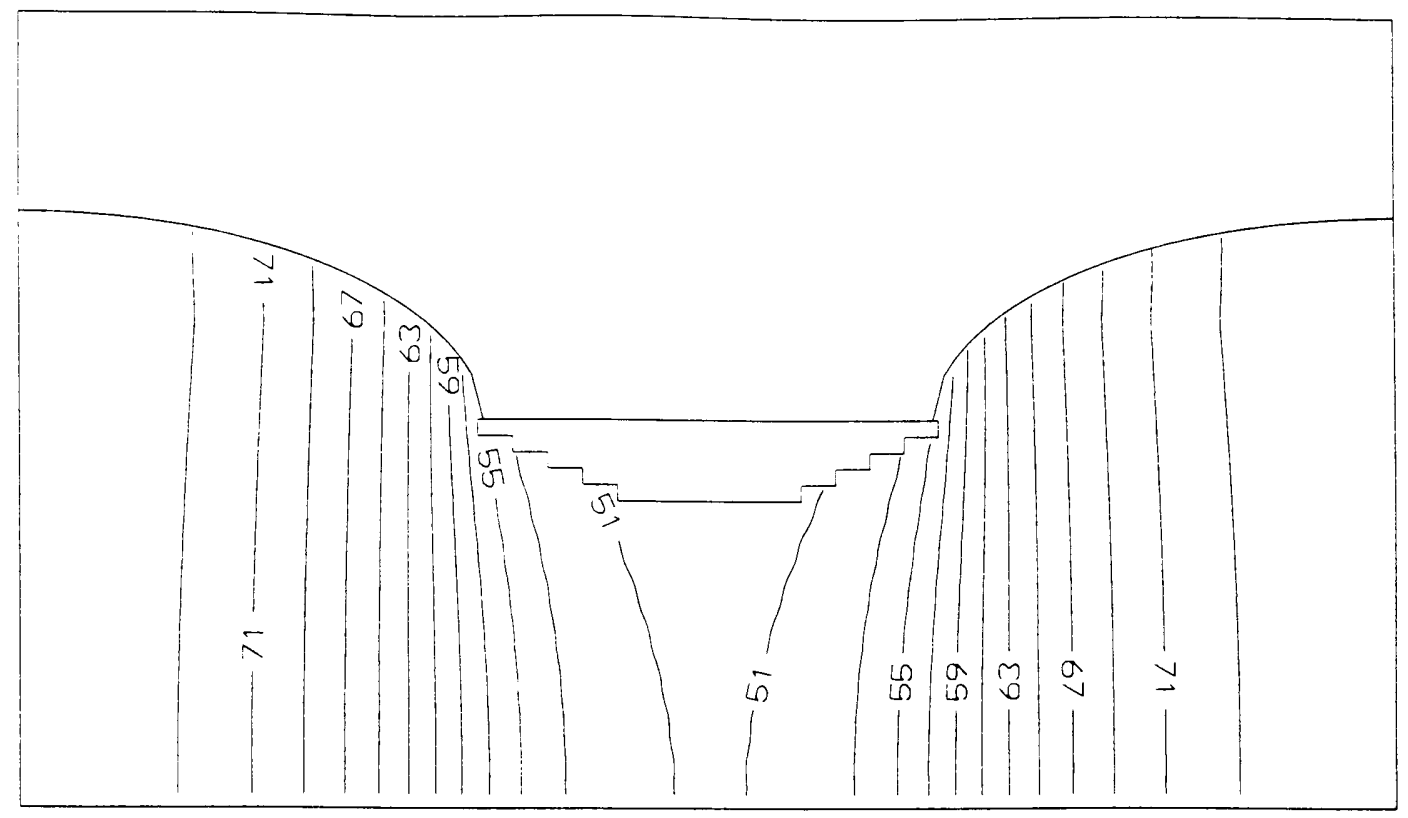

Anisotropy Ratio $=100$

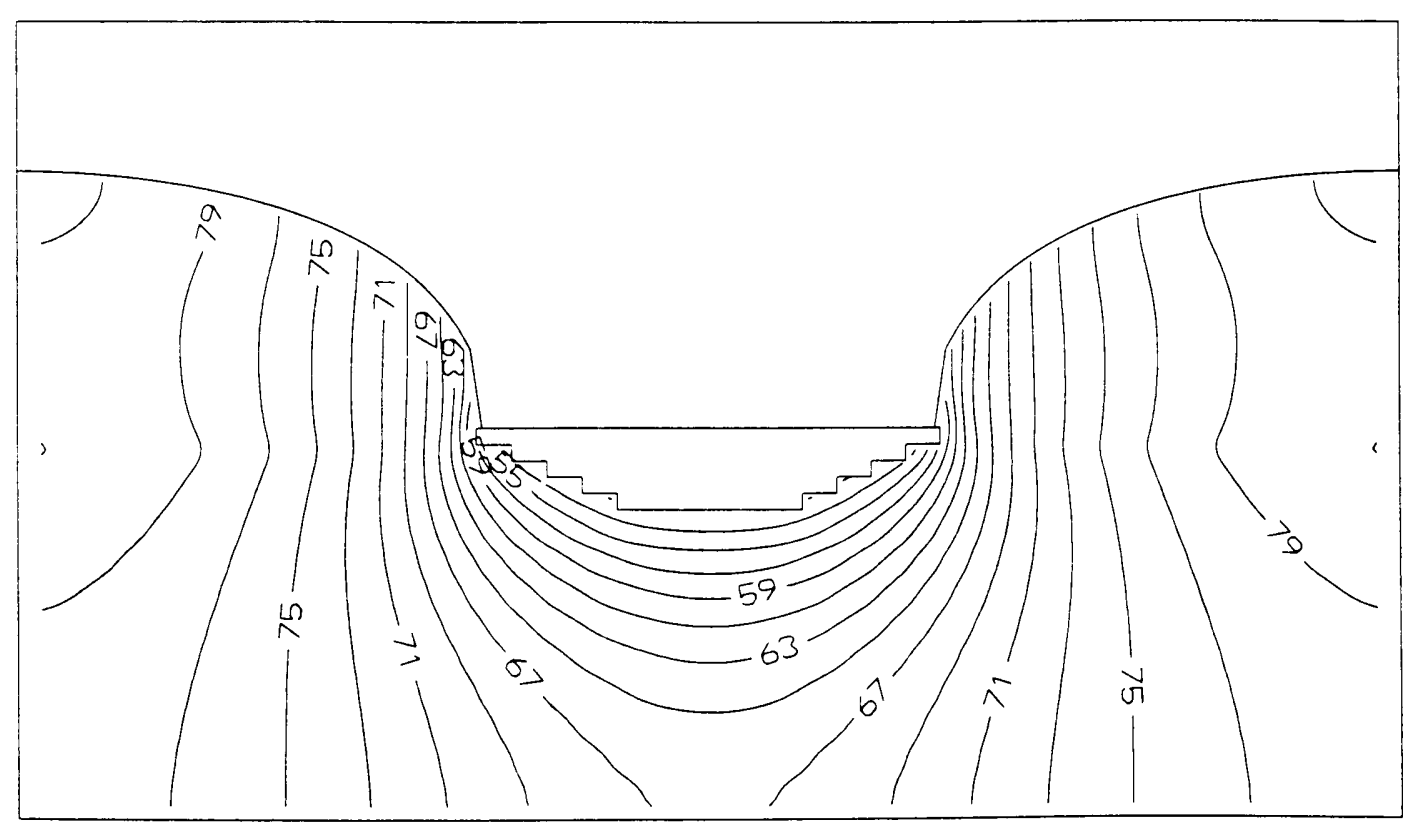

Anisotropy Ratio $=1000$

Fig. 12.2. Distribution of hydraulic heads in the porous medium surrounding shallow inflow lakes with low lake bed slope at $R=100$ and $R=1000$. Figs. 10.2 and 7.4 give analogous cross-sections of shallow inflow lakes with steep and moderate lake bed slopes at $R=100$ and $R=1000$ respectively. 

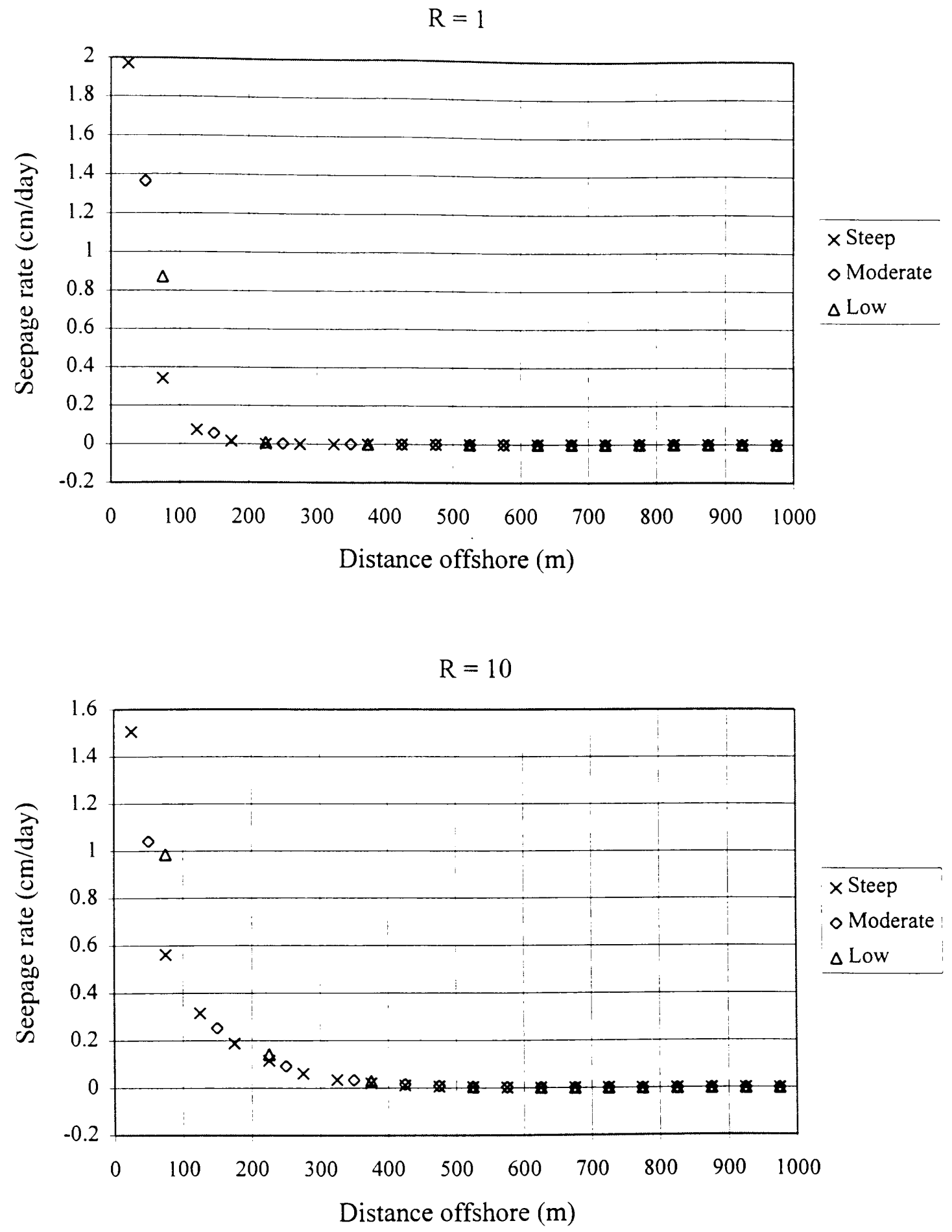

Fig. 12.3. Seepage rate versus distance offshore for the simulations of shallow inflow lakes with different lake bed slopes at $\mathrm{R}=1$ and $\mathrm{R}=10$. 

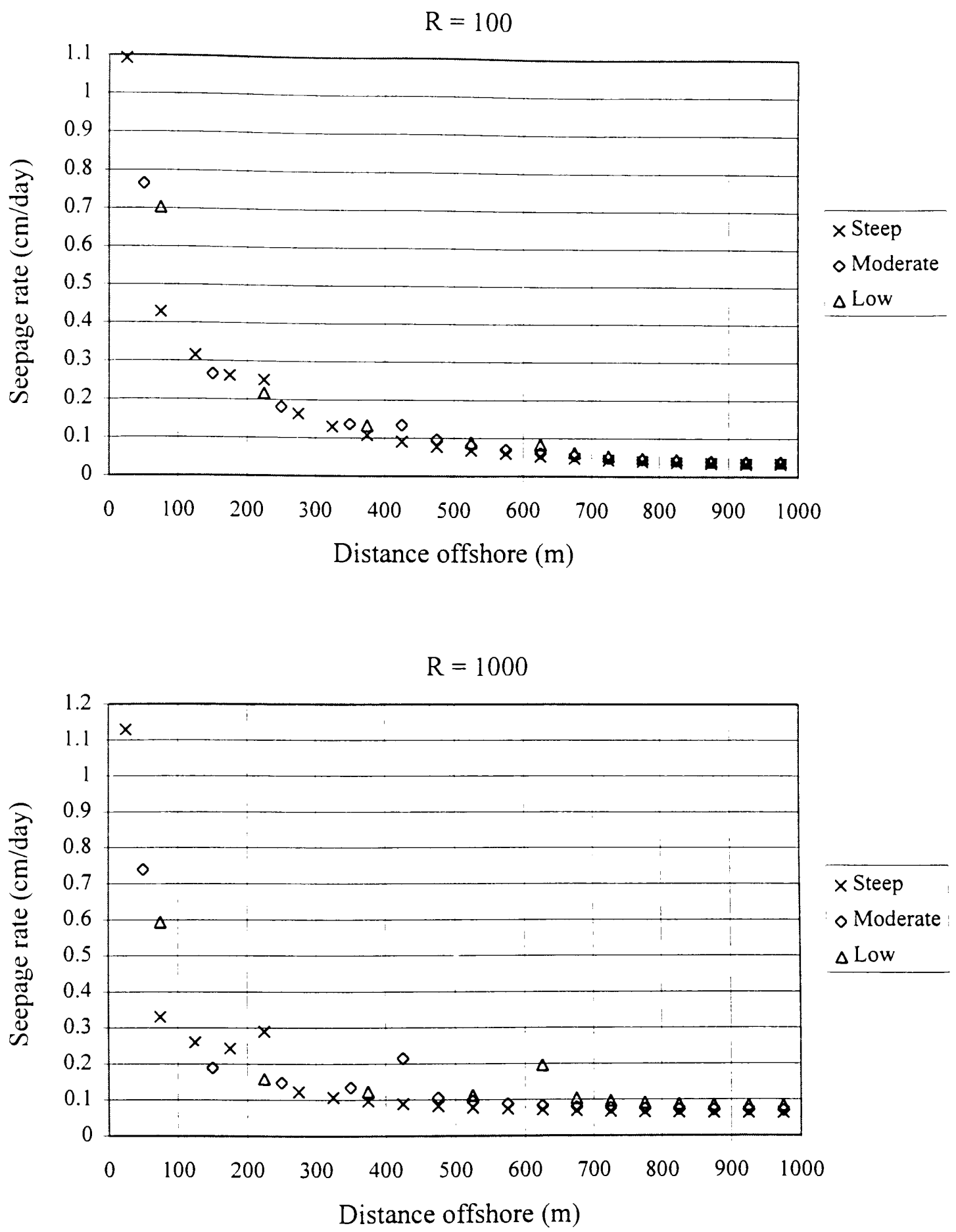

Fig. 12.4. Seepage rate versus distance offshore for the simulations of shallow inflow lakes with different lake bed slopes at $R=100$ and $R=1000$. 


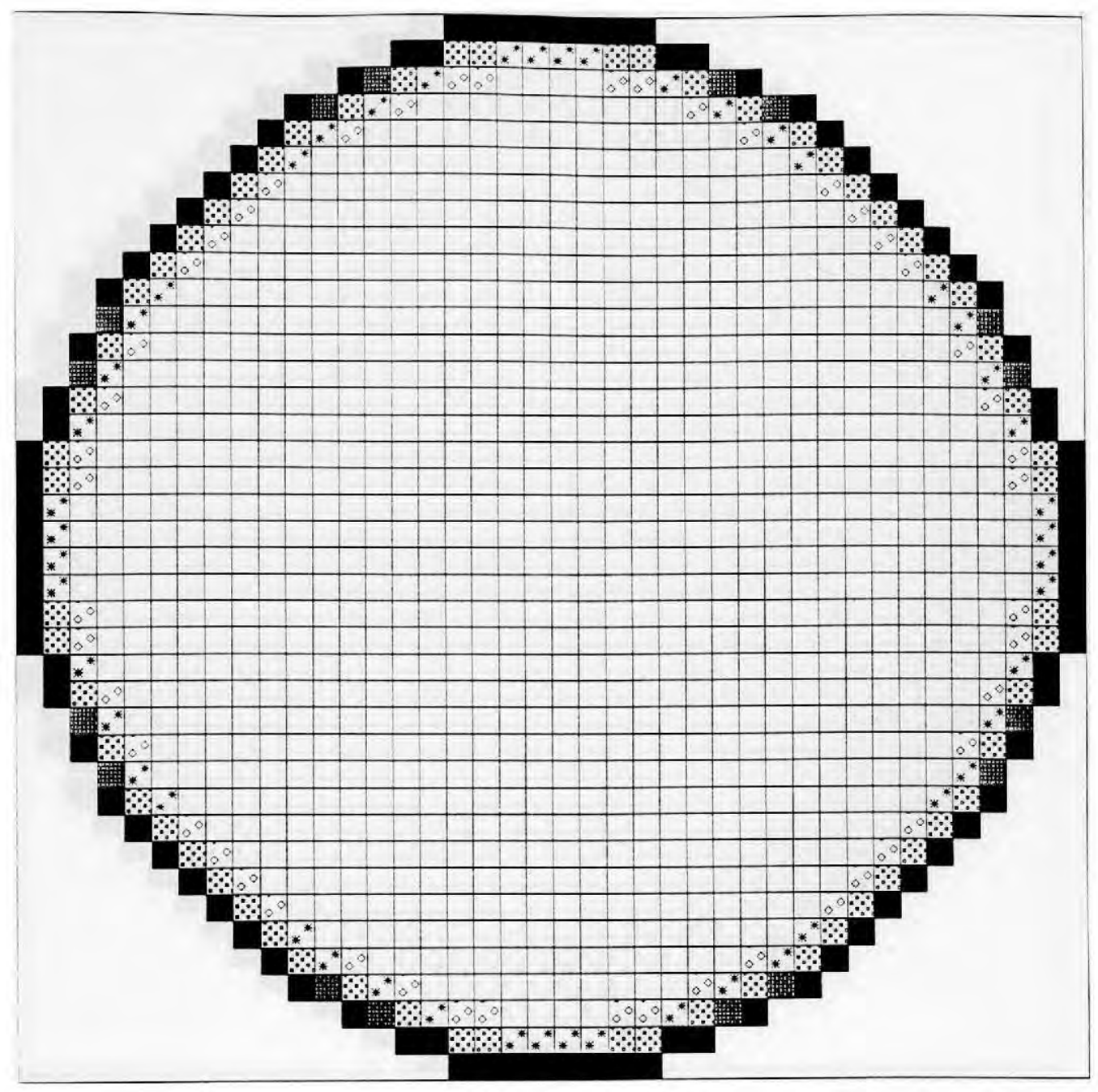

Fig. 12.5. Distribution of seepage rates ( $\mathrm{cm} /$ day) over the lake bed for a shallow inflow lake with low lake bed slope at $\mathrm{R}=1$. Figs, 10.6 and 7.8 give analogous maps of simulations of shallow inflow lakes with steep and moderate lake bed slope respectively.

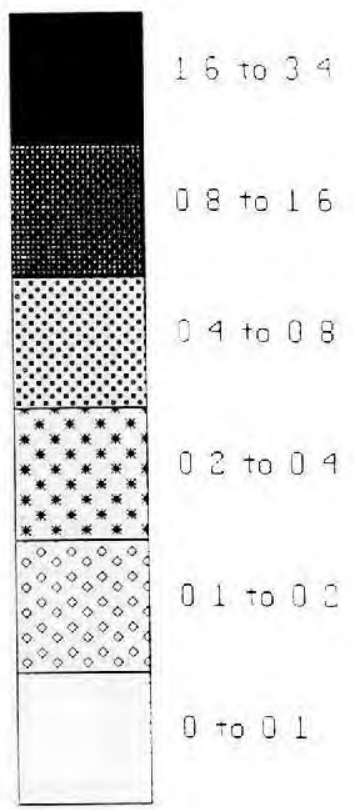




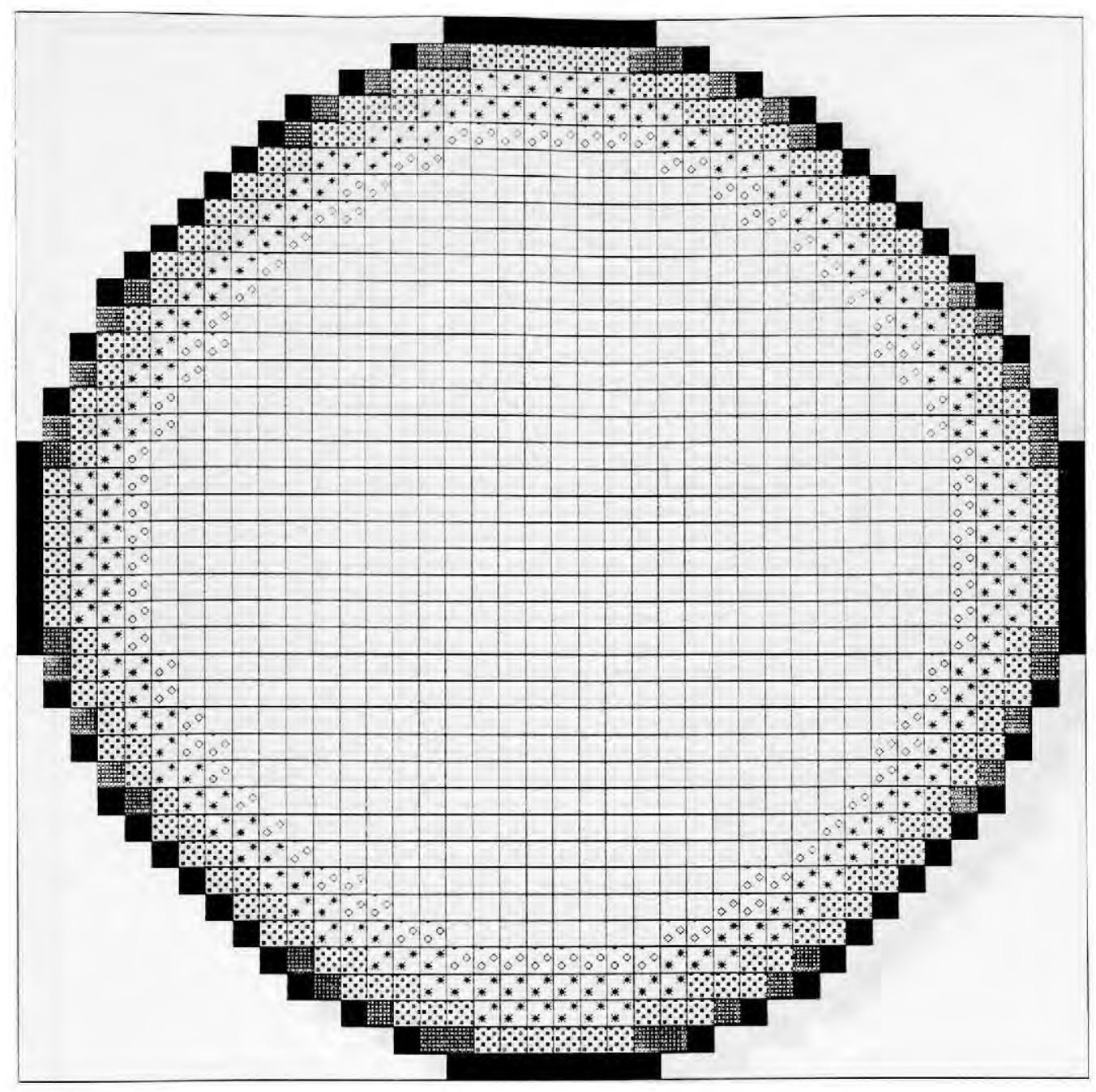

Fig. 12.6. Distribution of seepage rates (cm/day) over the lake bed for a shallow inflow lake with low lake bed slope at $R=10$. Figs. 10.7 and 7.10 give analogous maps of simulations of shallow inflow lakes with steep and moderate lake bed slope respectively.

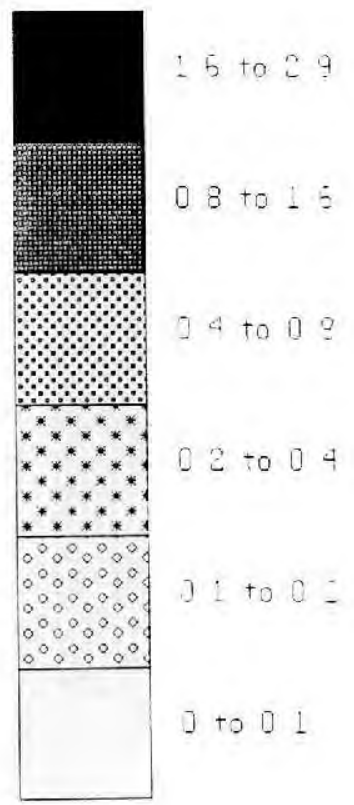




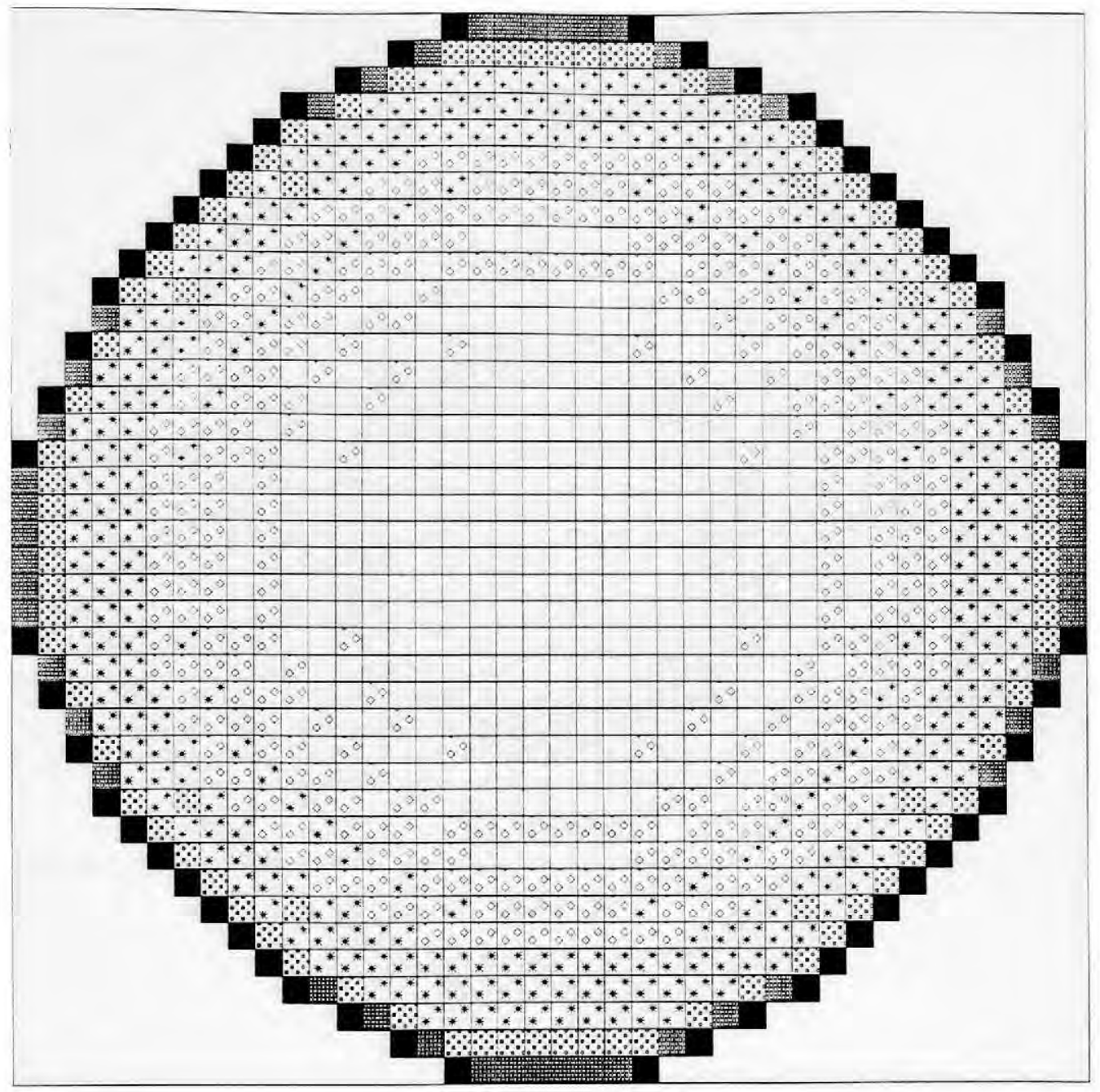

Fig. 12.7. Distribution of seepage rates ( $\mathrm{cm} /$ day) over the lake bed for a shallow inflow lake with low lake bed slope at $\mathrm{R}=100$. Figs. 10.8 and 7.12 give analogous maps of simulations of shallow inflow lakes with steep and moderate lake bed slope respectively.

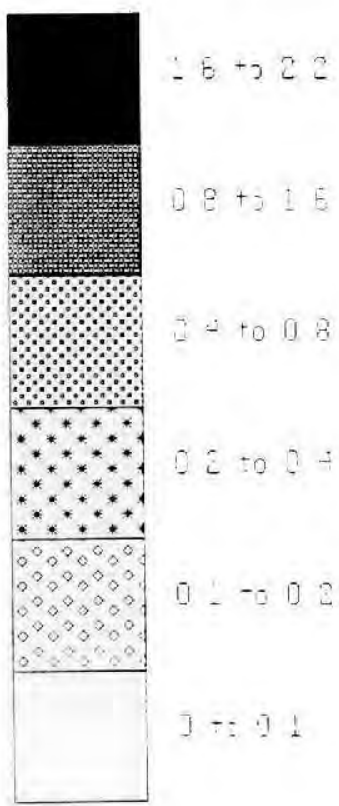




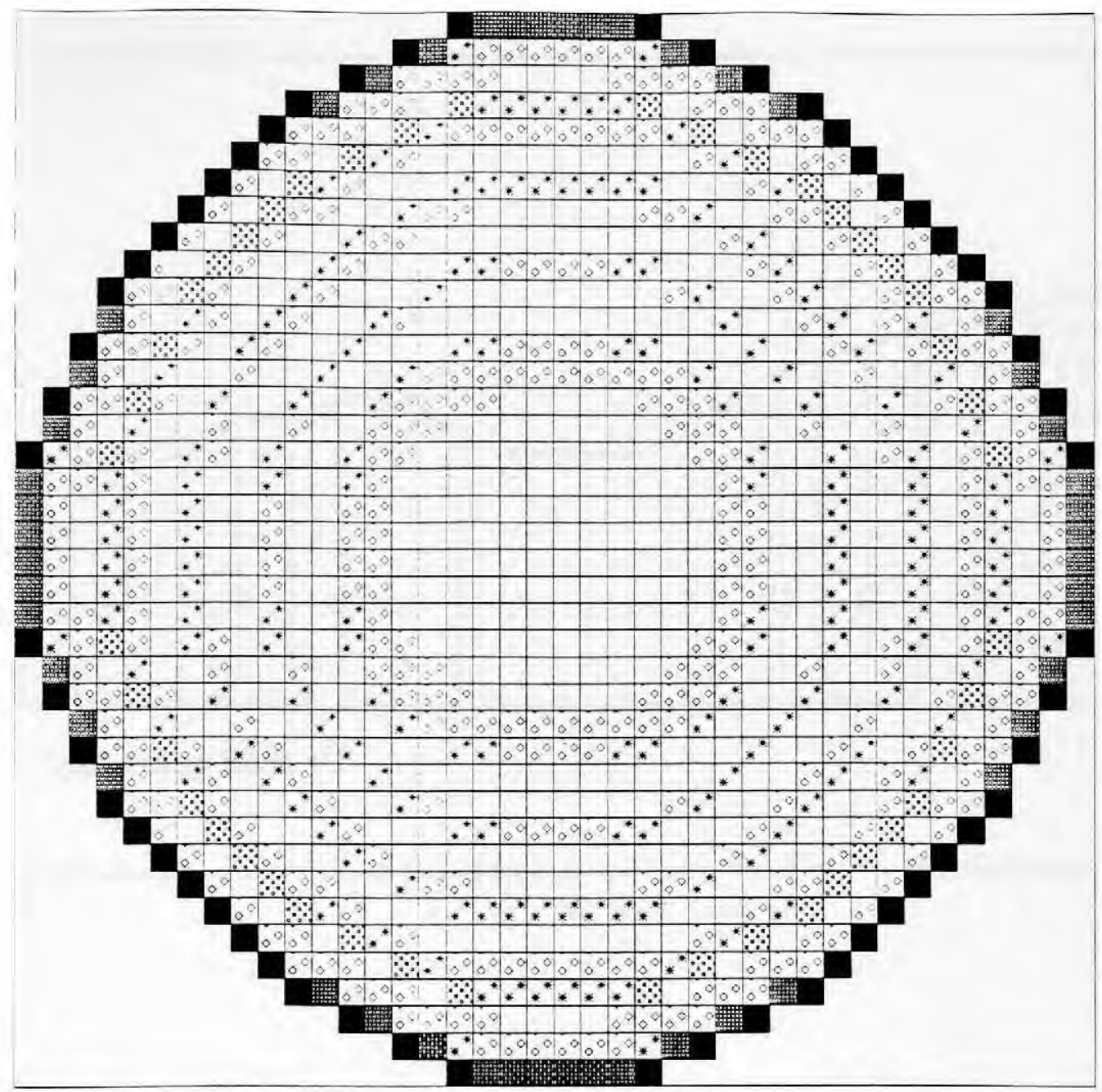

Fig. 12.8. Distribution of seepage rates ( $\mathrm{cm} /$ day) over the lake bed for a shallow inflow lake with low lake bed slope at $\mathrm{R}=1000$. Figs. 10.9 and 7.14 gives analogous maps for simulation of a shallow inflow lakes with steep and moderate lake bed slope respectively.

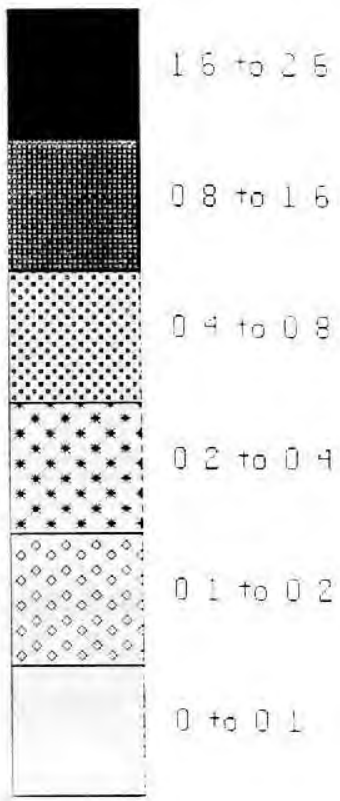




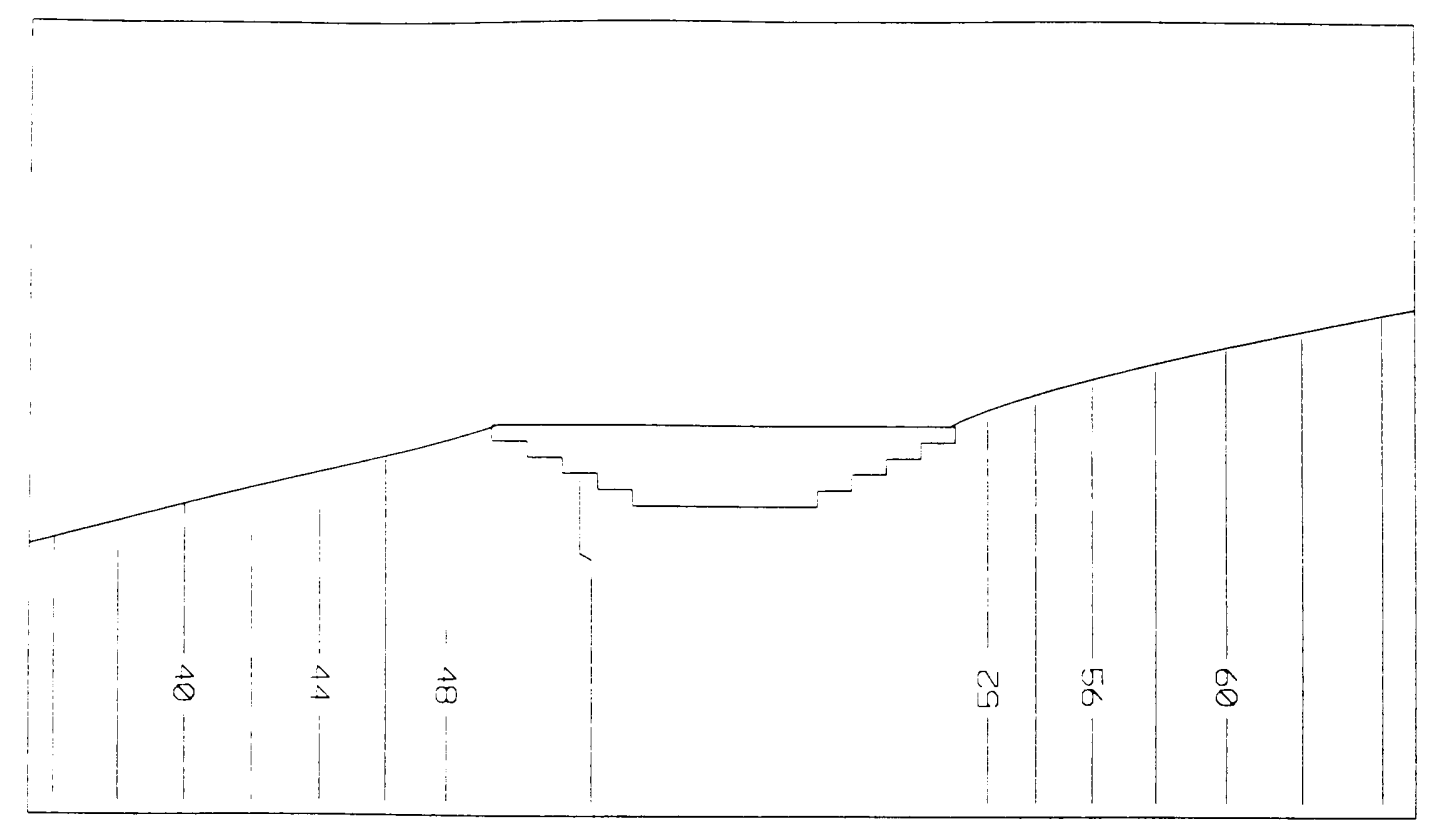

Anisotropy Ratio $=1$

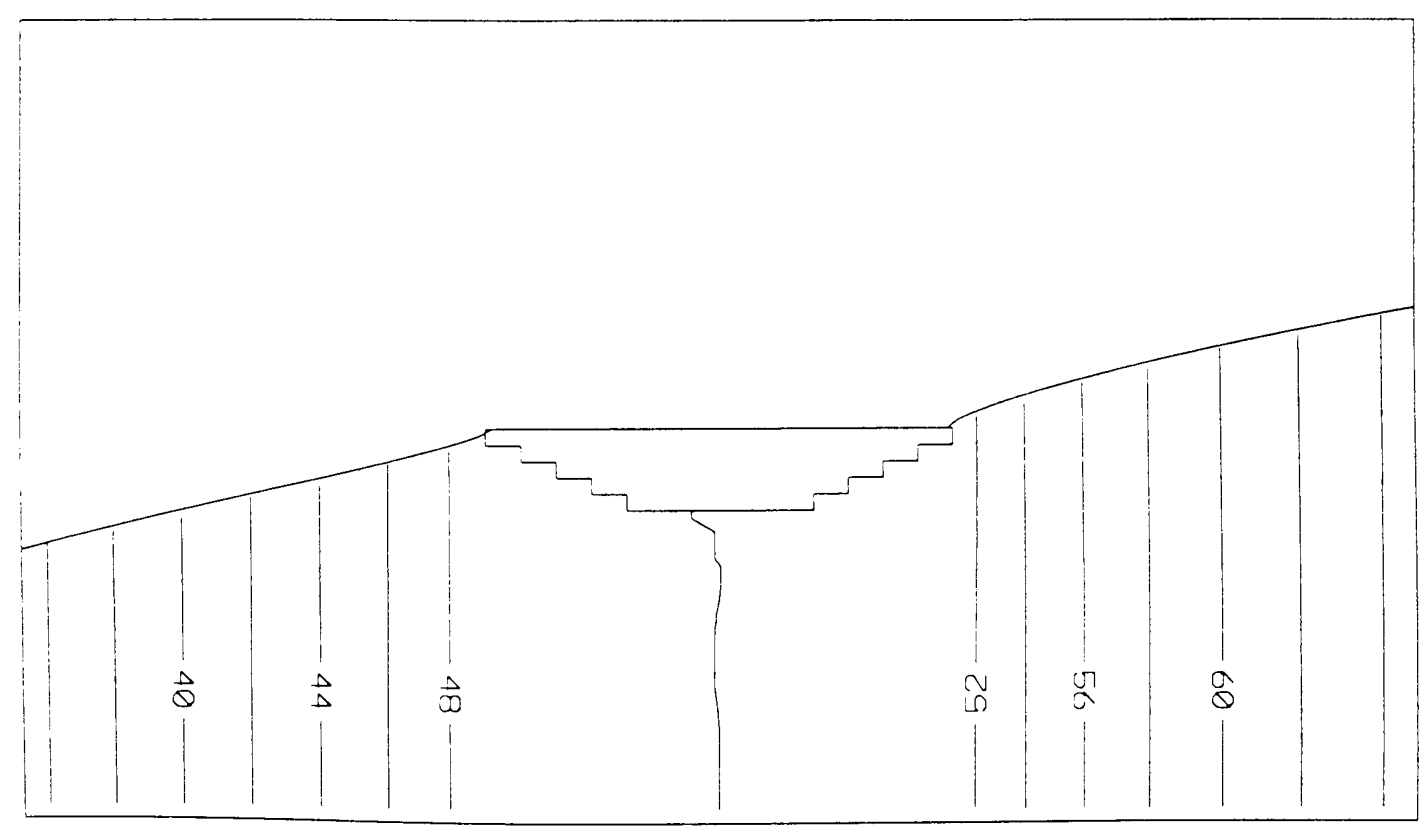

Anisotropy Ratio $=10$

Fig. 12.9. Distribution of hydraulic heads in the porous medium surrounding shallow flowthrough lakes with low lake bed slope at $R=1$ and $R=10$. Figs. $10.10,7.15$, and 7.16 give analogous cross-sections of shallow flow-through lakes with steep and moderate lake bed slopes at $\mathrm{R}=1$ and $\mathrm{R}=10$. 


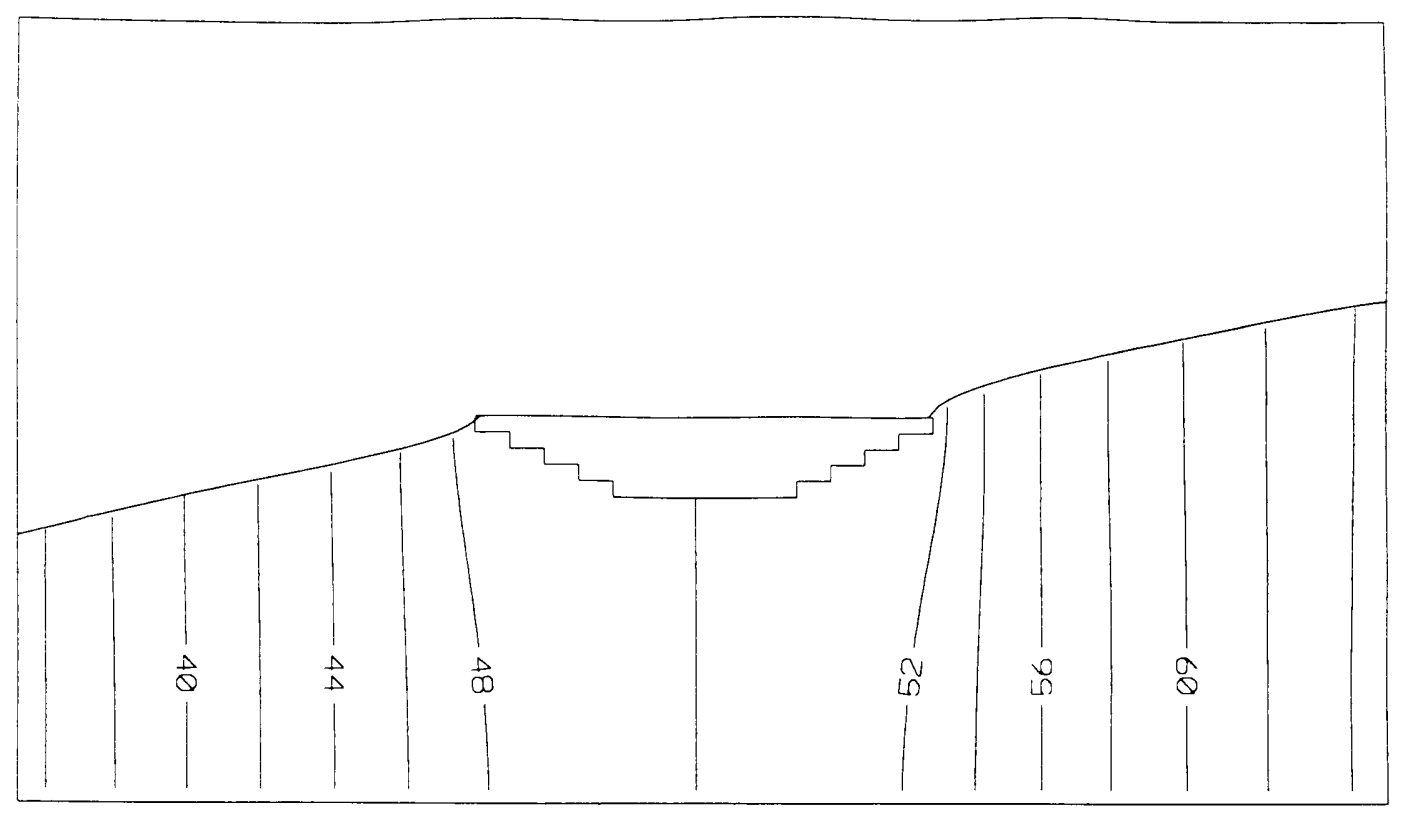

Anisotropy Ratio $=100$

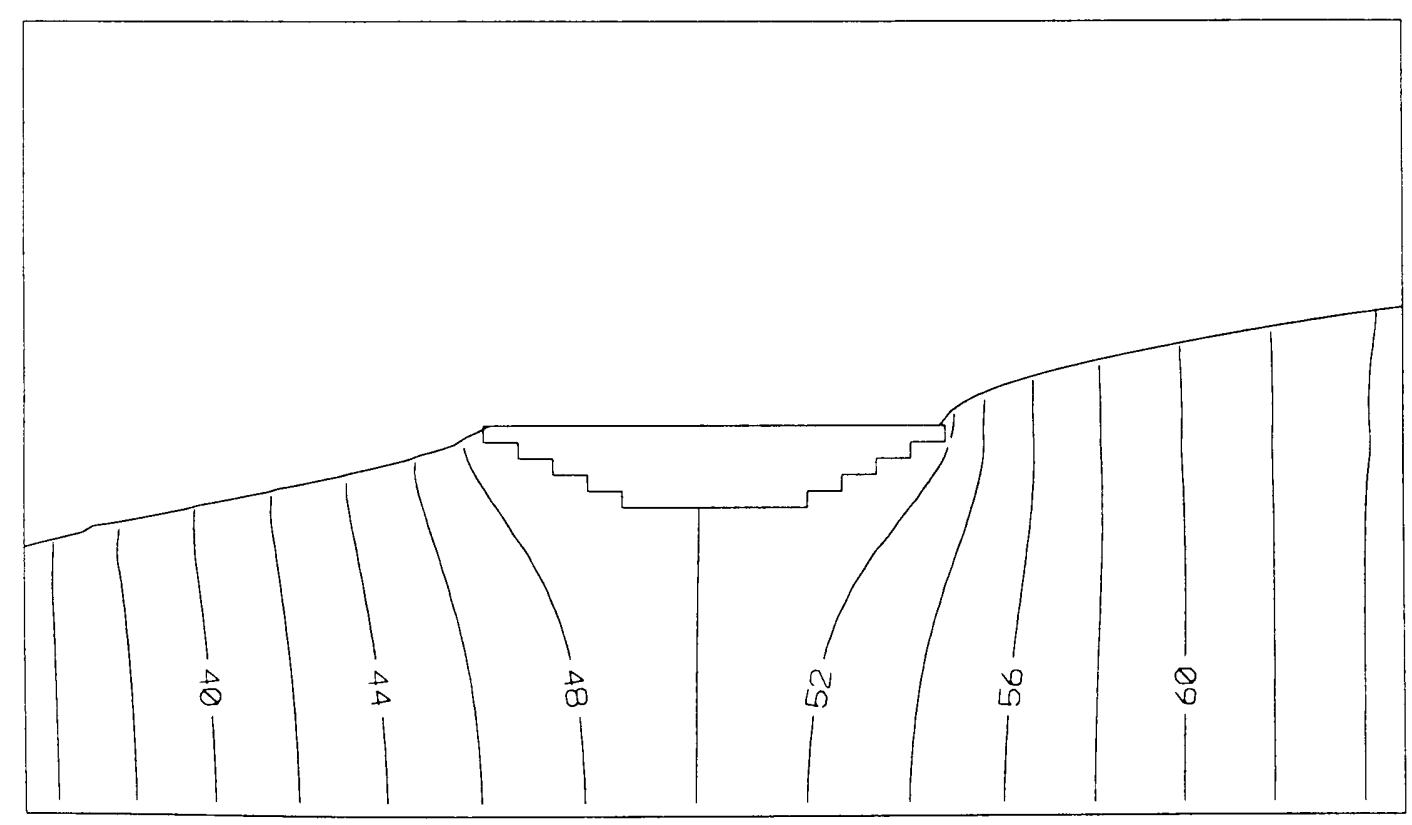

Anisotropy Ratio $=1000$

Fig. 12.11. Distribution of hydraulic heads in the porous medium surrounding shallow flow-through lakes with low lake bed slope at $R=100$ and $R=1000$. Figs. 10.11 and 7.17 , and 7.18 give analogous cross-sections of shallow inflow lakes with steep and moderate lake bed slopes at $R=100$ and $R=1000$ respectively. 

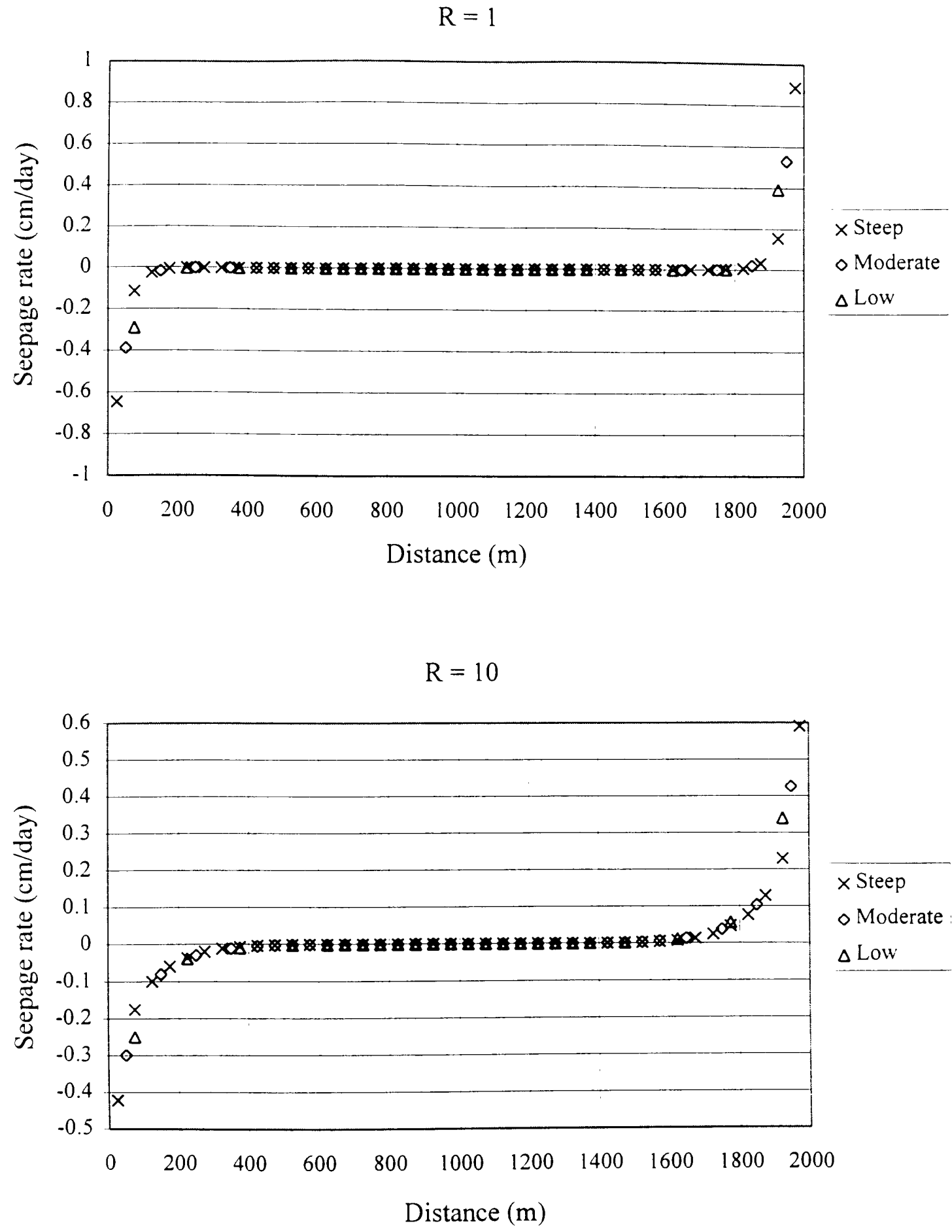

Fig. 12.11. Seepage rate versus distance from the downgradient lake shore for simulations of shallow flow-through lakes with different lake bed slopes at $R=1$ and $R=10$. 


$$
\mathrm{R}=100
$$

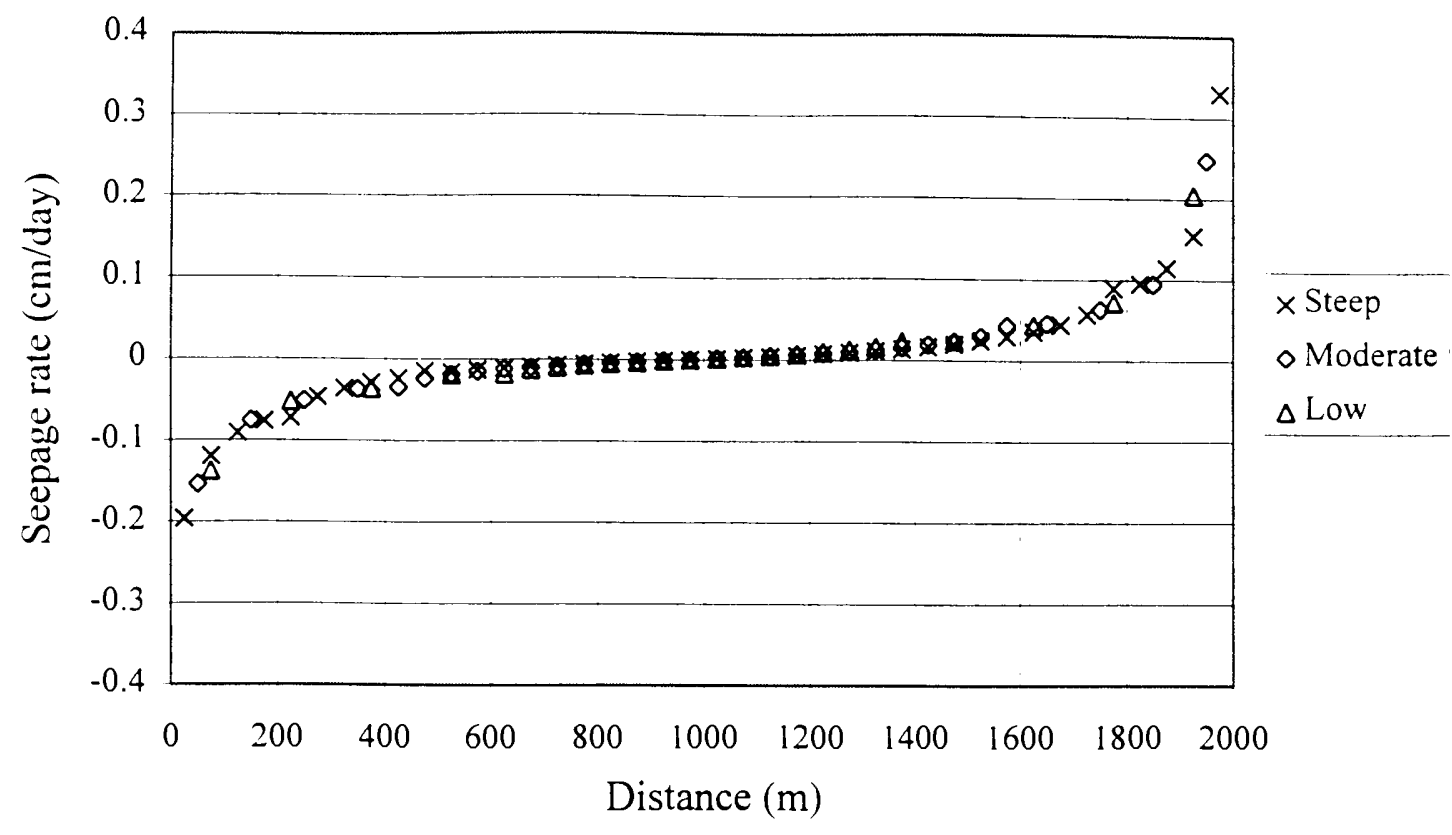

$$
\mathrm{R}=1000
$$

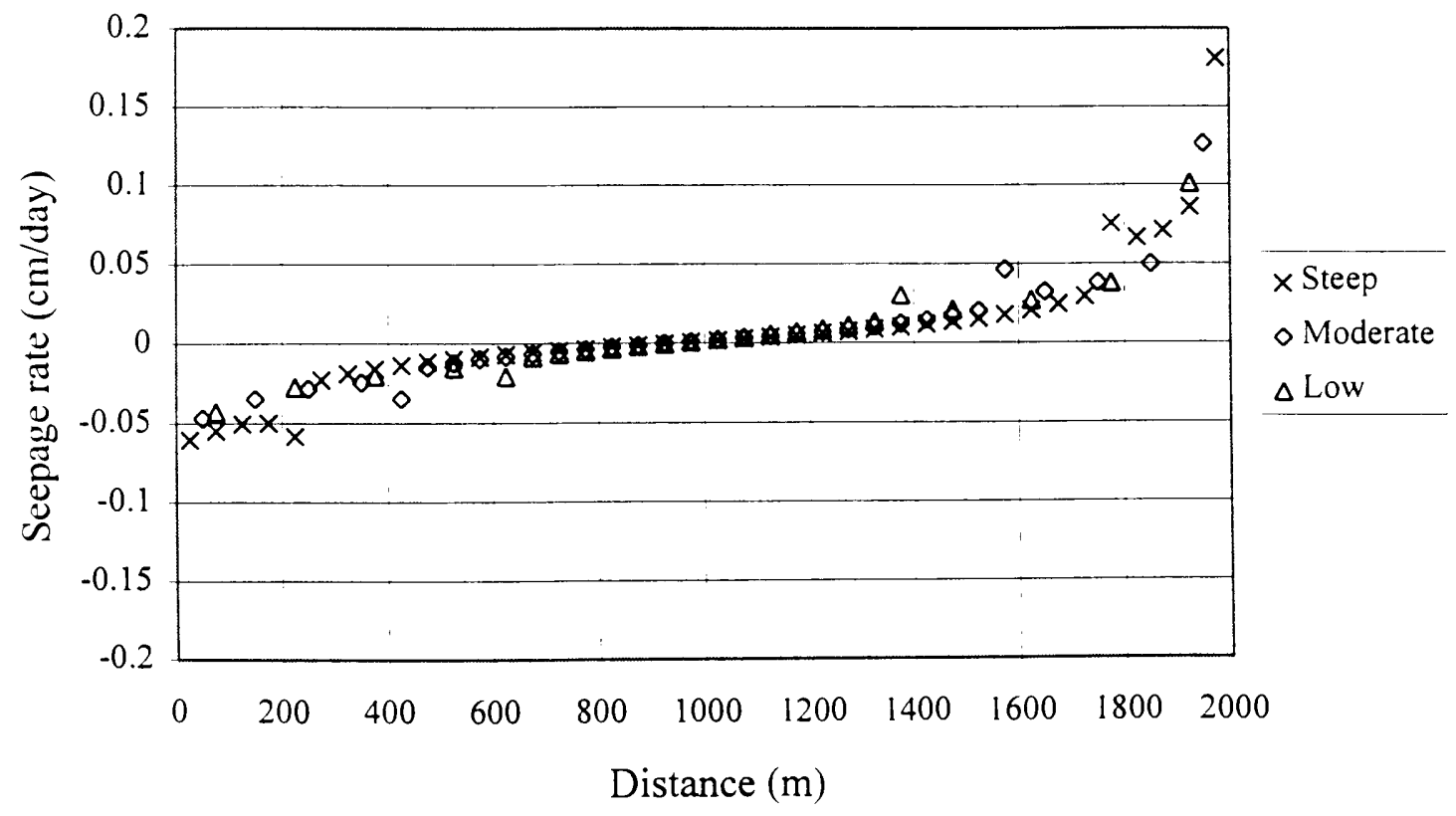

Fig. 12.12. Seepage rate versus distance from the downgradient lake shore for simulations of shallow flow-through lakes with different lake bed slopes at $R=100$ and $R=1000$. 


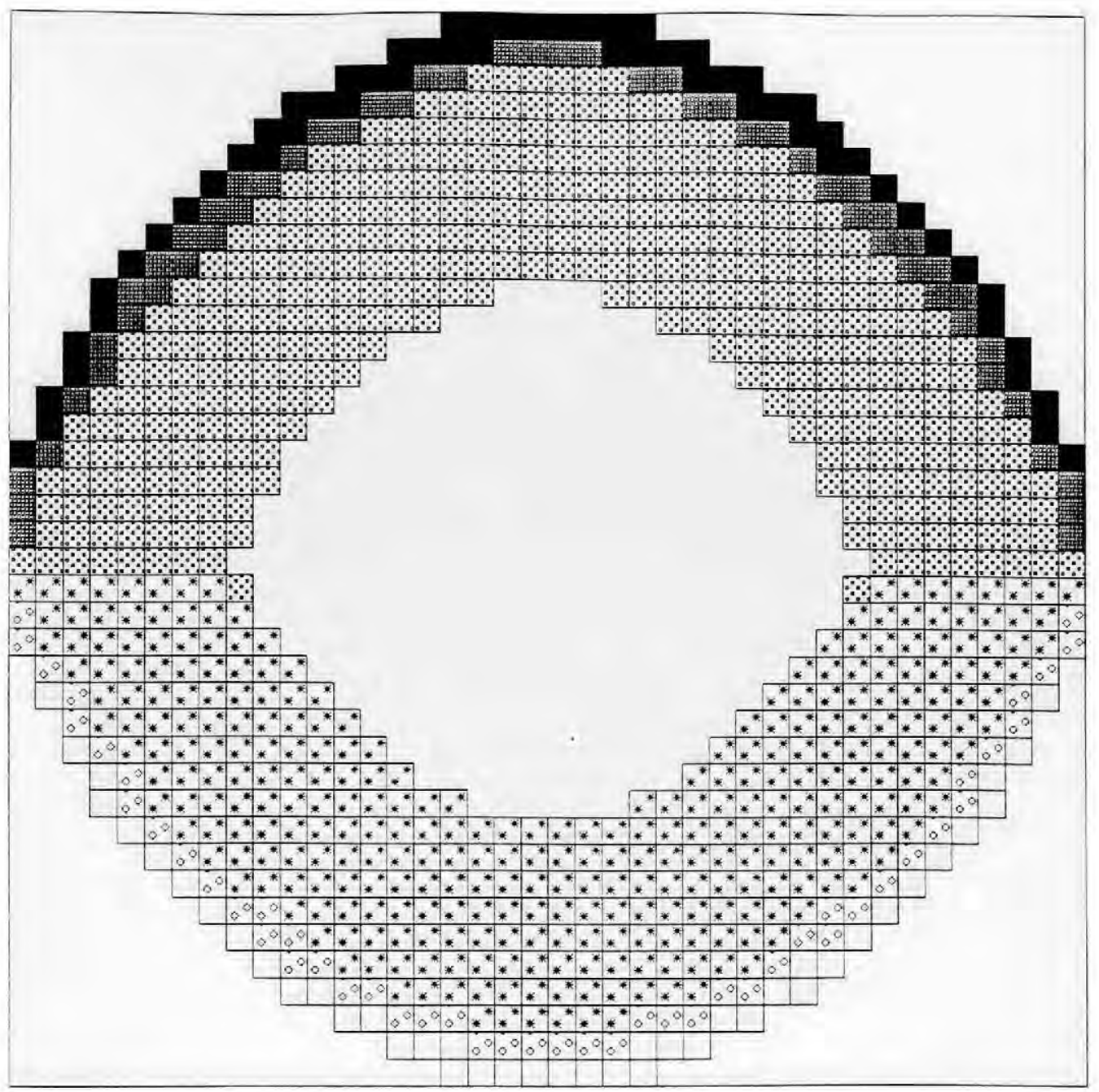

Fig. 12.13. Distribution of seepage rates ( $\mathrm{cm} /$ day) over the lake bed for a shallow flow-through lake with low lake bed slope at $\mathrm{R}=1$. The regional gradient of groundwater flow is from the top to the bottom of the figure. Figs. 10.14 and 7.22 give analogous maps for the simulation of shallow flow-through lake with steep and moderate lake bed slope respectively. The white area in the center represents cells having seepage rates with absolute values $<10^{-7} \mathrm{~cm} /$ day.

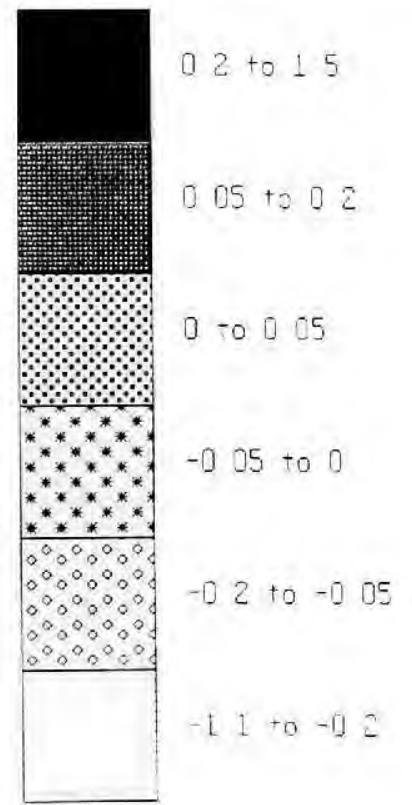




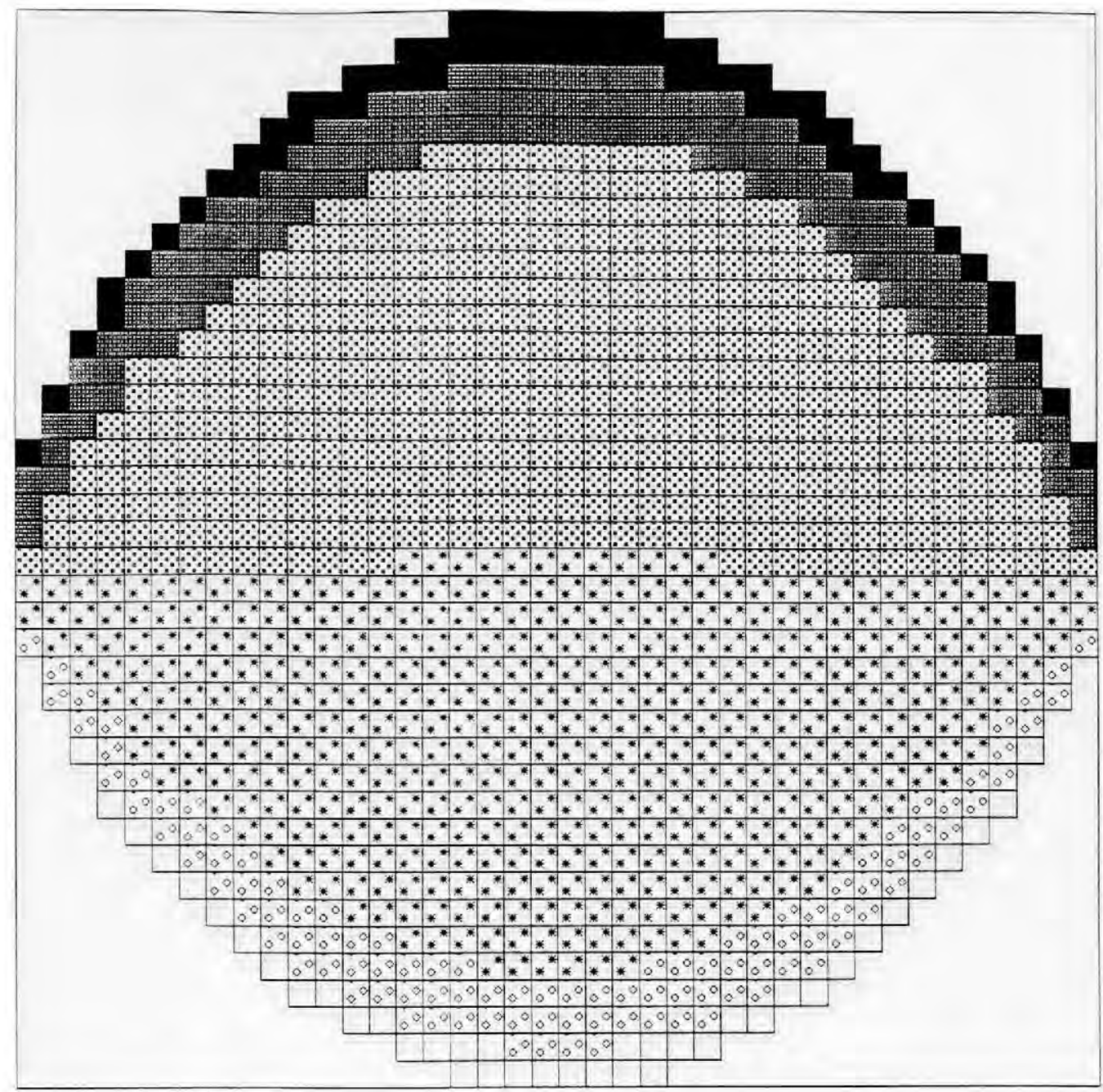

Fig. 12.14. Distribution of seepage rates ( $\mathrm{cm} /$ day) over the lake bed for a shallow flow-through lake with low lake bed slope at $\mathrm{R}=10$. The regional gradient of groundwater flow is from the top to the bottom of the figure. Figs. 10.15 and 7.24 give analogous maps for the simulation of shallow flow-through lake with steep and moderate lake bed slope respectively.

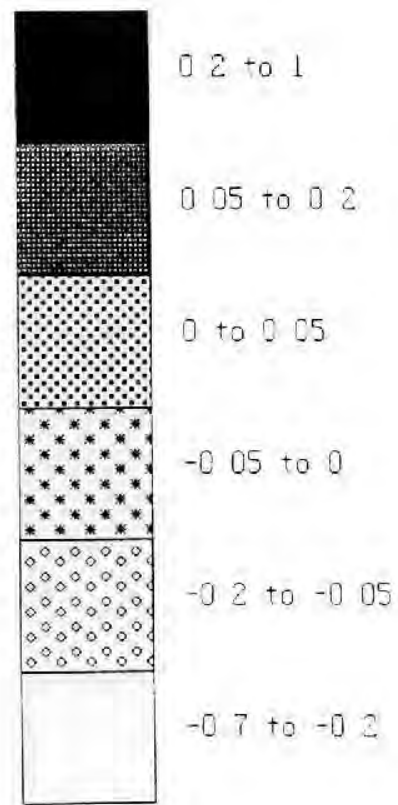




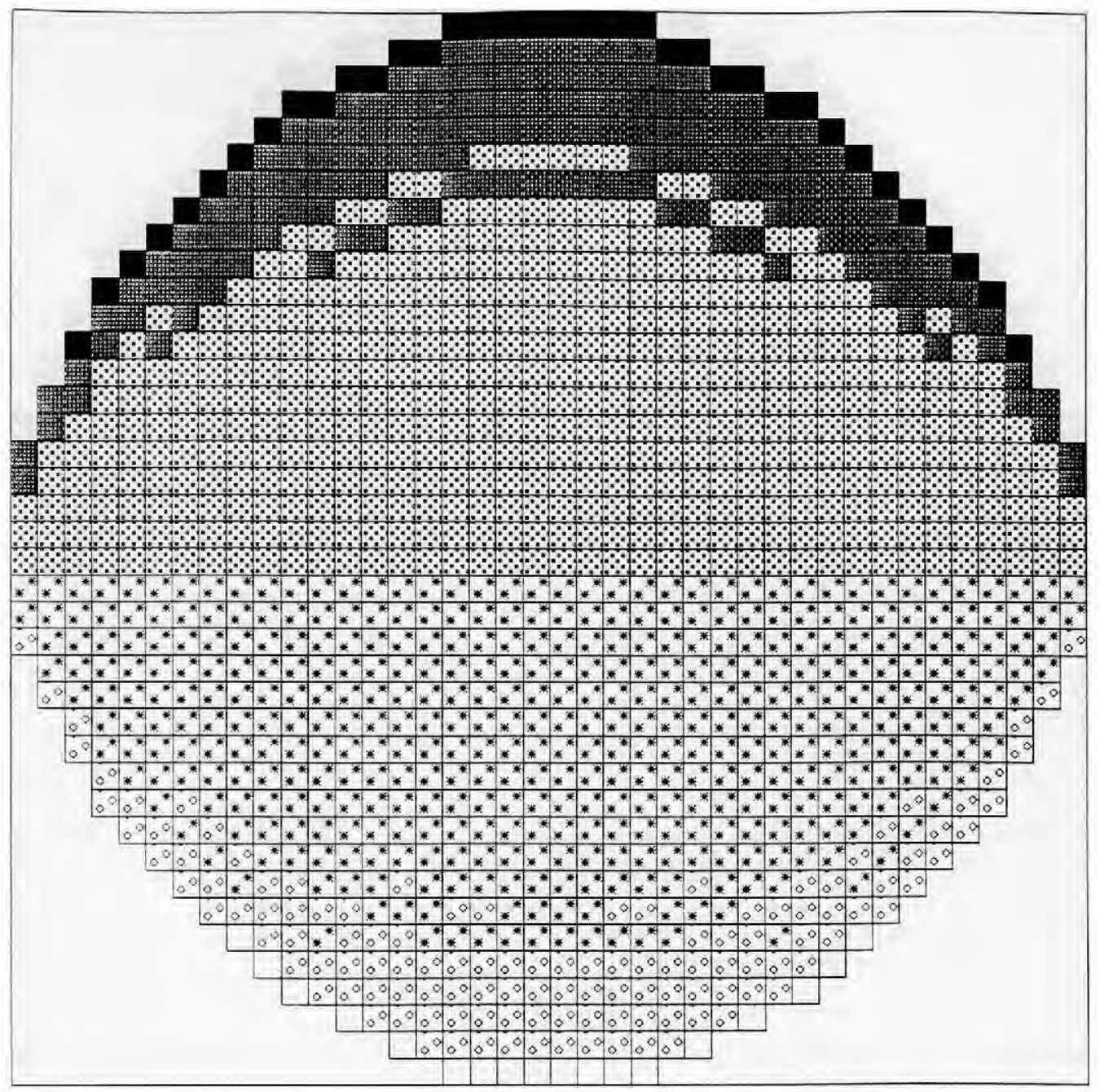

Fig. 12.15. Distribution of seepage rates ( $\mathrm{cm} /$ day) over the lake bed for a shallow flow-through lake with low lake bed slope at $\mathrm{R}=100$. The regional gradient of groundwater flow is from the top to the bottom of the figure. Figs. 10.16 and 7.26 give analogous maps for the simulation of shallow flow-through lake with steep and moderate lake bed slope respectively.

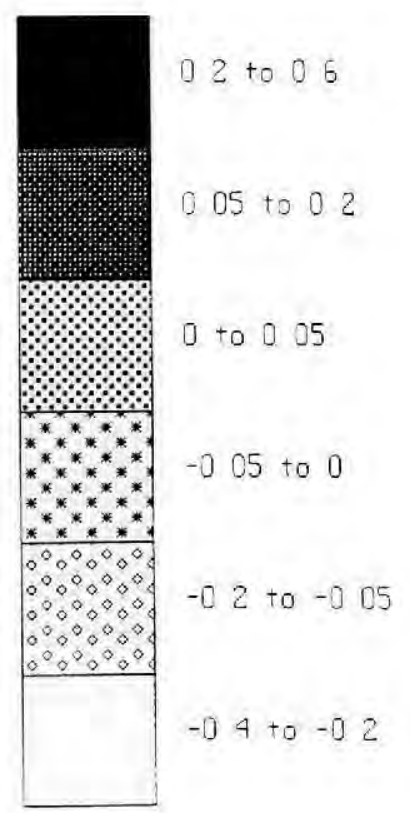




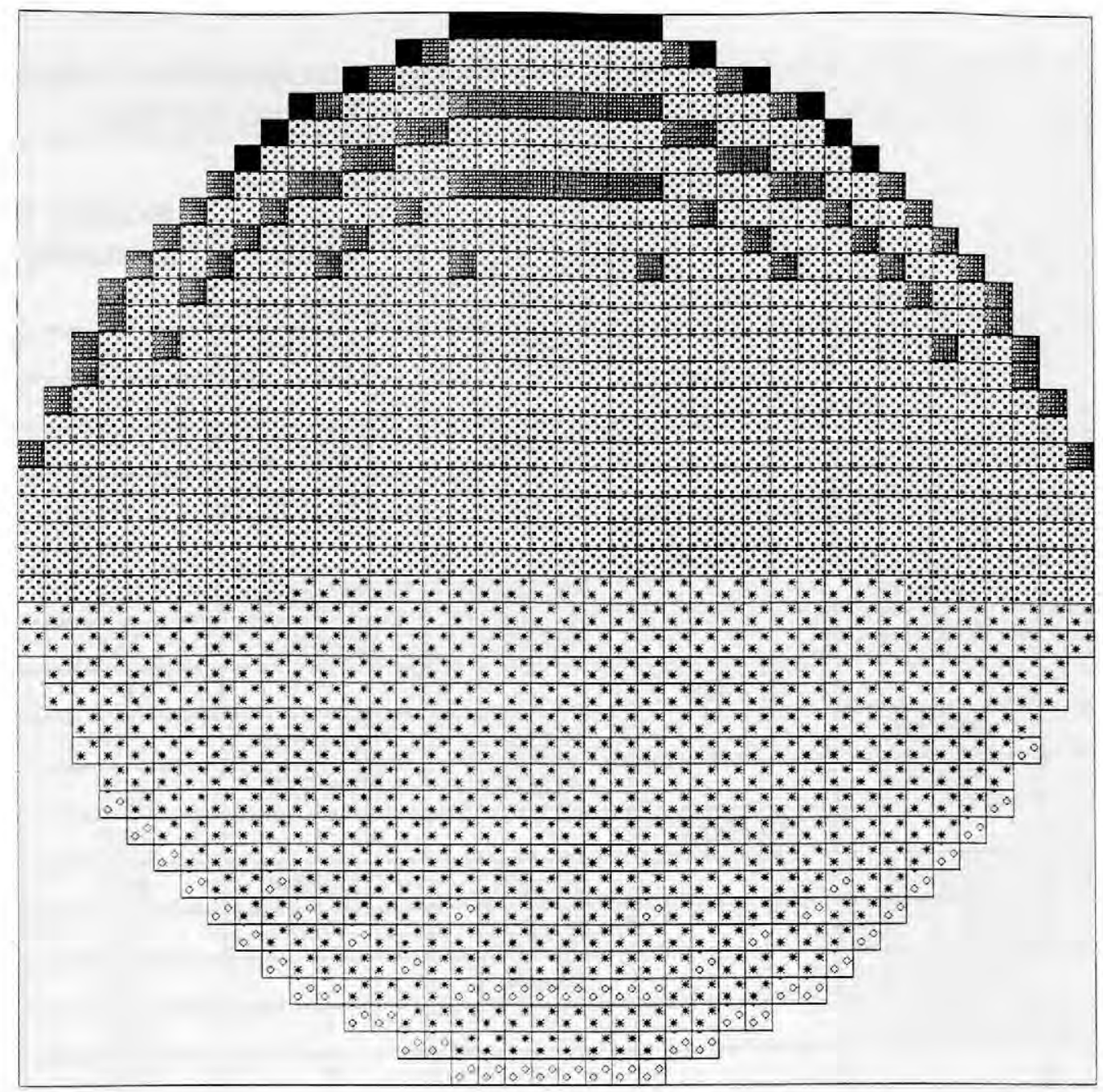

Fig. 12.16. Distribution of seepage rates (cm/day) over the lake bed for a shallow flow-through lake with low lake bed slope at $\mathrm{R}=1000$. The regional gradient of groundwater flow is from the top to the bottom of the figure. Figs. 10.17 and 7.28 give analogous maps for the simulation of shallow flow-through lake with steep and moderate lake bed slope respectively.

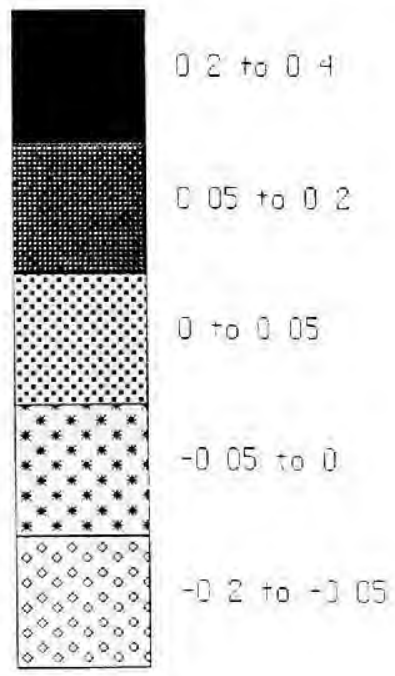


Table 12.4. Seepage rate versus distance offshore for shallow inflow lakes with different lake bed slope at $\mathrm{R}=1$. $^{*}$ denotes where seepage rate is less than $10^{-7} \mathrm{~cm} /$ dav.

\begin{tabular}{|c|c|c|c|c|c|}
\hline \multirow{4}{*}{$\begin{array}{c}\text { Distance } \\
\text { offshore }(m)\end{array}$} & \multicolumn{5}{|c|}{ Seepage rate $(\mathrm{cm} /$ day $)$} \\
\hline & \multicolumn{5}{|c|}{ Lake bed slope } \\
\hline & Steep & \multicolumn{2}{|c|}{ Moderate } & \multicolumn{2}{|c|}{ Low } \\
\hline & raw output & raw output & average & raw output & average \\
\hline 25 & 1.97153 & 2.32826 & & 2.15507 & \\
\hline 50 & & & 1.36537 & & \\
\hline 75 & 0.34260 & 0.40248 & & 0.37721 & 0.87268 \\
\hline 125 & 0.07383 & 0.09130 & & 0.08576 & \\
\hline 150 & & & 0.05573 & & \\
\hline 175 & 0.01540 & 0.02016 & & 0.02022 & \\
\hline 225 & 0.00010 & 0.00446 & & 0.00458 & 0.00861 \\
\hline 250 & & & 0.00270 & & \\
\hline 275 & $1.93 e-05$ & 0.00094 & & 0.00103 & \\
\hline 325 & $3.61 \mathrm{e}-06$ & 0.00020 & & 0.00023 & \\
\hline 350 & & & 0.00012 & & \\
\hline 375 & $6.85 e-07$ & $3.86 \mathrm{e}-05$ & & $5.11 \mathrm{e}-05$ & $9.87 \mathrm{e}-05$ \\
\hline 425 & $*$ & $7.63 e-06$ & & $1.11 \mathrm{e}-05$ & \\
\hline 475 & * & $1.46 \mathrm{e}-06$ & & $2.54 \mathrm{e}-06$ & \\
\hline 525 & $*$ & $*$ & & $5.19 \mathrm{e}-07$ & $1.53 \mathrm{e}-06$ \\
\hline 575 & $*$ & $*$ & & $*$ & \\
\hline 625 & $*$ & $*$ & & $*$ & \\
\hline 675 & $*$ & $*$ & & $*$ & \\
\hline 725 & * & * & & $*$ & \\
\hline 775 & $*$ & $*$ & & * & \\
\hline 825 & * & $*$ & & * & \\
\hline 875 & $*$ & $*$ & & * & \\
\hline 925 & $*$ & * & & * & \\
\hline 975 & $*$ & $*$ & & $*$ & \\
\hline
\end{tabular}


Table 12.5. Seepage rate versus distance offshore for shallow inflow lakes with different lake bed slope at $\mathrm{R}=10$.

\begin{tabular}{|c|c|c|c|c|c|}
\hline \multirow{4}{*}{$\begin{array}{c}\text { Distance } \\
\text { offshore }(\mathrm{m})\end{array}$} & \multicolumn{5}{|c|}{ Seepage rate $(\mathrm{cm} /$ day $)$} \\
\hline & \multicolumn{5}{|c|}{ Lake bed slope } \\
\hline & Steep & \multicolumn{2}{|c|}{ Moderate } & \multicolumn{2}{|c|}{ Low } \\
\hline & raw output & raw output & average & raw output & average \\
\hline 25 & 1.50688 & 1.55937 & & 1.95545 & \\
\hline 50 & & & 1.04227 & & \\
\hline 75 & 0.56290 & 0.52516 & & 0.65806 & 0.98676 \\
\hline 125 & 0.31618 & 0.32666 & & 0.34678 & \\
\hline 150 & & & 0.25275 & & \\
\hline 175 & 0.18819 & 0.17885 & & 0.22763 & \\
\hline 225 & 0.11545 & 0.11965 & & 0.12795 & 0.14268 \\
\hline 250 & & & 0.09312 & & \\
\hline 275 & 0.06233 & 0.06660 & & 0.07247 & \\
\hline 325 & 0.03512 & 0.04428 & & 0.04817 & \\
\hline 350 & & & 0.03432 & & \\
\hline 375 & 0.02010 & 0.02436 & & 0.02692 & 0.03005 \\
\hline 425 & 0.01159 & 0.01599 & & 0.01506 & \\
\hline 475 & 0.00672 & 0.00892 & & 0.00986 & \\
\hline 525 & 0.00392 & 0.00514 & & 0.00543 & 0.00610 \\
\hline 575 & 0.00231 & 0.00301 & & 0.00300 & \\
\hline 625 & 0.00137 & 0.00178 & & 0.00194 & \\
\hline 675 & 0.00082 & 0.00106 & & 0.00106 & \\
\hline 725 & 0.00050 & 0.00064 & & 0.00061 & \\
\hline 775 & 0.00031 & 0.00040 & & 0.00036 & \\
\hline 825 & 0.00020 & 0.00026 & & 0.00021 & \\
\hline 875 & 0.00014 & 0.00017 & & 0.00014 & \\
\hline 925 & 0.00010 & 0.00013 & & $9.59 \mathrm{e}-05$ & \\
\hline 975 & $8.57 \mathrm{e}-05$ & 0.00011 & & $7.81 \mathrm{e}-05$ & \\
\hline
\end{tabular}


Table 12.6. Seepage rate versus distance offshore for shallow inflow lakes with different lake bed slope at $\mathrm{R}=100$.

\begin{tabular}{|c|c|c|c|c|c|}
\hline \multirow{4}{*}{$\begin{array}{c}\text { Distance } \\
\text { offshore (m) }\end{array}$} & \multicolumn{5}{|c|}{ Seepage rate $(\mathrm{cm} /$ day $)$} \\
\hline & \multicolumn{5}{|c|}{ Lake bed slope } \\
\hline & Steep & \multicolumn{2}{|c|}{ Moderate } & \multicolumn{2}{|c|}{ Low } \\
\hline & raw output & raw output & average & raw output & average \\
\hline 25 & 1.09265 & 1.20732 & & 1.43922 & \\
\hline 50 & & & 0.76509 & & \\
\hline 75 & 0.42907 & 0.32287 & & 0.41428 & 0.70335 \\
\hline 125 & 0.31599 & 0.34509 & & 0.25654 & \\
\hline 150 & & & 0.26734 & & \\
\hline 175 & 0.26286 & 0.18958 & & 0.30952 & \\
\hline 225 & 0.25079 & 0.22837 & & 0.20069 & 0.21716 \\
\hline 250 & & & 0.18198 & & \\
\hline 275 & 0.16387 & 0.13560 & & 0.14128 & \\
\hline 325 & 0.13041 & 0.16920 & & 0.18343 & \\
\hline 350 & & & 0.13693 & & \\
\hline 375 & 0.10795 & 0.10465 & & 0.12564 & 0.13333 \\
\hline 425 & 0.09133 & 0.13437 & & 0.09093 & \\
\hline 475 & 0.07843 & 0.09681 & & 0.12022 & \\
\hline 525 & 0.06814 & 0.08108 & & 0.08441 & 0.08906 \\
\hline 575 & 0.05983 & 0.06992 & & 0.06253 & \\
\hline 625 & 0.05308 & 0.06143 & & 0.08382 & \\
\hline 675 & 0.04762 & 0.05478 & & 0.06269 & \\
\hline 725 & 0.04323 & 0.04956 & & 0.05410 & \\
\hline 775 & 0.03977 & 0.04548 & & 0.04821 & \\
\hline 825 & 0.03712 & 0.04239 & & 0.04401 & \\
\hline 875 & 0.03519 & 0.04016 & & 0.04108 & \\
\hline 925 & 0.03394 & 0.03872 & & 0.03921 & \\
\hline 975 & 0.03333 & 0.03800 & & 0.03830 & \\
\hline
\end{tabular}


Table 12.7. Seepage rate versus distance offshore for shallow inflow lakes with different lake bed slope at $\mathrm{R}=1000$.

\begin{tabular}{|c|c|c|c|c|c|}
\hline \multirow{4}{*}{$\begin{array}{c}\text { Distance } \\
\text { offshore }(\mathrm{m})\end{array}$} & \multicolumn{5}{|c|}{ Seepage rate $(\mathrm{cm} /$ day $)$} \\
\hline & \multicolumn{5}{|c|}{ Lake bed slope } \\
\hline & Steep & \multicolumn{2}{|c|}{ Moderate } & \multicolumn{2}{|c|}{ Low } \\
\hline & raw output & raw output & average & raw output & average \\
\hline 25 & 1.12945 & 1.37073 & & 1.51365 & \\
\hline 50 & & & 0.74010 & & \\
\hline 75 & 0.33101 & 0.10946 & & 0.17117 & 0.59368 \\
\hline 125 & 0.26009 & 0.30210 & & 0.09622 & \\
\hline 150 & & & 0.18949 & & \\
\hline 175 & 0.24331 & 0.07689 & & 0.29709 & \\
\hline 225 & 0.29031 & 0.22887 & & 0.11048 & 0.15815 \\
\hline 250 & & & 0.14745 & & \\
\hline 275 & 0.12253 & 0.06604 & & 0.06688 & \\
\hline 325 & 0.10756 & 0.20525 & & 0.22156 & \\
\hline 350 & & & 0.13502 & & \\
\hline 375 & 0.09689 & 0.06479 & & 0.09151 & 0.12337 \\
\hline 425 & 0.08902 & 0.21531 & & 0.05705 & \\
\hline 475 & 0.08305 & 0.10599 & & 0.19555 & \\
\hline 525 & 0.07841 & 0.09612 & & 0.08604 & 0.11235 \\
\hline 575 & 0.07475 & 0.08904 & & 0.05548 & \\
\hline 625 & 0.07183 & 0.08384 & & 0.19575 & \\
\hline 675 & 0.06950 & 0.07993 & & 0.10416 & \\
\hline 725 & 0.06764 & 0.07698 & & 0.09692 & \\
\hline 775 & 0.06618 & 0.07475 & & 0.09190 & \\
\hline 825 & 0.06506 & 0.07309 & & 0.08842 & \\
\hline 875 & 0.06426 & 0.07192 & & 0.08607 & \\
\hline 925 & 0.06373 & 0.07116 & & 0.08462 & \\
\hline 975 & 0.06347 & 0.07079 & & 0.08393 & \\
\hline
\end{tabular}


Table 12.8. Seepage rate versus distance from the downgradient shoreline for shallow flowthrough lakes with different lake bed slope at $\mathrm{R}=1 .{ }^{*}$ denotes where seepage rate was less than $10^{-7} \mathrm{~cm} /$ day.

\begin{tabular}{|c|c|c|c|c|c|}
\hline \multirow{4}{*}{$\begin{array}{c}\text { Distance } \\
\text { offshore (m) }\end{array}$} & \multicolumn{5}{|c|}{ Seepage rate $(\mathrm{cm} /$ day $)$} \\
\hline & \multicolumn{5}{|c|}{ Lake bed slope } \\
\hline & \multirow{2}{*}{$\frac{\text { Steep }}{\text { raw output }}$} & \multicolumn{2}{|c|}{ Moderate } & \multicolumn{2}{|c|}{ Low } \\
\hline & & raw output & average & raw output & average \\
\hline 25 & -0.64488 & -0.65818 & & -0.71098 & \\
\hline 50 & & & -0.38764 & & \\
\hline 75 & -0.11509 & -0.11710 & & -0.12834 & -0.28952 \\
\hline 125 & -0.02476 & -0.02655 & & -0.02925 & \\
\hline 150 & & & -0.01620 & & \\
\hline 175 & -0.00516 & -0.00585 & & -0.00690 & \\
\hline 225 & -0.00102 & -0.00129 & & -0.00156 & -0.00247 \\
\hline 250 & & & -0.00078 & & \\
\hline 275 & -0.00019 & -0.00027 & & -0.00035 & \\
\hline 325 & $-3.47 e-05$ & $-5.70 e-05$ & & $-7.87 \mathrm{e}-05$ & \\
\hline 350 & & & $-3.42 e-05$ & & \\
\hline 375 & $-6.43 e-06$ & $-1.13 e-05$ & & $-1.71 \mathrm{e}-05$ & $-2.35 e-05$ \\
\hline 425 & $-1.20 \mathrm{e}-06$ & $-2.25 e-06$ & & $-3.70 e-06$ & \\
\hline 475 & $*$ & $-4.24 \mathrm{e}-07$ & & $-8.12 \mathrm{e}-07$ & \\
\hline 525 & $*$ & $*$ & & $*$ & $-4.24 \mathrm{e}-07$ \\
\hline 575 & $*$ & $*$ & & $*$ & \\
\hline 625 & $*$ & $*$ & & $*$ & \\
\hline 675 & $*$ & $*$ & & $*$ & \\
\hline 725 & * & $*$ & & * & \\
\hline 775 & $*$ & $*$ & & * & \\
\hline 825 & * & $*$ & & $*$ & \\
\hline 875 & $*$ & $*$ & & $*$ & \\
\hline 925 & $*$ & $*$ & & $*$ & \\
\hline 975 & $*$ & $*$ & & $*$ & \\
\hline 1025 & $*$ & $*$ & & $*$ & \\
\hline 1075 & * & * & & $*$ & \\
\hline 1125 & * & $*$ & & * & \\
\hline 1175 & $*$ & $*$ & & * & \\
\hline 1225 & $*$ & $*$ & & $*$ & \\
\hline 1275 & $*$ & $*$ & & $*$ & \\
\hline
\end{tabular}


Table 12.8. (Contd.)

\begin{tabular}{|c|c|c|c|c|c|}
\hline \multirow{2}{*}{$\begin{array}{c}\text { Distance } \\
\text { offshore (m) }\end{array}$} & \multicolumn{5}{|c|}{ Seepage rate (cm/day) } \\
\cline { 2 - 6 } & Steep & \multicolumn{2}{|c|}{ Moderate } & \multicolumn{2}{c|}{ Low } \\
\cline { 2 - 6 } & raw output & raw output & average & raw output & average \\
\hline 1325 & $*$ & $*$ & & $*$ & \\
\hline 1375 & $*$ & $*$ & & $*$ & \\
\hline 1425 & $*$ & $*$ & & $*$ & \\
\hline 1475 & $*$ & $*$ & & $*$ & $5.73 \mathrm{e}-07$ \\
\hline 1525 & $*$ & $5.73 \mathrm{e}-07$ & & $1.08 \mathrm{e}-06$ & \\
\hline 1575 & $1.62 \mathrm{e}-06$ & $3.05 \mathrm{e}-06$ & & $4.94 \mathrm{e}-06$ & \\
\hline 1625 & $8.72 \mathrm{e}-06$ & $1.53 \mathrm{e}-05$ & & $2.29 \mathrm{e}-05$ & $3.48 \mathrm{e}-05$ \\
\hline 1650 & & & $4.62 \mathrm{e}-05$ & & \\
\hline 1675 & $4.71 \mathrm{e}-05$ & $7.71 \mathrm{e}-05$ & & 0.00011 & \\
\hline 1725 & 0.00026 & 0.00037 & & 0.00046 & \\
\hline 1750 & & & 0.00106 & & \\
\hline 1775 & 0.00138 & 0.00175 & & 0.00207 & 0.00389 \\
\hline 1825 & 0.00698 & 0.00789 & & 0.00914 & \\
\hline 1850 & & & 0.02182 & & \\
\hline 1875 & 0.03349 & 0.03576 & & 0.03883 & \\
\hline 1925 & 0.15570 & 0.15783 & & 0.17117 & 0.39345 \\
\hline 1950 & & & 0.53113 & & \\
\hline 1975 & 0.88894 & 0.90443 & & 0.97035 & \\
\hline & & & & & \\
\hline
\end{tabular}

Table 12.9. Seepage rate versus distance from the downgradient shoreline for shallow flowthrough lakes with different lake bed slope at $R=10$.

\begin{tabular}{|c|c|c|c|c|c|}
\hline \multirow{3}{*}{$\begin{array}{c}\text { Distance } \\
\text { offshore (m) }\end{array}$} & \multicolumn{5}{|c|}{ Seepage rate (cm/day) } \\
\cline { 2 - 6 } & Steep & \multicolumn{2}{|c|}{ Lake bed slope } \\
\cline { 2 - 6 } & raw output & raw output & average & raw output & average \\
\hline 25 & -0.42141 & -0.43978 & & -0.46690 & \\
\hline 50 & & & -0.29917 & & \\
\hline 75 & -0.17543 & -0.15856 & & -0.18260 & -0.24973 \\
\hline 125 & -0.09890 & -0.10285 & & -0.09967 & \\
\hline 150 & & & -0.07952 & & \\
\hline 175 & -0.05876 & -0.05619 & & -0.06777 & \\
\hline
\end{tabular}


Table 12.9. (Contd.)

\begin{tabular}{|c|c|c|c|c|c|}
\hline \multirow{4}{*}{$\begin{array}{c}\text { Distance } \\
\text { offshore }(m)\end{array}$} & \multicolumn{5}{|c|}{ Seepage rate $(\mathrm{cm} /$ day $)$} \\
\hline & \multicolumn{5}{|c|}{ Lake bed slope } \\
\hline & \multirow{2}{*}{$\begin{array}{c}\text { Steep } \\
\text { raw output }\end{array}$} & \multicolumn{2}{|c|}{ Moderate } & \multicolumn{2}{|c|}{ Low } \\
\hline & & raw output & average & raw output & average \\
\hline 225 & -0.03588 & -0.03743 & & -0.03959 & -0.03811 \\
\hline 250 & & & -0.02906 & & \\
\hline 275 & -0.01925 & -0.02070 & & -0.02325 & \\
\hline 325 & -0.01077 & -0.01367 & & -0.01605 & \\
\hline 350 & & & -0.01056 & & \\
\hline 375 & -0.00611 & -0.00746 & & -0.00934 & -0.00866 \\
\hline 425 & -0.00349 & -0.00485 & & -0.00543 & \\
\hline 475 & -0.00200 & -0.00268 & & -0.00370 & \\
\hline 525 & -0.00115 & -0.00152 & & -0.00212 & -0.00169 \\
\hline 575 & -0.00067 & -0.00088 & & -0.00122 & \\
\hline 625 & -0.00039 & -0.00051 & & -0.00082 & \\
\hline 675 & -0.00023 & -0.00030 & & -0.00046 & \\
\hline 725 & -0.00013 & -0.00017 & & -0.00027 & \\
\hline 775 & $-7.69 e-05$ & -0.00010 & & -0.00016 & \\
\hline 825 & $-4.43 e-05$ & $-5.77 e-05$ & & $-9.15 e-05$ & \\
\hline 875 & $-2.43 e-05$ & $-3.17 e-05$ & & $-5.05 e-05$ & \\
\hline 925 & $-1.12 \mathrm{e}-05$ & $-1.47 \mathrm{e}-05$ & & $-2.35 e-05$ & \\
\hline 975 & $-1.28 \mathrm{e}-06$ & $-1.90 \mathrm{e}-06$ & & $-3.00 \mathrm{e}-06$ & \\
\hline 1025 & $8.05 e-06$ & $1.01 \mathrm{e}-05$ & & $1.64 \mathrm{e}-05$ & \\
\hline 1075 & $1.93 e-05$ & $2.47 \mathrm{e}-05$ & & $3.96 \mathrm{e}-05$ & \\
\hline 1125 & $3.56 e-05$ & $4.57 e-05$ & & $7.30 \mathrm{e}-05$ & \\
\hline 1175 & $6.15 \mathrm{e}-05$ & $7.91 \mathrm{e}-05$ & & 0.00013 & \\
\hline 1225 & 0.00010 & 0.00013 & & 0.00021 & \\
\hline 1275 & 0.00018 & 0.00023 & & 0.00036 & \\
\hline 1325 & 0.00030 & 0.00039 & & 0.00061 & \\
\hline 1375 & 0.00051 & 0.00067 & & 0.00107 & \\
\hline 1425 & 0.00088 & 0.00115 & & 0.00160 & \\
\hline 1475 & 0.00152 & 0.00199 & & 0.00278 & 0.00221 \\
\hline 1525 & 0.00264 & 0.00350 & & 0.00483 & \\
\hline 1575 & 0.00459 & 0.00633 & & 0.00708 & \\
\hline 1625 & 0.00801 & 0.00971 & & 0.01216 & 0.01175 \\
\hline 1650 & & & 0.01374 & & \\
\hline
\end{tabular}


Table 12.9. (Contd.)

\begin{tabular}{|c|c|c|c|c|c|}
\hline \multirow{2}{*}{$\begin{array}{c}\text { Distance } \\
\text { offshore (m) }\end{array}$} & \multicolumn{5}{|c|}{ Seepage rate (cm/day) } \\
\cline { 2 - 6 } & Steep & \multicolumn{2}{|c|}{ Lake bed slope } \\
\cline { 2 - 6 } & raw output & raw output & average & raw output & average \\
\hline 1675 & 0.01409 & 0.01778 & & 0.02085 & \\
\hline 1725 & 0.02514 & 0.02688 & & 0.03015 & \\
\hline 1750 & & & 0.03771 & & \\
\hline 1775 & 0.04680 & 0.04853 & & 0.05127 & 0.05637 \\
\hline 1825 & 0.07657 & 0.07282 & & 0.08770 & \\
\hline 1850 & & & 0.10311 & & \\
\hline 1875 & 0.12894 & 0.13339 & & 0.12903 & \\
\hline 1925 & 0.22939 & 0.21446 & & 0.23703 & 0.33937 \\
\hline 1950 & & & 0.42627 & & \\
\hline 1975 & 0.59099 & 0.63807 & & 0.65204 & \\
\hline
\end{tabular}

Table 12.10. Seepage rate versus distance from the downgradient shoreline for shallow flowthrough lakes with different lake bed slope at $R=100$.

\begin{tabular}{|c|c|c|c|c|c|}
\hline \multirow{3}{*}{$\begin{array}{c}\text { Distance } \\
\text { offshore } \\
(\mathrm{m})\end{array}$} & \multicolumn{5}{|c|}{ Seepage rate (cm/day) } \\
\cline { 2 - 6 } & Steep & \multicolumn{2}{|c|}{ Loderate bed slope } & \multicolumn{2}{c|}{ Low } \\
\cline { 2 - 6 } & raw output & raw output & average & raw output & average \\
\hline 25 & -0.19613 & -0.22134 & & -0.23645 & \\
\hline 50 & & & -0.15363 & & \\
\hline 75 & -0.11970 & -0.08591 & & -0.10748 & -0.13730 \\
\hline 125 & -0.09106 & -0.09737 & & -0.06798 & \\
\hline 150 & & & -0.07555 & & \\
\hline 175 & -0.07624 & -0.05374 & & -0.08274 & \\
\hline 225 & -0.07213 & -0.06429 & & -0.05368 & -0.05189 \\
\hline 250 & & & -0.05096 & & \\
\hline 275 & -0.04621 & -0.03763 & & -0.03760 & \\
\hline 325 & -0.03590 & -0.04607 & & -0.04838 & \\
\hline 350 & & & -0.03689 & & \\
\hline 375 & -0.02884 & -0.02771 & & -0.03260 & -0.03606 \\
\hline 425 & -0.02353 & -0.03441 & & -0.02318 & \\
\hline 475 & -0.01932 & -0.02356 & & -0.02988 & \\
\hline
\end{tabular}


Table 12.10. (Contd.)

\begin{tabular}{|c|c|c|c|c|c|}
\hline \multirow{4}{*}{$\begin{array}{c}\text { Distance } \\
\text { offshore (m) }\end{array}$} & \multicolumn{5}{|c|}{ Seepage rate $(\mathrm{cm} /$ day $)$} \\
\hline & \multicolumn{5}{|c|}{ Lake bed slope } \\
\hline & \multirow{2}{*}{$\begin{array}{c}\text { Steep } \\
\text { raw output }\end{array}$} & \multicolumn{2}{|c|}{ Moderate } & \multicolumn{2}{|c|}{ Low } \\
\hline & & raw output & average & raw output & average \\
\hline 525 & -0.01588 & -0.01864 & & -0.02015 & -0.01907 \\
\hline 575 & -0.01302 & -0.01499 & & -0.01429 & \\
\hline 625 & -0.01059 & -0.01206 & & -0.01798 & \\
\hline 675 & -0.00850 & -0.00962 & & -0.01210 & \\
\hline 725 & -0.00667 & -0.00752 & & -0.00915 & \\
\hline 775 & -0.00505 & -0.00567 & & -0.00679 & \\
\hline 825 & -0.00358 & -0.00401 & & -0.00475 & \\
\hline 875 & -0.00221 & -0.00248 & & -0.00290 & \\
\hline 925 & -0.00092 & -0.00102 & & -0.00117 & \\
\hline 975 & 0.00035 & 0.00039 & & 0.00051 & \\
\hline 1025 & 0.00161 & 0.00181 & & 0.00219 & \\
\hline 1075 & 0.00292 & 0.00328 & & 0.00393 & \\
\hline 1125 & 0.00430 & 0.00483 & & 0.00578 & \\
\hline 1175 & 0.00580 & 0.00652 & & 0.00781 & \\
\hline 1225 & 0.00746 & 0.00839 & & 0.01013 & \\
\hline 1275 & 0.00933 & 0.01052 & & 0.01288 & \\
\hline 1325 & 0.01147 & 0.01298 & & 0.01640 & \\
\hline 1375 & 0.01394 & 0.01588 & & 0.02367 & \\
\hline 1425 & 0.01685 & 0.01939 & & 0.01851 & \\
\hline 1475 & 0.02031 & 0.02382 & & 0.02581 & 0.02435 \\
\hline 1525 & 0.02448 & 0.02983 & & 0.03788 & \\
\hline 1575 & 0.02963 & 0.04324 & & 0.02919 & \\
\hline 1625 & 0.03616 & 0.03468 & & 0.04088 & 0.04442 \\
\hline 1650 & & & 0.04611 & & \\
\hline 1675 & 0.04488 & 0.05753 & & 0.06044 & \\
\hline 1725 & 0.05769 & 0.04695 & & 0.04690 & \\
\hline 1750 & & & 0.06365 & & \\
\hline 1775 & 0.09015 & 0.08034 & & 0.06694 & 0.07242 \\
\hline 1825 & 0.09571 & 0.06736 & & 0.10344 & \\
\hline 1850 & & & 0.09523 & & \\
\hline 1875 & 0.11537 & 0.12309 & & 0.08545 & \\
\hline 1925 & 0.15468 & 0.11446 & & 0.13656 & 0.20506 \\
\hline
\end{tabular}


Table 12.10.(Contd.)

\begin{tabular}{|c|c|c|c|c|c|}
\hline \multirow{3}{*}{$\begin{array}{c}\text { Distance } \\
\text { offshore }(\mathrm{m})\end{array}$} & \multicolumn{5}{|c|}{ Seepage rate (cm/day) } \\
\cline { 2 - 6 } & Steep & \multicolumn{3}{|c|}{ Lake bed slope } \\
\cline { 2 - 6 } & raw output & raw output & average & raw output & average \\
\hline 1950 & & & 0.24806 & & \\
\hline 1975 & 0.33006 & 0.38166 & & 0.39317 & \\
\hline
\end{tabular}

Table 12.11. Seepage rate versus distance from the downgradient shoreline for shallow flowthrough lakes with different lake bed slope at $R=1000$.

\begin{tabular}{|l|l|l|l|l|l|}
\hline \multirow{2}{*}{$\begin{array}{c}\text { Distance } \\
\text { offshore (m) }\end{array}$} & \multicolumn{5}{|c|}{ Seepage rate (cm/day) } \\
\cline { 2 - 6 } & Steep & \multicolumn{2}{|c|}{ Moderate bed slope } & \multicolumn{2}{c|}{ Low } \\
\cline { 2 - 6 } & raw output & raw output & average & rav output & average \\
\hline 25 & -0.06053 & -0.07580 & & -0.08498 & \\
\hline 50 & & & -0.04695 & & \\
\hline 75 & -0.05479 & -0.01811 & & -0.02801 & -0.04308 \\
\hline 125 & -0.05052 & -0.05449 & & -0.01625 & \\
\hline 150 & & & -0.03464 & & \\
\hline 175 & -0.04975 & -0.01479 & & -0.05124 & \\
\hline 225 & -0.05838 & -0.04403 & & -0.01929 & -0.02735 \\
\hline 250 & & & -0.02827 & & \\
\hline 275 & -0.02287 & -0.01250 & & -0.01153 & \\
\hline 325 & -0.01893 & -0.03783 & & -0.03730 & \\
\hline 350 & & & -0.02450 & & \\
\hline 375 & -0.01592 & -0.01117 & & -0.01452 & -0.02018 \\
\hline 425 & -0.01352 & -0.03486 & & -0.00872 & \\
\hline 475 & -0.01151 & -0.01483 & & -0.02826 & \\
\hline 525 & -0.00979 & -0.01211 & & -0.01101 & -0.01529 \\
\hline 575 & -0.00827 & -0.00993 & & -0.00660 & \\
\hline 625 & -0.00690 & -0.00810 & & -0.02078 & \\
\hline 675 & -0.00564 & -0.00650 & & -0.00850 & \\
\hline 725 & -0.00445 & -0.00506 & & -0.00643 & \\
\hline 775 & -0.00333 & -0.00373 & & -0.00465 & \\
\hline 825 & -0.00225 & -0.00248 & & -0.00306 & \\
\hline 875 & -0.00120 & -0.00129 & & -0.00159 & \\
\hline & & & & & \\
\hline
\end{tabular}


Table 12.11.(Contd.)

\begin{tabular}{|c|c|c|c|c|c|}
\hline \multirow{4}{*}{$\begin{array}{c}\text { Distance } \\
\text { offshore (m) }\end{array}$} & \multicolumn{5}{|c|}{ Seepage rate $(\mathrm{cm} /$ day $)$} \\
\hline & \multicolumn{5}{|c|}{ Lake bed slope } \\
\hline & Steep & \multicolumn{2}{|c|}{ Moderate } & \multicolumn{2}{|c|}{ Low } \\
\hline & raw output & raw output & average & raw output & average \\
\hline 925 & -0.00017 & -0.00012 & & -0.00019 & \\
\hline 975 & 0.00086 & 0.00104 & & 0.00119 & \\
\hline 1025 & 0.00189 & 0.00220 & & 0.00256 & \\
\hline 1075 & 0.00293 & 0.00337 & & 0.00397 & \\
\hline 1125 & 0.00399 & 0.00459 & & 0.00546 & \\
\hline 1175 & 0.00509 & 0.00586 & & 0.00706 & \\
\hline 1225 & 0.00624 & 0.00721 & & 0.00883 & \\
\hline 1275 & 0.00745 & 0.00867 & & 0.01088 & \\
\hline 1325 & 0.00875 & 0.01029 & & 0.01335 & \\
\hline 1375 & 0.01016 & 0.01213 & & 0.03018 & \\
\hline 1425 & 0.01171 & 0.01429 & & 0.00932 & \\
\hline 1475 & 0.01347 & 0.01691 & & 0.01529 & 0.02101 \\
\hline 1525 & 0.01548 & 0.02023 & & 0.03842 & \\
\hline 1575 & 0.01788 & 0.04647 & & 0.01176 & \\
\hline 1625 & 0.02080 & 0.01479 & & 0.01952 & 0.02717 \\
\hline 1650 & & & 0.03246 & & \\
\hline 1675 & 0.02452 & 0.05013 & & 0.05022 & \\
\hline 1725 & 0.02946 & 0.01662 & & 0.01559 & \\
\hline 1750 & & & 0.03816 & & \\
\hline 1775 & 0.07577 & 0.05969 & & 0.02624 & 0.03797 \\
\hline 1825 & 0.06652 & 0.02032 & & 0.07209 & \\
\hline 1850 & & & 0.04985 & & \\
\hline 1875 & 0.07123 & 0.07937 & & 0.02343 & \\
\hline 1925 & 0.08583 & 0.02846 & & 0.04151 & 0.10110 \\
\hline 1950 & & & 0.12619 & & \\
\hline 1975 & 0.18127 & 0.22393 & & 0.23835 & \\
\hline
\end{tabular}




\section{CHAPTER 13}

\section{Results : Orientation of Asymmetric Flow-through Lakes with Respect to Regional Gradient}

While spatial patterns of lake bed seepage did not differ substantially among radially symmetric lakes with different bed slope (Chapter 12), a few simulations were done to evaluate whether asymmetric lakes with different bed slopes in different areas would exhibit different patterns of seepage, especially when aligned in different orientations with respect to a regional groundwater head gradient. An asymmetric lake was designed with steep lake bed slope (i.e., one cell per step along the slope) on one side and moderate lake bed slope (i.e., two cells per step along the slope) on the opposite side. Slope was varied as smoothly as possible, given the constraints of a finite difference grid, between the steep slope and the moderate slope sides. This asymmetric lake had mirror plane rather than radial symmetry, with the mirror plane connecting the steep and moderate slope sides. Three different orientations of flowthrough asymmetric lakes with respect to the regional groundwater gradient were investigated. These three orientations were described as, (1) steep side downgradient (SDG), (2) steep side upgradient (SUG), and (3) mirror plane normal to the regional gradient (NRG). All these settings with different 
simulations and key results are listed in Table 13.1.

\begin{tabular}{|c|c|c|c|c|}
\hline \multirow{2}{*}{ Type of lake } & \multicolumn{4}{|c|}{ Anisotropy Ratio (R) } \\
\cline { 2 - 5 } & $\mathrm{R}=1$ & $\mathrm{R}=10$ & $\mathrm{R}=100$ & $\mathrm{R}=1000$ \\
\hline $\begin{array}{c}\text { Asymmetric } \\
\text { (SDG) }\end{array}$ & $*$ & $\begin{array}{c}969 \\
(-0.974 / 1.516)\end{array}$ & $\begin{array}{c}937 \\
(-0.549 / 0.917)\end{array}$ & $\begin{array}{c}901 \\
(-0.252 / 0.554)\end{array}$ \\
\hline $\begin{array}{c}\text { Asymmetric } \\
\text { (SUG) }\end{array}$ & $* 0.092 / 0.362)$ \\
\hline $\begin{array}{c}\text { Asymmetric } \\
\text { (NRG) }\end{array}$ & $(-1.052 / 1.457)$ & $\begin{array}{c}980 \\
(-0.546 / 0.860)\end{array}$ & $\begin{array}{c}956 \\
(-0.269 / 0.493)\end{array}$ & $\begin{array}{c}930 \\
(-0.094 / 0.305)\end{array}$ \\
\hline
\end{tabular}

Table 13.1. Summary of the position of seepage boundary and the nearshore seepage rate in the downgradient and upgradient side for three different orientations of asymmetric flow-through lakes with regional gradient. The first line in each result box indicates the location the seepage boundary measured in meters from the downgradient shore and the second line indicates the nearshore seepage rate in $\mathrm{cm} /$ day (both downgradient and upgradient sides). ${ }^{*}$ denotes where unknown seepage rates below $10^{-7} \mathrm{~cm} /$ day prevented precise location of the seepage boundary.

When the asymmetric flow-through lake was rotated with respect to the regional gradient, the heads in the porous medium changed everywhere though slightly and consequently the seepage rates did not vary significantly either nearshore or offshore. The vertical sections through the center of the lake showing the head distributions in the porous medium are nearly identical in all simulations at all $\mathrm{R}$ (Figs. 13.1 to 13.6 ). At low anisotropy (i.e., $\mathrm{R}=1,10$ ) the equipotential lines were almost vertical and straight suggesting strong horizontal flow and almost no vertical flow in all simulations. At all anisotropy ratios, the area of outseepage was smaller when the steep side was 
facing downgradient compared to when the moderate side was facing downgradient. The area of outseepage was largest for lakes with their mirror planes oriented normal to the regional groundwater gradient. Also, there was a uniform trend of movement of the seepage boundary toward the upgradient side with increasing anisotropy ratio.

Plots of seepage rate versus distance offshore showed the same sort of small variations described in chapter 12 . The seepage patterns generated by the seepage maps reflected the variation of seepage rates over the entire lake bed among the different simulations (Figs. 13.9 to 13.20). The seepage maps seemed to be very similar at low R for the SUG, SDG, and NRG simulations. At $R=1000$, the SDG simulation had a larger area with the highest inseepage rates $(>0.2 \mathrm{~cm} /$ day $)$, and a somewhat smaller area of the second highest inseepage rate category $(0.05-0.2 \mathrm{~cm} /$ day $)$. 


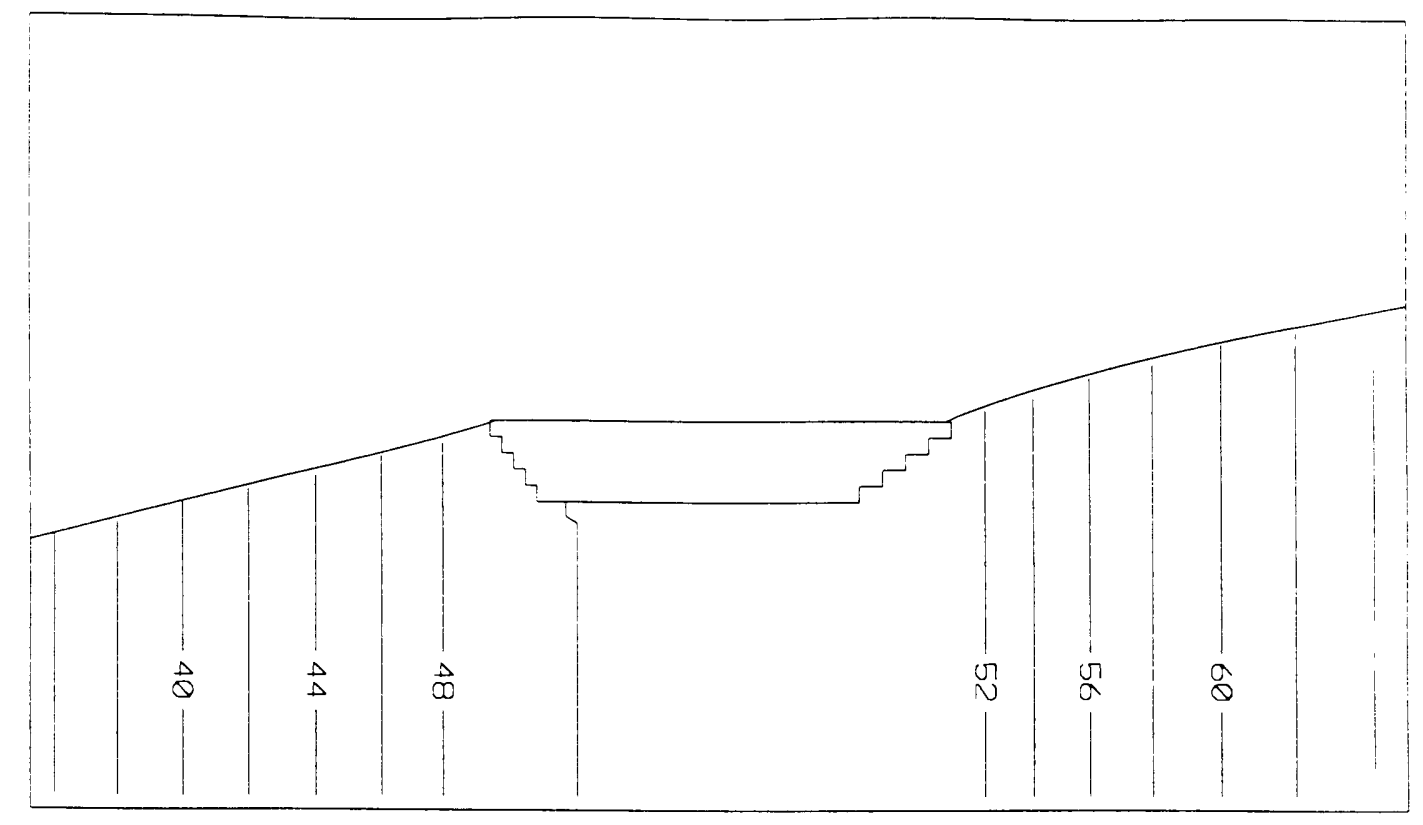

Anisotropy Ratio $=1$

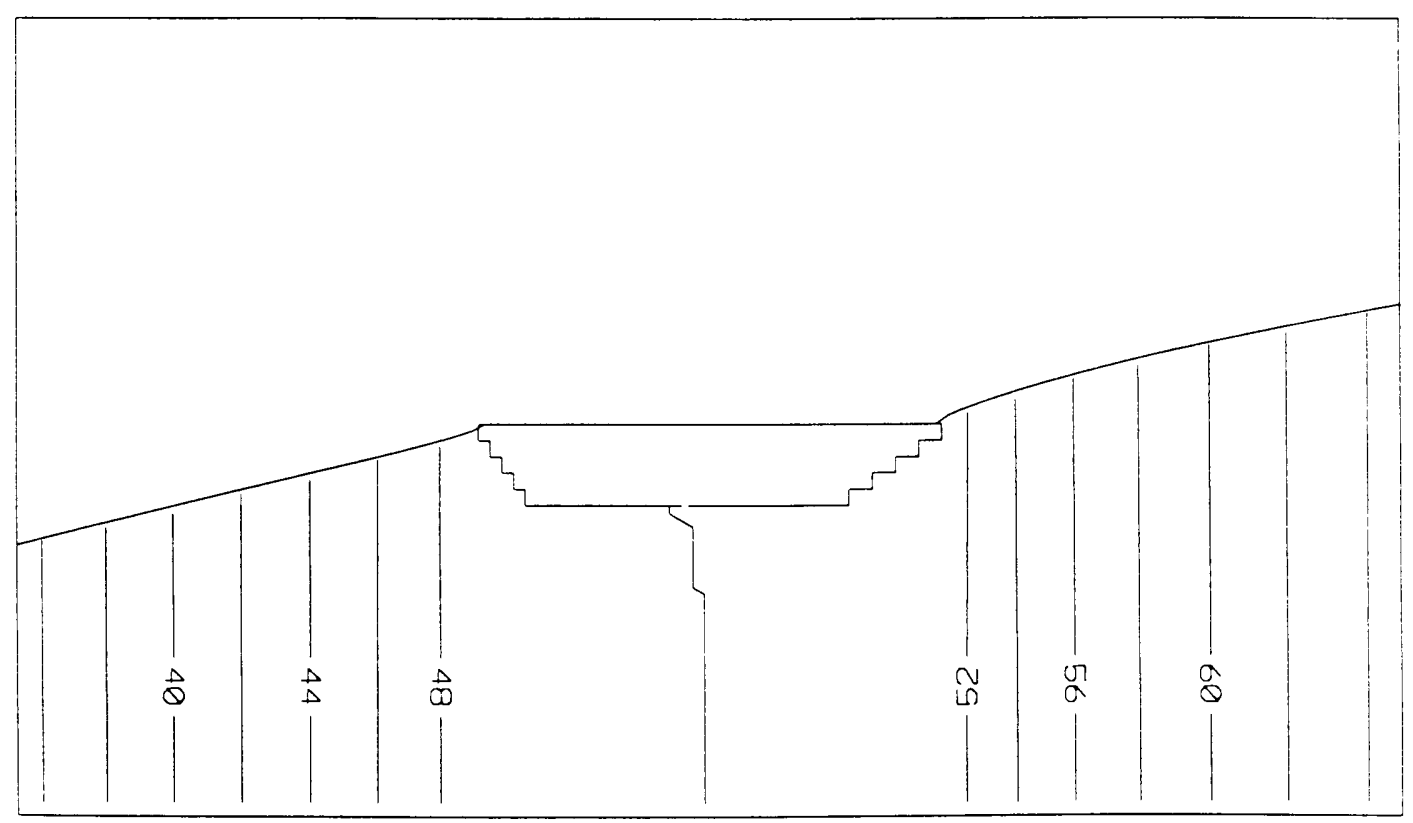

Anisotropy Ratio $=10$

Fig. 13.1. Distribution of hydraulic heads in the porous medium surrounding shallow flowthrough lakes with asymmetric lake bed slope (steep side facing downgradient) at $\mathrm{R}=1$ and $\mathrm{R}=10$. 


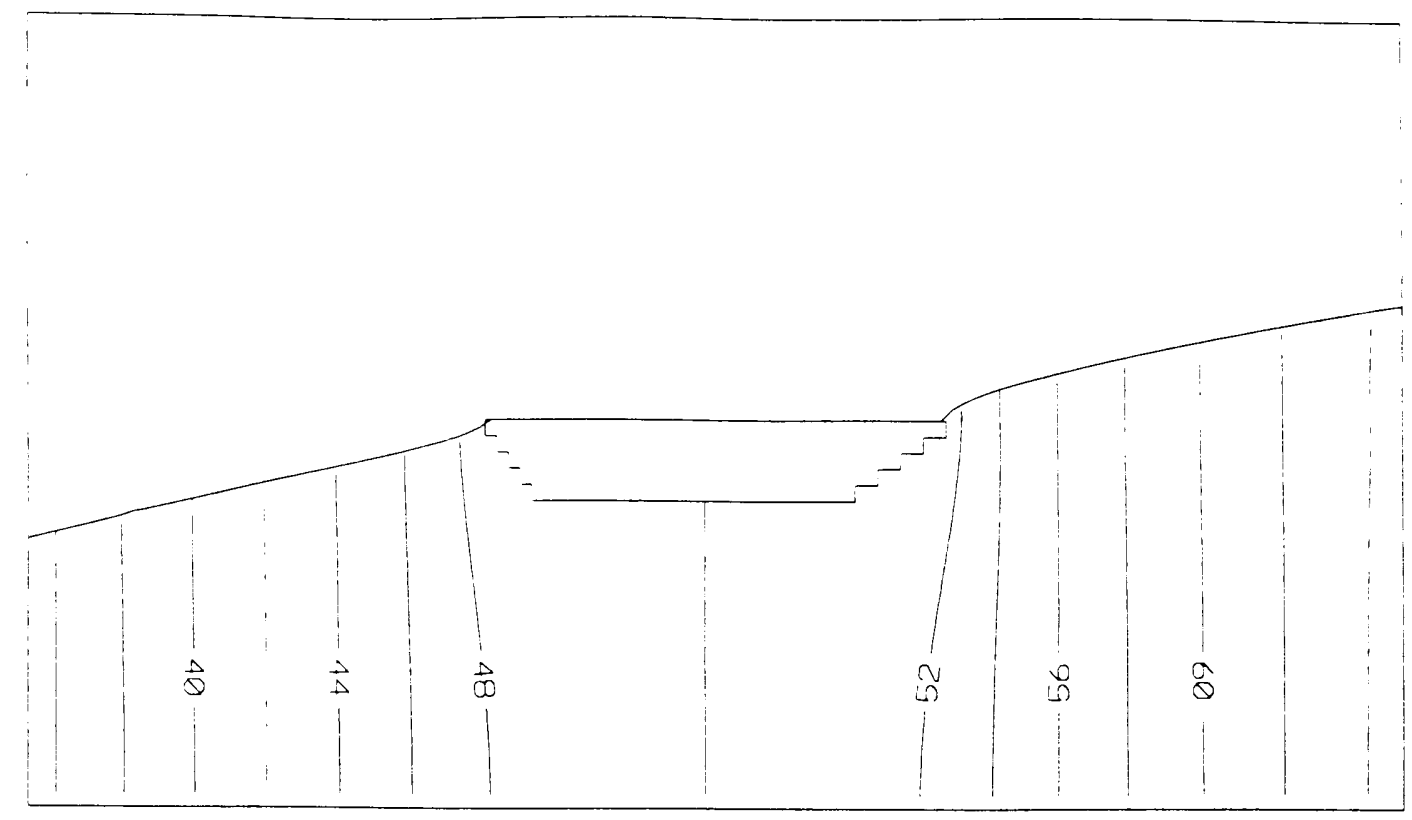

Anisotropy Ratio $=100$

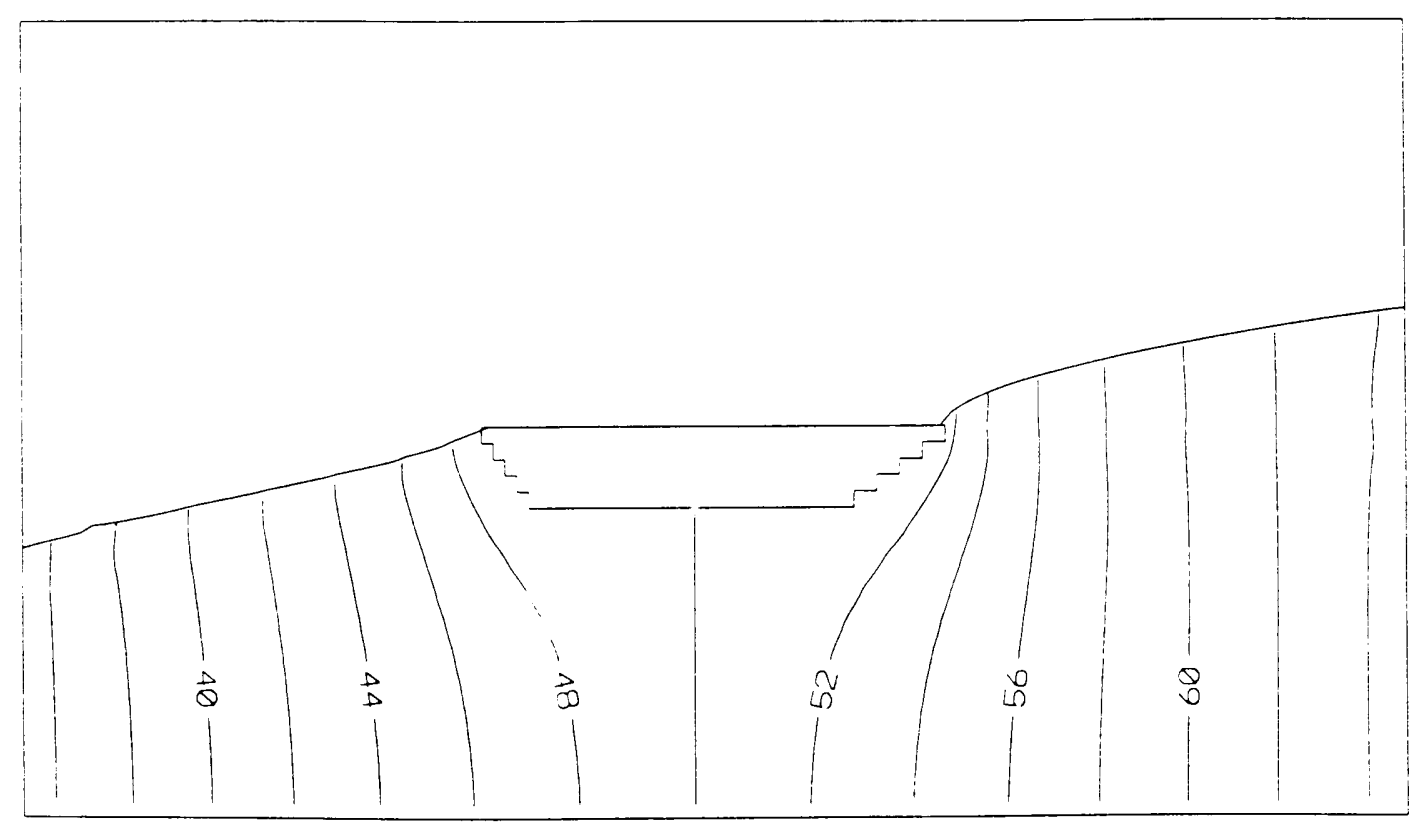

Anisotropy Ratio $=1000$

Fig. 13.2. Distribution of hydraulic heads in the porous medium surrounding shallow flowthrough lakes with asymmetric lake bed slope (steep side facing downgradient) at $\mathrm{R}=100$ and $\mathrm{R}=1000$. 


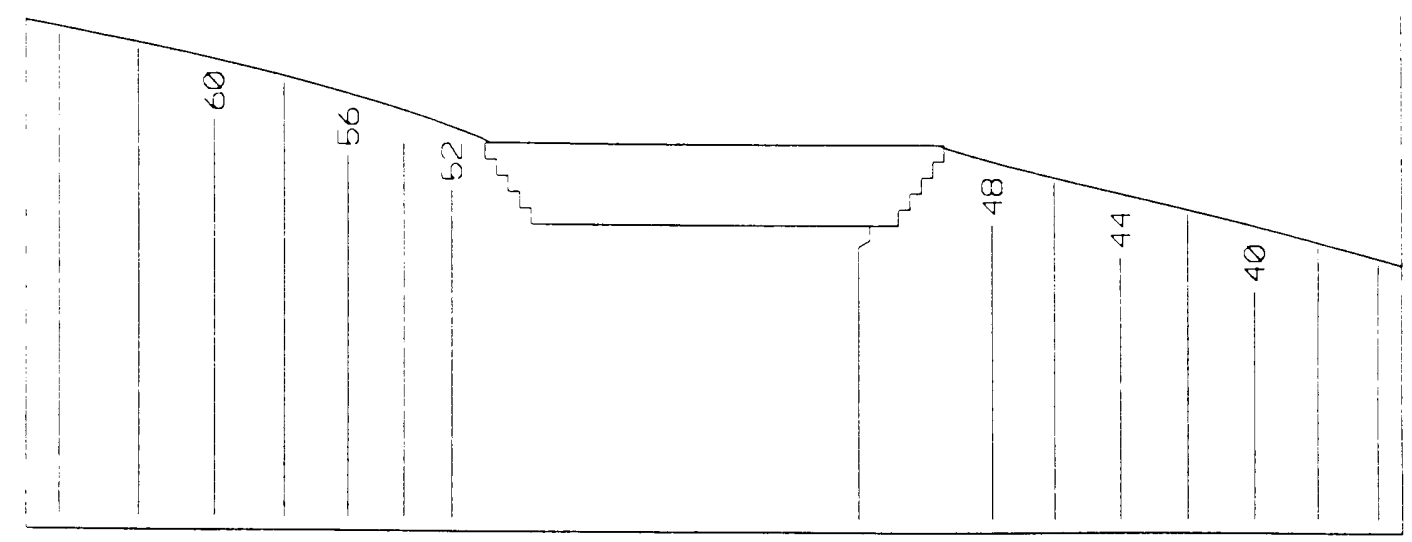

Anisotropy Ratio $=1$

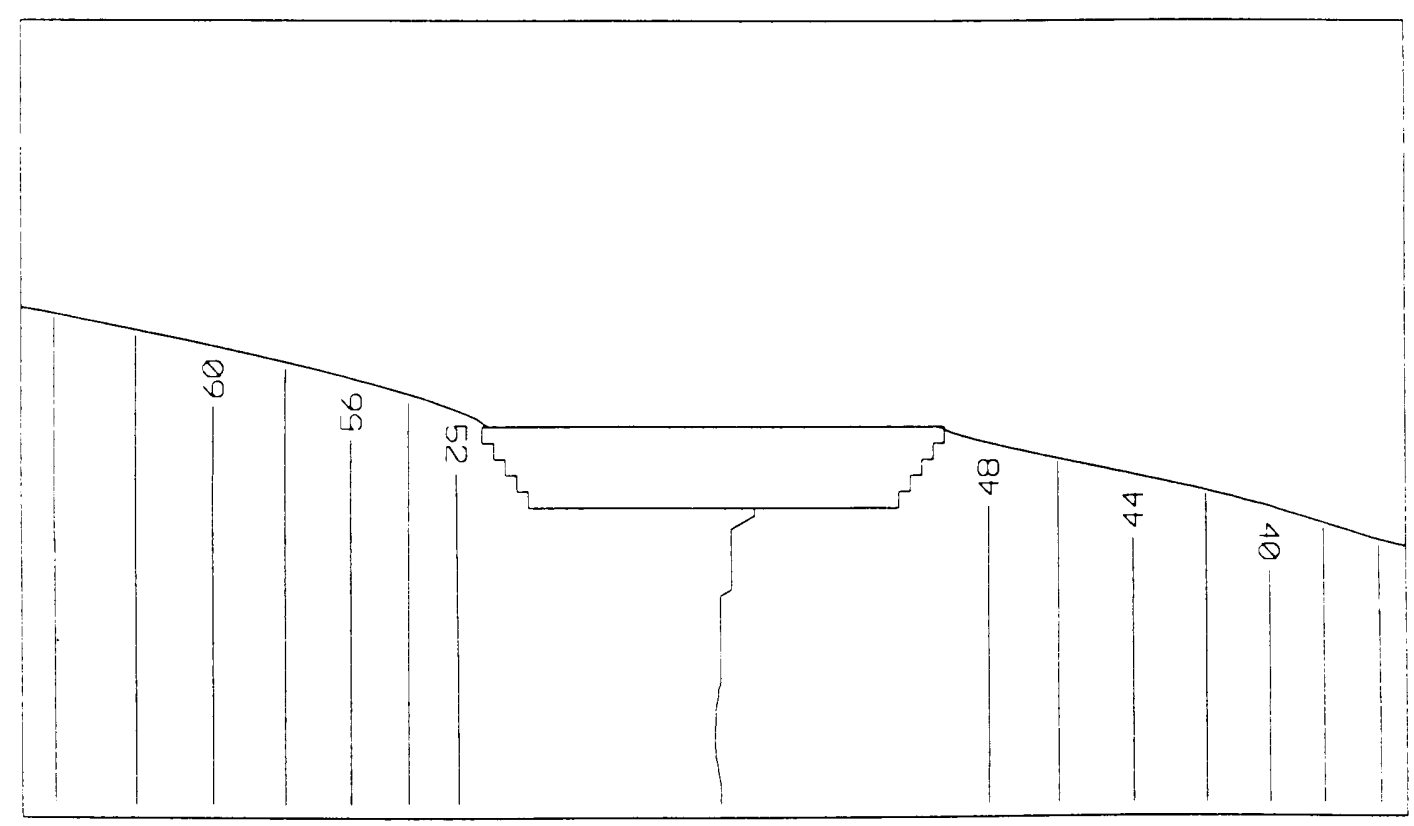

Anisotropy Ratio $=10$

Fig. 13.3. Distribution of hydraulic heads in the porous medium surrounding shallow flowthrough lakes with asymmetric lake bed slope (normal to regional gradient) at $R=1$ and $\mathrm{R}=10$. 


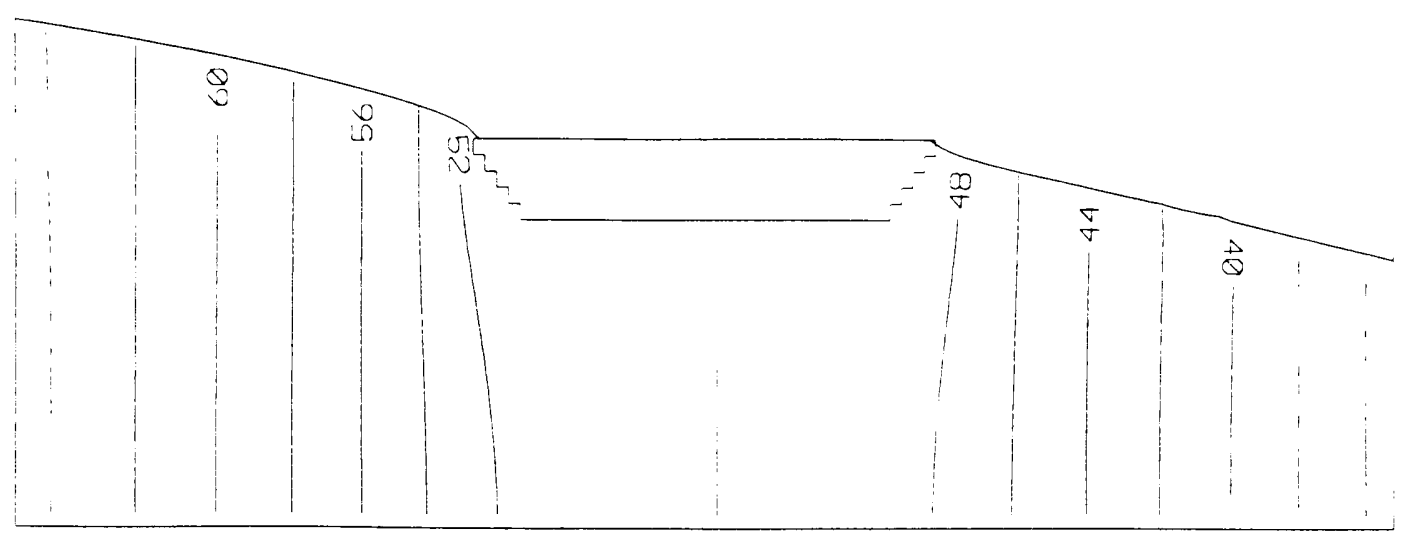

Anisotropy Ratio $=100$

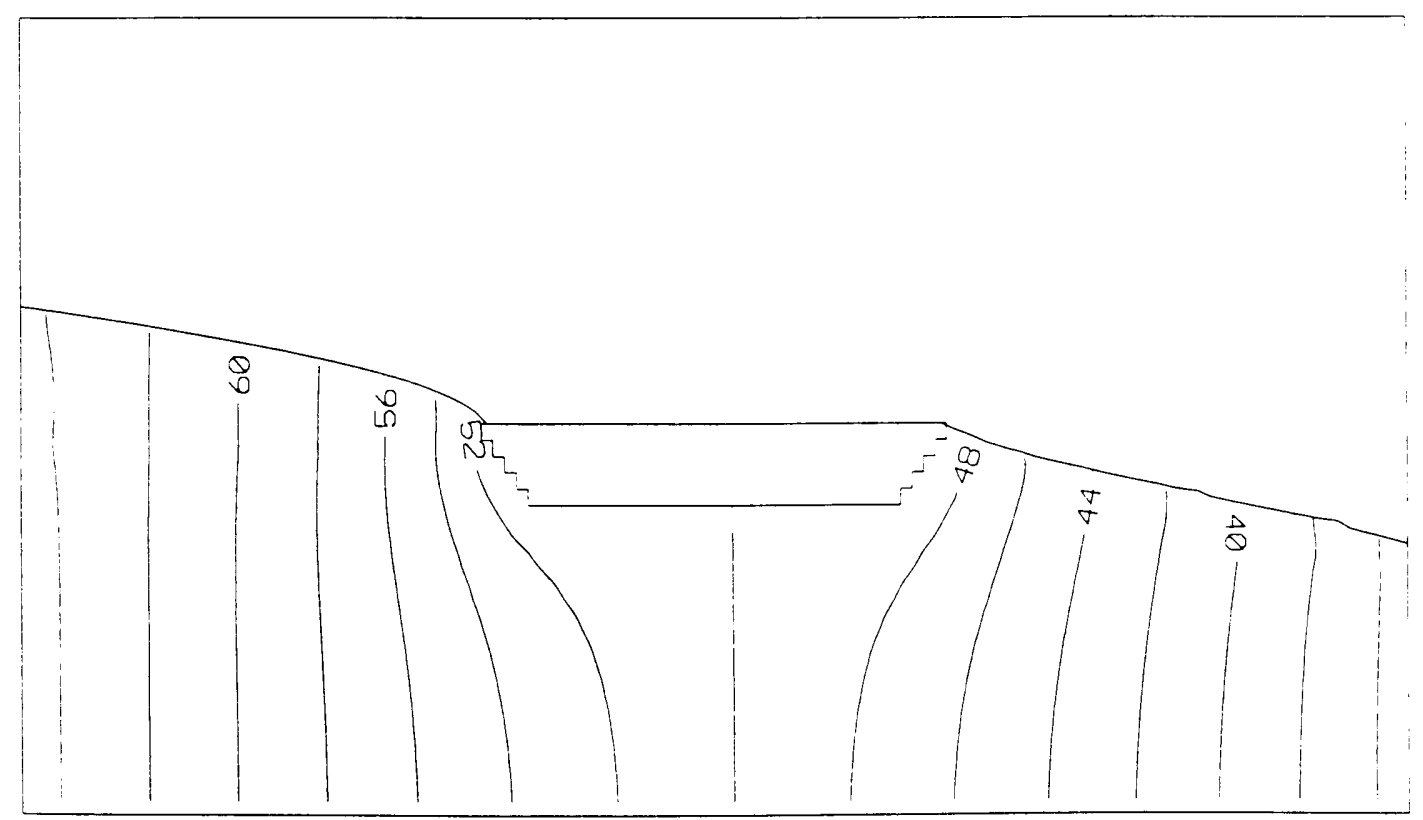

Anisotropy Ratio $=1000$

Fig. 13.4. Distribution of hydraulic heads in the porous medium surrounding shallow flowthrough lakes with asymmetric lake bed slope (normal to regional gradient) at $\mathrm{R}=100$ and $\mathrm{R}=1000$. 


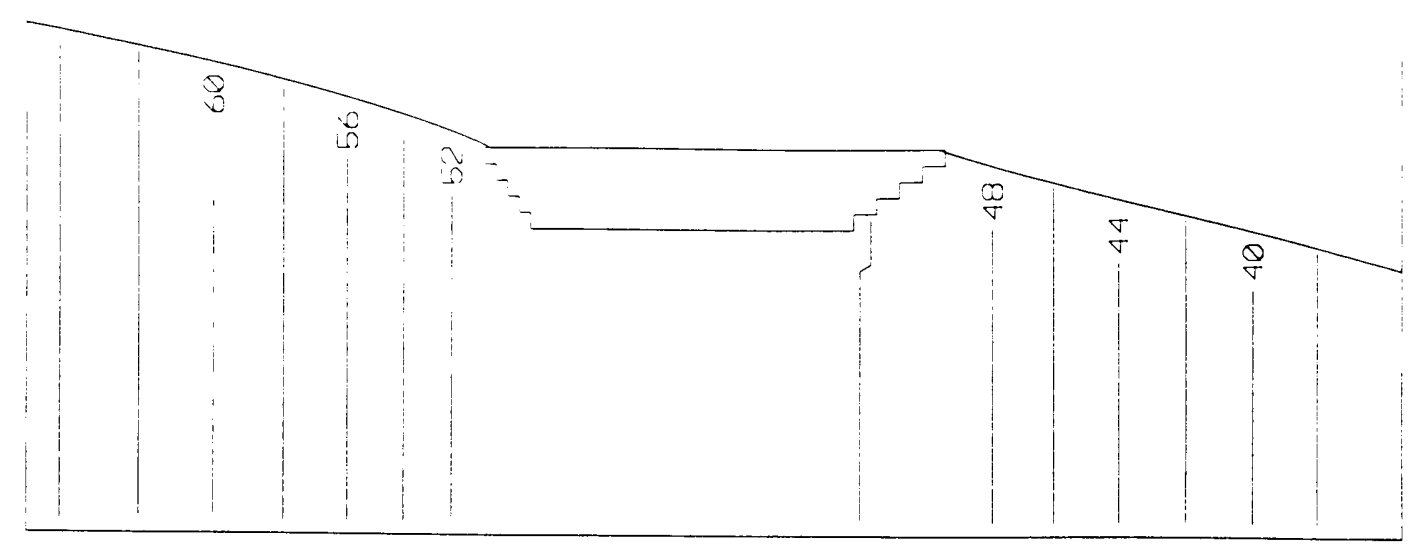

Anisotropy Ratio $=1$

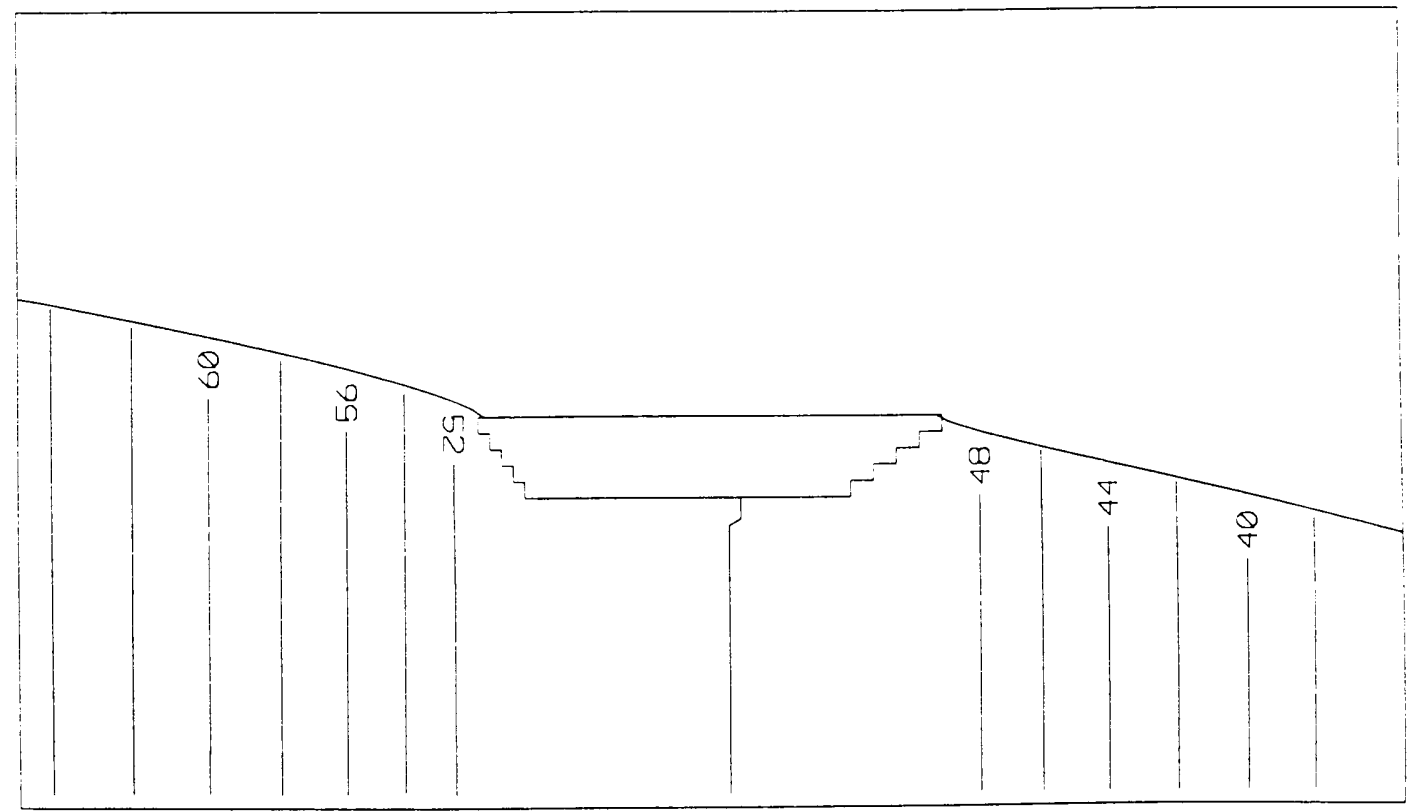

Anisotropy Ratio $=10$

Fig. 13.5. Distribution of hydraulic heads in the porous medium surrounding shallow flowthrough lakes with asymmetric lake bed slope (steep side facing upgradient) at $\mathrm{R}=1$ and $\mathrm{R}=10$. 


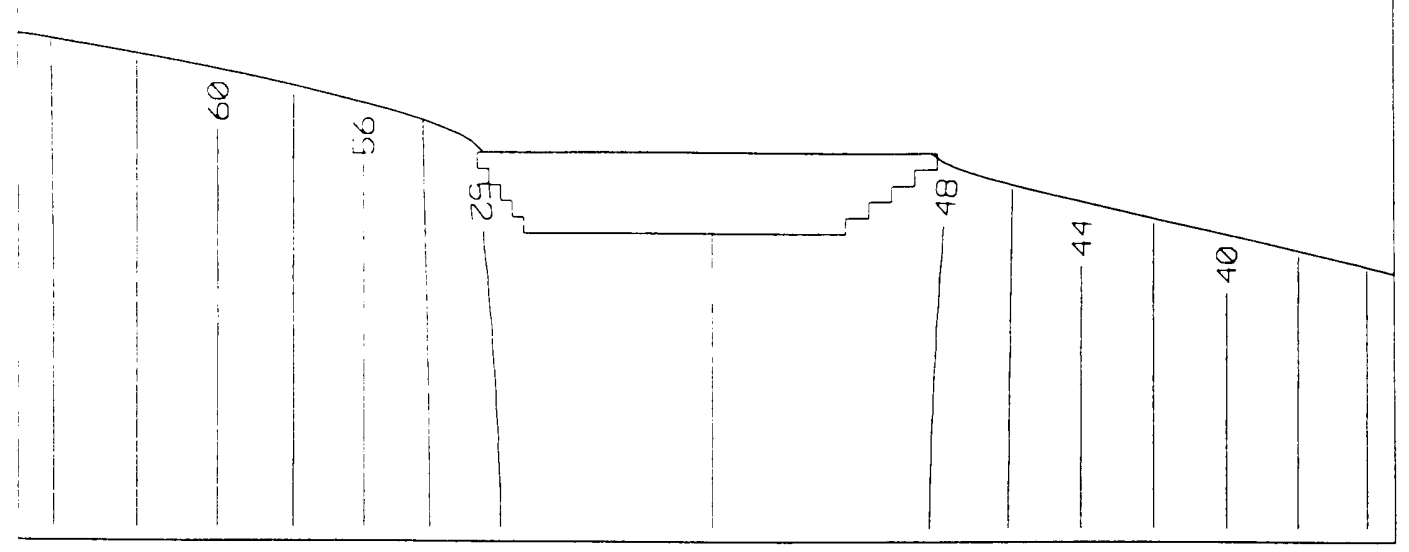

Anisotropy Ratio $=100$

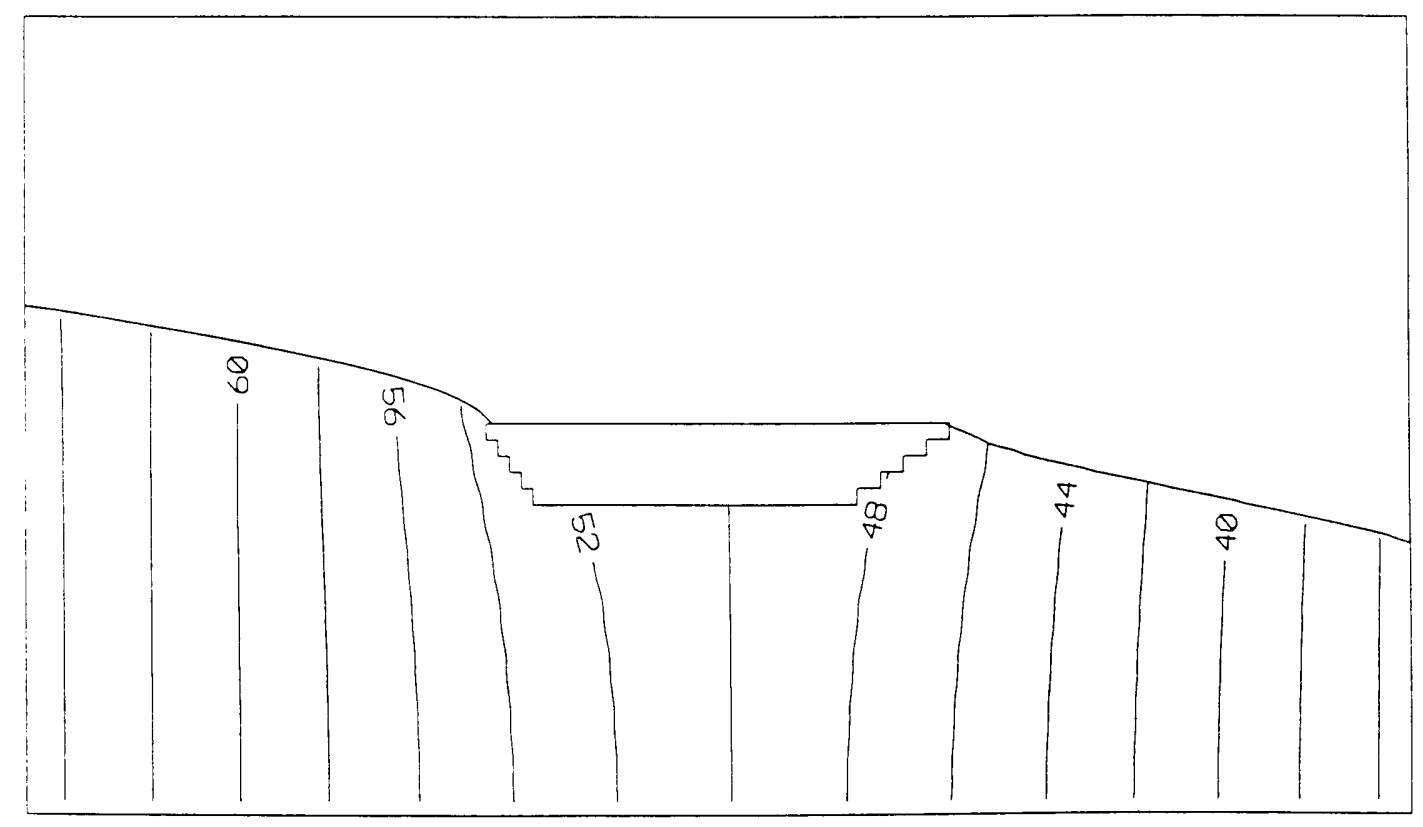

Anisotropy Ratio $=1000$

Fig. 13.6. Distribution of hydraulic heads in the porous medium surrounding shallow flowthrough lakes with asymmetric lake bed slope (steep side facing upgradient) at $\mathrm{R}=100$ and $\mathrm{R}=1000$. 

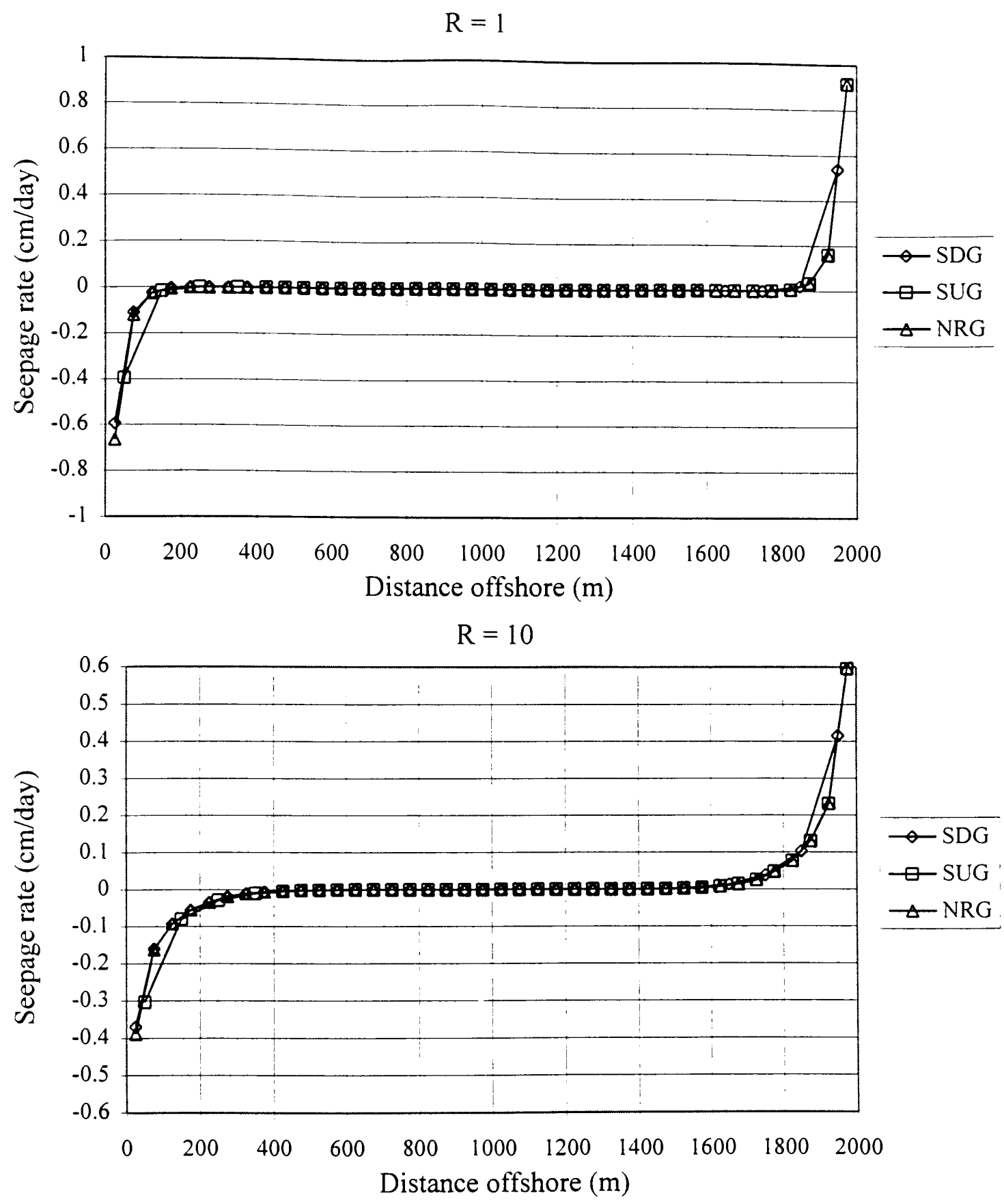

Fig. 13.7. Seepage rate versus distance offshore for simulations of shallow flow-through lakes with asymmetric (SDG, NRG, and SUG) lake bed slope at $R=1$ and $R=10$. 

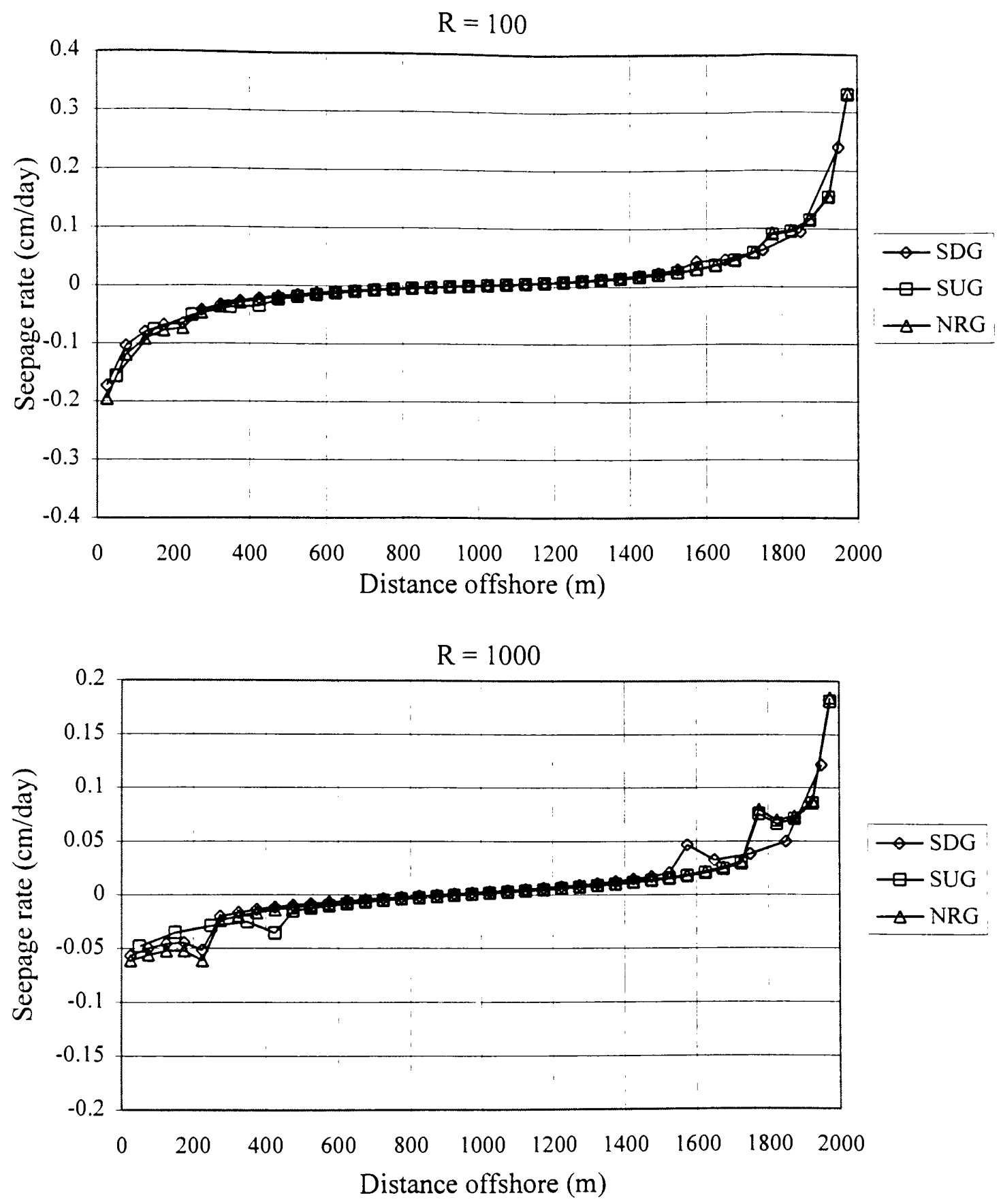

Fig. 13.8. Seepage rate versus distance offshore for simulations of shallow flow-through lakes with asymmetric (SDG, NRG, and SUG) lake bed slope at $R=100$ and $R=1000$. 


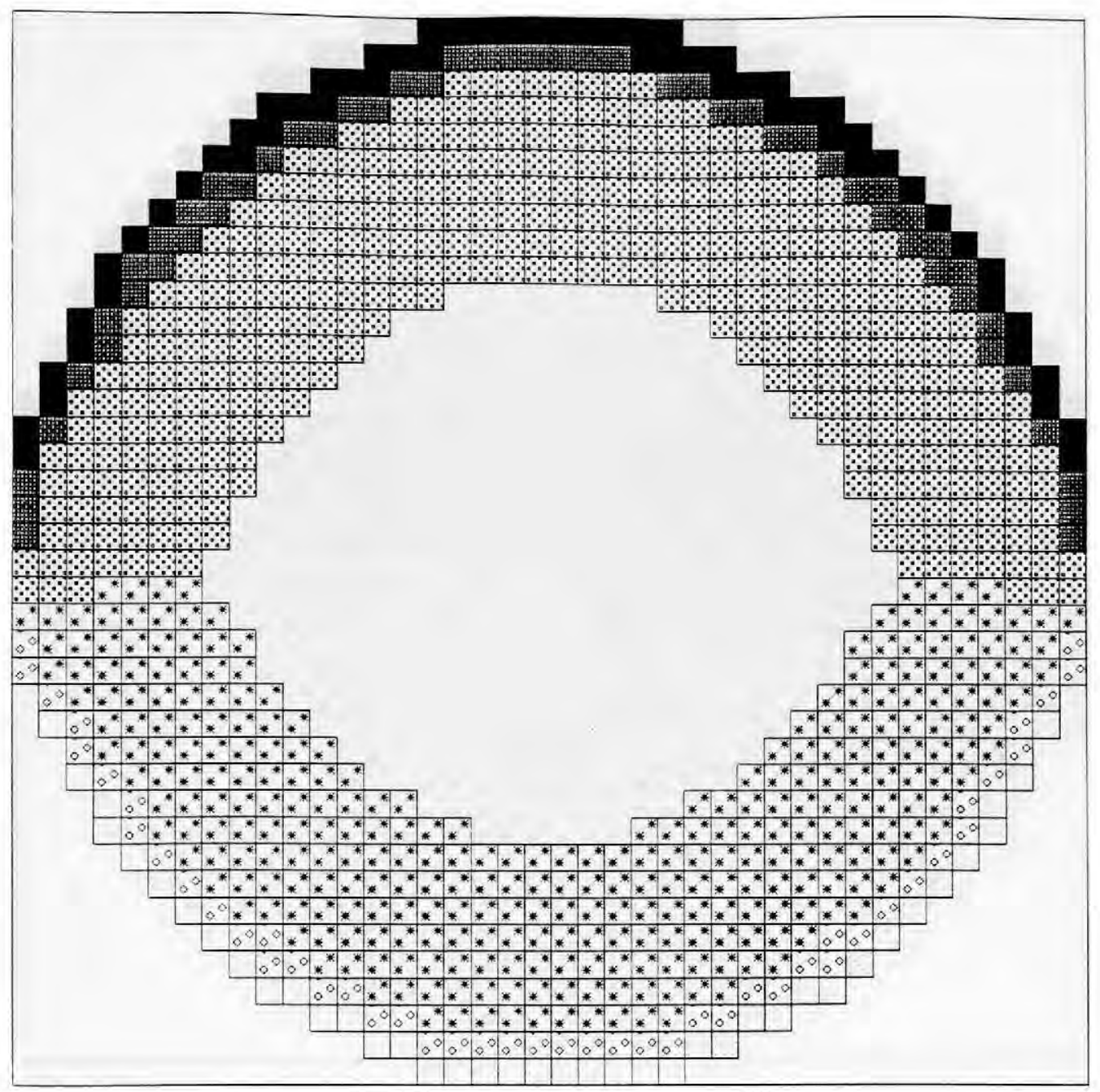

Fig. 13.9. Distribution of seepage rates ( $\mathrm{cm} /$ day) over the lake bed for a shallow flow-through lake with asymmetric (steep side facing downgradient) lake bed slope at $R=1$. The regional gradient of groundwater flow is from the top to the bottom of the figure. The white area in the center represents cells having seepage rates with absolute values $<10^{-7} \mathrm{~cm} /$ day.

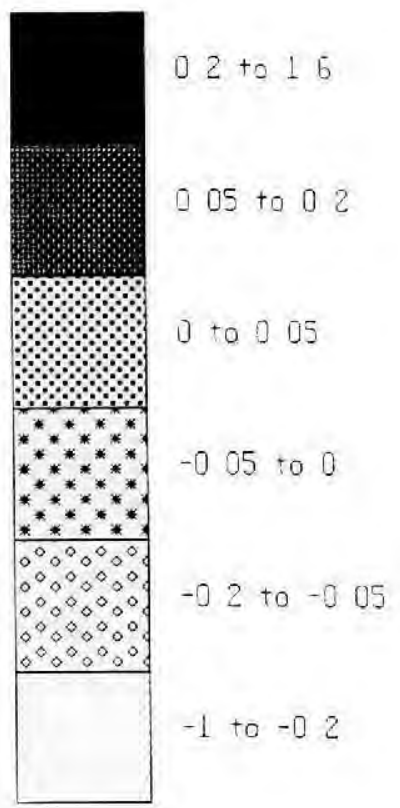




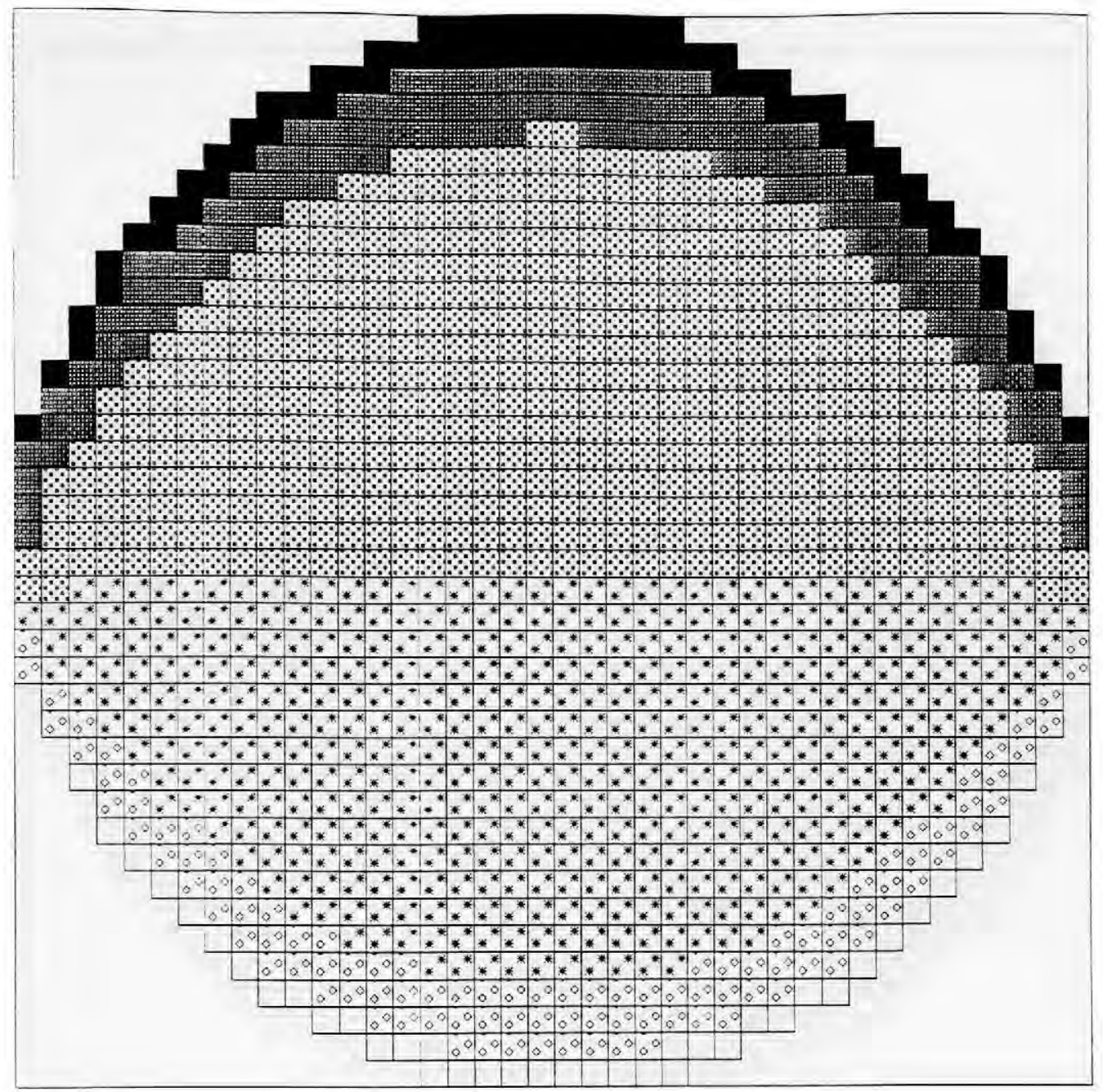

Fig. 13.10. Distribution of seepage rates ( $\mathrm{cm} /$ day) over the lake bed for a shallow flow-through lake with asymmetric (steep side facing downgradient) lake bed slope at $\mathrm{R}=10$. The regional gradient of groundwater flow is from the top to the bottom of the figure.

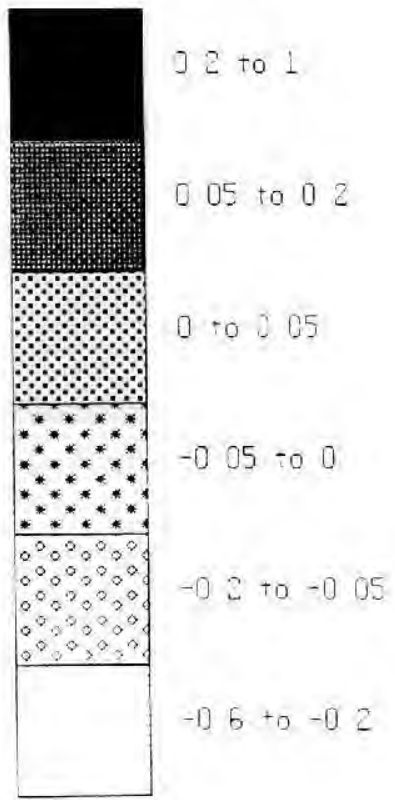




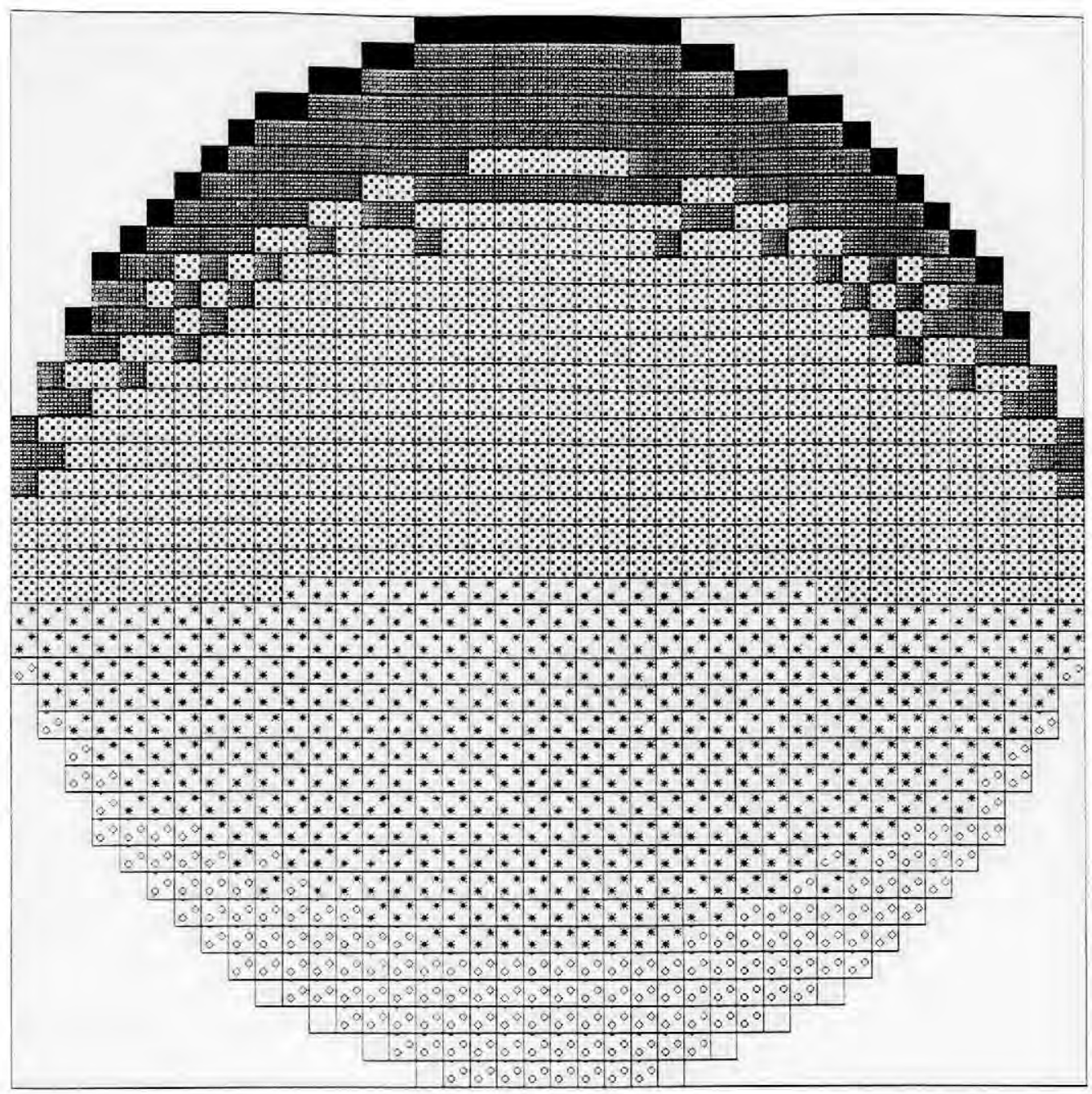

Fig. 13.11. Distribution of seepage rates ( $\mathrm{cm} /$ day) over the lake bed for a shallow flow-through lake with asymmetric (steep side facing downgradient) lake bed slope at $\mathrm{R}=100$. The regional gradient of groundwater flow is from the top to the bottom of the figure.

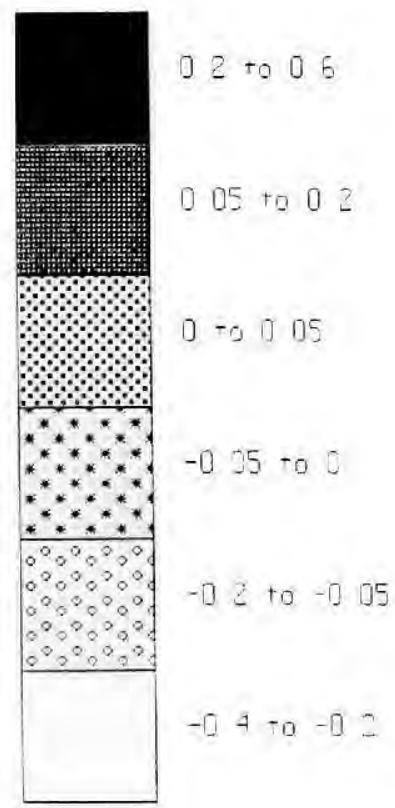




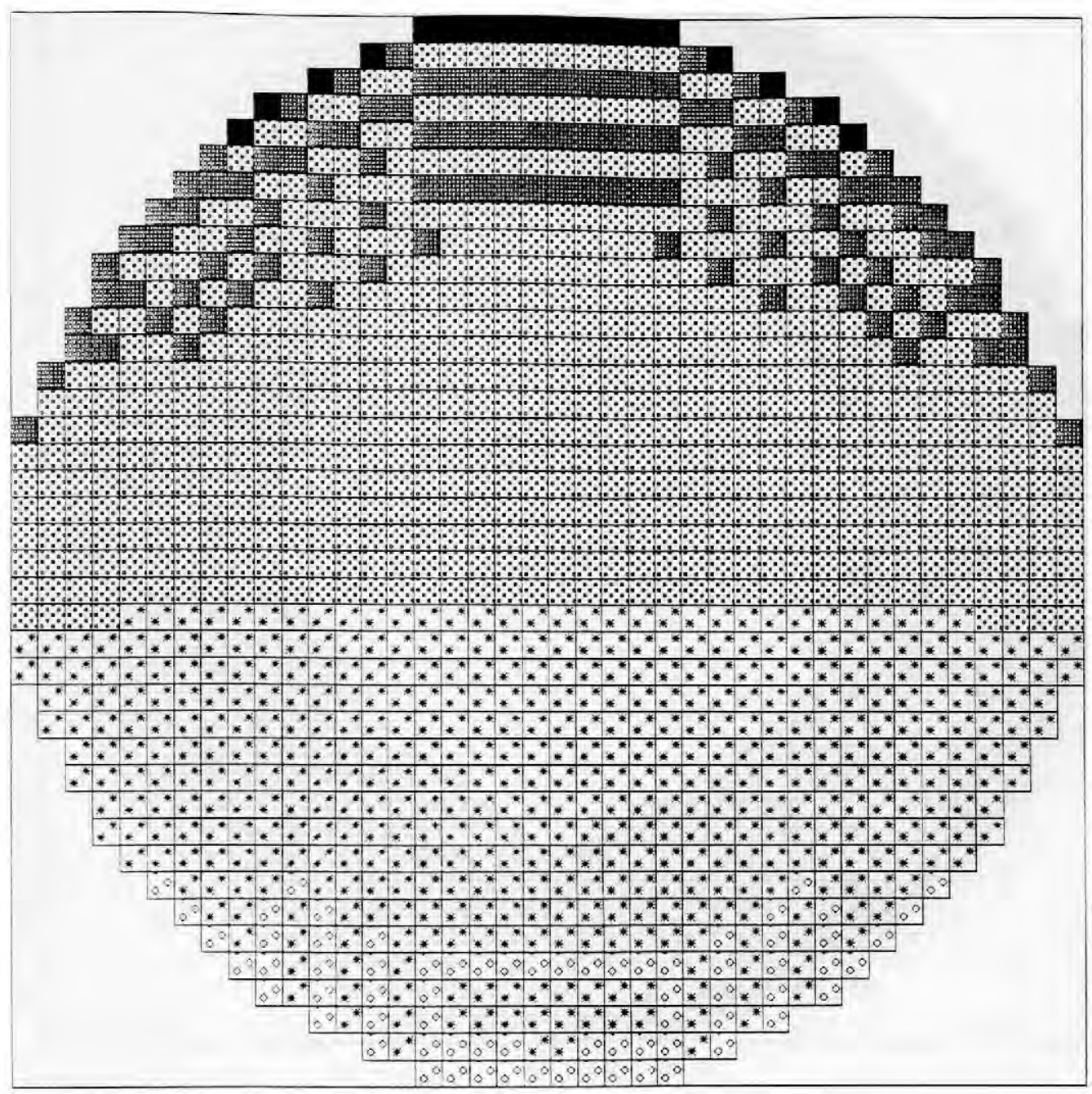

Fig. 13.12. Distribution of seepage rates ( $\mathrm{cm} /$ day) over the lake bed for a shallow flow-through lake with asymmetric (steep side facing downgradient) lake bed slope at $R=1000$. The regional gradient of groundwater flow is from the top to the bottom of the figure.

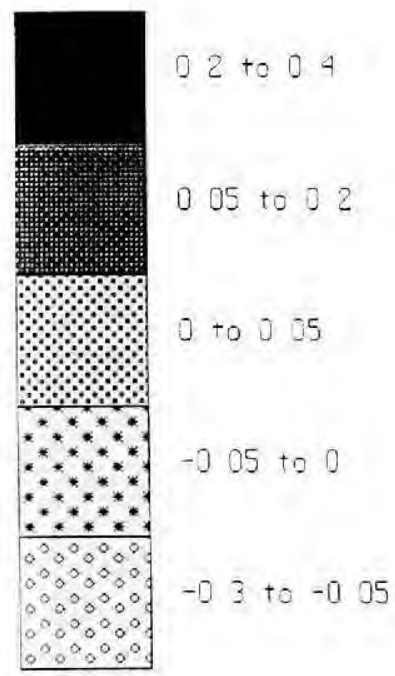




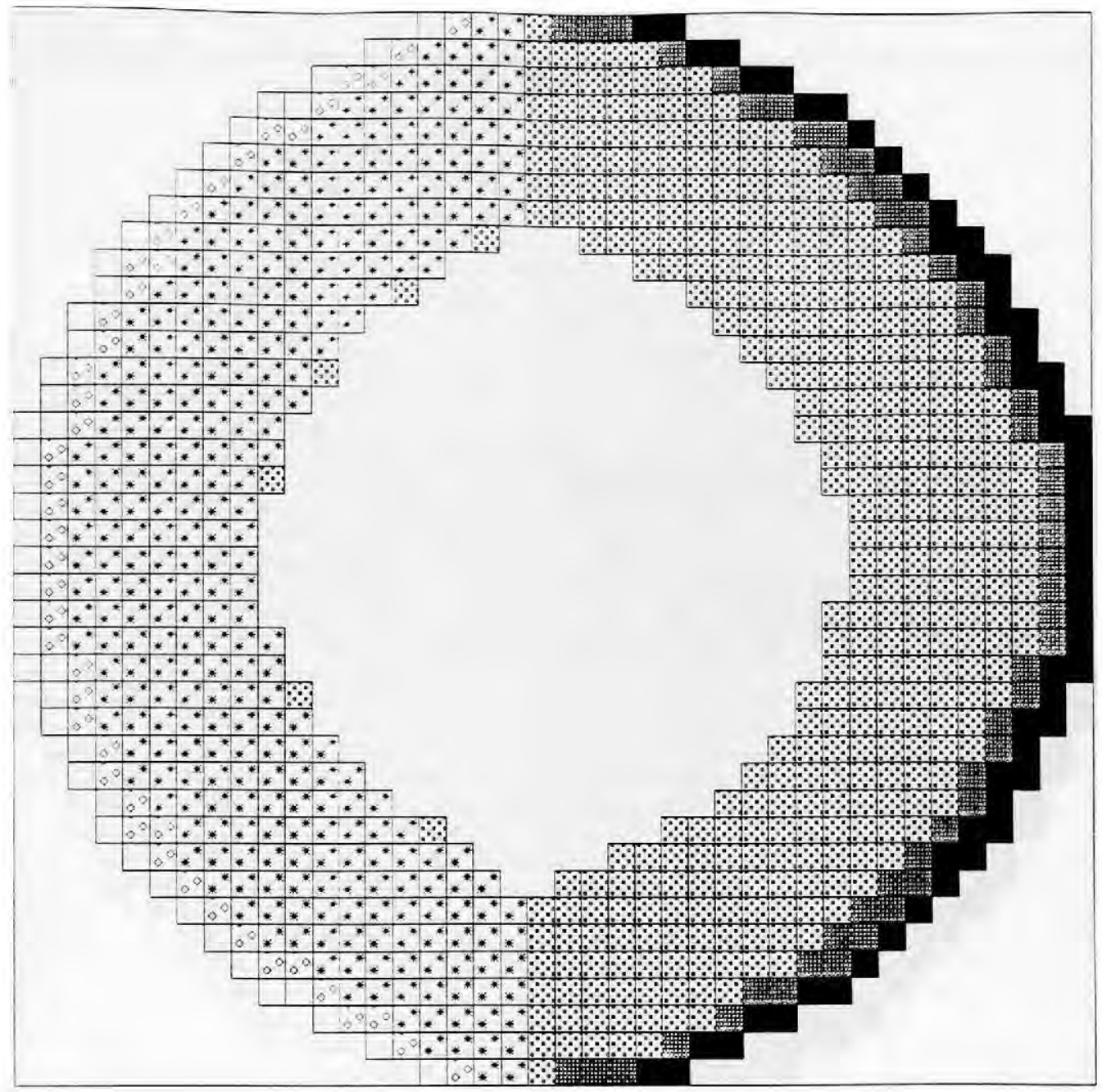

Fig. 13.13. Distribution of seepage rates ( $\mathrm{cm} /$ day) over the lake bed for a shallow flow-through lake with asymmetric (normal to regional gradient) lake bed slope at $\mathrm{R}=1$. The regional gradient of groundwater flow is from the right to the left of the figure. The white area in the center represents cells having seepage rates with absolute values $<$ $10^{-7} \mathrm{~cm} /$ day.

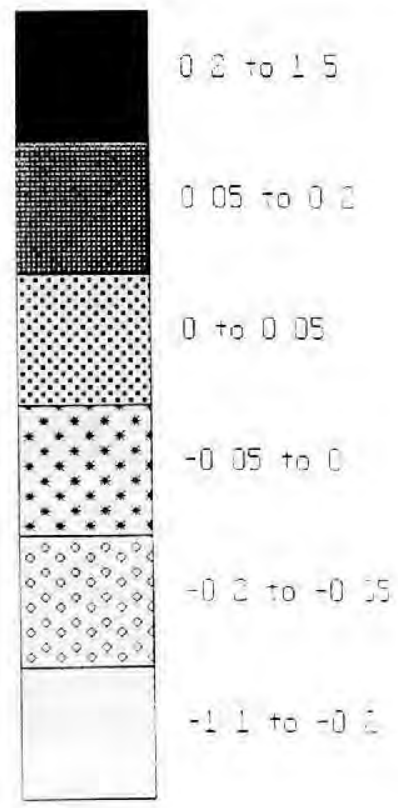




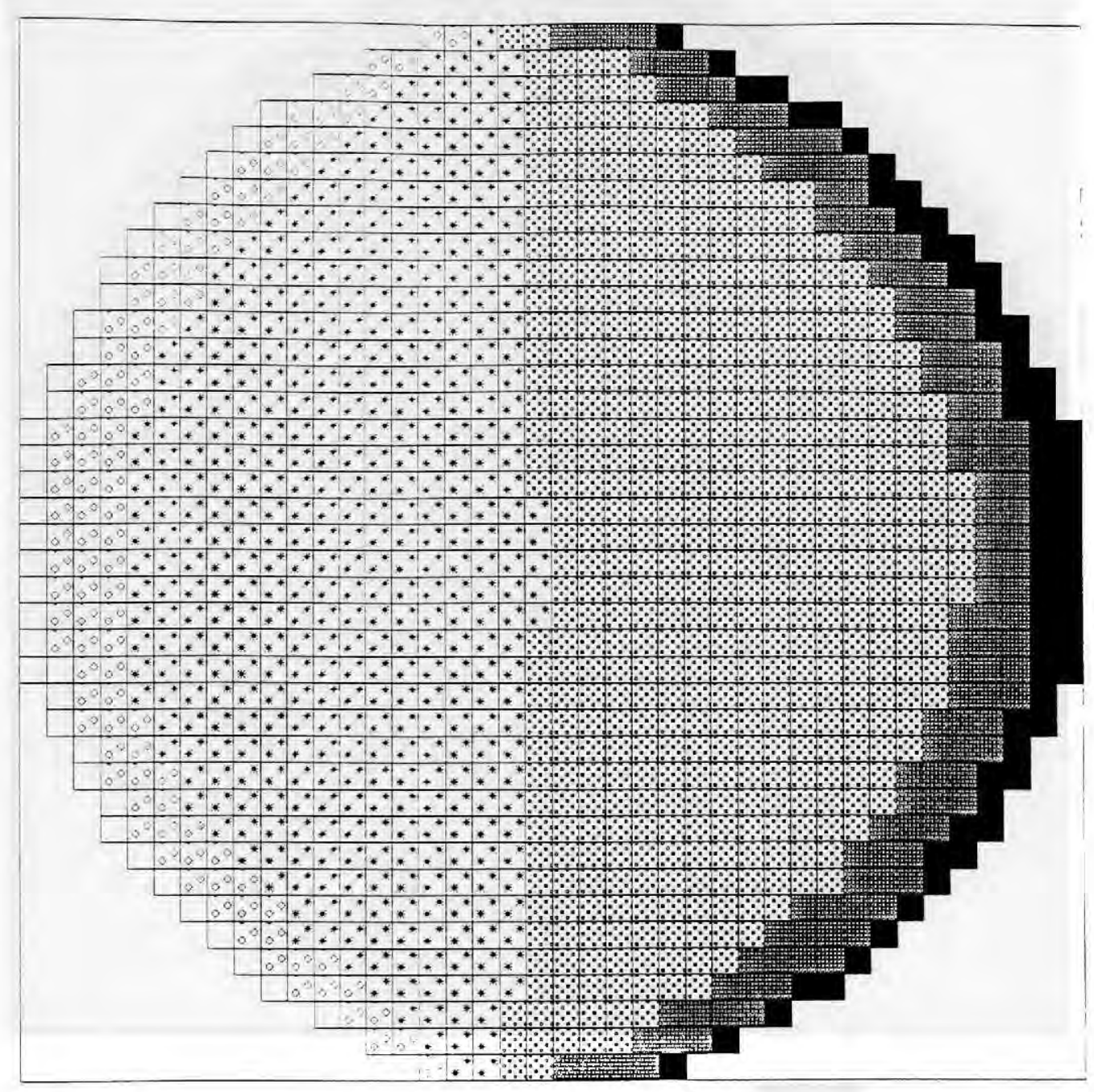

Fig. 13.14. Distribution of seepage rates ( $\mathrm{cm} /$ day) over the lake bed for a shallow flow-through lake with asymmetric (normal to regional gradient) lake bed slope at $\mathrm{R}=10$. The regional gradient of

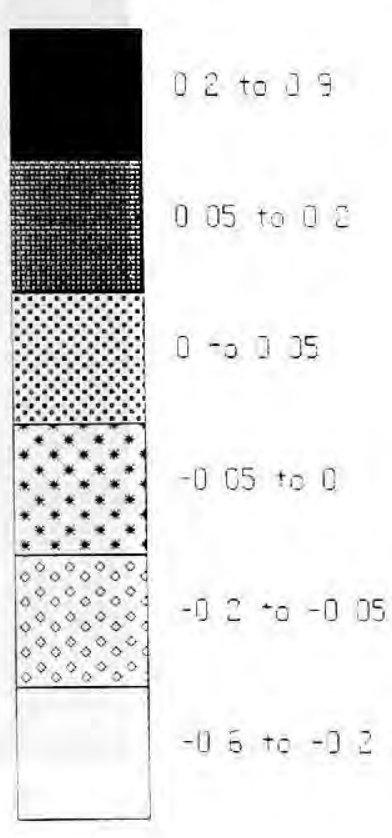
groundwater flow is from the right to the left of the figure. 


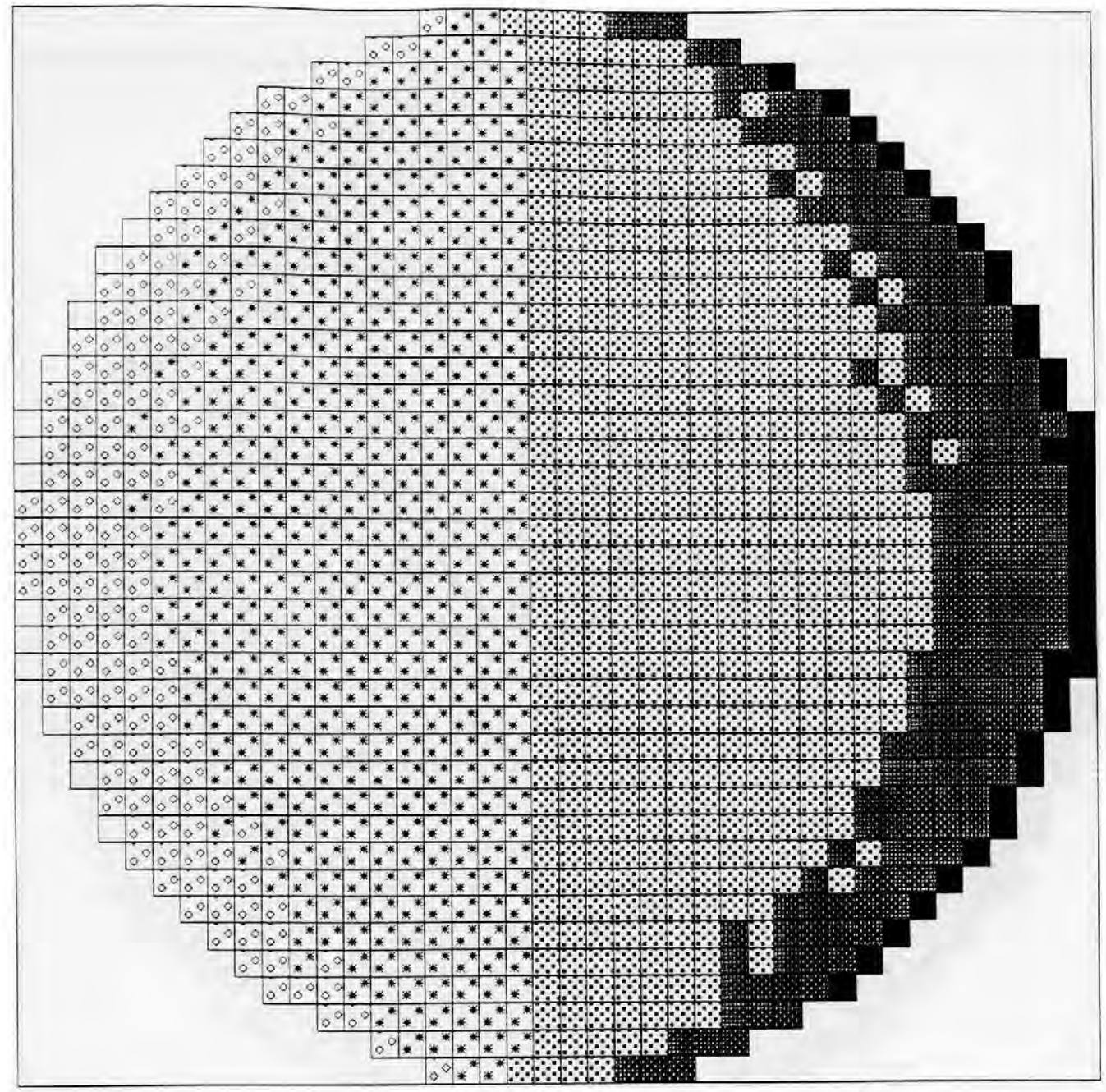

Fig. 13.15. Distribution of seepage rates ( $\mathrm{cm} /$ day) over the lake bed for a shallow flow-through lake with asymmetric (normal to regional gradient) lake bed slope at $R=100$. The regional gradient of groundwater flow is from the right to the left of the figure.

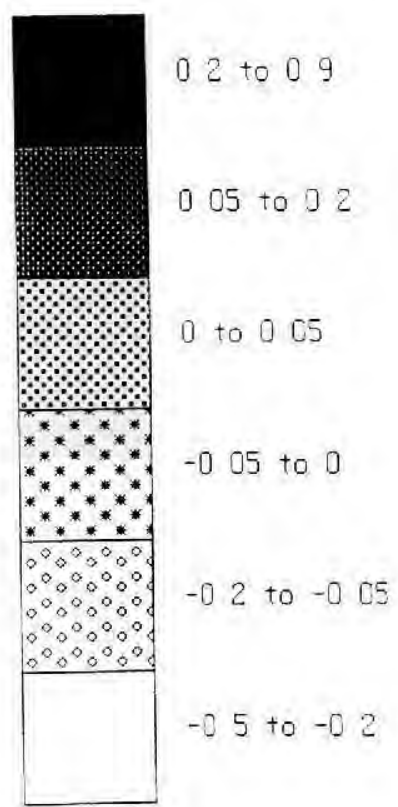




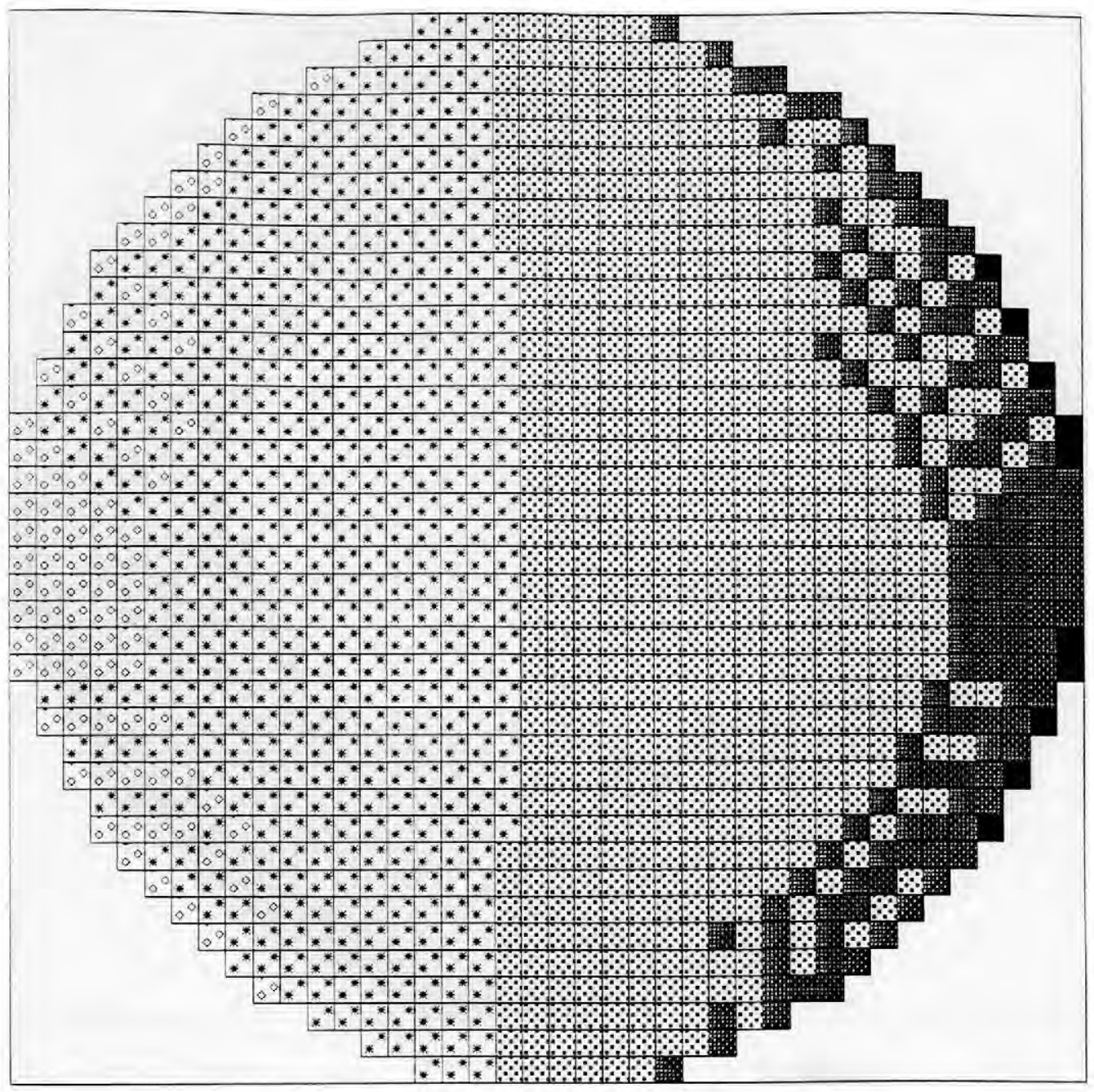

Fig. 13.16. Distribution of seepage rates ( $\mathrm{cm} /$ day) over the lake bed for a shallow flow-through lake with asymmetric (normal to regional gradient) lake bed slope at $\mathrm{R}=1000$. The regional gradient of groundwater flow is from the right to the left of the figure.

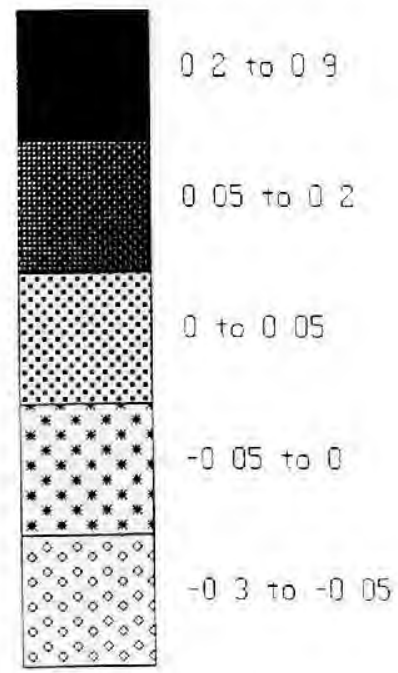




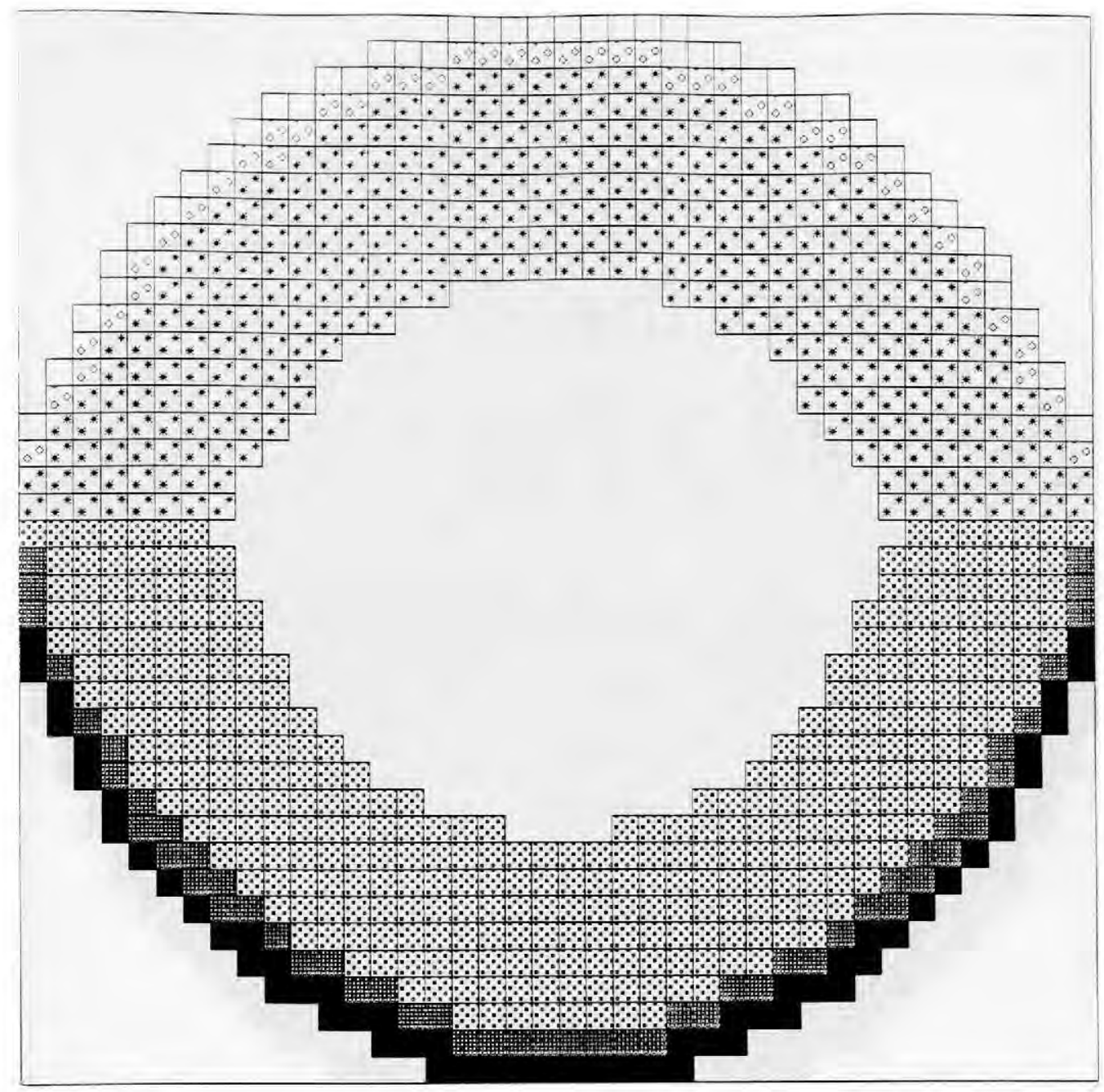

Fig. 13.17. Distribution of seepage rates ( $\mathrm{cm} /$ day) over the lake bed for a shallow flow-through lake with asymmetric (steep side facing upgradient) lake bed slope at $\mathrm{R}=1$. The regional gradient of groundwater flow is from the bottom to the top of the figure. The white area in the center represents cells having seepage rates with absolute values $<$ $10^{-7} \mathrm{~cm} /$ day.

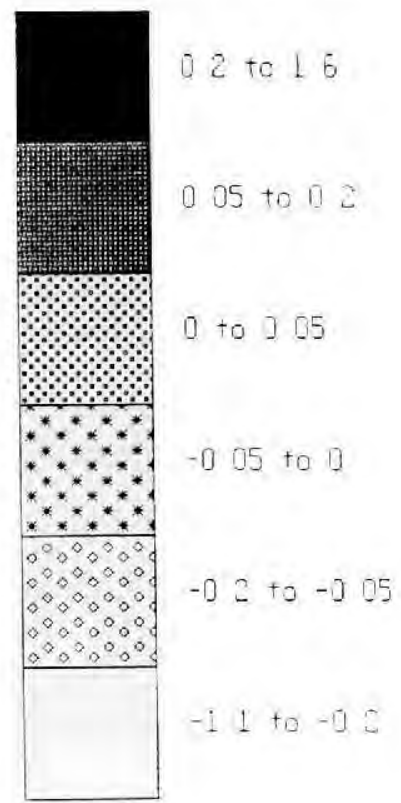




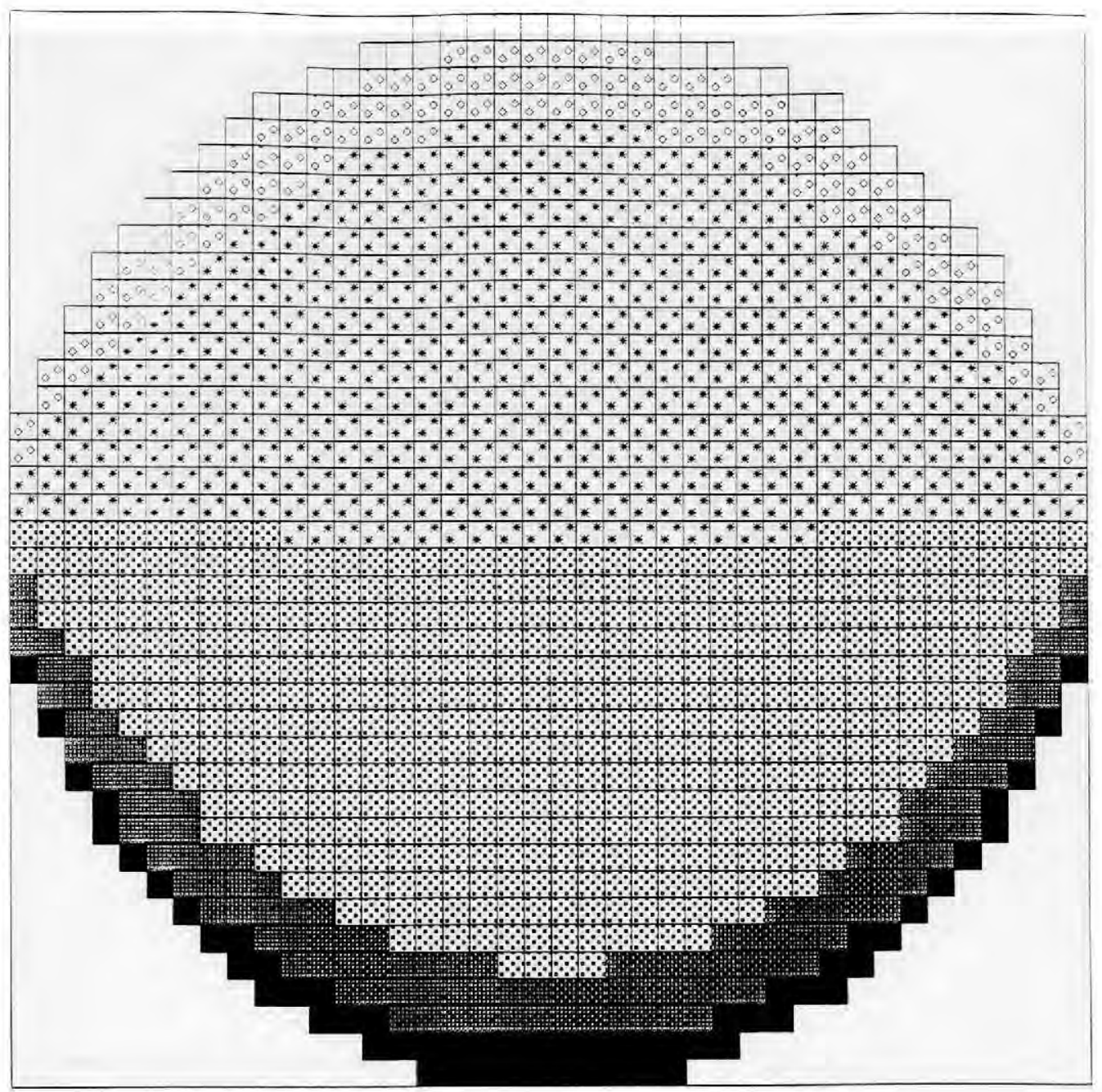

Fig. 13.18. Distribution of seepage rates $(\mathrm{cm} /$ day) over the lake bed for a shallow flow-through lake with asymmetric (steep side facing upgradient) lake bed slope at $\mathrm{R}=10$. The regional gradient of groundwater flow is from the bottom to the top of the figure.

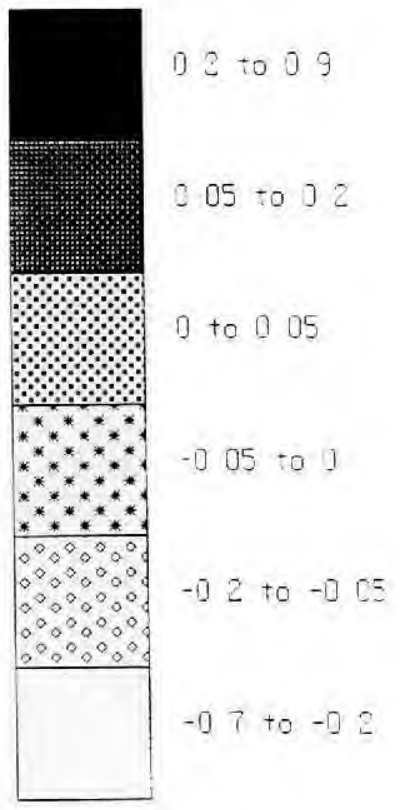




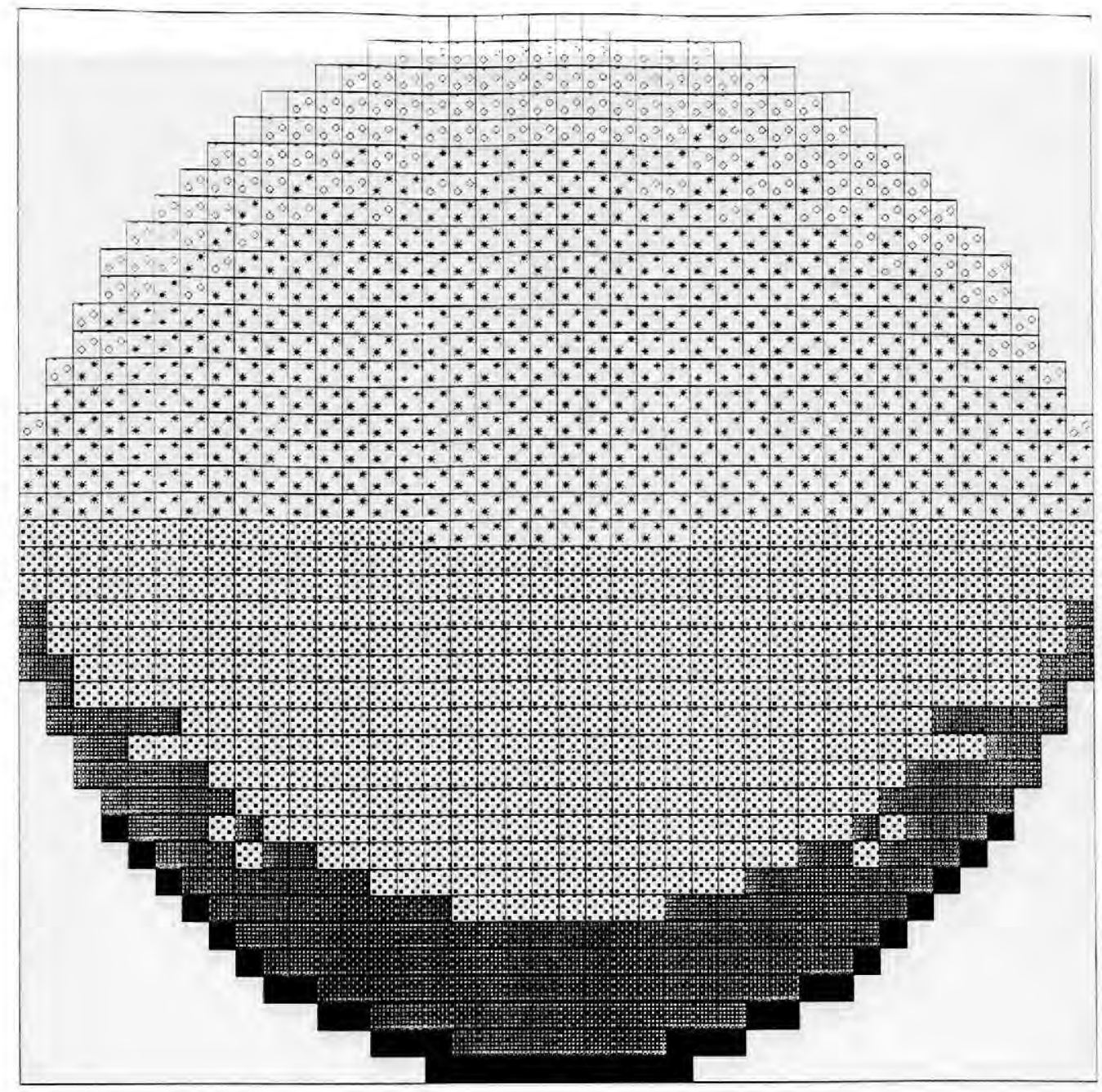

Fig. 13.19. Distribution of seepage rates ( $\mathrm{cm} /$ day) over the lake bed for a shallow flow-through lake with asymmetric (steep side facing upgradient) lake bed slope at $R=100$. The regional gradient of groundwater flow is from the bottom to the top of the figure.

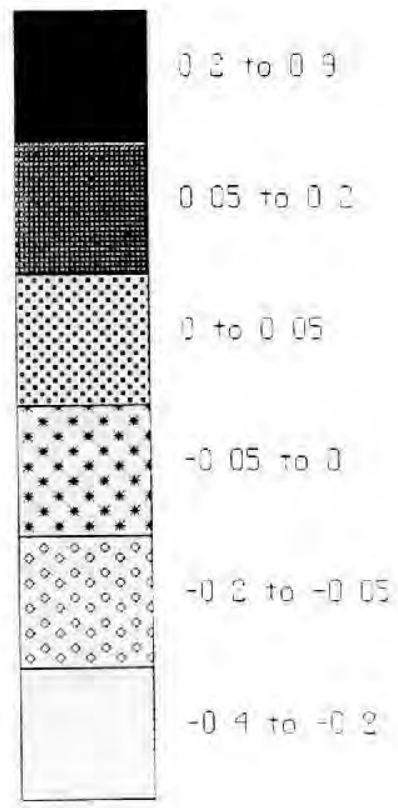




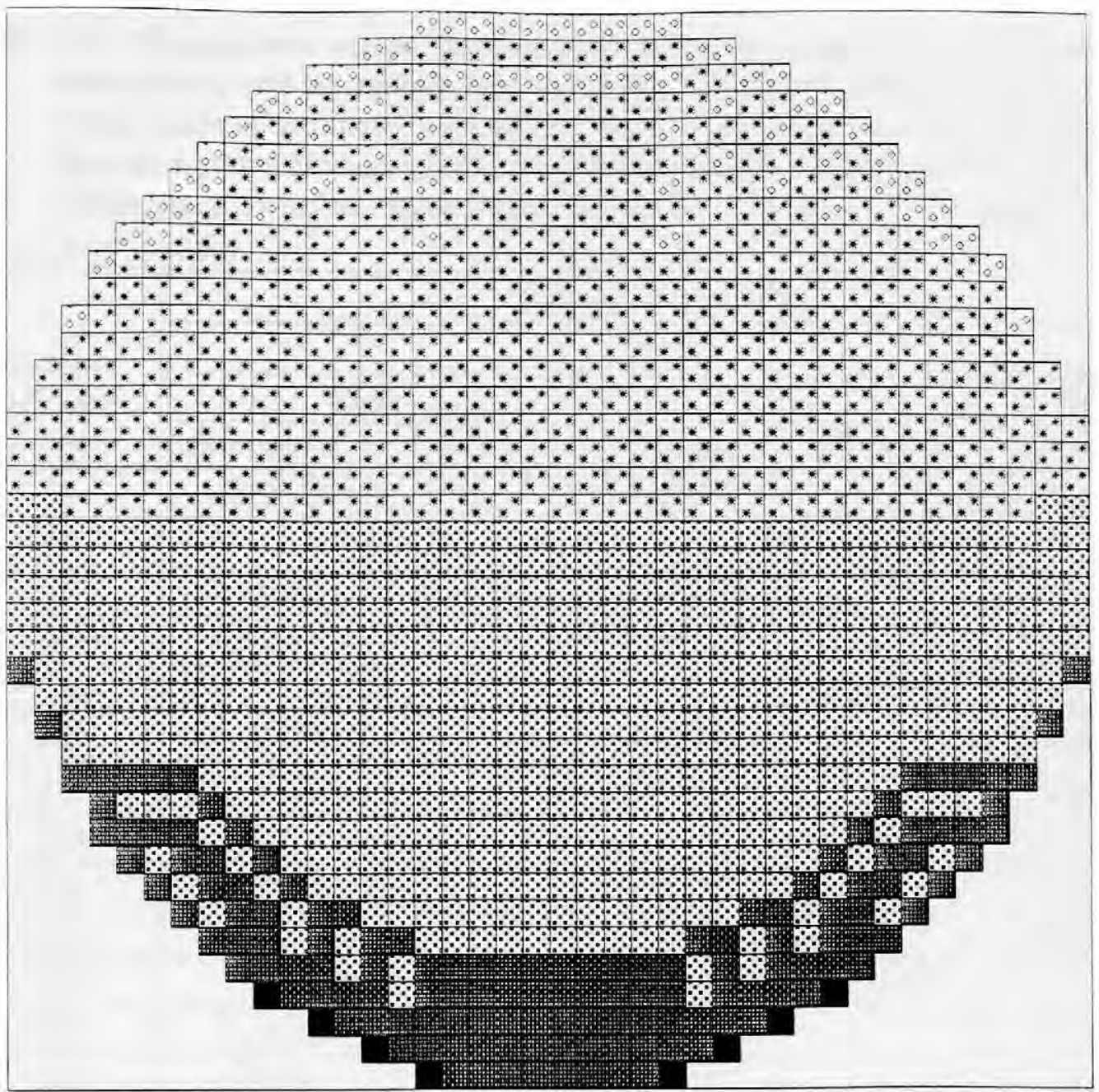

Fig. 13,20. Distribution of seepage rates ( $\mathrm{cm} /$ day) over the lake bed for a shallow flow-through lake with asymmetric (steep side facing upgradient) lake bed slope at $\mathrm{R}=1000$. The regional gradient of groundwater flow is from the bottom to the top of the figure.

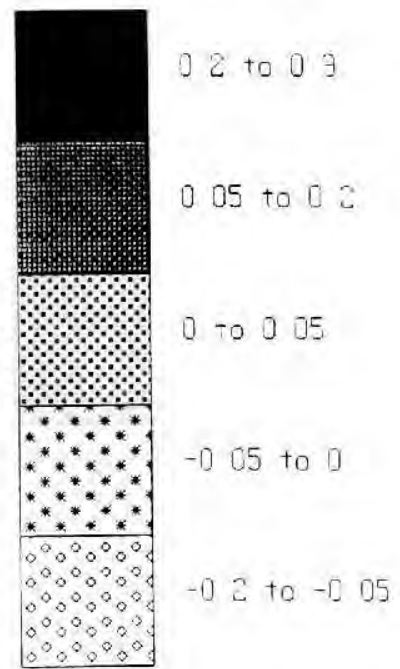


Table 13.2. Seepage rate versus distance offshore for the simulations of shallow flowthrough lake with asymmetric lake bed slope. The three different orientations of the mirror plane of symmetry with respect to the regional gradient are steep side of the lake facing downgradient (SDG), steep side of the lake facing upgradient (SUG), and mirror plane normal to regional gradient $(\mathrm{NRG}) .{ }^{*}$ denotes where seepage rates are $<10^{-7} \mathrm{~cm} /$ day.

\begin{tabular}{|c|c|c|c|c|c|}
\hline \multirow{4}{*}{$\begin{array}{c}\text { Distance } \\
\text { offshore } \\
(\mathrm{m})\end{array}$} & \multicolumn{5}{|c|}{ Seepage rate $(\mathrm{cm} /$ day $)$} \\
\hline & \multicolumn{5}{|c|}{$\mathrm{R}=1$} \\
\hline & \multicolumn{2}{|c|}{$\mathrm{SDG}$} & \multicolumn{2}{|c|}{ SUG } & \multirow{2}{*}{$\begin{array}{c}\text { NRG } \\
\text { raw output }\end{array}$} \\
\hline & raw output & average & raw output & average & \\
\hline 25 & -0.59240 & & -0.66997 & & -0.66366 \\
\hline 50 & & & & -0.39457 & \\
\hline 75 & -0.10967 & & -0.11917 & & -0.11881 \\
\hline 125 & -0.02387 & & -0.02700 & & -0.02568 \\
\hline 150 & & & & -0.01648 & \\
\hline 175 & -0.00499 & & -0.00596 & & -0.00537 \\
\hline 225 & -0.00098 & & -0.00132 & & -0.00106 \\
\hline 250 & & & & -0.00080 & \\
\hline 275 & -0.00018 & & -0.00028 & & -0.00020 \\
\hline 325 & $-3.30 e-05$ & & $-5.8 \mathrm{e}-05$ & & $-3.60 e-05$ \\
\hline 350 & & & & -0.00003 & \\
\hline 375 & $-6.2 e-06$ & & $-1.2 \mathrm{e}-05$ & & $-6.69 e-06$ \\
\hline 425 & $-1.2 \mathrm{e}-06$ & & $-2.3 e-06$ & & $-1.25 \mathrm{e}-06$ \\
\hline 475 & $*$ & & $-6.0 \mathrm{e}-07$ & & $*$ \\
\hline 525 & $*$ & & $*$ & & $*$ \\
\hline 575 & $*$ & & $*$ & & $*$ \\
\hline 625 & $*$ & & $*$ & & $*$ \\
\hline 675 & $*$ & & $*$ & & $*$ \\
\hline 725 & $*$ & & $*$ & & $*$ \\
\hline 775 & $*$ & & $*$ & & $*$ \\
\hline 825 & * & & $*$ & & $*$ \\
\hline 875 & $*$ & & $*$ & & $*$ \\
\hline 925 & $*$ & & $*$ & & $*$ \\
\hline 975 & * & & * & & ${ }^{*}$ \\
\hline 1025 & $*$ & & * & & $*$ \\
\hline 1075 & $*$ & & $*$ & & $*$ \\
\hline 1125 & $*$ & & $*$ & & $*$ \\
\hline
\end{tabular}


Table 13.2 (Contd.)

\begin{tabular}{|c|c|c|c|c|c|}
\hline \multirow{4}{*}{$\begin{array}{c}\text { Distance } \\
\text { offshore } \\
(\mathrm{m})\end{array}$} & \multicolumn{5}{|c|}{ Seepage rate $(\mathrm{cm} /$ day $)$} \\
\hline & \multicolumn{5}{|c|}{$\mathrm{R}=1$} \\
\hline & \multicolumn{2}{|c|}{ SDG } & \multicolumn{2}{|c|}{$\mathrm{SUG}$} & \multirow{2}{*}{$\frac{\mathrm{NRG}}{\text { raw output }}$} \\
\hline & raw output & average & raw output & average & \\
\hline 1175 & $*$ & & $*$ & & $*$ \\
\hline 1225 & $*$ & & $*$ & & $*$ \\
\hline 1275 & $*$ & & $*$ & & $*$ \\
\hline 1325 & * & & $*$ & & $*$ \\
\hline 1375 & $*$ & & $*$ & & $*$ \\
\hline 1425 & $*$ & & * & & $*$ \\
\hline 1475 & $*$ & & $*$ & & $*$ \\
\hline 1525 & $5.82 \mathrm{e}-07$ & & $*$ & & $*$ \\
\hline 1575 & $3.10 \mathrm{e}-06$ & & $1.67 \mathrm{e}-06$ & & $1.70 \mathrm{e}-06$ \\
\hline 1625 & $1.56 \mathrm{e}-05$ & & $8.97 \mathrm{e}-06$ & & $9.10 \mathrm{e}-06$ \\
\hline 1650 & & 0.00005 & & & \\
\hline 1675 & $7.85 e-05$ & & $4.84 \mathrm{e}-05$ & & $4.89 e-05$ \\
\hline 1725 & 0.00037 & & 0.00026 & & 0.00026 \\
\hline 1750 & & 0.00108 & & & \\
\hline 1775 & 0.00178 & & 0.00142 & & 0.00142 \\
\hline 1825 & 0.00803 & & 0.00719 & & 0.00720 \\
\hline 1850 & & 0.02221 & & & \\
\hline 1875 & 0.03639 & & 0.03448 & & 0.03452 \\
\hline 1925 & 0.16065 & & 0.16029 & & 0.16046 \\
\hline 1950 & & 0.54069 & & & \\
\hline 1975 & 0.92073 & & 0.91530 & & 0.91630 \\
\hline
\end{tabular}

Table 13.3. Seepage rate versus distance offshore for the simulations of shallow flowthrough lake with asymmetric lake bed slope. The three different orientations of the mirror plane of symmetry with respect to the regional gradient are steep side of the lake facing downgradient (SDG), steep side of the lake facing upgradient (SUG), and mirror plane normal to regional gradient (NRG).

\begin{tabular}{|c|c|c|c|c|c|}
\hline \multirow{4}{*}{$\begin{array}{c}\text { Distance } \\
\text { offshore } \\
\text { (m) }\end{array}$} & \multicolumn{5}{|c|}{ Seepage rate $(\mathrm{cm} /$ day $)$} \\
\hline & \multicolumn{5}{|c|}{$\mathrm{R}=10$} \\
\hline & \multicolumn{2}{|c|}{ SDG } & \multicolumn{2}{|c|}{ SUG } & NRG \\
\hline & raw output & average & raw output & average & raw output \\
\hline 25 & -0.36917 & & -0.44210 & & -0.38795 \\
\hline
\end{tabular}


Table 13.3 (Contd.)

\begin{tabular}{|c|c|c|c|c|c|}
\hline \multirow{4}{*}{$\begin{array}{l}\text { Distance } \\
\text { offshore } \\
(\mathrm{m})\end{array}$} & \multicolumn{5}{|c|}{ Seepage rate $(\mathrm{cm} /$ day $)$} \\
\hline & \multicolumn{5}{|c|}{$\mathrm{R}=10$} \\
\hline & \multicolumn{2}{|c|}{ SDG } & \multicolumn{2}{|c|}{ SUG } & \multirow{2}{*}{$\frac{\mathrm{NRG}}{\text { raw output }}$} \\
\hline & raw output & average & raw output & average & \\
\hline 50 & & & & -0.30389 & \\
\hline 75 & -0.16010 & & -0.16568 & & -0.16213 \\
\hline 125 & -0.09321 & & -0.10331 & & -0.09172 \\
\hline 150 & & & & -0.07988 & \\
\hline 175 & -0.05623 & & -0.05646 & & -0.05475 \\
\hline 225 & -0.03454 & & -0.03763 & & -0.03368 \\
\hline 250 & & & & -0.02924 & \\
\hline 275 & -0.01855 & & -0.02085 & & -0.01817 \\
\hline 325 & -0.01038 & & -0.01379 & & -0.01021 \\
\hline 350 & & & & -0.01066 & \\
\hline 375 & -0.00588 & & -0.00753 & & -0.00582 \\
\hline 425 & -0.00336 & & -0.00491 & & -0.00333 \\
\hline 475 & -0.00192 & & -0.00271 & & -0.00192 \\
\hline 525 & -0.00111 & & -0.00155 & & -0.00111 \\
\hline 575 & -0.00064 & & -0.00089 & & -0.00064 \\
\hline 625 & -0.00037 & & -0.00052 & & -0.00037 \\
\hline 675 & -0.00022 & & -0.00030 & & -0.00022 \\
\hline 725 & -0.00013 & & -0.00018 & & -0.00013 \\
\hline 775 & $-7.31 e-05$ & & -0.00010 & & $-7.54 \mathrm{e}-05$ \\
\hline 825 & $-4.17 e-05$ & & $-5.97 e-05$ & & $-4.36 \mathrm{e}-05$ \\
\hline 875 & $-2.22 e-05$ & & $-3.36 \mathrm{e}-05$ & & $-2.40 \mathrm{e}-05$ \\
\hline 925 & $-9.16 e-06$ & & $-1.69 \mathrm{e}-05$ & & $-1.10 \mathrm{e}-05$ \\
\hline 975 & $1.23 \mathrm{e}-06$ & & $-4.85 e-06$ & & $-9.67 e-07$ \\
\hline 1025 & $1.18 \mathrm{e}-05$ & & $5.73 e-06$ & & $8.67 \mathrm{e}-06$ \\
\hline 1075 & $2.53 \mathrm{e}-05$ & & $1.77 \mathrm{e}-05$ & & $2.05 e-05$ \\
\hline 1125 & $4.57 \mathrm{e}-05$ & & $3.45 e-05$ & & $3.76 \mathrm{e}-05$ \\
\hline 1175 & $7.87 e-05$ & & $6.06 \mathrm{e}-05$ & & $6.48 \mathrm{e}-05$ \\
\hline 1225 & 0.00013 & & 0.00010 & & 0.00011 \\
\hline 1275 & 0.00023 & & 0.00018 & & 0.00019 \\
\hline 1325 & 0.00039 & & 0.00030 & & 0.00032 \\
\hline 1375 & 0.00067 & & 0.00051 & & 0.00054 \\
\hline
\end{tabular}


Table 13.3 (Contd.)

\begin{tabular}{|c|c|c|c|c|c|}
\hline \multirow{2}{*}{$\begin{array}{c}\text { Distance } \\
\text { offshore } \\
(\mathrm{m})\end{array}$} & \multicolumn{5}{|c|}{ Seepage rate (cm/day) } \\
\cline { 2 - 6 } & \multicolumn{4}{|c|}{ SDG } & \multicolumn{4}{c|}{$\mathrm{R}=10$} & SUG \\
\hline & raw output & average & raw output & average & raw output \\
\hline 1425 & 0.00115 & & 0.00089 & & 0.00092 \\
\hline 1475 & 0.00200 & & 0.00153 & & 0.00159 \\
\hline 1525 & 0.00351 & & 0.00265 & & 0.00274 \\
\hline 1575 & 0.00635 & & 0.00461 & & 0.00475 \\
\hline 1625 & 0.00974 & & 0.00806 & & 0.00828 \\
\hline 1650 & & 0.01379 & & & \\
\hline 1675 & 0.01783 & & 0.01419 & & 0.01452 \\
\hline 1725 & 0.02697 & & 0.02532 & & 0.02582 \\
\hline 1750 & & 0.03784 & & & \\
\hline 1775 & 0.04870 & & 0.04714 & & 0.04789 \\
\hline 1825 & 0.07308 & & 0.07714 & & 0.07789 \\
\hline 1850 & & 0.10348 & & & \\
\hline 1875 & 0.13387 & & 0.12991 & & 0.13071 \\
\hline 1925 & 0.21524 & & 0.23111 & & 0.23208 \\
\hline 1950 & & 0.41553 & & & \\
\hline 1975 & 0.61582 & & 0.59552 & & 0.59744 \\
\hline & & & & & \\
\hline
\end{tabular}

Table 13.4. Seepage rate versus distance offshore for the simulations of shallow flowthrough lake with asymmetric lake bed slope. The three different orientations of the mirror plane of symmetry with respect to the regional gradient are steep side of the lake facing downgradient (SDG), steep side of the lake facing upgradient (SUG), and mirror plane normal to regional gradient (NRG).

\begin{tabular}{|c|c|c|c|c|c|}
\hline \multirow{2}{*}{$\begin{array}{c}\text { Distance } \\
\text { offshore }(\mathrm{m})\end{array}$} & \multicolumn{5}{|c|}{ Seepage rate (cm/day) } \\
\cline { 2 - 6 } & \multicolumn{4}{|c|}{ SDG } & \multicolumn{3}{c|}{$\mathrm{R}=100$} \\
\cline { 2 - 6 } & raw output & average & raw output & average & raw output \\
\hline 25 & -0.17269 & -0.17269 & -0.22290 & & -0.19534 \\
\hline 50 & & & & -0.15651 & \\
\hline 75 & -0.10350 & -0.10350 & -0.09012 & & -0.11943 \\
\hline 125 & -0.07963 & -0.07963 & -0.09823 & & -0.09128 \\
\hline 150 & & & & -0.07623 & \\
\hline 175 & -0.06777 & -0.06777 & -0.05422 & & -0.07693 \\
\hline 225 & -0.06530 & -0.06530 & -0.06489 & & -0.07327 \\
\hline
\end{tabular}


Table 13.4 (contd.)

\begin{tabular}{|c|c|c|c|c|c|}
\hline \multirow{4}{*}{$\begin{array}{c}\text { Distance } \\
\text { offshore } \\
(\mathrm{m})\end{array}$} & \multicolumn{5}{|c|}{ Seepage rate $(\mathrm{cm} /$ day $)$} \\
\hline & \multicolumn{5}{|c|}{$\mathrm{R}=100$} \\
\hline & \multicolumn{2}{|c|}{$\mathrm{SDG}$} & \multicolumn{2}{|c|}{ SUG } & \multirow{2}{*}{$\frac{\mathrm{NRG}}{\text { raw output }}$} \\
\hline & raw output & average & raw output & average & \\
\hline 250 & & & & -0.05144 & \\
\hline 275 & -0.04247 & -0.04247 & -0.03798 & & -0.04699 \\
\hline 325 & -0.03327 & -0.03327 & -0.04652 & & -0.03645 \\
\hline 350 & & & & -0.03726 & \\
\hline 375 & -0.02687 & & -0.02800 & & -0.02925 \\
\hline 425 & -0.02197 & & -0.03479 & & -0.02384 \\
\hline 475 & -0.01804 & & -0.02385 & & -0.01956 \\
\hline 525 & -0.01480 & & -0.01891 & & -0.01607 \\
\hline 575 & -0.01208 & & -0.01524 & & -0.01316 \\
\hline 625 & -0.00976 & & -0.01231 & & -0.01069 \\
\hline 675 & -0.00775 & & -0.00987 & & -0.00857 \\
\hline 725 & -0.00598 & & -0.00778 & & -0.00671 \\
\hline 775 & -0.00439 & & -0.00595 & & -0.00506 \\
\hline 825 & -0.00294 & & -0.00432 & & -0.00355 \\
\hline 875 & -0.00158 & & -0.00283 & & -0.00216 \\
\hline 925 & -0.00027 & & -0.00142 & & -0.00083 \\
\hline 975 & 0.00103 & & -0.00007 & & 0.00047 \\
\hline 1025 & 0.00234 & & 0.00127 & & 0.00177 \\
\hline 1075 & 0.00372 & & 0.00265 & & 0.00312 \\
\hline 1125 & 0.00520 & & 0.00408 & & 0.00455 \\
\hline 1175 & 0.00683 & & 0.00563 & & 0.00609 \\
\hline 1225 & 0.00865 & & 0.00733 & & 0.00781 \\
\hline 1275 & 0.01073 & & 0.00924 & & 0.00973 \\
\hline 1325 & 0.01316 & & 0.01141 & & 0.01194 \\
\hline 1375 & 0.01603 & & 0.01392 & & 0.01450 \\
\hline 1425 & 0.01952 & & 0.01685 & & 0.01750 \\
\hline 1475 & 0.02393 & & 0.02034 & & 0.02107 \\
\hline 1525 & 0.02993 & & 0.02455 & & 0.02538 \\
\hline 1575 & 0.04334 & & 0.02972 & & 0.03070 \\
\hline 1625 & 0.03474 & & 0.03628 & & 0.03747 \\
\hline 1650 & & 0.04616 & & & \\
\hline
\end{tabular}


Table 13.4 (Contd.)

\begin{tabular}{|c|c|c|c|c|c|}
\hline \multirow{2}{*}{$\begin{array}{c}\text { Distance } \\
\text { offshore (m) }\end{array}$} & \multicolumn{5}{|c|}{ Seepage rate (cm/day) } \\
\cline { 2 - 6 } & \multicolumn{4}{|c|}{ SDG } & \multicolumn{4}{c|}{$\mathrm{R}=100$} \\
\hline & raw output & average & raw output & average & raw output \\
\hline 1675 & 0.05758 & & 0.04502 & & 0.04653 \\
\hline 1725 & 0.04697 & & 0.05785 & & 0.05985 \\
\hline 1750 & & 0.06364 & & & \\
\hline 1775 & 0.08032 & & 0.09035 & & 0.09330 \\
\hline 1825 & 0.06731 & & 0.09587 & & 0.09828 \\
\hline 1850 & & 0.09511 & & & \\
\hline 1875 & 0.12291 & & 0.11552 & & 0.11759 \\
\hline 1925 & 0.11424 & & 0.15485 & & 0.15683 \\
\hline 1950 & & 0.24018 & & & \\
\hline 1975 & 0.36611 & & 0.33048 & & 0.33373 \\
\hline
\end{tabular}

Table 13.5. Seepage rate versus distance offshore for the simulations of shallow flowthrough lake with asymmetric lake bed slope. The three different orientations of the mirror plane of symmetry with respect to the regional gradient are steep side of the lake facing downgradient (SDG), steep side of the lake facing upgradient (SUG), and mirror plane normal to regional gradient (NRG).

\begin{tabular}{|c|c|c|c|c|c|}
\hline \multirow{3}{*}{$\begin{array}{c}\text { Distance } \\
\text { offshore (m) }\end{array}$} & \multicolumn{5}{|c|}{ Seepage rate (cm/day) } \\
\cline { 2 - 6 } & \multicolumn{2}{|c|}{ SDG } & \multicolumn{4}{c|}{ SUG 1000} & NRG \\
\cline { 2 - 6 } & raw output & average & raw output & average & raw output \\
\hline 25 & -0.05670 & & -0.07672 & & -0.06118 \\
\hline 50 & & & & -0.04789 & \\
\hline 75 & -0.04980 & & -0.01906 & & -0.05588 \\
\hline 125 & -0.04545 & & -0.05517 & & -0.05202 \\
\hline 150 & & & & -0.03508 & \\
\hline 175 & -0.04434 & & -0.01499 & & -0.05184 \\
\hline 225 & -0.05150 & & -0.04465 & & -0.06099 \\
\hline 250 & & & & -0.02868 & \\
\hline 275 & -0.01997 & & -0.01270 & & -0.02378 \\
\hline 325 & -0.01646 & & -0.03848 & & -0.01966 \\
\hline 350 & & & & -0.02494 & \\
\hline 375 & -0.01376 & & -0.01140 & & -0.01649 \\
\hline
\end{tabular}


Table 13.5.(Contd.)

\begin{tabular}{|c|c|c|c|c|c|}
\hline \multirow{4}{*}{$\begin{array}{c}\text { Distance } \\
\text { offshore }(\mathrm{m})\end{array}$} & \multicolumn{5}{|c|}{ Seepage rate $(\mathrm{cm} /$ day $)$} \\
\hline & \multicolumn{5}{|c|}{$\mathrm{R}=1000$} \\
\hline & \multicolumn{2}{|c|}{ SDG } & \multicolumn{2}{|c|}{ SUG } & \multirow{2}{*}{$\frac{\mathrm{NRG}}{\text { raw output }}$} \\
\hline & raw output & average & raw output & average & \\
\hline 425 & -0.01160 & & -0.03565 & & -0.01396 \\
\hline 475 & -0.00980 & & -0.01527 & & -0.01186 \\
\hline 525 & -0.00823 & & -0.01254 & & -0.01006 \\
\hline 575 & -0.00684 & & -0.01036 & & -0.00848 \\
\hline 625 & -0.00557 & & -0.00854 & & -0.00705 \\
\hline 675 & -0.00439 & & -0.00695 & & -0.00574 \\
\hline 725 & -0.00328 & & -0.00553 & & -0.00452 \\
\hline 775 & -0.00220 & & -0.00423 & & -0.00336 \\
\hline 825 & -0.00116 & & -0.00302 & & -0.00224 \\
\hline 875 & -0.00013 & & -0.00186 & & -0.00116 \\
\hline 925 & 0.00090 & & -0.00075 & & -0.00010 \\
\hline 975 & 0.00194 & & 0.00035 & & 0.00096 \\
\hline 1025 & 0.00299 & & 0.00144 & & 0.00202 \\
\hline 1075 & 0.00408 & & 0.00252 & & 0.00309 \\
\hline 1125 & 0.00522 & & 0.00363 & & 0.00419 \\
\hline 1175 & 0.00642 & & 0.00476 & & 0.00532 \\
\hline 1225 & 0.00771 & & 0.00594 & & 0.00651 \\
\hline 1275 & 0.00912 & & 0.00718 & & 0.00777 \\
\hline 1325 & 0.01070 & & 0.00850 & & 0.00912 \\
\hline 1375 & 0.01250 & & 0.00993 & & 0.01059 \\
\hline 1425 & 0.01462 & & 0.01151 & & 0.01222 \\
\hline 1475 & 0.01721 & & 0.01328 & & 0.01406 \\
\hline 1525 & 0.02051 & & 0.01531 & & 0.01619 \\
\hline 1575 & 0.04686 & & 0.01771 & & 0.01872 \\
\hline 1625 & 0.01488 & & 0.02065 & & 0.02182 \\
\hline 1650 & & 0.03260 & & & \\
\hline 1675 & 0.05032 & & 0.02438 & & 0.02576 \\
\hline 1725 & 0.01667 & & 0.02933 & & 0.03098 \\
\hline 1750 & & 0.03823 & & & \\
\hline 1775 & 0.05978 & & 0.07555 & & 0.07990 \\
\hline 1825 & 0.02034 & & 0.06641 & & 0.06980 \\
\hline
\end{tabular}


Table 13.5 (Contd.)

\begin{tabular}{|c|c|c|c|c|c|}
\hline \multirow{4}{*}{$\begin{array}{c}\text { Distance } \\
\text { offshore (m) }\end{array}$} & \multicolumn{5}{|c|}{ Seepage rate (cm/day) } \\
\cline { 2 - 6 } & \multicolumn{4}{|c|}{ SDG } & \multicolumn{4}{c|}{ S $=1000$} \\
\hline & raw output & average & raw output & average & raw output \\
\hline 1850 & & 0.04987 & & & \\
\hline 1875 & 0.07939 & & 0.07115 & & 0.07371 \\
\hline 1925 & 0.02845 & & 0.08578 & & 0.08786 \\
\hline 1950 & & 0.12181 & & & \\
\hline 1975 & 0.21517 & & 0.18120 & & 0.18470 \\
\hline
\end{tabular}




\section{CHAPTER 14}

\section{Results : Heterogeneity of the Porous Medium}

In all the simulations discussed earlier, the porous medium was homogeneous. Introduction of heterogeneity could presumably influence the distribution of hydraulic heads in the porous medium and seepage through the lake bed. Winter (1976) dealt with the question of heterogeneity by introducing either a horizontally extensive "aquifer" (high permeability zone) occupying an entire layer in a model domain or a laterally restricted aquifer occupying part of a layer. He varied the position of aquifers in the vicinity of flow-through lakes, to demonstrate the effects on groundwater flow and exchange with the lakes. Heterogeneity in this present research has been dealt with in a somewhat similar manner by introducing high conductivity zones (aquifers) occupying either a full layer or part of a layer in the model domain. The present study, unlike Winter (1976), focuses on the seepage through lake beds in both inflow and flow-through lakes. The aquifer had a hydraulic conductivity two orders of magnitude higher than that of the porous medium (i.e., $100 \mathrm{~m} /$ day in the horizontal, $1 \mathrm{~m} /$ day in the vertical, in the aquifer). In all simulations the anisotropy ratio was 100 for the porous medium, including the 
aquifer. Recharge to the medium for inflow lake simulations was always 10 $\mathrm{cm} /$ year and boundary conditions of inflow and flow-through lakes were identical to the simulations described earlier.

\subsection{Horizontally extensive aquifer}

As mentioned earlier in this chapter, the horizontally extensive aquifer occupied an entire layer in the model domain, and it was allowed to move vertically from the bottom of the lake toward the base of the porous medium, to occupy different layers in different simulations. In shallow lakes, the aquifer occupied layer 6,11 , or 15 , and in deep lakes layer 11,13 , or 15 .

\subsubsection{Inflow lake}

The introduction of an aquifer in different inflow lake simulations decreased the hydraulic heads considerably compared to a simulation with homogenous porous medium (Figs. 6.4, 8.5, and 14.1 to 14.5 ). The head at the boundary of the model domain (along the usual vertical section) was 73.24 meters for the shallow lake with moderate slope when surrounded by a homogenous medium, and the head for the same cell for the same lake was 54.52 meters when the aquifer was just below the lake in layer 6 . Thus, the overall slope of the water table was lower when the aquifer was present. Compared to the deep lake simulation with no aquifer, the simulations with 
aquifers showed significantly higher head under most of the lake (Figs. 8.5, 14.1 to 14.3 ). As the aquifer was moved vertically downward toward the base of the porous medium, the heads started to increase in the porous medium, though not to the level of the simulations without aquifers (Table 14.1). Thus, the overall effect of the aquifer was to serve as a high permeability conduit that allowed the same amount of water to move through the system with lower head gradients. This was particularly the case when the top of the aquifer came in contact with the lake bottom (Fig. 14.1, and 14.4). In this case groundwater entering the aquifer could travel through it directly to the discharge surface (i.e., the lake bed), without re-entering the lower conductivity porous medium. In plotting seepage rates versus distance offshore (Figs. 14.6, and 14.7), the averaging method described in previous chapters was applied only for lakes with low slope (which had 3 cells per "step" on the sloping portion of the lake bed). The general trend of all these plots indicated an increase in nearshore seepage and decrease in offshore seepage as the aquifer moved downward, with the "limiting" seepage profile (that with highest nearshore and lowest offshore seepage) being the exponential profile associated with a homogenous medium (no aquifer). In effect, adding a horizontally extensive aquifer, and raising it closer to the lake bottom, resulted in the seepage plots rotating about 
Table 14.1. Summary of head and seepage rate results along the line of the vertical cross-section from the twenty simulations used to investigate the role of a horizontally extensive aquifer near an inflow lake. Each result box gives the head in meters (first line) and the seepage rate in $\mathrm{cm} / \mathrm{day}$ (second line within parentheses) at the lake shore and at the center of the lake for one simulation.

\begin{tabular}{|c|c|c|c|c|}
\hline \multirow{2}{*}{ Type of lake } & \multicolumn{4}{|c|}{ Position of aquifer (model layer), shallow lake/deep lake } \\
\cline { 2 - 5 } & $(6 / 11)$ & $(11 / 13)$ & $(15 / 15)$ & no aquifer \\
\hline $\begin{array}{c}\text { shallow lake with steep } \\
\text { slope }\end{array}$ & $\begin{array}{c}50.53,55.30 \\
(0.3262,0.1604)\end{array}$ & $\begin{array}{c}50.51,57.77 \\
(0.6026,0.1904)\end{array}$ & $\begin{array}{c}50.48,60.40 \\
(0.6908,0.1656)\end{array}$ & $\begin{array}{c}50.09,72.03 \\
(0.0334,1.0926)\end{array}$ \\
\hline \multirow{2}{*}{$\begin{array}{c}\text { shallow lake with } \\
\text { moderate slope }\end{array}$} & $\begin{array}{c}50.18,54.52 \\
(0.2930,0.2425)\end{array}$ & $\begin{array}{c}50.65,58.77 \\
(0.4567,0.2128)\end{array}$ & $\begin{array}{c}50.55,60.91 \\
(0.5133,0.1825)\end{array}$ & $\begin{array}{c}50.11,73.24 \\
(0.0428,0.7387)\end{array}$ \\
\hline deep lake with & $52.87,56.56$ & $51.48,58.88$ & $51.21,60.57$ & $50.15,73.28$ \\
moderate slope & $(0.3559,0.7268)$ & $(0.4429,0.3796)$ & $(0.4915,0.3102)$ & $(0.0577,0.7414)$ \\
\hline $\begin{array}{c}\text { shallow lake with low } \\
\text { slope }\end{array}$ & $\begin{array}{c}51.00,55.14 \\
(0.2948,0.3363)\end{array}$ & $\begin{array}{c}50.69,58.54 \\
(0.4168,0.2295)\end{array}$ & $\begin{array}{c}50.56,61.28 \\
(0.4727,0.1873)\end{array}$ & $\begin{array}{c}50.11,75.34 \\
(0.0383,0.7033)\end{array}$ \\
\hline
\end{tabular}


a point roughly 200 meters offshore, on the sloping portion of the lake bed.

Superimposed on this general rotation was the phenomenon (discussed in previous chapters) of local seepage rate maxima at breaks in lake bed slope (between the sloping and flat portions of the lake beds) and at the bottom tip of the deep lakes with moderate slope (Chapter 11). For example, for a shallow lake with moderate bed slope, adding an aquifer and raising it up closer to the lake bottom resulted in a counter-clockwise rotation of the seepage plots about a point approximately 210 meters offshore (Fig. 14.6). In addition, a local maximum in seepage rate occurred at the break in the lake bed slope, especially when the aquifer was in contact with the lake bottom (layer 6). For this simulation, the cell at the break in lake bed slope represented the first point of direct contact between the lake bottom and aquifer ("first" in the sense that it was the first such point to be encountered along a groundwater flowpath from the water table to the lake via the aquifer). Having direct contact between the aquifer and lake bottom thus accentuated the local seepage maximum at the slope break. Other seepage plots (Figs. 14.6 and 14.7) can be thought of similarly, in terms of clockwise rotation with the appearance and upward movement of the aquifer. This indicates clearly that an aquifer is effective in displacing lake bed seepage further offshore, and is more effective 
when it is closer to the lake bottom.

In the case of the shallow lake with steep bed slope, the low seepage zone defined by a seepage of $0.2 \mathrm{~cm} /$ day or lower increased in aerial extent as the aquifer moved deeper into the medium (Figs. 14.8 to 14.13), and offshore seepage was dominated by a zone of seepage rates $0.1 \mathrm{~cm} /$ day or lower when the aquifer was absent (Fig.10.8). This indicates a gradual decrease in offshore seepage with the downward movement of the aquifer. As mentioned above, seepage increased significantly at the break in the lake bed slope when the aquifer was right at the bottom of the lake. This is evident in Fig. 14.9 as a ring of high seepage cells around the flat central portion of the lake bed. With the movement of the aquifer downward, the seepage rate near the shore increased and attained its maximum value in the simulation without an aquifer. The map for this simulation (Fig. 10.8) showed a seepage zone of $1.6 \mathrm{~cm} /$ day or higher at the shore line.

\subsubsection{Flow-through lake}

Figs. 14.14 to 14.18 show the distribution of hydraulic heads in the porous medium for differential vertical positions of the horizontally extensive aquifer below the lake. Equipotential lines close to the lake bent sharply toward the lake, and those close to the domain boundary bent away from the 
lake as they cut across the aquifer (Fig. 14.14). The shallow and the deep lakes showed more or less the same trend. The sharp bending of the equipotential lines compared to the simulation without any heterogeneity of the medium for shallow flow-through lakes with moderate bed slope (Fig. 7.17) indicated that the heads close to the upgradient side of the lake increased while head at the downgradient side of the lake decreased. The higher head in the upgradient side seemed to force more groundwater into the lake, and conversely the downgradient side of the lake started losing more water to outseepage, as discussed below. However, there was no change in the position of the seepage boundary separating inseepage and outseepage portions of the lake bed (Table 14.2).

In all cases, adding an aquifer to the simulation (even at the bottom of the model domain) and bringing the aquifer upward, closer to the lake, increased the amount of water exchanged across the lake bed (both into and out of the lake). The effect was particularly large when the aquifer was just below the lake. Seepage rates decreased in both upgradient and downgradient sides of the lake as the aquifer was moved downward in the porous medium. When the aquifer was just below the shallow lake (in layer 6) there was a local maximum in both inseepage and outseepage at the break in lake bed slope (as 
Table 14.2. Summary of the position of the seepage boundary and seepage rates along the line of the vertical cross-section from the twenty simulations compared in the flow-through lake section of this chapter. Each result box gives location of the seepage boundary in meters* (first line) and the nearshore and offshore seepage rates in $\mathrm{cm} /$ day (second line within parentheses) for one simulation.

\begin{tabular}{|c|c|c|c|c|}
\hline \multirow{2}{*}{ Type of lake } & \multicolumn{4}{|c|}{ Position of aquifer (model layer), shallow lake/deep lake } \\
\hline & $(6 / 11)$ & $(11 / 13)$ & $(15 / 15)$ & no aquifer \\
\hline $\begin{array}{c}\text { shallow lake with steep } \\
\text { slope }\end{array}$ & $\begin{array}{c}973 \\
(-0.3105,0.4882)\end{array}$ & $\begin{array}{c}973 \\
(-0.2649,0.4010)\end{array}$ & $\begin{array}{c}964 \\
(-0.2315,0.3472)\end{array}$ & $\begin{array}{c}961 \\
(-0.1961,0.3300)\end{array}$ \\
\hline $\begin{array}{l}\text { shallow lake with } \\
\text { moderate slope }\end{array}$ & $\begin{array}{c}967 \\
(-0.2536,0.3590)\end{array}$ & $\begin{array}{c}972 \\
(-0.1888,0.2663)\end{array}$ & $\begin{array}{c}956 \\
(-0.1593,0.2256)\end{array}$ & $\begin{array}{c}962 \\
(-0.1454,0.2299)\end{array}$ \\
\hline $\begin{array}{l}\text { deep lake with } \\
\text { moderate slope }\end{array}$ & $\begin{array}{c}.055 \\
(-0.1863,0.2684)\end{array}$ & $\begin{array}{c}957 \\
(-0.1624,0.2277)\end{array}$ & $\begin{array}{c}942 \\
(-0.1382,0.1939)\end{array}$ & $\begin{array}{c}970 \\
(-0.1446,0.2293)\end{array}$ \\
\hline $\begin{array}{c}\text { shallow lake with low } \\
\text { slope }\end{array}$ & $\begin{array}{c}970 \\
(-0.2721,0.3712)\end{array}$ & $\begin{array}{c}974 \\
(-0.1954,0.2543)\end{array}$ & $\begin{array}{c}965 \\
(-0.1659,0.2180)\end{array}$ & $\begin{array}{c}960 \\
(-0.1373,0.2050)\end{array}$ \\
\hline
\end{tabular}

*the distance was measured from the downgradient shore of the lake. 
for the inflow lakes); the maxima were observed in the fifth cell from the downgradient and upgradient shorelines. As with the deep inflow lakes, there were no local maxima in seepage for the deep flow-through lakes, since there was no break in bed slope for the deep lakes. The seepage boundary was always very close to halfway through the lake in all simulations. The aerial extent of high inseepage and outseepage zones was reduced substantially as the aquifer was moved downward in the model domain (Figs. 14.21 to 14.26). Consequently, the central low seepage zone defined by a seepage of \pm 0.5 $\mathrm{cm} /$ day became larger in aerial extent as the aquifer was moved downward, and attained maximum size when the aquifer was absent (Fig. 10.17).

Amounts of annual groundwater inseepage and lake water outseepage was calculated for shallow flow-through lake with moderate slope for different vertical positions of the horizontally extensive aquifer. When the aquifer was in contact with the lake bottom (i.e., aquifer in layer 6), annual groundwater inseepage to the lake was at its maximum ( $5.3 \%$ of the lake volume). As the aquifer was moved downward, the amount of groundwater inseepage decreased (Table 14.3). Similarly, the lake water outseepage decreased as the aquifer moved downward. The high permeability of the aquifer, forced water to move through the layer containing the aquifer and the lake lost and gained more 
water. As the aquifer moved downward, the effect of the aquifer on the lake gradually diminished and total inseepage and outseepage decreased.

\begin{tabular}{|c|c|c|c|c|}
\hline $\begin{array}{c}\text { Position of the } \\
\text { aquifer (layer) }\end{array}$ & $\begin{array}{c}\text { Total } \\
\text { volumetric } \\
\text { groundwater } \\
\text { inseepage } \\
\left(\mathrm{m}^{3} / \text { year }\right)\end{array}$ & $\begin{array}{c}\text { Total } \\
\text { volumetric } \\
\text { lake water } \\
\text { outseepage } \\
\left(\mathrm{m}^{3} / \text { year }\right)\end{array}$ & $\begin{array}{c}\text { Groundwater } \\
\text { inseepage per } \\
\text { year as a } \\
\text { percentage of } \\
\text { lake volume }\end{array}$ & $\begin{array}{c}\text { Lake water } \\
\text { outseepage per } \\
\text { year as a } \\
\text { percentage of } \\
\text { lake volume }\end{array}$ \\
\hline 6 & $1.09 \times 10^{6}$ & $8.35 \times 10^{5}$ & 5.28 & 4.04 \\
\hline 11 & $4.96 \times 10^{5}$ & $3.99 \times 10^{5}$ & 2.40 & 1.93 \\
\hline 15 & $3.90 \times 10^{5}$ & $2.96 \times 10^{5}$ & 1.89 & 1.43 \\
\hline absent & $3.34 \times 10^{5}$ & $2.26 \times 10^{5}$ & 1.62 & 1.09 \\
\hline
\end{tabular}

Table 14.3. Groundwater inseepage and lake water outseepage per year as a percentage of lake volume in coarse grid shallow flow-through lake with moderate slope with different vertical positions of a horizontally extensive aquifer. Lake volume was $2.064 \times 10^{7} \mathrm{~m}^{3}$.

\subsection{Position of a laterally restricted aquifer}

The spatial position of a laterally restricted aquifer below the lake was varied to evaluate the effect on the distribution of head in the porous medium and seepage through the lake bed. The aquifer occupied one-third of a layer in the model domain (layer 11 for shallow lakes and layer 13 for deep lakes). The aquifer occupied three different positions for the inflow lake simulations: at the side of the model domain (three sides of the aquifer on the domain boundary), partially under the lake (the center of the aquifer under the lake shore), and directly under the lake (the center of the aquifer under the center 
of the lake). For flow-through lakes, the three aquifer positions were at the downgradient side of the model domain, directly under the lake, and at the upgradient side of the model domain.

\subsubsection{Inflow lake}

As with a horizontally extensive aquifer, the presence of a laterally restricted aquifer (LRA) led to a lower water table in the model domain (Figs. $10.2,14.1$, and 14.27). The asymmetry introduced into the model domain by the laterally restricted aquifer was reflected in the head and seepage distributions. When the LRA shared a side with the model domain, the LRA was effective in draining that side of the model domain, leading to a steep nearshore gradient on the side of the lake closest to the LRA (Fig. 14.27). While the water table was higher on the side of the model domain without the LRA, it was still lower than it was in the absence of the LRA. The distribution of seepage with distance offshore was similar to the simulation with no aquifer, but with a much higher near-shore seepage rate at the side of the lake closest to the LRA (Figs. 14.29 and 14.30).

When the LRA was partially under the lake, the water table was even lower (over the entire model domain), though head was higher in the small area directly between the LRA and the lake bed (Fig. 14.27). This led to a highly 
Table 14.4. Summary of head and seepage rate results along the line of the vertical cross-section from the twenty simulations used to investigate the role of a laterally restricted aquifer near an inflow lake. Each result box gives the head in meters (first line) and the seepage rate in $\mathrm{cm} /$ day (second line within parentheses) at the opposing ends of the lake shore for one simulation.

\begin{tabular}{|c|c|c|c|c|}
\hline \multirow{2}{*}{ Type of lake } & \multicolumn{4}{|c|}{ Position of aquifer in model layer } \\
\cline { 2 - 5 } & near domain boundary & partially under the lake & $\begin{array}{c}\text { directly below below } \\
\text { the lake }\end{array}$ & no aquifer \\
\hline $\begin{array}{c}\text { shallow lake with steep } \\
\text { slope }\end{array}$ & $\begin{array}{c}66.24,71.78 \\
(1.3118,1.0151)\end{array}$ & $\begin{array}{c}61.72,69.71 \\
(0.6712,0.8859)\end{array}$ & $\begin{array}{c}66.53,66.53 \\
(0.7294,0.7331)\end{array}$ & $\begin{array}{c}50.09,72.03 \\
(0.0334,1.0926)\end{array}$ \\
\hline \multirow{2}{*}{$\begin{array}{c}\text { shallow lake with } \\
\text { moderate slope }\end{array}$} & $\begin{array}{c}67.64,72.78 \\
(0.9185,0.7030)\end{array}$ & $\begin{array}{c}62.51,70.54 \\
(0.5109,0.6159)\end{array}$ & $\begin{array}{c}67.25,67.25 \\
(0.5271,0.5272)\end{array}$ & $\begin{array}{c}50.11,73.24 \\
(0.0428,0.7387)\end{array}$ \\
\hline deep lake with & $\begin{array}{c}67.37,72.63 \\
\text { moderate slope }\end{array}$ & $\begin{array}{c}62.02,70.25 \\
(0.9950,0.6059)\end{array}$ & $\begin{array}{c}66.84,66.84 \\
(0.5200,0.5199)\end{array}$ & $\begin{array}{c}50.15,73.28 \\
(0.0577,0.7414)\end{array}$ \\
\hline $\begin{array}{c}\text { shallow lake with low } \\
\text { slope }\end{array}$ & $\begin{array}{c}67.07,72.57 \\
(0.8112,0.6227)\end{array}$ & $\begin{array}{c}62.32,70.37 \\
(0.4745,0.5478)\end{array}$ & $\begin{array}{c}67.15,67.15 \\
(0.4849,0.4848)\end{array}$ & $\begin{array}{c}50.11,75.34 \\
(0.0383,0.7033)\end{array}$ \\
\hline
\end{tabular}


asymmetric distribution of seepage, with higher seepage rates on that portion of the lake bed underlain by the LRA and lower seepage on the other side of the lake bed (Figs. 14.29, 14.30, and 14.32). Superimposed on this effect were some of the phenomena discussed earlier in this and other chapters, such as the increase in seepage with distance offshore for deep lakes with moderate bed slope (Fig. 14.29), and the local seepage maxima at breaks in lake bed slope (Fig. 14.30).

The head and seepage distributions were symmetric in cross-section when the LRA was directly under the lake (Figs. 14.28 to 14.30), though there was still an asymmetry in map view (Fig. 14.33) because the LRA stretched the full way across the model domain in one direction but only one-third of the way across in the perpendicular direction. In this case, there were local seepage maxima at the lake center for the deep lake and at the breaks in lake bed slope for the shallow lakes (Figs. 14.29 and 14.30), as had been observed for the simulations with horizontally extensive aquifers.

\subsubsection{Flow-through lake}

The spatial position of the laterally restricted aquifer was also varied in flow-through lakes to investigate the movement of the inseepage-outseepage boundary and seepage through the lake beds. As with the inflow lakes, the 
aquifer in the downgradient side lowered the water table on that side of the model domain (Fig. 14.34). Unlike inflow lakes, the boundary heads were fixed in flow-through lakes and in order to maintain the overall gradient across the entire model domain, the nearshore gradient closest to the LRA became steep in flow-through lakes. The water table near the shore on the other side was relatively unaffected. The steep gradient on the downgradient side facilitated more loss of lake water and the inseepage-outseepage boundary moved much farther toward the upgradient side compared to a simulation without any aquifer (Table 14.5). Also, the movement of the seepage boundary was evident when the seepage rates were plotted along a section normal to the regional gradient (Figs. 14.36 to 14.39) and seepage maps (Figs. 14.40 to 14.42 ). The distribution of seepage over the lake bed was roughly similar to the simulation without any aquifer except with much higher seepage rate at the side closest to the LRA (i.e., more outseepage when the aquifer at the downgradient side and more inseepage when the aquifer at the upgradient side). Overall, changing the position of the LRA had a significant effect on the spatial patterns of lake bed seepage (Figs. 14.40 to 14.42).

When the LRA was directly under the lake, there was no effect on the overall water table gradient (Fig. 14.34). The reason is that the aquifer had 
Table 14.5. Summary of the position of the seepage boundary and seepage rates along the line of the vertical cross-section from the twenty simulations compared in the flow-through lake section of this chapter. Each result box gives location of seepage boundary in meters* (first line) and the nearshore (upgradient and downgradient) seepage rates in $\mathrm{cm} /$ day (second line within parentheses) for one simulation.

\begin{tabular}{|c|c|c|c|c|}
\hline \multirow{2}{*}{ Type of lake } & \multicolumn{4}{|c|}{ Position of aquifer in model layer } \\
\hline & downgradient & directly below the lake & upgradient & no aquifer \\
\hline $\begin{array}{l}\text { shallow lake with steep } \\
\text { slope }\end{array}$ & $\begin{array}{c}1155 \\
(-0.4119,0.3235)\end{array}$ & $\begin{array}{c}754 \\
(-0.1202,0.2115)\end{array}$ & $\begin{array}{c}805 \\
(-0.1920,0.8328)\end{array}$ & $\begin{array}{c}961 \\
(-0.1961,0.3300)\end{array}$ \\
\hline $\begin{array}{l}\text { shallow lake with } \\
\text { moderate slope }\end{array}$ & $\begin{array}{c}1148 \\
(-0.3384,0.2242)\end{array}$ & $\begin{array}{c}742 \\
(-0.0822,0.1416)\end{array}$ & $\begin{array}{c}810 \\
(-0.1414,0.5550)\end{array}$ & $\begin{array}{c}962 \\
(-0.1454,0.2299)\end{array}$ \\
\hline $\begin{array}{l}\text { deep lake with } \\
\text { moderate slope }\end{array}$ & $\begin{array}{c}1124 \\
(-0.3405,0.2233)\end{array}$ & $\begin{array}{c}621 \\
(-0.0757,0.1352)\end{array}$ & $\begin{array}{c}843 \\
(-0.1405,0.5610)\end{array}$ & $\begin{array}{c}970 \\
(-0.1446,0.2293)\end{array}$ \\
\hline $\begin{array}{c}\text { shallow lake with low } \\
\text { slope }\end{array}$ & $\begin{array}{c}1152 \\
(-0.3411,0.1999)\end{array}$ & $\begin{array}{c}735 \\
(-0.0710,0.1222)\end{array}$ & $\begin{array}{c}805 \\
(-0.1324,0.5141)\end{array}$ & $\begin{array}{c}960 \\
(-0.1373,0.2050)\end{array}$ \\
\hline
\end{tabular}

*the distance was measured from the downgradient shore of the lake. 
somewhat similar influence on both sides of the lake, though the inseepageoutseepage boundary moved toward the downgradient side leading to a smaller area of outseepage. A total movement of about 400 meters was noticed between the former simulation with the LRA at the downgradient side and this simulation (i.e., the LRA directly under the lake) in the shallow lake with steep lake bed slope (Table 14.5). Again, the movement was clearly observed from the plot of seepage rates across the regional gradient and seepage maps (Fig. 14.40 to 14.42 ). The distribution of seepage rates was similar to the simulation with no aquifer but with less seepage on both upgradient and downgradient sides of the lake bed (Figs. 14.36 to 14.39 , and 14.41). Local phenomena mentioned previously such as slightly elevated seepage near the slope break or general exponential decline of seepage rate on both upgradient and downgradient sides were observed.

The LRA at the upgradient side had relatively less influence on the seepage distribution or on the movement of the seepage boundary (Figs 14.35 to 14.39 ). The water table gradient near the upgradient shore was steeper, as it was near the downgradient shore when the LRA was at the downgradient side of the model domain. The downgradient side showed little or no effect of the aquifer. The seepage boundary moved a little toward the upgradient side, 
with a total movement of about 50 meters in the shallow lake with steep lake bed slope between the two positions of the LRA (directly under the lake and at the upgradient side). A major difference observed between the two seepage maps is that the area occupied by the low seepage zone, i.e., $\pm 0.05 \mathrm{~cm} /$ day was greatly reduced when the LRA was moved to the upgradient side from a position directly below the lake, especially the low inseepage zone (Figs 14.40 to 14.42$)$.

The annual groundwater seepage to and from the lake was calculated for the simulations of shallow flow-through lakes with moderate bed slope and the

\begin{tabular}{|c|c|c|c|c|}
\hline $\begin{array}{c}\text { Position of the } \\
\text { aquifer }\end{array}$ & $\begin{array}{c}\text { Total } \\
\text { volumetric } \\
\text { groundwater } \\
\text { inseepage } \\
\left(\mathrm{m}^{3} / \text { year }\right)\end{array}$ & $\begin{array}{c}\text { Total } \\
\text { volumetric } \\
\text { lake water } \\
\text { outseepage } \\
\left(\mathrm{m}^{3} / \text { year }\right)\end{array}$ & $\begin{array}{c}\text { Groundwater } \\
\text { inseepage per } \\
\text { year as a } \\
\text { percentage of } \\
\text { lake volume }\end{array}$ & $\begin{array}{c}\text { Lake water } \\
\text { outseepage per } \\
\text { year as a } \\
\text { percentage of } \\
\text { lake volume }\end{array}$ \\
\hline downgradient & $2.82 \times 10^{5}$ & $6.67 \times 10^{5}$ & 1.37 & 3.23 \\
\hline under the lake & $1.85 \times 10^{5}$ & $7.48 \times 10^{4}$ & 0.89 & 0.36 \\
\hline upgradient & $8.41 \times 10^{5}$ & $1.87 \times 10^{5}$ & 4.07 & 0.90 \\
\hline absent & $3.34 \times 10^{5}$ & $2.26 \times 10^{5}$ & 1.62 & 1.09 \\
\hline
\end{tabular}

Table 14.6. Groundwater inseepage and lake water outseepage per year as a percentage of lake volume in coarse grid shallow flow-through lake with moderate slope at different horizontal positions of a laterally restricted aquifer. Lake volume was $2.064 \times 10^{7} \mathrm{~m}^{3}$.

LRA (Table 14.6). Lake water outseepage was at its maximum when the aquifer was at the downgradient side of the lake. Groundwater inseepage was 
highest with the LRA at the upgradient side of the model domain.

It follows from the above discussions that heterogeneity has significant effects on the distribution of hydraulic head in the porous medium near lakes, and on the spatial distribution of lake bed seepage rates. Winter (1978) showed that a limited aquifer on the downgradient side some distance above the base of the system was efficient to drain water from the downgradient side of the lake, and in this present study it was found that the area of outseepage increases and flow-through lakes lose water when the aquifer is on the downgradient side. 


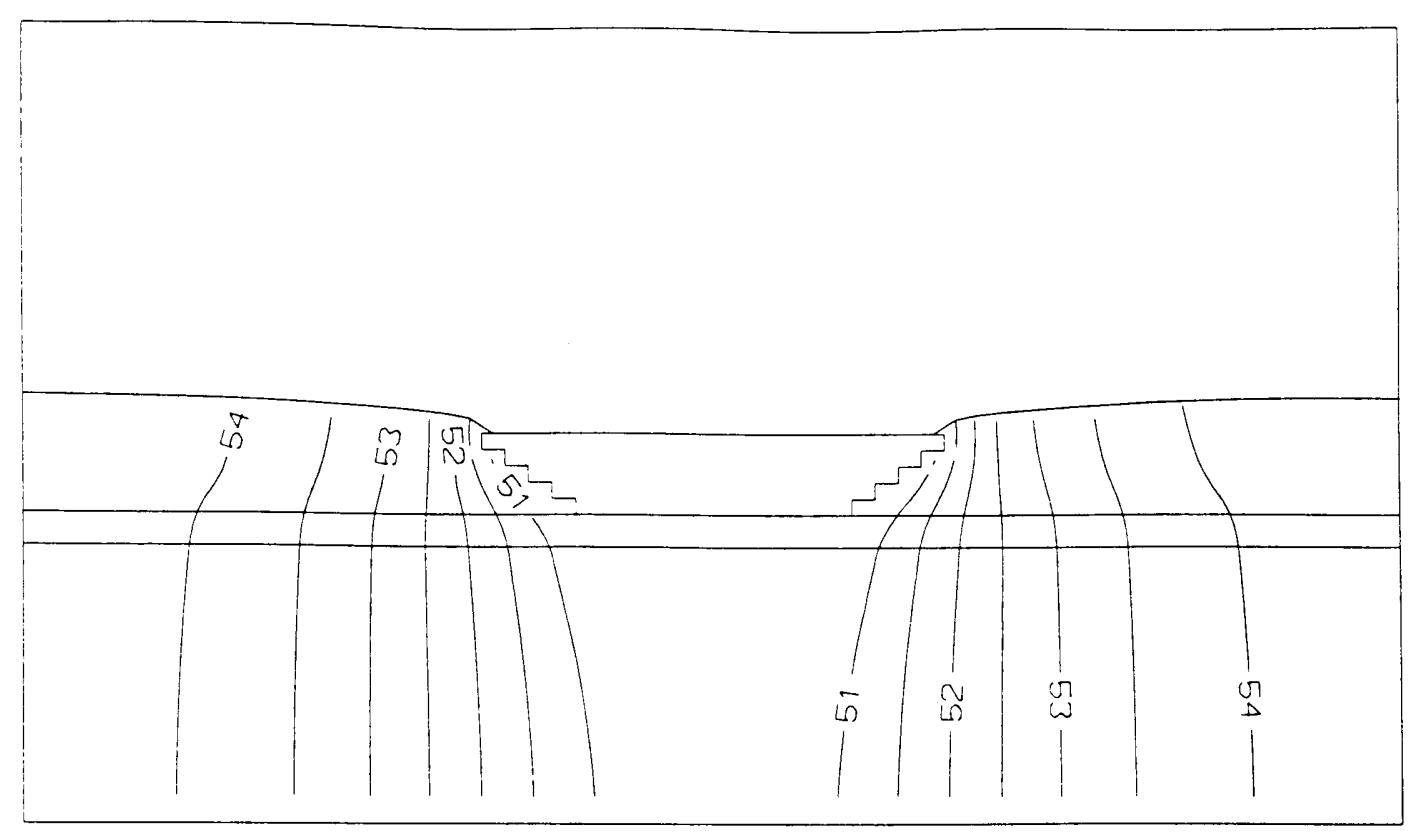

Shallow lake

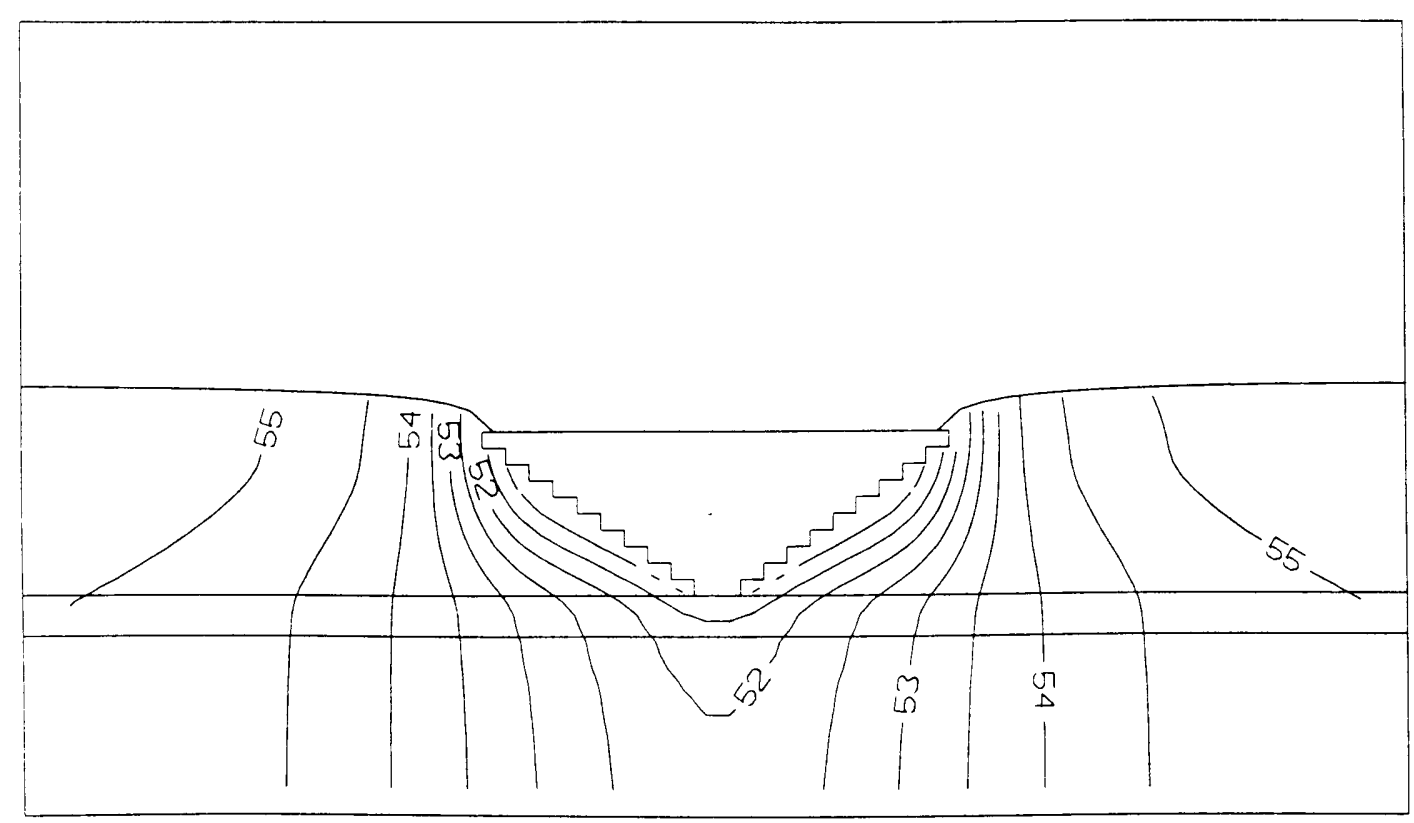

Deep lake

Fig. 14.1. Distribution of hydraulic heads in the porous medium surrounding shallow and deep inflow lakes with moderate lake bed slope and a horizontally extensive aquifer just under the lakes (layer 6 for the shallow lake, layer 11 for the deep lake). 


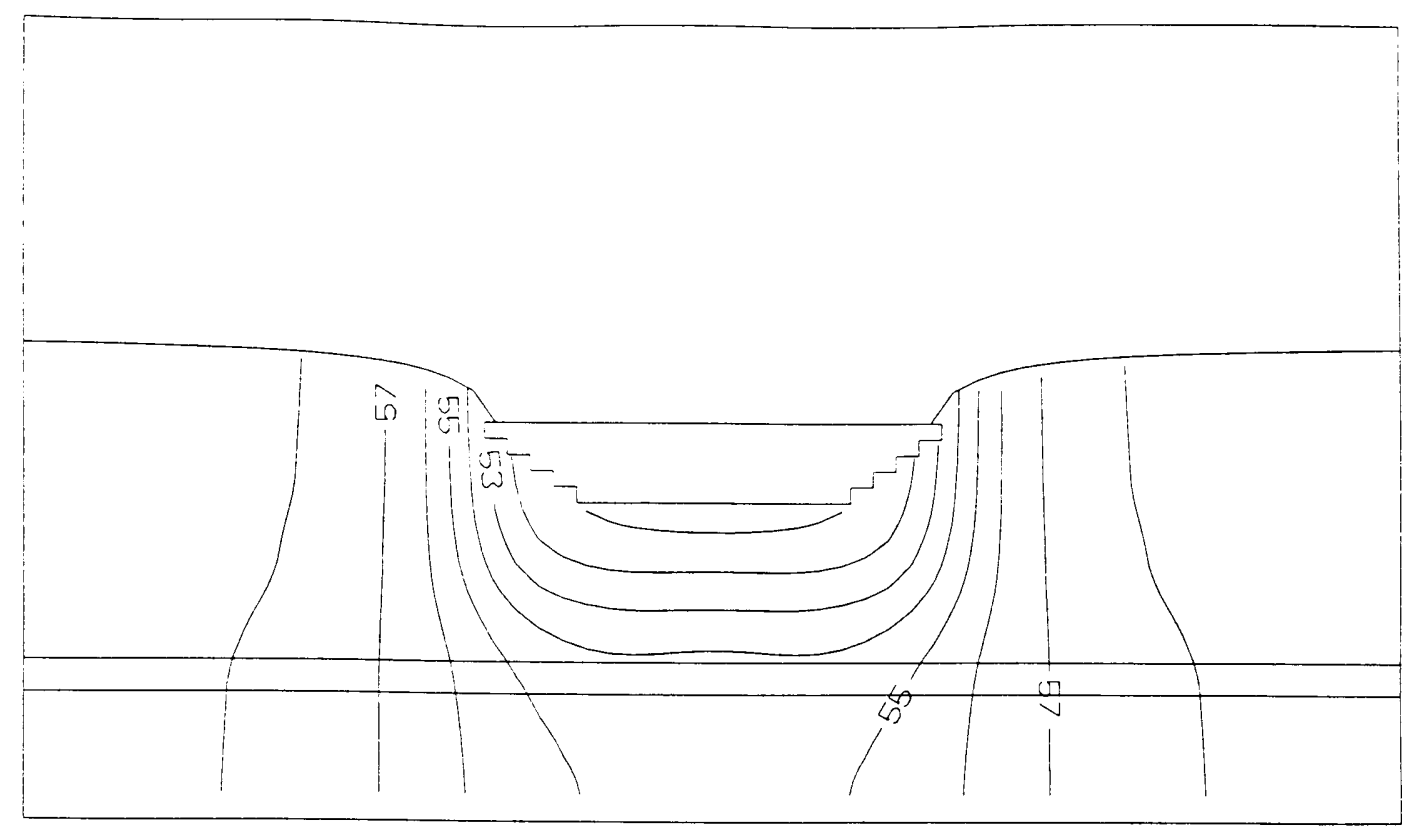

Shallow lake

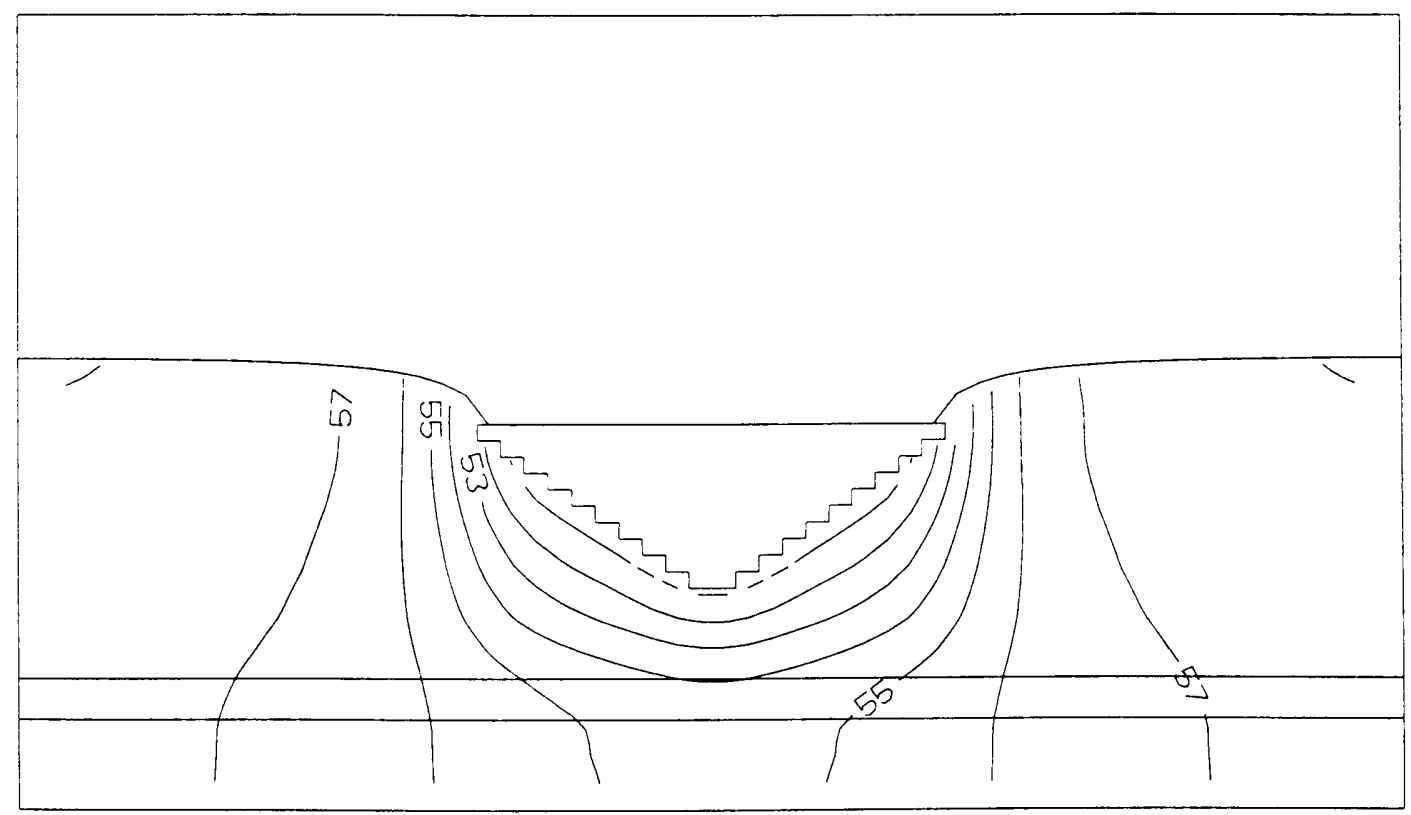

Deep lake

Fig. 14.2. Distribution of hydraulic heads in the porous medium surrounding shallow and deep inflow lakes with moderate lake bed slope and a horizontally extensive aquifer in layer 11 (shallow lake) or layer 13 (deep lake). 


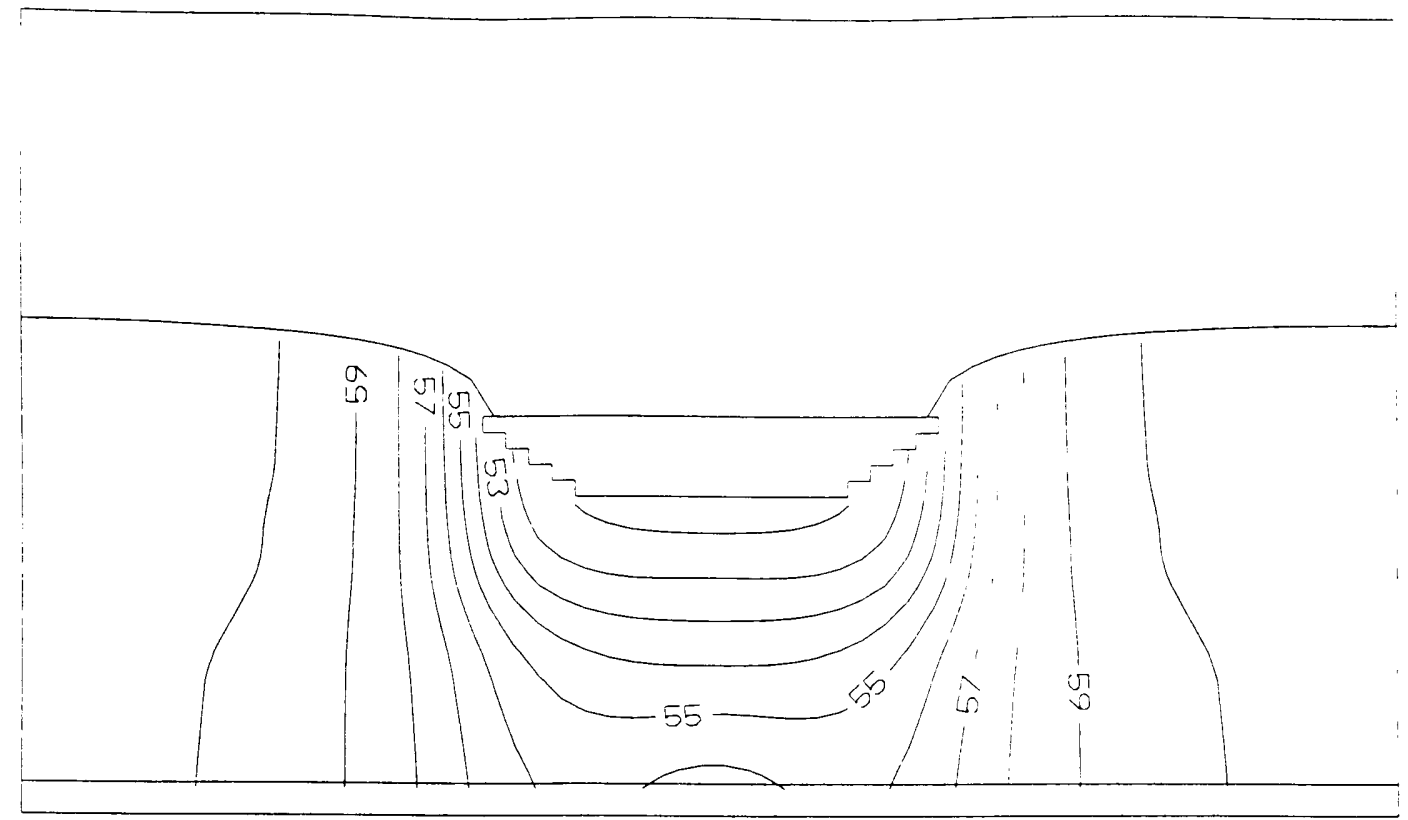

Shallow lake

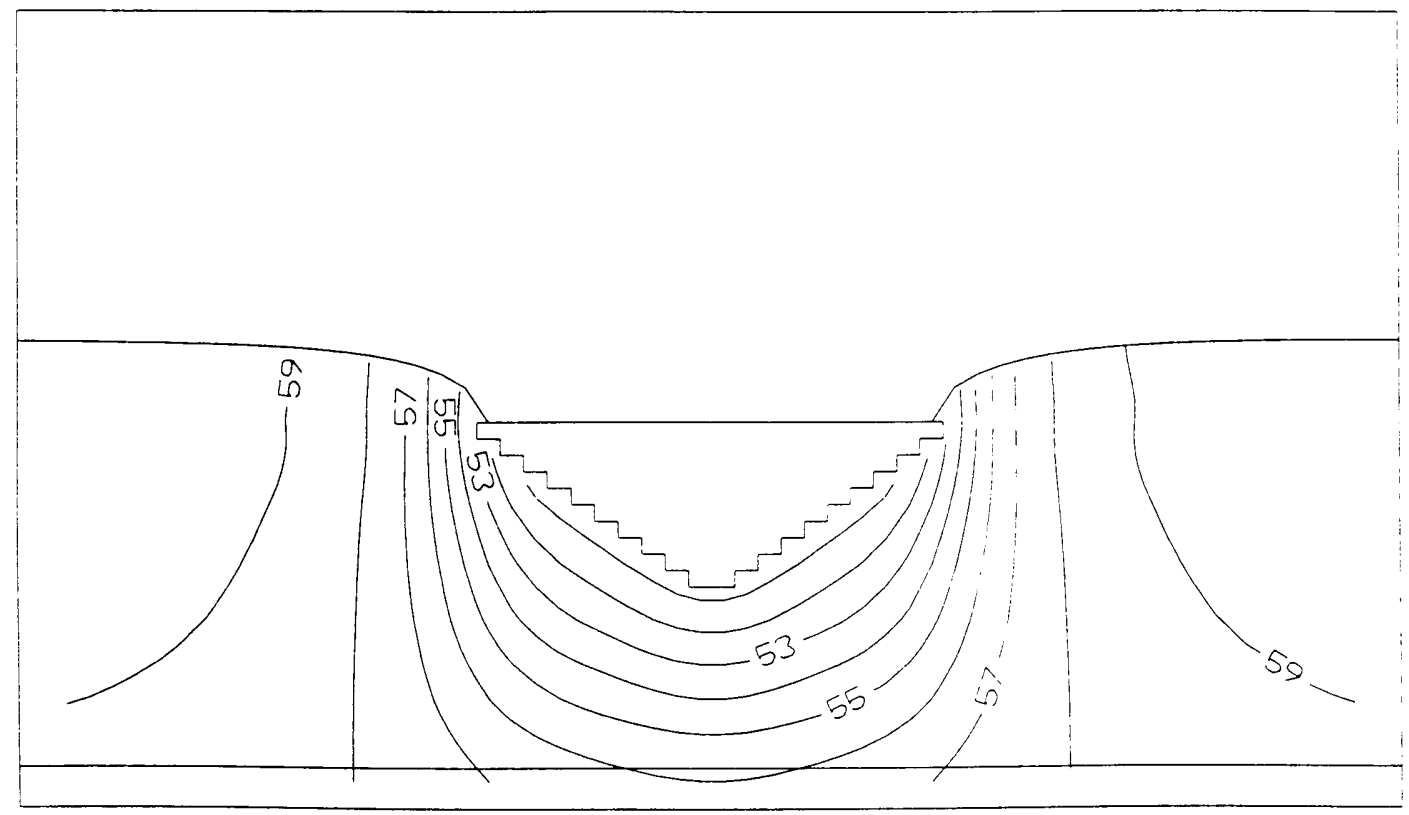

Deep lake

Fig. 14.3. Distribution of hydraulic heads in the porous medium surrounding shallow and deep inflow lakes with moderate lake bed slope and a horizontally extensive aquifer at the bottom of the porous medium (layer 15). 


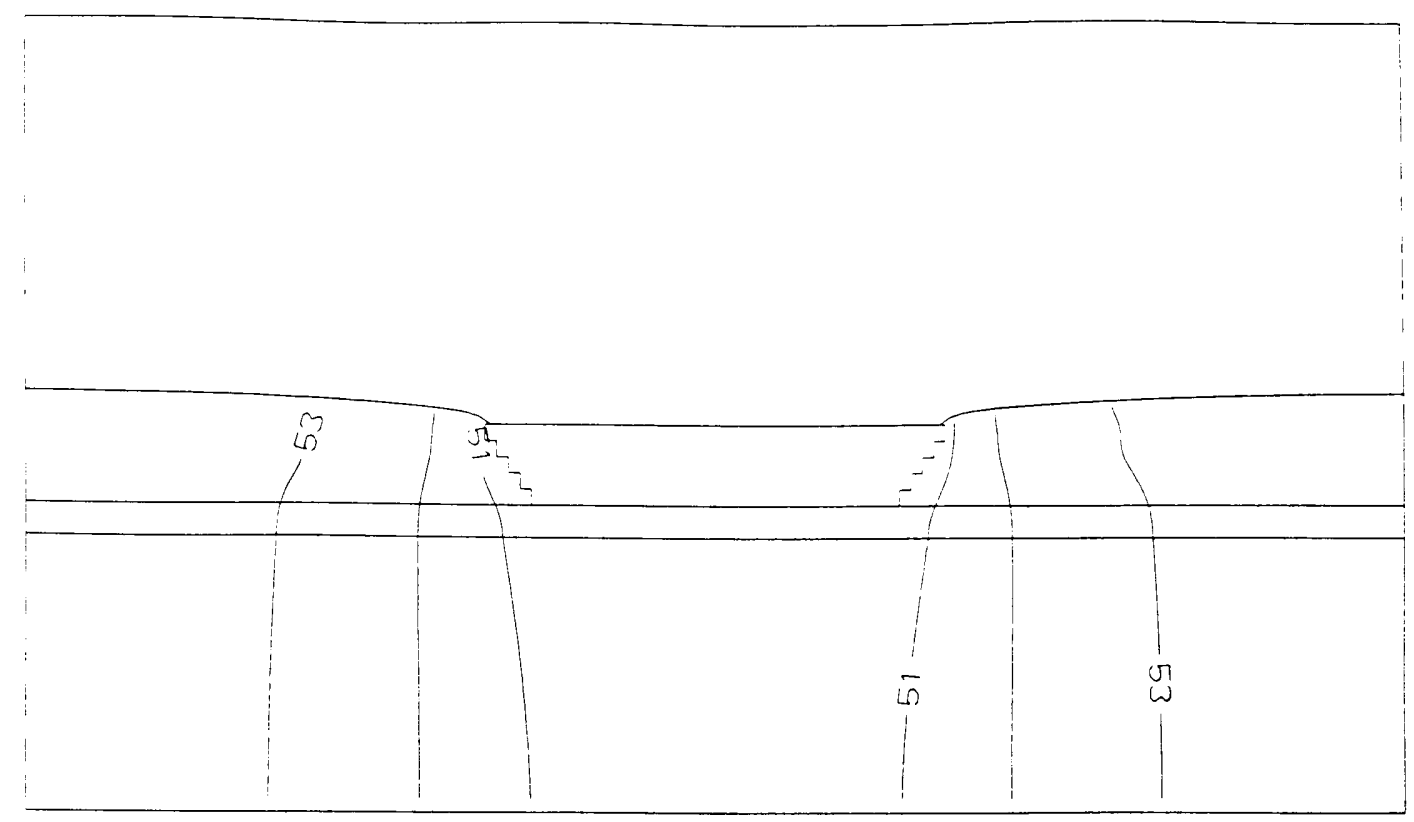

Aquifer just under the lake

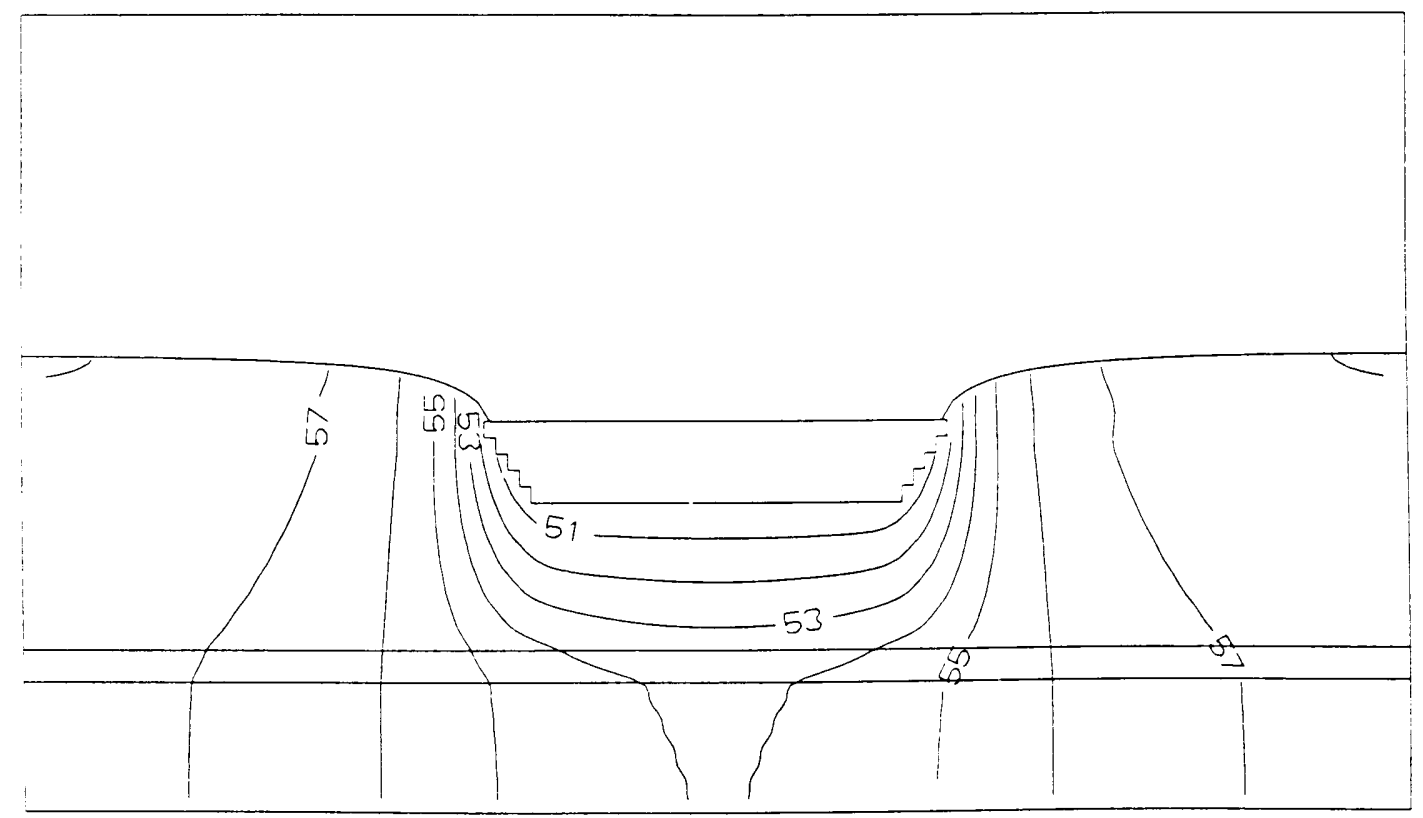

Aquifer in layer 11

Fig. 14.4. Distribution of hydraulic heads in the porous medium surrounding shallow inflow lake with steep lake bed slope and a horizontally extensive aquifer just under the lake (above) and in layer 11 (below). 


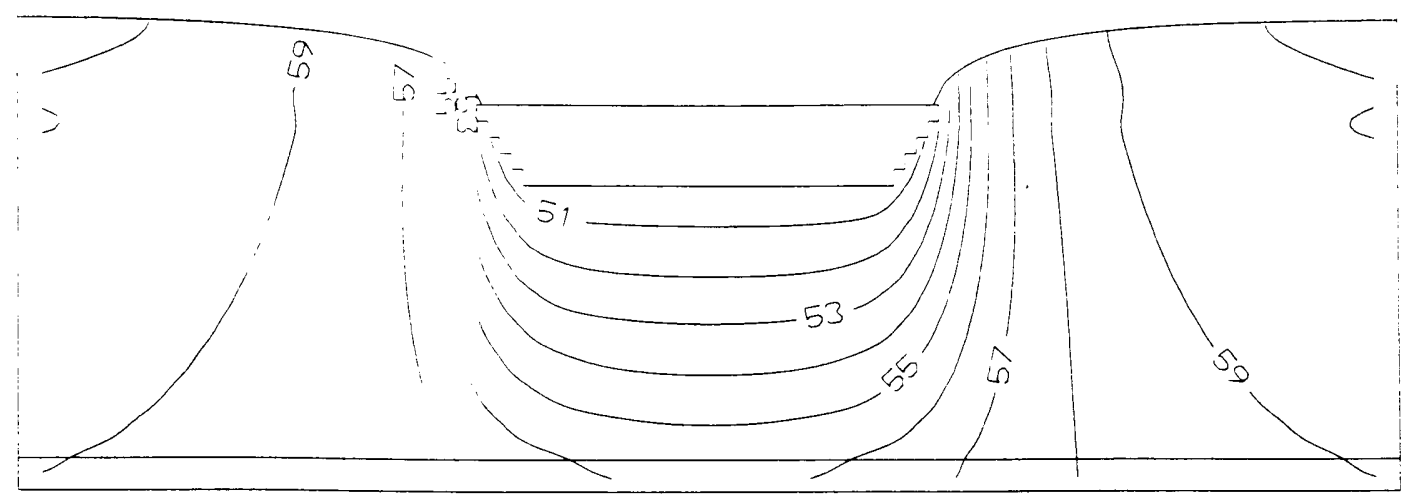

Aquifer at the bottom of the porous medium

Fig. 14.5. Distribution of hydraulic heads in the porous medium surrounding shallow inflow lake with steep lake bed slope and a horizontally extensive aquifer at the bottom of the porous medium (layer 15). 

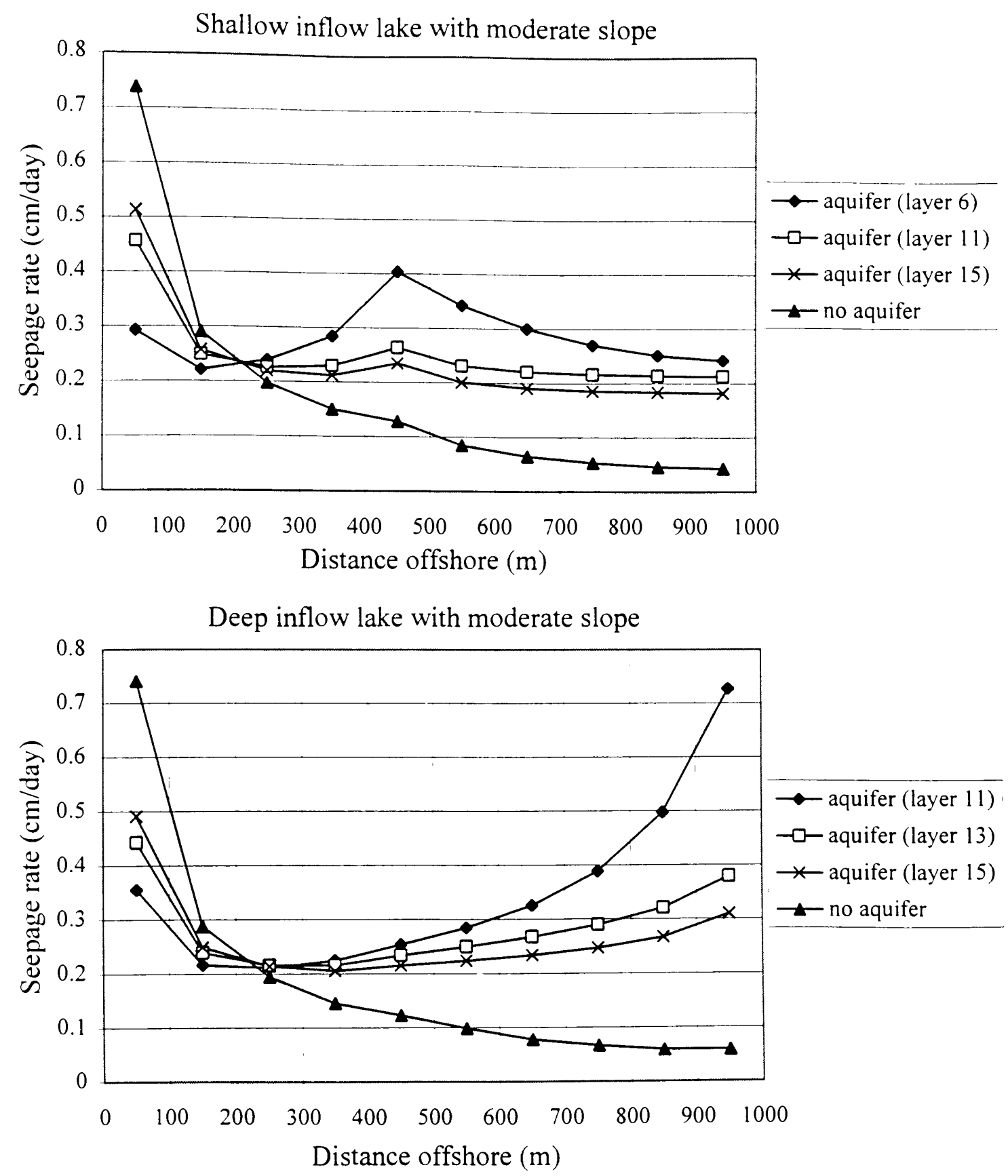

Fig. 14.6. Seepage rate versus distance offshore for simulations of shallow and deep inflow lakes with moderate lake bed slopes and different vertical positions of a horizontally extensive aquifer. 

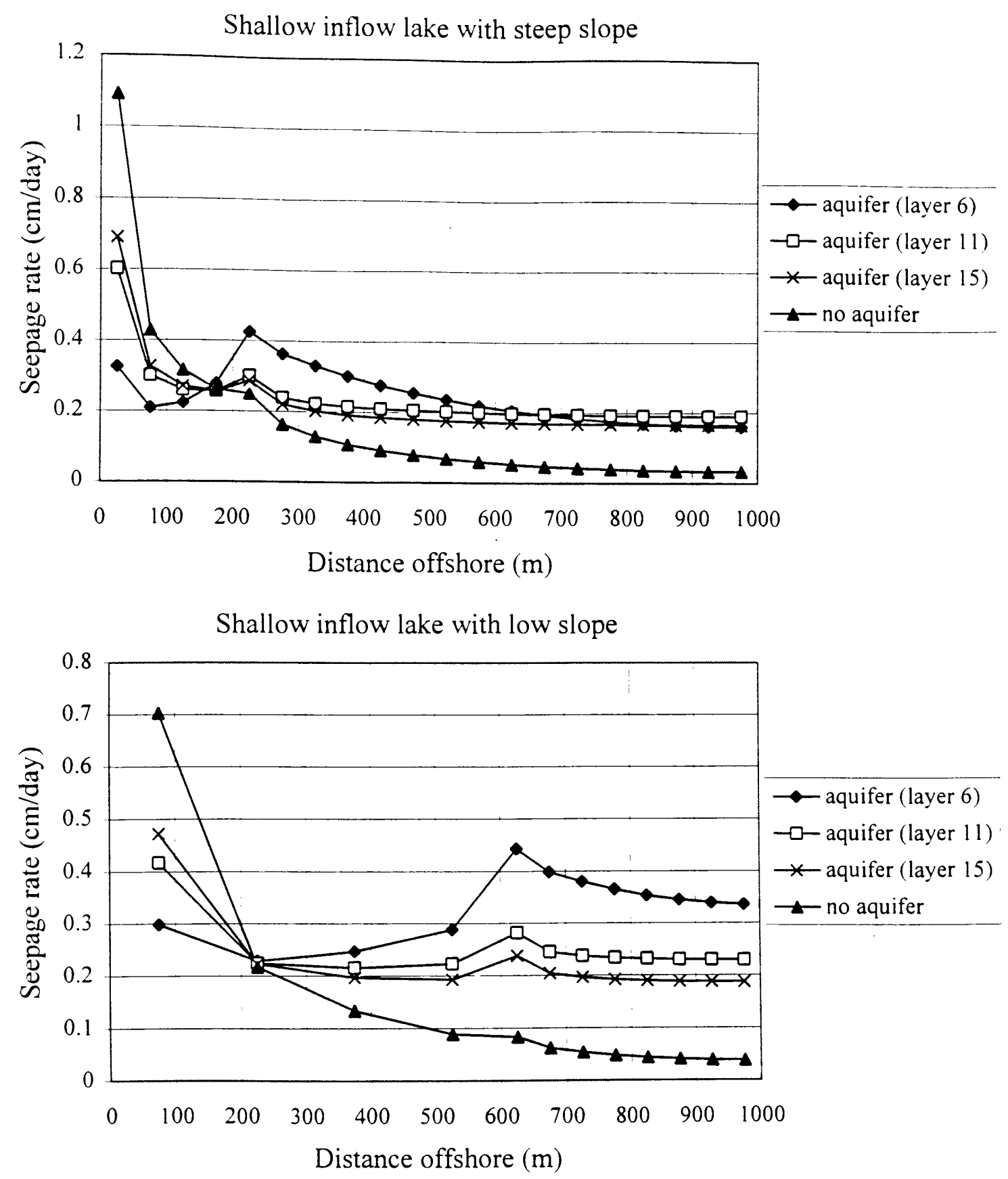

Fig. 14.7. Seepage rate versus distance offshore for simulations of shallow inflow lakes with steep and low lake bed slopes and different vertical positions of a horizontally extensive aquifer. 


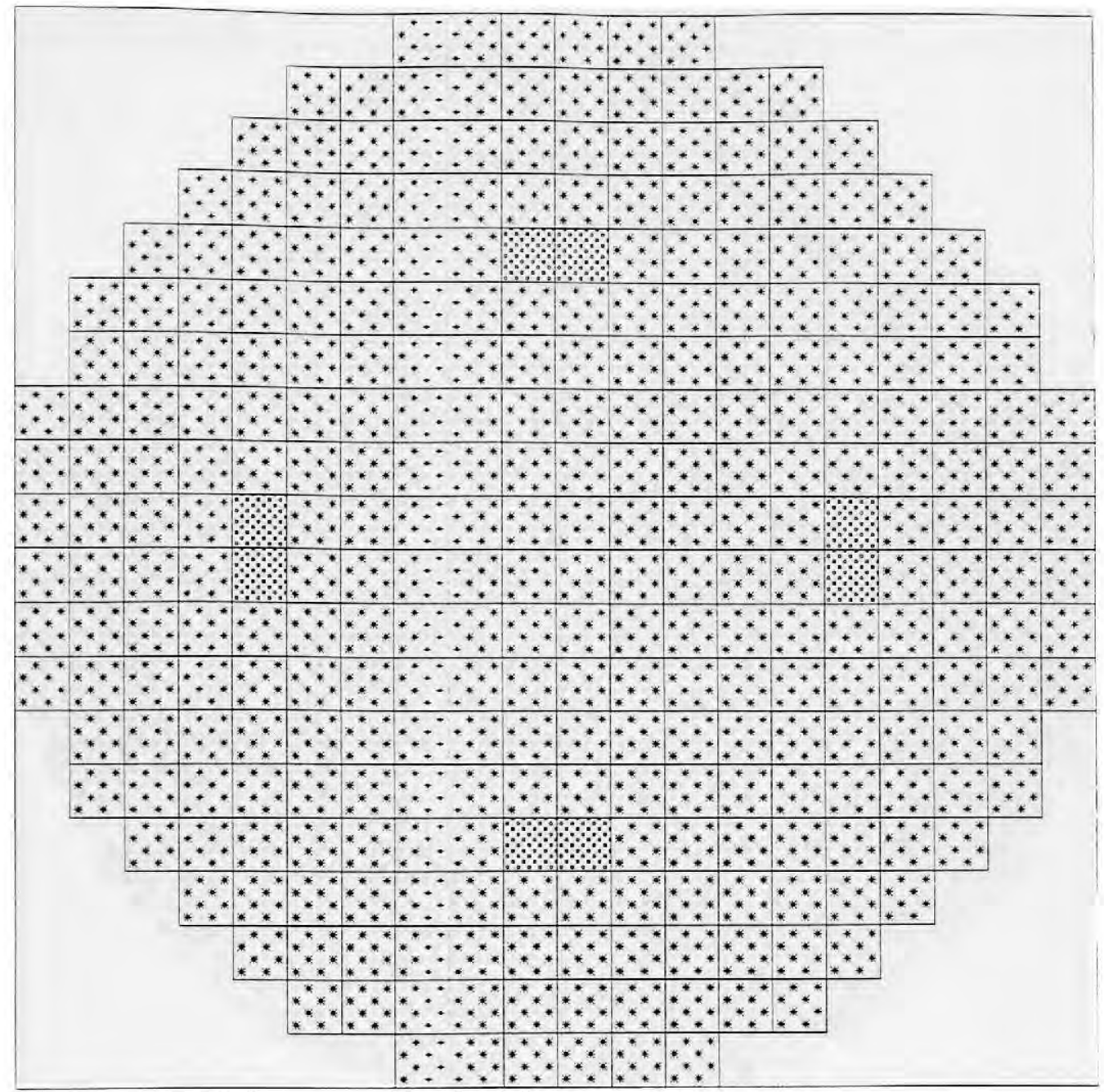

Fig. 14.8. Distribution of seepage rates ( $\mathrm{cm} /$ day) over

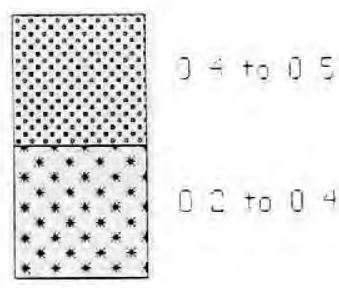
the lake bed for a shallow inflow lake with moderate lake bed slope and a horizontally extensive aquifer just under the lake in layer 6 . 


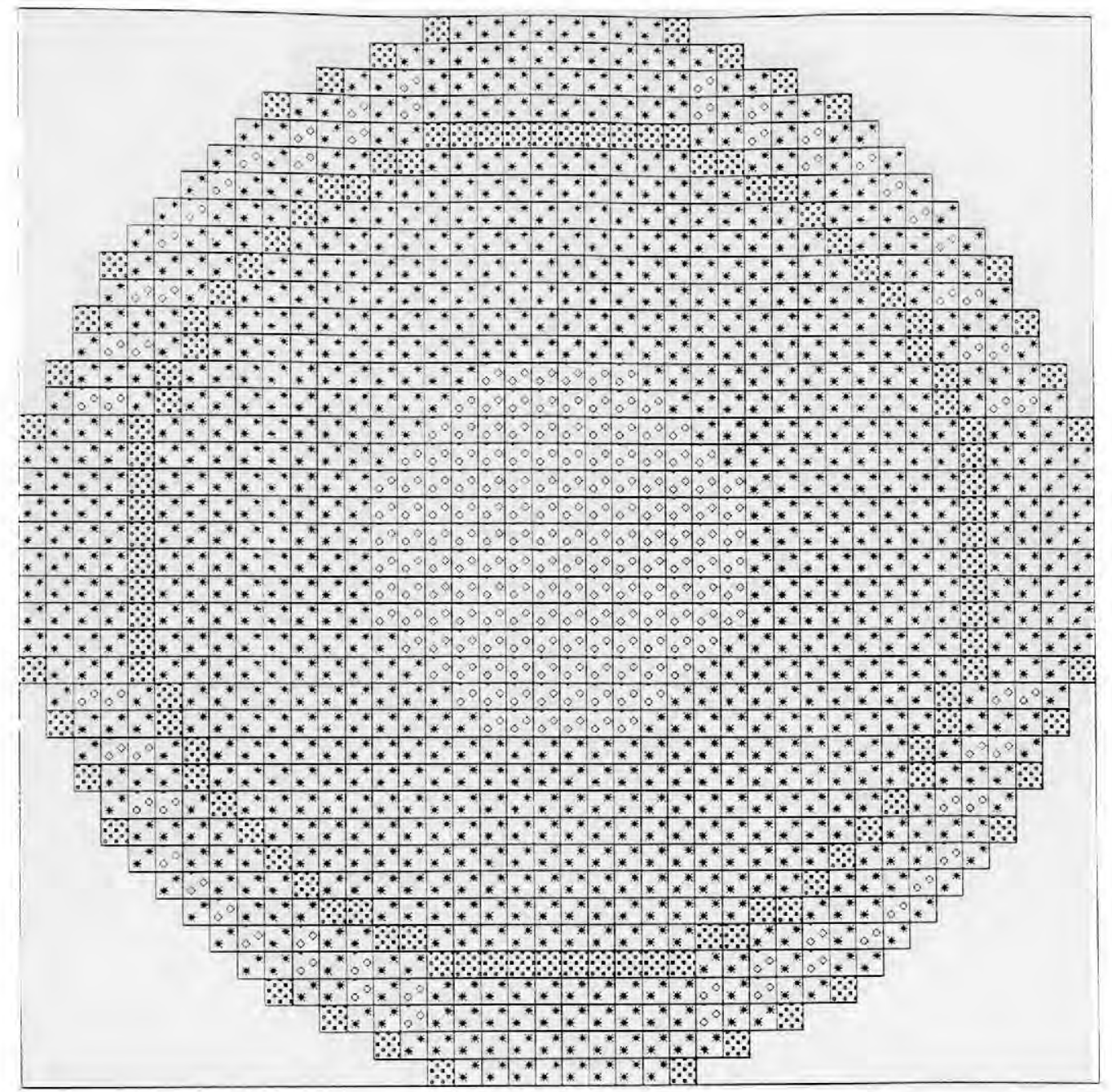

Fig. 14.9. Distribution of seepage rates ( $\mathrm{cm} /$ day) over the lake bed for a shallow inflow lake with steep lake bed slope and a horizontally extensive aquifer just under the lake in layer 6 .

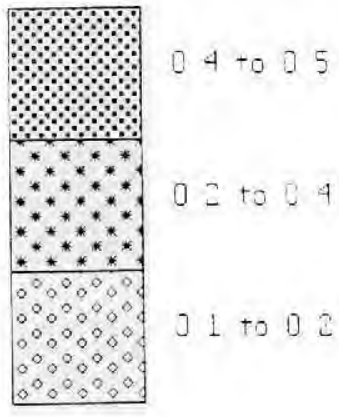




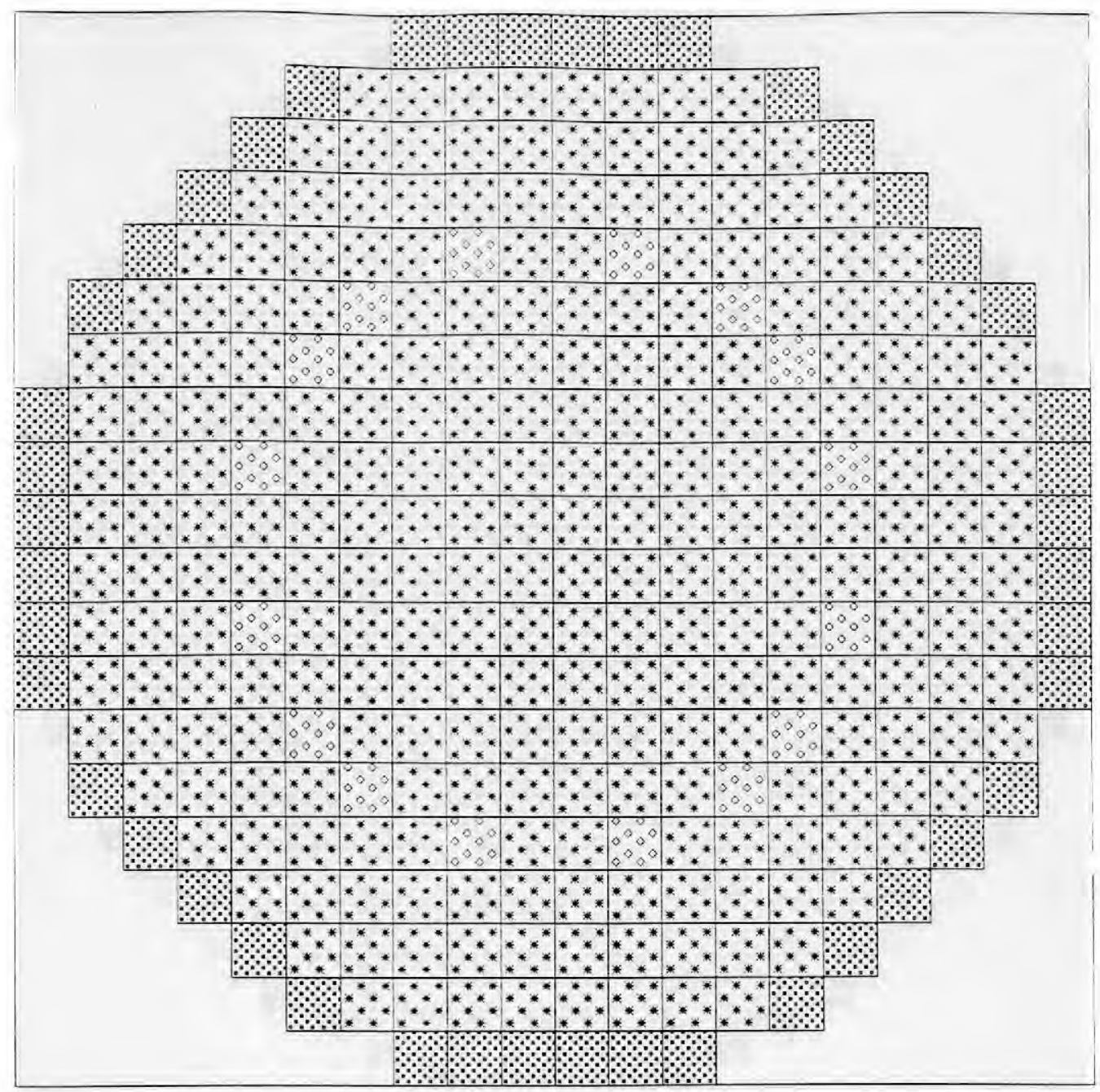

Fig. 14.10. Distribution of seepage rates ( $\mathrm{cm} /$ day) over the lake bed for a shallow inflow lake with moderate lake bed slope and a horizontally extensive aquifer below the lake in layer 11 .

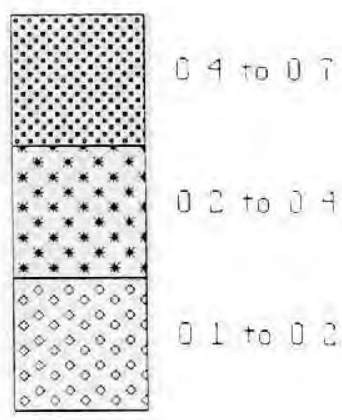




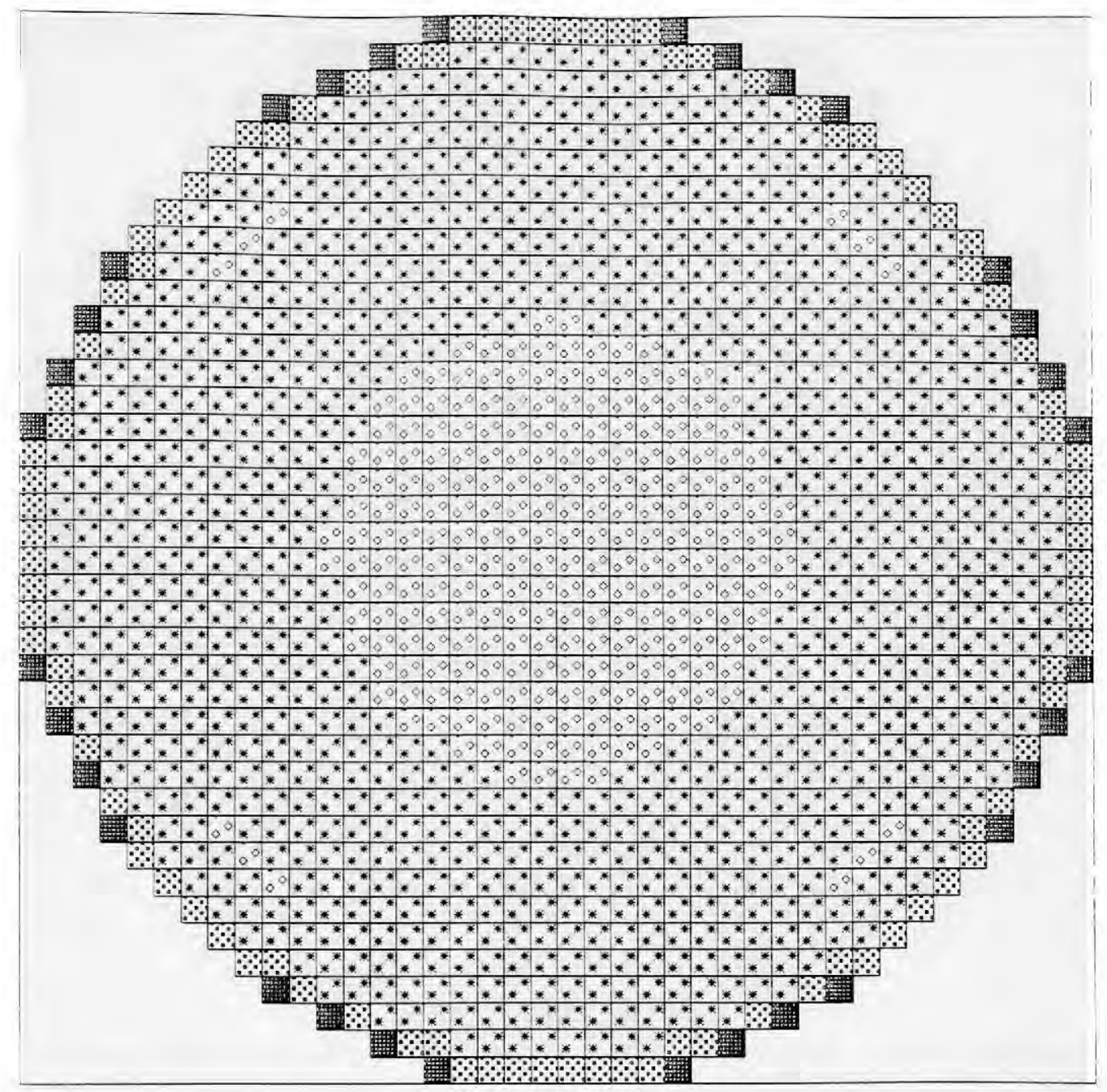

Fig. 14.11. Distribution of seepage rates (cm/day) over the lake bed for a shallow inflow lake with steep lake bed slope and a horizontally extensive aquifer below the lake in layer 11 .

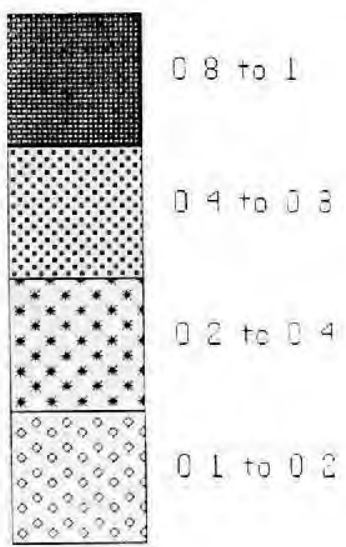




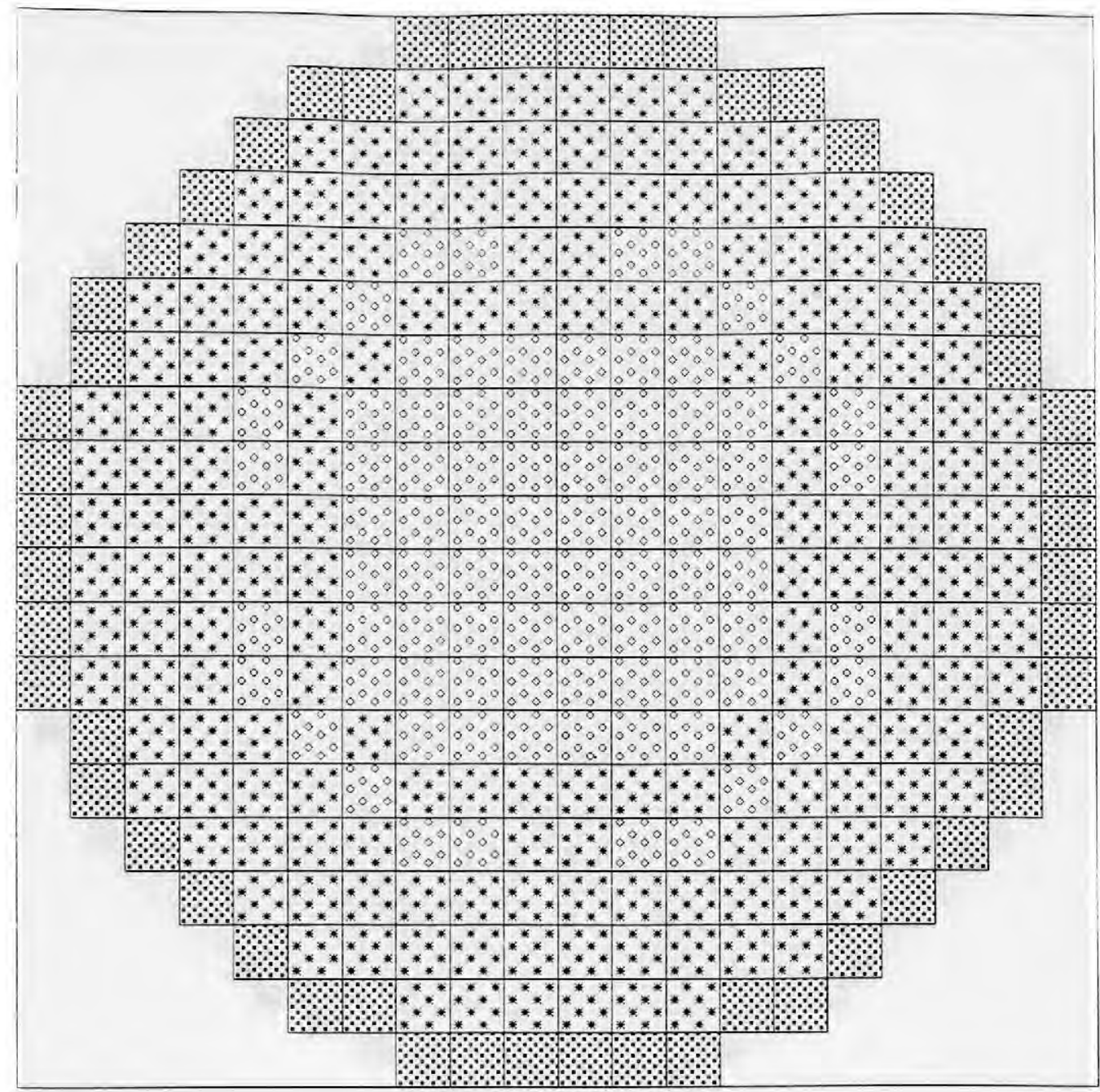

Fig. 14.12. Distribution of seepage rates ( $\mathrm{cm} /$ day) over the lake bed for a shallow inflow lake with moderate lake bed slope and a horizontally extensive aquifer at the bottom of the porous

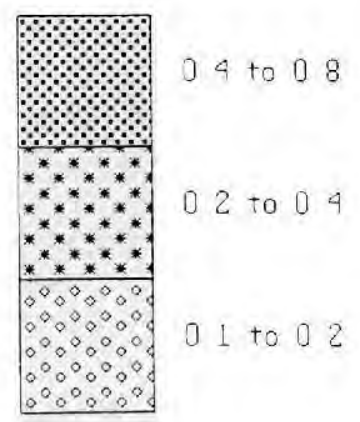
medium in layer 15 . 


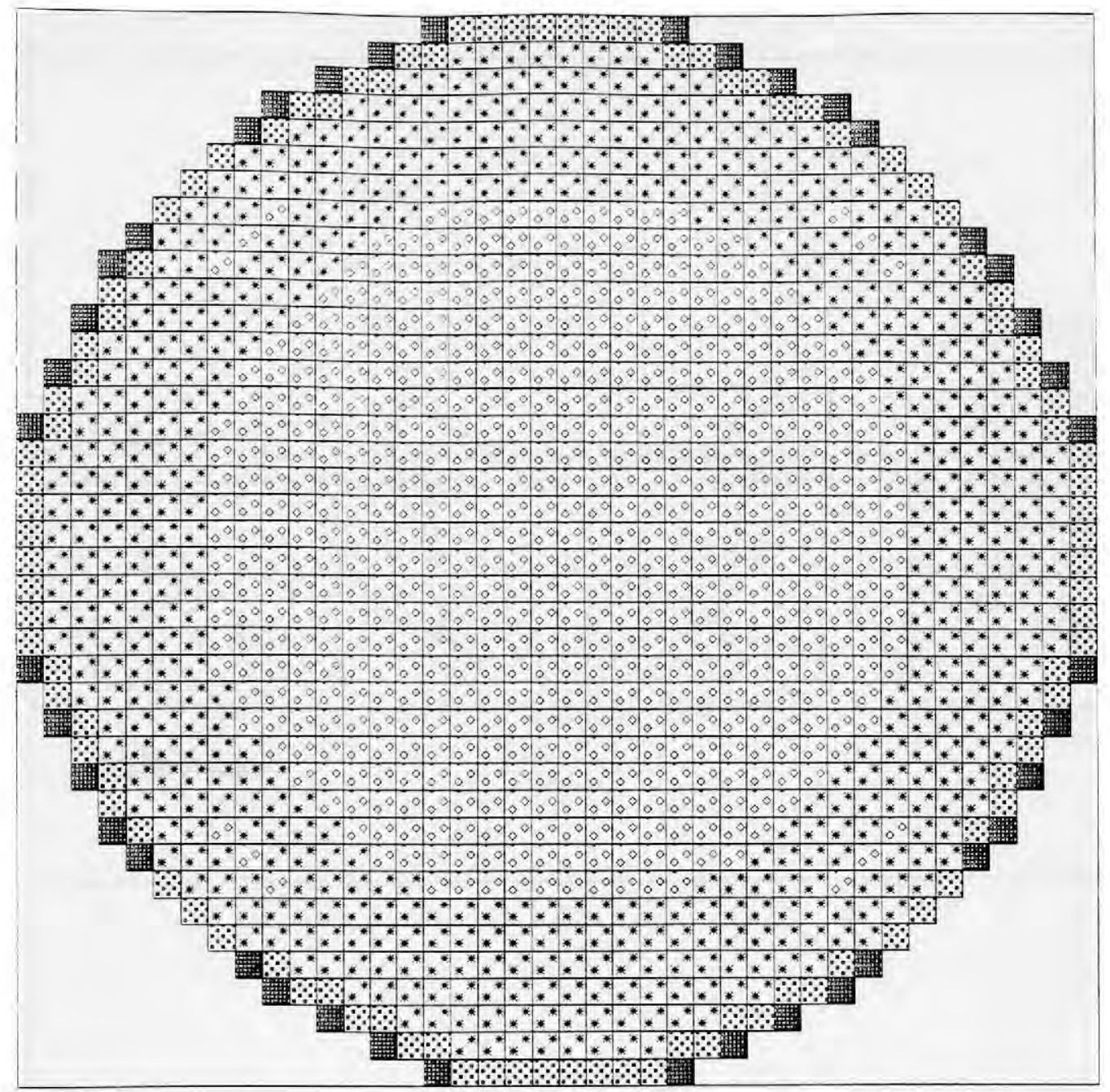

Fig. 14.13. Distribution of seepage rates (cm/day) over the lake bed for a shallow inflow lake with steep lake bed slope and a horizontally extensive aquifer at the bottom of the porous medium in layer 15 .

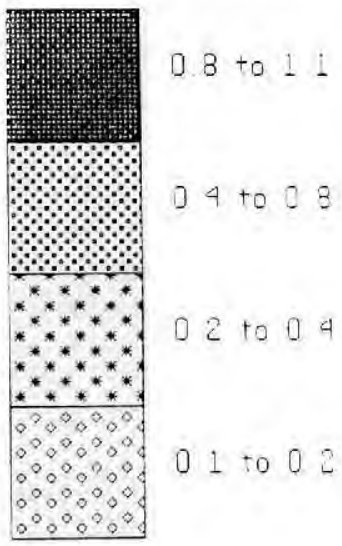




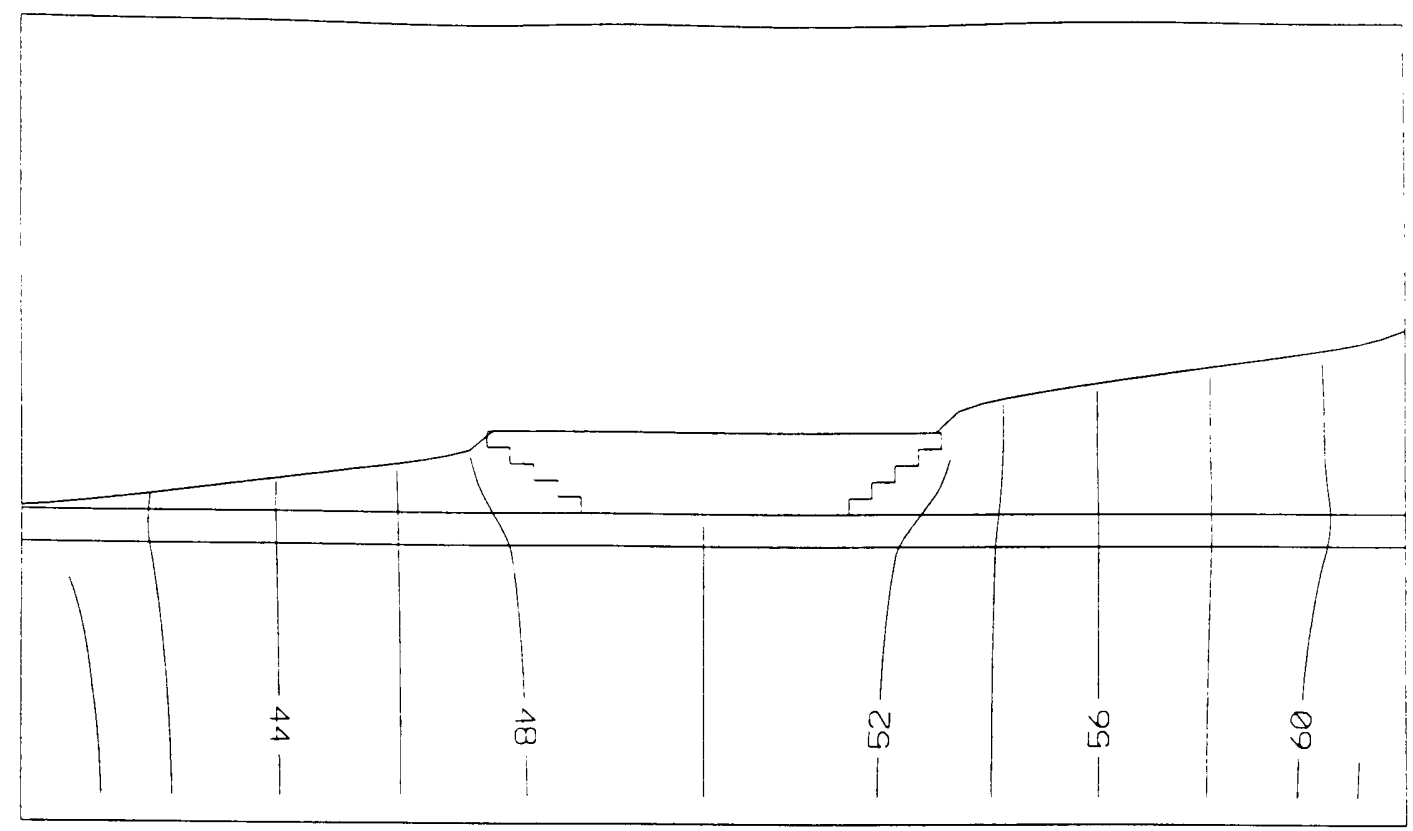

Shallow lake

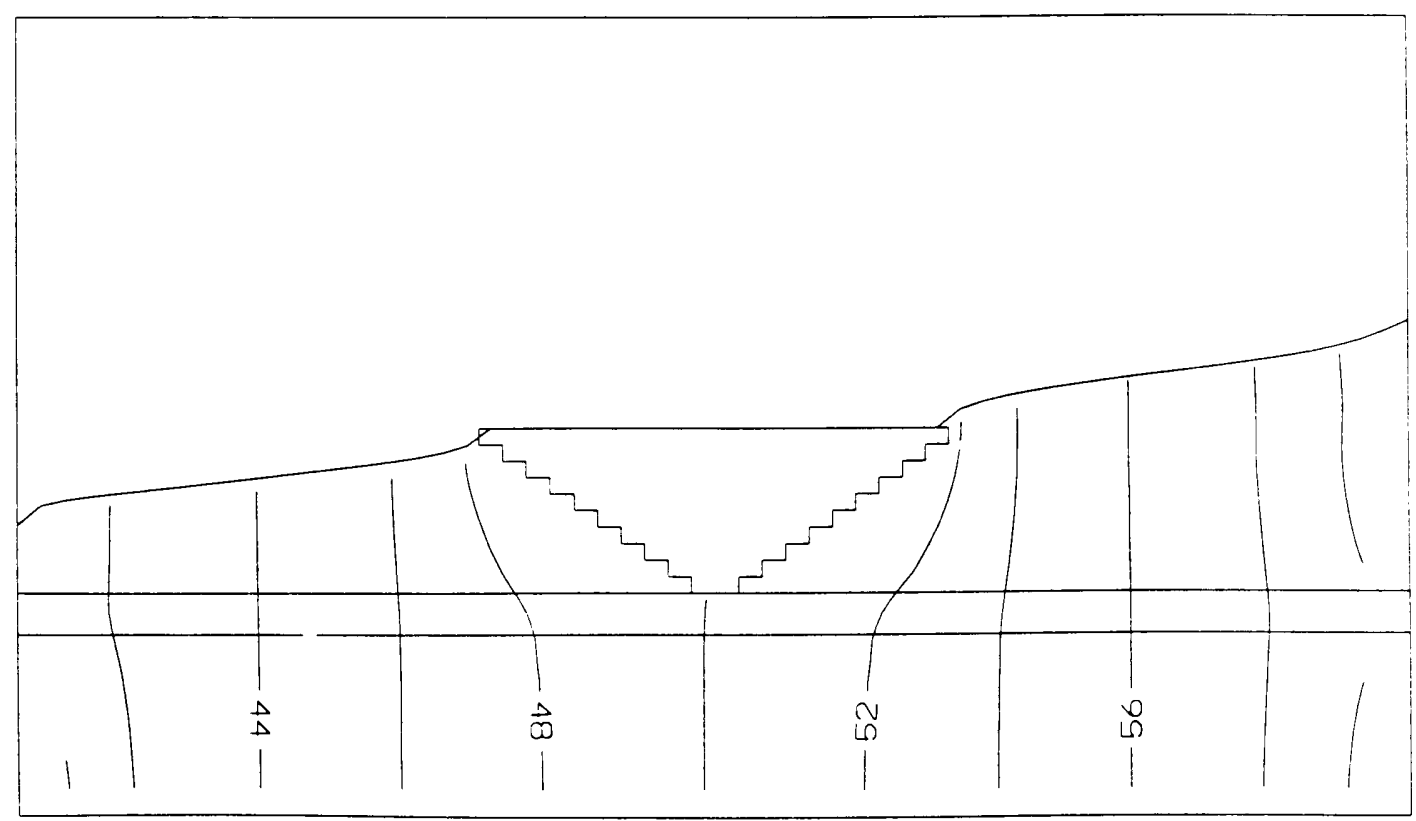

Deep lake

Fig. 14.14. Distribution of hydraulic heads in the porous medium surrounding shallow and deep flow-through lakes with moderate lake bed slope and a horizontally extensive aquifer just under the lakes (layer 6 for the shallow lake, layer 11 for the deep lake). 


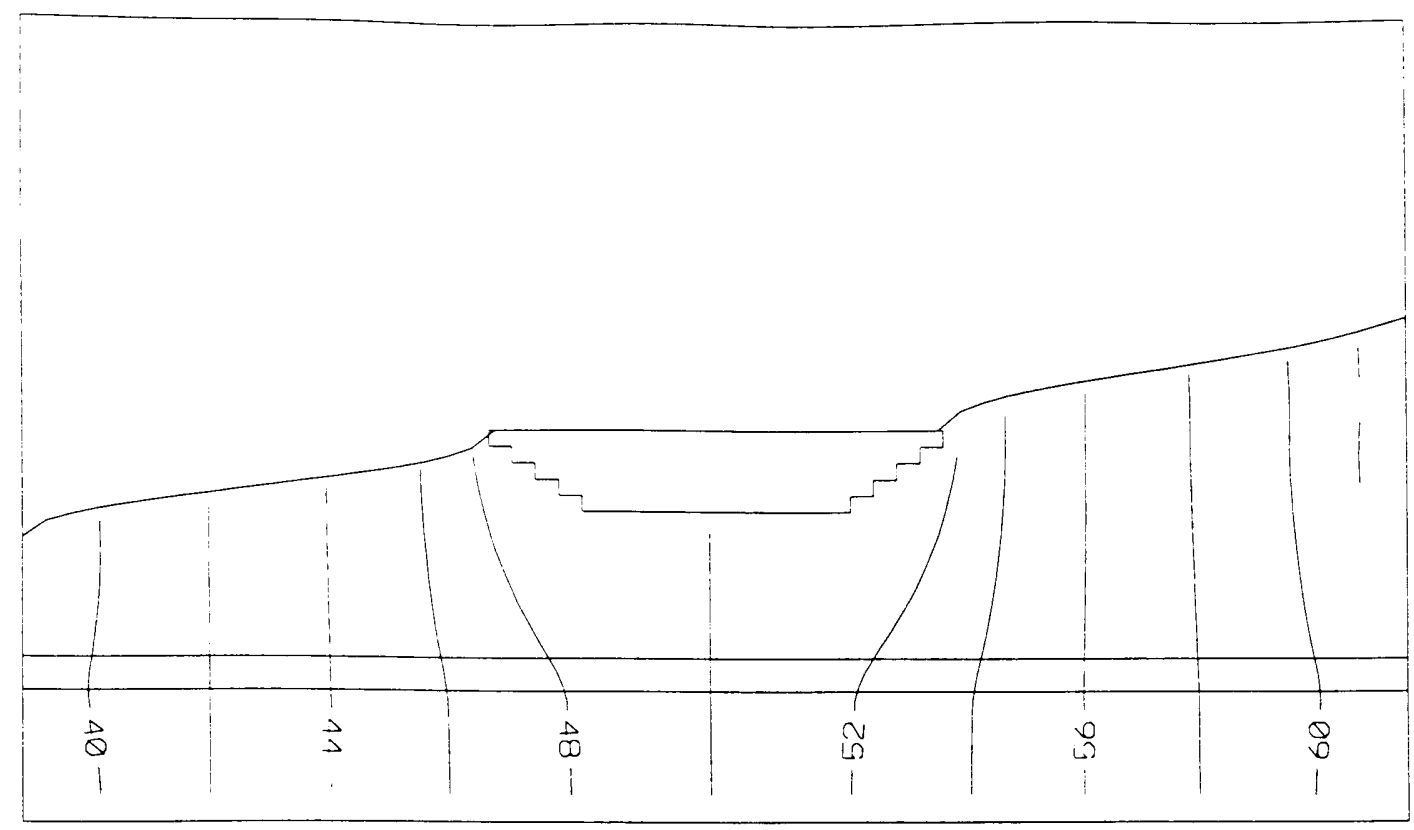

Shallow lake

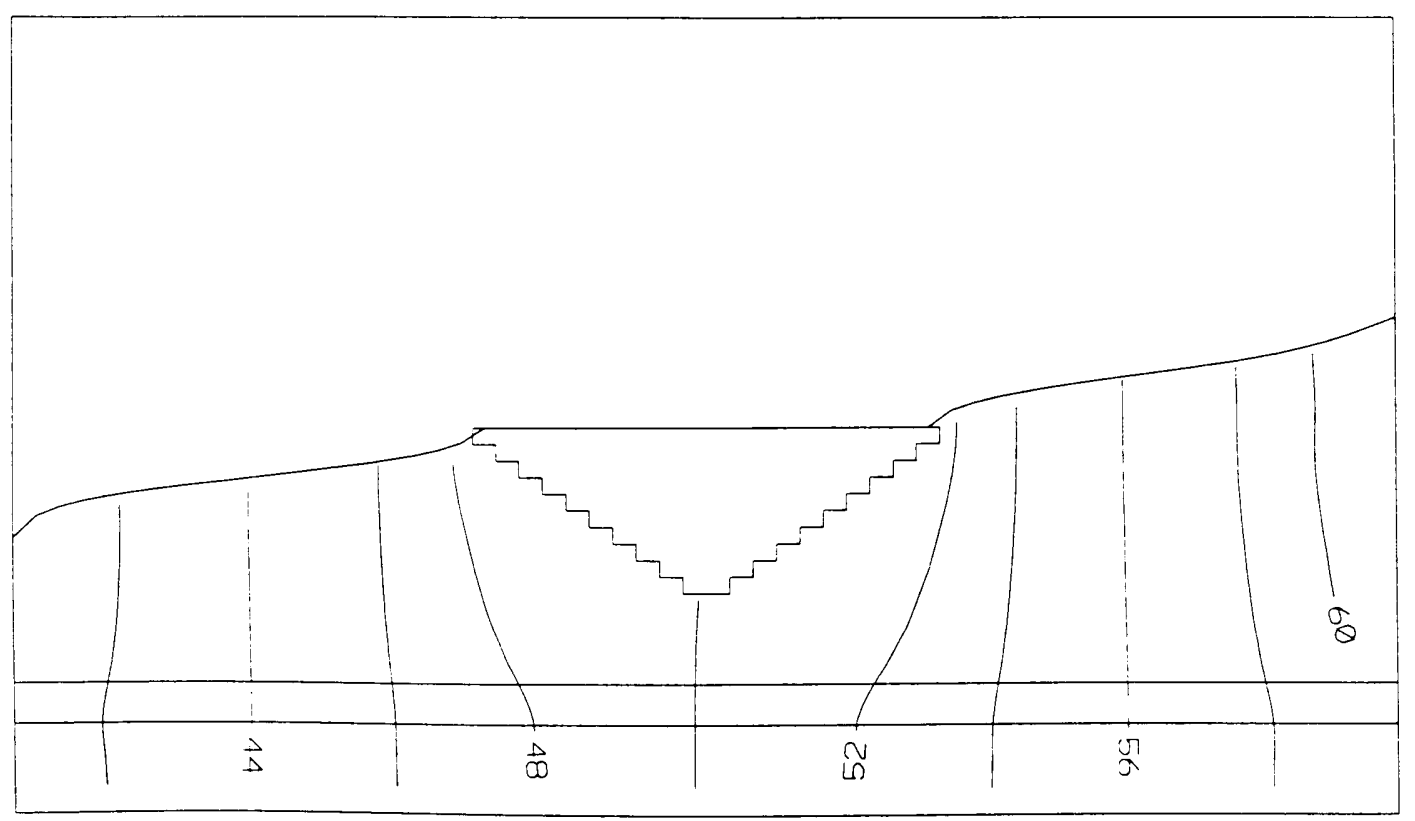

Deep lake

Fig. 14.15. Distribution of hydraulic heads in the porous medium surrounding shallow and deep flow-through lakes with moderate lake bed slope and a horizontally extensive aquifer in layer 11 (shallow lake) or layer 13 (deep lake). 


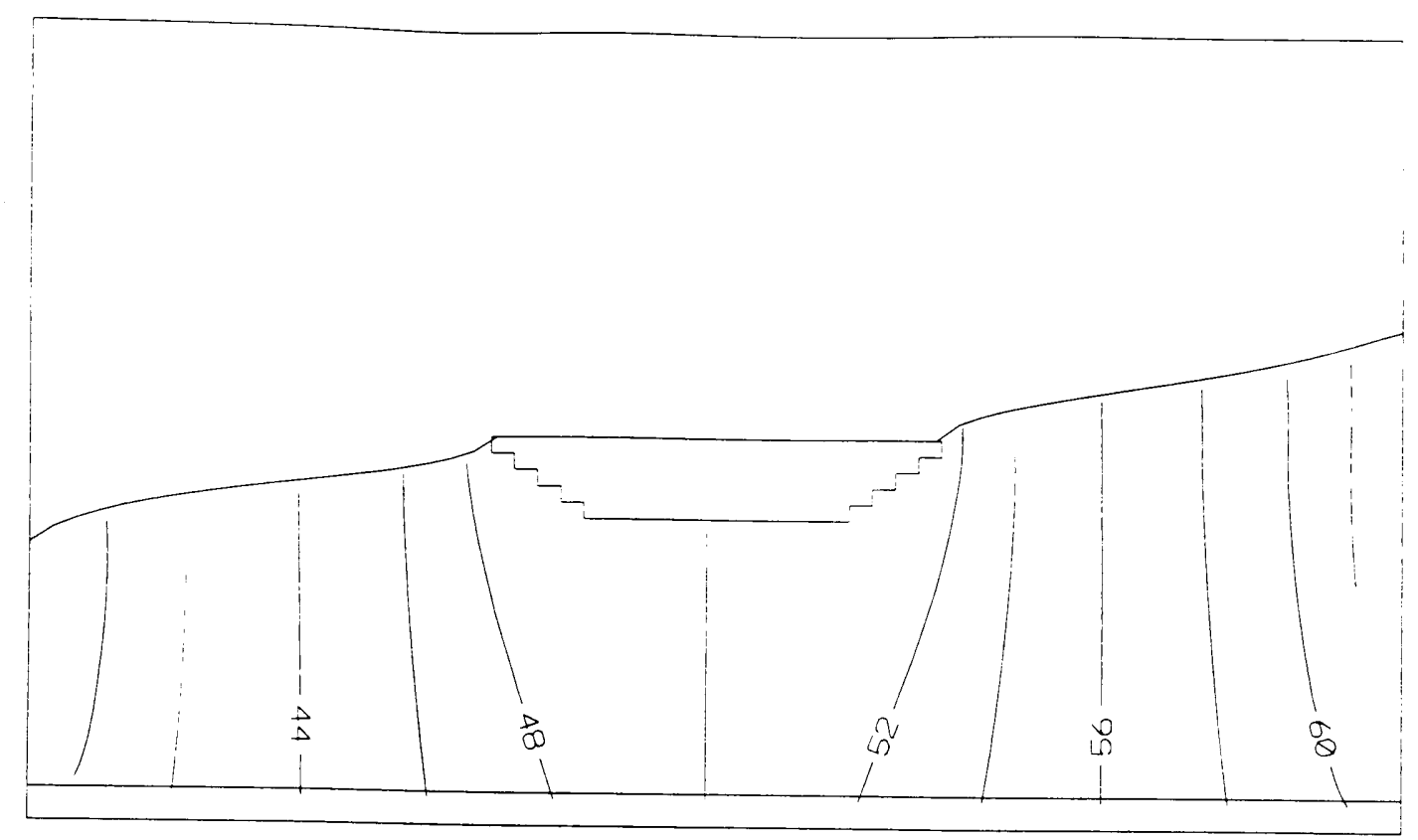

Shallow lake

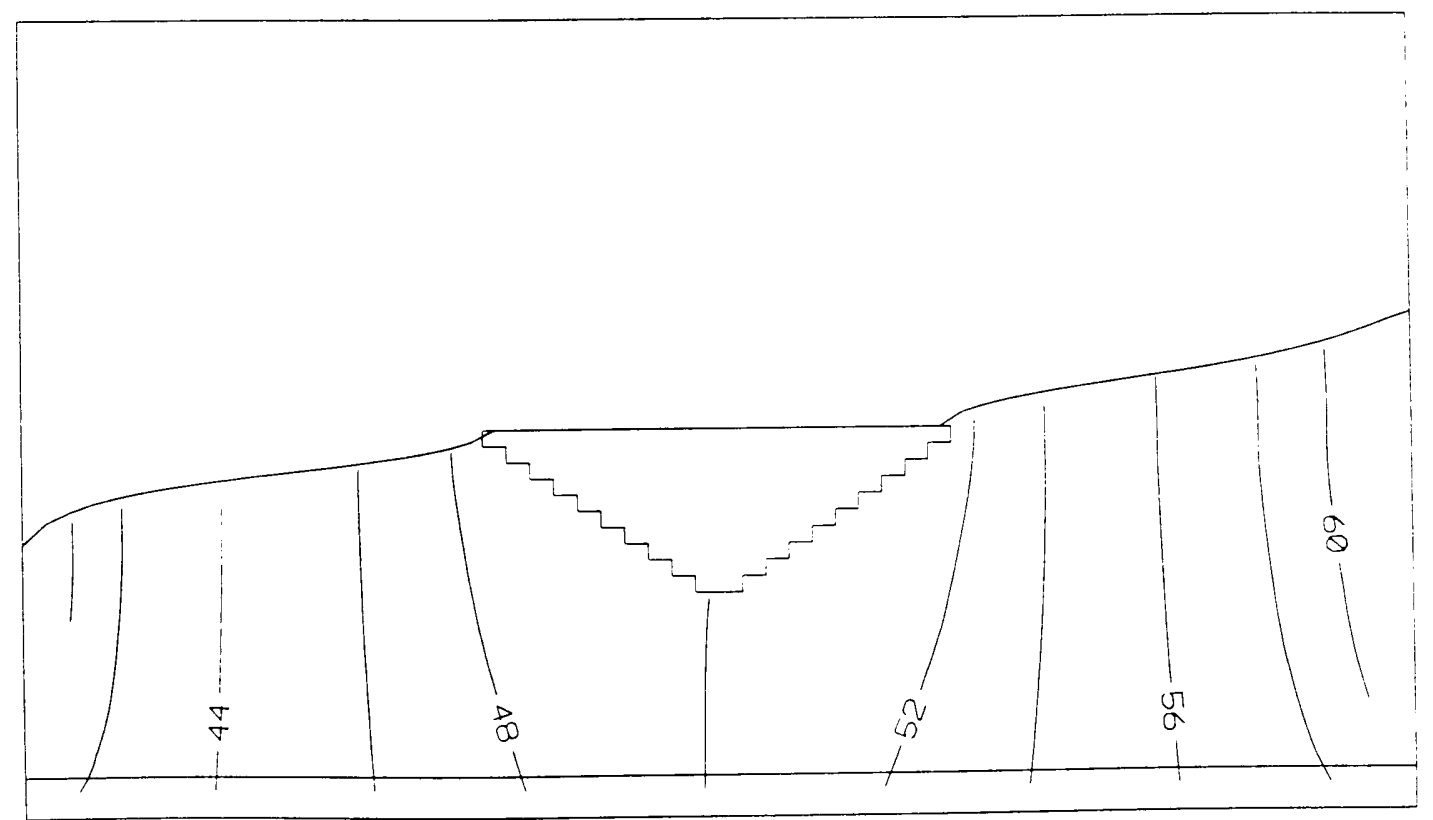

Deep lake

Fig. 14.16. Distribution of hydraulic heads in the porous medium surrounding shallow and deep flow-through lakes with moderate lake bed slope and a horizontally extensive aquifer at the bottom of the porous medium (layer 15). 


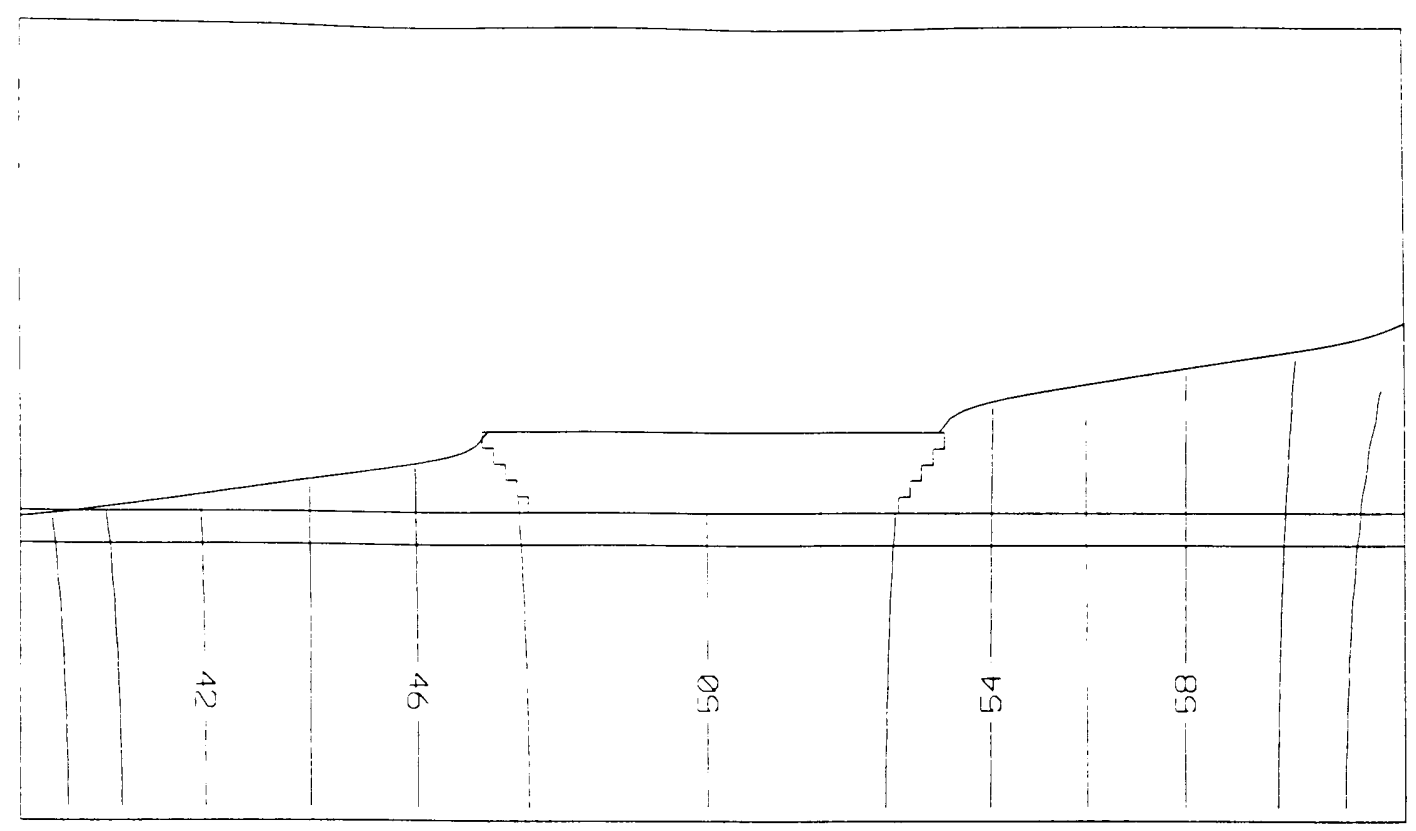

Aquifer just under the lake

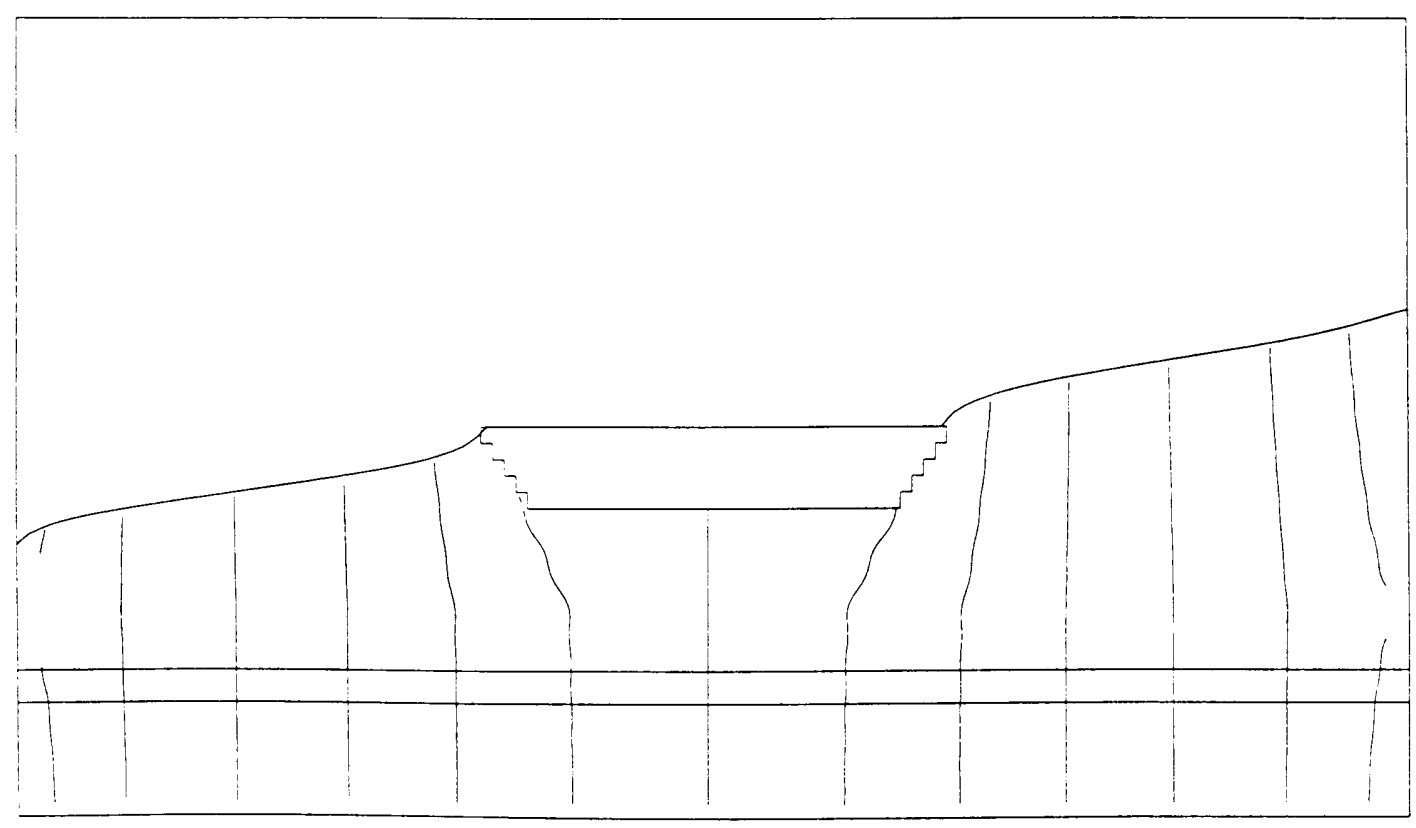

Aquifer in layer 11

Fig. 14.17. Distribution of hydraulic heads in the porous medium surrounding shallow flowthrough lakes with steep lake bed slope and a horizontally extensive aquifer just under the lake (above) and in layer 11 (below). 


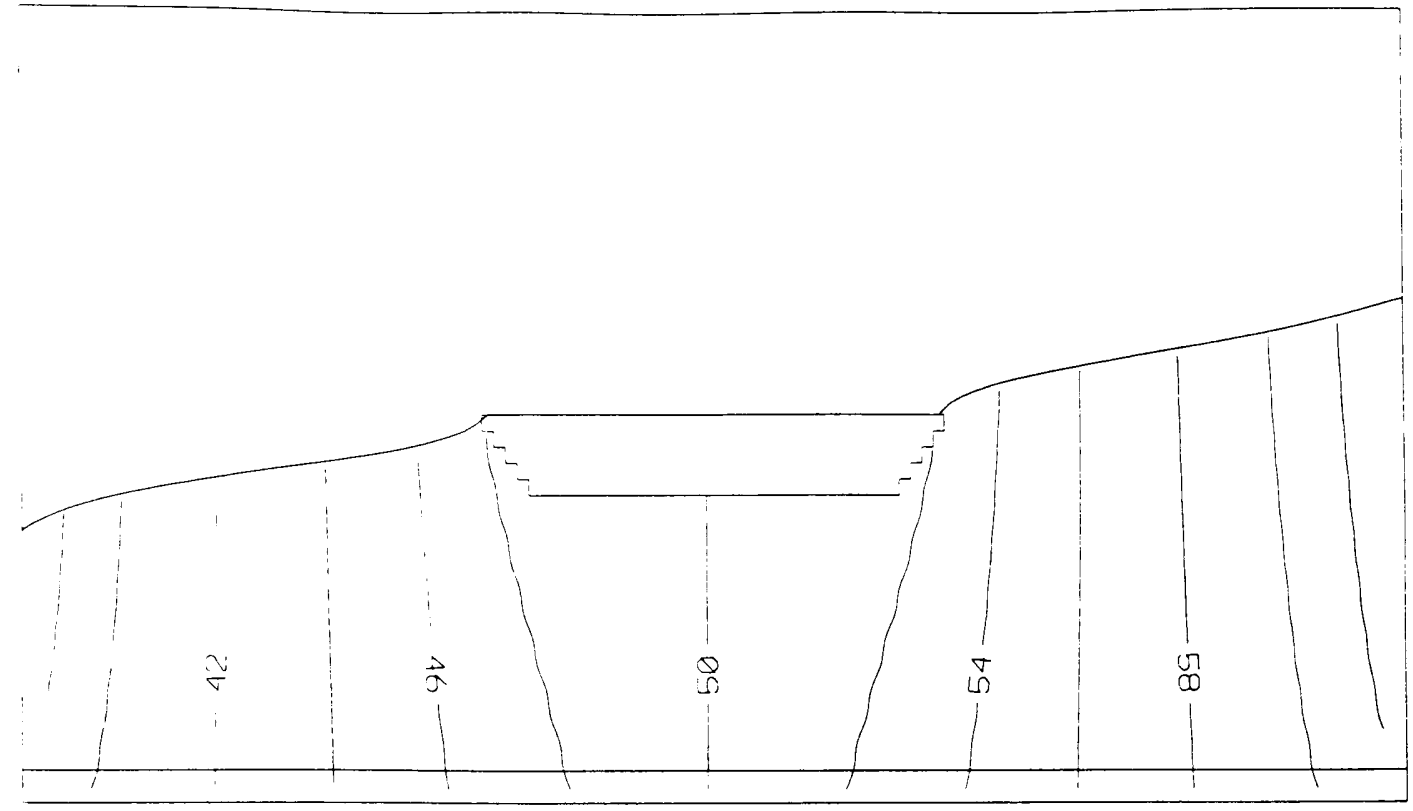

Aquifer at the bottom of the porous medium

Fig. 14.18. Distribution of hydraulic heads in the porous medium surrounding a shallow flow-through lake with steep lake bed slope and a horizontally extensive aquifer at the bottom of the porous medium (layer 15). 


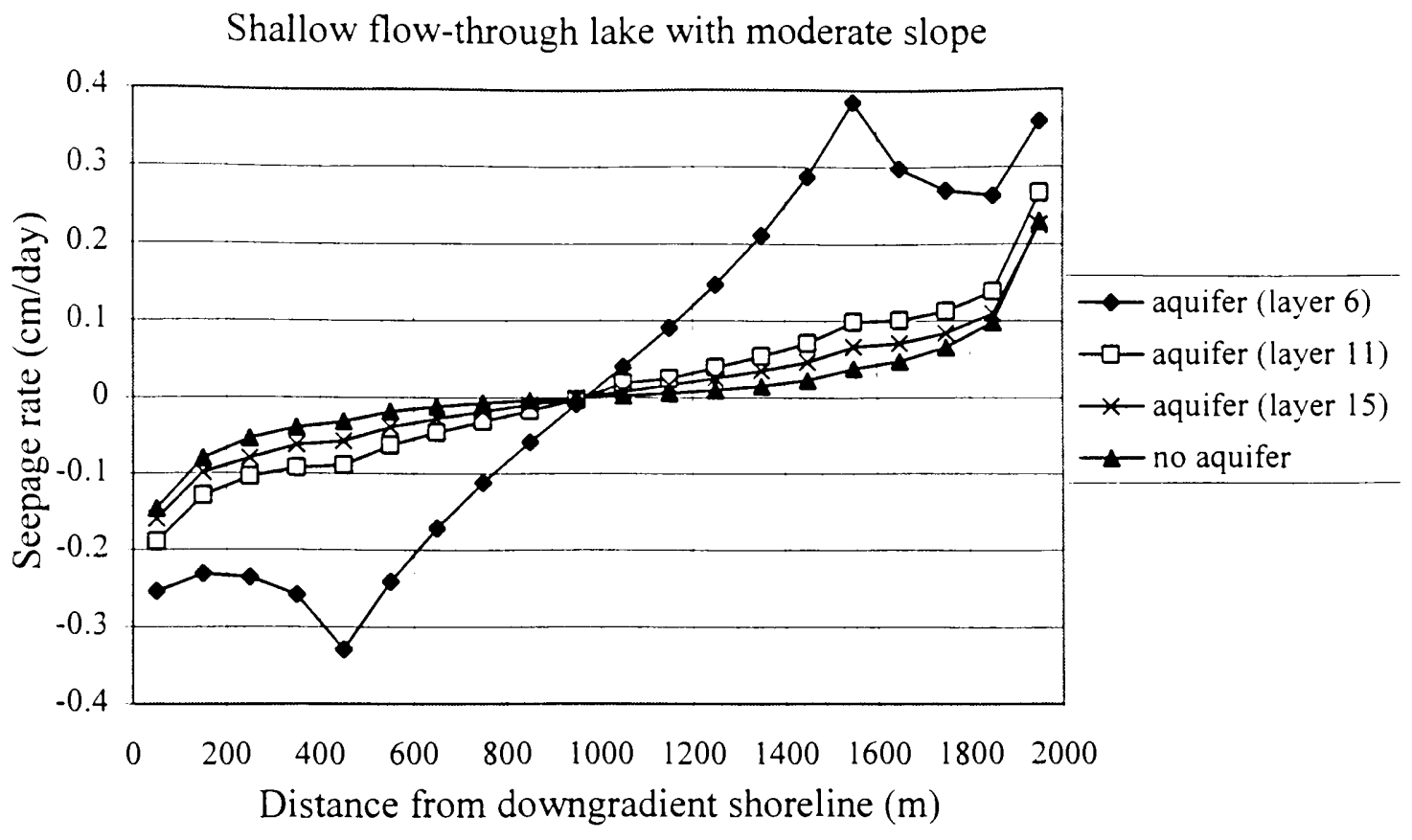

Deep flow-through lake with moderate slope

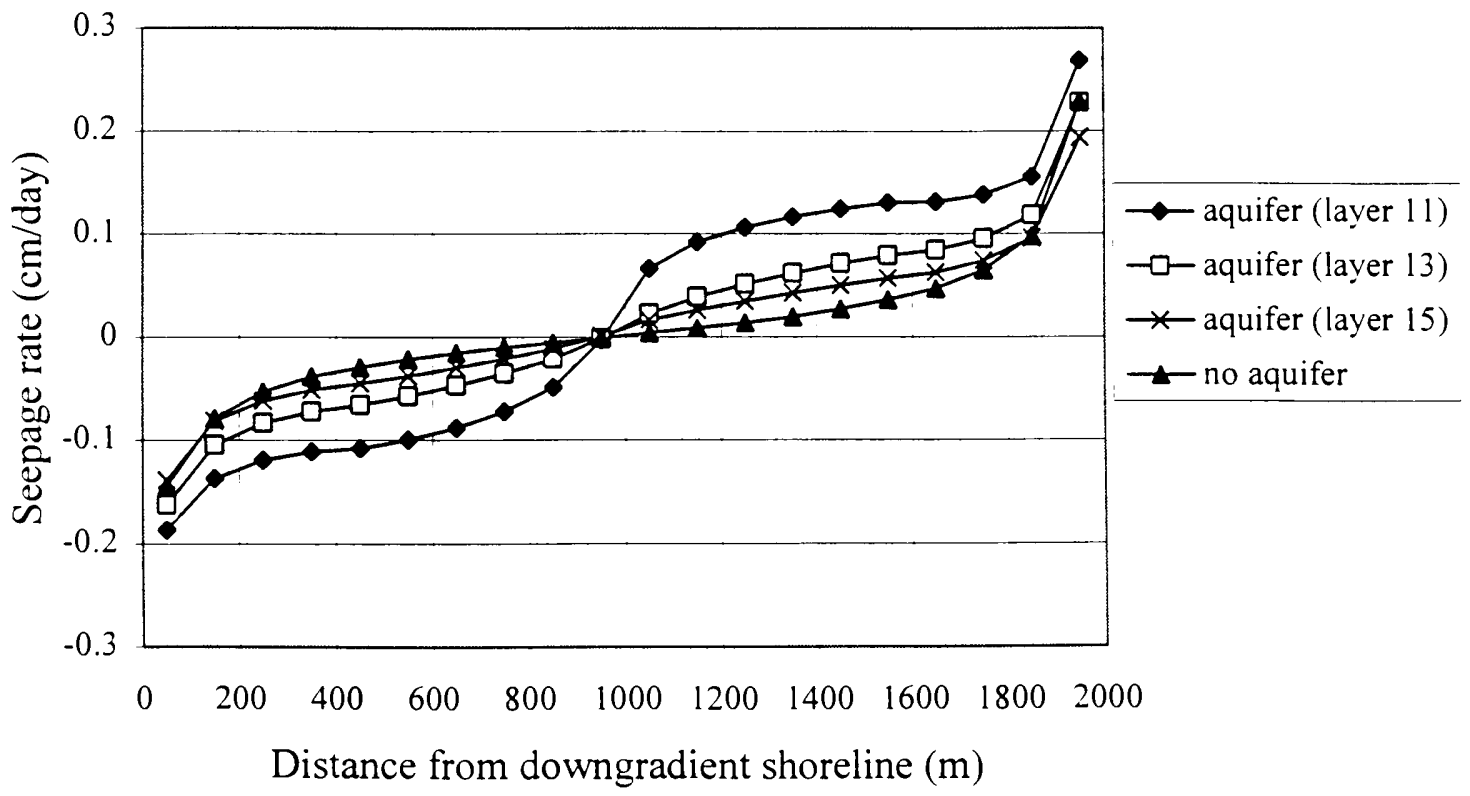

Fig. 14.19. Seepage rate versus distance from the downgradient shoreline for simulations of shallow and deep flow-through lakes with moderate lake bed slope and different vertical positions of a horizontally extensive aquifer. 


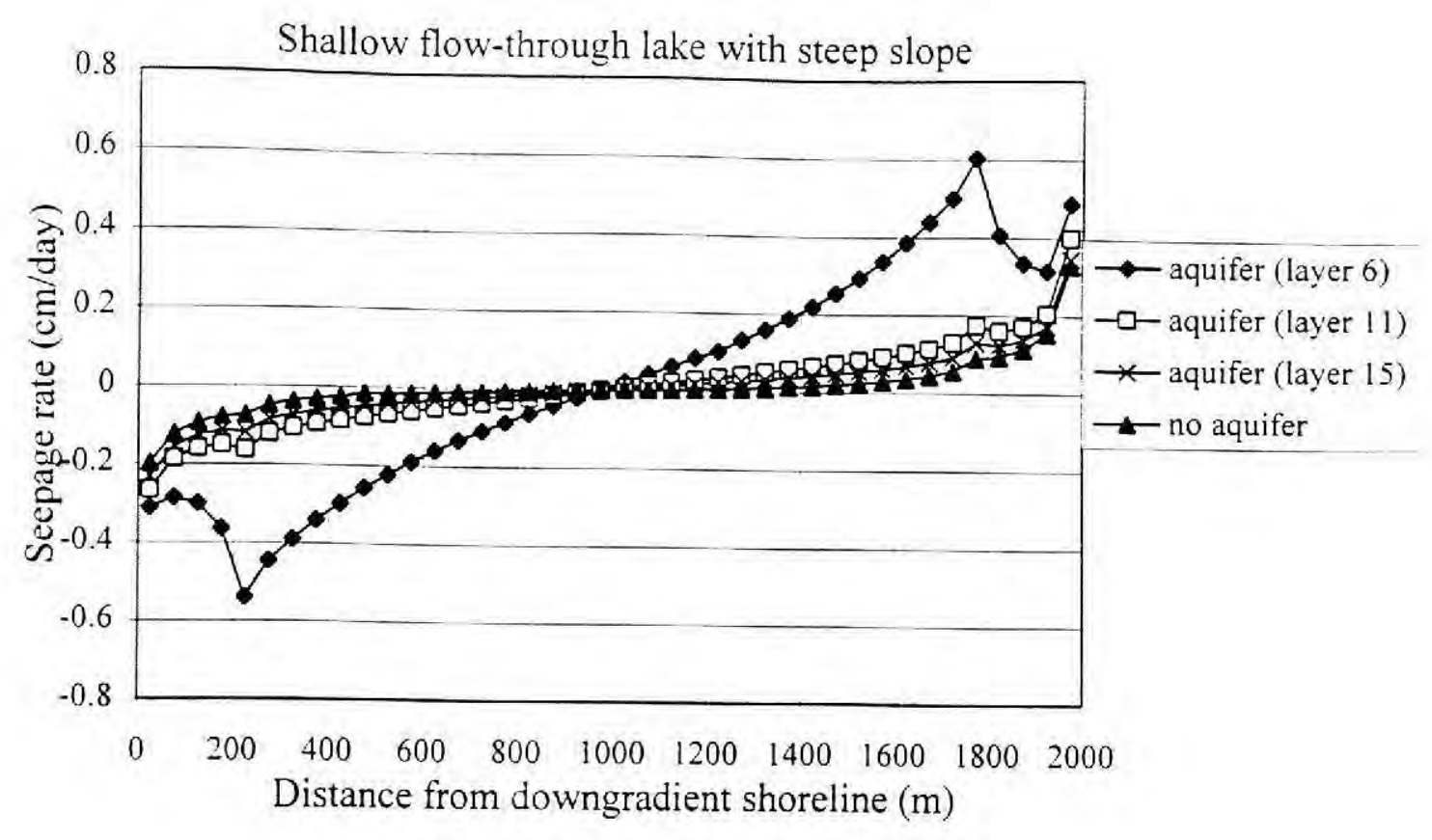

Shallow flow-through lake with low slope

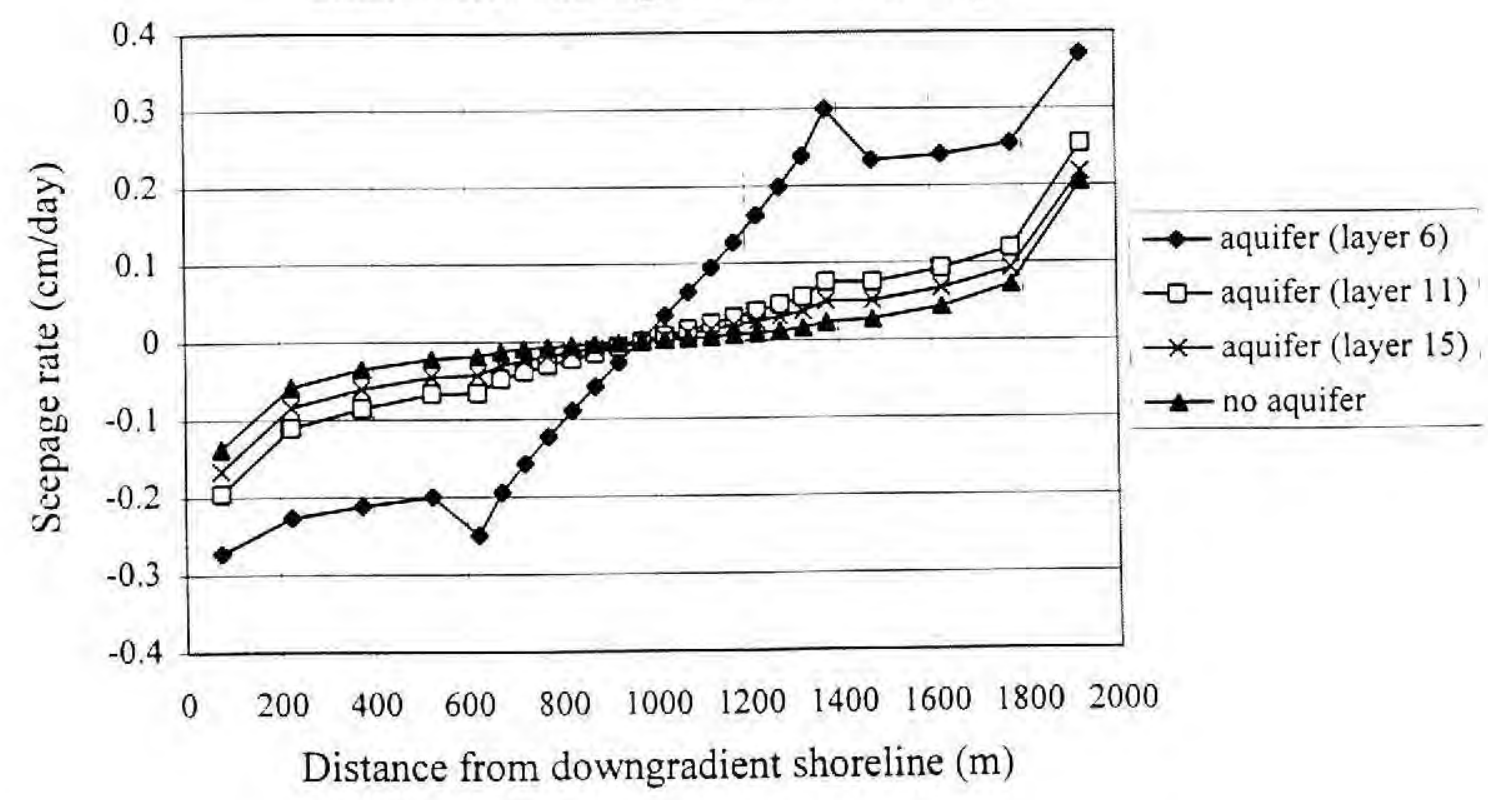

Fig. 14.20. Seepage rate versus distance from the downgradient shoreline for simulations of shallow flow-through lakes with steep and low lake bed slope and different vertical positions of a horizontally extensive aquifer. 


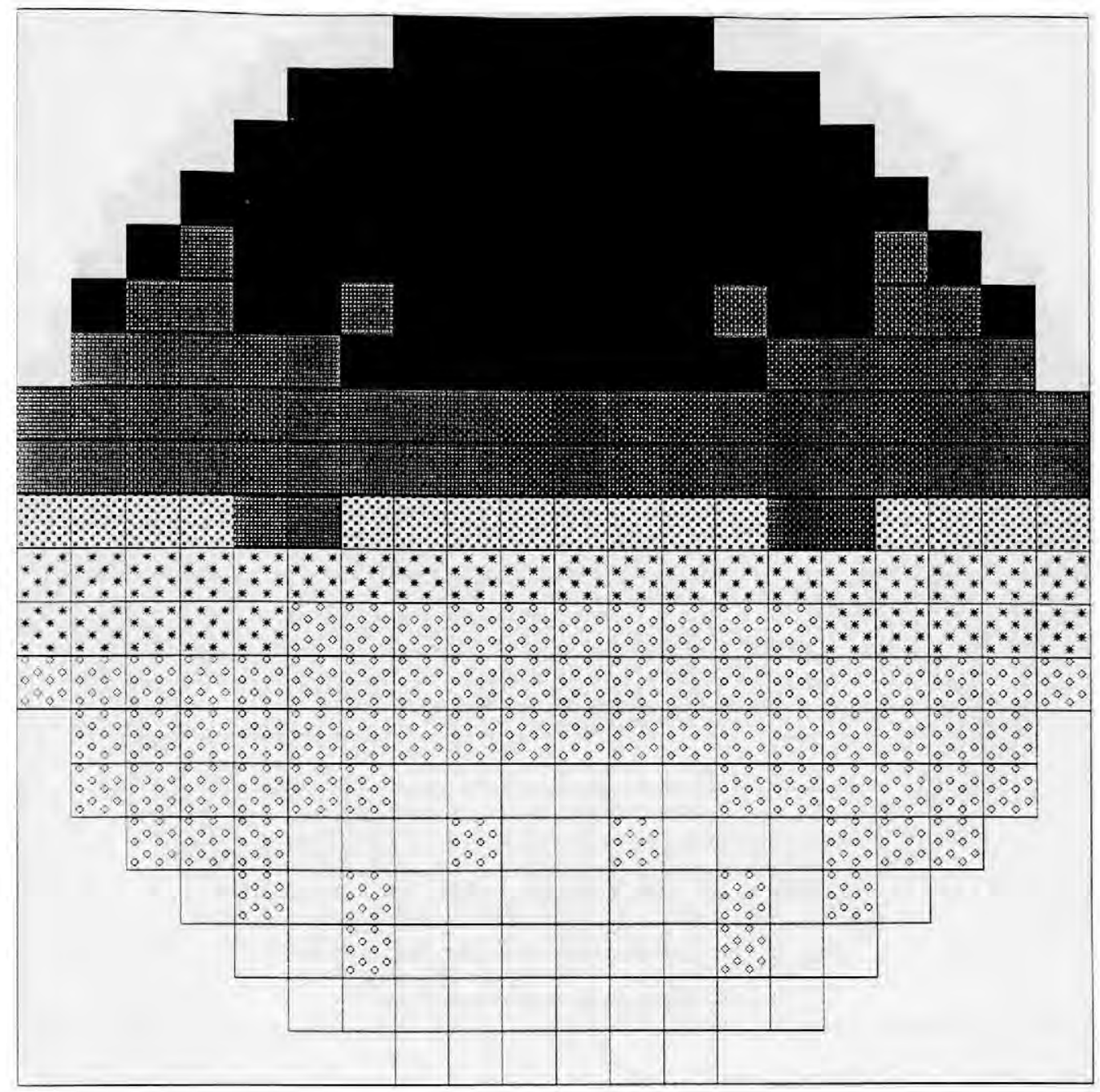

Fig. 14.21. Distribution of seepage rates (cm/day) over the lake bed for a shallow flow-through lake with moderate lake bed slope and a horizontally extensive aquifer just under the lake in layer 6 . The regional gradient of groundwater flow is from the top to the bottom of the figure.

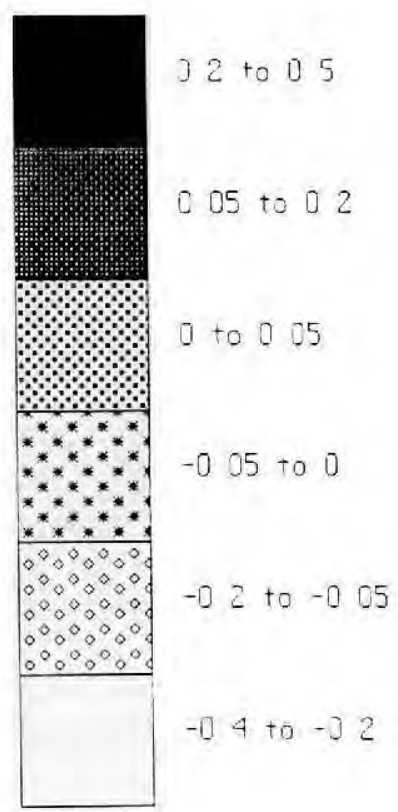




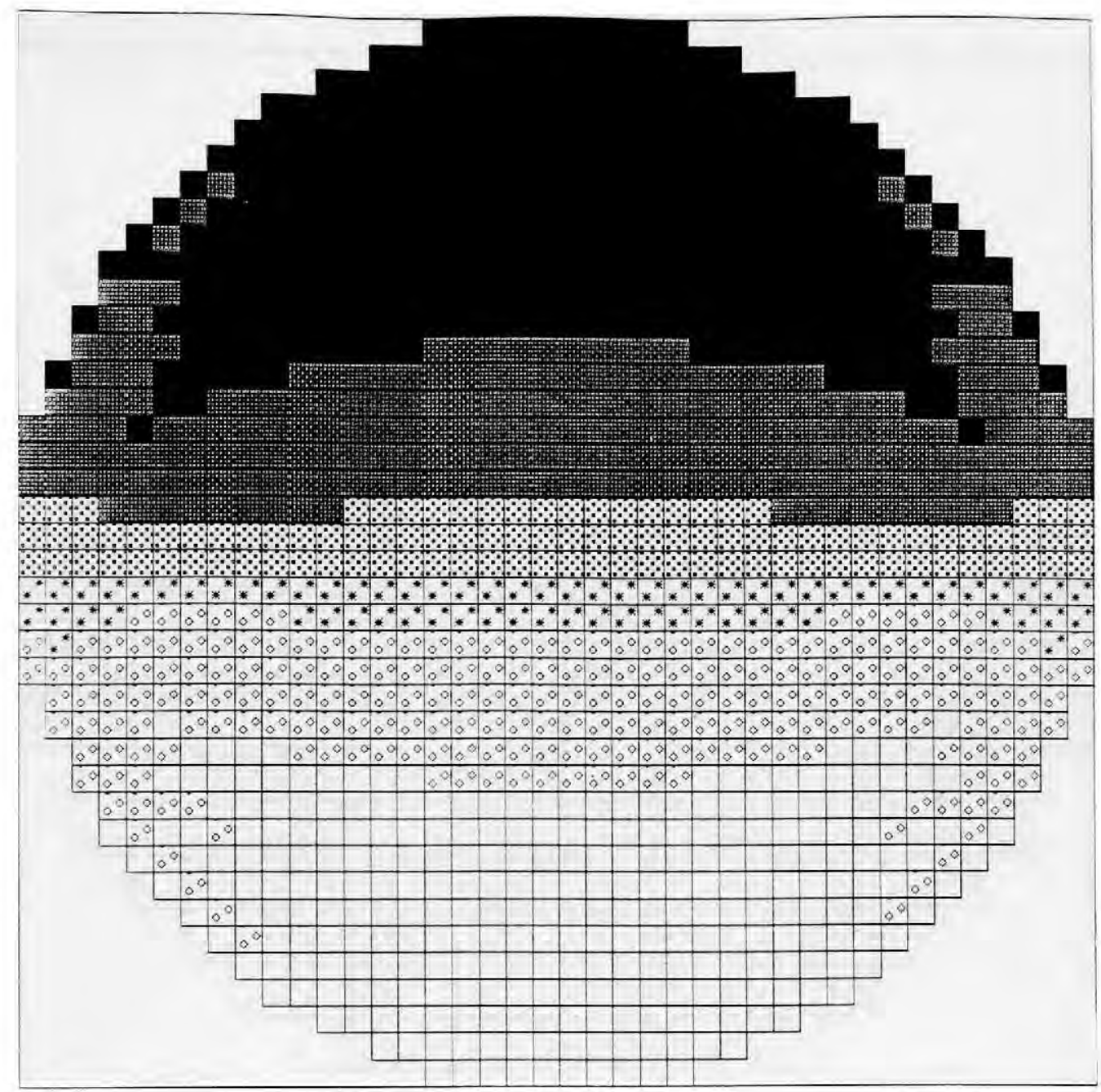

Fig. 14.22. Distribution of seepage rates ( $\mathrm{cm} /$ day) over the lake bed for a shallow flow-through lake with steep lake bed slope and a horizontally extensive aquifer just under the lake in layer 6 . The regional gradient of groundwater flow is from the top to the bottom of the figure.

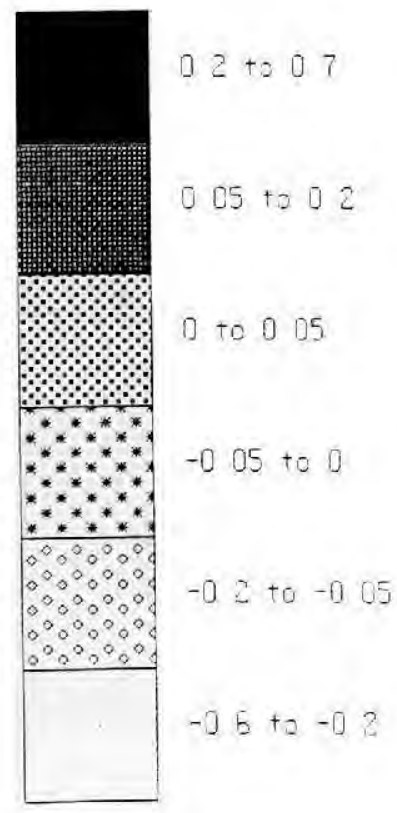




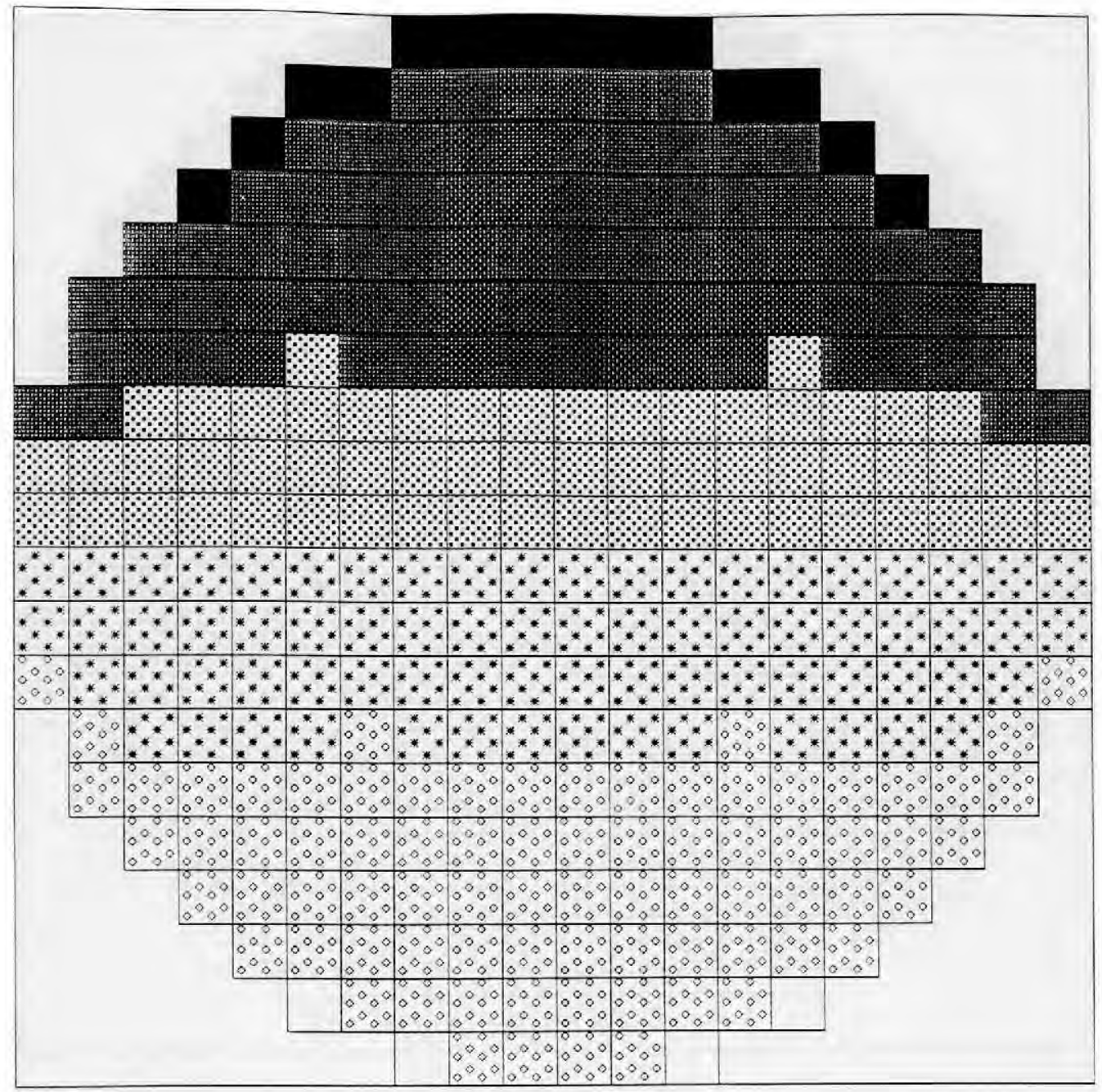

Fig. 14.23. Distribution of seepage rates ( $\mathrm{cm} /$ day) over the lake bed for a shallow flow-through lake with moderate lake bed slope and a horizontally extensive aquifer below the lake in layer 11 . The regional gradient of groundwater flow is from the top to the bottom of the figure.

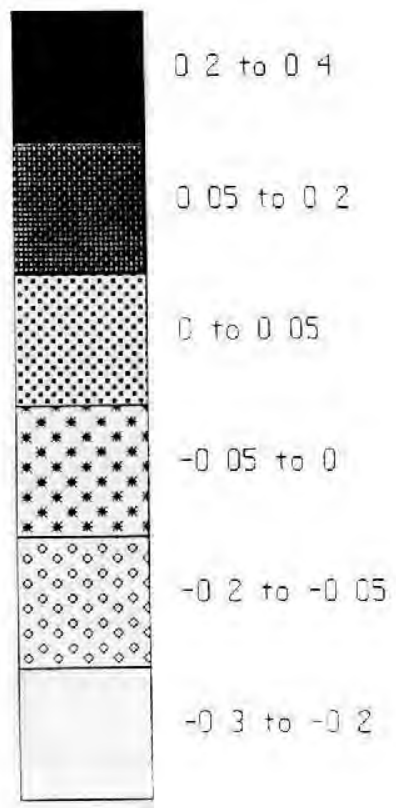




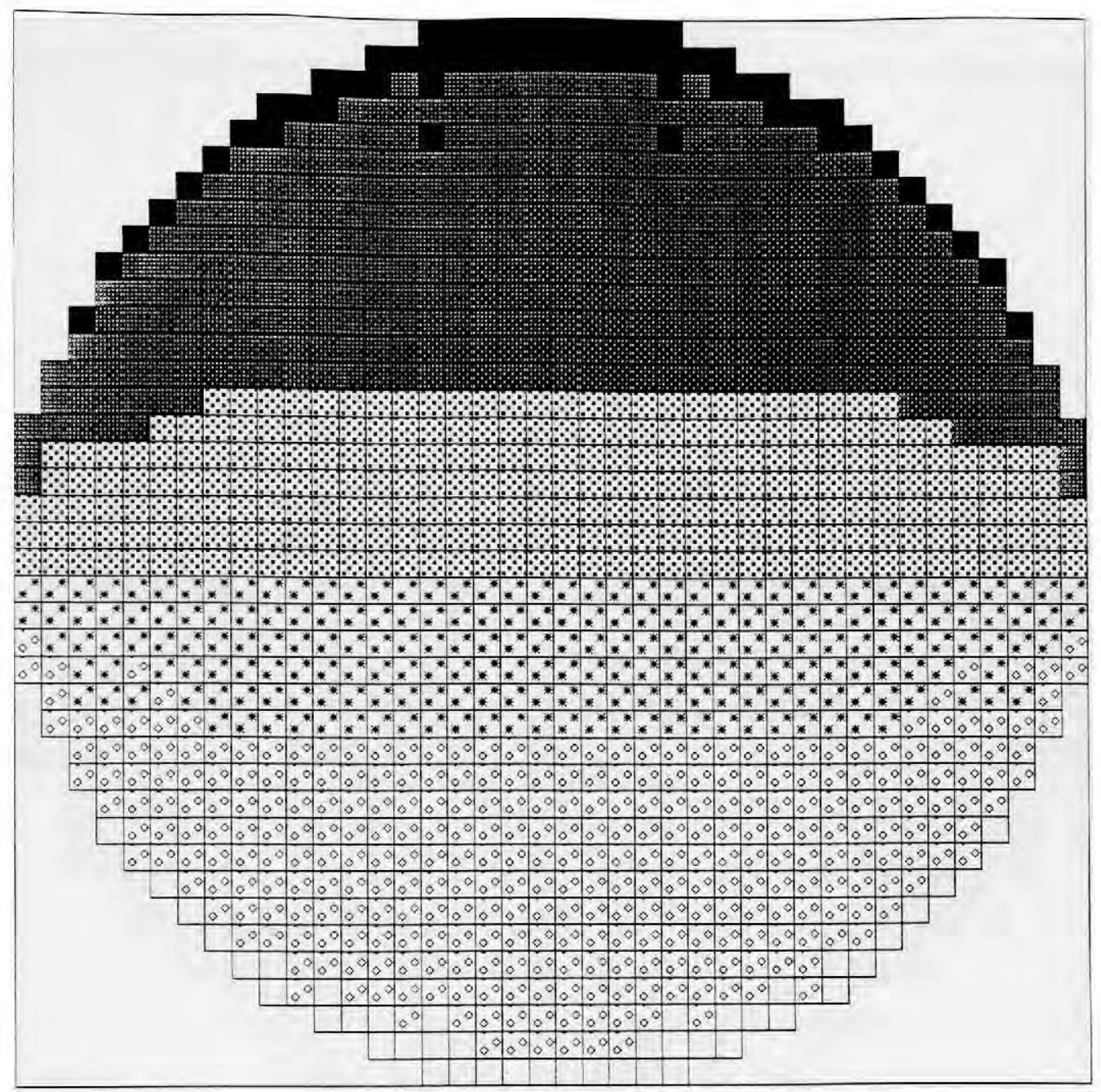

Fig. 14.24. Distribution of seepage rates ( $\mathrm{cm} /$ day) over the lake bed for a shallow flow-through lake with steep lake bed slope and a horizontally extensive aquifer below the lake in layer 11 . The regional gradient of groundwater flow is from the top to the bottom of the figure.

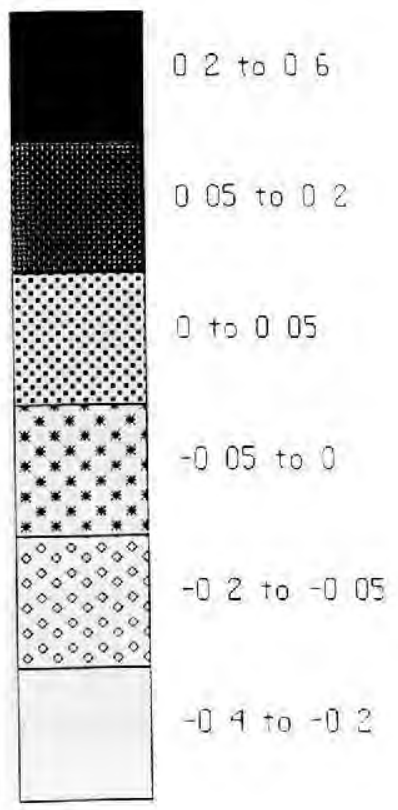




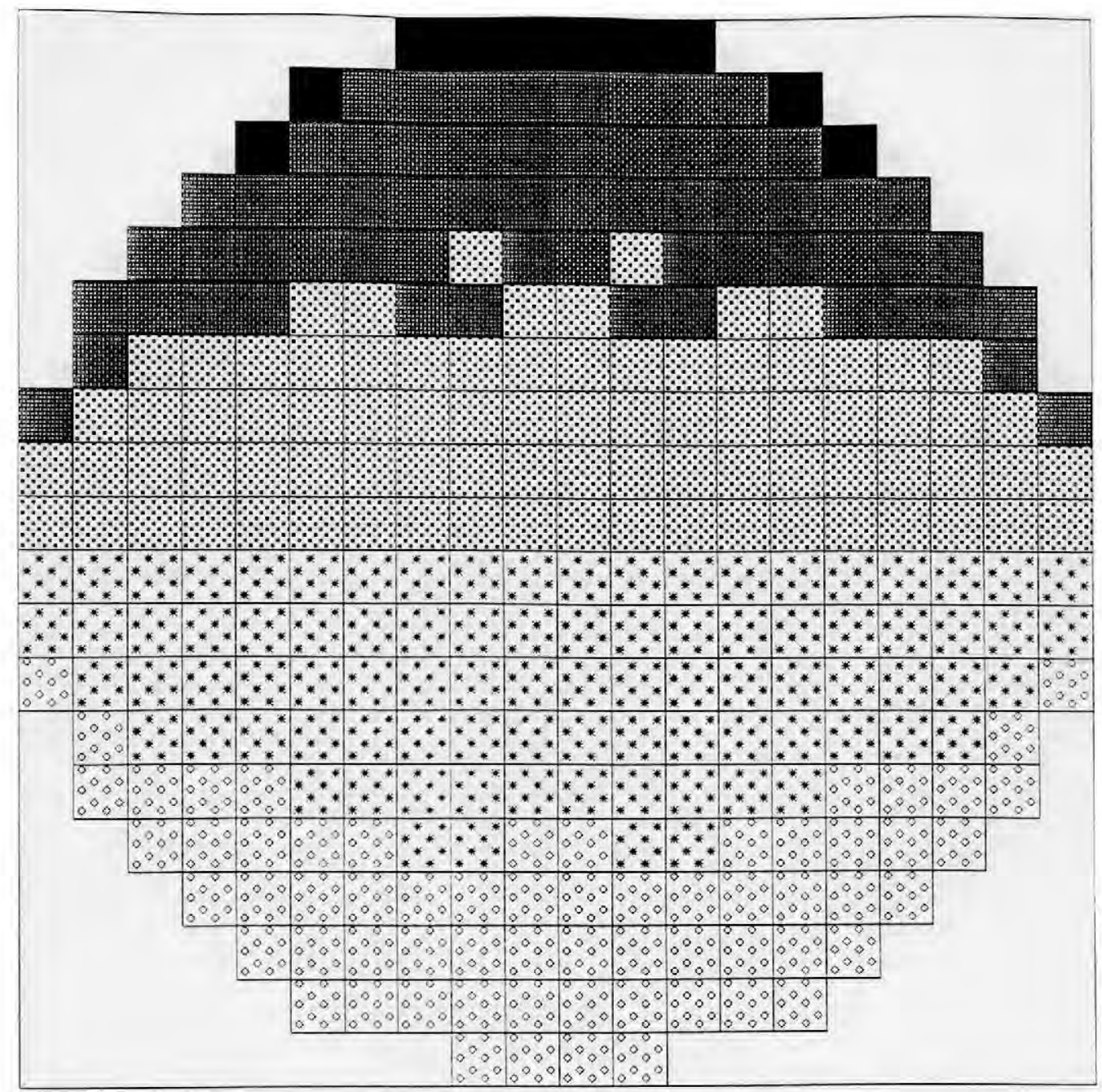

Fig. 14.25. Distribution of seepage rates ( $\mathrm{cm} /$ day) over the lake bed for a shallow flow-through lake with moderate lake bed slope and a horizontally extensive aquifer at the bottom of the porous medium in layer 15 . The regional gradient of groundwater flow is from the top to the bottom of the figure.

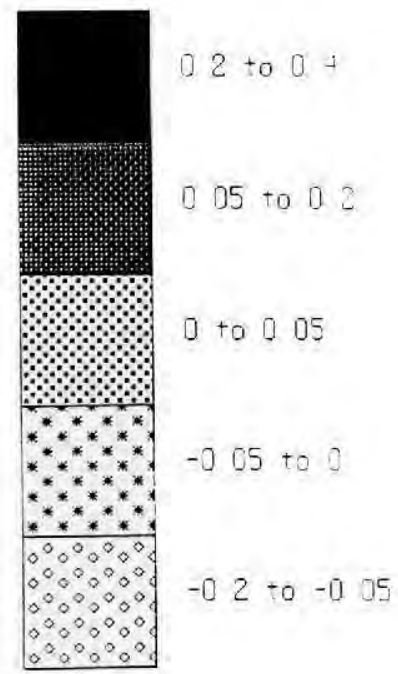




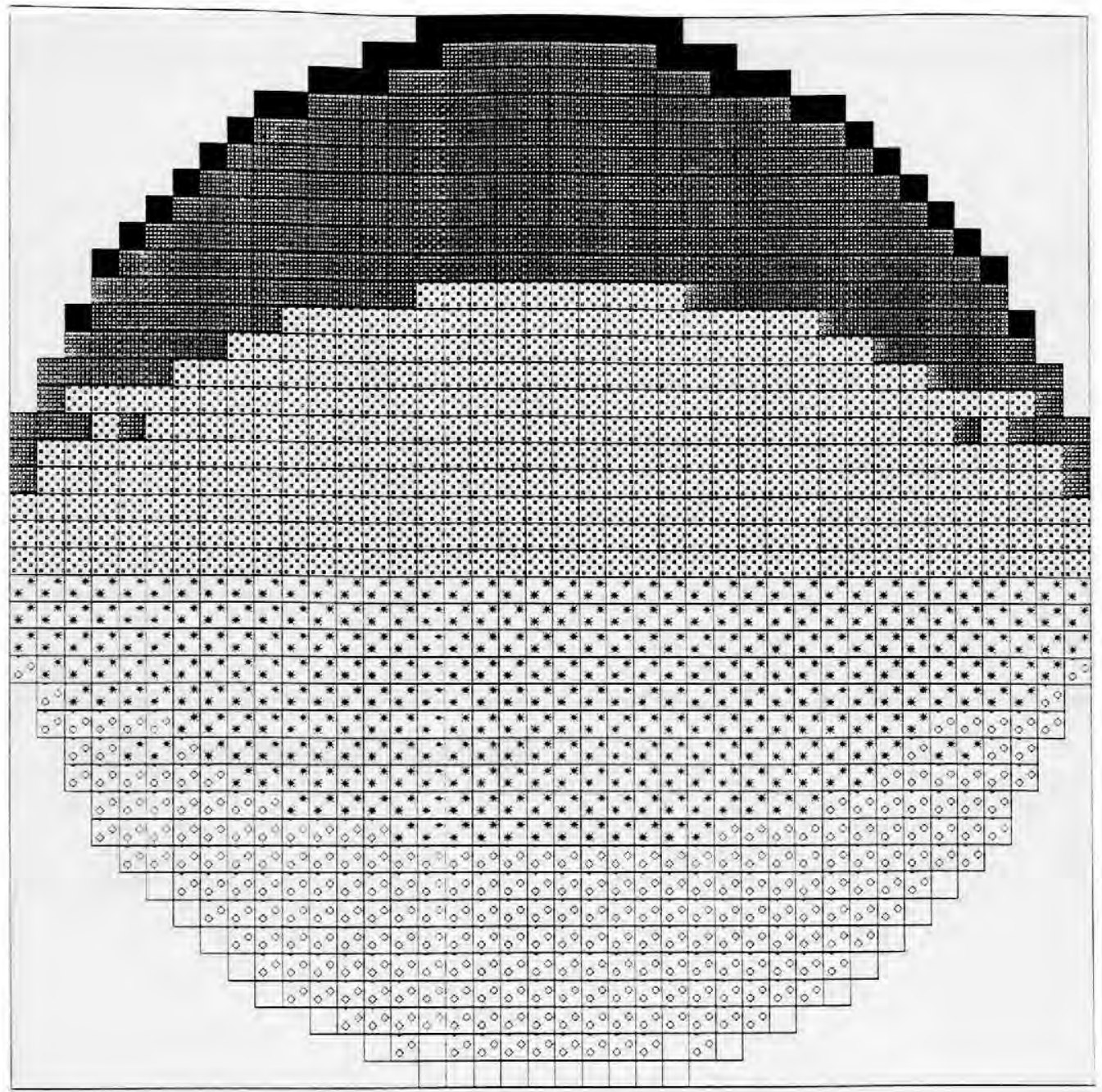

Fig. 14.26. Distribution of seepage rates ( $\mathrm{cm} /$ day) over the lake bed for a shallow flow-through lake with steep lake bed slope and a horizontally extensive aquifer at the bottom of the porous medium in layer 15 . The regional gradient of groundwater flow is from the top to the bottom of the figure.

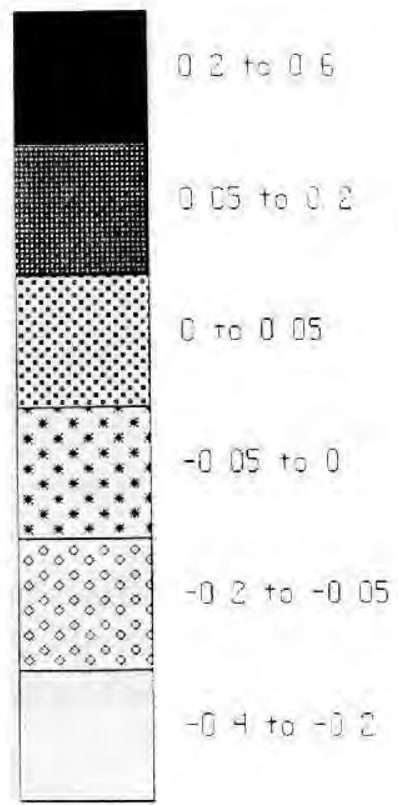




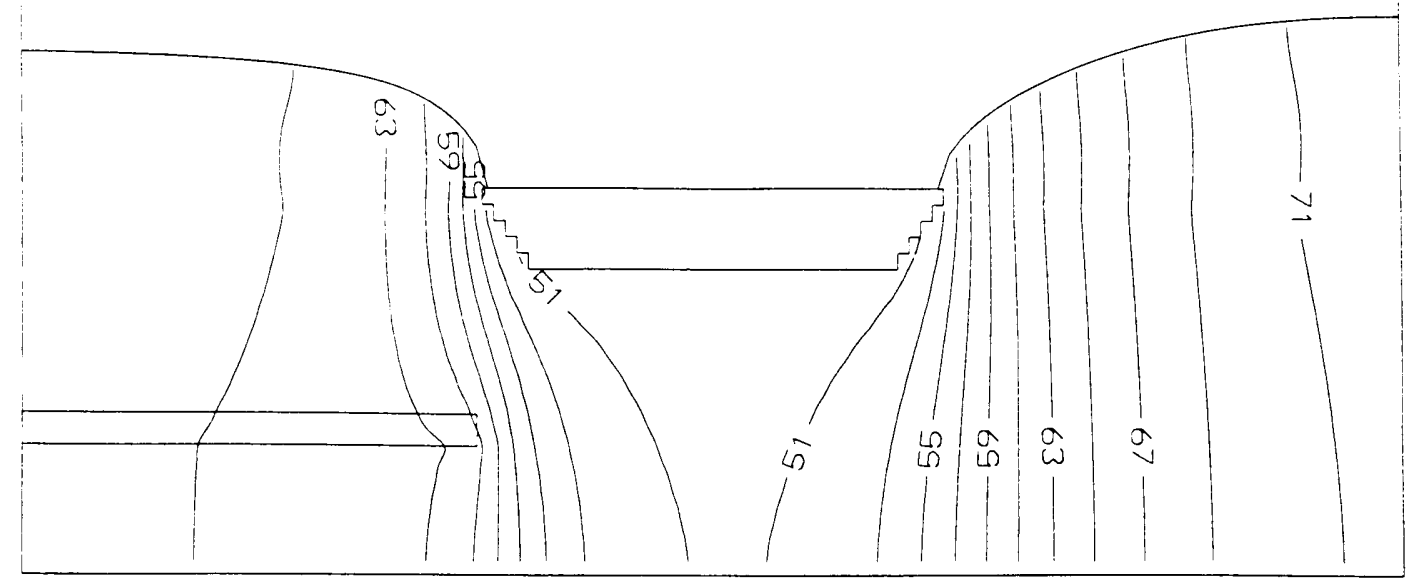

Aquifer near the domain boundary

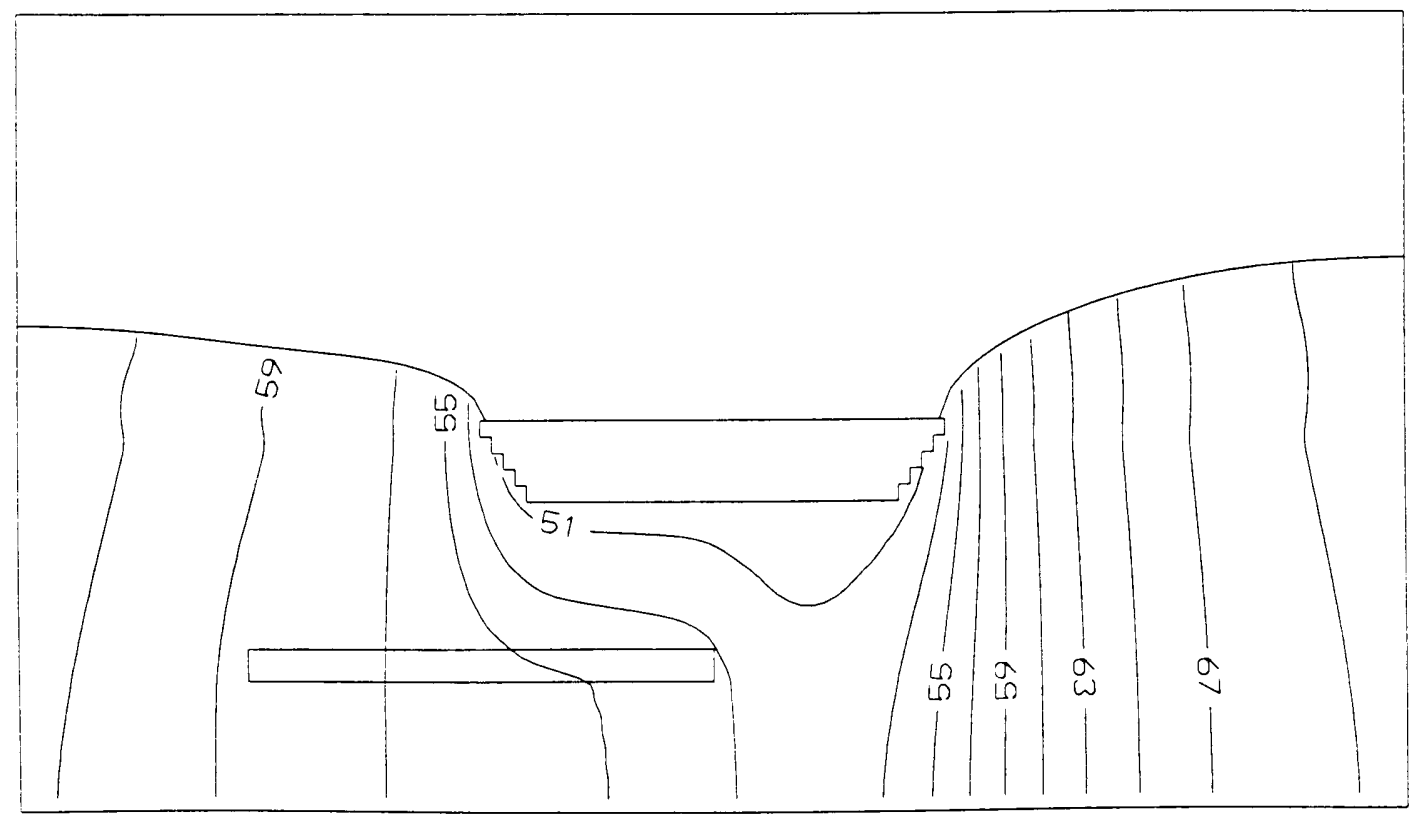

Aquifer partially under the lake

Fig. 14.27. Distribution of hydraulic heads in the porous medium surrounding shallow inflow lakes with steep lake bed slopes and a laterally restricted aquifer near the domain boundary (above) and partially under the lake (below). 


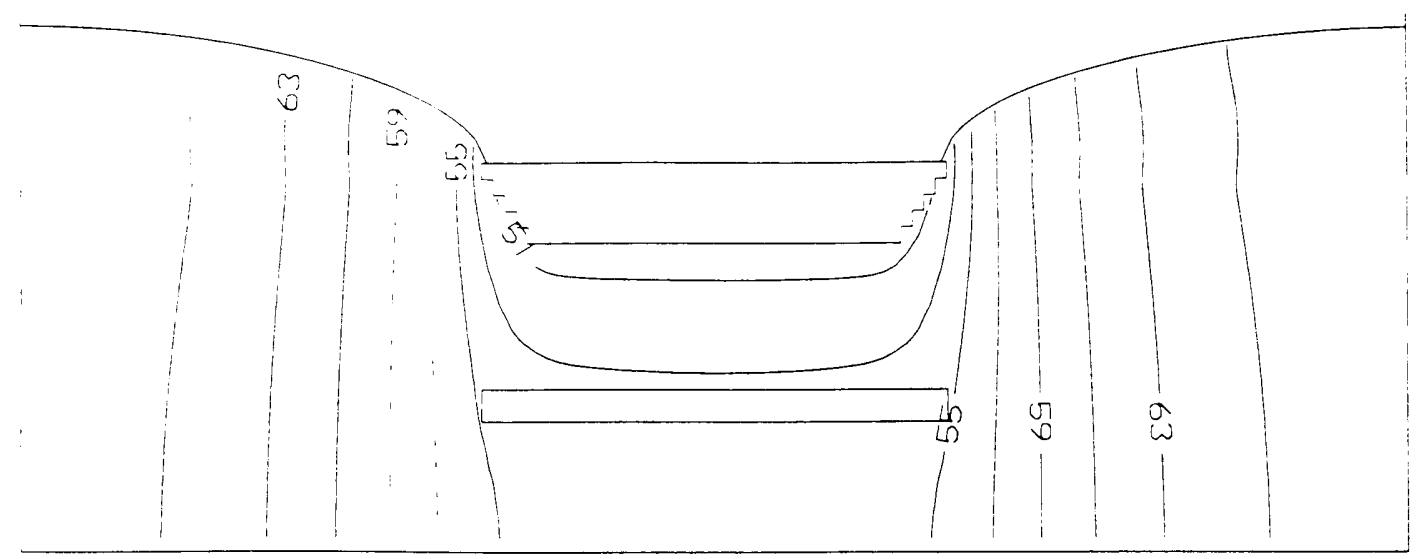

Aquifer directly under the lake

Fig. 14.28. Distribution of hydraulic heads in the porous medium surrounding shallow inflow lake with steep lake bed slope and a laterally restricted aquifer directly under the lake. 
Shallow inflow lake with moderate slope

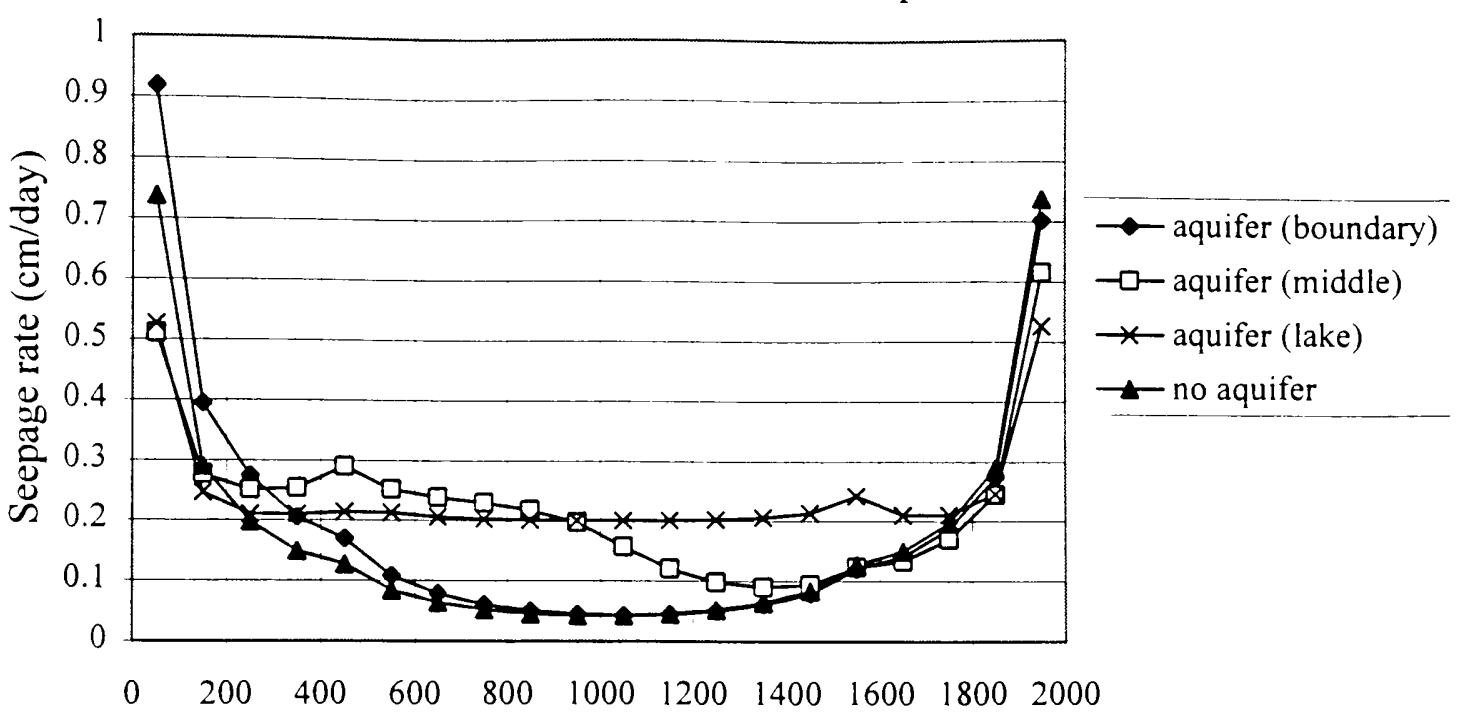

Distance offshore $(\mathrm{m})$

Deep inflow lake with moderate slope

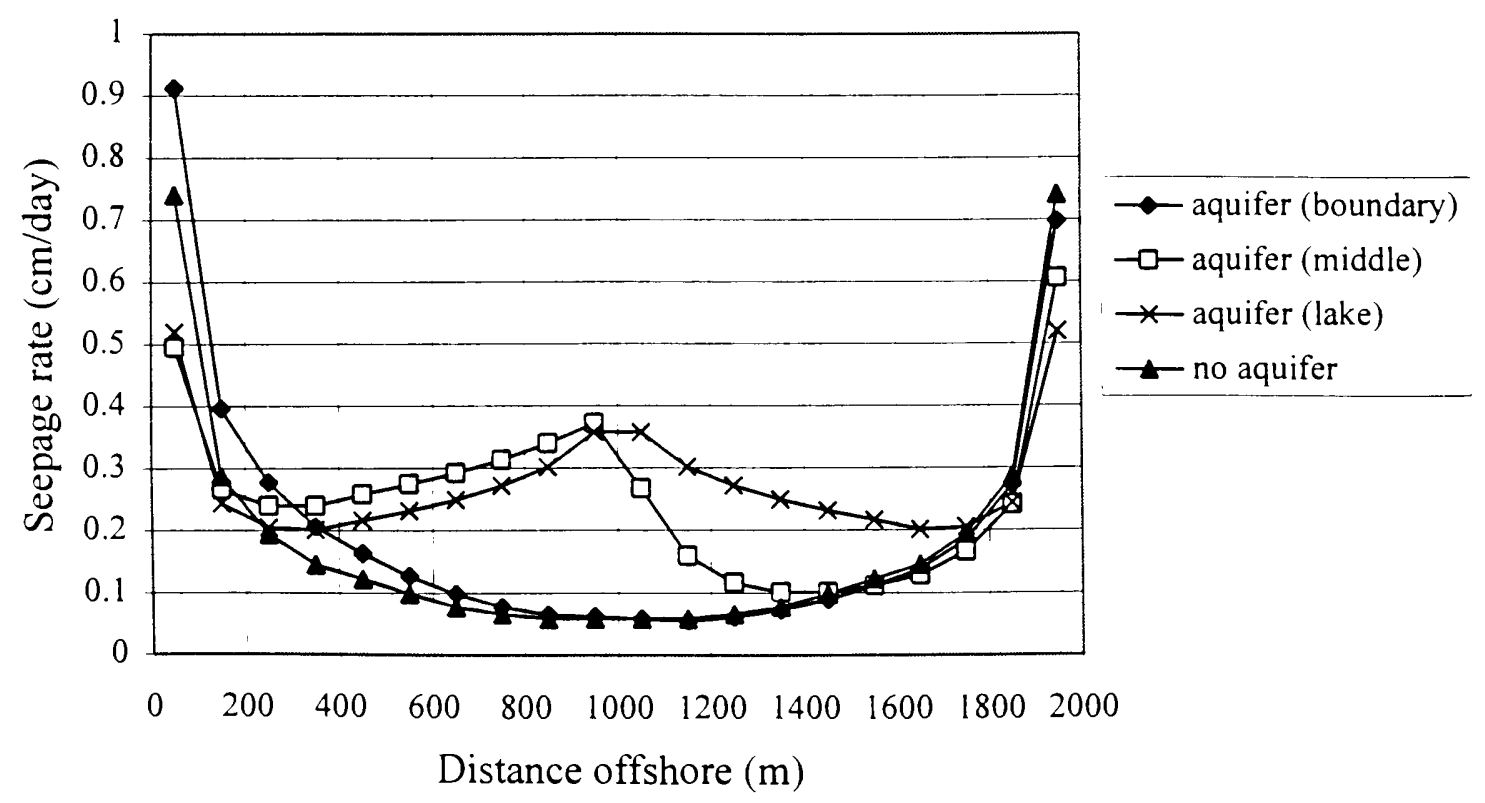

Fig. 14.29. Seepage rate versus distance offshore for simulations of shallow and deep inflow lakes with moderate lake bed slope and different horizontal positions of a laterally restricted aquifer (no aquifer, and aquifer near the domain boundary, partially under the lake, and directly under the lake). Distance offshore is measured from the lake shore on the left hand side of Figs. 14.17 and 14.18. 

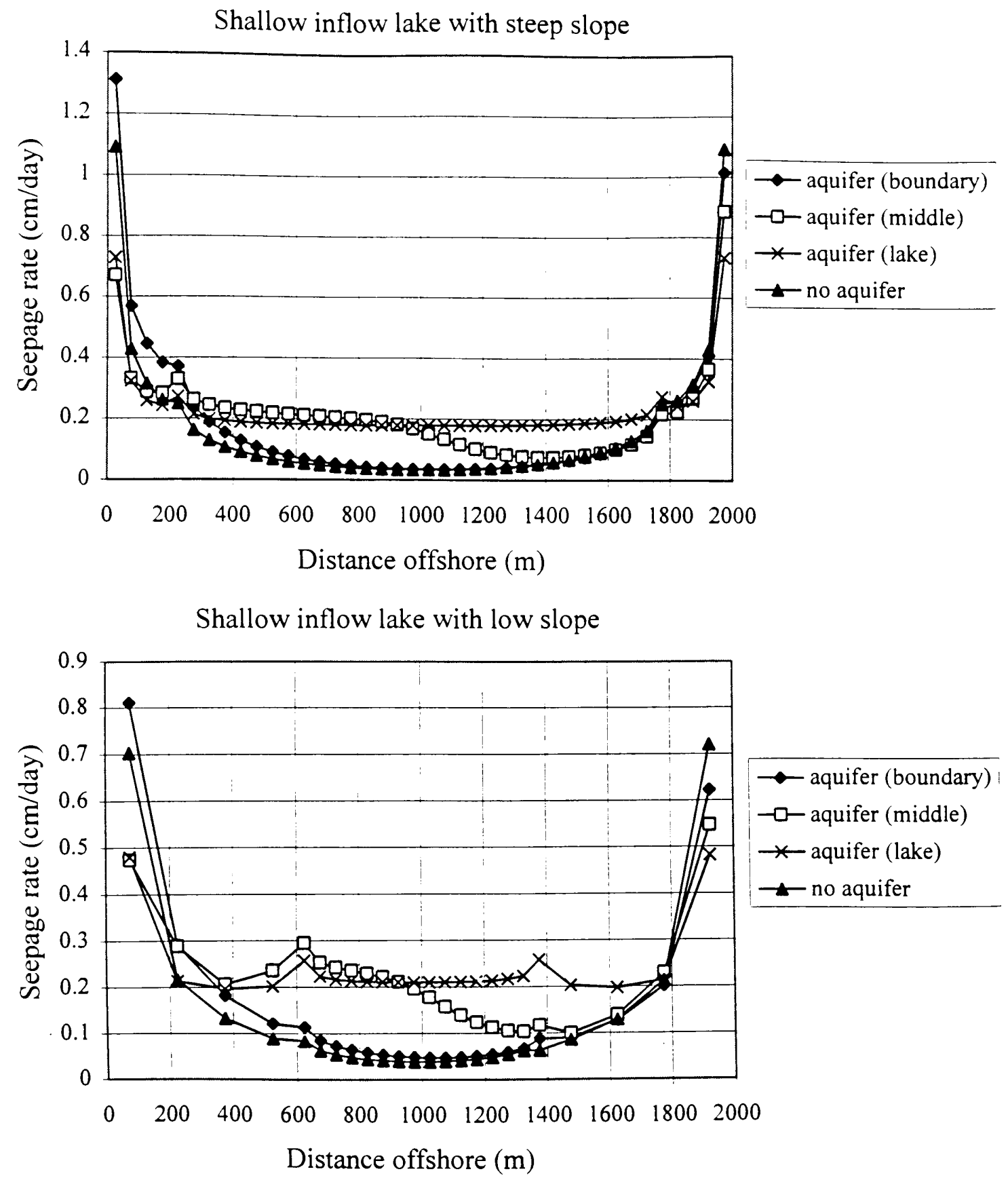

Fig. 14.30. Seepage rate versus distance offshore for simulations of shallow inflow lakes with steep and low lake bed slope and different horizontal positions of a laterally restricted aquifer (no aquifer, and aquifer near the domain boundary, partially under the lake, and directly under the lake). Distance offshore is measured from the lake shore on the left hand side of Figs. 14.17 and 14.18. 


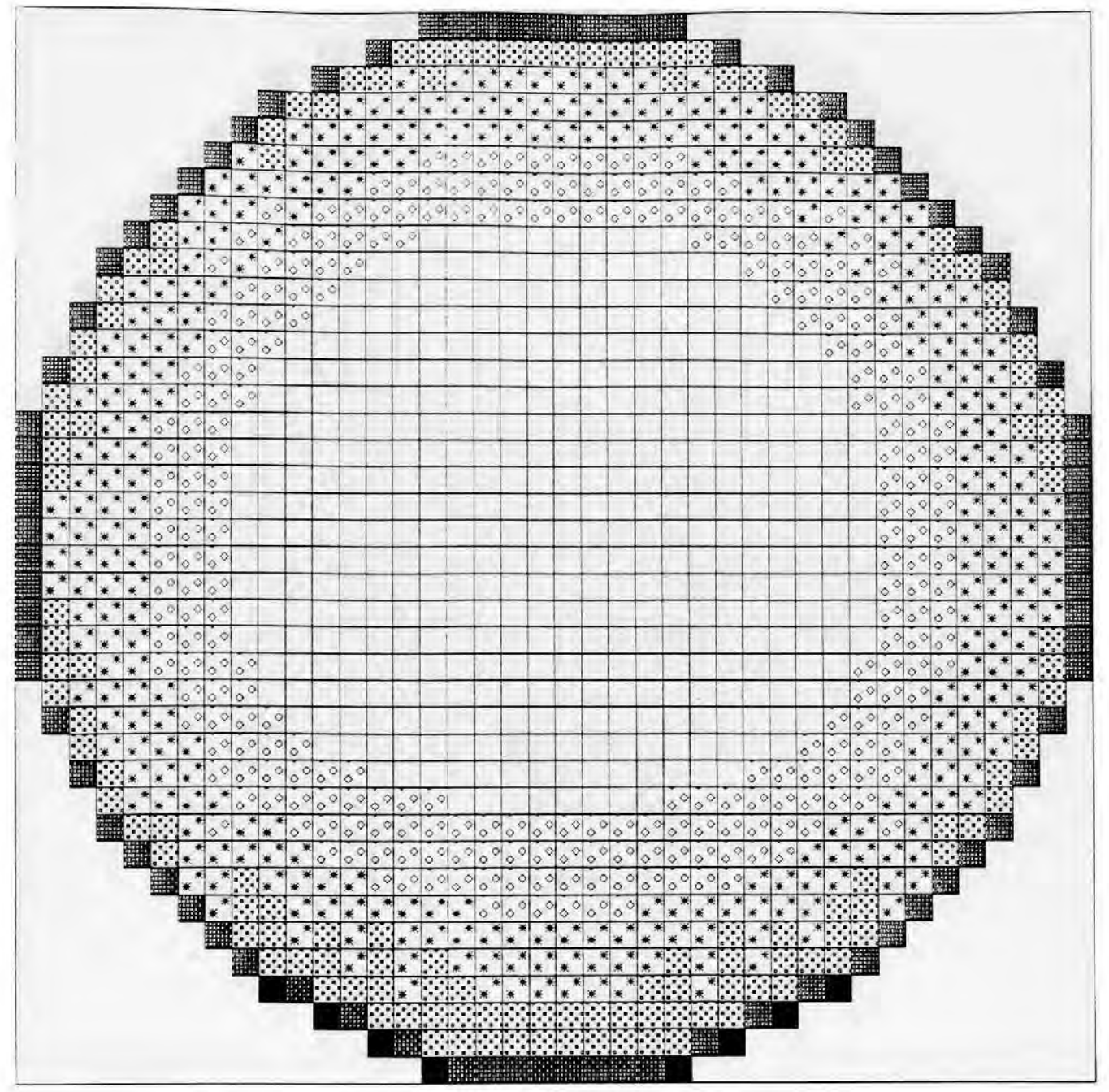

Fig. 14.31. Distribution of seepage rates ( $\mathrm{cm} /$ day) over the lake bed for a shallow inflow lake with steep lake bed slope and a laterally restricted aquifer at the domain boundary (at the bottom of the above figure).

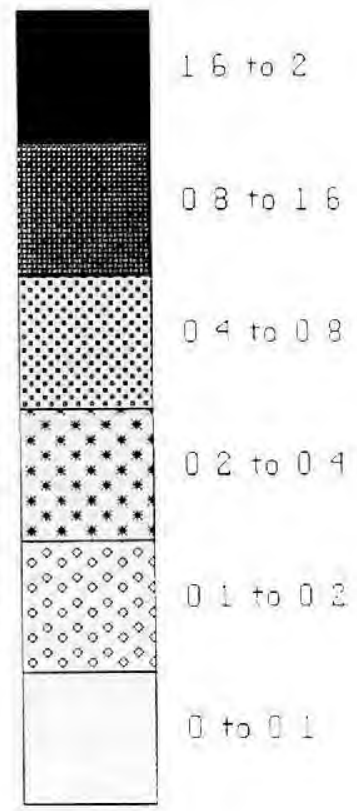




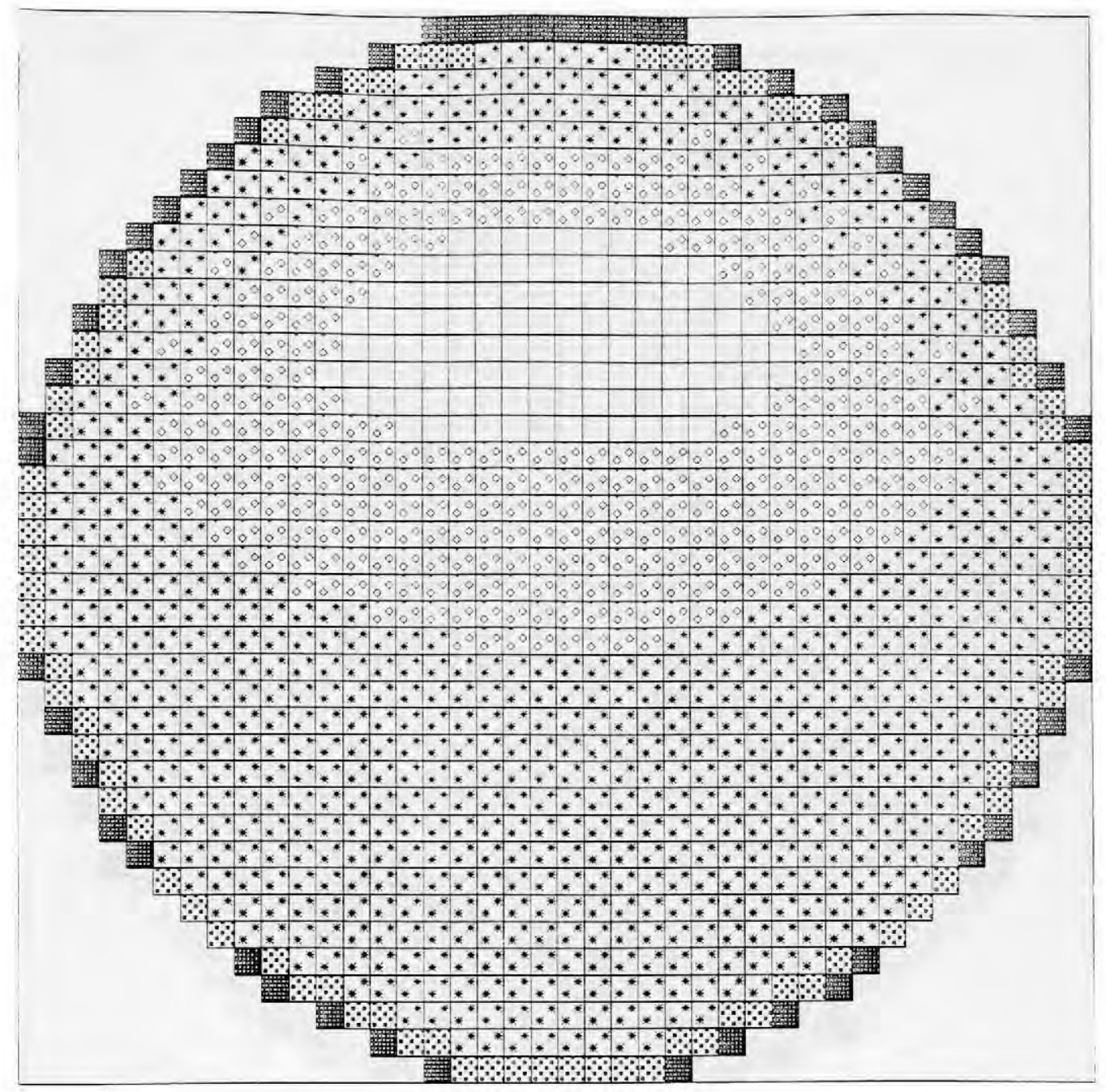

Fig. 14.32. Distribution of seepage rates ( $\mathrm{cm} /$ day) over the lake bed for a shallow inflow lake with steep lake bed slope and a laterally restricted aquifer partially under the lake (between the bottom and center of the figure).

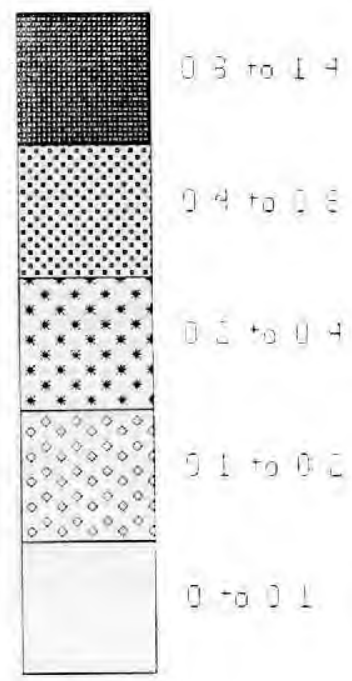




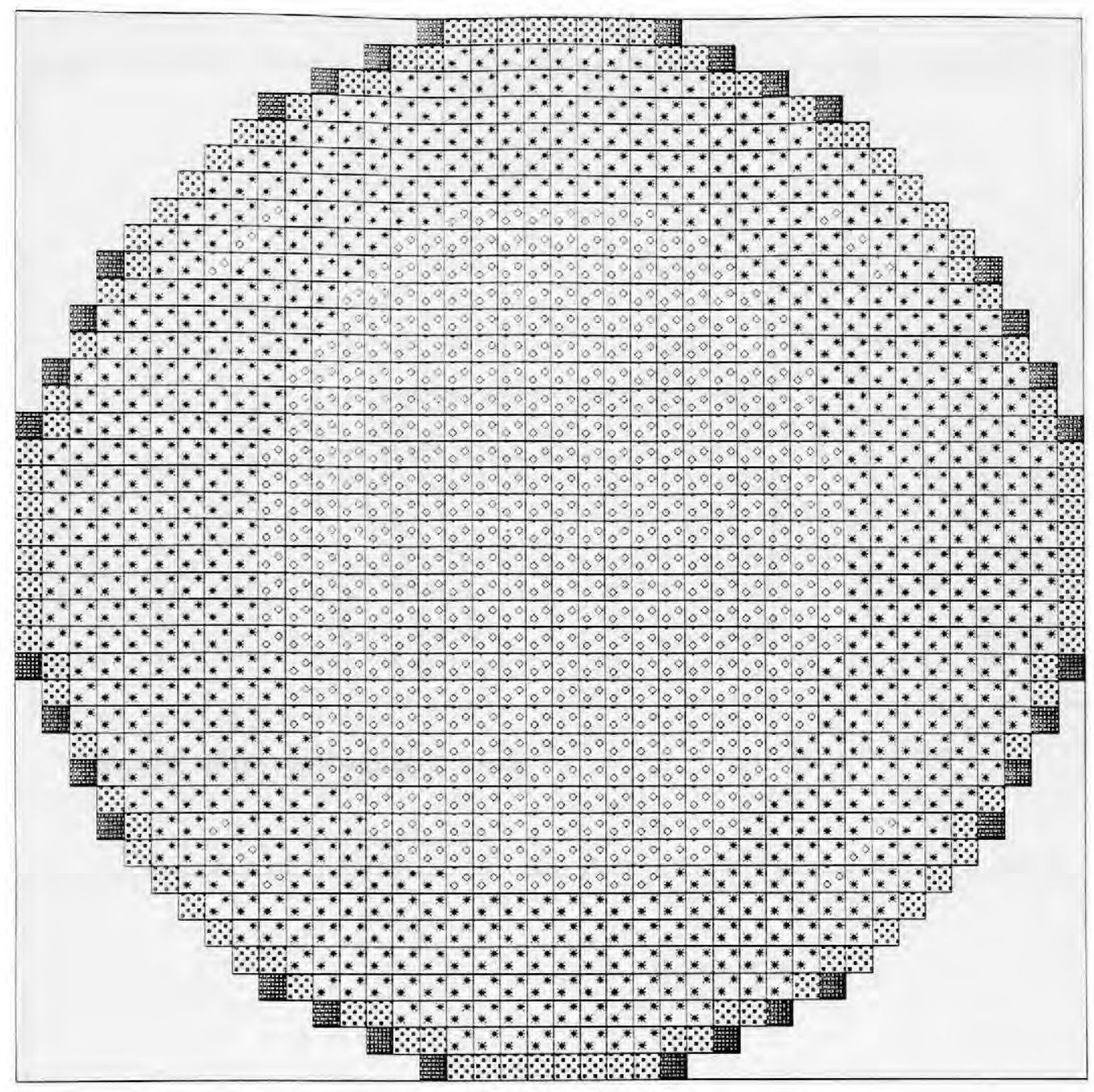

Fig. 14.33. Distribution of seepage rates ( $\mathrm{cm} /$ day) over the lake bed for a shallow inflow lake with steep lake bed slope and a laterally restricted aquifer directly under the lake (in the center of the figure from left to right).

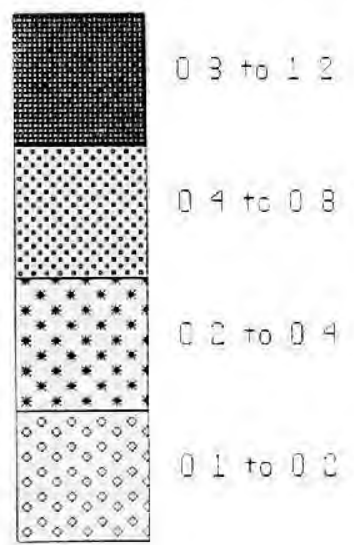




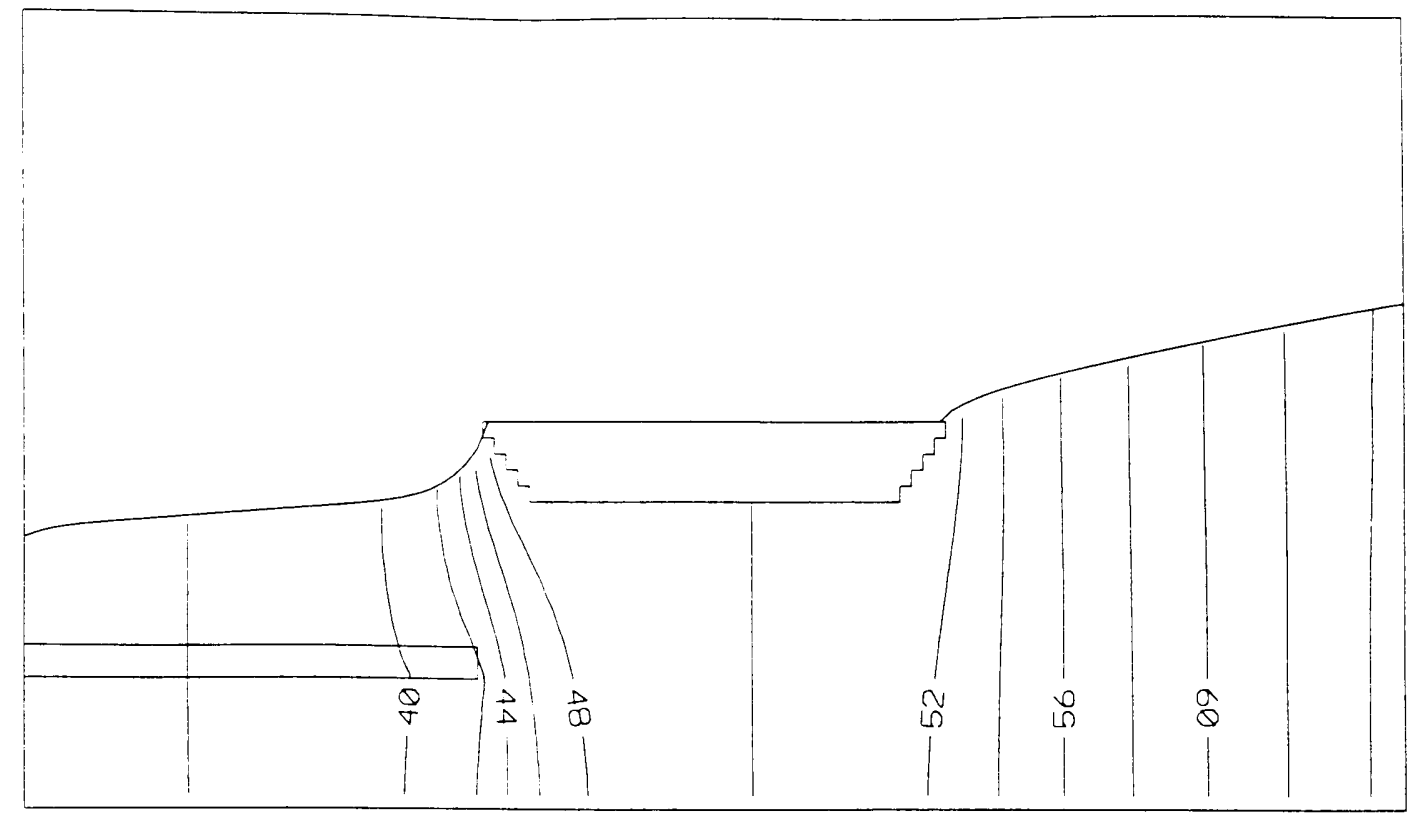

Aquifer at the downgradient side

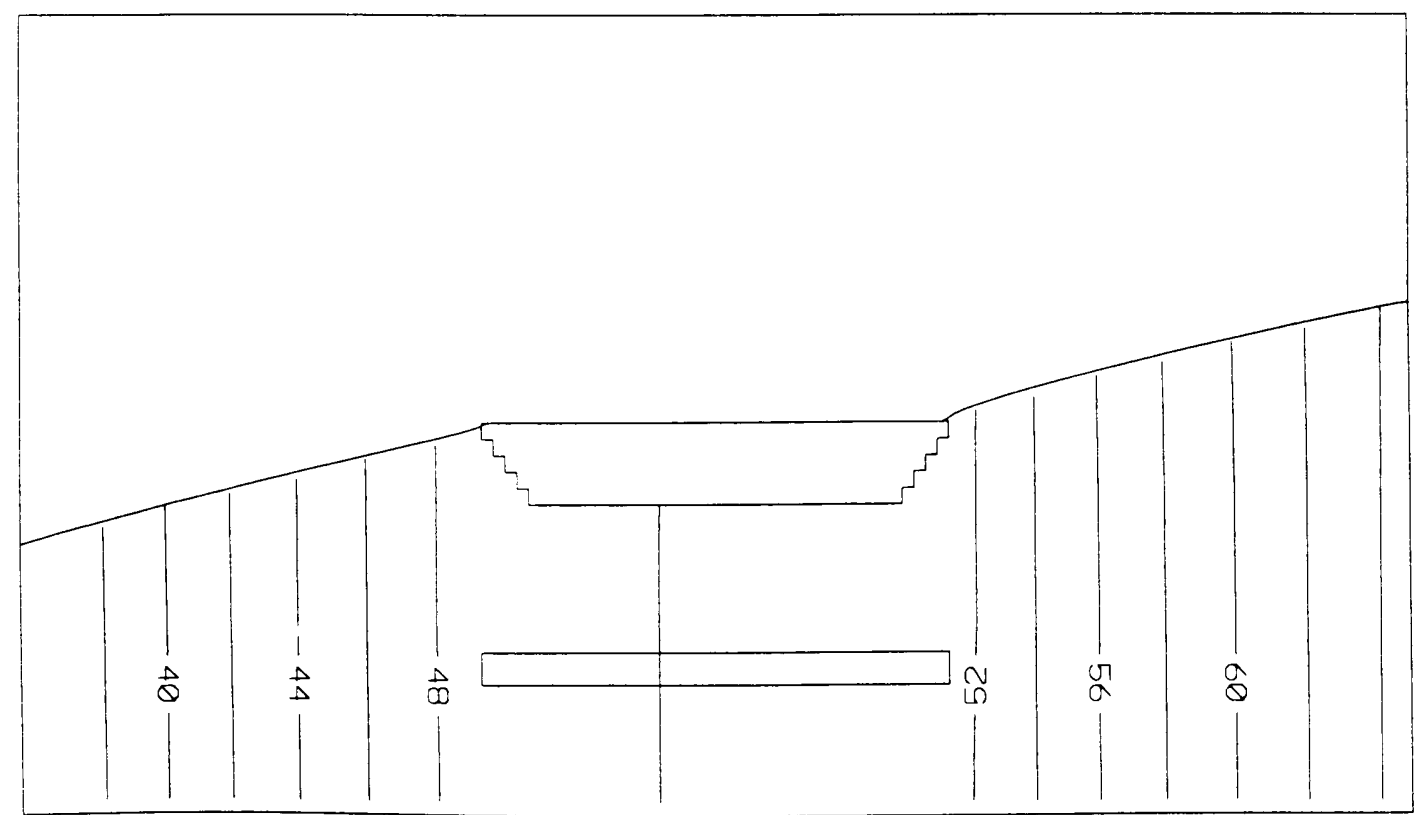

Aquifer directly under the lake

Fig. 14.34. Distribution of hydraulic heads in the porous medium surrounding shallow flowthrough lakes with steep lake bed slope and a laterally restricted aquifer at the downgradient side of the model domain (above) and directly under the lake (below). 


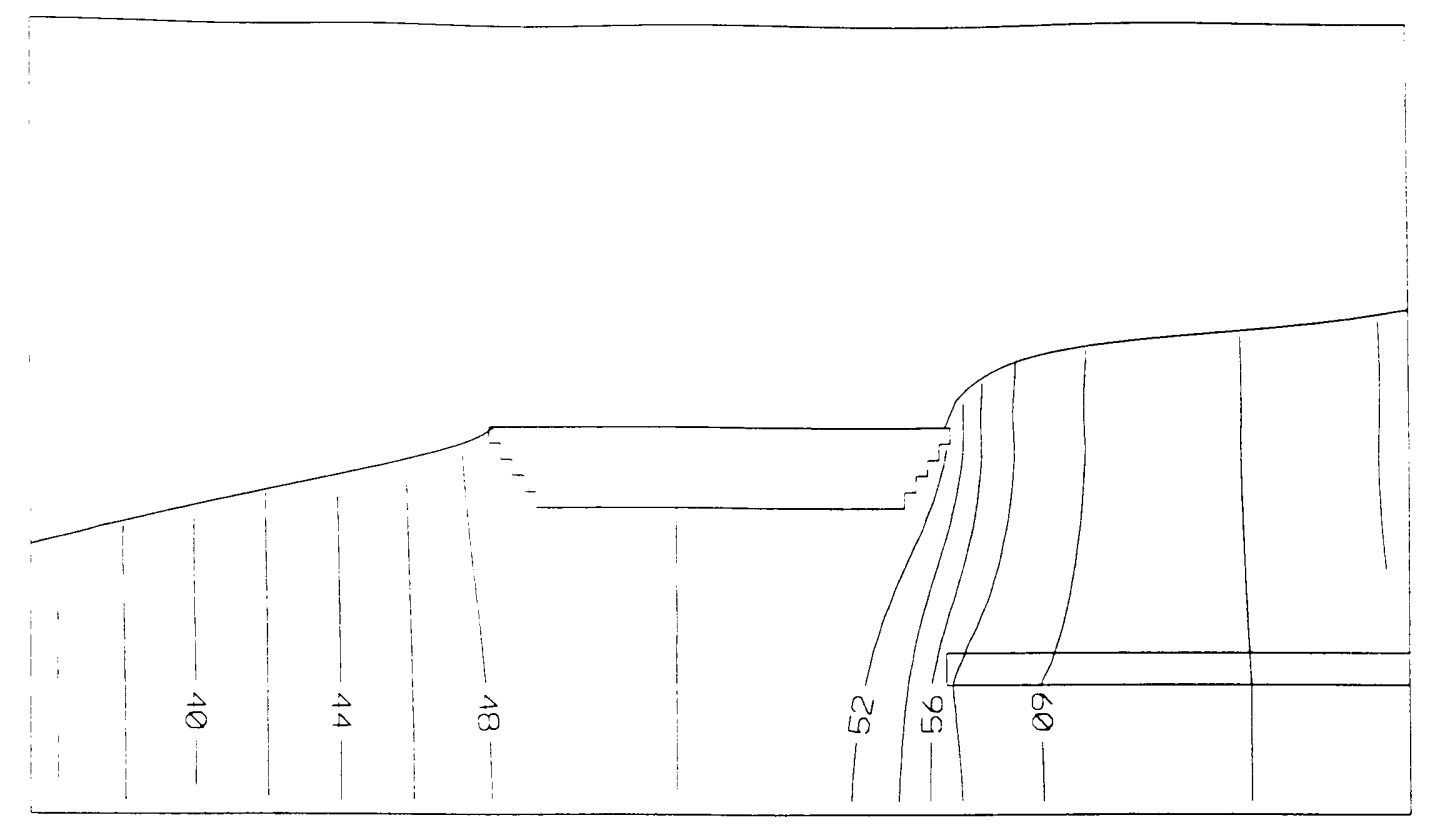

Aquifer at the upgradient side

Fig. 14.35. Distribution of hydraulic heads in the porous medium surrounding shallow flowthrough lakes with steep lake bed slope and a laterally restricted aquifer at the upgradient side of the model domain. 
Section parallel to the regional gradient

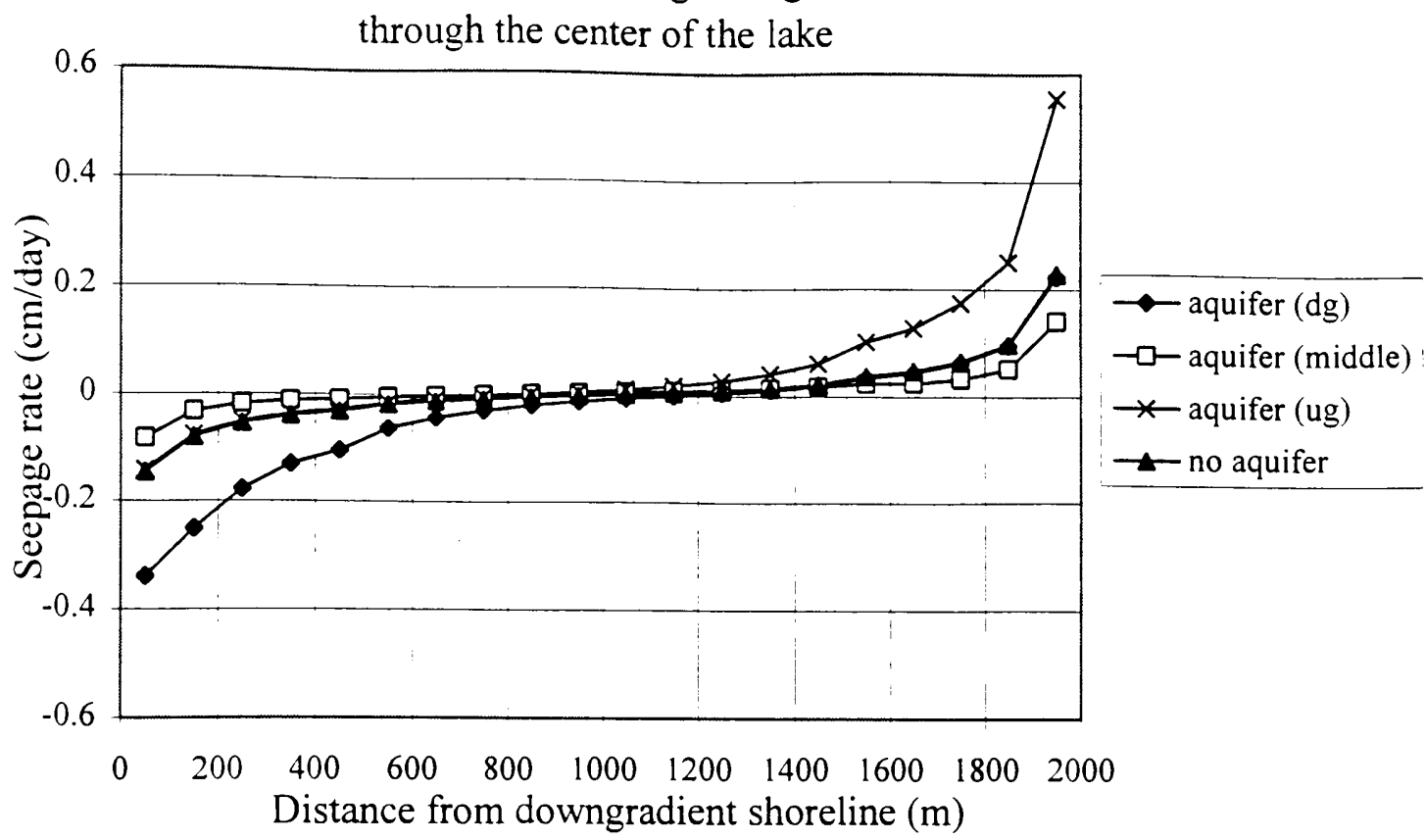

Section normal to the regional gradient

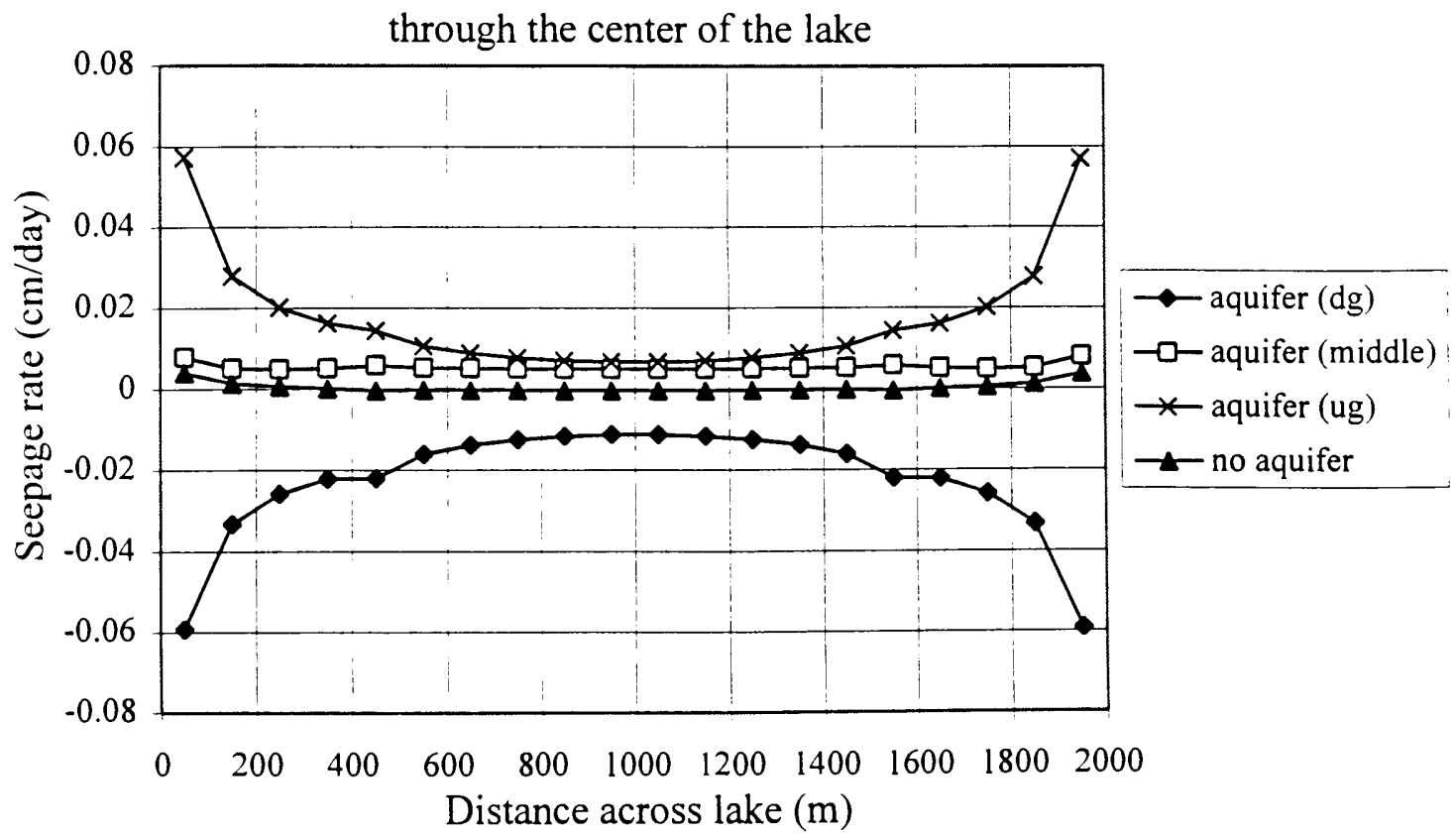

Fig. 14.36. Seepage rate versus distance for simulations of shallow flow-through lakes with moderate lake bed slope and different horizontal positions of a laterally restricted aquifer (no aquifer, and aquifer on the downgradient (dg) and upgradient (ug) sides of the model domain, and directly under the lake). 
Section parallel to the regional gradient

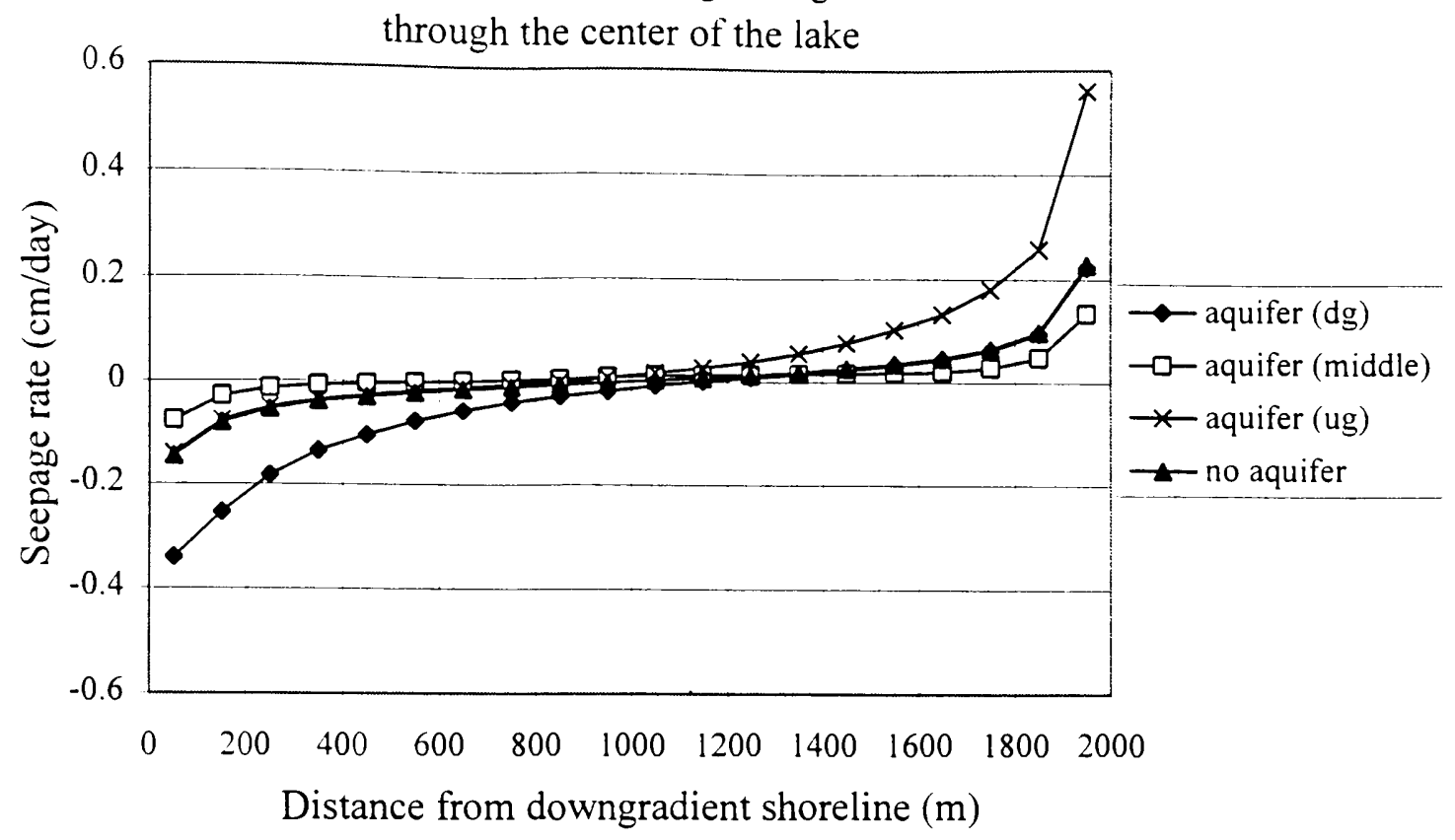

Section normal to the regional gradient

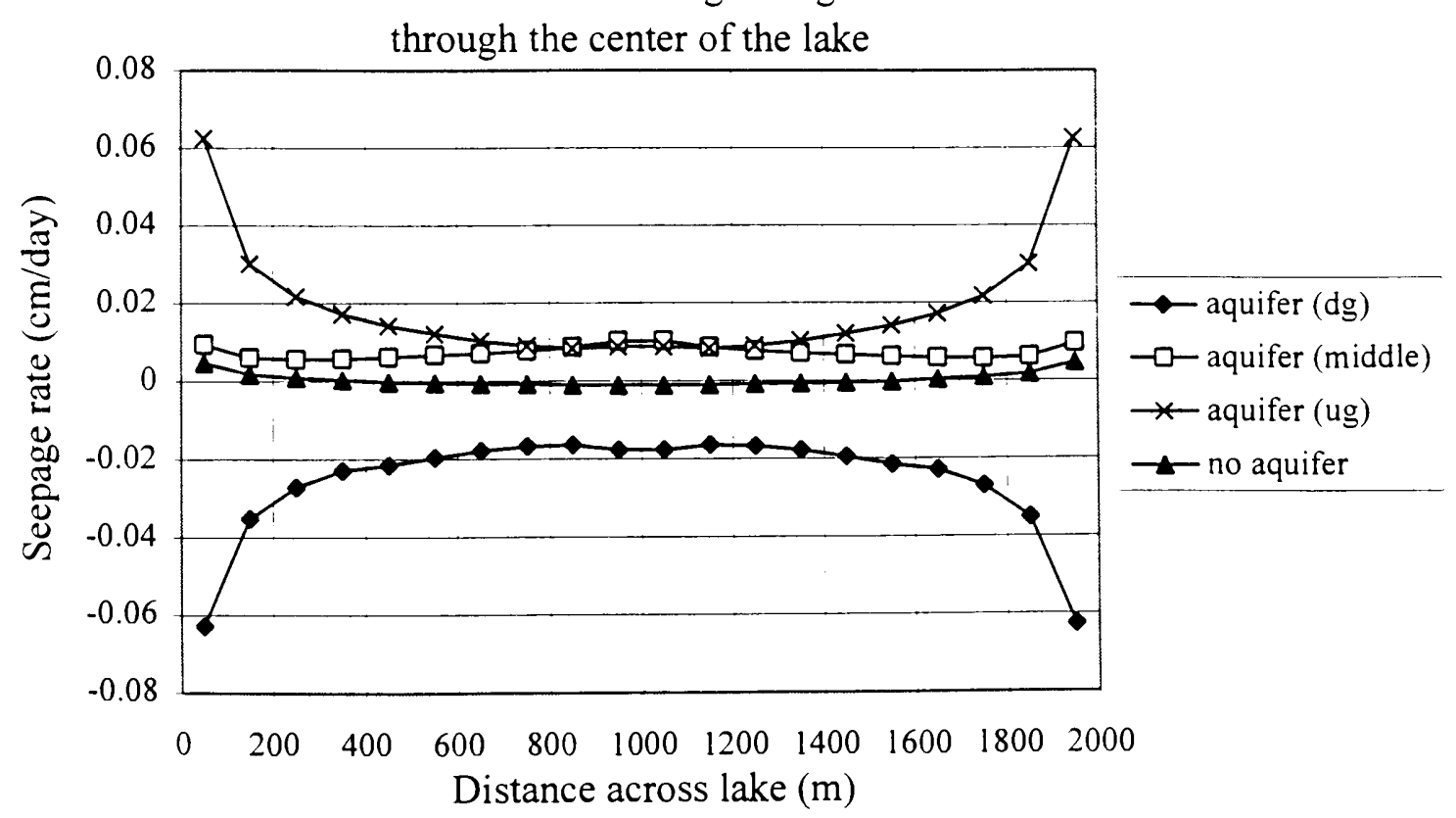

Fig. 14.37. Seepage rate versus distance for simulations of deep flow-through lakes with moderate lake bed slope and different horizontal positions of a laterally restricted aquifer (no aquifer, and aquifer on the downgradient (dg) and upgradient (ug) sides of the model domain, and directly under the lake). 
Section parallel to the regional gradient

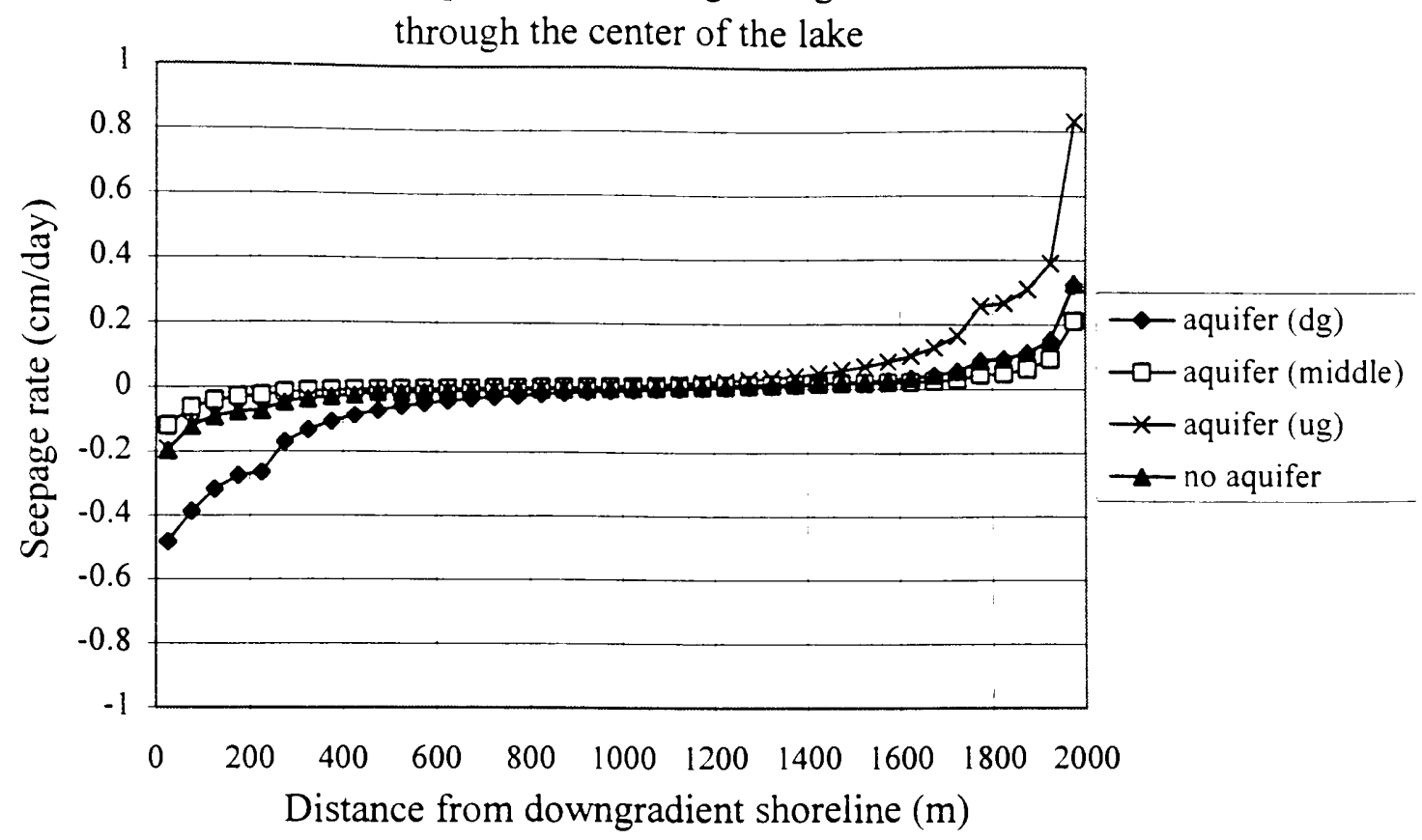

Section normal to the regional gradient

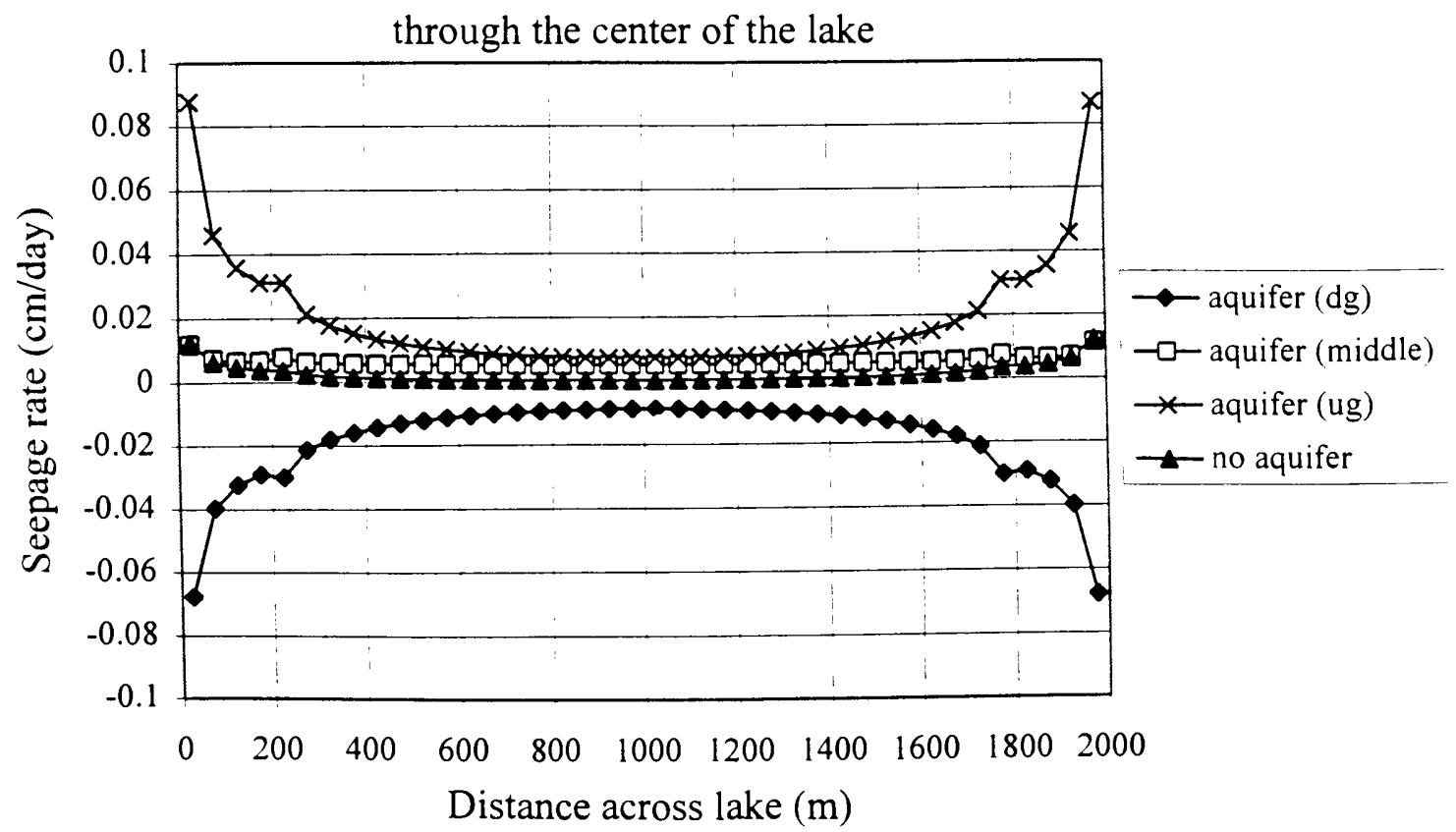

Fig. 14.38. Seepage rate versus distance for simulations of shallow flow-through lakes with steep lake bed slope and different horizontal positions of a laterally restricted aquifer (no aquifer, and aquifer on the downgradient (dg) and upgradient (ug) sides of the model domain, and directly under the lake). 


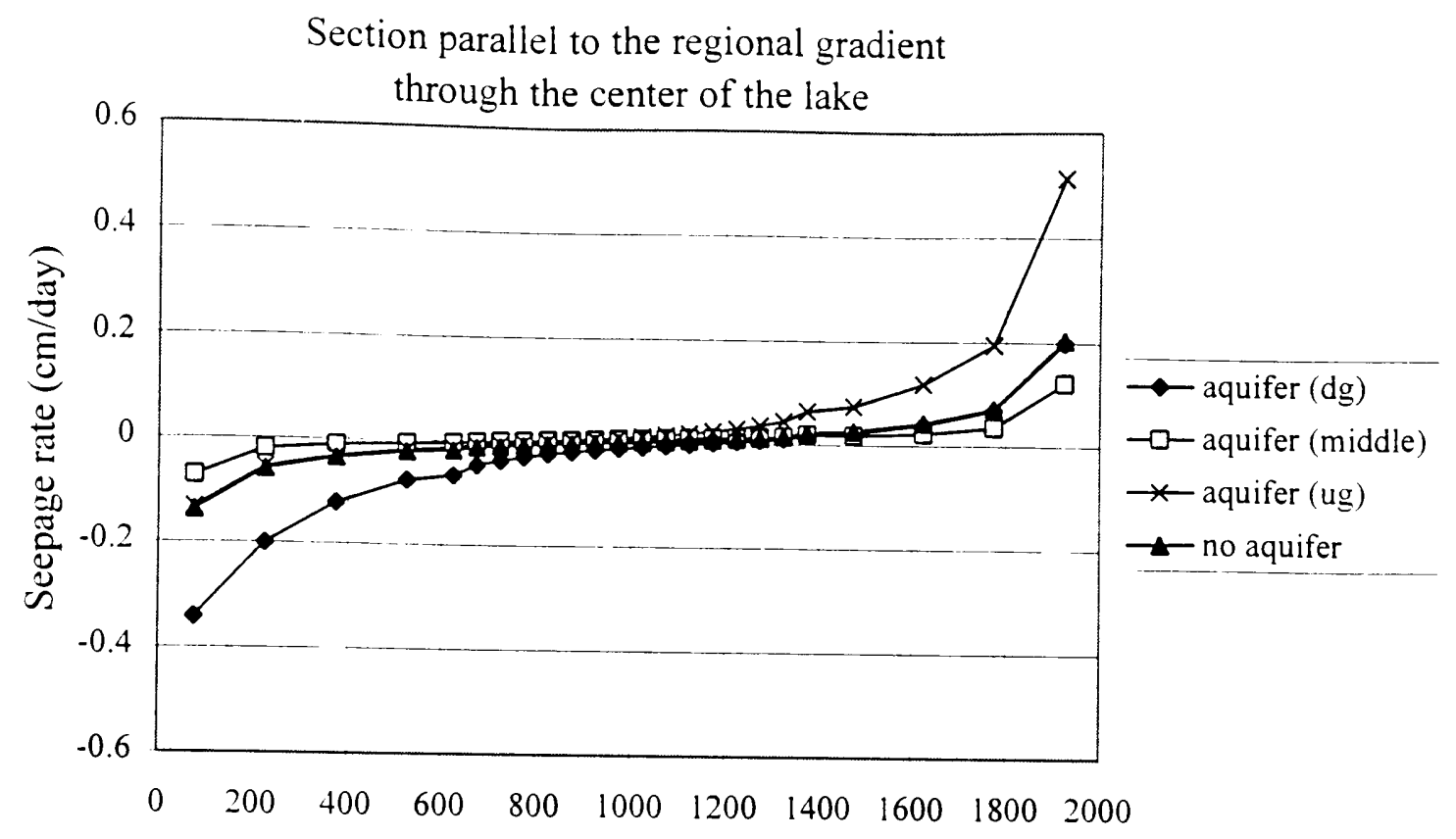

Distance from downgradient shoreline $(\mathrm{m})$

Section normal to the regional gradient

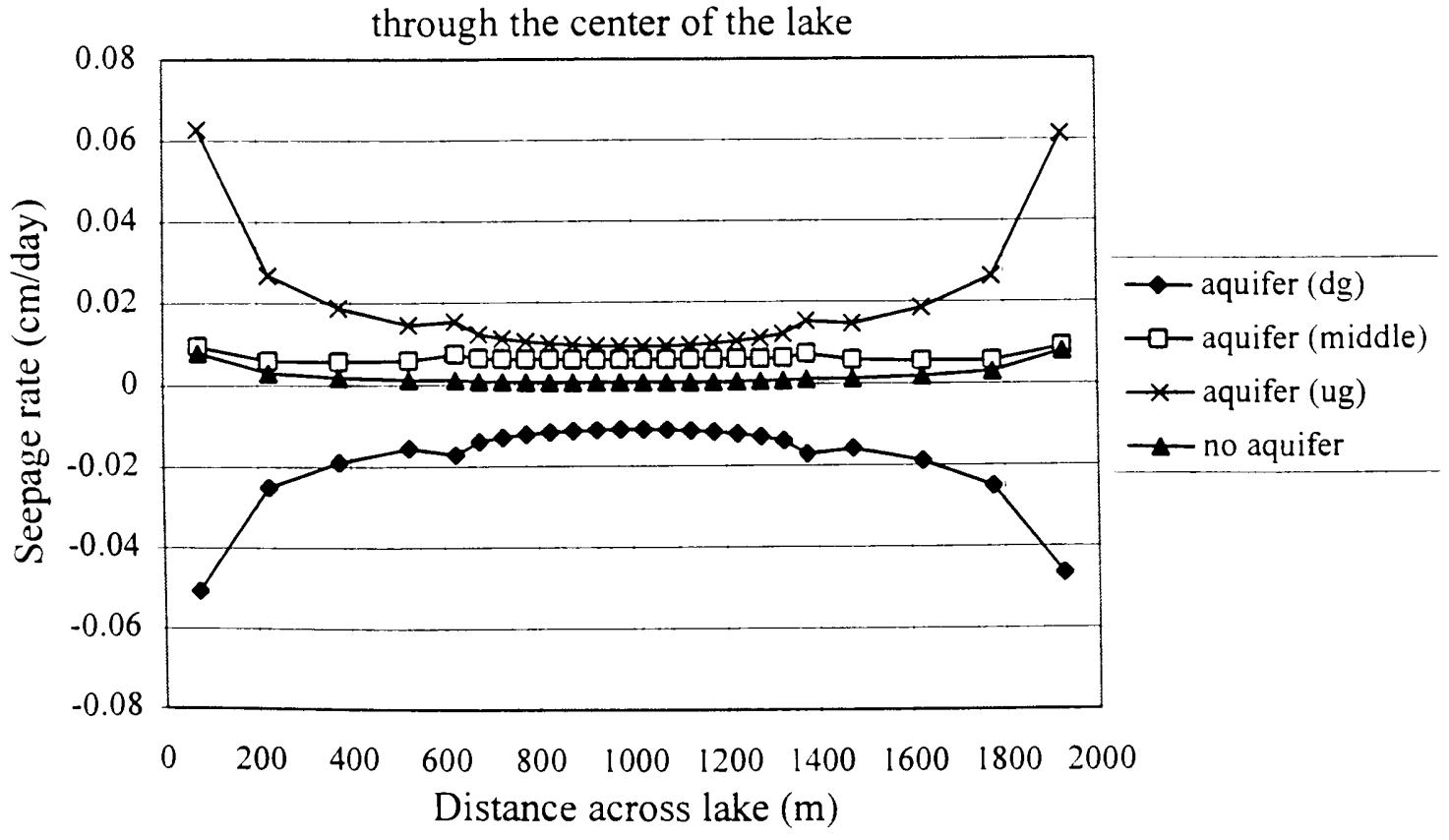

Fig. 14.39. Seepage rate versus distance for simulations of shallow flow-through lakes with low lake bed slope and different horizontal positions of a laterally restricted aquifer (no aquifer, and aquifer on the downgradient ( $\mathrm{dg}$ ) and upgradient (ug) sides of the model domain, and directly under the lake. 


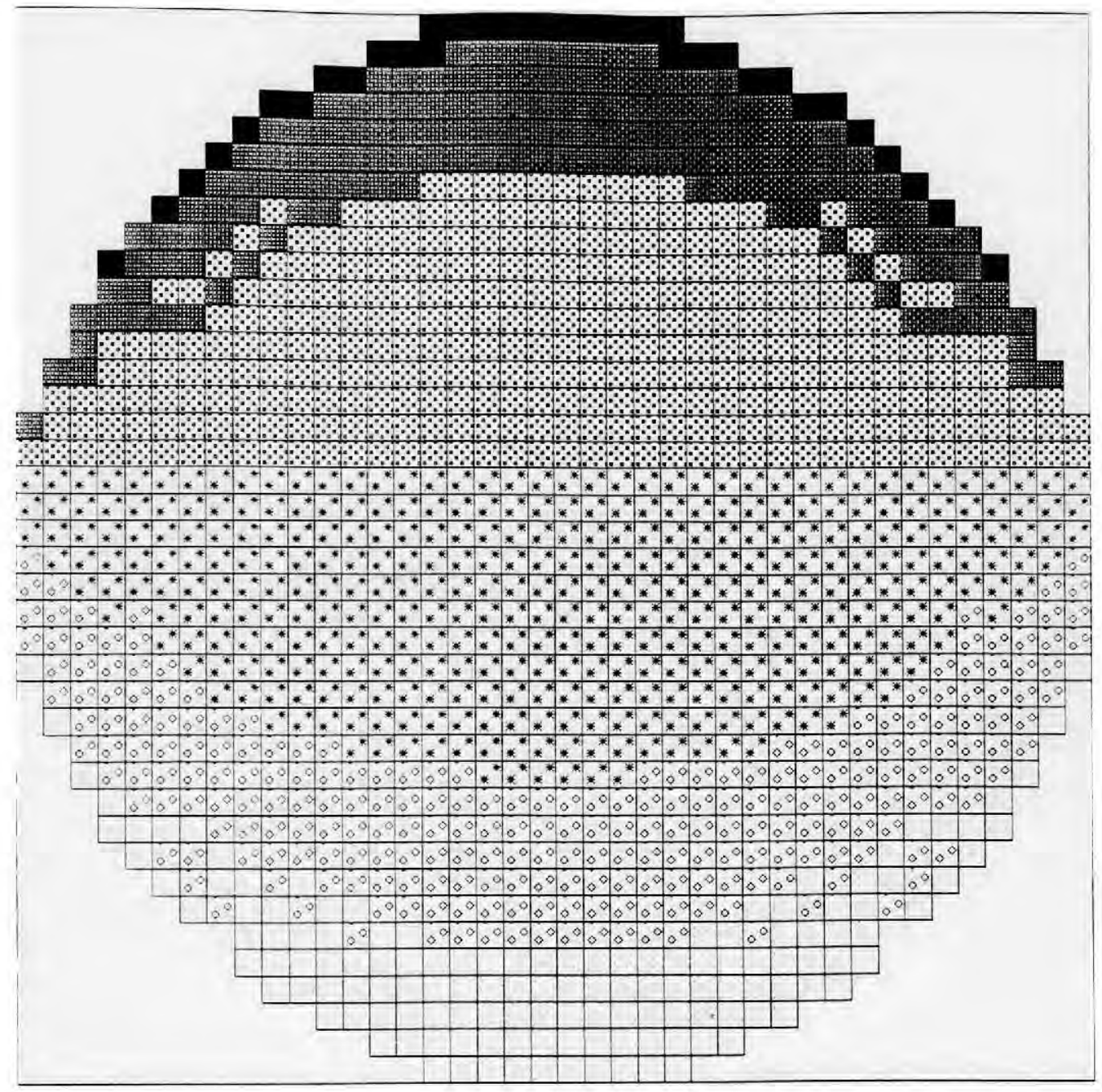

Fig. 14.40. Distribution of seepage rates ( $\mathrm{cm} /$ day) over the lake bed for a shallow flow-through lake with steep lake bed slope and a laterally restricted aquifer at the downgradient side of the model domain (the bottom of the figure). The regional gradient of groundwater flow is from the top to the bottom of the figure.

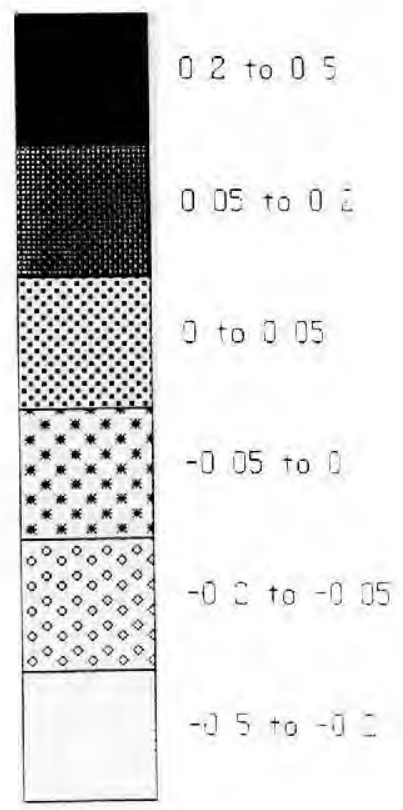




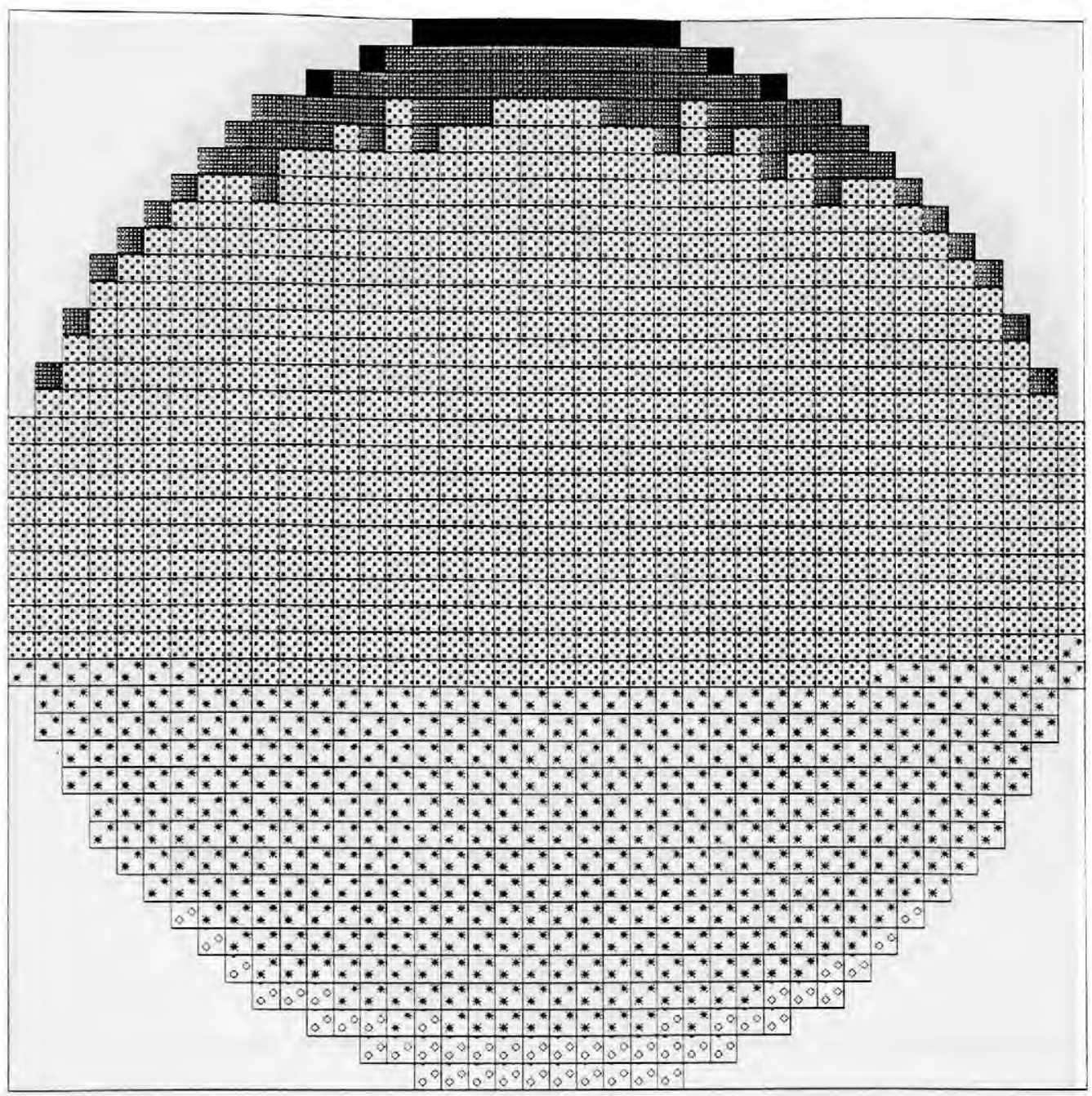

Fig. 14.41. Distribution of seepage rates (cm/day) over the lake bed for a shallow flow-through lake with steep lake bed slope and a laterally restricted aquifer directly under the lake. The regional gradient of groundwater flow is from the top to the bottom of the figure.

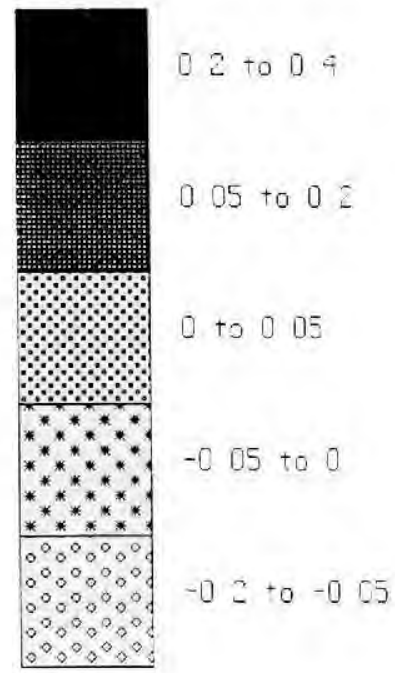




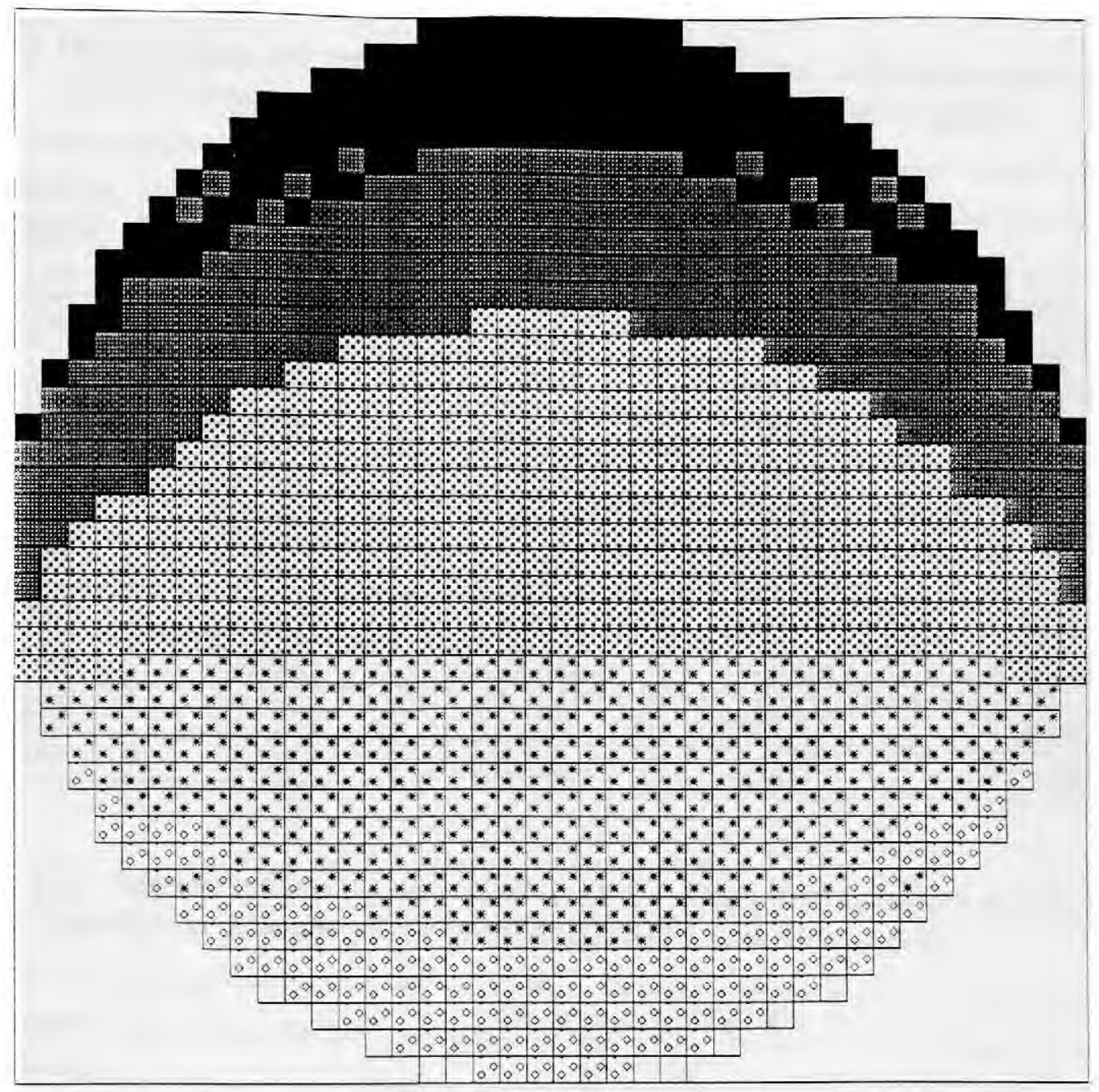

Fig. 14.42. Distribution of seepage rates ( $\mathrm{cm} /$ day) over the lake bed for a shallow flow-through lake with steep lake bed slope and a laterally restricted aquifer at the upgradient side of the model domain (the top of the figure). The regional gradient of groundwater flow is from the top to the bottom of the figure.

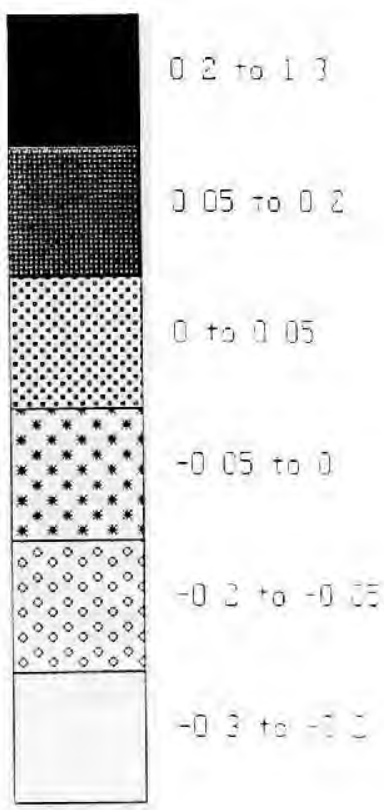


Table 14.7. Seepage rate versus distance offshore for shallow inflow lake with moderate lake bed slope at different positions of a horizontally extensive aquifer.

\begin{tabular}{|c|c|c|c|c|}
\hline \multirow{2}{*}{$\begin{array}{c}\text { Distance } \\
\text { offshore } \\
(\mathrm{m})\end{array}$} & \multicolumn{4}{|c|}{ Seepage rate (cm/day) } \\
\cline { 2 - 5 } & aquifer (layer 6) & aquifer (layer 11) & aquifer (layer 15) & no aquifer \\
\hline 50 & 0.29300 & 0.45668 & 0.51334 & 0.73872 \\
\hline 150 & 0.22145 & 0.24941 & 0.25794 & 0.29099 \\
\hline 250 & 0.24003 & 0.22659 & 0.21981 & 0.19789 \\
\hline 350 & 0.28494 & 0.23022 & 0.21233 & 0.14986 \\
\hline 450 & 0.40363 & 0.26442 & 0.23536 & 0.12821 \\
\hline 550 & 0.34240 & 0.23099 & 0.20126 & 0.08492 \\
\hline 650 & 0.30033 & 0.22145 & 0.19103 & 0.06498 \\
\hline 750 & 0.27065 & 0.21670 & 0.18615 & 0.05305 \\
\hline 850 & 0.25174 & 0.21406 & 0.18363 & 0.04606 \\
\hline 950 & 0.24254 & 0.21283 & 0.18252 & 0.04280 \\
\hline
\end{tabular}

Table 14.8. Seepage rate versus distance offshore for deep inflow lake with moderate lake bed slope at different positions of a horizontally extensive aquifer.

\begin{tabular}{|c|c|c|c|c|}
\hline \multirow{2}{*}{$\begin{array}{c}\text { Distance } \\
\text { offshore } \\
(\mathrm{m})\end{array}$} & \multicolumn{4}{|c|}{ Seepage rate (cm/day) } \\
\cline { 2 - 5 } & aquifer (layer 11) & aquifer (layer 13) & aquifer (layer 15) & no aquifer \\
\hline 50 & 0.35589 & 0.44295 & 0.49152 & 0.74144 \\
\hline 150 & 0.21687 & 0.23971 & 0.24964 & 0.28812 \\
\hline 250 & 0.21162 & 0.21586 & 0.21400 & 0.19498 \\
\hline 350 & 0.22473 & 0.21654 & 0.20602 & 0.14594 \\
\hline 450 & 0.25421 & 0.23439 & 0.21587 & 0.11834 \\
\hline 550 & 0.28450 & 0.24992 & 0.22404 & 0.09496 \\
\hline 650 & 0.32565 & 0.26767 & 0.23403 & 0.07693 \\
\hline 750 & 0.38887 & 0.29008 & 0.24744 & 0.06411 \\
\hline 850 & 0.49794 & 0.32124 & 0.26750 & 0.05674 \\
\hline 950 & 0.72685 & 0.37963 & 0.31021 & 0.05775 \\
\hline
\end{tabular}


Table 14.9. Seepage rate versus distance offshore for shallow inflow lake with steep lake bed slope at different positions of a horizontally extensive aquifer.

\begin{tabular}{|c|c|c|c|c|}
\hline \multirow{3}{*}{$\begin{array}{l}\text { Distance } \\
\text { offshore } \\
(\mathrm{m})\end{array}$} & \multicolumn{4}{|c|}{ Seepage rate $(\mathrm{cm} /$ day $)$} \\
\hline & \multicolumn{4}{|c|}{$\mathrm{R}=100$} \\
\hline & aquifer (layer 6) & aquifer (layer 11) & aquifer (layer 15) & no aquifer \\
\hline 25 & 0.32624 & 0.60262 & \begin{tabular}{|l|}
0.69084 \\
\end{tabular} & 1.09265 \\
\hline 75 & 0.20912 & 0.30125 & 0.32696 & 0.42907 \\
\hline 125 & 0.22429 & 0.26032 & 0.27100 & 0.31599 \\
\hline 175 & 0.27888 & 0.25756 & 0.25701 & 0.26286 \\
\hline 225 & 0.42565 & 0.29991 & 0.28677 & 0.25079 \\
\hline 275 & 0.36364 & 0.23902 & 0.22072 & 0.16387 \\
\hline 325 & 0.33057 & 0.22353 & 0.20189 & 0.13041 \\
\hline 375 & 0.30169 & 0.21502 & 0.19118 & 0.10795 \\
\hline 425 & 0.27650 & 0.20949 & 0.18427 & 0.09133 \\
\hline 475 & 0.25458 & 0.20545 & 0.17945 & 0.07843 \\
\hline 525 & 0.23560 & 0.20228 & 0.17593 & 0.06814 \\
\hline 575 & 0.21925 & 0.19968 & 0.17327 & 0.05983 \\
\hline 625 & 0.20529 & 0.19750 & 0.17122 & 0.05308 \\
\hline 675 & 0.19350 & 0.19566 & 0.16962 & 0.04762 \\
\hline 725 & 0.18369 & 0.19412 & 0.16837 & 0.04323 \\
\hline 775 & 0.17574 & 0.19286 & 0.16740 & 0.03977 \\
\hline 825 & 0.16952 & 0.19186 & 0.16666 & 0.03712 \\
\hline 875 & 0.16493 & 0.19112 & 0.16613 & 0.03519 \\
\hline 925 & 0.16192 & 0.19063 & 0.16579 & 0.03394 \\
\hline 975 & 0.16044 & 0.19039 & 0.16562 & 0.03333 \\
\hline
\end{tabular}

Table 14.10. Seepage rate versus distance offshore for shallow inflow lake with low lake bed slope at different positions of a horizontally extensive aquifer.

\begin{tabular}{|c|c|c|c|c|c|c|c|c|}
\hline & \multicolumn{7}{|c|}{ Seepage rate (cm/day) } \\
\cline { 2 - 9 } & \multicolumn{7}{|c|}{$\mathrm{R}=100$} \\
\cline { 2 - 9 } $\begin{array}{c}\text { Distance } \\
\text { offshore } \\
(\mathrm{m})\end{array}$ & aquifer (layer 6) & $\begin{array}{c}\text { aquifer (layer 11) } \\
\text { output }\end{array}$ & aquifer (layer 15) & \multicolumn{2}{|c|}{ no aquifer } \\
\hline 25 & 0.48188 & & $\begin{array}{c}\text { raw } \\
\text { output }\end{array}$ & average & $\begin{array}{c}\text { raw } \\
\text { output }\end{array}$ & average & $\begin{array}{c}\text { raw } \\
\text { output }\end{array}$ & average \\
\hline 75 & 0.23214 & 0.29848 & 0.75779 & & 0.88645 & & 1.43922 & \\
\hline
\end{tabular}


Table 14.10 (Contd.)

\begin{tabular}{|c|c|c|c|c|c|c|c|c|}
\hline \multirow{4}{*}{$\begin{array}{c}\text { Distance } \\
\text { offshore } \\
(\mathrm{m})\end{array}$} & \multicolumn{8}{|c|}{ Seepage rate $(\mathrm{cm} /$ day $)$} \\
\hline & \multicolumn{8}{|c|}{$\mathrm{R}=100$} \\
\hline & \multicolumn{2}{|c|}{ aquifer (layer 6) } & \multicolumn{2}{|c|}{ aquifer (layer 11) } & \multicolumn{2}{|c|}{ aquifer (layer 15) } & \multicolumn{2}{|c|}{ No aquifer } \\
\hline & $\begin{array}{c}\text { raw } \\
\text { output } \\
\end{array}$ & average & $\begin{array}{c}\text { raw } \\
\text { output }\end{array}$ & average & $\begin{array}{c}\text { raw } \\
\text { output }\end{array}$ & average & $\begin{array}{c}\text { raw } \\
\text { output }\end{array}$ & average \\
\hline 125 & 0.18141 & & 0.20359 & & 0.21527 & & 0.25654 & \\
\hline 175 & 0.27411 & & 0.28278 & & 0.28868 & & 0.30952 & \\
\hline 225 & 0.22436 & 0.22840 & 0.21656 & 0.22435 & 0.21290 & 0.22263 & 0.20069 & 0.21716 \\
\hline 275 & 0.18672 & & 0.17371 & & 0.16632 & & 0.14128 & \\
\hline 325 & 0.29126 & & 0.26056 & & 0.24302 & & 0.18343 & \\
\hline 375 & 0.24330 & 0.24682 & 0.21084 & 0.21506 & 0.19154 & 0.19655 & 0.12564 & 0.13333 \\
\hline 425 & 0.20590 & & 0.17379 & & 0.15508 & & 0.09093 & \\
\hline 475 & 0.33245 & & 0.26507 & & 0.23247 & & 0.12022 & \\
\hline 525 & 0.28479 & 0.28854 & 0.21884 & 0.22255 & 0.18868 & 0.19258 & 0.08441 & 0.08906 \\
\hline 575 & 0.24839 & & 0.18374 & & 0.15661 & & 0.06253 & \\
\hline 625 & 0.44299 & & 0.28205 & & 0.23774 & & 0.08382 & \\
\hline 675 & 0.39877 & & 0.24472 & & 0.20413 & & 0.06269 & \\
\hline 725 & 0.38040 & & 0.23732 & & 0.19656 & & 0.05410 & \\
\hline 775 & 0.36551 & & 0.23372 & & 0.19255 & & 0.04821 & \\
\hline 825 & 0.35383 & & 0.23169 & & 0.19014 & & 0.04401 & \\
\hline 875 & 0.34516 & & 0.23047 & & 0.18864 & & 0.04108 & \\
\hline 925 & 0.33935 & & 0.22978 & & 0.18775 & & 0.03921 & \\
\hline 975 & 0.33631 & & 0.22946 & & 0.18734 & & 0.03830 & \\
\hline
\end{tabular}

Table 14.11. Seepage rate versus distance from downgradient shoreline for shallow flowthrough lake with moderate lake bed slope at different positions of a horizontally extensive aquifer.

\begin{tabular}{|c|c|c|c|c|}
\hline \multirow{2}{*}{$\begin{array}{c}\text { Distance } \\
\text { offshore } \\
(\mathrm{m})\end{array}$} & \multicolumn{4}{|c|}{ Seepage rate (cm/day) } \\
\cline { 2 - 5 } & aquifer (layer 11) & aquifer (layer 13) & aquifer (layer 15) & no aquifer \\
\hline 50 & -0.25364 & -0.18879 & -0.15928 & -0.14544 \\
\hline 150 & -0.23069 & -0.12855 & -0.09828 & -0.07969 \\
\hline 250 & -0.23519 & -0.10410 & -0.07453 & -0.05346 \\
\hline 350 & -0.25812 & -0.09200 & -0.06203 & -0.03884 \\
\hline 450 & -0.32867 & -0.08876 & -0.05688 & -0.03089 \\
\hline
\end{tabular}


Table 14.11 (Contd.)

\begin{tabular}{|c|c|c|c|c|}
\hline \multirow{2}{*}{$\begin{array}{c}\text { Distance } \\
\text { offshore } \\
(\mathrm{m})\end{array}$} & \multicolumn{4}{|c|}{ Seepage rate (cm/day) } \\
\cline { 2 - 5 } & aquifer (layer 11) & aquifer (layer 13) & aquifer (layer 15) & no aquifer \\
\hline 550 & -0.24056 & -0.06242 & -0.03842 & -0.01823 \\
\hline 650 & -0.17095 & -0.04585 & -0.02735 & -0.01169 \\
\hline 750 & -0.11130 & -0.03108 & -0.01791 & -0.00711 \\
\hline 850 & -0.05818 & -0.01692 & -0.00910 & -0.00351 \\
\hline 950 & -0.00856 & -0.00299 & -0.00054 & -0.00038 \\
\hline 1050 & 0.04037 & 0.01089 & 0.00796 & 0.00267 \\
\hline 1150 & 0.09138 & 0.02489 & 0.01657 & 0.00601 \\
\hline 1250 & 0.14737 & 0.03918 & 0.02552 & 0.01004 \\
\hline 1350 & 0.21154 & 0.05420 & 0.03521 & 0.01537 \\
\hline 1450 & 0.28757 & 0.07121 & 0.04678 & 0.02316 \\
\hline 1550 & 0.38501 & 0.09894 & 0.06681 & 0.03853 \\
\hline 1650 & 0.29854 & 0.10098 & 0.07118 & 0.04802 \\
\hline 1750 & 0.26975 & 0.11306 & 0.08428 & 0.06593 \\
\hline 1850 & 0.26293 & 0.13854 & 0.11020 & 0.09872 \\
\hline 1950 & 0.35897 & 0.26634 & 0.22559 & 0.22998 \\
\hline
\end{tabular}

Table 14.12. Seepage rate versus distance from downgradient shoreline for deep flowthrough lake with moderate lake bed slope at different positions of a horizontally extensive aquifer.

\begin{tabular}{|c|c|c|c|c|}
\hline \multirow{2}{*}{$\begin{array}{c}\text { Distance } \\
\text { offshore } \\
(\mathrm{m})\end{array}$} & \multicolumn{4}{|c|}{ Seepage rate (cm/day) } \\
\cline { 2 - 5 } & aquifer (layer 11) & aquifer (layer 13) & aquifer (layer 15) & no aquifer \\
\hline 50 & -0.18633 & -0.16242 & -0.13822 & -0.14462 \\
\hline 150 & -0.13660 & -0.10454 & -0.08134 & -0.07892 \\
\hline 250 & -0.11921 & -0.08323 & -0.06178 & -0.05276 \\
\hline 350 & -0.11119 & -0.07215 & -0.05112 & -0.03806 \\
\hline 450 & -0.10770 & -0.06587 & -0.04476 & -0.02908 \\
\hline 550 & -0.09940 & -0.05726 & -0.03746 & -0.02141 \\
\hline 650 & -0.08799 & -0.04711 & -0.02964 & -0.01517 \\
\hline 750 & -0.07241 & -0.03520 & -0.02113 & -0.01007 \\
\hline 850 & -0.04864 & -0.02084 & -0.01144 & -0.00566 \\
\hline
\end{tabular}


Table 14.12 (Contd.)

\begin{tabular}{|c|c|c|c|c|}
\hline \multirow{2}{*}{$\begin{array}{c}\text { Distance } \\
\text { offshore } \\
(\mathrm{m})\end{array}$} & \multicolumn{4}{|c|}{ Seepage rate (cm/day) } \\
\cline { 2 - 5 } & aquifer (layer 11) & aquifer (layer 13) & aquifer (layer 15) & no aquifer \\
\hline 950 & -0.00321 & -0.00160 & 0.00104 & -0.00112 \\
\hline 1050 & 0.06647 & 0.02279 & 0.01632 & 0.00444 \\
\hline 1150 & 0.09206 & 0.03879 & 0.02644 & 0.00897 \\
\hline 1250 & 0.10645 & 0.05146 & 0.03503 & 0.01388 \\
\hline 1350 & 0.11664 & 0.06217 & 0.04284 & 0.01983 \\
\hline 1450 & 0.12459 & 0.07139 & 0.05016 & 0.02727 \\
\hline 1550 & 0.13038 & 0.07920 & 0.05709 & 0.03651 \\
\hline 1650 & 0.13139 & 0.08455 & 0.06301 & 0.04740 \\
\hline 1750 & 0.13830 & 0.09566 & 0.07433 & 0.06550 \\
\hline 1850 & 0.15579 & 0.11832 & 0.09641 & 0.09835 \\
\hline 1950 & 0.26845 & 0.22773 & 0.19394 & 0.22926 \\
\hline
\end{tabular}

Table 14.13. Seepage rate versus distance from downgradient shoreline for shallow flowthrough lake with steep lake bed slope at different positions of a horizontally extensive aquifer.

\begin{tabular}{|c|c|c|c|c|}
\hline \multirow{2}{*}{$\begin{array}{c}\text { Distance } \\
\text { offshore } \\
(\mathrm{m})\end{array}$} & \multicolumn{4}{|c|}{ Seepage rate (cm/day) } \\
\cline { 2 - 5 } & aquifer (layer 11) & aquifer (layer 13) & aquifer (layer 15) & no aquifer \\
\hline 25 & -0.31052 & -0.26494 & -0.23146 & -0.19613 \\
\hline 75 & -0.28417 & -0.18863 & -0.15368 & -0.11970 \\
\hline 125 & -0.29973 & -0.15851 & -0.12465 & -0.09106 \\
\hline 175 & -0.36368 & -0.14909 & -0.11253 & -0.07624 \\
\hline 225 & -0.53843 & -0.16188 & -0.11672 & -0.07213 \\
\hline 275 & -0.44436 & -0.11921 & -0.08245 & -0.04621 \\
\hline 325 & -0.38932 & -0.10362 & -0.06958 & -0.03590 \\
\hline 375 & -0.34031 & -0.09228 & -0.06051 & -0.02884 \\
\hline 425 & -0.29648 & -0.08275 & -0.05324 & -0.02353 \\
\hline 475 & -0.25712 & -0.07412 & -0.04697 & -0.01932 \\
\hline 525 & -0.22161 & -0.06599 & -0.04131 & -0.01588 \\
\hline 575 & -0.18938 & -0.05817 & -0.03604 & -0.01302 \\
\hline 625 & -0.15994 & -0.05056 & -0.03103 & -0.01059 \\
\hline
\end{tabular}


Table 14.13 (Contd.)

\begin{tabular}{|c|c|c|c|c|}
\hline \multirow{3}{*}{$\begin{array}{c}\text { Distance } \\
\text { offshore } \\
(\mathrm{m})\end{array}$} & \multicolumn{4}{|c|}{ Seepage rate $(\mathrm{cm} /$ day $)$} \\
\hline & \multicolumn{4}{|c|}{$\mathrm{R}=100$} \\
\hline & aquifer (layer 11) & aquifer (layer 13) & aquifer (layer 15) & no aquifer \\
\hline 675 & -0.13285 & -0.04308 & -0.02621 & -0.00850 \\
\hline 725 & -0.10771 & -0.03572 & -0.02152 & -0.00667 \\
\hline 775 & -0.08414 & -0.02843 & -0.01692 & -0.00505 \\
\hline 825 & -0.06180 & -0.02121 & -0.01239 & -0.00358 \\
\hline 875 & -0.04037 & -0.01403 & -0.00790 & -0.00221 \\
\hline 925 & -0.01956 & -0.00688 & -0.00343 & -0.00092 \\
\hline 975 & 0.00095 & 0.00026 & 0.00102 & 0.00035 \\
\hline 1025 & 0.02143 & 0.00740 & 0.00547 & 0.00161 \\
\hline 1075 & 0.04218 & 0.01455 & 0.00993 & 0.00292 \\
\hline 1125 & 0.06349 & 0.02172 & 0.01442 & 0.00430 \\
\hline 1175 & 0.08566 & 0.02894 & 0.01894 & 0.00580 \\
\hline 1225 & 0.10900 & 0.03622 & 0.02351 & 0.00746 \\
\hline 1275 & 0.13386 & 0.04357 & 0.02816 & 0.00933 \\
\hline 1325 & 0.16060 & 0.05101 & 0.03291 & 0.01147 \\
\hline 1375 & 0.18960 & 0.05858 & 0.03782 & 0.01394 \\
\hline 1425 & 0.22131 & 0.06631 & 0.04293 & 0.01685 \\
\hline 1475 & 0.25620 & 0.07427 & 0.04833 & 0.02031 \\
\hline 1525 & 0.29481 & 0.08256 & 0.05418 & 0.02448 \\
\hline 1575 & 0.33775 & 0.09139 & 0.06071 & 0.02963 \\
\hline 1625 & 0.38570 & 0.10120 & 0.06834 & 0.03616 \\
\hline 1675 & 0.43945 & 0.11296 & 0.07797 & 0.04488 \\
\hline 1725 & 0.49992 & 0.12932 & 0.09181 & 0.05769 \\
\hline 1775 & 0.60396 & 0.17484 & 0.12934 & 0.09015 \\
\hline 1825 & 0.40691 & 0.16066 & 0.12451 & 0.09571 \\
\hline 1875 & 0.33447 & 0.17104 & 0.13844 & 0.11537 \\
\hline 1925 & 0.31545 & 0.20539 & 0.17305 & 0.15468 \\
\hline 1975 & 0.48820 & 0.40104 & 0.34722 & 0.33006 \\
\hline
\end{tabular}


Table 14.14. Seepage rate versus distance from downgradient shoreline for shallow flowthrough lake with low lake bed slope at different positions of a horizontally extensive aquifer.

\begin{tabular}{|c|c|c|c|c|c|c|c|c|}
\hline \multirow{4}{*}{$\begin{array}{c}\text { Distance } \\
\text { offshore } \\
(\mathrm{m})\end{array}$} & \multicolumn{8}{|c|}{ Seepage rate $(\mathrm{cm} /$ day $)$} \\
\hline & \multicolumn{8}{|c|}{$\mathrm{R}=100$} \\
\hline & \multicolumn{2}{|c|}{ aquifer (laver 6) } & \multicolumn{2}{|c|}{ aquifer (layer 11) } & \multicolumn{2}{|c|}{ aquifer (layer 15) } & \multicolumn{2}{|c|}{ no aquifer } \\
\hline & $\begin{array}{c}\text { raw } \\
\text { output }\end{array}$ & average & \begin{tabular}{|c|} 
raw \\
output \\
\end{tabular} & average & \begin{tabular}{|c|} 
raw \\
output \\
\end{tabular} & average & \begin{tabular}{|c|} 
raw \\
output \\
\end{tabular} & average \\
\hline 25 & -0.36487 & & -0.30898 & & -0.27357 & & -0.23645 & \\
\hline 75 & -0.25746 & -0.27214 & -0.16560 & -0.19547 & -0.13501 & \begin{tabular}{|l|}
-0.16594 \\
\end{tabular} & -0.10748 & -0.13730 \\
\hline 125 & -0.19409 & & -0.11184 & & -0.08923 & & -0.06798 & \\
\hline 175 & -0.28201 & & -0.14713 & & -0.11434 & & -0.08274 & \\
\hline 225 & -0.22027 & -0.22615 & -0.10506 & -0.11053 & -0.07913 & -0.08397 & -0.05368 & -0.05800 \\
\hline 275 & -0.17617 & & -0.07941 & & -0.05842 & & -0.03760 & \\
\hline 325 & -0.26178 & & -0.11107 & & -0.07973 & & -0.04838 & \\
\hline 375 & -0.20568 & -0.21073 & -0.08241 & -0.08552 & -0.05762 & -0.06021 & -0.03260 & -0.03472 \\
\hline 425 & -0.16473 & & -0.06307 & & -0.04328 & & -0.02318 & \\
\hline 475 & -0.24842 & & -0.08796 & & -0.05923 & & -0.02988 & \\
\hline 525 & -0.19477 & -0.19970 & -0.06479 & -0.06728 & -0.04276 & -0.04465 & -0.02015 & -0.02144 \\
\hline 575 & -0.15590 & & -0.04910 & & -0.03195 & & -0.01429 & \\
\hline 625 & -0.24945 & & -0.06620 & & -0.04243 & & -0.01798 & \\
\hline 675 & -0.19423 & & -0.04810 & & -0.03032 & & -0.01210 & \\
\hline 725 & -0.15701 & & -0.03866 & & -0.02401 & & -0.00915 & \\
\hline 775 & -0.12220 & & -0.03035 & & -0.01855 & & -0.00679 & \\
\hline 825 & -0.08928 & & -0.02251 & & -0.01347 & & -0.00475 & \\
\hline 875 & -0.05775 & & -0.01489 & & -0.00859 & & -0.00290 & \\
\hline 925 & -0.02713 & & -0.00737 & & -0.00381 & & -0.00117 & \\
\hline 975 & 0.00303 & & 0.00009 & & 0.00091 & & 0.00051 & \\
\hline 1025 & 0.03316 & & 0.00754 & & 0.00563 & & 0.00219 & \\
\hline 1075 & 0.06371 & & 0.01501 & & 0.01037 & & 0.00393 & \\
\hline 1125 & 0.09513 & & 0.02256 & & 0.01518 & & 0.00578 & \\
\hline 1175 & 0.12787 & & 0.03024 & & 0.02013 & & 0.00781 & \\
\hline 1225 & 0.16243 & & 0.03818 & & 0.02531 & & 0.01013 & \\
\hline 1275 & 0.19933 & & 0.04665 & & 0.03093 & & 0.01288 & \\
\hline 1325 & 0.23916 & & 0.05638 & & 0.03753 & & 0.01640 & \\
\hline 1375 & 0.30011 & & 0.07581 & & 0.05087 & & 0.02367 & \\
\hline
\end{tabular}


Table 14.14 (Contd.)

\begin{tabular}{|c|c|c|c|c|c|c|c|c|}
\hline \multirow{4}{*}{$\begin{array}{c}\begin{array}{c}\text { Distance } \\
\text { offshore } \\
(\mathrm{m})\end{array}\end{array}$} & \multicolumn{8}{|c|}{ Seepage rate $(\mathrm{cm} /$ day $)$} \\
\hline & \multicolumn{8}{|c|}{$\mathrm{R}=100$} \\
\hline & \multicolumn{2}{|c|}{ aquifer (layer 6) } & \multicolumn{2}{|c|}{ aquifer (layer 11) } & \multicolumn{2}{|c|}{ aquifer (layer 15) } & \multicolumn{2}{|c|}{ no aquifer } \\
\hline & $\begin{array}{c}\text { raw } \\
\text { output }\end{array}$ & average & $\begin{array}{c}\text { raw } \\
\text { output }\end{array}$ & average & $\begin{array}{c}\text { raw } \\
\text { output }\end{array}$ & average & $\begin{array}{c}\text { raw } \\
\text { output }\end{array}$ & average \\
\hline 1425 & 0.18469 & & 0.05541 & & 0.03754 & & 0.01851 & \\
\hline 1475 & 0.22823 & 0.23368 & 0.07236 & 0.07500 & 0.04954 & 0.05157 & 0.02581 & 0.02740 \\
\hline 1525 & 0.28811 & & 0.09721 & & 0.06765 & & 0.03788 & \\
\hline 1575 & 0.18967 & & 0.06919 & & 0.04895 & & 0.02919 & \\
\hline 1625 & 0.23552 & 0.24108 & 0.08991 & 0.09319 & 0.06470 & 0.06751 & 0.04088 & 0.04351 \\
\hline 1675 & 0.29805 & & 0.12046 & & 0.08889 & & 0.06044 & \\
\hline 1725 & 0.19974 & & 0.08577 & & 0.06483 & & 0.04690 & \\
\hline 1775 & 0.24889 & 0.25531 & 0.11311 & 0.11894 & 0.08756 & 0.09291 & 0.06694 & 0.07242 \\
\hline 1825 & 0.31728 & & 0.15795 & & 0.12633 & & 0.10344 & \\
\hline 1875 & 0.21730 & & 0.11990 & & 0.09873 & & 0.08545 & \\
\hline 1925 & 0.28567 & 0.37125 & 0.17769 & 0.25433 & 0.15028 & 0.21797 & 0.13656 & 0.20506 \\
\hline 1975 & 0.61079 & & 0.46539 & & 0.40489 & & 0.39317 & \\
\hline
\end{tabular}

Table 14.15. Seepage rate versus distance offshore for shallow inflow lake with moderate lake bed slope at different positions of a laterally restricted aquifer.

\begin{tabular}{|c|c|c|c|c|}
\hline \multirow{2}{*}{$\begin{array}{c}\text { Distance } \\
\text { offshore } \\
(\mathrm{m})\end{array}$} & $\begin{array}{c}\text { Seepage rate (cm/day) } \\
\text { (near the domain } \\
\text { boundary) }\end{array}$ & $\begin{array}{c}\text { aquifer } \\
\text { (partially under } \\
\text { the lake) }\end{array}$ & $\begin{array}{c}\text { aquifer } \\
\text { (directly under } \\
\text { the lake) }\end{array}$ & no aquifer \\
\hline 50 & 0.91849 & 0.51094 & 0.52713 & 0.73872 \\
\hline 150 & 0.39520 & 0.27746 & 0.24703 & 0.29099 \\
\hline 250 & 0.27494 & 0.25155 & 0.21106 & 0.19789 \\
\hline 350 & 0.20553 & 0.25465 & 0.21078 & 0.14986 \\
\hline 450 & 0.17017 & 0.29089 & 0.24277 & 0.12821 \\
\hline 550 & 0.10815 & 0.25218 & 0.21383 & 0.08492 \\
\hline 650 & 0.07911 & 0.23923 & 0.20660 & 0.06498 \\
\hline 750 & 0.06154 & 0.22998 & 0.20340 & 0.05305 \\
\hline 850 & 0.05087 & 0.21866 & 0.20174 & 0.04606 \\
\hline 950 & 0.04511 & 0.19743 & 0.20099 & 0.04280 \\
\hline
\end{tabular}


Table 14.15 (Contd.)

\begin{tabular}{|c|c|c|c|c|}
\hline \multirow{2}{*}{$\begin{array}{c}\text { Distance } \\
\text { offshore } \\
(\mathrm{m})\end{array}$} & $\begin{array}{c}\text { Seepage rate (cm/day) } \\
\text { (near the domain } \\
\text { boundary) }\end{array}$ & $\begin{array}{c}\text { aquifer } \\
\text { (partially under } \\
\text { the lake) }\end{array}$ & $\begin{array}{c}\text { aquifer } \\
\text { (directly under } \\
\text { the lake) }\end{array}$ & no aquifer \\
\hline 1050 & 0.04332 & 0.15727 & 0.20100 & 0.04280 \\
\hline 1150 & 0.04522 & 0.12130 & 0.20175 & 0.04606 \\
\hline 1250 & 0.05104 & 0.09905 & 0.20341 & 0.05305 \\
\hline 1350 & 0.06182 & 0.09027 & 0.20662 & 0.06498 \\
\hline 1450 & 0.08034 & 0.09472 & 0.21386 & 0.08492 \\
\hline 1550 & 0.12105 & 0.12364 & 0.24281 & 0.12821 \\
\hline 1650 & 0.14148 & 0.13373 & 0.21083 & 0.14985 \\
\hline 1750 & 0.18691 & 0.17018 & 0.21111 & 0.19787 \\
\hline 1850 & 0.27484 & 0.24574 & 0.24709 & 0.29095 \\
\hline 1950 & 0.70304 & 0.61594 & 0.52722 & 0.73858 \\
\hline
\end{tabular}

Table 14.16. Seepage rate versus distance offshore for deep inflow lake with moderate lake bed slope at different positions of a laterally restricted aquifer.

\begin{tabular}{|c|c|c|c|c|}
\hline \multirow{2}{*}{$\begin{array}{c}\text { Distance } \\
\text { offshore } \\
(\mathrm{m})\end{array}$} & $\begin{array}{c}\text { aquifer } \\
\text { (near the domain } \\
\text { boundary) }\end{array}$ & $\begin{array}{c}\text { Seepage rate (cm/day) } \\
\text { (partially under } \\
\text { the lake) }\end{array}$ & $\begin{array}{c}\text { aquifer } \\
\text { (directly under } \\
\text { the lake) }\end{array}$ & no aquifer \\
\hline 50 & 0.91230 & 0.49497 & 0.52001 & 0.74144 \\
\hline 150 & 0.39625 & 0.26690 & 0.24420 & 0.28812 \\
\hline 250 & 0.27749 & 0.23997 & 0.20601 & 0.19498 \\
\hline 350 & 0.20691 & 0.24009 & 0.20159 & 0.14594 \\
\hline 450 & 0.16351 & 0.25893 & 0.21724 & 0.11834 \\
\hline 550 & 0.12667 & 0.27475 & 0.23230 & 0.09496 \\
\hline 650 & 0.09836 & 0.29231 & 0.24996 & 0.07693 \\
\hline 750 & 0.07801 & 0.31357 & 0.27206 & 0.06411 \\
\hline 850 & 0.06526 & 0.33984 & 0.30224 & 0.05674 \\
\hline 950 & 0.06238 & 0.37170 & 0.35778 & 0.05775 \\
\hline 1050 & 0.05873 & 0.26780 & 0.35778 & 0.05775 \\
\hline 1150 & 0.05548 & 0.15935 & 0.30223 & 0.05673 \\
\hline 1250 & 0.06145 & 0.11659 & 0.27205 & 0.06410 \\
\hline
\end{tabular}


Table 14.16 (Contd.)

\begin{tabular}{|c|c|c|c|c|}
\hline \multirow{2}{*}{$\begin{array}{c}\text { Distance } \\
\text { offshore } \\
(\mathrm{m})\end{array}$} & $\begin{array}{c}\text { aquifer } \\
\text { (near the domain } \\
\text { boundary) }\end{array}$ & $\begin{array}{c}\text { aquifer } \\
\text { (partially under } \\
\text { the lake) }\end{array}$ & $\begin{array}{c}\text { aquifer } \\
\text { (directly under } \\
\text { the lake) }\end{array}$ & no aquifer \\
\hline 1350 & 0.07308 & 0.10128 & 0.24995 & 0.07691 \\
\hline 1450 & 0.08991 & 0.10134 & 0.23229 & 0.09493 \\
\hline 1550 & 0.11198 & 0.11176 & 0.21722 & 0.11830 \\
\hline 1650 & 0.13818 & 0.12893 & 0.20158 & 0.14588 \\
\hline 1750 & 0.18479 & 0.16645 & 0.20600 & 0.19488 \\
\hline 1850 & 0.27332 & 0.24193 & 0.24419 & 0.28798 \\
\hline 1950 & 0.69853 & 0.60595 & 0.51999 & 0.74124 \\
\hline
\end{tabular}

Table 14.17. Seepage rate versus distance offshore for shallow inflow lake with steep lake bed slope at different positions of a laterally restricted aquifer.

\begin{tabular}{|c|c|c|c|c|}
\hline \multirow{2}{*}{$\begin{array}{c}\text { Distance } \\
\text { offshore } \\
(\mathrm{m})\end{array}$} & $\begin{array}{c}\text { Squifer } \\
\text { (near the domain } \\
\text { boundary) }\end{array}$ & $\begin{array}{c}\text { aquifer } \\
\text { (partially under } \\
\text { the lake) }\end{array}$ & $\begin{array}{c}\text { aquifer } \\
\text { (directly under } \\
\text { the lake) }\end{array}$ & no aquifer \\
\hline 25 & 1.31186 & 0.67123 & 0.72946 & 1.09265 \\
\hline 75 & 0.56955 & 0.33265 & 0.32442 & 0.42907 \\
\hline 125 & 0.44569 & 0.28740 & 0.25974 & 0.31599 \\
\hline 175 & 0.38433 & 0.28419 & 0.24305 & 0.26286 \\
\hline 225 & 0.37165 & 0.33047 & 0.27341 & 0.25079 \\
\hline 275 & 0.24153 & 0.26286 & 0.21491 & 0.16387 \\
\hline 325 & 0.18960 & 0.24529 & 0.20069 & 0.13041 \\
\hline 375 & 0.15422 & 0.23537 & 0.19359 & 0.10795 \\
\hline 425 & 0.12792 & 0.22865 & 0.18948 & 0.09133 \\
\hline 475 & 0.10751 & 0.22350 & 0.18680 & 0.07843 \\
\hline 525 & 0.09130 & 0.21920 & 0.18487 & 0.06814 \\
\hline 575 & 0.07827 & 0.21541 & 0.18339 & 0.05983 \\
\hline 625 & 0.06773 & 0.21192 & 0.18220 & 0.05308 \\
\hline 675 & 0.05920 & 0.20857 & 0.18121 & 0.04762 \\
\hline 725 & 0.05233 & 0.20515 & 0.18040 & 0.04323 \\
\hline 775 & 0.04684 & 0.20137 & 0.17974 & 0.03977 \\
\hline
\end{tabular}


Table 14.17 (Contd.)

\begin{tabular}{|c|c|c|c|c|}
\hline \multirow[b]{2}{*}{$\begin{array}{l}\text { Distance } \\
\text { offshore } \\
(\mathrm{m})\end{array}$} & \multicolumn{4}{|c|}{ Seepage rate $(\mathrm{cm} /$ day $)$} \\
\hline & $\begin{array}{c}\text { aquifer } \\
\text { (near the domain } \\
\text { boundary) }\end{array}$ & $\begin{array}{c}\text { aquifer } \\
\text { (partially under } \\
\text { the lake) } \\
\end{array}$ & $\begin{array}{c}\text { aquifer } \\
\text { (directly under } \\
\text { the lake) }\end{array}$ & no aquifer \\
\hline 825 & 0.04253 & 0.19673 & 0.17922 & 0.03712 \\
\hline 875 & 0.03924 & 0.19043 & 0.17884 & 0.03519 \\
\hline 925 & 0.03687 & 0.18138 & 0.17859 & 0.03394 \\
\hline 975 & 0.03532 & 0.16850 & 0.17847 & 0.03333 \\
\hline 1025 & 0.03453 & 0.15181 & 0.17849 & 0.03333 \\
\hline 1075 & 0.03448 & 0.13363 & 0.17863 & 0.03395 \\
\hline 1125 & 0.03516 & 0.11662 & 0.17891 & 0.03520 \\
\hline 1175 & 0.03657 & 0.10230 & 0.17933 & 0.03712 \\
\hline 1225 & 0.03875 & 0.09115 & 0.17988 & 0.03977 \\
\hline 1275 & 0.04177 & 0.08308 & 0.18057 & 0.04324 \\
\hline 1325 & 0.04573 & 0.07786 & 0.18141 & 0.04763 \\
\hline 1375 & 0.05076 & 0.07523 & 0.18243 & 0.05309 \\
\hline 1425 & 0.05705 & 0.07506 & 0.18366 & 0.05984 \\
\hline 1475 & 0.06487 & 0.07731 & 0.18519 & 0.06816 \\
\hline 1525 & 0.07459 & 0.08213 & 0.18717 & 0.07845 \\
\hline 1575 & 0.08684 & 0.08990 & 0.18992 & 0.09137 \\
\hline 1625 & 0.10265 & 0.10141 & 0.19412 & 0.10799 \\
\hline 1675 & 0.12406 & 0.11838 & 0.20134 & 0.13047 \\
\hline 1725 & 0.15598 & 0.14512 & 0.21576 & 0.16395 \\
\hline 1775 & 0.23893 & 0.21797 & 0.27473 & 0.25093 \\
\hline 1825 & 0.25066 & 0.22588 & 0.24442 & 0.26299 \\
\hline 1875 & 0.30158 & 0.26988 & 0.26123 & 0.31612 \\
\hline 1925 & 0.40980 & 0.36480 & 0.32620 & 0.42916 \\
\hline 1975 & 1.01512 & 0.88594 & 0.73314 & 1.09273 \\
\hline
\end{tabular}


Table 14.18. Seepage rate versus distance offshore for shallow inflow lake with low lake bed slope at different positions of a laterally restricted aquifer.

\begin{tabular}{|c|c|c|c|c|c|c|c|c|}
\hline \multirow{3}{*}{$\begin{array}{l}\text { Distance } \\
\text { offshore } \\
(\mathrm{m})\end{array}$} & \multicolumn{8}{|c|}{ Seepage rate $(\mathrm{cm} /$ day $)$} \\
\hline & \multicolumn{2}{|c|}{$\begin{array}{c}\text { aquifer } \\
\text { (near the domain } \\
\text { boundary) }\end{array}$} & \multicolumn{2}{|c|}{$\begin{array}{c}\text { aquifer } \\
\text { (partially under the } \\
\text { lake) }\end{array}$} & \multicolumn{2}{|c|}{\begin{tabular}{|c|} 
aquifer \\
(directly under the \\
lake)
\end{tabular}} & \multicolumn{2}{|c|}{ no aquifer } \\
\hline & $\begin{array}{c}\text { raw } \\
\text { output }\end{array}$ & average & $\begin{array}{c}\text { raw } \\
\text { output }\end{array}$ & average & $\begin{array}{c}\text { raw } \\
\text { output }\end{array}$ & average & $\begin{array}{c}\text { raw } \\
\text { output }\end{array}$ & average \\
\hline 25 & 1.58934 & & 0.87068 & & 0.93155 & & 1.43922 & \\
\hline 75 & 0.51341 & 0.81129 & 0.32524 & 0.47453 & 0.31366 & 0.48489 & 0.41428 & 0.70335 \\
\hline 125 & 0.33113 & & 0.22767 & & 0.20947 & & 0.25654 & \\
\hline 175 & 0.41118 & & 0.31430 & & 0.27902 & & 0.30952 & \\
\hline 225 & 0.27207 & 0.29208 & 0.31430 & 0.28920 & 0.20663 & 0.21626 & 0.20069 & 0.21716 \\
\hline 275 & 0.19298 & & 0.23901 & & 0.16313 & & 0.14128 & \\
\hline 325 & 0.25156 & & 0.23901 & & 0.24214 & & 0.18343 & \\
\hline 375 & 0.17244 & 0.18288 & 0.19066 & 0.20678 & 0.19466 & 0.19897 & 0.12564 & 0.13333 \\
\hline 425 & 0.12464 & & 0.19066 & & 0.16011 & & 0.09093 & \\
\hline 475 & 0.16452 & & 0.28341 & & 0.24397 & & 0.12022 & \\
\hline 525 & 0.11513 & 0.12155 & 0.23214 & 0.23639 & 0.20145 & 0.20489 & 0.08441 & 0.08906 \\
\hline 575 & 0.08500 & & 0.19363 & & 0.16925 & & 0.06253 & \\
\hline 625 & 0.11351 & & 0.29479 & & 0.25993 & & 0.08382 & \\
\hline 675 & 0.08438 & & 0.25314 & & 0.22573 & & 0.06269 & \\
\hline 725 & 0.07229 & & 0.24283 & & 0.21907 & & 0.05410 & \\
\hline 775 & 0.06385 & & 0.23589 & & 0.21587 & & 0.04821 & \\
\hline 825 & 0.05766 & & 0.22941 & & 0.21409 & & 0.04401 & \\
\hline 875 & 0.05312 & & 0.22171 & & 0.21304 & & 0.04108 & \\
\hline 925 & 0.04995 & & 0.21123 & & 0.21244 & & 0.03921 & \\
\hline 975 & 0.04795 & & 0.19664 & & 0.21216 & & 0.03830 & \\
\hline 1025 & 0.04703 & & 0.17792 & & 0.21217 & & 0.03830 & \\
\hline 1075 & 0.04715 & & 0.15772 & & 0.21245 & & 0.03921 & \\
\hline 1125 & 0.04832 & & 0.13907 & & 0.21307 & & 0.04107 & \\
\hline 1175 & 0.05060 & & 0.12375 & & 0.21413 & & 0.04400 & \\
\hline 1225 & 0.05419 & & 0.11244 & & 0.21592 & & 0.04820 & \\
\hline 1275 & 0.05945 & & 0.10540 & & 0.21913 & & 0.05409 & \\
\hline 1325 & 0.06737 & & 0.10331 & & 0.22582 & & 0.06268 & \\
\hline 1375 & 0.08792 & & 0.11713 & & 0.26006 & & 0.08381 & \\
\hline
\end{tabular}


Table 14.18 (Contd.)

\begin{tabular}{|c|c|c|c|c|c|c|c|c|}
\hline \multirow{3}{*}{$\begin{array}{l}\text { Distance } \\
\text { offshore } \\
(\mathrm{m})\end{array}$} & \multicolumn{8}{|c|}{ Seepage rate $(\mathrm{cm} /$ day $)$} \\
\hline & \multicolumn{2}{|c|}{$\begin{array}{c}\text { aquifer } \\
\text { (near the domain } \\
\text { boundary) }\end{array}$} & \multicolumn{2}{|c|}{$\begin{array}{c}\text { aquifer } \\
\text { (partially under the } \\
\text { lake) }\end{array}$} & \multicolumn{2}{|c|}{$\begin{array}{c}\text { aquifer } \\
\text { (directly under the } \\
\text { lake) }\end{array}$} & \multicolumn{2}{|c|}{ no aquifer } \\
\hline & $\begin{array}{c}\text { raw } \\
\text { output }\end{array}$ & average & $\begin{array}{c}\text { raw } \\
\text { output }\end{array}$ & average & \begin{tabular}{|c|} 
raw \\
output
\end{tabular} & $\longdiv { \text { average } }$ & $\begin{array}{c}\text { raw } \\
\text { output }\end{array}$ & average \\
\hline 1425 & 0.06434 & & 0.07760 & & 0.16936 & & 0.06252 & \\
\hline 1475 & 0.08547 & 0.08976 & 0.09603 & 0.09965 & 0.20158 & 0.20502 & 0.08441 & 0.08905 \\
\hline 1525 & 0.11947 & & 0.12531 & & 0.24411 & & 0.12021 & \\
\hline 1575 & 0.08902 & & 0.12339 & & 0.16020 & & 0.09091 & \\
\hline 1625 & 0.12149 & 0.12845 & 0.12339 & 0.13945 & 0.19474 & 0.19904 & 0.12561 & 0.13330 \\
\hline 1675 & 0.17483 & & 0.17157 & & 0.24220 & & 0.18339 & \\
\hline 1725 & 0.13317 & & 0.17157 & & 0.16316 & & 0.14126 & \\
\hline 1775 & 0.18743 & 0.20221 & 0.25890 & 0.22979 & 0.20664 & 0.21626 & 0.20067 & 0.21716 \\
\hline 1825 & 0.28604 & & 0.25890 & & 0.27898 & & 0.30954 & \\
\hline 1875 & 0.23519 & & 0.21136 & & 0.20943 & & 0.25659 & \\
\hline 1925 & 0.37724 & 0.62277 & 0.33722 & 0.54783 & 0.31356 & 0.48488 & 0.41437 & 0.70340 \\
\hline 1975 & 1.25587 & & 1.09493 & & 0.93165 & & 1.43925 & \\
\hline
\end{tabular}

Table 14.19. Seepage rate versus distance from downgradient shoreline for shallow flowthrough lake with moderate lake bed slope at different positions of a laterally restricted aquifer.

\begin{tabular}{|c|c|c|c|c|}
\hline \multirow{2}{*}{$\begin{array}{c}\text { Distance } \\
\text { offshore } \\
(\mathrm{m})\end{array}$} & $\begin{array}{c}\text { aquifer } \\
(\mathrm{dg})\end{array}$ & $\begin{array}{c}\text { Seepage rate (cm/day) } \\
(\text { middle })\end{array}$ & $\begin{array}{c}\text { aquifer } \\
(\mathrm{ug})\end{array}$ & no aquifer \\
\cline { 2 - 5 } & -0.33844 & -0.08222 & -0.14142 & -0.14544 \\
\hline 50 & -0.25035 & -0.03252 & -0.07625 & -0.07969 \\
\hline 150 & -0.17768 & -0.01776 & -0.05061 & -0.05346 \\
\hline 250 & -0.13065 & -0.01162 & -0.03610 & -0.03884 \\
\hline 350 & -0.10440 & -0.00891 & -0.02769 & -0.03089 \\
\hline 450 & -0.06257 & -0.00487 & -0.01516 & -0.01823 \\
\hline 550 & -0.04183 & -0.00223 & -0.00822 & -0.01169 \\
\hline 650 & -0.02822 & 0.00018 & -0.00289 & -0.00711 \\
\hline 750 & -0.01855 & 0.00255 & 0.00187 & -0.00351 \\
\hline 850 & & & & \\
\hline
\end{tabular}


Table 14.19 (Contd.)

\begin{tabular}{|c|c|c|c|c|}
\hline \multirow{2}{*}{$\begin{array}{c}\text { Distance } \\
\text { offshore } \\
(\mathrm{m})\end{array}$} & $\begin{array}{c}\text { aquifer } \\
(\mathrm{dg})\end{array}$ & $\begin{array}{c}\text { Seepage rate } \\
\text { aquifer } \\
\text { (middle) }\end{array}$ & $\begin{array}{c}\text { aquifer } \\
(\mathrm{ug})\end{array}$ & no aquifer \\
\hline 950 & -0.01124 & 0.00493 & 0.00673 & -0.00038 \\
\hline 1050 & -0.00528 & 0.00733 & 0.01229 & 0.00267 \\
\hline 1150 & 0.00006 & 0.00978 & 0.01925 & 0.00601 \\
\hline 1250 & 0.00548 & 0.01232 & 0.02858 & 0.01004 \\
\hline 1350 & 0.01173 & 0.01503 & 0.04180 & 0.01537 \\
\hline 1450 & 0.02007 & 0.01827 & 0.06204 & 0.02316 \\
\hline 1550 & 0.03546 & 0.02442 & 0.10300 & 0.03853 \\
\hline 1650 & 0.04552 & 0.02558 & 0.12853 & 0.04802 \\
\hline 1750 & 0.06343 & 0.03272 & 0.17488 & 0.06593 \\
\hline 1850 & 0.09580 & 0.05235 & 0.25234 & 0.09872 \\
\hline 1950 & 0.22419 & 0.14165 & 0.55502 & 0.22998 \\
\hline
\end{tabular}

Table 14.20. Seepage rate versus distance across lake for shallow flow-through lake with moderate lake bed slope at different positions of a laterally restricted aquifer. These data are from the section normal to the regional gradient.

\begin{tabular}{|c|c|c|c|c|}
\hline \multirow{2}{*}{$\begin{array}{c}\text { Distance } \\
\text { offshore } \\
(\mathrm{m})\end{array}$} & $\begin{array}{c}\text { aquifer } \\
(\mathrm{dg})\end{array}$ & $\begin{array}{c}\text { aquifer } \\
\text { (middle) }\end{array}$ & $\begin{array}{c}\text { aquifer } \\
\text { (ug) }\end{array}$ & no aquifer \\
\cline { 2 - 5 } & -0.05907 & 0.00792 & 0.05737 & 0.00405 \\
\hline 50 & -0.03320 & 0.00514 & 0.02787 & 0.00141 \\
\hline 150 & -0.02580 & 0.00488 & 0.02023 & 0.00065 \\
\hline 250 & -0.02209 & 0.00507 & 0.01626 & 0.00021 \\
\hline 350 & -0.02199 & 0.00578 & 0.01441 & -0.00038 \\
\hline 450 & -0.01611 & 0.00523 & 0.01062 & -0.00024 \\
\hline 550 & -0.01377 & 0.00507 & 0.00878 & -0.00030 \\
\hline 650 & -0.01241 & 0.00499 & 0.00767 & -0.00034 \\
\hline 750 & -0.01161 & 0.00495 & 0.00703 & -0.00037 \\
\hline 850 & -0.01124 & 0.00493 & 0.00673 & -0.00038 \\
\hline 950 & -0.01123 & 0.00493 & 0.00673 & -0.00038 \\
\hline 1050 & -0.01161 & 0.00495 & 0.00703 & -0.00036 \\
\hline 1150 & & & & \\
\hline
\end{tabular}


Table 14.20 (Contd.)

\begin{tabular}{|c|c|c|c|c|}
\hline \multirow{2}{*}{$\begin{array}{c}\text { Distance } \\
\text { offshore } \\
(\mathrm{m})\end{array}$} & \multicolumn{4}{|c|}{ Seepage rate (cm/day) } \\
\cline { 2 - 5 } & $\begin{array}{c}\text { aquifer } \\
(\mathrm{dg})\end{array}$ & $\begin{array}{c}\text { aquifer } \\
(\text { middle })\end{array}$ & $\begin{array}{c}\text { aquifer } \\
(\mathrm{ug})\end{array}$ & no aquifer \\
\hline 1250 & -0.01240 & 0.00499 & 0.00767 & -0.00034 \\
\hline 1350 & -0.01377 & 0.00508 & 0.00877 & -0.00029 \\
\hline 1450 & -0.01610 & 0.00524 & 0.01060 & -0.00023 \\
\hline 1550 & -0.02197 & 0.00579 & 0.01438 & -0.00037 \\
\hline 1650 & -0.02208 & 0.00509 & 0.01621 & 0.00021 \\
\hline 1750 & -0.02578 & 0.00490 & 0.02016 & 0.00062 \\
\hline 1850 & -0.03317 & 0.00517 & 0.02774 & 0.00133 \\
\hline 1950 & -0.05902 & 0.00798 & 0.05711 & 0.00385 \\
\hline
\end{tabular}

Table 14.21. Seepage rate versus distance from downgradient shoreline for deep flowthrough lake with moderate lake bed slope at different positions of a laterally restricted aquifer.

\begin{tabular}{|c|c|c|c|c|}
\hline \multirow{2}{*}{$\begin{array}{c}\text { Distance } \\
\text { offshore } \\
(\mathrm{m})\end{array}$} & $\begin{array}{c}|c| \\
\text { aquifer } \\
(\mathrm{dg})\end{array}$ & $\begin{array}{c}\text { aquifer } \\
\text { (middle) }\end{array}$ & $\begin{array}{c}\text { aquifer } \\
\text { (ug) }\end{array}$ & no aquifer \\
\cline { 2 - 5 } & -0.34052 & -0.07575 & -0.14055 & -0.14462 \\
\hline 50 & -0.25384 & -0.02810 & -0.07550 & -0.07892 \\
\hline 150 & -0.18186 & -0.01340 & -0.04997 & -0.05276 \\
\hline 250 & -0.13402 & -0.00701 & -0.03546 & -0.03806 \\
\hline 350 & -0.10321 & -0.00384 & -0.02633 & -0.02908 \\
\hline 450 & -0.07678 & -0.00155 & -0.01841 & -0.02141 \\
\hline 550 & -0.05587 & 0.00058 & -0.01168 & -0.01517 \\
\hline 650 & -0.03976 & 0.00293 & -0.00567 & -0.01007 \\
\hline 750 & -0.02741 & 0.00582 & 0.00042 & -0.00566 \\
\hline 850 & -0.01774 & 0.01015 & 0.00872 & -0.00112 \\
\hline 950 & -0.00648 & 0.01361 & 0.01930 & 0.00444 \\
\hline 1050 & 0.00230 & 0.01429 & 0.02835 & 0.00897 \\
\hline 1150 & 0.00914 & 0.01524 & 0.04032 & 0.01388 \\
\hline 1250 & 0.01616 & 0.01621 & 0.05609 & 0.01983 \\
\hline 1350 & 0.02421 & 0.01730 & 0.07662 & 0.02727 \\
\hline 1450 & 0.03380 & 0.01882 & 0.10260 & 0.03651 \\
\hline 1550 & & & & \\
\hline
\end{tabular}


Table 14.21 (Contd.)

\begin{tabular}{|c|c|c|c|c|}
\hline \multirow{2}{*}{$\begin{array}{c}\text { Distance } \\
\text { offshore } \\
(\mathrm{m})\end{array}$} & $\begin{array}{c}\text { aquifer } \\
(\mathrm{dg})\end{array}$ & $\begin{array}{c}\text { aquifer } \\
\text { (middle) }\end{array}$ & $\begin{array}{c}\text { aquifer } \\
(\mathrm{ug})\end{array}$ & no aquifer \\
\hline 1650 & 0.04493 & 0.02138 & 0.13293 & 0.04740 \\
\hline 1750 & 0.06296 & 0.02908 & 0.18047 & 0.06550 \\
\hline 1850 & 0.09536 & 0.04895 & 0.25779 & 0.09835 \\
\hline 1950 & 0.22335 & 0.13520 & 0.56106 & 0.22926 \\
\hline
\end{tabular}

Table 14.22. Seepage rate versus distance across lake for deep flow-through lake with moderate lake bed slope at different positions of a laterally restricted aquifer. These data are from the section normal to the regional gradient.

\begin{tabular}{|c|c|c|c|c|}
\hline \multirow{2}{*}{$\begin{array}{c}\text { Distance } \\
\text { offshore } \\
(\mathrm{m})\end{array}$} & \begin{tabular}{c} 
Seepage rate (cm/day) \\
\cline { 2 - 5 }
\end{tabular} & $\begin{array}{c}\text { aquifer } \\
\text { (middle) }\end{array}$ & $\begin{array}{c}\text { aquifer } \\
\text { (ug) }\end{array}$ & no aquifer \\
\hline 50 & -0.06266 & 0.00940 & 0.06246 & 0.00473 \\
\hline 150 & -0.03514 & 0.00601 & 0.03019 & 0.00176 \\
\hline 250 & -0.02711 & 0.00561 & 0.02176 & 0.00091 \\
\hline 350 & -0.02290 & 0.00572 & 0.01720 & 0.00040 \\
\hline 450 & -0.02155 & 0.00615 & 0.01421 & -0.00026 \\
\hline 550 & -0.01955 & 0.00659 & 0.01196 & -0.00053 \\
\hline 650 & -0.01787 & 0.00709 & 0.01022 & -0.00070 \\
\hline 750 & -0.01673 & 0.00771 & 0.00897 & -0.00083 \\
\hline 850 & -0.01641 & 0.00855 & 0.00828 & -0.00097 \\
\hline 950 & -0.01774 & 0.01015 & 0.00872 & -0.00112 \\
\hline 1050 & -0.01774 & 0.01016 & 0.00872 & -0.00112 \\
\hline 1150 & -0.01640 & 0.00858 & 0.00828 & -0.00098 \\
\hline 1250 & -0.01672 & 0.00775 & 0.00898 & -0.00084 \\
\hline 1350 & -0.01785 & 0.00714 & 0.01023 & -0.00071 \\
\hline 1450 & -0.01952 & 0.00664 & 0.01197 & -0.00054 \\
\hline 1550 & -0.02151 & 0.00621 & 0.01422 & -0.00028 \\
\hline 1650 & -0.02285 & 0.00579 & 0.01721 & 0.00038 \\
\hline 1750 & -0.02704 & 0.00569 & 0.02176 & 0.00087 \\
\hline 1850 & -0.03504 & 0.00611 & 0.03018 & 0.00170 \\
\hline 1950 & -0.06246 & 0.00959 & 0.06246 & 0.00462 \\
\hline & & & & \\
\hline & & & & \\
\hline & & & & \\
\hline
\end{tabular}


Table 14.23. Seepage rate versus distance from downgradient shoreline for shallow flowthrough lake with steep lake bed slope at different positions of a laterally restricted aquifer.

\begin{tabular}{|c|c|c|c|c|}
\hline \multirow{2}{*}{$\begin{array}{c}\text { Distance } \\
\text { offshor } \\
(\mathrm{m})\end{array}$} & \begin{tabular}{c} 
Seepage rate (cm/day) \\
\cline { 2 - 5 }
\end{tabular} & $\begin{array}{c}\text { aquifer } \\
\text { (middle) }\end{array}$ & $\begin{array}{c}\text { aquifer } \\
\text { (ug) }\end{array}$ & no aquifer \\
\hline 25 & -0.41194 & -0.12021 & -0.19205 & -0.19613 \\
\hline 75 & -0.38635 & -0.06180 & -0.11648 & -0.11970 \\
\hline 125 & -0.31681 & -0.04097 & -0.08834 & -0.09106 \\
\hline 175 & -0.27507 & -0.02990 & -0.07366 & -0.07624 \\
\hline 225 & -0.26518 & -0.02525 & -0.06925 & -0.07213 \\
\hline 275 & -0.17082 & -0.01525 & -0.04397 & -0.04621 \\
\hline 325 & -0.13262 & -0.01175 & -0.03380 & -0.03590 \\
\hline 375 & -0.10636 & -0.00955 & -0.02679 & -0.02884 \\
\hline 425 & -0.08669 & -0.00791 & -0.02145 & -0.02353 \\
\hline 475 & -0.07128 & -0.00653 & -0.01716 & -0.01932 \\
\hline 525 & -0.05891 & -0.00528 & -0.01359 & -0.01588 \\
\hline 575 & -0.04881 & -0.00409 & -0.01054 & -0.01302 \\
\hline 625 & -0.04046 & -0.00294 & -0.00788 & -0.01059 \\
\hline 675 & -0.03350 & -0.00180 & -0.00549 & -0.00850 \\
\hline 725 & -0.02765 & -0.00066 & -0.00329 & -0.00667 \\
\hline 775 & -0.02269 & 0.00047 & -0.00121 & -0.00505 \\
\hline 825 & -0.01845 & 0.00161 & 0.00082 & -0.00358 \\
\hline 875 & -0.01478 & 0.00275 & 0.00285 & -0.00221 \\
\hline 925 & -0.01156 & 0.00390 & 0.00495 & -0.00092 \\
\hline 975 & -0.00869 & 0.00506 & 0.00718 & 0.00035 \\
\hline 1025 & -0.00608 & 0.00622 & 0.00961 & 0.00161 \\
\hline 1075 & -0.00365 & 0.00739 & 0.01232 & 0.00292 \\
\hline 1125 & -0.00134 & 0.00857 & 0.01538 & 0.00430 \\
\hline 1175 & 0.00094 & 0.00976 & 0.01889 & 0.00580 \\
\hline 1225 & 0.00325 & 0.01096 & 0.02297 & 0.00746 \\
\hline 1275 & 0.00565 & 0.01218 & 0.02775 & 0.00933 \\
\hline 1325 & 0.00824 & 0.01341 & 0.03341 & 0.01147 \\
\hline 1375 & 0.01108 & 0.01467 & 0.04016 & 0.01394 \\
\hline 1425 & 0.01428 & 0.01597 & 0.04826 & 0.01685 \\
\hline 1475 & 0.01798 & 0.01733 & 0.05807 & 0.02031 \\
\hline
\end{tabular}


Table 14.23 (contd.)

\begin{tabular}{|c|c|c|c|c|}
\hline \multirow{2}{*}{$\begin{array}{c}\text { Distance } \\
\text { offshore } \\
(\mathrm{m})\end{array}$} & $\begin{array}{c}\text { aquifer } \\
(\mathrm{dg})\end{array}$ & $\begin{array}{c}\text { aquifer } \\
\text { (middle) }\end{array}$ & $\begin{array}{c}\text { aquifer } \\
\text { (ug) }\end{array}$ & no aquifer \\
\cline { 2 - 5 } & 0.02233 & 0.01880 & 0.07010 & 0.02448 \\
\hline 1525 & 0.02760 & 0.02048 & 0.08509 & 0.02963 \\
\hline 1575 & 0.03420 & 0.02257 & 0.10423 & 0.03616 \\
\hline 1625 & 0.04292 & 0.02550 & 0.12979 & 0.04488 \\
\hline 1675 & 0.05563 & 0.03037 & 0.16698 & 0.05769 \\
\hline 1725 & 0.08750 & 0.04549 & 0.25894 & 0.09015 \\
\hline 1775 & 0.09332 & 0.04934 & 0.26854 & 0.09571 \\
\hline 1825 & 0.11281 & 0.06373 & 0.31047 & 0.11537 \\
\hline 1875 & 0.15157 & 0.09338 & 0.39185 & 0.15468 \\
\hline 1925 & 0.32351 & 0.21152 & 0.83281 & 0.33006 \\
\hline 1975 & & & & \\
\hline
\end{tabular}

Table 14.24. Seepage rate versus distance across lake for shallow flow-through lake with steep lake bed slope at different positions of a laterally restricted aquifer. These data are from the section normal to the regional gradient.

\begin{tabular}{|c|c|c|c|c|}
\hline \multirow{2}{*}{$\begin{array}{c}\text { Distance } \\
\text { offshore } \\
(\mathrm{m})\end{array}$} & $\begin{array}{c}\text { aquifer } \\
(\mathrm{dg})\end{array}$ & $\begin{array}{c}\text { aquifer } \\
\text { (middle) }\end{array}$ & $\begin{array}{c}\text { aquifer } \\
(\mathrm{ug})\end{array}$ & no aquifer \\
\cline { 2 - 5 } & -0.06764 & 0.01178 & 0.08783 & 0.01248 \\
\hline 25 & -0.03970 & 0.00722 & 0.04606 & 0.00642 \\
\hline 75 & -0.03217 & 0.00647 & 0.03590 & 0.00477 \\
\hline 125 & -0.02892 & 0.00655 & 0.03123 & 0.00394 \\
\hline 175 & -0.02982 & 0.00775 & 0.03118 & 0.00370 \\
\hline 225 & -0.02105 & 0.00624 & 0.02134 & 0.00236 \\
\hline 275 & -0.01788 & 0.00587 & 0.01768 & 0.00184 \\
\hline 325 & -0.01577 & 0.00567 & 0.01524 & 0.00149 \\
\hline 375 & -0.01421 & 0.00554 & 0.01345 & 0.00123 \\
\hline 425 & -0.01300 & 0.00545 & 0.01206 & 0.00103 \\
\hline 475 & -0.01203 & 0.00537 & 0.01095 & 0.00087 \\
\hline 525 & -0.01124 & 0.00531 & 0.01005 & 0.00075 \\
\hline 575 & -0.01060 & 0.00525 & 0.00932 & 0.00064 \\
\hline 625 & -0.01007 & 0.00521 & 0.00873 & 0.00056 \\
\hline 675 & & & & \\
\hline
\end{tabular}


Table 14.24 (Contd.)

\begin{tabular}{|c|c|c|c|c|}
\hline \multirow{2}{*}{$\begin{array}{l}\text { Distance } \\
\text { offshore } \\
(\mathrm{m})\end{array}$} & \multicolumn{4}{|c|}{ Seepage rate $(\mathrm{cm} /$ day $)$} \\
\hline & $\begin{array}{c}\text { aquifer } \\
\text { (dg) }\end{array}$ & $\begin{array}{l}\text { aquifer } \\
\text { (middle) }\end{array}$ & $\begin{array}{l}\text { aquifer } \\
\text { (ug) }\end{array}$ & no aquifer \\
\hline 725 & -0.00965 & 0.00517 & 0.00826 & 0.00049 \\
\hline 775 & -0.00931 & 0.00513 & 0.00788 & 0.00044 \\
\hline 825 & -0.00906 & 0.00510 & 0.00759 & 0.00040 \\
\hline 875 & -0.00887 & 0.00508 & 0.00739 & 0.00037 \\
\hline 925 & -0.00875 & 0.00507 & 0.00725 & 0.00036 \\
\hline 975 & -0.00869 & 0.00506 & 0.00718 & 0.00035 \\
\hline 1025 & -0.00869 & 0.00505 & 0.00718 & 0.00035 \\
\hline 1075 & -0.00875 & 0.00505 & 0.00725 & 0.00036 \\
\hline 1125 & -0.00887 & 0.00506 & 0.00738 & 0.00038 \\
\hline 1175 & -0.00906 & 0.00507 & 0.00759 & 0.00041 \\
\hline 1225 & -0.00932 & 0.00509 & 0.00787 & 0.00045 \\
\hline 1275 & -0.00965 & 0.00512 & 0.00825 & 0.00050 \\
\hline 1325 & -0.01008 & 0.00515 & 0.00872 & 0.00057 \\
\hline 1375 & -0.01060 & 0.00518 & 0.00931 & 0.00066 \\
\hline 1425 & -0.01125 & 0.00523 & 0.01003 & 0.00076 \\
\hline 1475 & -0.01203 & 0.00528 & 0.01092 & 0.00089 \\
\hline 1525 & -0.01301 & 0.00534 & 0.01202 & 0.00105 \\
\hline 1575 & -0.01422 & 0.00543 & 0.01340 & 0.00125 \\
\hline 1625 & -0.01578 & 0.00554 & 0.01518 & 0.00151 \\
\hline 1675 & -0.01789 & 0.00573 & 0.01759 & 0.00185 \\
\hline 1725 & -0.02107 & 0.00608 & 0.02122 & 0.00237 \\
\hline 1775 & -0.02985 & 0.00753 & 0.03097 & 0.00368 \\
\hline 1825 & -0.02895 & 0.00634 & 0.03099 & 0.00390 \\
\hline 1875 & -0.03221 & 0.00625 & 0.03561 & 0.00471 \\
\hline 1925 & -0.03976 & 0.00695 & 0.04566 & 0.00632 \\
\hline 1975 & -0.06776 & 0.01131 & 0.08705 & 0.01227 \\
\hline
\end{tabular}


Table 14.25. Seepage rate versus distance from downgradient shoreline for shallow flowthrough lake with low lake bed slope at different positions of a laterally restricted aquifer.

\begin{tabular}{|c|c|c|c|c|c|c|c|c|}
\hline \multirow{3}{*}{$\begin{array}{c}\text { Distance } \\
\text { offshore } \\
(\mathrm{m})\end{array}$} & \multicolumn{8}{|c|}{ Seepage rate $(\mathrm{cm} /$ day $)$} \\
\hline & \multicolumn{2}{|c|}{$\begin{array}{c}\text { aquifer } \\
\text { (dg) }\end{array}$} & \multicolumn{2}{|c|}{$\begin{array}{l}\text { aquifer } \\
\text { (middle) }\end{array}$} & \multicolumn{2}{|c|}{$\begin{array}{c}\text { aquifer } \\
\text { (ug) }\end{array}$} & \multicolumn{2}{|c|}{ no aquifer } \\
\hline & $\begin{array}{c}\text { raw } \\
\text { output }\end{array}$ & average & $\begin{array}{c}\text { raw } \\
\text { output }\end{array}$ & average & $\begin{array}{c}\text { raw } \\
\text { output }\end{array}$ & average & $\begin{array}{c}\text { raw } \\
\text { output }\end{array}$ & average \\
\hline 25 & -0.46397 & & -0.13524 & & -0.22915 & & -0.23645 & \\
\hline 75 & -0.33480 & -0.34117 & -0.04979 & -0.07105 & -0.10302 & -0.13236 & -0.10748 & -0.13730 \\
\hline 125 & -0.22473 & & -0.02813 & & -0.06491 & & -0.06798 & \\
\hline 175 & -0.28138 & & -0.03057 & & -0.07860 & & -0.08274 & \\
\hline 225 & -0.18577 & -0.19935 & -0.01764 & -0.01992 & -0.05062 & -0.05481 & -0.05368 & -0.05800 \\
\hline 275 & -0.13090 & & -0.01154 & & -0.03521 & & -0.03760 & \\
\hline 325 & -0.16896 & & -0.01412 & & -0.04486 & & -0.04838 & \\
\hline 375 & -0.11407 & -0.12141 & -0.00913 & -0.00987 & -0.02977 & -0.03182 & -0.03260 & -0.03472 \\
\hline 425 & -0.08121 & & -0.00635 & & -0.02083 & & -0.02318 & \\
\hline 475 & -0.10507 & & -0.00799 & & -0.02624 & & -0.02988 & \\
\hline 525 & -0.07138 & -0.07587 & -0.00513 & -0.00550 & -0.01702 & -0.01826 & -0.02015 & -0.02144 \\
\hline 575 & -0.05115 & & -0.00339 & & -0.01153 & & -0.01429 & \\
\hline 625 & -0.06558 & & -0.00365 & & -0.01344 & & -0.01798 & \\
\hline 675 & -0.04578 & & -0.00162 & & -0.00774 & & -0.01210 & \\
\hline 725 & -0.03650 & & -0.00025 & & -0.00445 & & -0.00915 & \\
\hline 775 & -0.02946 & & 0.00103 & & -0.00159 & & -0.00679 & \\
\hline 825 & -0.02374 & & 0.00228 & & 0.00109 & & -0.00475 & \\
\hline 875 & -0.01893 & & 0.00352 & & 0.00373 & & -0.00290 & \\
\hline 925 & -0.01477 & & 0.00476 & & 0.00644 & & -0.00117 & \\
\hline 975 & -0.01108 & & 0.00600 & & 0.00930 & & 0.00051 & \\
\hline 1025 & -0.00774 & & 0.00726 & & 0.01241 & & 0.00219 & \\
\hline 1075 & -0.00462 & & 0.00853 & & 0.01588 & & 0.00393 & \\
\hline 1125 & -0.00162 & & 0.00983 & & 0.01985 & & 0.00578 & \\
\hline 1175 & 0.00135 & & 0.01116 & & 0.02446 & & 0.00781 & \\
\hline 1225 & 0.00444 & & 0.01256 & & 0.02997 & & 0.01013 & \\
\hline 1275 & 0.00780 & & 0.01409 & & 0.03679 & & 0.01288 & \\
\hline 1325 & 0.01175 & & 0.01594 & & 0.04582 & & 0.01640 & \\
\hline 1375 & 0.01894 & & 0.02024 & & 0.06525 & & 0.02367 & \\
\hline
\end{tabular}


Table 14.25 (Contd.)

\begin{tabular}{|c|c|c|c|c|c|c|c|c|}
\hline \multirow{3}{*}{$\begin{array}{c}\text { Distance } \\
\text { offshore } \\
(\mathrm{m})\end{array}$} & \multicolumn{8}{|c|}{ Seepage rate $(\mathrm{cm} /$ day $)$} \\
\hline & \multicolumn{2}{|c|}{$\begin{array}{l}\text { aquifer } \\
\text { (dg) }\end{array}$} & \multicolumn{2}{|c|}{$\begin{array}{l}\text { aquifer } \\
\text { (middle) }\end{array}$} & \multicolumn{2}{|c|}{$\begin{array}{c}\text { aquifer } \\
\text { (ug) }\end{array}$} & \multicolumn{2}{|c|}{ no aquifer } \\
\hline & $\begin{array}{c}\text { raw } \\
\text { output }\end{array}$ & average & $\begin{array}{c}\text { raw } \\
\text { output }\end{array}$ & average & $\begin{array}{c}\text { raw } \\
\text { output }\end{array}$ & average & $\begin{array}{c}\text { raw } \\
\text { output }\end{array}$ & average \\
\hline 1425 & 0.01569 & & 0.01425 & & 0.05069 & & 0.01851 & \\
\hline 1475 & 0.02268 & 0.02424 & 0.01815 & 0.01877 & 0.07053 & 0.07491 & 0.02581 & 0.02740 \\
\hline 1525 & 0.03435 & & 0.02391 & & 0.10351 & & 0.03788 & \\
\hline 1575 & 0.02698 & & 0.01693 & & 0.07982 & & 0.02919 & \\
\hline 1625 & 0.03829 & 0.04087 & 0.02217 & 0.02328 & 0.11192 & 0.11906 & 0.04088 & 0.04351 \\
\hline 1675 & 0.05733 & & 0.03074 & & 0.16545 & & 0.06044 & \\
\hline 1725 & 0.04485 & & 0.02308 & & 0.12800 & & 0.04690 & \\
\hline 1775 & 0.06439 & 0.06978 & 0.03279 & 0.03609 & 0.18150 & 0.19494 & 0.06694 & 0.07242 \\
\hline 1825 & 0.10010 & & 0.05239 & & 0.27532 & & 0.10344 & \\
\hline 1875 & 0.08303 & & 0.04566 & & 0.22161 & & 0.08545 & \\
\hline 1925 & 0.13309 & 0.19997 & 0.07811 & 0.12220 & 0.34159 & 0.51406 & 0.13656 & 0.20506 \\
\hline 1975 & 0.38380 & & 0.24282 & & 0.97898 & & 0.39317 & \\
\hline
\end{tabular}

Table 14.26. Seepage rate versus distance across lake for shallow flow-through lake with low lake bed slope at different positions of a laterally restricted aquifer. These data are from the section normal to the regional gradient.

\begin{tabular}{|c|c|c|c|c|c|c|c|c|}
\hline \multirow{3}{*}{$\begin{array}{c}\text { Distance } \\
\text { offshore } \\
(\mathrm{m})\end{array}$} & \multicolumn{8}{|c|}{ Seepage rate $(\mathrm{cm} /$ day $)$} \\
\hline & \multicolumn{2}{|c|}{$\begin{array}{l}\text { aquifer } \\
\text { (dg) }\end{array}$} & \multicolumn{2}{|c|}{$\begin{array}{l}\text { aquifer } \\
\text { (middle) }\end{array}$} & \multicolumn{2}{|c|}{$\begin{array}{l}\text { aquifer } \\
\text { (ug) }\end{array}$} & \multicolumn{2}{|c|}{ no aquifer } \\
\hline & $\begin{array}{c}\text { raw } \\
\text { output }\end{array}$ & average & $\begin{array}{c}\text { raw } \\
\text { output }\end{array}$ & average & $\begin{array}{c}\text { raw } \\
\text { output }\end{array}$ & average & $\begin{array}{l}\text { raw } \\
\text { output }\end{array}$ & average \\
\hline 25 & -0.08717 & & 0.01583 & & 0.11455 & & 0.01475 & \\
\hline 75 & -0.03866 & -0.05059 & 0.00731 & 0.00946 & 0.04480 & 0.06282 & 0.00560 & 0.00795 \\
\hline 125 & -0.02594 & & 0.00525 & & 0.02913 & & 0.00350 & \\
\hline 175 & -0.03366 & & 0.00738 & & 0.03678 & & 0.00425 & \\
\hline 225 & -0.02367 & -0.02501 & 0.00570 & 0.00589 & 0.02510 & 0.02675 & 0.00276 & 0.00299 \\
\hline 275 & -0.01771 & & 0.00459 & & 0.01838 & & 0.00195 & \\
\hline 325 & -0.02453 & & 0.00691 & & 0.02493 & & 0.00253 & \\
\hline 375 & -0.01817 & -0.01890 & 0.00559 & 0.00570 & 0.01801 & 0.01885 & 0.00174 & 0.00184 \\
\hline 425 & -0.01399 & & 0.00461 & & 0.01361 & & 0.00125 & \\
\hline
\end{tabular}


Table 14.26 (Contd.)

\begin{tabular}{|c|c|c|c|c|c|c|c|c|}
\hline & \multicolumn{9}{|c|}{ Seepage rate (cm/day) } \\
\cline { 2 - 10 } $\begin{array}{c}\text { Distance } \\
\text { offshore } \\
\text { (m) }\end{array}$ & $\begin{array}{c}\text { aquifer } \\
\text { (dg) }\end{array}$ & $\begin{array}{c}\text { aquifer } \\
\text { (middle) }\end{array}$ & \multicolumn{2}{c|}{$\begin{array}{c}\text { aquifer } \\
\text { (ug) }\end{array}$} & \multicolumn{2}{c|}{ no aquifer } \\
\hline 475 & -0.01980 & & 0.00703 & & 0.01888 & & 0.00166 & \\
\hline 525 & -0.01508 & -0.01560 & 0.00580 & 0.00590 & 0.01407 & 0.01463 & 0.00116 & 0.00122 \\
\hline 575 & -0.01193 & & 0.00486 & & 0.01094 & & 0.00085 & \\
\hline 625 & -0.01716 & & 0.00745 & & 0.01547 & & 0.00114 & \\
\hline 675 & -0.01394 & & 0.00646 & & 0.01234 & & 0.00085 & \\
\hline 725 & -0.01288 & & 0.00625 & & 0.01124 & & 0.00073 & \\
\hline 775 & -0.01219 & & 0.00615 & & 0.01051 & & 0.00065 & \\
\hline 825 & -0.01172 & & 0.00609 & & 0.00999 & & 0.00059 & \\
\hline 875 & -0.01139 & & 0.00605 & & 0.00964 & & 0.00055 & \\
\hline 925 & -0.01118 & & 0.00602 & & 0.00941 & & 0.00052 & \\
\hline 975 & -0.01108 & & 0.00600 & & 0.00930 & & 0.00051 & \\
\hline 1025 & -0.01108 & & 0.00600 & & 0.00929 & & 0.00051 & \\
\hline 1075 & -0.01118 & & 0.00600 & & 0.00940 & & 0.00052 & \\
\hline 1125 & -0.01139 & & 0.00601 & & 0.00961 & & 0.00055 & \\
\hline 1175 & -0.01172 & & 0.00604 & & 0.00995 & & 0.00059 & \\
\hline 1225 & -0.01220 & & 0.00608 & & 0.01045 & & 0.00065 & \\
\hline 1275 & -0.01289 & & 0.00617 & & 0.01116 & & 0.00073 & \\
\hline 1325 & -0.01395 & & 0.00636 & & 0.01225 & & 0.00085 & \\
\hline 1375 & -0.01717 & & 0.00732 & & 0.01534 & & 0.00115 & \\
\hline 1425 & -0.01194 & & 0.00477 & & 0.01083 & & 0.00086 & \\
\hline 1475 & -0.01510 & -0.01588 & 0.00567 & 0.00586 & 0.01392 & 0.01472 & 0.00116 & 0.00125 \\
\hline 1525 & -0.02061 & & 0.00713 & & 0.01940 & & 0.00173 & \\
\hline 1575 & -0.01401 & & 0.00449 & & 0.01343 & & 0.00126 & \\
\hline 1625 & -0.01819 & -0.01892 & 0.00543 & 0.00554 & 0.01775 & 0.01858 & 0.00175 & 0.00185 \\
\hline 1675 & -0.02457 & & 0.00669 & & 0.02455 & & 0.00255 & \\
\hline 1725 & -0.01774 & & 0.00444 & & 0.01808 & & 0.00196 & \\
\hline 1775 & -0.02371 & -0.02506 & 0.00549 & 0.00567 & 0.02467 & 0.02628 & 0.00278 & 0.00300 \\
\hline 1825 & -0.03373 & & 0.00709 & & 0.03608 & & 0.00427 & \\
\hline 1875 & -0.02600 & & 0.00502 & & 0.02855 & & 0.00351 & \\
\hline 1925 & -0.02600 & -0.04647 & 0.00698 & 0.00902 & 0.04385 & 0.06144 & 0.00561 & 0.00795 \\
\hline 1975 & -0.08740 & & 0.01507 & & 0.11191 & & 0.01475 & \\
\hline & & & & & & & & \\
\hline
\end{tabular}




\section{Chapter 15}

\section{Summary}

The interaction of lake and groundwater was studied by simulating different steady state hydrogeologic settings with MODFLOW, a very well known three-dimensional finite difference groundwater flow model. The factors or parameters assumed to influence or control the groundwater head distribution or spatial patterns of lake bed seepage may not include all possible variations of real systems. But the parameters chosen for investigation with their simulated realistic input values may help in interpreting natural systems with parameters similar to (or bracketed by) the values used in this study. For example, if increasing anisotropy ratio from 1 to 1000 decreased nearshore seepage rates and increased offshore seepage rates gradually, the seepage pattern near a lake surrounded by a porous medium with anisotropy ratio between 1 and 1000 can be interpolated if other parameters closely resemble the model values. It is not possible to simulate all natural systems, and steady state simulations might be a little oversimplified, but they are useful in gaining insight into the principles of the interaction of lakes and groundwater (Winter, 1976). 
The numerical model used in this model solved the 3-D groundwater flow equation coupled with the equation of continuity (Trescott, 1975). For the 2-D simulations the model used the 2-D version of that same analytical equation. Two finite difference grids were used, a coarse grid $(60 \times 60 \times 15$; only exception in the shallow lake with moderate slope and lake sediment having 16 layers in the vertical direction) and a fine grid $(120 \times 120 \times 15)$. The lake was circular and the diameter was one-third the horizontal extent of the model domain. The input parameters for inflow lakes were the lake head, hydraulic conductivity of the porous medium (and lake sediment if present), anisotropy ratio, recharge rate, heterogeneity if present, and layer bottom elevations. In flow-through lakes, instead of the recharge rate, the groundwater flow gradient was specified. The model boundaries were assumed to be hydrologic divides.

The parameters that were varied to see the effects on spatial patterns of lake bed seepage were recharge rate, lake sediment, anisotropy ratio, lake depth, lake bed slope, heterogeneity, and the orientation of asymmetric flowthrough lakes in a regional gradient. Additionally, comparison of results between 2-D and 3-D simulation and coarse grid and fine grid simulation were performed. The parameter values were chosen from the published reports cited 
in Chapter 5. The results in each simulation focused on the groundwater head distribution in the porous medium, spatial patterns of lake bed seepage, variation of seepage rate with distance offshore in a vertical cross-section and the location of the seepage boundary in flow-through lakes. The groundwater head distribution in a vertical section or the equipotential lines were produced through a contouring package called SURFER and spatial patterns of seepage rates were plotted with GRIDZO, a gridding and contouring program from Rockware.

The results of the different simulations are listed below:

- A 3-D simulation which was identical in all respect with a 2-D simulation showed that the former had higher heads everywhere in the porous medium. The seepage rates were also comparatively higher both nearshore and offshore in 3-D simulation than the respective 2-D simulation. The seepage rates followed an exponential trend with distance offshore, with some deviation from this trend at higher anisotropy. Also, a local seepage maximum was noted at the break in the lake bed slope (where the sloping and horizontal portions of the lake bed met) at high anisotropy $(\mathrm{R}=1000)$.

- When compared between the coarse grid and fine grid, it was found that 
the grid size did not have a significant effect on the overall distribution of hydraulic heads or seepages through lake beds at least at lower anisotropy ratio (e.g., $\mathrm{R}=1,10$, and 100). Variation in lake bed seepage at $R=1000$ between the two grid sizes was related to the change in the number of grid cells per "step" in the sloping portion of the lake bed (1 cell per step in the coarse grid, 2 cells per step in the fine grid; Chapter 7). Thus both the coarse and fine grids captured the overall physics of the system and were adequate for the simulations carried out.

- Doubling the recharge rate from $10 \mathrm{~cm} /$ year to $20 \mathrm{~cm} /$ year introduced twice as much water into the system, and increased the heads and seepage rates everywhere in the medium. The spatial pattern of seepage rates was altered only at high anisotropy $(\mathrm{R}=1000)$, where the higher recharge rate shifted lake bed seepage toward the shoreline (seepage rates near the shore went up by a factor of 2.1 to 2.2 , when recharge rate was doubled).

- Low conductivity lake bed sediments had a significant effect on the distribution of hydraulic heads and seepage through lake beds. For inflow lakes, the addition of lake sediments, and lowering of their hydraulic conductivity, led to progressively lower seepage rates near the 
shore and higher seepage rates offshore. For flow-through lakes, adding sediments and decreasing their hydraulic conductivity forced the seepage boundary to move towards the downgradient side of the lake and reduced the annual volume of groundwater inseepage and lake water outseepage.

- Anisotropy ratio had a significant effect on the distribution of hydraulic heads and the spatial patterns of lake bed seepage. For inflow lakes, heads in the porous medium increased as $\mathrm{R}$ increased from 1 to 1000 (R was increased by lowering the vertical hydraulic conductivity, while keeping the horizontal hydraulic conductivity constant). The nearshore seepage rate decreased and offshore seepage increased with increase in anisotropy. Thus, the rate of exponential decay of the seepage rate with distance away from the shoreline dropped as $\mathrm{R}$ increased. For flowthrough lakes, increasing anisotropy shifted the seepage boundary toward the downgradient shoreline, and decreased the amounts of groundwater inseepage and lake water outseepage.

- Lake depth apparently did not have a significant effect on either inflow lakes or flow-through lakes except when $\mathrm{R}=1000$. At this high anisotropy, near shore seepage rates were slightly higher for the shallow 
inflow lake, compared to the deep inflow lake.

- The effect of lake bed slope was not very pronounced at low anisotropy (i.e., $\mathrm{R}=1,10$ ). At higher anisotropy, inflow lakes with low bed slope had higher maximum water table elevations and offshore seepage rates than did inflow lakes with steep or moderate slope.

- Heterogeneity of the porous medium had major effect on the interaction between the lakes and the groundwater. When a horizontally extensive aquifer was added to the model domain, and moved upward from the base of the system toward the lake, heads decreased in the porous medium, and the lake bed seepage rate decreased near the shore and increased offshore (seepage plots seemed to rotate counterclockwise about a point roughly 200 meters offshore). For flow-through lakes, adding and raising a horizontally extensive aquifer in the model domain had no effect on the position of the seepage boundary, but did increase seepage rates on both upgradient and downgradient sides of the lake (thus causing more water exchange between the subsurface and the lake). The presence of a laterally restricted aquifer (LRA) (occupying one-third of a model layer) in inflow lake simulations lowered the water table asymmetrically (lower water table over the aquifer). When the 
LRA was not under the lake it had relatively little effect on the distribution of lake bed seepage, though the LRA exerted a large effect when at least partially under the lake (offshore seepage rates were much higher). Compared to simulations without an LRA, flow-through lake simulations with an LRA showed increased seepage rates on the side of the lake nearer the LRA (i.e., outseepage rate was higher in the downgradient side when the LRA was present in the downgradient side and inseepage rate was higher in the upgradient side when the LRA was present in the upgradient side). The exception was when the LRA was directly under the lake; in this case, both inseepage and outseepage were lower than in the simulation with no LRA. The location of the seepage boundary varied significantly among the simulations (in order of increasing distance from the downgradient shoreline to the seepage boundary: LRA directly beneath the lake, LRA on the upgradient side of the model domain, no LRA, and LRA on the downgradient side of the domain).

- When an asymmetric flow-through lake was rotated with respect to the regional gradient, the area of outseepage was least when the steep side of the asymmetric lake faced the downgradient side of the model 
domain (SDG), intermediate when the steep side faced upgradient (SUG), and highest when the line separating the steep and moderate slope halves of the lake was normal to the regional gradient (NRG). The outseepage rate was maximum for NRG and minimum for SDG while the inseepage rate was maximum for SDG and minimum for SUG. 


\section{Chapter 16}

\section{Discussion and Conclusions}

Lake-groundwater interaction was studied in detail by Winter (1976,

1978, 1983). A few other studies were also conducted in late 80s and early

90s. Studies were either site specific with seepage measuring devices or numerical modeling of the complex dynamic system between surface water and groundwater. The importance of predicting groundwater flow surrounding lakes with numerical modeling has already been discussed in Chapter 3 . Numerical modeling conducted by Mcbride et al. (1975) showed that the seepage flux can be represented approximately as a function of distance from shore by an equation of the form $f=f_{o} \mathrm{e}^{-c X}$, where $f$ is the total flux across a vertical line through the aquifer at a distance $\mathrm{X}$ from shore, $f_{o}$ the flux at the shoreline, and $-c$ is the slope of the graph of flux against distance on semilogarithmic coordinates. A few other studies came to the same general conclusion (Cherkauer 1989a, 1989b; Shaw et al., 1990). An anisotropy ratio of 10 or 20 was assumed or used in most of these studies, or otherwise the precise value of the anisotropy ratio was not mentioned. The present study confirmed the exponential decline of seepage rate with distance offshore at low anisotropy ratio (i.e., $\mathrm{R}=1,10$ ), with increasing deviation from the exponential 
trend at higher anisotropy. Thus, present results suggest that a simple exponential decline of seepage rate with distance offshore may not apply to real lakes in highly anisotropic geological materials (e.g., stratified sedimentary deposits).

Winter (1978) studied the effect of groundwater flow surrounding lakes with a 3-D model and reconfirmed the major conclusions obtained from a 2-D vertical section model (Winter, 1976). He showed that the heads were higher in 3-D simulations near the downgradient side of the flow-through lakes compared to 2-D simulations. His studies focused on flow-through lakes, and the water table position was fixed. In this present study, 2-D vertical section models were also constructed for inflow lakes to compare the results with 3-D models. Unlike Winter, the water table was free to move in response to the recharge rate. It was found that the water table was lower in 2-D simulations compared to 3-D simulations. The seepage rates were also significantly lower in 2-D simulation. This difference in heads and seepage rates between 2-D and 3-D simulations was explained in terms of the difference in the area of recharge to discharge assuming no change in any hydrologic parameter in the direction normal to the vertical section. So, it can be concluded that the 2-D vertical section models are less applicable for real systems where the lakes are 
more circular than linear.

Two different grid sizes were investigated to test for any disparity in results from two grid sizes. In a study of groundwater exchange with a lake in a variably saturated porous medium, Winter (1983) showed that there were only minor differences in results when two different grid spacings in the vertical direction were considered. The present study provided evidence that the effect of grid size is minimum especially at low R; at higher R (i.e., $\mathrm{R}=1000$ ), differences in lake bed seepage with grid size were related to the change in the number of grid cells per "step" in the sloping portion of the lake bed ( 1 cell per step in the coarse grid, 2 cells per step in the fine grid; Figs. 7.1 and 7.2).

Thus, most of the simulations presented in this research utilized the

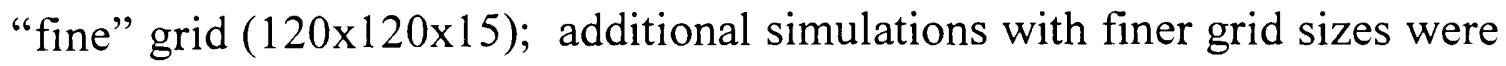
not necessary because the fine grid simulation produced results very similar to those of the coarse grid simulation $(60 \times 60 \times 15)$. Results from the coarse grid were used when the comparison was limited to simulations with the same lakes (i.e., lakes with same depth and bed slope). In order to compare the results among different lakes (i.e., lakes with different depth and bed slope), fine grid simulations were used. 
Most of the earlier models (Winter, 1976, 1978; Mcbride et al., 1975) assumed a fixed water table position and recharge rate was never varied to see the response of the water table. In this study two different recharge rates were used to demonstrate the difference in water table elevations and spatial patterns of lake bed seepage in inflow lake simulations. The higher recharge rate introduced more water into the system and resulted in higher heads in the porous medium. Consequently, the seepage rates were higher both nearshore and offshore. In general recharge rates have little or no effect on the spatial pattern of seepage rates on the lake bed, in the sense that doubling the recharge rate essentially doubled the seepage rate everywhere over the lake bed. The spatial pattern of seepage rates was altered only at high anisotropy $(R=1000)$, where the higher recharge rate increased seepage rates near the shore by a factor of 2.1 to 2.2 ; thus, lake bed seepage shifted toward the shoreline with a higher recharge rate.

Presence of low conductivity lake sediments had a significant effect on the spatial patterns of lake bed seepage for both inflow and flow-through lakes. For inflow lakes, adding lake sediments, and lowering their hydraulic conductivity $\left(\mathrm{K}_{\mathrm{s}} / \mathrm{K}_{\mathrm{h}(\mathrm{pm})}\right.$ was reduced by decreasing $\mathrm{K}_{\mathrm{s}}$, while $\mathrm{K}_{\mathrm{h}(\mathrm{pm})}$ remained constant), led to progressively higher heads, lower seepage rates near the shore, 
and higher seepage rates offshore. The same changes in $\mathrm{K}_{\mathrm{s}} / \mathrm{K}_{\mathrm{h}(\mathrm{pm})}$ forced the seepage boundary to move towards the downgradient side of the flow-through lake and reduced the amount of total annual seepage to and from the lake. Mcbride et al. (1975) ran a simulation with lake sediments having a hydraulic conductivity 3 orders of magnitude less than the horizontal hydraulic conductivity of the porous medium. They found that when the lake bed was entirely covered with lake sediments, the slope of a semi-logarithmic plot of seepage flux versus distance offshore was only half as great as for the simulation without any lake sediment. The lower slope in the above findings (Mcbride et al., 1975) supports the same conclusion obtained in this study, though this study dealt with three different orders of magnitude of the hydraulic conductivity of lake sediments and confirmed the trend suggested by the single simulation with sediments by Mcbride et al. (1975).

Anisotropy ratio $(\mathrm{R})$ was the next variable simulated in different inflow and flow-through lake settings. The four anisotropy ratios used in this study covered a wide range from 1 (isotropic medium) to 1000 (extremely anisotropic). Winter $(1976,1978)$ used $\mathrm{R}$ values of 100 and 1000 . He found that an increase in anisotropy ratio led to a tendency for more outseepage through the downgradient side of the flow-through lake. Anisotropy ratio did 
not influence the water table in any of his simulations because the water table was preset. In inflow lakes in this study, the heads increased with an increase in anisotropy ratio. In flow-through lakes this study showed a movement of the seepage boundary toward downgradient side indicating less area of outseepage. Also, the total amount of groundwater inflow and lake water outflow decreased as the anisotropy was increased. This reduction of the amount of outseepage is somewhat contrary to what Winter (1976) presented. The trends of the seepage rates in a semi-logarithmic plot of seepage rate versus distance offshore at different anisotropy values were very different as evidenced in Fig. 6.4. The nearshore seepage rate decreased and offshore seepage increased with increase in anisotropy. This shifting of the seepage rates from nearshore to offshore resulted in a decrease in the slope of the line in the semi-logarithmic plot of seepage rate versus distance offshore. The spatial distribution of seepage rates over the entire lake bed showed that most of the seepage is concentrated in a thin circular zone close to the shore in inflow lakes. In flow-through lakes, similar nearshore concentration of seepage rates was observed (i.e., near the upgradient and downgradient side of the lake).

Lake depth was varied in both inflow and flow-through lakes by 
considering two lake depths. Lake depth did not influence the spatial patterns of lake bed seepage in inflow lakes at low $R$. At $R=1000$, the deep inflow lake had slightly lower seepage near the shore compared to the shallow inflow lake. Offshore seepage rates were identical for both shallow and deep lakes with steep bed slope, but higher for the deep lake between lakes with moderate bed slope. The progressively higher seepage rate offshore in deep lakes with moderate bed slope could be attributed to a particular combination of lake shape, anisotropy ratio, and lake depth which in this case focused flow lines onto the narrowing conical lake bed which extended deep into the porous medium. Movement of the seepage boundary toward the upgradient side in deep flow-through lake showed that the deep lake had more area of outseepage than the shallow lake. Winter (1976) supported the same general conclusion when he showed that the deep lake had a tendency to lose water, whereas an identical setting with a shallow lake showed no sign of outseepage.

The effect of lake bed slope on spatial patterns of lake bed seepage had not been investigated in any previous studies. Three different lake bed slopes (steep, moderate, and low) were utilized in the present study. At low anisotropy ratio (i.e., $\mathrm{R}=1,10$ ), inflow lakes with steep or moderate bed slopes did not have any major difference in the distribution of hydraulic heads or 
seepage through lake beds. At $R=1000$, simulations with low bed slope had slightly higher maximum heads than simulations with steep or moderate bed slopes. Also, for inflow lakes, the seepage rate offshore was the highest for lakes with low bed slope at $\mathrm{R}=1000$. The position of the seepage boundary in flow-through lakes was always the same for simulations with different lake bed slopes. Overall, lake bed slope did not have a significant effect on spatial patterns of seepage rate on either inflow or flow-through lakes.

Heterogeneity was dealt with in this research by introducing an aquifer below the lake. When an aquifer occupying an entire layer, was introduced in different inflow lake simulations, the heads dropped significantly compared to a simulation without any aquifer. Also, the heads below the lake were much higher in inflow lake simulations when the aquifer was present. As the aquifer was moving upward toward the lake, the heads dropped and the head was minimum when the top of the aquifer came in contact with the lake. Also, seepage shifted offshore (seepage plots rotated counter-clockwise) when the aquifer was moving upward.

A similar conclusion was drawn by Mcbride et al. (1975) when they placed an aerially extensive aquifer below the lake. They showed a decrease in the slope of the line in the semi-logarithmic plot of seepage rate versus 
distance offshore, compared to the line without the aquifer. As opposed to Mcbride et al. (1975), who simulated one particular position of the aquifer below the lake, this study utilized three different spatial positions of the aquifer below the lake. So, this study extended the results of lake groundwater interaction in a heterogeneous medium to show the effect of vertical distance between the lake and aquifer. In flow-through lakes, the seepage boundary did not show any significant movement with the vertical movement of the aquifer. As the aquifer moved vertically upward, the seepage rate increased both at the upgradient and the downgradient side. The seepage rate was the highest when the aquifer was in contact with the lake.

Winter (1978) did some simulations with a full layer aquifer below flowthrough lake and showed that the head at the downgradient side decreased when the aquifer was at the base of the porous medium, compared to the simulation with no aquifer (similar to the simulations with the aquifer occupying layer 15 and simulation with no aquifer in the present study). As he allowed the aquifer to move vertically upward, the flow-through lake started to lose water. Also, in this present study there were higher rates of outseepage and inseepage when the aquifer moved upward toward the lake. Winter did not quantify the variation of seepage rate with distance offshore and the spatial 
variability of the seepage rates over the lake bed, which were included in this study.

Heterogeneity was also introduced by placing a laterally restricted aquifer (LRA) in both inflow and flow-through lake simulations and moving it laterally either from the domain boundary toward the center of the lake (inflow lake) or from the downgradient side to the upgradient side of the model domain (flow-through lake). Movement of the LRA from the domain boundary toward the center of the lake resulted in a shifting of the nearshore seepage farther offshore for inflow lakes. Mcbride et al. (1975) introduced a smaller aquifer of limited aerial extent below the lake, and showed that the seepage rate decreased linearly with distance offshore. The present study also showed higher offshore seepage rates, and lower nearshore seepage rate when the aquifer was partially or directly below the lake. A linear trend is not supported in the present study but the overall slope of the seepage rate with distance offshore decreased in the side closer to the LRA.

For flow-through lakes, adding an LRA increased seepage rates on sides of the lake nearer to the LRA (exception: when the LRA was directly under the lake, both inseepage and outseepage were lower than simulation with no LRA). The location of the seepage boundary varied significantly with the position of 
the LRA (in order of increasing distance from the downgradient side to the seepage boundary: LRA directly beneath the lake, LRA on the upgradient side of the model domain, no LRA, and LRA on the downgradient side of the domain). Winter (1976) showed that an LRA placed at the downgradient side of flow-through lakes increased outseepage compared to a simulation with the LRA at the upgradient side. He mentioned that the position of the limited aquifer beneath or upslope from the lake has little influence on the interaction of lakes and groundwater. Also, the present study showed that the seepage rates were higher at the sides nearer to the LRA (i.e., outseepage rate was higher when the LRA was at the downgradient side and inseepage rate was higher when the LRA was at the upgradient side). This is very similar to the conclusion drawn by Winter $(1976,1978)$.

All the simulations discussed above involved circular lakes with radial symmetry. An asymmetric flow-through lake with steep lake bed slope (i.e., one cell per step along the slope) on one side and moderate lake bed slope (i.e., two cells per step along the slope) on the opposite side showed a significant difference in the position of the seepage boundary when rotated in a regional groundwater gradient. The position of the seepage boundary, the area of seepage, and seepage rates were dependent on the relative alignment of the 
lake and the regional gradient, as discussed in Chapter 15. These are the first simulations to evaluate groundwater exchange with asymmetric lakes, and they suggest the potential importance of lake shape and alignment with regional groundwater flow direction in determining spatial patterns of lake/groundwater seepage.

It follows from the above discussion that some of the above mentioned hydrologic variables are more important than others in lake groundwater interaction and these are:

- application of 3-D models as opposed to 2-D vertical section models,

- presence of lake sediments,

- $\quad$ anisotropy ratio, and

- heterogeneity of the porous medium.

Winter (1976) mentioned that the height of the water table mound on the downslope side of the lake relative to the lake level is an important control on the interaction of lakes and groundwater. He also mentioned that lakes in a setting of a straight line water table simply would gain groundwater inflow on one side and lose water out the other. The present study showed that even in the absence of the mound, the effects are sometimes significant in flowthrough lakes. Inflow lake studies are of particular interest in this study 
because they helped in understanding the response of the water table in presence of recharge. Spatial pattens of the seepage maps give seepage rates of the entire lake bed as opposed to a few vertical sections through the center of the lake. The annual inflow and outflow calculated as a percentage of lake volume was also included in this study because water budget is an important aspect of lake hydrology.

As mentioned in the introductory paragraph, the implications of this research is predicting and analyzing field results of groundwater exchange with lakes. This study will help in understanding the complex dynamic system of lake and groundwater and can guide the placement of seepage meters and piezometers used in field studies. Seepage meter and piezometer results can also be interpreted in a more scientific way. For example, seepage rate increases offshore locally and rapid groundwater exchange with lakes occurs at places where the lake bed slope changes. Fellows et al. (1980) documented that a large amount of seepage entered the East Pool side of lake Conway, Florida through the slanting portion of the lake bottom, where dredging had made a canal-like depression parallel to the shore. Results from the present study suggest that high seepage rates such as observed by Fellows et al. (1980) are more likely due to the local change in lake bed slope, than to the magnitude 
of the slope (i.e., whether it is high or low). As shown in Chapter 12, the magnitude of lake bed slope has relatively little effect on lake bed seepage patterns, when the slope is uniform.

For highly anisotropic porous media $(\mathrm{R}=1000)$, the seepage rate may progressively increase offshore for inflow lakes if the lake shape narrows progressively to the bottom, with constant lake bed slope (configuration similar to the deep lake with moderate bed slope; e.g., Figs. 10.4, 11.6). Cherkauer et al. (1989b) documented a type of seepage pattern (type B) with a decline of seepage rate offshore in the nearshore area succeeded by higher values offshore. They interpreted the type $\mathrm{B}$ pattern as being due to a combination of increase in permeability of the porous medium and decrease in the thickness of the lake sediment. The present study can interpret the same result as a combination of gradually increasing lake depth to a narrow lake bottom, with high anisotropy ratio. High anisotropy ratio in the porous medium (bulk anisotropy of 5000) was reported by Cherkauer et al. (1989b) in the study area, though the profile of the lake bottom was not given. Nonetheless, an increase in seepage rate offshore does not necessarily indicate a change in hydraulic conductivity of the porous medium or a change in the thickness of the lake bed sediment; lake shape/depth could also be a factor. 
Another interesting phenomenon is the interpretation of type $\mathrm{C}$ pattern of seepage by Cherkauer et al. (1989b). As alrady mentioned in Chapter 2, seepage rates in the Type $\mathrm{C}$ distribution reached a peak near the shore and then declined further offshore. They interpreted the high seepage offshore as due to local thinning of the lake sediments at places. However, the present study demonstrated a very similar pattern of seepage when a horizontally extensive aquifer just underlies the lake (Fig. 14.4). This suggests that it may be necessary to reconsider Cherkauer et al.'s (1989b) conclusion that the seepage pattern could not be due to heterogeneity of hydraulic conductivity within the underlying porous medium.

The present study showed a roughly similar effect on seepage patterns in inflow lakes from two types of changes: introduction of lake sediments and gradual lowering of their hydraulic conductivity (Fig. 9.3), and adding and moving upward a horizontally extensive aquifer (Fig. 14.1). Thus, differences in the rate of decline of seepage rate with distance offshore for two real lakes could be due to differences in either lake sediments or deeper heterogeneities below the lakes. Knowing which factor is responsible would require further information beyond lake bed seepage rates (i.e., information on the porous medium surrounding the lakes, or the sediments in the lakes). 
The input parameters used in this study are believed to be realistic and a discussion about their validity is included in Chapter 5. The relative dimensions of the whole simulation process of lake groundwater system are unitless (though for the sake of description, the metric system is considered in this study). Thus, results from the present study can be used for other real lake/groundwater systems provided the model input parameters resemble or bracket the values in nature.

Because lake groundwater interaction is of tremendous interest for chemistry, hydrology and ecology of lakes, a thorough understanding of the dynamic system in essential. This study provides evidence for how the most common hydrologic variables alter or influence the hydraulic gradient near lakes and lake bed seepage. Further work that needs to be done is to evaluate the effect of these key variables in transient (unsteady) simulations where the water table fluctuation may influence the patterns of seepage rate and the total annual inflow and outflow. Also, the results of this study should be compared with field situations where the geology closely resembles the hypothetical groundwater system in this study. One example of the successful application of modeling techniques in this project to a Florida lake was published recently (Grubbs, 1995). The overall hydrologic budget of a lake can also be calculated 
if variables like surface water runoff, evapotranspiration, and precipitation data are available to use with the groundwater exchange rates computed as shown in this work. 


\section{References Cited}

Allred, E.R., P.W. Mason, G.M. Schwartz, P. Golany, and J.W. Reinke. 1971.

Continuation of studies on the hydrology of ponds and small lakes. Agricultural Experiment Station, University of Minnesota Technical Bulletin 274: 1-62.

Anderson, M.P., and C.J. Bowser. 1986. The role of groundwater in delaying lake acidification. Water Resources Research 22(7): 1101-1108.

Barwell, V.K., and D.R. Lee. 1981. Determination of horizontal-to-vertical hydraulic conductivity ratios from seepage measurements on lake beds. Water Resources Research 17(3): 565-570.

Born, S.M., S.A. Smith, and D.A. Stephenson. 1979. Hydrogeology of glacial terrain lakes with management and planning application. Journal of Hydrology 43: 7-43.

Bradner, L.A. 1994. Groundwater resources of the Okeechobee County, Florida. U.S. Geological Survey Water Resources Investigation Report 92-4166: $1-41$.

Causey, L.V., and G.G. Phelps. 1978. Availability and quality of water from shallow aquifers in Duval County, Florida. U.S. Geological Survey 
Water Resources Investigation Report 78-92: 1-36.

Cherkauer, D.S., P.F. McKereghan, and L.H. Schalch. 1992. Delivery of

Chloride and Nitrate by groundwater to the great lakes: Case study for the Door Peninsula, Wisconsin. Groundwater 30(6): 887-894.

Cherkauer, D.S., and P.F. Mckereghan. 1991. Groundwater discharge to lakes:focusing in embayments. Groundwater 29(1): 72-81.

Cherkauer, D.A., and D.C. Nader. 1989a. Distribution of groundwater sepage to large surface water bodies: the effect of hydraulic heterogeneities. Journal of Hydrology 109: 151-165.

Cherkauer, D.A., and J.P. Zager. 1989b. Groundwater interaction with a kettle hole lake: relation of observation to digital simulation. Journal of Hydrology 109: 167-184.

Cherkauer, D.A., and J.M. McBride. 1988. A remotely operated seepage meter for use in large lakes and rivers. Groundwater 26(2): 165-170.

Cherkauer, D.A., and B.R. Hensel. 1986. Groundwater flow into lake Michigan from Wisconsin. Journal of Hydrology 84: 261-271.

Eckhardt, D.A.V., and J.W. Eliezer. 1983. Groundwater movement in the upper Glacial aquifer in the Manorville Area, Town of Brookhaven, Long Island, New York in November 1983. U.S. Geological Survey 
Water Resources Investigation Report 85-4035: 1-12.

Eisenlohr, W.S., J.B. Shjeflo, C.E. Sloan, R.E. Stewart, and H.A. Kantrud.

1972. Hydrologic investigation of the prairie potholes in North Dakota,

1959-1968. U.S. Geological Survey Professional Paper 585-A: 1-102.

Emmons, P.J. 1990. A digital simulation of the glacial aquifer system in the northern three fourths of Brown County, South Dakota. U.S. Geological Survey Water Resorces Investigation Report 88-4198: 1-74.

Fellows, C.R., and P.L. Brezonik. 1980. Seepage flows into Florida lakes. Water Resources Bulletin 16(4): 635-641.

Fish, J.E., and M. Stewart. 1991. Hydrogeology of the surficial aquifer system, Dade County, Florida. U.S. Geological Survey Water Resources Investigation Report 90-4108: 1-50.

Franks, B.J. 1980. The surficial aquifer at the U.S. Naval Station near Mayport, Florida. U.S. Department of Interior Geological Survey Open File Report 80-765: 1-13.

Freeze, R.A., and J.A. Cherry. 1979. Groundwater. Printice Hall, Inc., Englewood Cliffs, New Jersy: 1-604.

Getzen, R.T. 1977. Analog model analysis of regional three dimensional flow in the groundwater reservoir of Long Island, New York. U.S. 
Geological Survey Professional Paper 982: 1-49.

Grubbs, J.W. 1995. Evaluation of groundwater flow and hydrologic budget for Lake Five-O, a seepage lake in northwestern Florida. U.S. geological Survey Water Resources Investigation Report 94-4145: 141.

Harte, P.T. and J.M. Thomas 1992. Geohydrology of, and simulation of groundwater flow in, Milford-Souneghan Glacial-Drift Aquifer, Milford, New Hampshire. U.S. Geological Survey Water Resources Investigation Report 91-4177: 1-75.

Hennings, R.G. 1978. Hydrogeology of the little St. Germain Lake Basin, Vilas County, Wisconsin. University of Wisconsin, Madison M.S. thesis: $1-75$.

Hurley, J.P., D.E. Armstrong, G.J. Kenoyer, and C.J. Bowser. 1985. Groundwater as a silica source for diatom production in a precipitation dominated lake. Science 227: 1576-1578.

Israelson, O.W., and R.C. Reeve. 1944. Canal lining experiments in the Delta area, Utah. Utah Agricultural Experiment Station Bulletin 313: 15-35. Krabbenhoft, D.P., C.J. Bowser, M.P. Anderson, and J.W.Valley. 1990a. Estimating groundwater exchange with lakes 1 . The stable isotope mass 
balance method. Water Resources Research 26(10): 2445-2453.

Krabbenhoft, D.P., M.P. Anderson, and C.J. Bowser. 1990b. Estimating groundwater exchange with lakes 2. Calibration of a three dimensional, solute transport model to a stable isotope plume. Water Resources Research 26(10): 2455-2462.

Krulikas, R.K., and G.L. Giese. 1995. Recharge to surficial aquifer in Lee, and Hendry Counties, Florida. U.S. geological Survey Water resources Investigation Report 95-4003: 1-21.

Larson, S.P., M.S. McBride, and R.J. Wolf. 1975. Digital models of a glacial outwash aquifer in the Pearl-Sallie Lakes area, West Central Minnesota. U.S. Geological Survey Water Resouces Investigation Report 40-75: 139.

Lee, D.R. 1977. A device for measuring seepage flux in lakes and estuaries. Limnology and Oceanography 22(1): 140-147.

Mann, W.B., and M.S. McBride. 1972. The hydrologic balance of Lake Salie, Becker County, Minnesota. U.S. Geological Survey Professional Paper 800-D: $189-191$.

Manson, P.W., G.M. Scwartz, and E.R. Allred. 1968. Some aspects of the hydrology of ponds and small lakes. University of Minnesota 
Agricultural Experiment Station Technology Bulletin 257: 1-88.

McBride, M.S. 1969. Hydrology of lake Sallie, North Western Minnesota, with special attention to groundwater-surfacewater interactions. University of Minnesota M.S. thesis: 1-61.

McBride, M.S., and H.O. Pfannkuch. 1975. The distribution of seepage within lakebeds. U.S. Geological Survey Journal Research 3(5): $505-$ 512.

McClymonds, N.E., and O.L. Franke. 1972. Water transmitting properties of aquifer on Long Island, New York. U.S. Geological Survey Professional Paper 627-E: 1-24.

McDonald, M.G., and B.R. Harbaugh. 1988. A modular three dimensional finite difference groundwater flow model. U.S. Geological Survey Techniques of Water-Resorces Investigations 6-A1: 1-586.

Munter, J.A. 1979. Groundwater modeling of three lake/aquifer systems in Wisconsin. University of Wisconsin, Madison M.S. thesis: 1-100.

Pfannkuch, H.O., and T.C. Winter. 1984. Effect of anisotropy and groundwater system geometry on seepage through lakebeds. 1) Analog and Dimensional analysis. Journal of hydrology 75: 213-237.

Possin, B. 1973. Hydrology of Mirror and Shadow Lakes in Waupaca, 
Wisconsin. University of Wisconsin, Madison M.S. thesis: 1-66.

Shaw, R.D., and E.E. Prepas. 1990. Groundwater-lake interaction: II. nearshore seepage patterns and the contribution of groundwater to lakes in central Alberta. Journal of Hydrology 119: 121-136.

Stauffer, R.E. 1985. Use of solute released tracers by weathering to estimate groundwater inflow to seepage lakes. Environmental Science and Technology 19: 405-411.

Trescott, P.C. 1975. Documentation of finite difference model for simulation of three dimensional groundwater flow. U.S. Geological Survey Open File Report 75-438: 1-32.

Vecchioli, J., H.Tibbals, A.D. Duerr, and C.B. Hutchinson. 1990. Groundwater recharge in Florida: A pilot study in Okaloosa, Pasco, and Valusia Counties. U.S. Geological Survey Water Resources Investigation Report 90-4195: 1-16.

Warnick, C.C. 1957. A study of the control of canal seepage. University of Idaho Engineering Experiment Station, Special Research Project 20C(1): $1-38$.

Warren, M.A., W. deLaguna, and N.J. Lusczynski. 1968. Hydrology of the Brook National Laboratory and vicinity, Suffolk County, New York. 
U.S. Geological Survey Bulletin 1156-C: 1-127.

Winter, T.C. 1976. Numerical simulation analysis of the interaction of lakes and groundwater. U.S. Geological Survey Professional Paper 1001: 145.

Winter, T.C. 1978a. Numerical simulation of steady state three dimensional groundwater flow near lakes. Water Resources Research 14(2): 245254.

Winter, T.C. 1978b. Groundwater component of lake water and nutrient budgets. Verh. Int. Verein. Limnology 20: 438-444.

Winter, T.C. 1981a. Effects of water table configuration on seepage through lake beds. Limnology and Oceanography 25(5): 925-935.

Winter, T.C. 1981b. Uncertainties in estimating the water balance of lakes. Water Resources Bulletin 17(1): 82-115.

Winter, T.C. 1983. The interaction of lakes with variably saturated porous media. Water Resources Research 14(2): 245-254.

Winter, T.C., and H.O. Pfannkuch. 1984. Effect of anisotropy and groundwater system geometry on seepage through lakebeds. 2) Numerical simulation analysis. Journal of Hydrology 75: 239-253.

Winter, T.C. 1986. Effect of groundwater recharge on configuration of water 
table beneath sand dunes and on seepage in lakes in the sandhills of Nebraska. Journal of Hydrology 86: 221-237. 


\section{Appendix}

In addition to the ModelCad ${ }^{386}$ software used to design simulations (i.e., set up MODFLOW input files), a post-processing utility for preparing MODFLOW output for contouring, MODGRID, was also purchased from Geraghty and Miller (1993). MODGRID creates input for SURFER (a plotting/contouring package from Golden Software of Boulder, Colorado) from MODFLOW output; MODGRID works with three types of MODFLOW output files (those with .bas, .bcf, and .hds extensions), and creates head files that can contoured in SURFER. However, MODGRID was designed to work directly only with model layers, not the rows or columns needed for contouring head in vertical cross sections through the grid. To contour hydraulic head in vertical cross sections, 10 programs were written in the programing language "c". The purpose of these programs was to modify the format of MODFLOW output files so they could be read and contoured with the graphics software SURFER. The code for each program is given at the end of this appendix.

The first program was written to process the two-dimensional vertical section models and utilized MODFLOW output files with ".out" extension to create files for SURFER input. The beginning of the MODFLOW output files contain a short list of the parameter values used in the model, followed by the 
head values in each layer. The 2-D model grid contained only one column, with multiple rows and layers; heads in the output files were written in a 2-D array for each layer (the 60 head values in each layer were written in 6 rows and 10 columns). The initial statements containing the parameter values at the beginning of the MODFLOW output files (with .out extension) together with the lines addressing the layer numbres were deleted. The modified MODFLOW output files, containing heads in 90 rows (6 rows for each layer $\mathrm{x} 15$ layers) and 10 columns, were called directly into the 2-D program. The output file of the 2-D program contained three columns corresponding to the $\mathrm{X}, \mathrm{Z}$, and head values $\mathrm{X}$ is the horizontal distance along rows and $\mathrm{Z}$ is the vertical distance normal to the model layers). The $\mathrm{X}$ and $\mathrm{Z}$ values were taken from the model dimension. A second file containing $\mathrm{X}$ and head values for the top layer was created to produce the water table position.

SURFER used the first file (X, $\mathrm{Z}$, head) to generate the cross-section with contours of equal head (equipotentials); the cross-section was contained in a grid file (with .grd extension). The grid file was then smoothed one time using the "weighted inverse distance" method via the "matrix smoothing" option. The purpose of this was to improve the appearance of the contours (equipotentials) and to eliminate undesired "noise" from small scale variability 
that may be present in the original grid. The second file, containing the heads and locations of cells in the top layer, was then converted to a blanking file format. The purpose of this file was to "blank out" the area above the water table but within the border around the cross-section, so no equipotentials would be plotted here (by default, SURFER would extend equipotentials into this area, even though there are no head values above the water table). Also, a third file containing the precise location of the lake boundaries was created and converted into a blanking file format, so that groundwater equipotentials would not be plotted in the lake by SURFER. A simple DOS command (Type filel $>>$ file2) was used to combine the two blanking files (both with .bln extension). The combined file (with .bln extension) acted as a boundary line file (.bln extension) in SURFER and was used to import the water table position and the lake in the smoothed grid file. Vertical cross-sections with equipotential lines were plotted using the $(\mathrm{X}, \mathrm{Z}$, head) grid files and the boundary line blanking files.

The next set of programs was written for three-dimensional models. All these programs are very much similar in structure, but they are different in terms of four key parameters. These key parameters are lake depth (shallow versus deep), grid dimensions (coarse versus fine), and alignment of the 
section with either row or column. The eight different combinations of these parameters required eight different programs. These programs did not use the MODFLOW output files because of the many lines of text and head value format. Rather, these programs used the MODFLOW files containing the X, the Y, and the head values (".hds" extension). These files were written in the binary format and each file contained head values and their locations $(\mathrm{X}, \mathrm{Y})$ for one model layer. To convert these binary files into ASCII format, a ModelCad ${ }^{386}$ utility package called $M O D \_B 2 A$ was used. The $A S C I I$ files generated by this package compiled the head values of one model layer at a time. These layers containing the head values were combined using the same $D O S$ command mentioned earlier. Once all 15 layers with spatial locations of heads were combined into one file covering the entire model domain, that file was used as input for the different programs (from program 2 through 9). These programs are user interactive programs and ask along which row or column the $\mathrm{X}, \mathrm{Y}$, and head values are needed. The program also generates a second file containing the head values with location (i.e., either $\mathrm{X}$ and head values or $\mathrm{Y}$ and head values) of the top layer along that desired row or column; this second file contained the information needed to plot the water table position, as mentioned earlier for the first program which deals with 2-D 
models. SURFER used these two files along with the file containing lake coordinates and produced the vertical cross section with head contours in the same way mentioned earlier for the 2-D model output. Wherever aquifers were present (Chapter 14), a third file was generated with aquifer location and converted to a blanking file format before adding to the combined blanking file containing the location of the water table and lake, in order to show the location of the aquifer in the cross-section. Unlike the other two blanking files, the blanking file with aquifer location was not run with the grid file; this blanking file was needed to show the aquifer location but not to blank out the equipotentials in the aquifer location.

The flow through lake simulations required one step more data processing because they produced "dry" cells on the downgradient side of the model domain ("dry" cells in MODFLOW are those cells where the head values were less than the bottom elevation of the cell). MODFLOW was set up such that any dry cells would be assigned a head value of 999.99 meters. After the model was run, and the single layer MODFLOW output files with hds extension were combined, the head values in dry cells were deleted. The water table on the downgradient side of the lake was located by identifying the uppermost "wet" cell at each $\mathrm{X}, \mathrm{Y}$ location. 
The last program was written for processing the simulation containing lake sediments. For shallow lake simulations, the thickness of the top five layers of the model domain (i.e., the layers penetrated by the lake) was half the thickness of the layers below the lake (i.e., layers 6 through 15). In order to introduce lake sediments of uniform thickness below the lake, the layer just underlying the lake was divided into two layers and this added one more layer to the existing 15 layers. The program structure was essentially the same as any of the programs from 2 through 9, except this program dealt with 16 layers.

To produce a seepage map, the same ModelCad ${ }^{386}$ utility package called MOD_B2A was used. Three MODFLOW output files used in this package were files with .bas, .bcf, and .cbb extensions. $M O D_{-} B 2 A$ calculated the volumetric flow passing through all the constant head cells over the lake bed. The volumetric flow in each cell was then divided by the total area of seepage exposed for the cell. The resultant values were the seepage rates in the respective cells over the lake bed, in a file containing the seepage rates and $\mathrm{X}$, Y locations on the lake bed. After adding a few header lines containing minimum and maximum seepage rates, and minimum and maximum $\mathrm{X}$ and $\mathrm{Y}$ locations, a seepage map was made from the file, using the "pattern map" 
option of GRIDZO (Rockware Scientific Software, Colorado). The pattern map option cannot produce a legend directly, so two additional files were created: one contained a few line statements about legend and the other the range of seepage values supporting the legend. The file with seepage values was needed to produce the seepage pattern map. The legend file was converted from $A S C I I$ to binary through a suboption within GRIDZO named "tape $\rightarrow g r f$ ".

The binary file was then combined with the binary file of the seepage pattern map through another GRIDZO suboption called "grafstuf" and the final seepage map was generated.

The plots of seepage rate versus distance offshore were generated by extracting the values of the seepage rates along either $\mathrm{X}$ or $\mathrm{Y}$ direction from the file containing the values of seepage rates of all the constant head cells in the lake bed. Excel was the spreadsheet used for data handling and manipulation. 
/* A program to convert 2-D MODFLOW output file to SURFER compatible format for coarse grid shallow lake.

$\begin{array}{lll} & * & \text { Input file: } c s \\ * & \text { Output file: } c \text { cs.dat } & *\end{array}$

\#include $<$ stdio.h $>$

main()

\{int $\mathrm{i}, \mathrm{j}, \mathrm{k}, \mathrm{x}, \mathrm{y}$;

FILE *fp, *pr;

double a,b,c[901];

$\mathrm{fp}=$ fopen("cs","r+");

pr=fopen("cs.dat","w+");

for $(i=1 ; i<=900 ; i++)$

fscanf(fp, "\%lf",\&c[i]);

$\mathrm{x}=50 ; \mathrm{y}=47$;

for $(\mathrm{i}=0 ; \mathrm{i}<901 ; \mathrm{i}++)$

\{

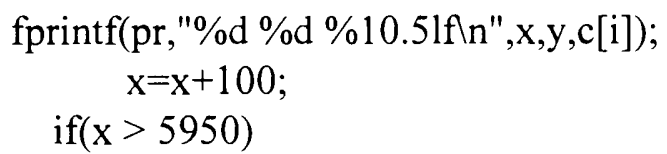

fclose(fp);

fclose(pr);

\}

\{

$\mathrm{x}=50$;

\}

$y=y-2$;

)

fclose(pr); 
/* A program to convert MODFLOW output file to SURFER compatible

* format for coarse grid, shallow lake, and section along rows for inflow lake

* or along the direction of the regional gradient for flow-through lake.

/* Input file: csr

* Output file: csr.dat, csr2.dat */

\#include $<$ stdio.h $>$

\#include $<$ stdlib.h $>$

FILE ${ }^{*}$ fptr, ${ }^{*}$ optr, ${ }^{*}$ optr 1

float $\mathrm{A}[1][60][60]$;

void read(int v)

\{

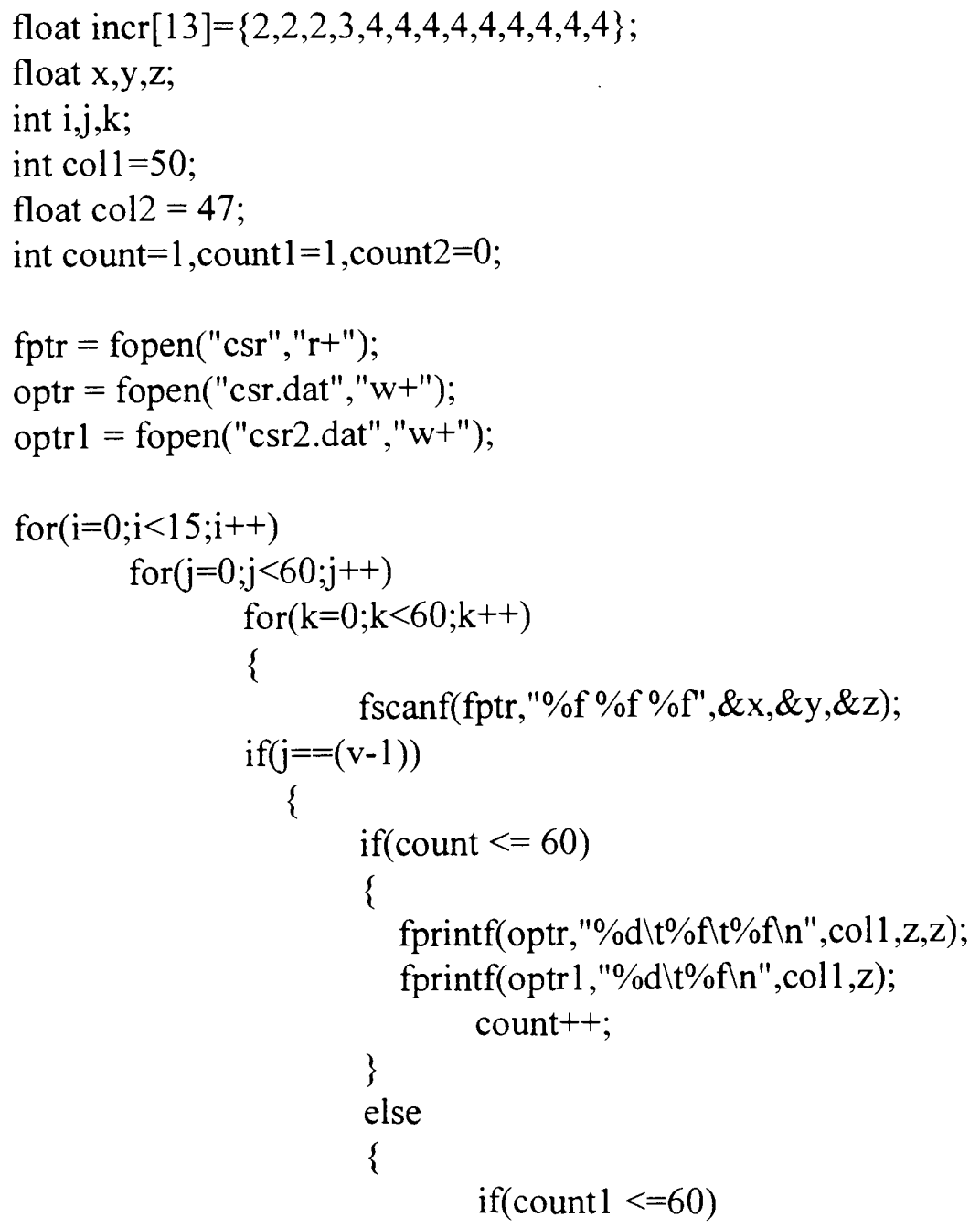




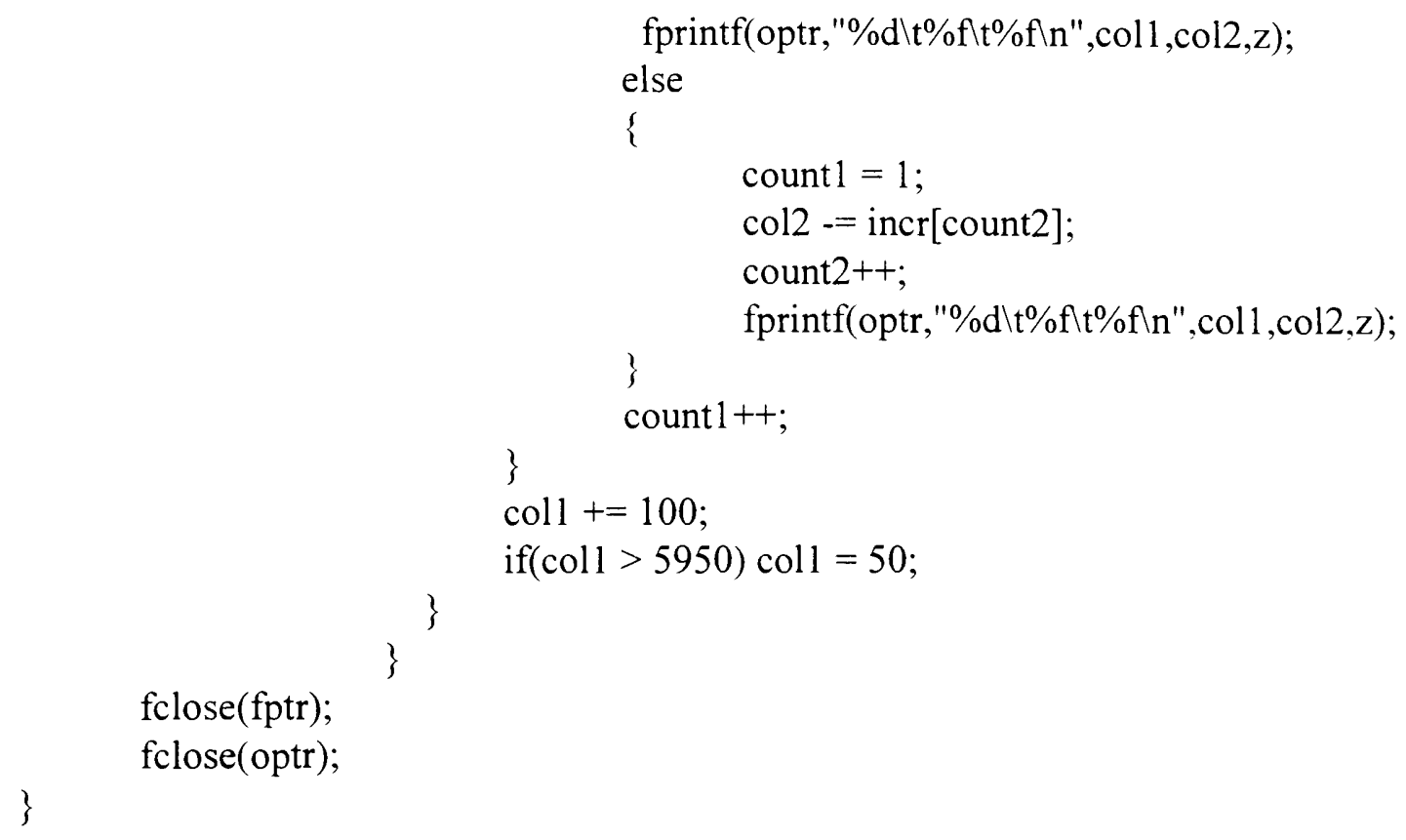


/* A program to convert MODFLOW output file to SURFER compatible

* format for coarse grid, shallow lake, and section along columns for inflow lake *

* or along the direction normal to the regional gradient for flow-through lake.

* Input file: csc

* Output file: csc.dat, $\csc 2$.dat */

\#include $<$ stdio.h $>$

\#include $<$ stdlib.h $>$

FILE * fptr, ${ }^{*}$ optr; ${ }^{*}$ optr l

float A[1][60][60];

void read(int v)

\{

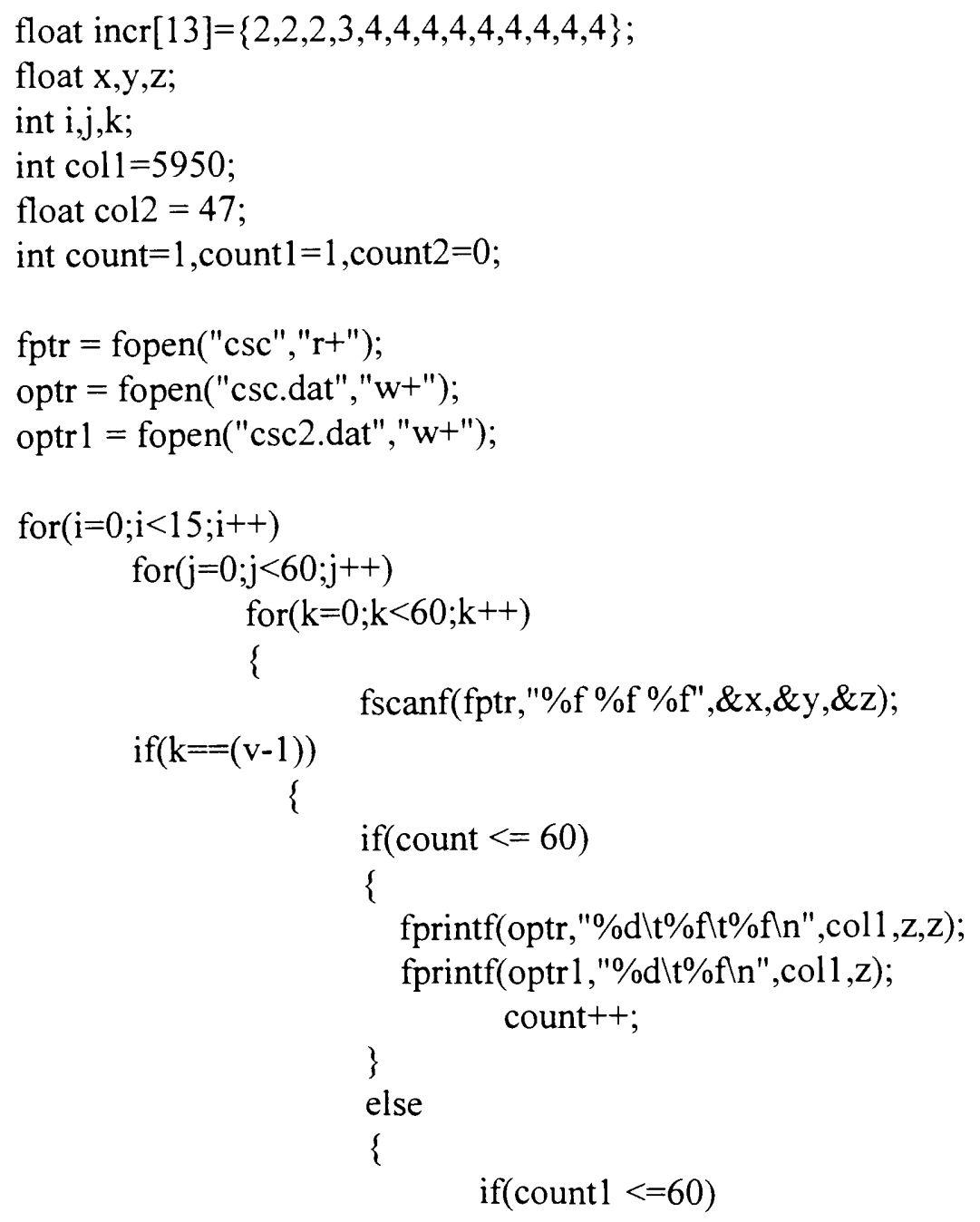




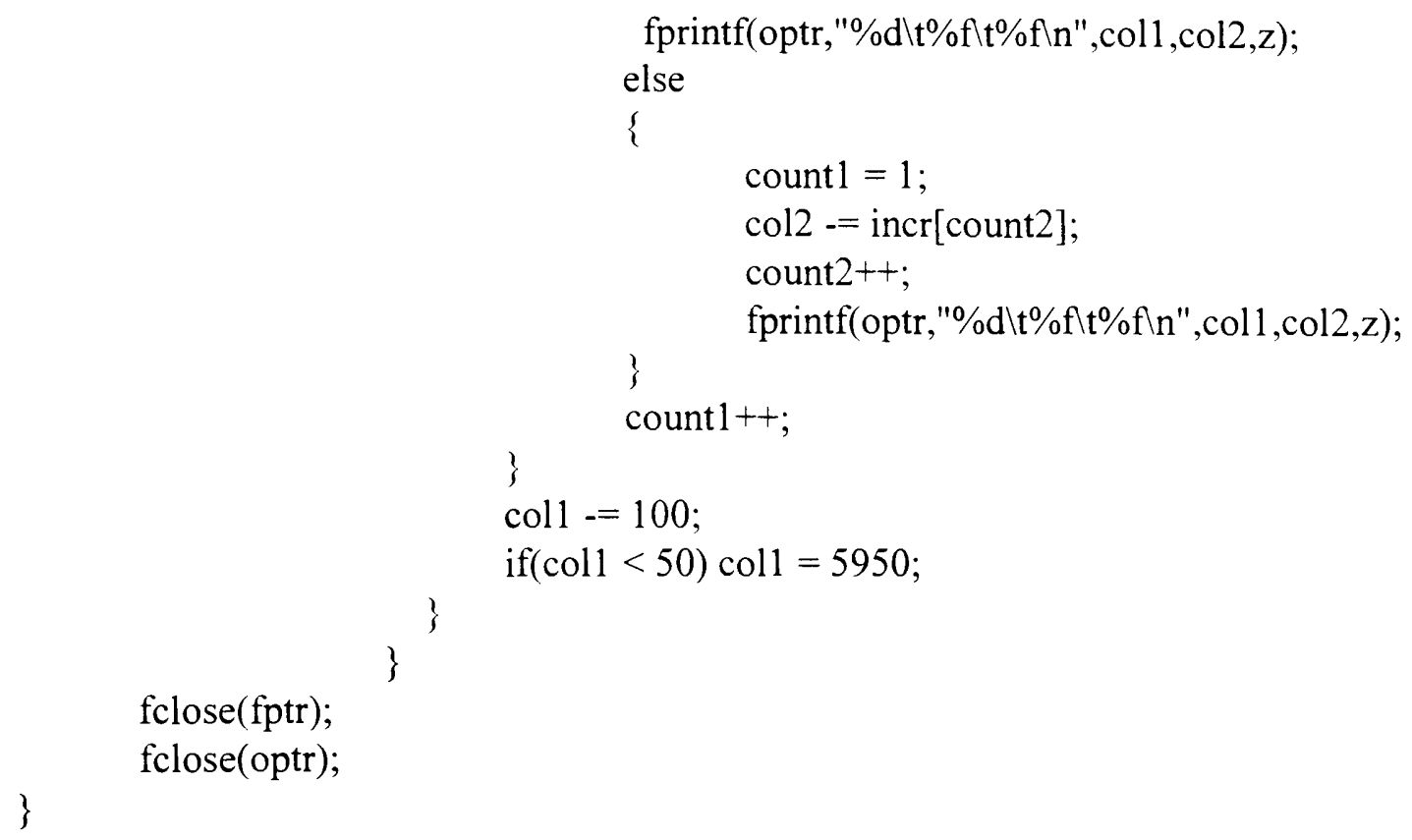


/* A program to convert MODFLOW output file to SURFER compatible *

* format for coarse grid, deep lake, and section along rows for inflow lake *

* or along the direction of the regional gradient for flow-through lake. */

/* Input file: cdr

* Output file: cdr.dat */

\#include $<$ stdio.h $>$

\#include $<$ stdlib.h $>$

FILE ${ }^{*}$ fptr, ${ }^{*}$ optr;

float $\mathrm{A}[1][60][60]$;

void read(int $\mathrm{v})$

\{

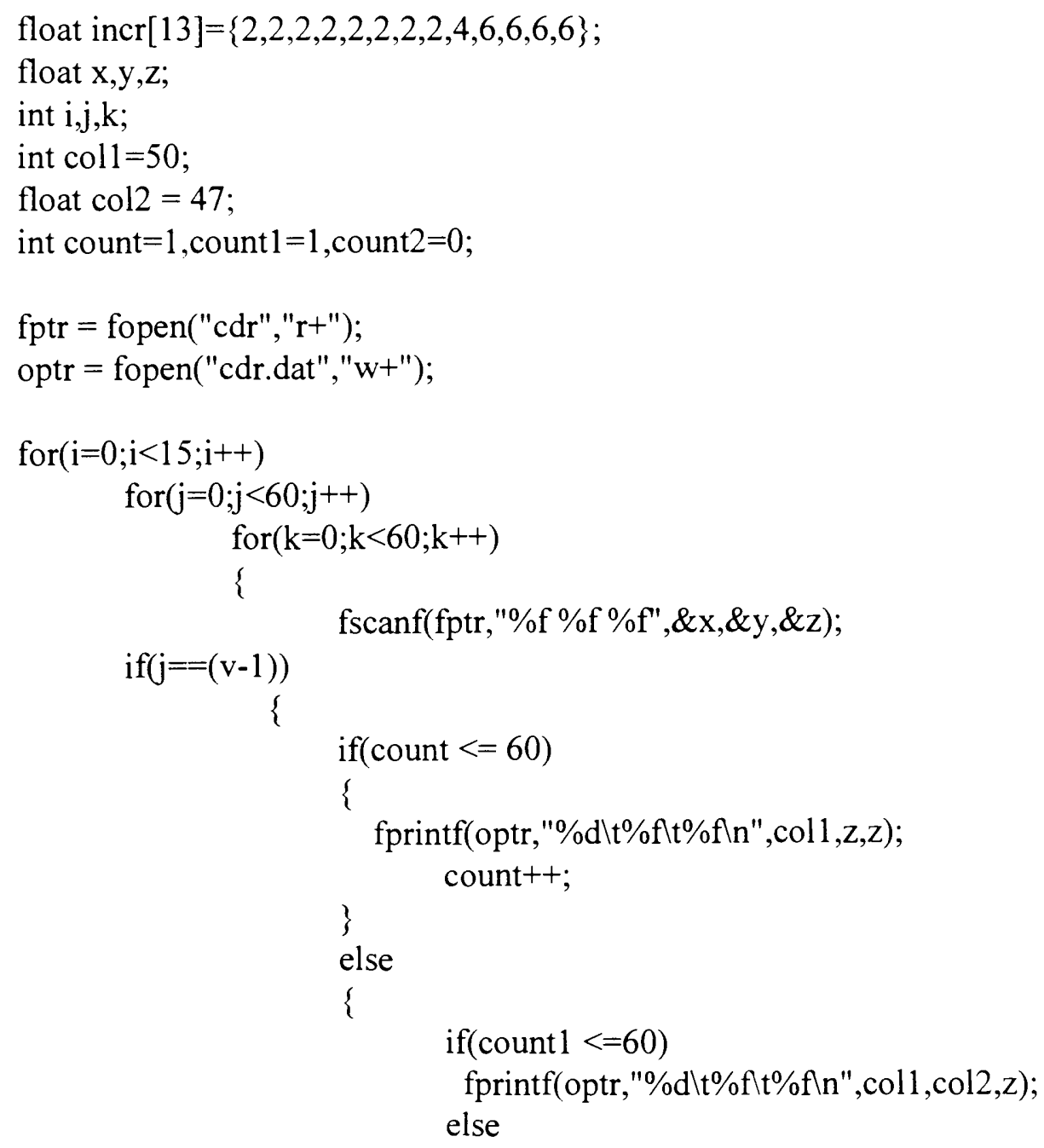




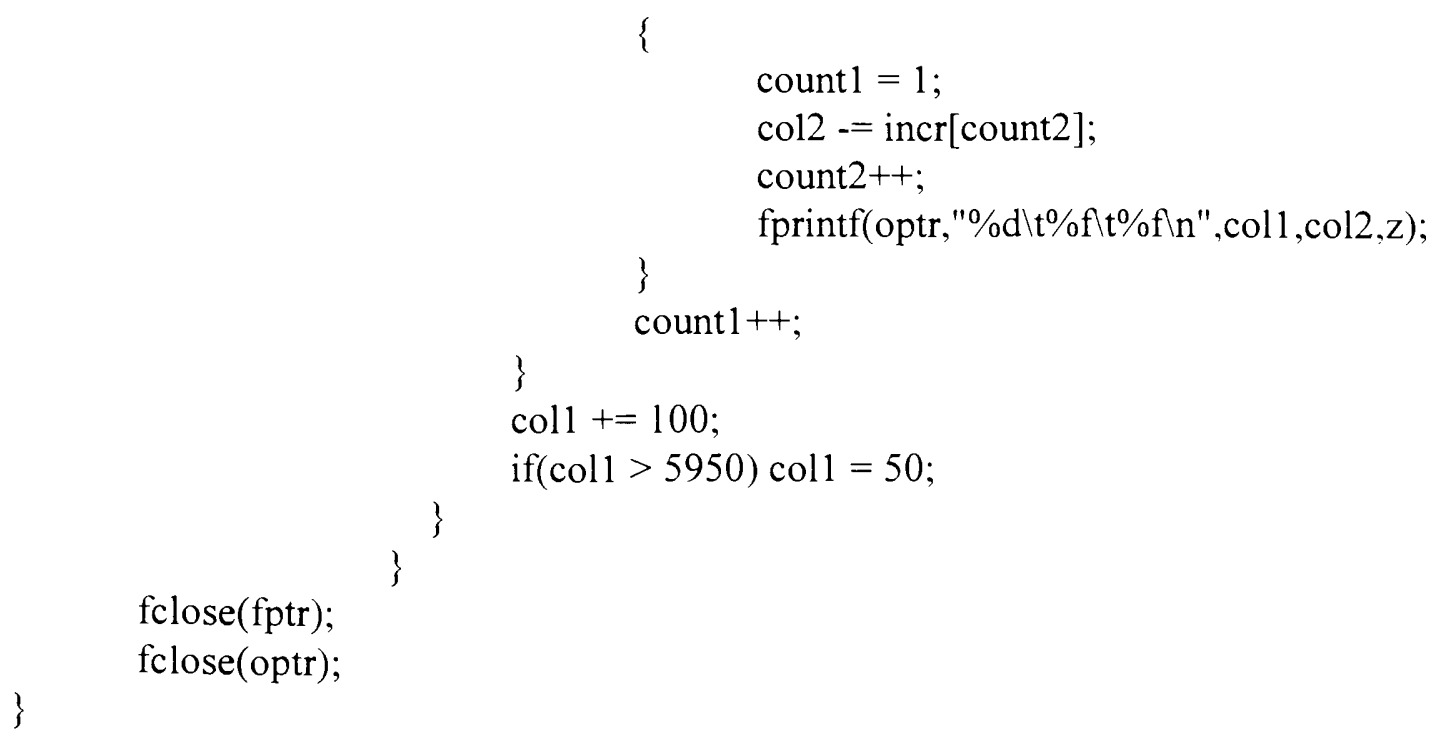

fclose(fptr);

fclose(optr);

\}

void main()

\{

int val;

printf("\nEnter the Row number: ");

scanf("\%d",\&val);

$\operatorname{read}(\mathrm{val})$;

\} 
/* A program to convert MODFLOW output file to SURFER compatible

* format for coarse grid, deep lake, and section along columns for inflow lake or along the direction normal to the regional gradient for flow-through lake.

$*$

* Input file: cdc *

* Output file: cdc.dat, cdc2.dat */

\#include $<$ stdio.h $>$

\#include $<$ stdlib.h $>$

FILE ${ }^{*}$ fptr, ${ }^{*}$ optr, ${ }^{*}$ optr 1

float $\mathrm{A}[1][60][60]$;

void read(int $v$ )

\{

float incr[13] $=\{2,2,2,2,2,2,2,2,4,6,6,6,6\}$;

float $\mathrm{x}, \mathrm{y}, \mathrm{z}$;

int $\mathrm{i}, \mathrm{j}, \mathrm{k}$;

int $\operatorname{col} 1=5950$;

float $\operatorname{col} 2=47$;

int count $=1$, count $1=1$, count $2=0$;

fptr = fopen("cdc","r+");

optr = fopen("cdc.dat","w+");

optrl = fopen("cdc2.dat","w+");

for $(\mathrm{i}=0 ; \mathrm{i}<15 ; \mathrm{i}++)$

for $(j=0 ; j<60 ; j++)$

for $(\mathrm{k}=0 ; \mathrm{k}<60 ; \mathrm{k}++)$

\{

if $(k==(v-1))$

fscanf(fptr, "\%f \%f \%f",\&x,\&y,\&z);

\{

if $($ count $<=60)$

\{

fprintf(optr,"\%dlt\%flt\%fln",coll,z,z);

count ++ ;

fprintf(optr 1,"\%dlt\%fln",coll,z);

\}

else

\{

if $($ count $1<=60)$ 


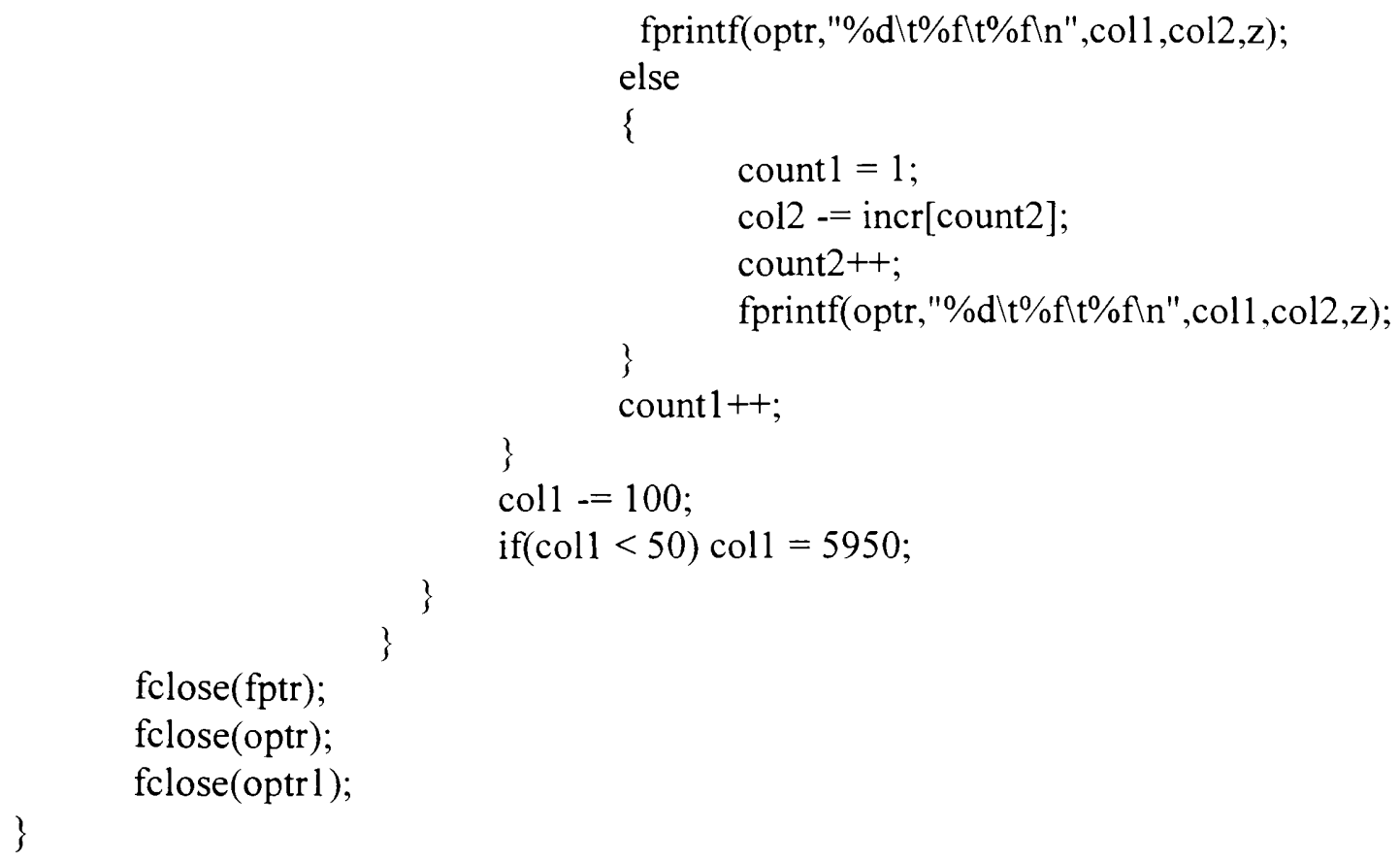


/* A program to convert MODFLOW output file to SURFER compatible

* format for fine grid, shallow lake, and section along rows for inflow lake

* or along the direction of the regional gradient for flow-through lake.

/* Input file: fsr

* Output file: fsr.dat, fsr2.dat */

\#include $<$ stdio.h $>$

\#include $<$ stdlib.h $>$

FILE ${ }^{*}$ fptr, ${ }^{*}$ optr, ${ }^{*}$ optr 1

float $\mathrm{A}[1][120][120]$;

void read(int $v)$

\{

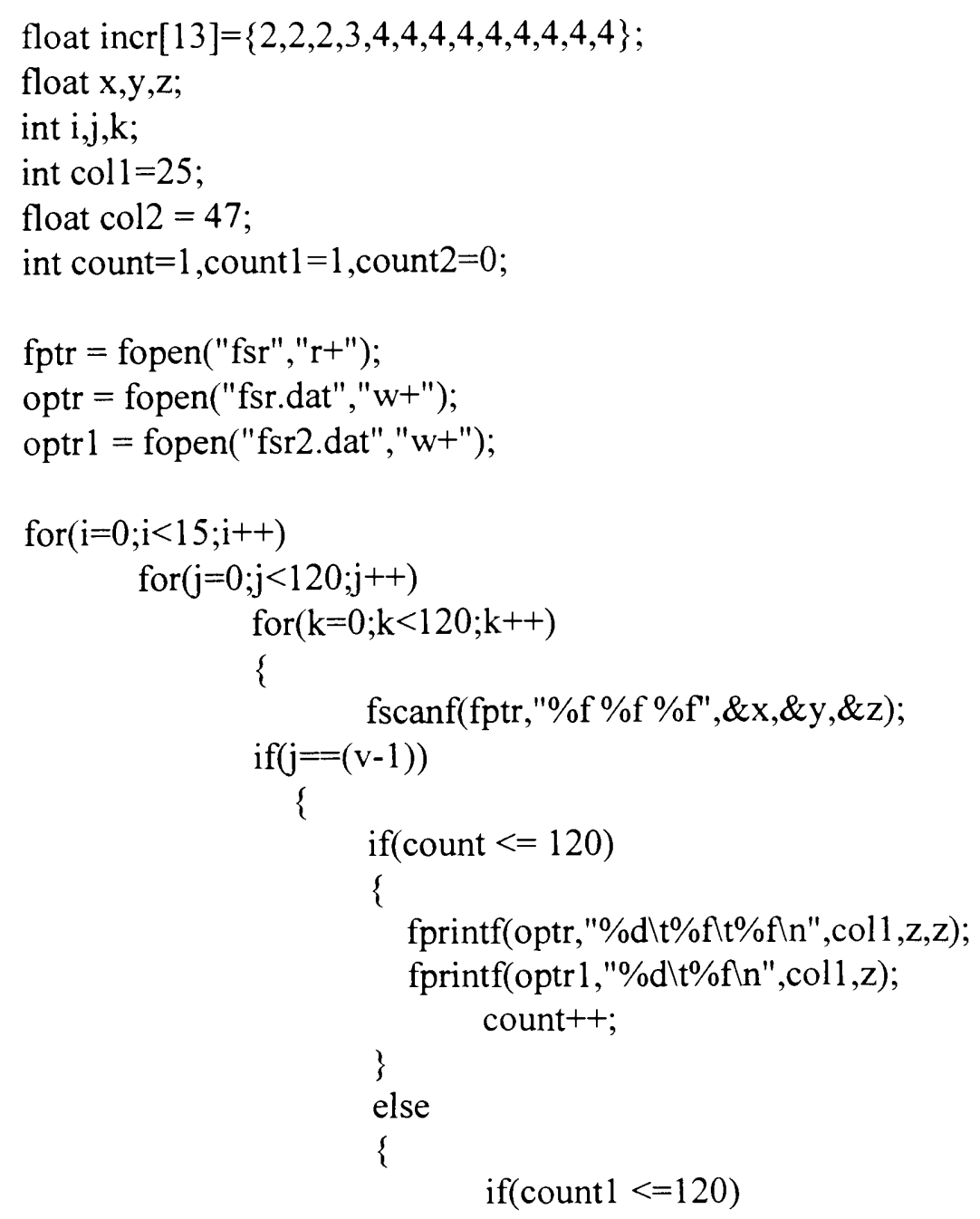




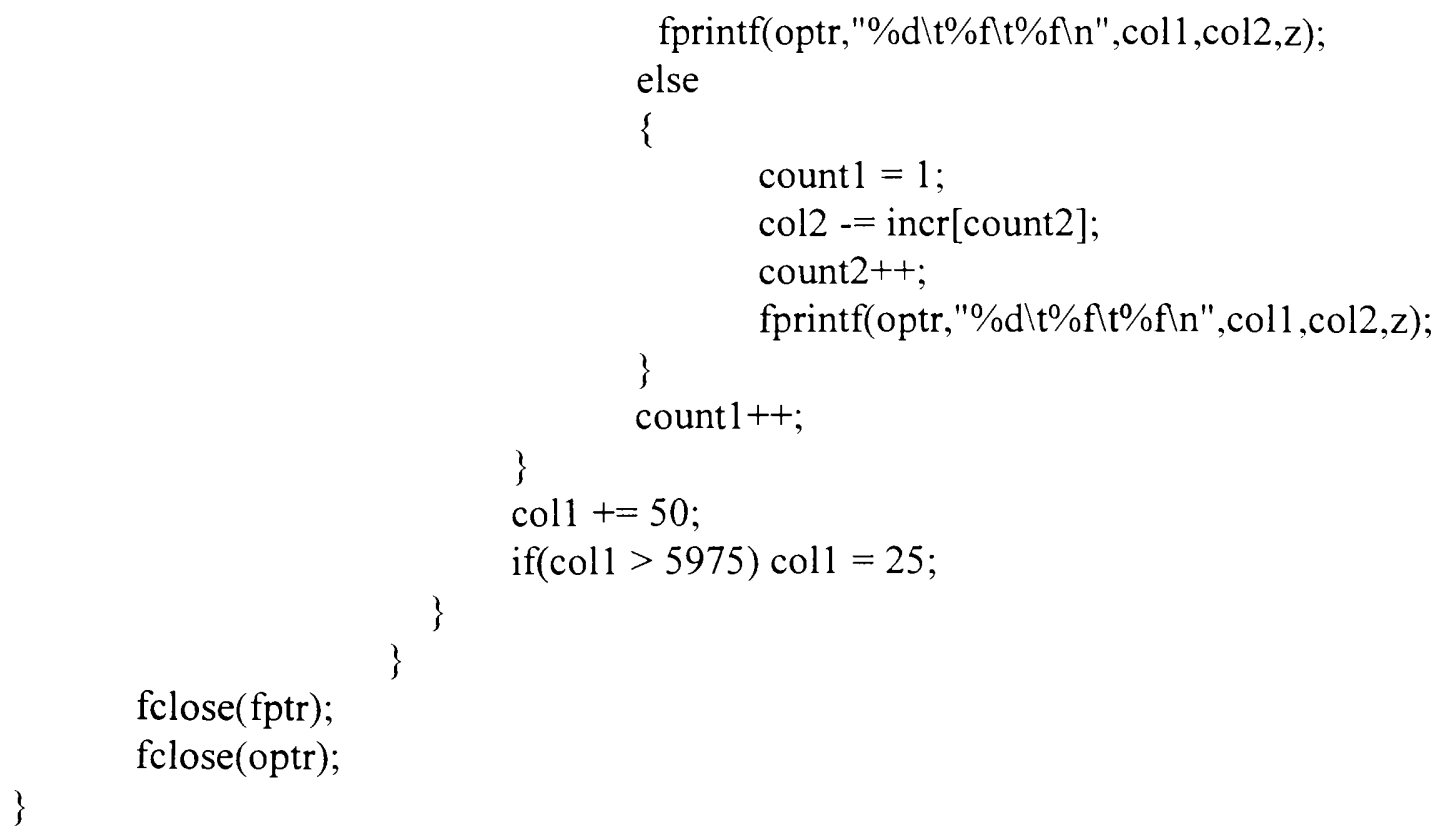


/* A program to convert MODFLOW output file to SURFER compatible

* format for fine grid, shallow lake, and section along columns for inflow lake

* or along the direction normal to the regional gradient for flow-through lake.

$\begin{array}{ll}{ }^{*} \text { Input file: fsc } & * \\ * & \text { Output file: fsc.dat, fsc2.dat } \\ & * /\end{array}$

\#include $<$ stdio.h $>$

\#include $<$ stdlib.h $>$

FILE ${ }^{*}$ fptr, ${ }^{*}$ optr; ${ }^{*}$ optr 1

float $\mathrm{A}[1][120][120]$;

void read(int $v)$

\{

float incr[13] $=\{2,2,2,3,4,4,4,4,4,4,4,4,4\}$;

float $\mathrm{x}, \mathrm{y}, \mathrm{z}$;

int $\mathrm{i}, \mathrm{j}, \mathrm{k}$;

int coll $=5975$;

float $\operatorname{col} 2=47$;

int count $=1$, count $1=1$, count $2=0$;

fptr = fopen $($ "fsc","r+");

optr = fopen("fsc.dat","w+");

optrl = fopen("fsc2.dat","w+");

for $(\mathrm{i}=0 ; \mathrm{i}<15 ; \mathrm{i}++)$

for $(j=0 ; j<120 ; j++)$

for $(\mathrm{k}=0 ; \mathrm{k}<120 ; \mathrm{k}++)$

\{

fscanf(fptr,"\%f \%f \%f",\&x,\&y,\&z);

if $(k==(v-1))$

\{

if(count $1<=120$ ) 


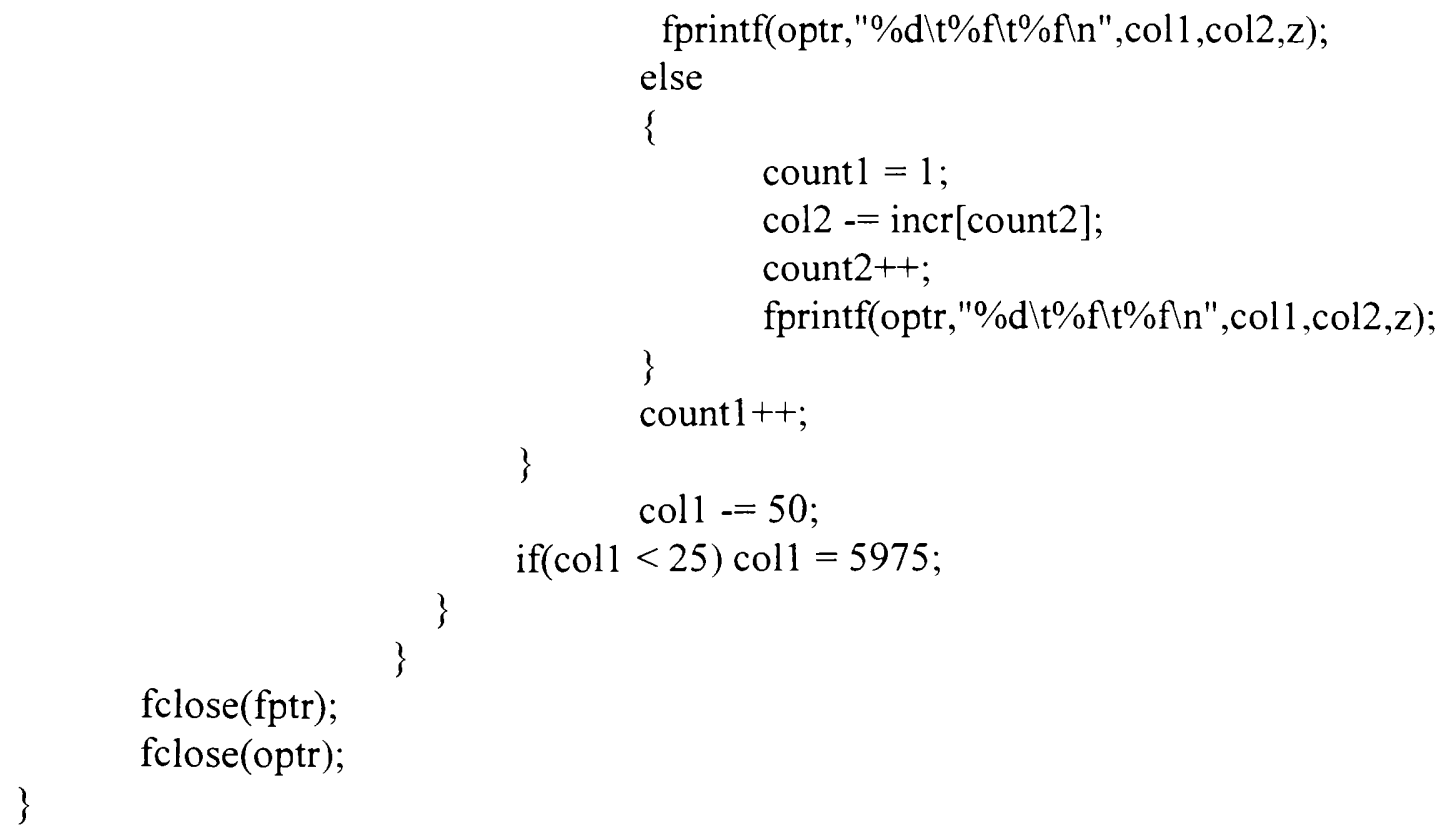


/* A program to convert MODFLOW output file to SURFER compatible

* format for fine grid, deep lake, and section along rows for inflow lake

* or along the direction of the regional gradient for flow-through lake.

/* Input file: fdr

* Output file: fdr.dat */

\#include $<$ stdio.h $>$

\#include $<$ stdlib.h $>$

FILE $^{*}{ }^{\mathrm{fptr}},{ }^{*} \mathrm{optr}$

float $A[1][120][120]$;

void read(int v)

\{

float incr $[13]=\{2,2,2,2,2,2,2,2,4,6,6,6,6\}$;

float $\mathrm{x}, \mathrm{y}, \mathrm{z}$;

int $\mathrm{i}, \mathrm{j}, \mathrm{k}$;

int $\operatorname{col} 1=25$;

float $\operatorname{col} 2=47$;

int count $=1$, count $1=1$, count $2=0$;

fptr = fopen("fdr","r+");

optr = fopen("fdr.dat","w+");

for $(\mathrm{i}=0 ; \mathrm{i}<15 ; \mathrm{i}++)$

for $(\mathrm{j}=0 ; \mathrm{j}<120 ; \mathrm{j}++)$

for $(\mathrm{k}=0 ; \mathrm{k}<120 ; \mathrm{k}++)$

\{

if $(j==(v-1))$

fscanf(fptr," \%f \%f \%f",\&x,\&y,\&z);

if $j=-(v-1))$
q

if $($ count $<=120)$

\{

fprintf(optr,"\%dlt\%flt \%fln",col1,z,z); count++;

\}

else

\{

if (count $1<=120)$ fprintf(optr,"\%d $1 \mathrm{t} \% \mathrm{f} \backslash \mathrm{t} \% \mathrm{f} \backslash \mathrm{n}$ ",coll ,col2,z); else 


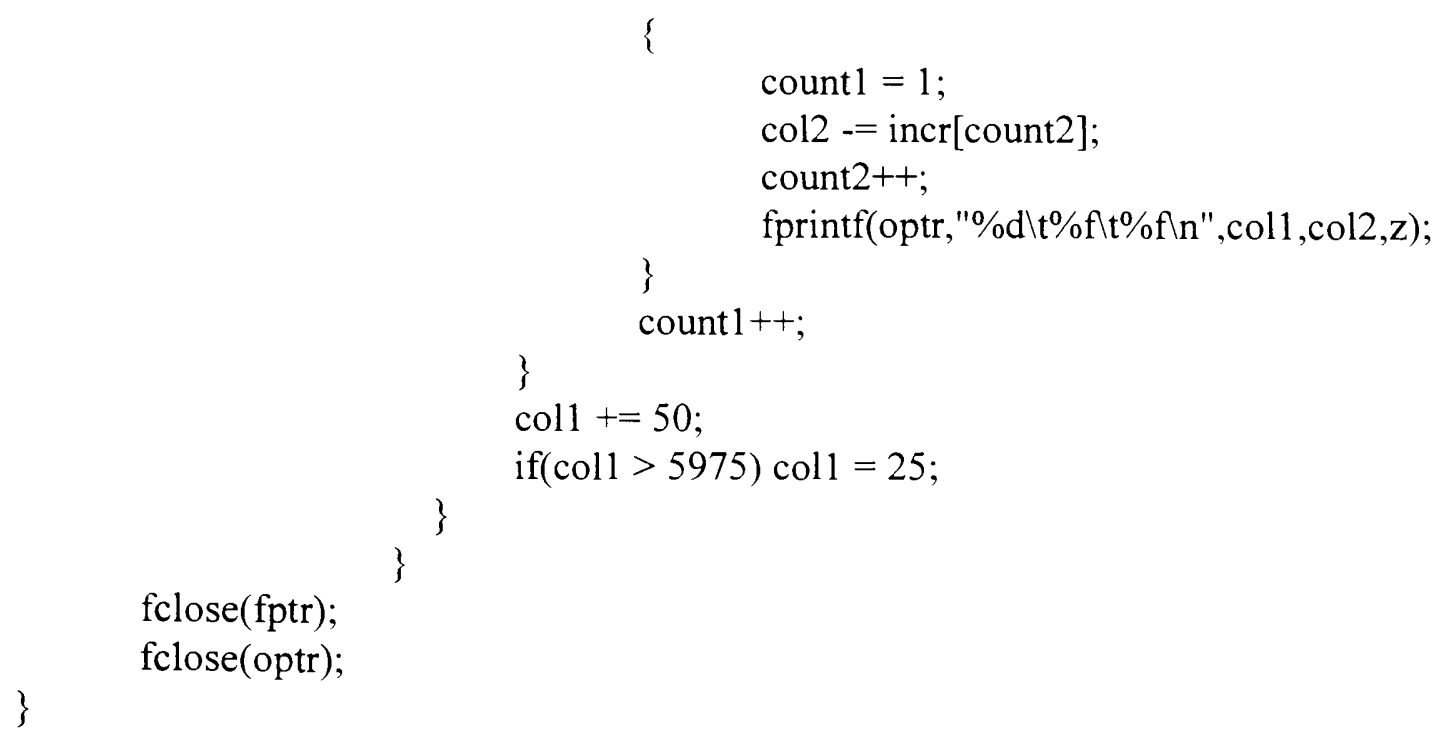


* A program to convert MODFLOW output file to SURFER compatible

* format for fine grid, deep lake, and section along columns for inflow lake

* or along the direction normal to the regional gradient for flow-through lake.

/* Input file: fdc

* Output file: fdc.dat, fdc2.dat */

\#include $<$ stdio.h $>$

\#include $<$ stdlib.h>

FILE ${ }^{*}$ fptr, ${ }^{*}$ optr, ${ }^{*}$ optr 1

float $A[1][120][120]$;

void read(int v)

\{

float incr[13] $=\{2,2,2,2,2,2,2,2,4,6,6,6,6\}$;

float $\mathrm{x}, \mathrm{y}, \mathrm{z}$;

int $\mathrm{i}, \mathrm{j}, \mathrm{k}$;

int $\operatorname{col} 1=5975$;

float $\operatorname{col} 2=47$;

int $\operatorname{count}=1$, count $1=1$, $\operatorname{count} 2=0$;

fptr = fopen("fdc","r+");

optr = fopen("fdc.dat","w+");

optr1 = fopen("fdc2.dat","w+");

for $(\mathrm{i}=0 ; \mathrm{i}<15 ; \mathrm{i}++)$

for $(j=0 ; j<120 ; j++)$

for $(\mathrm{k}=0 ; \mathrm{k}<120 ; \mathrm{k}++)$

\{

fscanf(fptr,"\%f \%f \%f",\&x,\&y,\&z);

if $(k==(v-1))$

(

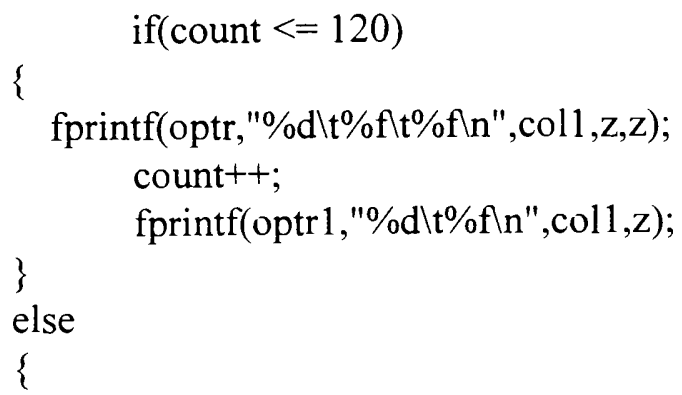

if( count $1<=120)$ 


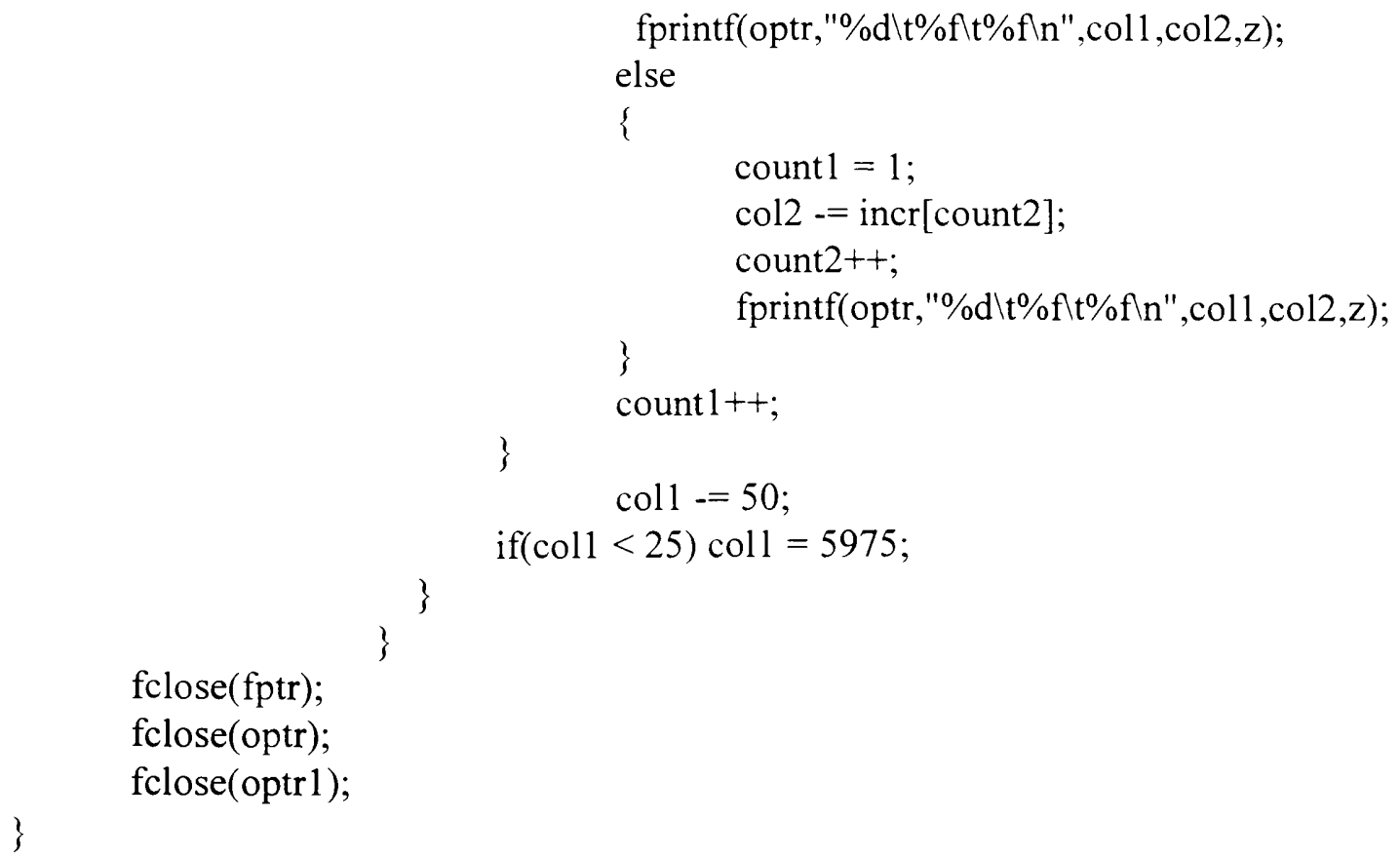


* A program to convert MODFLOW output file to SURFER compatible

* format for coarse grid, shallow lake with lake sediments, and section along

* rows for inflow lake or along the direction of the regional gradient for flow-

* through lake.

/* Input file: cssr

* Output file: cssr.dat, cssr2.dat */

\#include $<$ stdio.h $>$

\#include $<$ stdlib.h>

FILE ${ }^{*}$ fptr, ${ }^{*}$ optr, ${ }^{*}$ optr 1

float $\mathrm{A}[1][60][60]$;

void read(int $v)$

\{

float incr $[14]=\{2,2,2,2,2,3,4,4,4,4,4,4,4,4\}$;

float $\mathrm{x}, \mathrm{y}, \mathrm{Z}$;

int $\mathrm{i}, \mathrm{j}, \mathrm{k}$;

int $\operatorname{col} 1=50$;

float $\operatorname{col} 2=47$;

int $\operatorname{count}=1$, ount $1=1$, count $2=0$;

fptr = fopen("cssr","r+");

optr = fopen("cssr.dat","w+");

optr1 = fopen("cssr2.dat","w+");

for $(\mathrm{i}=0 ; \mathrm{i}<16 ; \mathrm{i}++)$

for $(j=0 ; j<60 ; j++)$

for $(k=0 ; k<60 ; k++)$

\{

fscanf(fptr," \%f \%f \%f",\&x,\&y,\&z);

if $(j==(v-1))$

if $($ count $<=60)$

\{

fprintf(optr,"\%dlt $\%$ flt $\%$ fln",coll $, z, z)$;

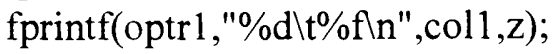

count++;

\}

else

\{ 


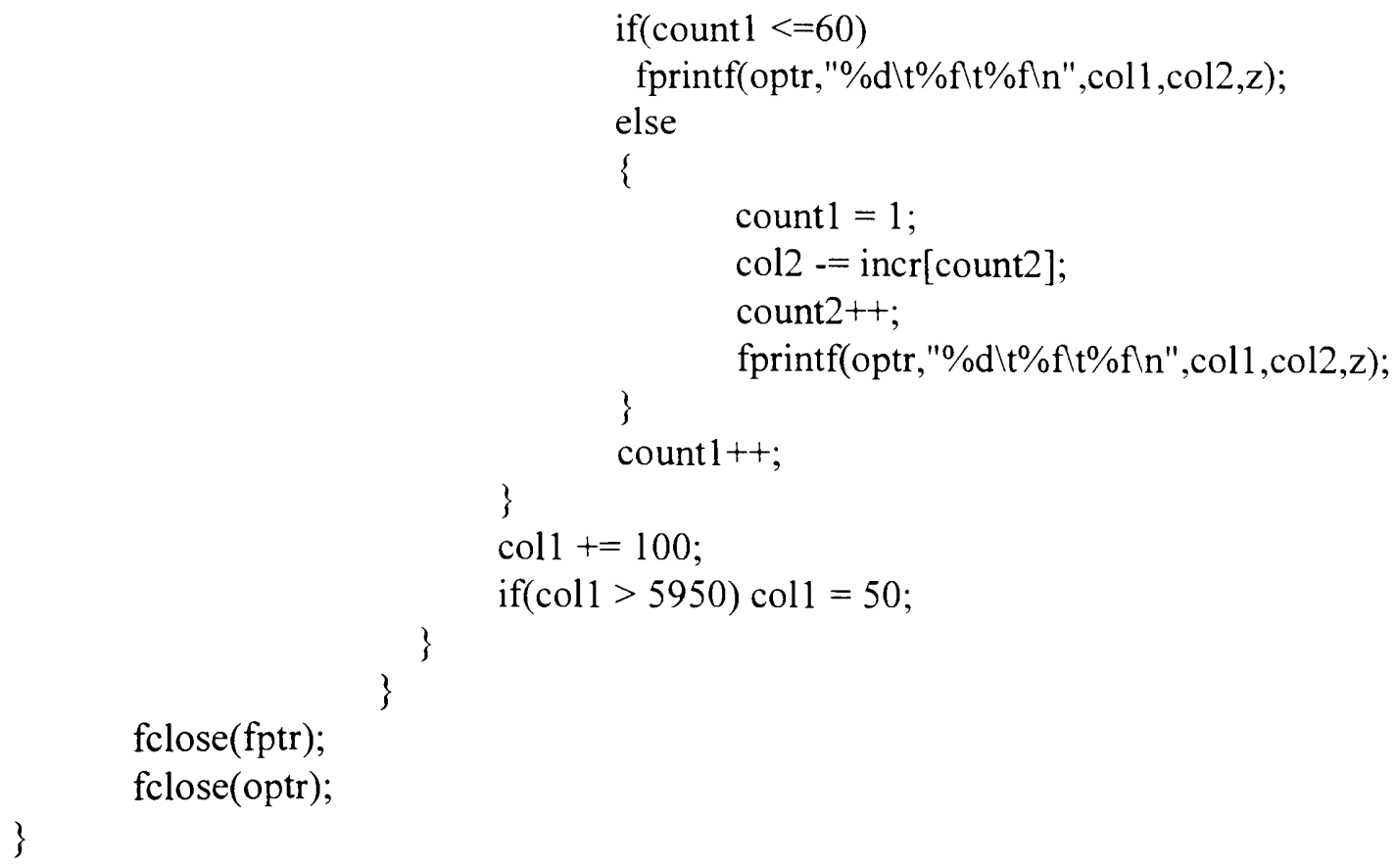

